DANIARA CRISTINA FERNANDES

\title{
Estudo químico e atividade biológica de Garcinia xanthochymus (Clusiaceae)
}

Dissertação apresentada ao Instituto de Química, Universidade Estadual Paulista, como parte dos requisitos para obtenção do título de Mestre em Química

Orientadora: Profa. Dra. Dulce Helena Siqueira Silva 


\section{SÚMULA CURRICULAR}

\section{DANIARA CRISTINA FERNANDES}

\section{DADOS PESSOAIS}

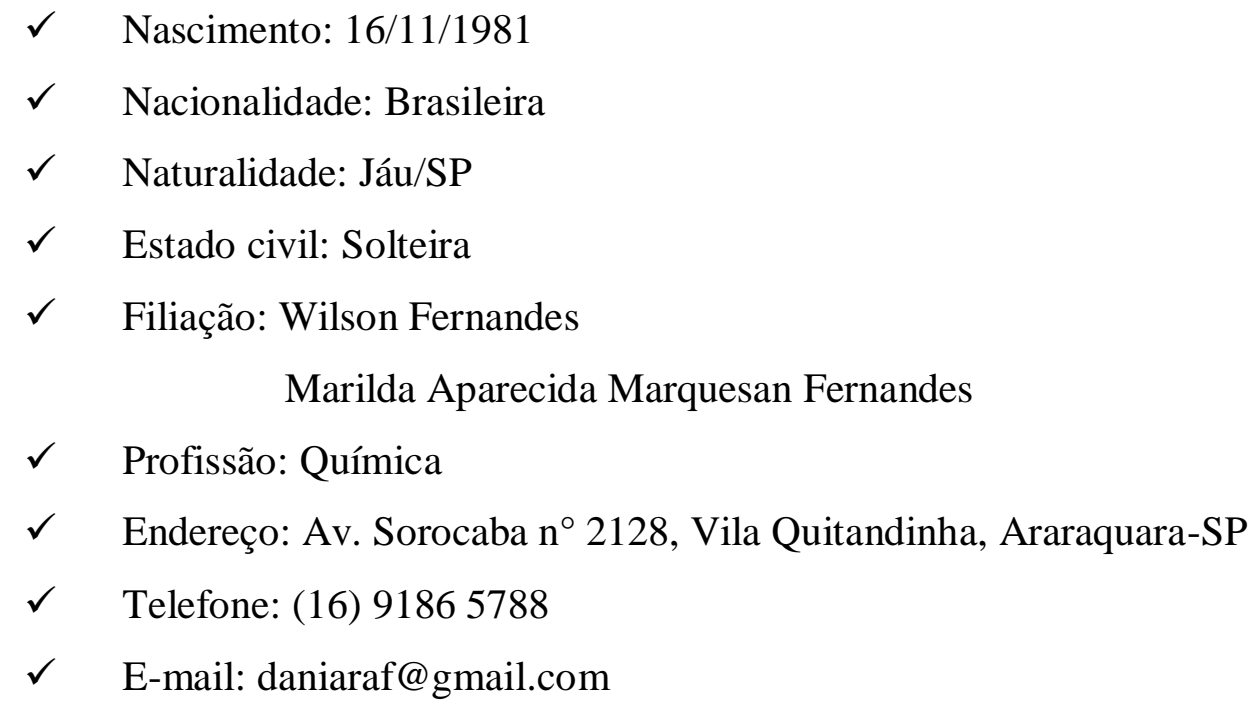

$\checkmark \quad$ Nacionalidade: Brasileira

$\checkmark \quad$ Naturalidade: Jáu/SP

$\checkmark \quad$ Estado civil: Solteira

$\checkmark \quad$ Filiação: Wilson Fernandes

Marilda Aparecida Marquesan Fernandes

$\checkmark \quad$ Profissão: Química

$\checkmark \quad$ Endereço: Av. Sorocaba $\mathrm{n}^{\circ} 2128$, Vila Quitandinha, Araraquara-SP

$\checkmark \quad$ Telefone: (16) 91865788

$\checkmark \quad$ E-mail: daniaraf@gmail.com

\section{FORMAÇÃO ACADÊMICA}

\section{$\checkmark \quad$ Licenciatura em Química}

Instituto de Química de Araraquara, Universidade Estadual Paulista “Júlio de Mesquita Filho"

Período: 2003-2007

$\checkmark \quad$ Mestrado em Química

Área de Concentração: Química Orgânica

Instituto de Química de Araraquara, Universidade Estadual Paulista "Júlio de Mesquita Filho" 


\section{ESTÁGIOS REALIZADOS}

\section{$\checkmark \quad$ Iniciação à Pesquisa Científica}

Título do projeto: Estudo químico e atividade antioxidante de Pterogyne nitens (Leguminosae)

Instituto de Química de Araraquara, Universidade Estadual Paulista "Júlio de Mesquita Filho"

Orientação: Dulce Helena Siqueira Silva

Período: 2006-2007

Bolsa: Fundação de Amparo a Pesquisa do Estado de São Paulo-FAPESP

\section{PARTICIPAÇÕES EM CONGRESSOS E COMISSÕES}

$\checkmark \quad$ Perfil químico e atividade biológica das folhas de Garcinia xanthochymus (clusiaceae). 2009. 17 ${ }^{\circ}$ Encontro Regional da Sociedade Brasileira de Química, Araraquara-SP.

$\checkmark \quad$ Obtenção e estudo do potencial de híbridos orgânico-inorgânicos para aplicações como filtros em protetores solares. 2009. $17^{\circ}$ Encontro Regional da Sociedade Brasileira de Química, Araraquara-SP.

The leaves chemical profile and biological activity of Garcinia xanthochymus. 2009. $2^{\circ}$ Brazilian Conference on Natural Products, São Pedro-SP.

$\checkmark \quad$ Perfil químico e atividade biológica das folhas de Garcinia xanthochymus (Clusiaceae). 2009. 32ª Reunião Anual da Sociedade Brasileira de Química, Fortaleza-CE.

$\checkmark \quad$ Perfil cromatográfico por HPLC-DAD e atividade biológica dos extratos dos frutos de Eugenia jambolana (Myrtaceae). 2009. 32 $2^{\text {a }}$ Reunião Anual da Sociedade Brasileira de Química, Fortaleza-CE.

$\checkmark \quad$ Identificação de triterpenos e esteróides de Pterogyne nitens (FabaceaeCaesalpinioideae) utilizando cromatografia gasosa de alta resolução. 2008. XII Congresso Latino-Americano de Cromatografia e Técnicas Relacionadas e III Simpósio Brasileiro de Cromatografia e Técnicas Afins, Florianópolis-SC.

Atividade sequestradora de radicais livres de extratos obtidos de Pterogyne nitens (Fabaceae). 2007. Simpósio Paulista de Farmacognosia, Araraquara-SP. 
Myeloperoxidase inhibitory flavonoids from fruits and leaves of Pterogyne nitens (Fabaceae). 2007. $48^{\text {th }}$ Annual Meeting of the American Society of Pharmacognosy, Portland-OR, EUA.

$\checkmark \quad$ Avaliação eletroquímica de flavonóides isolados de Pterogyne nitens (Fabaceae) empregando voltametria cíclica. 2007. 30 Reunião Anual da Sociedade Brasileira de Química, Águas de Lindóia-SP.

$\checkmark \quad$ Interaction of potential antimalarial guanidine alkaloids from Pterogyne nitens (Leguminosae) with heme using spectrophotometry. 2007. $6^{\text {th }}$ International Congress of Pharmaceutical Sciences, Ribeirão Preto-SP.

Mieloperoxidase inhibitory flavonoids from fruits and leaves of Pterogyne nitens (Fabaceae). 2007. $1^{\text {st }}$ Brazilian Conference on Natural Products, São Pedro-SP.

$\checkmark \quad$ Study of interaction of potential antimalarial guanidine alkaloids and flavonoids from Pterogyne nitens (Leguminosae) with heme using spectrophotometry. 2007. $1^{\text {st }}$ Brazilian Conference on Natural Products, São Pedro-SP.

Alternativas às barreiras encontradas na aplicação de teorias pedagógicas no ensino de química. 2007. 30ª Reunião Anual da Sociedade Brasileira de Química, Águas de Lindóia-SP.

$\checkmark \quad$ Pterogyne nitens (FABACEAE) como fonte de produtos naturais bioativos. 2007. XV Jornadas de Jóvenes Investigadores de la Asociación de Universidades Grupo Montevideo, Assunción, Paraguai.

Ação antioxidante e constituintes químicos de Pterogyne nitens (Leguminosae). 2006. XVIII Congresso de Iniciação Científica da UNESP, Bauru-SP.

Atividade antiinflamatória e constituintes químicos das folhas de Pterogyne nitens (Leguminosae). 2006. 29a Reunião Anual da Sociedade Brasileira de Química, Águas de Lindóia-SP.

$\checkmark \quad$ Busca de substâncias antioxidantes em Pterogyne nitens (Leguminosae) empregando cromatografia líquida de alta eficiência com detecção eletroquímica. 2006. II Simpósio Brasileiro de Cromatografia e Técnicas Afins, São Pedro-SP.

$\checkmark \quad \mathrm{O}$ desenvolvimento de uma concepção científica através de metodologias alternativas. 2006. XIII Encontro Nacional do Ensino de Química, Campinas-SP.

$\checkmark \quad$ Três diferentes concepções geradas a partir de uma parceria Universidade-Escola Pública diferenciada. 2006. 29a Reunião Anual da Sociedade Brasileira de Química, Águas de Lindóia-SP. 
Atividade antiinflamatória e constituintes químicos das folhas de Pterogyne nitens (Leguminosae). 2006. I Escola de Inverno da USP-RP.

$\checkmark \quad$ Estudo dos constituintes químicos de baixa polaridade de Pterogyne nitens (Leguminosae). 2005. XII Congresso de Iniciação científica da UNESP, Araraquara-SP.

$\checkmark$ Espaços não-formais: motivação para a aprendizagem do ensino de física promovendo a educação científica. 2005. V Encontro Nacional de Pesquisa em Educação em Ciências, Bauru-SP.

$\checkmark \quad$ Centro de Ciências de Araraquara: Plantão de Dúvidas. 2004. II Evento de Educação em Química, Araraquara-SP.

Educação científica em espaços não-formais promovendo o ensino de química. 2004. XII Encontro Nacional do Ensino de Química, Goiânia-GO.

$\checkmark \quad$ Plantão de dúvidas como agente facilitador no processo ensino-aprendizagem em Química. 2004. XII Encontro Nacional do Ensino de Química, Goiânia-GO.

$\checkmark$ Comissão organizadora do VI Simpósio e VI Reunião de Avaliação do Programa Biota-Fapesp, 2008, Araraquara-SP.

Organização do III e IV Workshop do NuBBE, 2008 e 2009, Araraquara-SP.

\section{TRABALHOS CIENTÍFICOS PUBLICADOS}

$\checkmark \quad$ Regasini, L. O.; Vieira-Júnior, G. M.; Fernandes, D. C.; Bolzani, V. S.; Cavalheiro, A. J.; Silva, D. H. S. Identification of triterpenes and sterols from Pterogyne nitens (Fabaceae-Caesalpinioideae) using high-resolution gas chromatography. Journal of the Chilean Chemical Society. v. 54, n. 3, p. 218-221, 2009.

Regasini L. O.; Fernandes D. C.; Silva D. H. S.; Furlan M.; Barreiro E. J.L.; Young M. C. M.; Bolzani V. Constituintes químicos das flores de Pterogyne nitens (Caesalpinioideae). Química Nova. v. 31, p. 802-806, 2008.

$\checkmark \quad$ Fernandes D. C.; Regasini L. O.; Vellosa J.C. R.; Oliveira O. M.; Bolzani V.; CastroGamboa I.; Silva D. H. S. Myeloperoxidase inhibitory and radical scavenging activities of flavones from Pterogyne Nitens. Chemical and Pharmaceutical Bulletin, v. 56, n. 5, p. 723-726, 2008. 


\section{INFORMAÇÕES ADICIONAIS}

$\checkmark$ Premiações:

- Auxílio-mérito pelo trabalho intitulado “Avaliação eletroquímica de flavonóides isolados de Pterogyne nitens (Fabaceae) empregando voltametria cíclica" apresentado na $30^{\mathrm{a}}$ Reunião Anual da Sociedade Brasileira de Química.

- Resumo completo selecionado pela PROEX entre os 40 melhores da UNESP. O trabalho intitulado como "Pterogyne nitens (FABACEAE) como fonte de produtos naturais Bioativos" foi selecionado para apresentação oral e premiado como melhor trabalho na categoria de Produtos naturais bioativos e suas aplicações, Reunião da AUGM, Assunción, Paraguai, 2007.

- Seleção entre os alunos do Instituto de Química/Araraquara/UNESP para cursar a disciplina intersemestral "Métodos Modernos de Caracterização Estrutural e Dinâmica de proteínas" oferecida pelo Instituto de Química da UNICAMP em janeiro de 2007. 
Aos meus pais Wilson Fernandes e Marilda Ap. M. Fernandes que me auxiliaram a continuar com dedicação esta pesquisa, por toda compreensão, por terem lutado para eu chegar à universidade e por estarem sempre comigo...

As minhas irmãs e verdadeiras amigas Daniele G. Fernandes e Daniane M. Fernandes, por compartilharem solidariamente a alegria das vitórias e o dissabor dos insucessos...

Ao meu noivo Marco Aurélio Cebim, minha maior conquista e credor do meu amor, carinho e respeito... 


\section{AGRADECIMENTOS}

Foram longos momentos de desafios e provações, porém momentos de intenso aprendizado e prazer. Muitas pessoas se notabilizaram por suas relevantes e despretensiosas cooperações, por isso terão seus nomes merecidamente mencionados, como forma de perpetuar suas valiosas participações. Meu grato reconhecimento:

À Deus por estar ao meu lado mesmo quando eu estava longe e perdida...

À doce prof ${ }^{a}$ Dra. Dulce Helena Siqueira Silva que me proporcionou grandes oportunidades de aprendizado, me mostrando sempre as opções e me apoiando nas minhas decisões. Agradeço pela confiança em mim depositada durante a realização deste trabalho e ainda, pelos ensinamentos, que com sua seriedade, tranquilidade e conhecimento, me guiaram para caminhos corretos e compensadores. Agradeço por ter despertado em mim o interesse pelo estudo das plantas. Muito obrigada...

Ao meu mestre Dr. Ian Castro-Gamboa, pesquisador obstinado e perfeccionista, o qual instigou minha paixão pela Química Orgânica e mesmo que distante, sua ousadia, motivação, alegria e capacidade intelectual me contagiam...

À prof ${ }^{a}$ Dra. Márcia Nasser e à prof ${ }^{a}$ Dra. Ângela R. Araújo, por sempre estarem dispostas a transmitir seus valiosos ensinamentos e por me incentivarem nesta longa caminhada. Meu estimado apreço pelo exemplo de docente, pesquisador e principalmente ao exemplo relacionado ao valor da vida...

Aos professores Dra. Vanderlan da Silva Bolzani, Dr. Alberto Cavalheiro, Dr. Lúcia Xavier, Dr. Maysa Furlan, Dra. Isabele Rodrigues Nascimento e Dra. Lourdes C. dos Santos, pela convivência e pelo aprendizado durante meus seis anos no laboratório...

Aos professores, membros da banca, que gentilmente aceitaram o convite de ler este manuscrito...

Ao Dr. Nivaldo Boralle, pela realização dos espectros de RMN, por seus valiosos conhecimentos e ensinamentos, pelos bons momentos de descontração, pela sua seriedade e disponibilidade em resolver meus "pepinos" e claro, por cuidar muito bem do Nerinho. Um cão é a única coisa na terra que nos ama mais do que ama a sí mesmo...

Ao Dr. Alberto C. Alécio, pela amizade, compreensão, por seus ensinamentos, por estar sempre solícito quando é necessário, e principalmente pela humildade em lidar com as pessoas. Admiro pessoas como vc...

Aos professores Dr. Norberto Peporine (USP- Ribeirão Preto) e ao especialista em 
Laboratório Dr. José Carlos Tomaz, pela realização dos espectros de massas, imprescindíveis para a elucidação estrutural das substâncias isoladas neste trabalho...

Ao professor Antonio Gilberto Ferreira da Universidade Federal de São Carlos pelas medidas dinâmicas de RMN...

Ao prof $^{\circ}$ Dr. Wagner Vilegas e em especial as doutorandas Juliana Severi e Juliana Rodrigues pela presteza na realização das medidas ópticas...

À prof ${ }^{a}$ Dra. Mary Rosa R. de Marchi e seu orientado Flavio Soares Silva pela disponibilidade do equipamento de CG-EM...

Aos Professores integrantes do Projeto Temático Biota/Bioprospecta-Fapesp e seus orientados pela realização dos ensaios farmacológicos. Em especial as alunas Tarsia, pelo ensaio quimiopreventivo; Mariana, pelo ensaio tripanocida e Luciana pelos ensaios antifúngicos...

Ao meu amigo, irmão e mestre Dr. Luis Octávio Regasini pelo seu esmero e dedicação na pesquisa e transmissão de conhecimentos científicos agregados a valores éticos (elementos fundamentais para uma boa qualificação profissional) e pelas oportunidades concedidas para meu aperfeiçoamento acadêmico, as quais têm me permitido acessar novos campos de estudo. "Espero corresponder às suas expectativas."

Aos amigos Amanda, Marcos, Marília, Vanessa, Sheila, Carol, Welington, Aline, Néia, Mike, Ana, Juliana, Thais, Luciene, Andréinha, João Marcos, Sílvia, Lidiane, Marcos Marçal, Sara, Otávio, Luciana, Magela, Vânia, Vivi, Cristiano e Fernando, por terem me ensinado muito sobre suas experiências em Química de Produtos Naturais, durante o período de Graduação e Pós-Graduação, cujo aprendizado acelerou o amadurecimento da minha formação científica. "Sou grata pelas informações que produziram atalhos, e pelo apoio emocional que me fortaleceu durante a caminhada."

À minha amiga Alessandra Cr. Dametto, minha parceira no estudo fitoquímico, nos grupos de sala de aula, nas confraternizações, nos congressos e como não se lembrar, das incansáveis organizações. Muito obrigada por fazer parte da minha história...

As minhas amigas inseparáveis Adriana, Sheila, Patrícia e Rosilene "O quarteto fantástico", ou melhor, "As agregadas" e à Thayz, por me ajudarem sempre, me acolherem e me ouvirem. Por tudo que vivemos juntas desde a graduação até hoje, amigas verdadeiras que quero sempre em minha vida, mesmo longe...

Aos colegas da gradução Aroldo, Flavia, João Medeiros, Leandro, Mônica, Éderson, Fabrícia, Renata, Jeane, Paulo, Ademar e Jorge, por fazerem parte da minha vida até hoje...

À FAPESP pela bolsa concedida e apoio financeiro ao projeto. 
"Primeiro aprenda a ser um artesão. Isso não impedirá você de ser um gênio".

Eugène Delacroix 


\section{RESUMO}

A espécie Garcinia xanthochymus, comumente conhecida como Gamboja, é uma árvore nativa da Índia com aproximadamente 8-10 metros, utilizada extensamente na medicina popular como antidiarréica. Este trabalho descreve o estudo químico e biológico das folhas e frutos de G. xanthochymus. Dentre as substâncias isoladas, podemos destacar 3 triterpenos obtidos do extrato hexânico das folhas: friedelina (1), lanosta-8,24-dien-3-ol (2) e lanosta7,24-dien-3-ol (3), sendo as substâncias 2 e 3 relatadas pela primeira vez na literatura da espécie. A prospecção química da fase acetato de etila das folhas revelou uma abundante presença de biflavonóides, sendo as substâncias saharanflavona (4), I3, II8-biapigenina (5), GB1a (6), (+)-morelloflavona (8), GB2a (11), volkensiflavona (12), GB2 (14), xantochimusídeo (15) e fukugisídeo (16), caracterizadas pela ligação interflavonoídica do tipo $3 \rightarrow 8$ ', e as substâncias podocarpusflavona (7) e amentoflavona (9), pela ligação do tipo 3' $\rightarrow 8$ '. Merece destaque a substância 4, isolada pela primeira vez de fontes naturais. A composição química de $G$. xanthochymus constituiu-se ainda das substâncias diidrokaempferol (10), ácido vanílico (13), cinco derivados de ácidos fenilpropanoídicos: ácido 3-O-cafeoilquínico (17), ácido 5-O-cafeoilquínico (18), ácido 3-p-coumaroilquínico (21), ácido 4-O-cafeoilquínico (22) e ácido 4-p-coumaroilquínico (23); e ainda a mistura binária das benzofenonas xantochimol (19) e cicloxantochimol (20). Todas as substâncias foram relatadas pela primeira vez nas folhas de G. xanthochymus, com exceção da substância 7 e as substâncias 10, 13, 17, 18, 21, 22 e 23 ainda não haviam sido identificadas na espécie. Através da técnica CG-DIC foram identificados 15 triterpenos e/ou esteróides nos extratos de baixa polaridade e através das técnicas hifenadas, como CLAE-UV e CLAE-EM, foi possível localizar substâncias já isoladas e/ou isoladas em trabalhos anteriores. Os resultados observados para os ensaios antioxidantes utilizando-se o radical DPPH evidenciaram a importância dos grupos catecólicos como essenciais para uma excelente ação antioxidante. Em relação à atividade antifúngica os extratos etanólico e hexânico dos frutos de G. xanthochymus apresentaram resultados muito atrativos, com CIM de $1,95 \mu \mathrm{g} / \mathrm{mL}$, oito vezes menor que o apresentado pelo padrão comercial fluconazol $(\mathrm{CIM}=16,0 \mu \mathrm{g} / \mathrm{mL})$. A (+)-morelloflavona $(8)$ mostrou elevada capacidade de indução da atividade da enzima quinona redutase, comparável ao da 4'-bromoflavona (padrão comercial), evidenciando o potencial quimiopreventivo de G. xanthochymus.

Palavras-chave: Garcinia xanthochymus. Biflavonóide. Bioprospecção. 


\section{ABSTRACT}

The species Garcinia xanthochymus, known as Gamboja is a native Indian tree ca. 8-10 m high, which is extensively used as folk medicine for treating diarrhea and dysentery. This work describes the study of the chemical profile of $G$. xanthochymus leaves and fruits. Among the isolated substances three triterpenes were obtained from the hexane extract of the leaves: friedelin (1), lanosta-8,24-dien-3-ol (2) e lanosta-7,24-dien-3-ol (3), with compounds (2) and (3) described for the first time in the literature of this species. The chemical prospection of the ethyl acetate extract of the leaves revealed an abundant amount of biflavonoids, with compounds saharanflavone (4), I3,II8-biapigenin (5), GB1a (6), (+)morelloflavone (8), GB2a (11), volkensiflavone (12), GB2 (14), xanthochymuside (15) and fukugiside (16) characterized by the interflavonoid $3 \rightarrow 8$ " bond, and compounds podocarpusflavone (7) and amentoflavone (9), by the interflavonoid $3^{\prime} \rightarrow 8^{\prime}$ ' bond. Substance 4 was isolated for the first time from a natural source. The chemical composition of G. xanthochymus included additionally dihydrokaempferol (10), vanillic acid (13), and five phenylpropanoid acid derivatives: 3-O-caffeoylquinic acid (17), 5-O-caffeoylquinic acid (18), 3-p-coumaroylquinic acid (21), 4- $O$-caffeoylquinic acid (22) and 4- $p$ coumaroylquinic acid (23); as well a binary mixture of xanthochymol (19) and cyclexanthochymol (20) benzophenones. All the compounds were reported for the first time in the leaves of G. xanthochymus, with the exception of compound 7, and compounds 10, 13, 17, 18, 21, 22 e 23, which had not yet been identified in this species. By CG-FID technique fifteen triterpenes and/or steroids were identified in the low polarity extracts. Hyphenated techniques such as HPLC-UV and HPLC-MS were used to locate previously isolated compounds from different fractions and/or isolated substances from other works. The bioactivity evaluation of extracts, semipurified fracions and pure compounds from $G$. xanthochymus displayed attractive results. The free radical scavenging assay with DPPH radical confirmed the importance of the cathecol group as essential for optimum antioxidant action. The ethanol and hexane extracts from the fruits of G. xanthochymus showed potent antifungal activity $(\mathrm{MIC}=1.95 \mu \mathrm{g} / \mathrm{mL}), c a$. eight times lower than the commercial standard fluconazole (MIC=16,0 $\mu \mathrm{g} / \mathrm{mL})$. Additionally, (+)-morelloflavone (8) showed strong induction of quinone reductase enzyme activity, comparable to the positive control 4'bromoflavone, evidencing the chemopreventive potential of G. xanthochymus.

Keywords: Garcinia xanthochymus. Biflavonoid. Bioprospection. 


\section{LISTA DE FIGURAS}

Figura 1 - Foto de diferentes partes de Garcinia xanthochymus.

Figura 2 - Algumas classes de substâncias isoladas da espécie de Garcinia xanthochymus.

Figura 3 - Esquema geral da rota biossintética de flavonóides (ACC-acetil CoAcarboxilase, CS-chalcona sintetase e CI-chalcona isomerase).

Figura 4 - Estrutura de biflavonóides tipo flavona-flavona.

Figura 5 - Experimento de RMN ${ }^{1} \mathrm{H}$ para a (士)-morelloflavona (Li et al., 2002) em temperaturas variáveis. $\mathrm{O}$ sinal $\mathbf{1 a}$ representa o confôrmero principal e $\mathbf{1 b}$ o confôrmero minoritário.

Figura 6 - Representação do equilíbrio entre as EROs e as defesas antioxidantes do nosso organismo (BARREIROS; DAVID; DAVID, 2006).

Figura 7 - Fracionamento cromatográfico dos frutos de Garcinia xanthochymus.

Figura 8 - Fracionamento cromatográfico das folhas de Garcinia xanthochymus.

Figura 9 - Fracionamento cromatográfico da fração AcOEt-FOL de Garcinia xanthochymus em coluna de permeação em gel (LH-20, Sephadex $\left.{ }^{\circledR}\right)$.

Figura 10 - Fracionamento cromatográfico da fração AcOEt-FOL de Garcinia xanthochymus em coluna de fase normal (sílica-gel 60-230 $\mu$ ).

Figura 11 - Fracionamento cromatográfico da fração BuOH-FOL de Garcinia xanthochymus.

Figura 12 - Cromatograma analítico obtido via CLAE-UV da subfração AcOEt-FOL-14, eluída com MeOH: $\mathrm{H}_{2} \mathrm{O}: \mathrm{HOAc}(57: 42,5: 0,5)$ e detecção em $\lambda=254 \mathrm{~nm}$.

Figura 13 - Cromatogramas analíticos obtidos via CLAE-UV das subfrações (a) AcOEtFOL-15 e (b) AcOEt-FOL-16, eluídas com MeOH: $\mathrm{H}_{2} \mathrm{O}$ : HOAc $(75: 24,5: 0,5)$ e detecção em $\lambda=254 \mathrm{~nm}$.

Figura 14 - Cromatogramas analíticos obtidos via CLAE-UV das subfrações (a) AcOEtSIL-3 e (b) AcOEt-SIL-9, eluídas com MeOH: $\mathrm{H}_{2} \mathrm{O}$ : $\mathrm{HOAc}(45: 54,5: 0,5)$ e detecção em $\lambda=254 \mathrm{~nm}$.

Figura 15 - Cromatogramas analíticos obtidos via CLAE-UV das subfrações (a) AcOEtSIL-4, eluída com MeOH: $\mathrm{H}_{2} \mathrm{O}: \mathrm{HOAc}(60: 39,5: 0,5)$ e (b) AcOEt-SIL-5, eluídas com $\mathrm{MeOH}: \mathrm{H}_{2} \mathrm{O}$ : $\mathrm{HOAc}(50: 49,5: 0,5)$.

Figura 16 - Cromatograma analítico obtido via CLAE-UV da subfração AcOEt-SIL-11, eluída com MeOH: $\mathrm{H}_{2} \mathrm{O}$ : HOAc $(35: 64,5: 0,5)$ e detecção em $\lambda=254 \mathrm{~nm}$. 
Figura 17 - Cromatograma analítico obtido via CLAE-UV da subfração BuOH-FOL-6, eluída com MeOH: $\mathrm{H}_{2} \mathrm{O}$ : HOAc $(20: 79,5: 0,5)$ e detecção em $\lambda=254 \mathrm{~nm}$.

Figura 18 - Cromatoplaca da subfração AcOEt-FRU-7 com (a) revelação física em $\lambda=254$ $\mathrm{nm}$ e (b) revelação química com anisaldeído sulfúrico (c) Cromatograma analítico da subfração AcOEt-FRU-7, obtido em coluna ODS (Phenomenex,

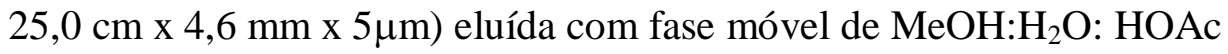
(75:24,5:0,5) e detecção em $\lambda=254 \mathrm{~nm}$.

Figura 19 - Cromatograma analítico obtido via CLAE-UV do extrato ETOH (a) e das frações AcOEt (b), $\mathrm{BuOH}$ (c) e HA (d) dos frutos (acima) e das folhas (abaixo) de Garcinia xanthochymus no modo gradiente em $\mathrm{H}_{2} \mathrm{O}: \mathrm{MeOH}$ (95:5) até $\mathrm{MeOH}$ (100) e suporte cromatográfico: ODS (Phenomenex, 25,0 cm x 4,6 mm x $5 \mu \mathrm{m})$.

Figura 20 - Espectro no UV de algumas substâncias isoladas da fração AcOEt-FOL de Garcinia xanthochymus.

Figura 21 - Espectro de massas da substância 1 obtido por CG-EM (IE=+70 eV). 70

Figura 22 - Espectro vibracional na região do IV da substância 1. 71

Figura 23 - Proposta de fragmentação da substância 1.

Figura 24 - Espectro vibracional na região do IV da substância 2.

Figura 25 - Espectro de massas da substância 2 obtido por CG-EM (IE= + 70 eV). 73

Figura 26 - Proposta de fragmentação da substância 2.

Figura 27 - Estrutura da substância 4. (a) Cromatograma analítico e (b) espectro de absorção da substância 4 obtido via CLAE-UV-DAD no modo isocrático 1:1 (MeOH: $\mathrm{H}_{2} \mathrm{O}$ ) e suporte cromatográfico: ODS (Phenomenex, 25,0 cm x 4,6 mm $\mathrm{x} 5 \mu \mathrm{m})$.

Figura 28 - Espectro vibracional na região do IV da substância 4.

Figura 29 - Espectro de massas de primeira-ordem da substância 4 obtido no modo negativo (ESI).

Figura 30 - Estrutura da substância 5. (a) Cromatograma analítico e (b) espectro de absorção da substância 5 obtido via CLAE-UV-DAD no modo isocrático 1:1 (MeOH: $\mathrm{H}_{2} \mathrm{O}$ ) e suporte cromatográfico: ODS (Phenomenex, 25,0 cm x 4,6 mm $\mathrm{x} 5 \mu \mathrm{m})$

Figura 31 - Espectro vibracional na região do IV da substância 5.

Figura 32 - Espectro de massas de primeira-ordem da substância 5 obtido no modo negativo (ESI). 
Figura 33 - Estrutura da substância 8. (a) Cromatograma analítico e (b) espectro de absorção da substância 8 obtido via CLAE-UV-DAD no modo isocrático 1:1 ( $\mathrm{MeOH}: \mathrm{H}_{2} \mathrm{O}$ ) e suporte cromatográfico: ODS (Phenomenex, 25,0 cm x 4,6 mm $\mathrm{x} 5 \mu \mathrm{m})$.

Figura 34 - Espectro vibracional na região do IV da substância 8.

Figura 35 - Espectro de massas (a) de primeira e (b) segunda-ordem da substância 8, obtido em modo negativo com energia de colisão de 5\% para EM2 (ESI).

Figura 36 - Proposta de fragmentação da substância 8.

Figura 37 - Curva de dicroísmo circular (DC) da substância 8.

Figura 38 - Estruturas do confôrmero principal (8a) e minoritário (8b) da morelloflavona.

Figura 39 - Estrutura da substância 9. (a) Cromatograma analítico e (b) espectro de absorção da substância 9 obtido via CLAE-UV-DAD no modo isocrático 1:1 $\left(\mathrm{MeOH}: \mathrm{H}_{2} \mathrm{O}\right.$ ) e suporte cromatográfico: ODS (Phenomenex, 25,0 cm x 4,6 mm x $5 \mu \mathrm{m})$.

Figura 40 - Espectro vibracional na região do IV da substância 9.

Figura 41 - Espectro de massas de primeira-ordem da substância 9 obtido no modo negativo (ESI).

Figura 42 - Estrutura da substância 10. (a) Cromatograma analítico e (b) espectro de absorção da substância 10 obtido via CLAE-UV-DAD no modo isocrático 1:1 ( $\mathrm{MeOH}: \mathrm{H}_{2} \mathrm{O}$ ) e suporte cromatográfico: ODS (Phenomenex, 25,0 cm x 4,6 mm x $5 \mu \mathrm{m})$.

Figura 43 - Espectro vibracional na região do IV da substância 10.

Figura 44 - Espectro de massas (a) de primeira e (b) segunda-ordem da substância 10, obtido em modo negativo com energia de colisão de $10 \%$ para EM2 (ESI).

Figura 45 - Proposta de fragmentação da substância 10.

Figura 46 - Curva de dicroísmo circular (DC) da substância 10.

Figura 47 - Estrutura da substância 11. (a) Cromatograma analítico e (b) espectro de absorção da substância 11 obtido via CLAE-UV-DAD no modo isocrático 1:1 (MeOH: $\mathrm{H}_{2} \mathrm{O}$ ) e suporte cromatográfico: ODS (Phenomenex, 25,0 cm x 4,6 mm x $5 \mu \mathrm{m})$.

Figura 48 - Espectro vibracional na região do IV da substância 11.

Figura 49 - Espectro de massas (a) de primeira e (b) segunda-ordem da substância 11, obtido em modo negativo com energia de colisão de 15\% para EM2 (ESI). 95

Figura 50 - Proposta de fragmentação da substância 11. 
Figura 51 - Experimento de RMN ${ }^{1} \mathrm{H}$ com temperatura variável da substância 11.

Figura 52 - Estrutura da substância 12. (a) Cromatograma analítico e (b) espectro de absorção da substância 12 obtido via CLAE-UV-DAD no modo isocrático 1:1 (MeOH: $\mathrm{H}_{2} \mathrm{O}$ ) e suporte cromatográfico: ODS (Phenomenex, 25,0 cm x 4,6 mm x $5 \mu \mathrm{m})$.

Figura 53 - Espectro vibracional na região do IV da substância 12.

Figura 54 - Espectro de massas (a) de primeira e (b) segunda-ordem da substância 12, obtido em modo negativo com energia de colisão de 10\% para EM2 (ESI).

Figura 55 - Proposta de fragmentação da substância 12.

Figura 56 - Curva de dicroísmo circular (DC) da substância 12.

Figura 57 - Estrutura da substância 13. (a) Cromatograma analítico e (b) espectro de absorção da substância 13 obtido via CLAE-UV-DAD no modo isocrático 1:1 ( $\mathrm{MeOH}: \mathrm{H}_{2} \mathrm{O}$ ) e suporte cromatográfico: ODS (Phenomenex, 25,0 cm x 4,6 mm x $5 \mu \mathrm{m})$.

Figura 58 - Espectro vibracional na região do IV da substância 13.

Figura 59 - Espectro de massas (a) de primeira e (b) segunda-ordem da substância 13, obtido em modo negativo com energia de colisão de 10\% para EM2 (ESI). 105

Figura 60 - Proposta de fragmentação da substância 13.

Figura 61 - Estrutura da substância 14. (a) Cromatograma analítico e (b) espectro de absorção da substância 14 obtido via CLAE-UV-DAD no modo isocrático 1:1 ( $\mathrm{MeOH}: \mathrm{H}_{2} \mathrm{O}$ ) e suporte cromatográfico: ODS (Phenomenex, 25,0 cm x 4,6 mm x $5 \mu \mathrm{m})$.

Figura 62 - Curva de dicroísmo circular (DC) das substâncias (a) 11 e (b) 14.

Figura 63 - Espectro de massas (a) de primeira e (b) segunda-ordem da substância 14, obtido em modo negativo com energia de colisão de 15\% para EM2 (ESI). 108

Figura 64 - Proposta de fragmentação da substância 14.

Figura 65 - Estruturas das substâncias 17 e 18. (a) Cromatogramas analíticos e (b) espectros de absorção das substâncias 17 e 18 obtido via CLAE-UV-DAD no modo isocrático 35:75 (MeOH: $\left.\mathrm{H}_{2} \mathrm{O}\right)$ e suporte cromatográfico: ODS

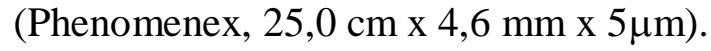

Figura 66 - Espectro vibracional na região do IV da substância 17.

Figura 67 - Estrutura do ácido quínico. (a) conformação de maior estabilidade. (b) conformação de menor estabilidade evidenciando interação 1,3-diaxial entre a carboxila e a hidroxila em C5. 
Figura 68 - Espectro de massas (a) de primeira e (b) segunda-ordem da substância 17, obtido em modo negativo com energia de colisão de 15\% para EM2 (ESI).

Figura 69 - Proposta de fragmentação da substância 17.

Figura 70 - Espectro de massas (a) de primeira e (b) segunda-ordem da substância 18, obtido em modo negativo com energia de colisão de 15\% para EM2 (ESI).

Figura 71 - Proposta de fragmentação da substância 18.

Figura 72 - Cromatograma analítico de alguns constituintes majoritários obtido via CLAEUV-DAD das subfrações (a) AcOEt-FRU-13 (b) e AcOEt-FRU-17, no modo gradiente em $\mathrm{H}_{2} \mathrm{O}: \mathrm{MeOH}$ (95:5) até $\mathrm{MeOH}$ (100) e suporte cromatográfico:

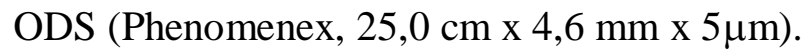

Figura 73 - Espectro de massas (a) de primeira e (b) segunda-ordem da substância 24, obtido em modo negativo com energia de colisão de 15\% para EM2 (ESI).

Figura 74 - Espectro de massas de primeira-ordem da substância 25 obtido no modo negativo (ESI).

Figura 75 - Proposta de fragmentação da substância 24.

Figura 76 - Proposta de fragmentação da substância 25.

Figura 77 - Estruturas das xantonas padrão utilizadas no processo de desreplicação das substâncias 24 e 25.

Figura 78 - (a) Espectro de absorção da substância 24, da xantona 1 e cromatograma analítico da xantona 1 (b) Espectro de absorção da substância 25, xantona 2 e cromatograma analítico da xantona 2. Modo gradiente em $\mathrm{H}_{2} \mathrm{O}: \mathrm{MeOH}$ (95:5) até $\mathrm{MeOH}$ (100) e suporte cromatográfico: ODS (Phenomenex, 25,0 cm x 4,6 $\mathrm{mm} \times 5 \mu \mathrm{m})$.

Figura 79 - Espectro de absorção no UV comparativo (a) da substância 11 e o pico 2 da fração AcOEt-FRU-17 e (b) da substância 14 e o pico 1 da fração AcOEt-FRU17.

Figura 80 - Espectro de massas (a) de primeira e (b) segunda-ordem dos picos 1 (esquerda) e 2 (direita) da subfração AcOEt-FRU-17, obtido em modo negativo com energia de colisão de 15\% para EM2 (ESI).

Figura 81 - (a) Cromatograma analítico e (b) espectro de absorção da substância 6 obtido via CLAE-UV-DAD no modo isocrático 1:1 ( $\left.\mathrm{MeOH}: \mathrm{H}_{2} \mathrm{O}\right)$ e suporte cromatográfico: ODS (Phenomenex, 25,0 cm x 4,6 mm x 5 $\mu \mathrm{m}$ ).

Figura 82 - Espectro de RMN de ${ }^{1} \mathrm{H}(500 \mathrm{MHz})$ da substância 6 (DMSO- $d_{6}$ ).

Figura 83 - Espectro de massas (a) de primeira e (b) segunda-ordem da substância 6, obtido em modo negativo com energia de colisão de 15\% para EM2 (ESI).

Figura 84 - Proposta de fragmentação da substância 6. 
Figura 85 - Espectro de RMN de ${ }^{1} \mathrm{H}(500 \mathrm{MHz})$ da substância 7 (DMSO- $d_{6}$ ).

Figura 86 - Espectro de massas de primeira-ordem da substância 7 obtido no modo negativo (ESI).

Figura 87 - Espectro de RMN de ${ }^{1} \mathrm{H}(500 \mathrm{MHz})$ da substância 15 (DMSO-d $)$.

Figura 88 - Espectro de RMN de ${ }^{1} \mathrm{H}(500 \mathrm{MHz})$ da substância 16 (DMSO-d $)$.

Figura 89 - Espectro de massas (a) de primeira e (b) segunda-ordem da substância 15, obtido em modo negativo com energia de colisão de 10\% para EM2 (ESI).

Figura 90 - Espectro de massas de primeira-ordem da substância 16 obtido no modo negativo (ESI).

Figura 91 - Cromatograma analítico e (b) espectro de absorção da subfração AcOEt-FRU-7 obtido via CLAE-UV-DAD no modo isocrático $\mathrm{MeOH}: \mathrm{H}_{2} \mathrm{O}: \mathrm{HOAc}$ (75:24,5:0,5), suporte cromatográfico: ODS (Phenomenex, 25,0 cm x 4,6 mm x $5 \mu \mathrm{m})$ e detecção em $\lambda=254 \mathrm{~nm}$.

Figura 92 - Espectro de RMN de ${ }^{1} \mathrm{H}(500 \mathrm{MHz})$ das substâncias 19 e 20 (DMSO- $\left.d_{6}\right) . \quad 128$

Figura 93 - Espectro de massas (a) de primeira e (b) segunda-ordem da subfração AcOEtFRU-7, obtido em modo negativo com energia de colisão de $30 \%$ para EM2 (ESI).

Figura 94 - Espectro de massas (a) de primeira e (b) segunda-ordem da substância 22, obtido em modo negativo com energia de colisão de 15\% para EM2 (ESI).

Figura 95 - Espectro de massas de primeira e segunda-ordem obtido em modo negativo com energia de colisão de 15\% para EM2 (ESI) da (a) substância 21 e da (b) substância 23.

Figura 96 - Estruturas dos triterpenos e esteróides identificados nos extratos e frações de baixa polaridade de Garcinia xanthochymus.

Figura 97 - Perfil cromatográfico (CG-DIC) em SPB-5 (a) do HEX-FRU [ $38 \mathrm{t}_{\mathrm{r}}=22,05 ; 39$ $\mathrm{t}_{\mathrm{r}}=23,38 ; 35 \mathrm{t}_{\mathrm{r}}=23,82 ; 27 \mathrm{t}_{\mathrm{r}}=24,43$ e $\left.32 \mathrm{t}_{\mathrm{r}}=26,84\right]$ (b) da FR. HEX-FOL [39 $\mathrm{t}_{\mathrm{r}}=23,38 ; \mathbf{3 5} \mathrm{t}_{\mathrm{r}}=23,75 ; \mathbf{2 7} \mathrm{t}_{\mathrm{r}}=24,33$ e $\left.32 \mathrm{t}_{\mathrm{r}}=26,75\right]$ (c) e do EXT-FOL [ $37 \mathrm{t}_{\mathrm{r}}=20,41$ e $34 t_{r}=24,82$ ], em presença de colesterol (padrão interno).

Figura 98 - Perfil cromatográfico (CG-DIC) em SPB-50 (a) do HEX-FRU [ $38 \mathrm{t}_{\mathrm{r}}=17,29 ; 39$ $\mathrm{t}_{\mathrm{r}}=19,24 ; \mathbf{3 5} \mathrm{t}_{\mathrm{r}}=22,97 ; \mathbf{2 7} \mathrm{t}_{\mathrm{r}}=24,06$ e $\left.\mathbf{3 2} \mathrm{t}_{\mathrm{r}}=25,46\right]$ (b) da FR. HEX-FOL [39 $\mathrm{t}_{\mathrm{r}}=19,11 ; \mathbf{3 5} \mathrm{t}_{\mathrm{r}}=22,80 ; \mathbf{2 7} \mathrm{t}_{\mathrm{r}}=23,31$ e $\left.\mathbf{3 2} \mathrm{t}_{\mathrm{r}}=25,35\right]$ (c) e do EXT-FOL [ $\mathbf{3 7} \mathrm{t}_{\mathrm{r}}=15,86$ e $34 t_{r}=25,64$ ], em presença de colesterol (padrão interno).

Figura 99 - Gráfico da curva de concentração dos extratos e frações (a) das folhas e dos (b) frutos de G. xanthochymus versus a \% de seqüestro de DPPH. 


\section{LISTA DE TABELAS}

Tabela 1 - Substâncias isoladas de Garcinia xanthochymus e bioatividades relatadas nas referências citadas.

Tabela 2 - Intervalos de absorção no UV para diferentes tipos de flavonóides.

Tabela 3 - Dados de RMN de ${ }^{13} \mathrm{C}(125 \mathrm{MHz})$ das substâncias 1, 2 e 3 em $\mathrm{CDCl}_{3}$.

Tabela 4 - Dados de RMN de ${ }^{1} \mathrm{H}(500 \mathrm{MHz})$ e RMN de ${ }^{13} \mathrm{C}(125 \mathrm{MHz})$ da substância 4 (DMSO- $d_{6}$ ).

Tabela 5 - Dados de RMN de ${ }^{1} \mathrm{H}(500 \mathrm{MHz})$ e RMN de ${ }^{13} \mathrm{C}(125 \mathrm{MHz})$ da substância 5 $\left(\mathrm{DMSO}-d_{6}\right)$.

Tabela 6 - Dados de RMN de ${ }^{1} \mathrm{H}(500 \mathrm{MHz})$ e RMN de ${ }^{13} \mathrm{C}(125 \mathrm{MHz})$ da substância 8 $\left(\mathrm{DMSO}-d_{6}\right)$.

Tabela 7 - Dados de RMN de ${ }^{1} \mathrm{H}(500 \mathrm{MHz})$ e RMN de ${ }^{13} \mathrm{C}(125 \mathrm{MHz})$ da substância 9 (DMSO- $d_{6}$ ).

Tabela 8 - Dados de RMN de ${ }^{1} \mathrm{H}(500 \mathrm{MHz})$ e RMN de ${ }^{13} \mathrm{C}$ (125 MHz) da substância 10 (DMSO- $d_{6}$ ).

Tabela 9 - Dados de RMN de ${ }^{1} \mathrm{H}(500 \mathrm{MHz})$ e RMN de ${ }^{13} \mathrm{C}(125 \mathrm{MHz})$ da substância 11 $\left(\mathrm{DMSO}-d_{6}\right)$.

Tabela 10 - Dados de RMN de ${ }^{1} \mathrm{H}(500 \mathrm{MHz})$ e RMN de ${ }^{13} \mathrm{C}(125 \mathrm{MHz})$ da substância 12 $\left(\mathrm{DMSO}-d_{6}\right)$.

Tabela 11 - Dados de RMN de ${ }^{1} \mathrm{H}$ (500 MHz) e RMN de ${ }^{13} \mathrm{C}$ (125 MHz) da substância 13 $\left(\mathrm{DMSO}-d_{6}\right)$.

Tabela 12 - Dados de RMN de ${ }^{1} \mathrm{H}$ (500 MHz) e RMN de ${ }^{13} \mathrm{C}$ (125 MHz) da substância 14 (DMSO- $d_{6}$ ).

Tabela 13 - Dados de RMN de ${ }^{1} \mathrm{H}(500 \mathrm{MHz})$ e RMN de ${ }^{13} \mathrm{C}(125 \mathrm{MHz})$ da substância 17 (DMSO- $d_{6}$ ).

Tabela 14 - Fragmentos obtidos dos analitos isolados de G. xanthochymus a partir da análise por EM e EM2 obtido em modo negativo com energia de colisão de $15 \%$.

Tabela 15 - Dados de RMN de ${ }^{1} \mathrm{H}(500 \mathrm{MHz})$ das substâncias 19 e 20 (DMSO- $d_{6}$ ).

Tabela 16 - Fragmentos obtidos de benzofenonas isoladas de G. xanthochymus através de EM e EM2.

Tabela 17 - Valores da retenção relativa das amostras com o colesterol. 
Tabela 18 - Atividade antioxidante dos extratos e frações de Garcinia xanthochymus frente ao radical DPPH.

Tabela 19 - Atividade inibitória in vitro no ensaio de formação de $\beta$-Hematina para os extratos e frações de Garcinia xanthochymus.

Tabela 20 - Atividade antifúngica in vitro dos extratos e frações de G. xanthochymus frente a fungos patogênicos humanos.

Tabela 21 - Atividade biológica dos constituintes isolados das folhas e frutos de Garcinia xanthochymus.

Tabela 22 - Atividade tripanocida dos extratos e frações de G. xanthochymus.

Tabela 23 - Avaliação da taxa de indução (IR) da atividade de QR em linhagem Hepa1c1c7 para 8. 


\section{LISTA DE ANEXOS}

Anexo 1. Espectro de RMN de ${ }^{1} \mathrm{H}$ da substância 1. ................................................... 156

Anexo 2. Ampliação do espectro de RMN de ${ }^{1} \mathrm{H}$ da substância 1. .................................156

Anexo 3. Ampliação do espectro de RMN de ${ }^{1} \mathrm{H}$ da substância 1. .................................157

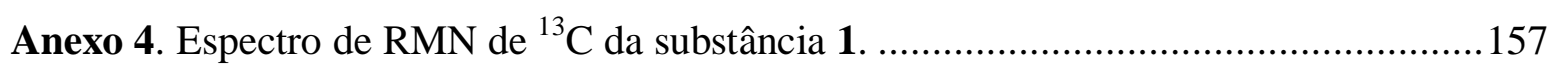

Anexo 5. Ampliação do espectro de RMN de ${ }^{13} \mathrm{C}$ da substância 1. .................................158

Anexo 6. Ampliação do espectro de $\mathrm{RMN}$ de ${ }^{13} \mathrm{C}$ da substância 1. .................................158

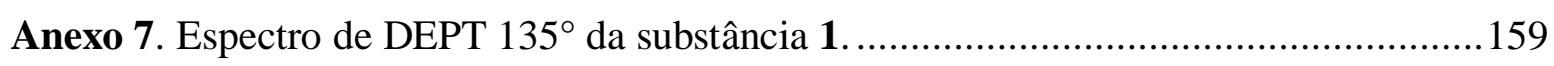

Anexo 8. Ampliação do espectro de DEPT $135^{\circ}$ da substância 1..................................159

Anexo 9. Espectro de DEPT $90^{\circ}$ da substância 1........................................................160

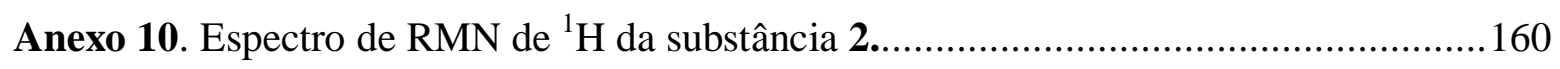

Anexo 11. Ampliação do espectro de RMN de ${ }^{1} \mathrm{H}$ da substância 1..................................161

Anexo 12. Ampliação do espectro de RMN de ${ }^{1} \mathrm{H}$ da substância 2..................................161

Anexo 13. Espectro de RMN de ${ }^{13} \mathrm{C}$ da substância 2 ....................................................162

Anexo 14. Ampliação do espectro de $\mathrm{RMN}$ de ${ }^{13} \mathrm{C}$ da substância 2. ................................162

Anexo 15. Ampliação do espectro de $\mathrm{RMN}$ de ${ }^{13} \mathrm{C}$ da substância 2. ...............................163

Anexo 16. Espectro de DEPT $135^{\circ}$ da substância 2 ................................................ 163

Anexo 17. Ampliação do espectro de DEPT $135^{\circ}$ da substância 2 ................................ 164

Anexo 18. Ampliação do espectro de DEPT $135^{\circ}$ da substância 2 ................................164

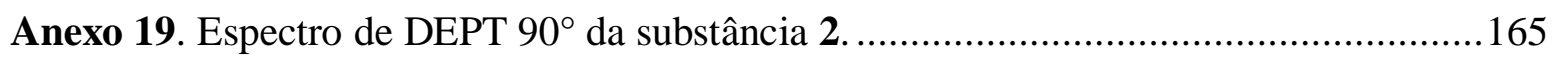

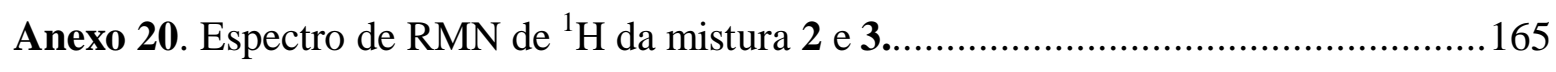

Anexo 21. Espectro de RMN de ${ }^{13} \mathrm{C}$ da mistura 2 e 3................................................... 166

Anexo 22. Ampliação do espectro de $\mathrm{RMN}$ de ${ }^{13} \mathrm{C}$ da mistura 2 e 3. ..............................166

Anexo 23. Ampliação do espectro de $\mathrm{RMN}$ de ${ }^{13} \mathrm{C}$ da mistura 2 e 3. ...............................167

Anexo 24. Ampliação do espectro de $\mathrm{RMN}$ de ${ }^{13} \mathrm{C}$ da mistura 2 e 3. ...............................167

Anexo 25. Espectro de RMN de ${ }^{1} \mathrm{H}$ da substância 4...................................................168

Anexo 26. Ampliação do espectro de RMN de ${ }^{1} \mathrm{H}$ da substância 4...................................168

Anexo 27. Mapa de contorno ${ }^{1} \mathrm{H}^{-}{ }^{1} \mathrm{H} g \mathrm{COSY}$ da substância 4. .......................................169

Anexo 28. Ampliação do mapa de contorno ${ }^{1} \mathrm{H}-{ }^{1} \mathrm{H} g \mathrm{COSY}$ da substância 4. ....................169

Anexo 29. Mapa de contorno ${ }^{1} \mathrm{H}^{13} \mathrm{C} g \mathrm{HMQC}$ da substância 4 .................................... 170

Anexo 30. Ampliação do mapa de contorno ${ }^{1} \mathrm{H}^{-13} \mathrm{C} g \mathrm{HMQC}$ da substância 4 ..................170

Anexo 31. Mapa de contorno ${ }^{1} \mathrm{H}^{13}{ }^{13} \mathrm{C} g \mathrm{HMBC}$ da substância 4.....................................171

Anexo 32. Ampliação do mapa de contorno ${ }^{1} \mathrm{H}^{-13} \mathrm{C} g \mathrm{HMBC}$ da substância 4.................171 
Anexo 33. Ampliação do mapa de contorno ${ }^{1} \mathrm{H}^{-13} \mathrm{C} g \mathrm{HMBC}$ da substância 4. .................172

Anexo 34. Ampliação do mapa de contorno ${ }^{1} \mathrm{H}^{-13} \mathrm{C} g \mathrm{HMBC}$ da substância 4.................172

Anexo 35. Espectro de HOMODEC da substância 4 ......................................................173

Anexo 36. Espectro de NOESY 1D (irradiação em $\delta_{H}$ 6,25) da substância 4...................173

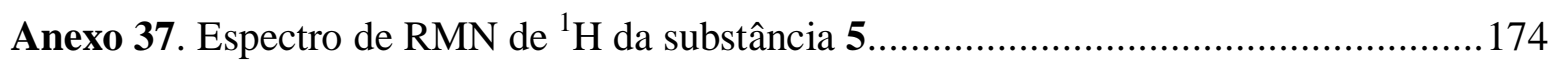

Anexo 38. Ampliação do espectro de RMN de ${ }^{1} \mathrm{H}$ da substância 5..................................174

Anexo 39. Espectro de $\mathrm{RMN}$ de ${ }^{13} \mathrm{C}$ da substância 5....................................................175

Anexo 40. Ampliação do espectro de RMN de ${ }^{13} \mathrm{C}$ da substância 5. ...............................175

Anexo 41. Ampliação do espectro de RMN de ${ }^{13} \mathrm{C}$ da substância 5. ...............................176

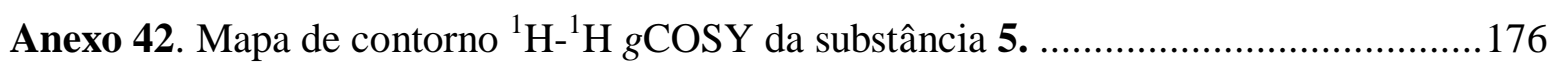

Anexo 43. Ampliação do mapa de contorno ${ }^{1} \mathrm{H}-{ }^{1} \mathrm{H} g \mathrm{COSY}$ da substância 5...................177

Anexo 44. Mapa de contorno ${ }^{1} \mathrm{H}^{13} \mathrm{C} g \mathrm{HMQC}$ da substância 5.....................................177

Anexo 45. Ampliação do mapa de contorno ${ }^{1} \mathrm{H}^{13} \mathrm{C} g \mathrm{HMQC}$ da substância 5..................178

Anexo 46. Ampliação do mapa de contorno ${ }^{1} \mathrm{H}^{-13} \mathrm{C} g \mathrm{HMQC}$ da substância 5.................178

Anexo 47. Ampliação do mapa de contorno ${ }^{1} \mathrm{H}_{-}{ }^{13} \mathrm{C} g \mathrm{HMQC}$ da substância 5..................179

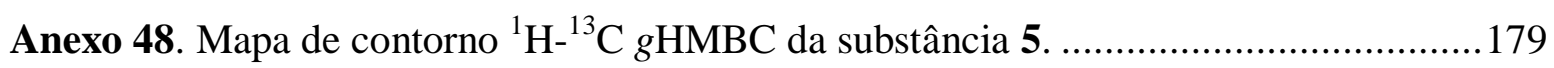

Anexo 49. Ampliação do mapa de contorno ${ }^{1} \mathrm{H}_{-}{ }^{13} \mathrm{C} g \mathrm{HMBC}$ da substância 5..................180

Anexo 50. Ampliação do mapa de contorno ${ }^{1} \mathrm{H}^{13} \mathrm{C} g \mathrm{HMBC}$ da substância 5..................180

Anexo 51. Ampliação do mapa de contorno ${ }^{1} \mathrm{H}^{13}{ }^{13} \mathrm{C} \mathrm{HMBC}$ da substância 5..................181

Anexo 52. Ampliação do mapa de contorno ${ }^{1} \mathrm{H}^{13}{ }^{13} \mathrm{C} g \mathrm{HMBC}$ da substância 5..................181

Anexo 53. Ampliação do mapa de contorno ${ }^{1} \mathrm{H}^{-13} \mathrm{C} g \mathrm{HMBC}$ da substância 5..................182

Anexo 54. Espectro de RMN de ${ }^{1} \mathrm{H}$ da substância 8..................................................... 182

Anexo 55. Ampliação do espectro de RMN de ${ }^{1} \mathrm{H}$ da substância 8..................................183

Anexo 56. Mapa de contorno ${ }^{1} \mathrm{H}^{-}{ }^{1} \mathrm{H} g \mathrm{COSY}$ da substância 8. ......................................183

Anexo 57. Ampliação do mapa de contorno ${ }^{1} \mathrm{H}-{ }^{1} \mathrm{H} g \mathrm{COSY}$ da substância 8. ....................184

Anexo 58. Mapa de contorno ${ }^{1} \mathrm{H}^{-13} \mathrm{C} g \mathrm{HMQC}$ da substância 8......................................184

Anexo 59. Ampliação do mapa de contorno ${ }^{1} \mathrm{H}_{-}{ }^{13} \mathrm{C} g \mathrm{HMQC}$ da substância 8..................185

Anexo 60. Ampliação do mapa de contorno ${ }^{1} \mathrm{H}^{-13} \mathrm{C} g \mathrm{HMQC}$ da substância 8..................185

Anexo 61. Ampliação do mapa de contorno ${ }^{1} \mathrm{H}^{-13} \mathrm{C} g \mathrm{HMQC}$ da substância 8..................186

Anexo 62. Mapa de contorno ${ }^{1} \mathrm{H}_{-}{ }^{13} \mathrm{C} g \mathrm{HMBC}$ da substância 8 .......................................186

Anexo 63. Ampliação do mapa de contorno ${ }^{1} \mathrm{H}_{-}{ }^{13} \mathrm{C} g \mathrm{HMBC}$ da substância 8. .................187

Anexo 64. Ampliação do mapa de contorno ${ }^{1} \mathrm{H}^{13}{ }^{13} \mathrm{C} \mathrm{HMBC}$ da substância 8..................187

Anexo 65. Ampliação do mapa de contorno ${ }^{1} \mathrm{H}^{13}{ }^{13} \mathrm{C} g \mathrm{HMBC}$ da substância 8. .................188

Anexo 66. Ampliação do mapa de contorno ${ }^{1} \mathrm{H}^{-13} \mathrm{C} g \mathrm{HMBC}$ da substância 8..................188 
Anexo 67. Ampliação do mapa de contorno ${ }^{1} \mathrm{H}^{-13} \mathrm{C} g \mathrm{HMBC}$ da substância 8. .................189

Anexo 68. Ampliação do mapa de contorno ${ }^{1} \mathrm{H}^{-13} \mathrm{C} g \mathrm{HMBC}$ da substância 8.................189

Anexo 69. Ampliação do mapa de contorno ${ }^{1} \mathrm{H}^{-13} \mathrm{C} g \mathrm{HMBC}$ da substância 8..................190

Anexo 70. Ampliação do mapa de contorno ${ }^{1} \mathrm{H}^{-13} \mathrm{C} g \mathrm{HMBC}$ da substância 8..................190

Anexo 71. Espectro de RMN de ${ }^{1} \mathrm{H}$ da substância 9.................................................... 191

Anexo 72. Ampliação do espectro de RMN de ${ }^{1} \mathrm{H}$ da substância 9...................................191

Anexo 73. Ampliação do espectro de RMN de ${ }^{1} \mathrm{H}$ da substância 9...................................192

Anexo 74. Espectro de RMN de ${ }^{13} \mathrm{C}$ da substância 9.....................................................192

Anexo 75. Ampliação do espectro de RMN de ${ }^{13} \mathrm{C}$ da substância 9. ................................193

Anexo 76. Ampliação do espectro de RMN de ${ }^{13} \mathrm{C}$ da substância 9. ................................193

Anexo 77. Mapa de contorno ${ }^{1} \mathrm{H}^{-1} \mathrm{H} g \mathrm{COSY}$ da substância 9. .......................................194

Anexo 78. Ampliação do mapa de contorno ${ }^{1} \mathrm{H}-{ }^{1} \mathrm{H} g \mathrm{COSY}$ da substância 9. ....................194

Anexo 79. Mapa de contorno ${ }^{1} \mathrm{H}^{13} \mathrm{C} g \mathrm{HMQC}$ da substância 9......................................195

Anexo 80. Ampliação do mapa de contorno ${ }^{1} \mathrm{H}_{-}{ }^{13} \mathrm{C} g \mathrm{HMQC}$ da substância 9..................195

Anexo 81. Ampliação do mapa de contorno ${ }^{1} \mathrm{H}^{-13} \mathrm{C} g \mathrm{HMQC}$ da substância 9..................196

Anexo 82. Mapa de contorno ${ }^{1} \mathrm{H}_{-}{ }^{13} \mathrm{C} g \mathrm{HMBC}$ da substância 9.......................................196

Anexo 83. Ampliação do mapa de contorno ${ }^{1} \mathrm{H}^{13}{ }^{13} \mathrm{C} \mathrm{HMBC}$ da substância 9..................197

Anexo 84. Ampliação do mapa de contorno ${ }^{1} \mathrm{H}^{13}{ }^{13} \mathrm{C} g \mathrm{HMBC}$ da substância 9..................197

Anexo 85. Ampliação do mapa de contorno ${ }^{1} \mathrm{H}^{13}{ }^{13} \mathrm{C} \mathrm{HMBC}$ da substância 9..................198

Anexo 86. Espectro de RMN de ${ }^{1} \mathrm{H}$ da substância 10.....................................................198

Anexo 87. Ampliação do espectro de RMN de ${ }^{1} \mathrm{H}$ da substância 10.................................199

Anexo 88. Mapa de contorno ${ }^{1} \mathrm{H}^{-}{ }^{1} \mathrm{H} g \mathrm{COSY}$ da substância 10.......................................199

Anexo 89. Ampliação do mapa de contorno ${ }^{1} \mathrm{H}-{ }^{1} \mathrm{H} g \mathrm{COSY}$ da substância 10. .................200

Anexo 90. Ampliação do mapa de contorno ${ }^{1} \mathrm{H}-{ }^{1} \mathrm{H} g \mathrm{COSY}$ da substância 10. .................200

Anexo 91. Mapa de contorno ${ }^{1} \mathrm{H}^{13} \mathrm{C} g \mathrm{HMQC}$ da substância 10. ...................................201

Anexo 92. Ampliação do mapa de contorno ${ }^{1} \mathrm{H}^{-13} \mathrm{C} g \mathrm{HMQC}$ da substância 10...............201

Anexo 93. Mapa de contorno ${ }^{1} \mathrm{H}^{13}{ }^{13} \mathrm{C} g \mathrm{HMBC}$ da substância 10. ...................................202

Anexo 94. Ampliação do mapa de contorno ${ }^{1} \mathrm{H}^{-13} \mathrm{C} g \mathrm{HMBC}$ da substância 10. ...............202

Anexo 95. Ampliação do mapa de contorno ${ }^{1} \mathrm{H}^{13}{ }^{13} \mathrm{C} g \mathrm{HMBC}$ da substância 10................203

Anexo 96. Ampliação do mapa de contorno ${ }^{1} \mathrm{H}_{-}{ }^{13} \mathrm{C} g \mathrm{HMBC}$ da substância 10...............203

Anexo 97. Espectro de RMN de ${ }^{1} \mathrm{H}$ da substância 11....................................................204

Anexo 98. Ampliação do espectro de RMN de ${ }^{1} \mathrm{H}$ da substância 11................................204

Anexo 99. Ampliação do espectro de RMN de ${ }^{1} \mathrm{H}$ da substância 11................................205

Anexo 100. Espectro de RMN de ${ }^{13} \mathrm{C}$ da substância 11................................................205 
Anexo 101. Ampliação do espectro de RMN de ${ }^{13} \mathrm{C}$ da substância 11.............................206

Anexo 102. Ampliação do espectro de RMN de ${ }^{13} \mathrm{C}$ da substância 11............................206

Anexo 103. Ampliação do espectro de RMN de ${ }^{13} \mathrm{C}$ da substância 11.............................207

Anexo 104. Ampliação do espectro de RMN de ${ }^{13} \mathrm{C}$ da substância 11.............................207

Anexo 105. Espectro de DEPT $135^{\circ}$ da substância 11 ....................................................208

Anexo 106. Ampliação do espectro de DEPT $135^{\circ}$ da substância 11.............................208

Anexo 107. Ampliação do espectro de DEPT $135^{\circ}$ da substância 11. .............................209

Anexo 108. Mapa de contorno ${ }^{1} \mathrm{H}^{-1} \mathrm{H} g \mathrm{COSY}$ da substância 11......................................209

Anexo 109. Ampliação do mapa de contorno ${ }^{1} \mathrm{H}-{ }^{1} \mathrm{H} g \operatorname{COSY}$ da substância 11. ...............210

Anexo 110. Ampliação do mapa de contorno ${ }^{1} \mathrm{H}-{ }^{1} \mathrm{H} g \operatorname{COSY}$ da substância 11. ...............210

Anexo 111. Ampliação do mapa de contorno ${ }^{1} \mathrm{H}-{ }^{1} \mathrm{H} g \operatorname{COSY}$ da substância 11. ...............211

Anexo 112. Mapa de contorno ${ }^{1} \mathrm{H}^{-}{ }^{13} \mathrm{C} g \mathrm{HMQC}$ da substância 11..................................211

Anexo 113. Ampliação do mapa de contorno ${ }^{1} \mathrm{H}-{ }^{13} \mathrm{C} g \mathrm{HMQC}$ da substância 11 ..............212

Anexo 114. Ampliação do mapa de contorno ${ }^{1} \mathrm{H}-{ }^{13} \mathrm{C} g \mathrm{HMQC}$ da substância 11..............212

Anexo 115. Ampliação do mapa de contorno ${ }^{1} \mathrm{H}^{13}{ }^{13} \mathrm{C} g \mathrm{HMQC}$ da substância 11.............213

Anexo 116. Mapa de contorno ${ }^{1} \mathrm{H}^{13}{ }^{13} \mathrm{C} g \mathrm{HMBC}$ da substância 11. .................................213

Anexo 117. Ampliação do mapa de contorno ${ }^{1} \mathrm{H}^{13}{ }^{13} \mathrm{C} g \mathrm{HMBC}$ da substância 11. .............214

Anexo 118. Ampliação do mapa de contorno ${ }^{1} \mathrm{H}-{ }^{13} \mathrm{C} g \mathrm{HMBC}$ da substância 11. .............214

Anexo 119. Ampliação do mapa de contorno ${ }^{1} \mathrm{H}-{ }^{13} \mathrm{C} g \mathrm{HMBC}$ da substância 11.............215

Anexo 120. Ampliação do mapa de contorno ${ }^{1} \mathrm{H}-{ }^{13} \mathrm{C} g \mathrm{HMBC}$ da substância 11. .............215

Anexo 121. Ampliação do mapa de contorno ${ }^{1} \mathrm{H}-{ }^{13} \mathrm{C} g \mathrm{HMBC}$ da substância 11. .............216

Anexo 122. Ampliação do mapa de contorno ${ }^{1} \mathrm{H}-{ }^{13} \mathrm{C} g \mathrm{HMBC}$ da substância 11. .............216

Anexo 123. Ampliação do mapa de contorno ${ }^{1} \mathrm{H}^{13}{ }^{13} \mathrm{C} g \mathrm{HMBC}$ da substância 11. .............217

Anexo 124. Ampliação do mapa de contorno ${ }^{1} \mathrm{H}^{13}{ }^{13} \mathrm{C} g \mathrm{HMBC}$ da substância 11. ............217

Anexo 125. Ampliação do mapa de contorno ${ }^{1} \mathrm{H}-{ }^{13} \mathrm{C} g \mathrm{HMBC}$ da substância 11. .............218

Anexo 126. Espectro de RMN de ${ }^{1} \mathrm{H}$ da substância 12 ..................................................218

Anexo 127. Ampliação do espectro de RMN de ${ }^{1} \mathrm{H}$ da substância 12 ..............................219

Anexo 128. Espectro de RMN de ${ }^{13} \mathrm{C}$ da substância 12 .............................................219

Anexo 129. Ampliação do espectro de $\mathrm{RMN}$ de ${ }^{13} \mathrm{C}$ da substância 12 ............................220

Anexo 130. Ampliação do espectro de RMN de ${ }^{13} \mathrm{C}$ da substância 12.............................220

Anexo 131. Ampliação do espectro de RMN de ${ }^{13} \mathrm{C}$ da substância 12.............................221

Anexo 132. Mapa de contorno ${ }^{1} \mathrm{H}-{ }^{1} \mathrm{H} g \mathrm{COSY}$ da substância 12....................................22

Anexo 133. Ampliação do mapa de contorno ${ }^{1} \mathrm{H}-{ }^{1} \mathrm{H} g \mathrm{COSY}$ da substância 12 ................222

Anexo 134. Ampliação do mapa de contorno ${ }^{1} \mathrm{H}-{ }^{1} \mathrm{H} g \operatorname{COSY}$ da substância 12 ...............222 
Anexo 135. Mapa de contorno ${ }^{1} \mathrm{H}^{13}{ }^{13} \mathrm{C} g \mathrm{HMQC}$ da substância 12..................................223

Anexo 136. Ampliação do mapa de contorno ${ }^{1} \mathrm{H}^{-13} \mathrm{C} g \mathrm{HMQC}$ da substância 12 .............223

Anexo 137. Ampliação do mapa de contorno ${ }^{1} \mathrm{H}^{-13} \mathrm{C} g \mathrm{HMQC}$ da substância 12.............224

Anexo 138. Ampliação do mapa de contorno ${ }^{1} \mathrm{H}^{13}{ }^{13} \mathrm{C} g \mathrm{HMQC}$ da substância 12 .............224

Anexo 139. Ampliação do mapa de contorno ${ }^{1} \mathrm{H}^{1}{ }^{13} \mathrm{C} g \mathrm{HMQC}$ da substância 12 .............22 25

Anexo 140. Ampliação do mapa de contorno ${ }^{1} \mathrm{H}-{ }^{13} \mathrm{C} g \mathrm{HMQC}$ da substância 12 ..............225

Anexo 141. Mapa de contorno ${ }^{1} \mathrm{H}^{-}{ }^{13} \mathrm{C} g \mathrm{HMBC}$ da substância 12. .................................226

Anexo 142. Ampliação do mapa de contorno ${ }^{1} \mathrm{H}^{-13} \mathrm{C} g \mathrm{HMBC}$ da substância 12. ............226

Anexo 143. Ampliação do mapa de contorno ${ }^{1} \mathrm{H}^{-13} \mathrm{C} g \mathrm{HMBC}$ da substância 12. .............227

Anexo 144. Ampliação do mapa de contorno ${ }^{1} \mathrm{H}^{13}{ }^{13} \mathrm{C} g \mathrm{HMBC}$ da substância 12. ............227

Anexo 145. Ampliação do mapa de contorno ${ }^{1} \mathrm{H}^{-13} \mathrm{C} g \mathrm{HMBC}$ da substância 12. .............228

Anexo 146. Ampliação do mapa de contorno ${ }^{1} \mathrm{H}^{13}{ }^{13} \mathrm{C} g \mathrm{HMBC}$ da substância 12. .............228

Anexo 147. Espectro de RMN de ${ }^{1} \mathrm{H}$ da substância 13...................................................229

Anexo 148. Ampliação do espectro de RMN de ${ }^{1} \mathrm{H}$ da substância 13...............................229

Anexo 149. Mapa de contorno ${ }^{1} \mathrm{H}^{-1} \mathrm{H} g \mathrm{COSY}$ da substância 13.....................................230

Anexo 150. Ampliação do mapa de contorno ${ }^{1} \mathrm{H}-{ }^{1} \mathrm{H} g \operatorname{COSY}$ da substância 13. ...............230

Anexo 151. Mapa de contorno ${ }^{1} \mathrm{H}^{-}{ }^{13} \mathrm{C} g \mathrm{HMQC}$ da substância 13.................................2231

Anexo 152. Ampliação do mapa de contorno ${ }^{1} \mathrm{H}-{ }^{13} \mathrm{C} g \mathrm{HMQC}$ da substância 13.............231

Anexo 153. Mapa de contorno ${ }^{1} \mathrm{H}^{-}{ }^{13} \mathrm{C} g \mathrm{HMBC}$ da substância 13. .................................232

Anexo 154. Ampliação do mapa de contorno ${ }^{1} \mathrm{H}-{ }^{13} \mathrm{C} g \mathrm{HMBC}$ da substância 13. .............232

Anexo 155. Espectro de RMN de ${ }^{1} \mathrm{H}$ da substância 14...................................................233

Anexo 156. Ampliação do espectro de RMN de ${ }^{1} \mathrm{H}$ da substância 14...............................233

Anexo 157. Ampliação do espectro de RMN de ${ }^{1} \mathrm{H}$ da substância 14...............................234

Anexo 158. Espectro de $\mathrm{RMN}$ de ${ }^{13} \mathrm{C}$ da substância 14...............................................2234

Anexo 159. Ampliação do espectro de $\mathrm{RMN}$ de ${ }^{13} \mathrm{C}$ da substância 14.............................235

Anexo 160. Ampliação do espectro de $\mathrm{RMN}$ de ${ }^{13} \mathrm{C}$ da substância 14............................235

Anexo 161. Ampliação do espectro de $\mathrm{RMN}$ de ${ }^{13} \mathrm{C}$ da substância 14............................226

Anexo 162. Mapa de contorno ${ }^{1} \mathrm{H}^{-1} \mathrm{H} g \mathrm{COSY}$ da substância 14....................................2...26

Anexo 163. Ampliação do mapa de contorno ${ }^{1} \mathrm{H}-{ }^{1} \mathrm{H} g \mathrm{COSY}$ da substância 14. ...............237

Anexo 164. Ampliação do mapa de contorno ${ }^{1} \mathrm{H}-{ }^{1} \mathrm{H} g \mathrm{COSY}$ da substância 14. ...............237

Anexo 165. Mapa de contorno ${ }^{1} \mathrm{H}^{-13} \mathrm{C} g \mathrm{HMQC}$ da substância 14..................................238

Anexo 166. Ampliação do mapa de contorno ${ }^{1} \mathrm{H}-{ }^{13} \mathrm{C} g \mathrm{HMQC}$ da substância 14..............238

Anexo 167. Ampliação do mapa de contorno ${ }^{1} \mathrm{H}^{13}{ }^{13} \mathrm{C} g \mathrm{HMQC}$ da substância 14..............239

Anexo 168. Mapa de contorno ${ }^{1} \mathrm{H}^{-}{ }^{13} \mathrm{C} g \mathrm{HMBC}$ da substância 14. .................................239 
Anexo 169. Ampliação do mapa de contorno ${ }^{1} \mathrm{H}^{13}{ }^{13} \mathrm{C} \mathrm{HMBC}$ da substância 14. .............240

Anexo 170. Ampliação do mapa de contorno ${ }^{1} \mathrm{H}^{13}{ }^{13} \mathrm{C} g \mathrm{HMBC}$ da substância 14. .............240

Anexo 171. Ampliação do mapa de contorno ${ }^{1} \mathrm{H}^{-13} \mathrm{C} g \mathrm{HMBC}$ da substância 14 .............241

Anexo 172. Ampliação do mapa de contorno ${ }^{1} \mathrm{H}^{13}{ }^{13} \mathrm{C} g \mathrm{HMBC}$ da substância 14 .............241

Anexo 173. Espectro de RMN de ${ }^{1} \mathrm{H}$ da substância 17..................................................242

Anexo 174. Ampliação do espectro de $\mathrm{RMN}$ de ${ }^{1} \mathrm{H}$ da substância 17.............................242

Anexo 175. Ampliação do espectro de $\mathrm{RMN}$ de ${ }^{1} \mathrm{H}$ da substância 17.............................243

Anexo 176. Ampliação do espectro de RMN de ${ }^{1} \mathrm{H}$ da substância 17..............................243

Anexo 177. Espectro de RMN de ${ }^{13} \mathrm{C}$ da substância 17.................................................24

Anexo 178. Mapa de contorno ${ }^{1} \mathrm{H}^{-1} \mathrm{H} g \mathrm{COSY}$ da substância 17.....................................244

Anexo 179. Ampliação do mapa de contorno ${ }^{1} \mathrm{H}-{ }^{1} \mathrm{H} g \mathrm{COSY}$ da substância 17. ...............245

Anexo 180. Ampliação do mapa de contorno ${ }^{1} \mathrm{H}-{ }^{1} \mathrm{H} g \mathrm{COSY}$ da substância 17. ...............245

Anexo 181. Mapa de contorno ${ }^{1} \mathrm{H}-{ }^{13} \mathrm{C} g \mathrm{HMQC}$ da substância 17. ..................................246

Anexo 182. Ampliação do mapa de contorno ${ }^{1} \mathrm{H}^{-13} \mathrm{C} g \mathrm{HMQC}$ da substância 17 ..............246

Anexo 183. Ampliação do mapa de contorno ${ }^{1} \mathrm{H}^{13}{ }^{13} \mathrm{C} g \mathrm{HMQC}$ da substância 17..............247

Anexo 184. Ampliação do mapa de contorno ${ }^{1} \mathrm{H}^{-13} \mathrm{C} g \mathrm{HMQC}$ da substância 17.............247

Anexo 185. Mapa de contorno ${ }^{1} \mathrm{H}^{13}{ }^{13} \mathrm{C} g \mathrm{HMBC}$ da substância 17. ..................................248

Anexo 186. Ampliação do mapa de contorno ${ }^{1} \mathrm{H}-{ }^{13} \mathrm{C} g \mathrm{HMBC}$ da substância 17. .............248

Anexo 187. Ampliação do mapa de contorno ${ }^{1} \mathrm{H}^{13}{ }^{13} \mathrm{C} g \mathrm{HMBC}$ da substância 17. .............249

Anexo 188. Ampliação do mapa de contorno ${ }^{1} \mathrm{H}-{ }^{13} \mathrm{C} g \mathrm{HMBC}$ da substância 17. .............249

Anexo 189. Ampliação do mapa de contorno ${ }^{1} \mathrm{H}-{ }^{13} \mathrm{C} g \mathrm{HMBC}$ da substância 17. .............250

Anexo 190. Ampliação do mapa de contorno ${ }^{1} \mathrm{H}-{ }^{13} \mathrm{C} g \mathrm{HMBC}$ da substância 17. .............250

Anexo 191. Espectro de RMN de ${ }^{1} \mathrm{H}$ da substância 18..................................................251

Anexo 192. Ampliação do espectro de RMN de ${ }^{1} \mathrm{H}$ da substância 18..............................251

Anexo 193. Ampliação do espectro de RMN de ${ }^{1} \mathrm{H}$ da substância 18...............................252

Anexo 194. Ampliação do espectro de RMN de ${ }^{1} \mathrm{H}$ da substância 18..............................252

Anexo 195. Espectro de $\mathrm{RMN}$ de ${ }^{13} \mathrm{C}$ da substância 18...............................................253

Anexo 196. Mapa de contorno ${ }^{1} \mathrm{H}^{-1} \mathrm{H} g \mathrm{COSY}$ da substância 18......................................253

Anexo 197. Ampliação do mapa de contorno ${ }^{1} \mathrm{H}-{ }^{1} \mathrm{H} g \mathrm{COSY}$ da substância 18. ...............254

Anexo 198. Ampliação do mapa de contorno ${ }^{1} \mathrm{H}-{ }^{1} \mathrm{H} g \mathrm{COSY}$ da substância 18. ...............254

Anexo 199. Mapa de contorno ${ }^{1} \mathrm{H}^{-13} \mathrm{C} g \mathrm{HMQC}$ da substância 18..................................25

Anexo 200. Ampliação do mapa de contorno ${ }^{1} \mathrm{H}-{ }^{13} \mathrm{C} g \mathrm{HMQC}$ da substância 18.............255

Anexo 201. Ampliação do mapa de contorno ${ }^{1} \mathrm{H}-{ }^{13} \mathrm{C} g \mathrm{HMQC}$ da substância 18.............256

Anexo 202. Ampliação do mapa de contorno ${ }^{1} \mathrm{H}^{13} \mathrm{C} g \mathrm{HMQC}$ da substância 18.............256 
Anexo 203. Mapa de contorno ${ }^{1} \mathrm{H}^{13}{ }^{13} \mathrm{C} g \mathrm{HMBC}$ da substância 18. ..................................257

Anexo 204. Ampliação do mapa de contorno ${ }^{1} \mathrm{H}^{-13} \mathrm{C} g \mathrm{HMBC}$ da substância 18. .............257

Anexo 205. Ampliação do mapa de contorno ${ }^{1} \mathrm{H}^{13}{ }^{13} \mathrm{C} g \mathrm{HMBC}$ da substância 18. .............258

Anexo 206. Ampliação do mapa de contorno ${ }^{1} \mathrm{H}^{13} \mathrm{C} g \mathrm{HMBC}$ da substância 18. ............258

Anexo 207. Ampliação do mapa de contorno ${ }^{1} \mathrm{H}-{ }^{13} \mathrm{C} g \mathrm{HMBC}$ da substância 18. .............259

Anexo 208. Ampliação do mapa de contorno ${ }^{1} \mathrm{H}-{ }^{13} \mathrm{C} g \mathrm{HMBC}$ da substância 18. .............259

Anexo 209. Ampliação do mapa de contorno ${ }^{1} \mathrm{H}^{-13} \mathrm{C} g \mathrm{HMBC}$ da substância 18. .............260 


\section{ABREVIATURAS E SÍMBOLOS}

$[\alpha]_{D}^{T}$ rotação óptica

$\lambda$ comprimento de onda

$\delta_{\mathrm{H}}$ deslocamento químico de hidrogênio

$\delta_{\mathrm{C}}$ deslocamento químico de carbono

ACC enzima acetil CoA-carboxilase

ACQ ácido cafeoilquínico

AcOEt acetato de etila

AcOEt-FOL fração acetato de etila das folhas

AcOEt-FRU fração acetato de etila dos frutos

AcOEt-SIL fração acetato de etila submetida a CC-FN

$\mathrm{A} p \mathrm{CoQ}$ ácido $p$-coumaroilquínico

$\mathrm{BuOH}-\mathrm{FOL}$ fração $n$-butanólica das folhas

$\mathrm{BuOH}-\mathrm{FRU}$ fração $n$-butanólica dos frutos

CC cromatografia em coluna

CCDC cromatografia em camada delgada comparativa

CC-FN cromatografia em coluna de fase normal

$\mathrm{CDCl}_{3}$ clorofórmio deuterado

CLAE cromatografia líquida de alta eficiência

CLAE-prep cromatografia líquida de alta eficiência preparativa

CI chalcona isomerase

$\mathrm{CI}_{50}$ concentração inibitória mínima

CG cromatografia gasosa

CPG cromatografia de permeação em gel

CS chalcona sintetase

$d$ dubleto

dd duplo dubleto

DAD detector com arranjo de diodos

DEPT Distortionless Enhancement by Polarisation Transfer

DIC detector de ionização de chama

DMSO- $d_{6}$ dimetilsulfóxido deuterado

DPPH radical 2,2-difenil-1-picrilhidrazila 
DNA Ácido desoxiribonucleíco

ELL extração líquido-líquido

EM espectrometria de massa

EM2 espectrometria de massa de segunda-ordem

EROs espécies reativas de oxigênio

ESI electrospray

FR. HEX-FOL fração hexânica das folhas

ETOH-FOL extrato etanólico das folhas

ETOH-FRU extrato etanólico dos frutos

gCOSY gradient Correlated Spectroscopy

gHMBC gradient Heteronuclear Multiple Bond Correlation

gHMQC gradient Heteronuclear Multiple Quantum Coherence

GSH enzima glutationa peroxidase

GSSG enzima glutationa redutase

GST enzima glutationa $s$-transferase

$J$ constante de acoplamento

HA-FOL fração hidroalcoólica das folhas

HA-FRU fração hidroalcoólica dos frutos

HEX hexano

HEX-FOL extrato hexânico das folhas

HEX-FRU extrato hexânico dos frutos

HOAc ácido acético

HOMODEC homonuclear decoupling

IV infravermelho

IE impacto eletrônico

$m$ multipleto

$\mathrm{m}$ massa

$\mathrm{m} / \mathrm{z}$ relação massa/carga

$\mathrm{MeOH}$ metanol

MTT 3-(4,5-Dimetiltiazol-2-il)-2,5-Difenil Brometo de Tetrazólio

$n$-BuOH $n$-butanol

$\mathrm{NaOH}$ hidróxido de sódio

NOESY Nuclear overhauser effect spectroscopy

NuBBE Núcleo de Bioensaios, Biossíntese e Ecofisiologia de Produtos Naturais 
RMN de ${ }^{1} \mathrm{H}$ ressonância magnética nuclear de hidrogênio

$\mathrm{RMN}$ de ${ }^{13} \mathrm{C}$ ressonância magnética nuclear de carbono

$s$ singleto

SPB-5 coluna capilar (5\% fenil-metil-siloxano)

SPB-50 coluna capilar (50\% fenil-metil-siloxano)

SNC Sistema Nervoso Central

SOD enzima superóxido dismutase

RR retenção relativa

ODS octadecilsilano

OMS Organização Mundial da Saúde

QR quinona redutase

$\mathrm{t}_{\mathrm{r}}$ tempo de retenção

$t$ tripleto

TMS tetrametilsilano

UV ultravioleta

UV-vis ultravioleta e visível

$\mathrm{v}$ volume 


\section{SUMÁRIO}

1 INTRODUÇÃ̃

1.1 O ESTADO DA ARTE 30

1.2 A FAMÍlIa CLUSIACEAE 31

1.3 A ESPÉCIE GARCINIA XANTHOCHYMUS 32

1.4 BIFLAVONÓIDES 36

1.4.1 Atropoisomerismo 38

1.5 ATIVIDADE ANTIOXIDANTE

1.6 BIFLAVONÓIDES COMO AGENTES ANTIOXIDANTES 41

1.7 AGENTES QUIMIOPREVENTIVOS

2 JUSTIFICATIVA

$\begin{array}{ll}3 \text { OBJETIVOS } & 47\end{array}$

4 MATERIAIS E EQUIPAMENTOS 48

4.1 MÉTOdOS CROMATOGRÁFICOS $\quad 48$

4.1.1 Cromatografia em camada delgada comparativa (CCDC) 48

4.1.2 Cromatografia em coluna de fase normal (CC-FN) 48

4.1.3 Extração líquido-líquido (ELL) 49

4.1.4 Cromatografia de permeação em gel (CPG) 49

4.1.5 Cromatografia líquida de alta eficiência com detector de arranjo de diodos (CLAEDAD) $\quad 49$

4.1.6 Cromatografia líquida de alta eficiência com detector UV (CLAE-UV) 49

4.1.7 Cromatografia líquida de alta eficiência preparativa (CLAE-UV-prep) 50

4.1.8 Cromatografia gasosa $(C G) \quad 50$

4.2 ESPECTROMETRIA $\quad 50$

4.3 SOLVENTES

5 PROCEDIMENTO EXPERIMENTAL

5.1 COLETA DO MATERIAL BOTÂNICO E PREPARAÇÃO DOS EXTRATOS E FRAÇÕES 52

5.2 PRÉ-TRATAMENTO DA AMOSTRA PARA CLAE-DAD E UV 55

5.3 ESTUDO QUÍMICO DO EXTRATO HEXÂNICO DAS FOLHAS DE GARCINIA XANTHOCHYMUS (HEX-FOL) 
5.4 FRACIONAMENTO CROMATOGRÁFICO DA FRAÇÃO ACOET DAS FOLHAS DE GARCINIA XАNTHOCHYMUS (ACOET-FOL) 56

5.5 ESTUdO QUÍMICO DA SUBFRAÇÃO ACOET-FOL-14 56

5.6 ESTUDO QUÍMICO DAS SUBFRAÇÕES ACOET-FOL-15 E 16

5.7 ESTUDO QUÍMICO DA SUBFRAÇÕES ACOET-SIL-3 E 9

5.8 ESTUDO QUÍMICO DAS SUBFRAÇÕES ACOET-SIL-4 E 5

5.9 ESTUDO QUÍMICO DA SUBFRAÇÃO ACOET-SIL-11 59

5.10 FRACIONAMENTO CROMATOGRÁFICO E ESTUDO QUÍMICO DA FRAÇÃO BUOH DAS FOLHAS DE GARCINIA XANTHOCHYMUS (BUOH-FOL) 60

5.11 FRACIONAMENTO CROMATOGRÁFICO E ESTUDO QUíMICO DA FRAÇÃO ACOET DOS FRUTOS DE GARCINIA XANTHOCHYMUS (ACOET -FRU)

5.12 IDENTIFICAÇÃO POR CLAE-DAD-EM DOS CONSTITUINTES DE FRAÇÕES SELECIONADAS DE GARCINIA XANTHOCHYMUS-ANÁLISE POR DESREPLICAÇÃO 62

5.13 IDENTIFICAÇÃO DE TRITERPENOS E ESTERÓIDES PRESENTES NOS EXTRATOS DE BAIXA POLARIDADE DE GARCINIA XANTHOCHYMUS UTILIZANDO CROMATOGRAFIA GASOSA (CG)

5.14 ENSAIOS ANTIOXIDANTES

5.14.1 Descoloração de $\beta$-caroteno

5.14.2 Atividade seqüestradora de radicais livres: DPPH (1,1-difenil-2-picrilhidrazila) 63

5.15 ENSAIO IN VITRO DA POLIMERIZAÇÃO DE HEME

5.16 ATIVIDADE ANTIFÚNGICA

5.17 ATIVIDADE TRIPANOCIDA $\quad 65$

5.18 ATIVIDADE QUIMIOPREVENTIVA 66

6 RESULTADOS E DISCUSSÃO 67

6.1 ANÁLISE DOS CROMATOGRAMAS E ESPECTROS DE ABSORÇÃO 67

6.2 ESTUDO QUÍMICO DAS FOLHAS

6.2.1 Caracterização espectrométrica da substância 1

6.2.3 Caracterização espectrométrica da substância 3

6.2.4 Caracterização espectrométrica da substância 4

6.2.5 Caracterização espectrométrica da substância 5

6.2.6 Caracterização espectrométrica da substância 8

6.2.7 Caracterização espectrométrica da substância 9

6.2.8 Caracterização espectrométrica da substância 10 
6.2.9 Caracterização espectrométrica da substância 11

6.2.10 Caracterização espectrométrica da substância 12

6.2.11 Caracterização espectrométrica da substância 13

6.2.12 Caracterização espectrométrica da substância $14 \quad 106$

6.2.13 Caracterização espectrométrica das substâncias $\mathbf{1 7}$ e $\mathbf{1 8}$

6.3 A DESREPLICAÇÃO EM ESTUDOS DE BIOPROSPECÇÃO 115

6.3.1 Identificação por CLAE-UV-DAD-EM dos constituintes de Garcinia xanthochymus 116

6.4 IDENTIFICAÇÃO DE TRITERPENOS E ESTERÓIDES PRESENTES NOS EXTRATOS DE BAIXA POLARIDADE DE GARCINIA XANTHOCHYMUS UTILIZANDO CROMATOGRAFIA GASOSA (CG)

6.5 ATIVIDADE BIOLÓGICA DOS EXTRATOS, FRAÇÕES E SUBSTÂNCIAS ISOLADAS DE GARCINIA XANTHOCHYMUS

6.5.1 Atividade antioxidante

6.5.2 Ensaio in vitro da polimerização de heme

6.5.3 Atividade antifúngica

6.5.4 Atividade tripanocida

6.5.5 Atividade quimiopreventiva

\section{CONCLUSÕES}




\section{INTRODUÇÃO}

\section{$1.1 O$ estado da arte}

A natureza, de forma geral, tem produzido a maioria das substâncias orgânicas conhecidas. Dentre os diversos reinos da natureza, o reino vegetal é o que tem contribuído de forma mais significativa para o fornecimento de metabólitos secundários, muitos destes de grande valor agregado devido às suas aplicações como medicamentos, cosméticos, alimentos e agroquímicos (PINTO et al., 2002).

Os trabalhos de isolamento das primeiras substâncias puras do reino vegetal tiveram início entre os séculos XVIII e XIX. Com o aparecimento da química combinatória na década de 80 e as triagens em alta escala, que são os paradigmas tecnológicos de desenvolvimento da química medicinal moderna ou atual, os departamentos de produtos naturais das grandes empresas farmacêuticas foram eliminados ou transferidos para empresas menores (YOUNES; VARELLA; SUFFREDINI, 2007). No entanto, nestes últimos 10 anos, mudanças importantes vêm sendo observadas no rumo da pesquisa por fármacos novos devido aos avanços da biologia molecular, mapeamento genético, bioensaios automatizados e quimiogenômica. Esses eventos têm levado a indústria farmacêutica a repensar sua maneira de investimento na busca por fármacos de origem natural (NEWMAN; CRAGG, 2007).

A descoberta dos alcalóides morfina, cocaína e quinina, entre tantas substâncias isoladas de plantas e utilizadas como medicamentos até os dias atuais, não deixam dúvidas quanto à importância das plantas, principalmente, de uso tradicional (PINTO et al., 2002).

Com a descoberta dos antibióticos e anticolesterolêmicos a partir de microrganismos, dos benefícios divulgados pela Organização Mundial de Saúde na década de 70 sobre a eficácia da medicina chinesa e da descoberta de quimioterápicos eficazes como vimblastina $\left(\operatorname{Velban}^{\circledR}\right)$, vincristina $\left(\right.$ Oncovin $\left.{ }^{\circledR}\right)$, podofilotoxina e análogos (VP-16-213; Vepeside $^{\circledR}$ ), Teniposídeo $\left(\mathrm{VM}-26\right.$; Vulmon ${ }^{\circledR}$ ) e taxol (plaxitaxel; taxol ${ }^{\circledR}$ ) a procura pelos produtos naturais como modelos para agentes terapêuticos voltou a ser um tema recorrente da indústria farmacêutica (KIRBY, 1996).

Um terço dos medicamentos mais prescritos e vendidos no mundo foi desenvolvido a partir de produtos naturais (CALIXTO, 2003). No caso dos agentes antitumorais e antibióticos, por exemplo, esse percentual atingiu aproximadamente 60\% e 75\%, respectivamente (NEWMAN; CRAGG, 2007). As estatinas foram responsáveis por um 
mercado de US\$ 19 bilhões em 2002 e a OMS estima que as vendas totais de ervas medicinais alcançaram um lucro de US\$ 400 milhões no Brasil em 2001 (SOYAMA, 2007), mostrando o forte impacto desses medicamentos no mercado mundial.

Diante destes dados, países como o Brasil, que detém grande parte da biodiversidade mundial, poderão usufruir deste patrimônio se esforços forem dirigidos para a pesquisa colaborativa na descoberta por fármacos potenciais desta biodiversidade (GREENWOOD; MUTABINGWA, 2002).

Nos últimos anos, o NuBBE (Núcleo de Bioensaios, Biossíntese e Ecofisiologia de Produtos Naturais do IQ-UNESP, Araraquara) vem concentrando esforços na busca por substâncias com atividades antitumoral, antifúngica, antimalárica e antioxidante, caracterizando uma pesquisa de bioprospecção multifocal. Várias espécies coletadas nos biomas do Estado de São Paulo foram selecionadas devido a alguma bioatividade apresentada na triagem preliminar, agregando valor à extratoteca, já bastante representativa com mais de 1800 extratos. Dentre as espécies selecionadas, Garcinia xanthochymus demonstrou especial interesse por conter substâncias fenólicas com potencial antitumoral e antioxidante. Além disso, ocorrem neste gênero substâncias da classe das xantonas, conhecidas por sua atividade antimalárica (CHANMAHASATHIEN et al., 2003a).

\subsection{A família Clusiaceae}

A família Clusiaceae compreende cerca de 50 gêneros e 1200 espécies de ocorrência exclusiva nas regiões tropicais. A maioria dos representantes desta família são árvores, arbustos ou ervas sendo raramente epífitas (DI STASI; HIRUMA-LIMA, 2002).

Alguns gêneros e espécies são endêmicos de certas áreas, por exemplo, o gênero Symphonia L. e Pentadesma sabine são encontradas unicamente na África (SULTANBAWA, 1980). No Brasil, há 21 gêneros e 183 espécies distribuídas na Amazônia, Cerrado e Mata Atlântica (CRUZ et al., 1998). Os gêneros são distribuídos em três subfamílias, destacando-se inúmeros com importância medicinal no Brasil, como Hypericum e Vismia (Hypericoideae), Clusia, Calophyllum e Garcinia (Calophylloideae) e Kielmeyera (Bonnetioideae). Destacam-se nesses gêneros importantes espécies econômicas para a produção de madeiras, gomas, pigmentos, óleos essenciais e resinas (DI STASI; HIRUMA-LIMA, 2002). 
O estudo da constituição química dos troncos de várias espécies de Clusiaceae brasileiras mostrou, além dos triterpenóides comuns, xantonas como constituintes predominantes (GOTTLIEB; RAMAIAH; LAVIE, 1985).

A família Clusiaceae apresenta um número de xantonas comparáveis com as da família Gentianaceae e se destaca por apresentar mais da metade dessas xantonas substituídas por isoprenóides (SIMÕES et al., 2002; PANTHONG, et al., 2006; ZHONG; CHEN; YANG, 2008).

\subsection{A espécie Garcinia xanthochymus}

O gênero Garcinia pertence à família Clusiaceae, sinonímia de Guttiferae, e contêm cerca de 200 espécies confinadas nos trópicos como árvores ou arbustos, raramente epífitas, das quais 21 espécies encontram-se na China (ZHONG; CHEN; YANG, 2008). No Brasil é nativa a espécie Garcinia brasiliensis conhecida como Bacupari, encontrada na Mata Atlântica e Amazônia, porém ocorrem outras espécies como Garcinia gardneriana e Garcinia xanthochymus.

A espécie Garcinia xanthochymus (Figura 1) comumente conhecida como Gamboja, é uma árvore nativa da Índia com aproximadamente 8-10 metros. As árvores possuem folhas verdes escuras e sua fruta é amarela com polpa suculenta ácida, possui diâmetro de 6-7 cm, duas sementes e é utilizada extensamente na medicina popular como antidiarréica. A Gamboja é usada como pigmento para aquarela e como corante amarelo de tecidos. $\mathrm{O}$ fruto acidificado é utilizado em geléias, conservas e vinagres (BAGGETT et al., 2005).

Revisão bibliográfica sobre o estudo fitoquímico das folhas, frutos, cascas e caules de Garcinia xanthochymus (Tabela 1) revelou a presença principalmente de benzofenonas, flavonóides, biflavonóides, triterpenos e xantonas (Figura 2), as quais possuem atividade analgésica, antibacteriana, antioxidante, antiviral e antitumoral. 


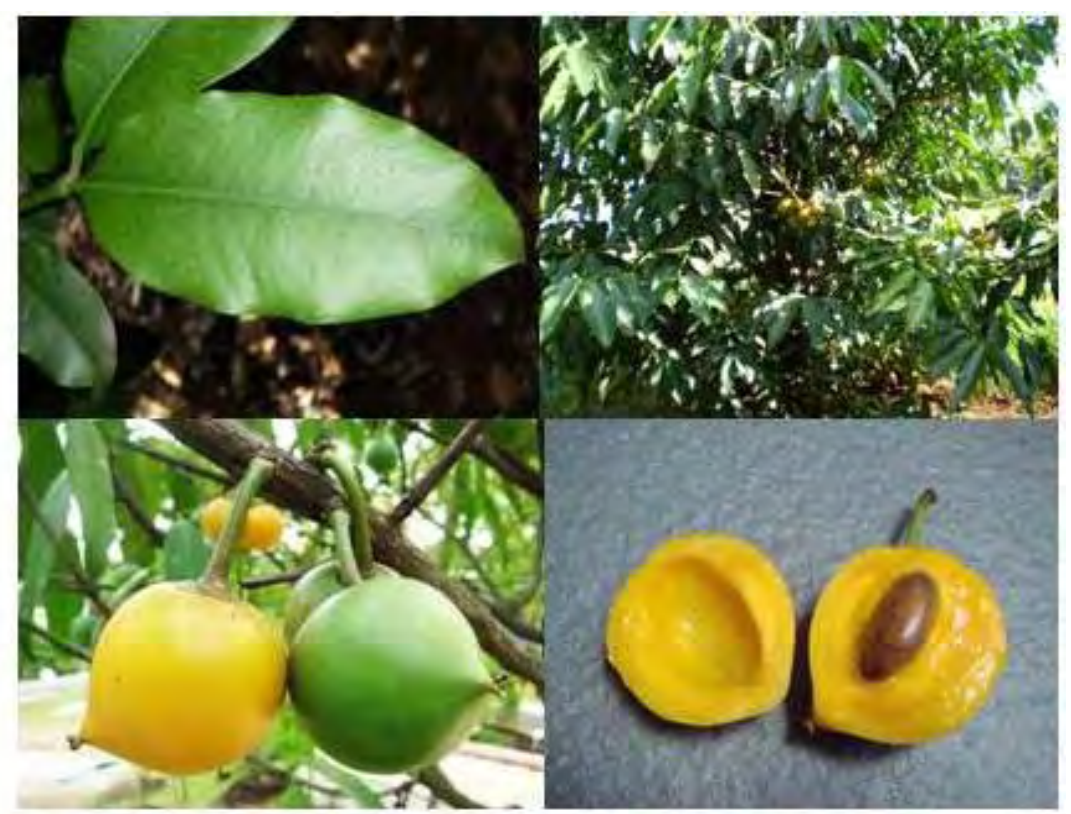

Figura 1 - Foto de diferentes partes de Garcinia xanthochymus.

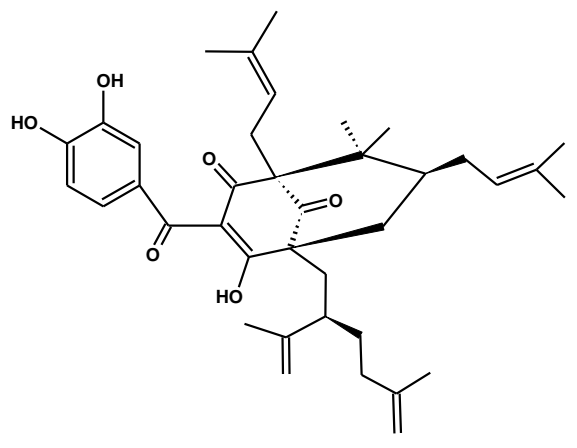

Benzofenonas<smiles>CC(C)=CCC/C(C)=C/CC1(C/C=C(\C)CO)C(=O)C(C(=O)C(C)C)=C(O)C2=C1OC(C(C)(C)O)C2</smiles>

Triterpenos<smiles>O=C1c2c(O)cc(O)cc2OC(c2ccc(O)cc2)C1c1c(O)cc(O)c2c(=O)cc(-c3ccc(O)cc3)oc12</smiles>

Biflavonoides<smiles>CC1C(=O)CC[C@@H]2C(C)(CCC3C4(C)CCC5(C)CCC(C)(C)C[C@H]5C4CCC32C)C1C</smiles>

Derivados do floroglucinol<smiles>O=C1c2c(O)cc(O)cc2OC(c2ccc(O)cc2)C1O</smiles>

Flavonoides<smiles>COc1cc2oc3c(O)cc(O)cc3c(=O)c2c(O)c1OC</smiles>

Xantonas

Figura 2 - Algumas classes de substâncias isoladas da espécie de Garcinia xanthochymus. 
Tabela 1 - Substâncias isoladas de Garcinia xanthochymus e bioatividades relatadas nas referências citadas.

\begin{tabular}{|c|c|c|c|c|}
\hline Classe & Substância & bioatividade & órgão & Referência \\
\hline \multirow{8}{*}{ benzofenona } & aristofenona $\mathrm{A}$ & - & frutos & BAGGETT et al., 2005 \\
\hline & cicloxantochimol & - & frutos & BAGGETT et al., 2005 \\
\hline & isoxantochimol & - & frutos & $\begin{array}{l}\text { BASLAS; KUMAR, } 1979 \\
\text { e 1981; BAGGETT et al., } \\
\text { 2005; KARANJGOAKAR, } \\
\text { et al., } 1973\end{array}$ \\
\hline & gambogenona & $\begin{array}{l}\text { antitumoral, } \\
\text { antioxidante }\end{array}$ & frutos & BAGGETT et al., 2005 \\
\hline & gutiferona $\mathrm{E}$ & - & frutos & BAGGETT et al., 2005 \\
\hline & gutiferona $\mathrm{H}$ & $\begin{array}{l}\text { antitumoral, } \\
\text { antioxidante }\end{array}$ & frutos & BAGGETT et al., 2005 \\
\hline & maclurina & - & frutos & $\begin{array}{c}\text { BASLAS; KUMAR, } 1979 \\
\text { e 1981; TANDON et al., } \\
\text { 1980; BAGGETT et al., } \\
2005\end{array}$ \\
\hline & xantochimol & antimicrobial & frutos & $\begin{array}{c}\text { KARANJGOAKAR et al., } \\
\text { 1973; RAMA RAO; } \\
\text { VENKATSWAMY; } \\
\text { YEMUL, } 1980\end{array}$ \\
\hline \multirow{12}{*}{ biflavonóide } & agatisflavona & - & folhas & PARVEEN et al., 1994 \\
\hline & amentoflavona & - & frutos & BAGGETT et al., 2005 \\
\hline & I3,II8-biapigenina & - & frutos & BAGGETT et al., 2005 \\
\hline & ( \pm )-fukugisídeo & - & frutos & $\begin{array}{l}\text { KONOSHIMA et al., 1970; } \\
\text { BAGGETT et al., } 2005\end{array}$ \\
\hline & ( \pm )-fukugetina & - & frutos & $\begin{array}{l}\text { KONOSHIMA et al., 1970; } \\
\text { BAGGETT et al., } 2005\end{array}$ \\
\hline & 7- $O$-metilamentoflavona & - & folhas & PARVEEN et al., 1994 \\
\hline & volkensiflavona & - & frutos & $\begin{array}{c}\text { KONOSHIMA et al., 1970; } \\
\text { BASLAS; KUMAR, } 1979 \\
\text { e 1981; BAGGETT et al., } \\
2005\end{array}$ \\
\hline & xantochimusídeo & - & caules & KONOSHIMA et al., 1970 \\
\hline & GB1 & - & frutos & $\begin{array}{c}\text { BASLAS; KUMAR, } 1979 \\
\text { e } 1981\end{array}$ \\
\hline & GB1a & - & frutos & $\begin{array}{l}\text { KONOSHIMA et al., } 1970 ; \\
\text { BASLAS; KUMAR, } 1979\end{array}$ \\
\hline & GB2 & - & caules & KONOSHIMA et al., 1970 \\
\hline & GB2a & - & caules & KONOSHIMA et al., 1970 \\
\hline bis-xantona & bigarcinenona $\mathrm{A}$ & antioxidante & cascas & $\begin{array}{l}\text { ZHONG; CHEN; } \\
\text { YANG, } 2008\end{array}$ \\
\hline éster & tereftalato de dimetila & - & folhas & SINGH et al., 1991 \\
\hline \multirow{2}{*}{ flavonóide } & 6-prenilapigenina & antitumoral & cascas & HAN et al., 2007 \\
\hline & vitexina & - & folhas & PARVEEN et al., 1994 \\
\hline $\begin{array}{l}\text { Derivado do } \\
\text { floroglucinol }\end{array}$ & garcinenona $\mathrm{F}$ & antioxidante & cascas & $\begin{array}{l}\text { ZHONG; CHEN; } \\
\text { YANG, } 2008\end{array}$ \\
\hline \multirow{4}{*}{ Terpeno } & betulina & - & folhas & SINGH et al., 1991 \\
\hline & canofilol & - & folhas & SINGH et al., 1991 \\
\hline & friedelina & - & folhas & SINGH et al., 1991 \\
\hline & $\beta$-sitosterol & - & folhas & SINGH et al., 1991 \\
\hline
\end{tabular}




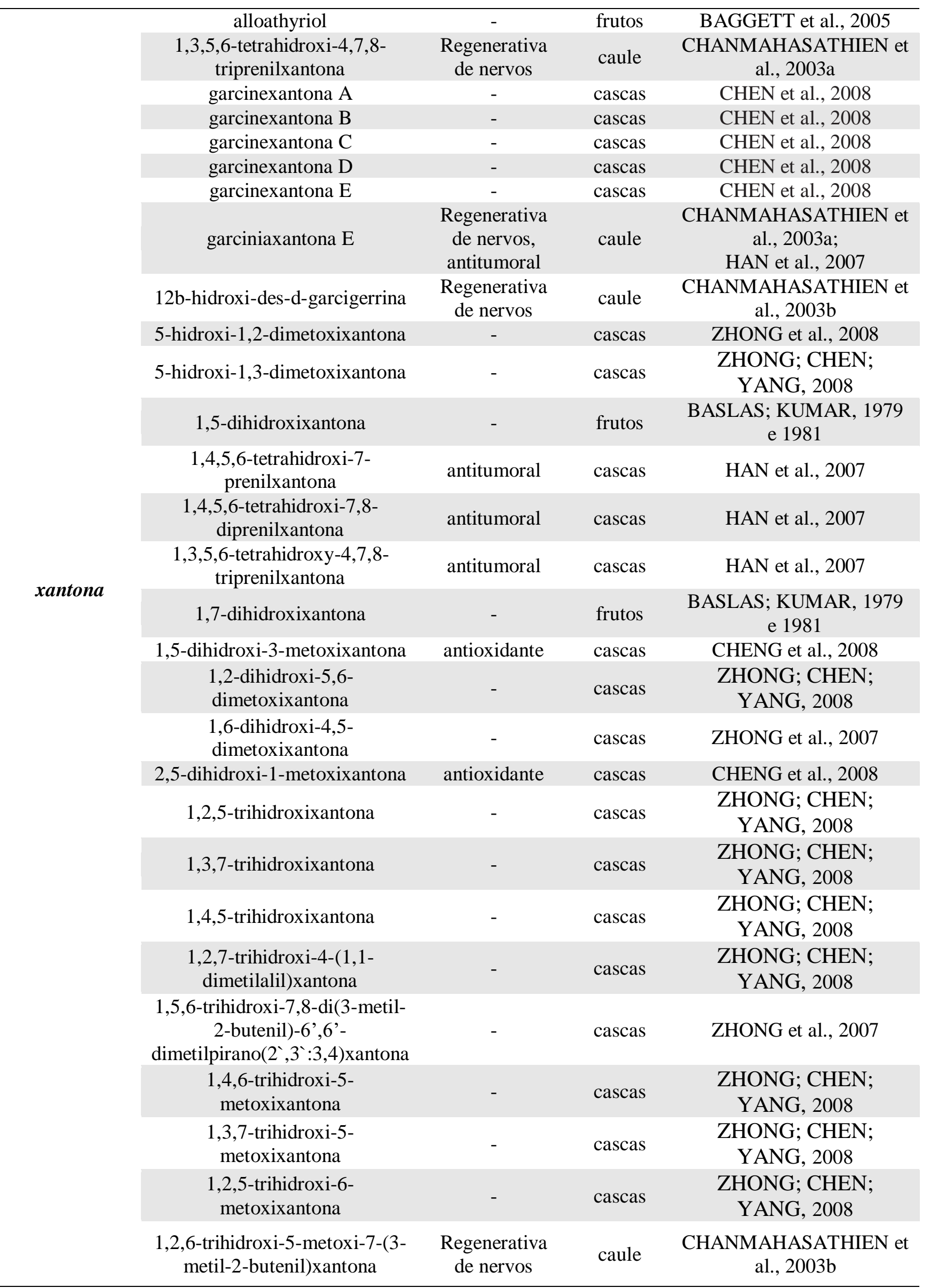




\begin{tabular}{cccc}
$\begin{array}{c}1,4,6 \text {-trihidroxi-5-metoxi-7- } \\
\text { prenilxantona }\end{array}$ & antitumoral & cascas & HAN et al., 2007 \\
$\begin{array}{c}\text { 1,2,5,6-tetrahidroxi-7- } \\
\text { geranilxantona }\end{array}$ & antitumoral & cascas & HAN et al., 2007 \\
$\begin{array}{c}\text { 1,4,5,6-tetrahidroxi-7,8-di(3- } \\
\text { metil-2-butenil)xantona }\end{array}$ & $\begin{array}{c}\text { Regenerativa } \\
\text { de nervos }\end{array}$ & caule & $\begin{array}{c}\text { CHANMAHASATHIEN et } \\
\text { al., 2003b }\end{array}$ \\
\hline
\end{tabular}

\subsection{Biflavonóides}

Os flavonóides figuram entre as classes de substâncias químicas de maior ocorrência botânica, sendo contabilizados em números superiores a seis mil exemplares (HARBORNE e WILLIAMS, 2000). São derivados de benzo- $\alpha$-pirona com a maioria de seus representantes formados por 15 átomos de carbono em seu núcleo fundamental.

A biossíntese dos flavonóides (Figura 3) apresenta a singularidade de seus anéis aromáticos serem formados por rotas metabólicas distintas. Sua porção fenil-propanoídica (anel B $+\mathrm{C} 2, \mathrm{C} 3, \mathrm{C} 4)$ é derivada do ácido $p$-cumárico formado pela via do chiquimato. Por outro lado, o anel A é formado basicamente pela condensação de unidades de acetato, pela via dos policetídeos, que se inicia com a formação de malonil CoA a partir de acetil CoA mediante a enzima acetil CoA-carboxilase (ACC). A biossíntese geral dos flavonóides tem como intermediário central o tio-éster $p$-cumaril-CoA, que será alongado pela condensação de três unidades de malonil-CoA, catalisado pela enzima chalcona sintetase (CS). A ciclização resulta na formação do anel A e produz a chalcona, que em condições fisiológicas, tende espontaneamente à flavona racêmica.

É relatado também que a ciclização da chalcona é catalisada pela enzima chalcona isomerase $(\mathrm{CI})$, que induz o fechamento estereoespecífico do anel (adição syn sobre a dupla ligação $E$ ) formando exclusivamente a 2-(S)-flavanona. Os outros tipos de flavonóides são formados por subseqüentes etapas de óxi-redução deste intermediário comum (CROTEAU; KUTCHAN; LEWIS, 2000; XIE e DIXON, 2005).

Os biflavonóides se caracterizam pela união covalente das unidades monoméricas dos flavonóides (Figura 4). Essas unidades podem ser semelhantes ou possuírem diferentes tipos estruturais e se diferenciam de outros oligômeros como as proantocianidinas, devido à origem biogenética das unidades constituintes (SUZART et al., 2007).

As ligações entre as unidades flavonoídicas podem ser C-C ou C-O-C envolvendo os anéis $\mathrm{A}, \mathrm{B}$ ou C dos monômeros. Raramente ocorre alteração no padrão de oxigenação dos precursores, sendo garantida a oxigenação em 5, 7 e 4'. Adicionalmente, podem ocorrer 
oxidações nas posições 6,8 ou 3' e quando isso acontece é, normalmente proveniente da outra unidade ligada nessa posição via ligação C-O-C (SUZART et al., 2007).

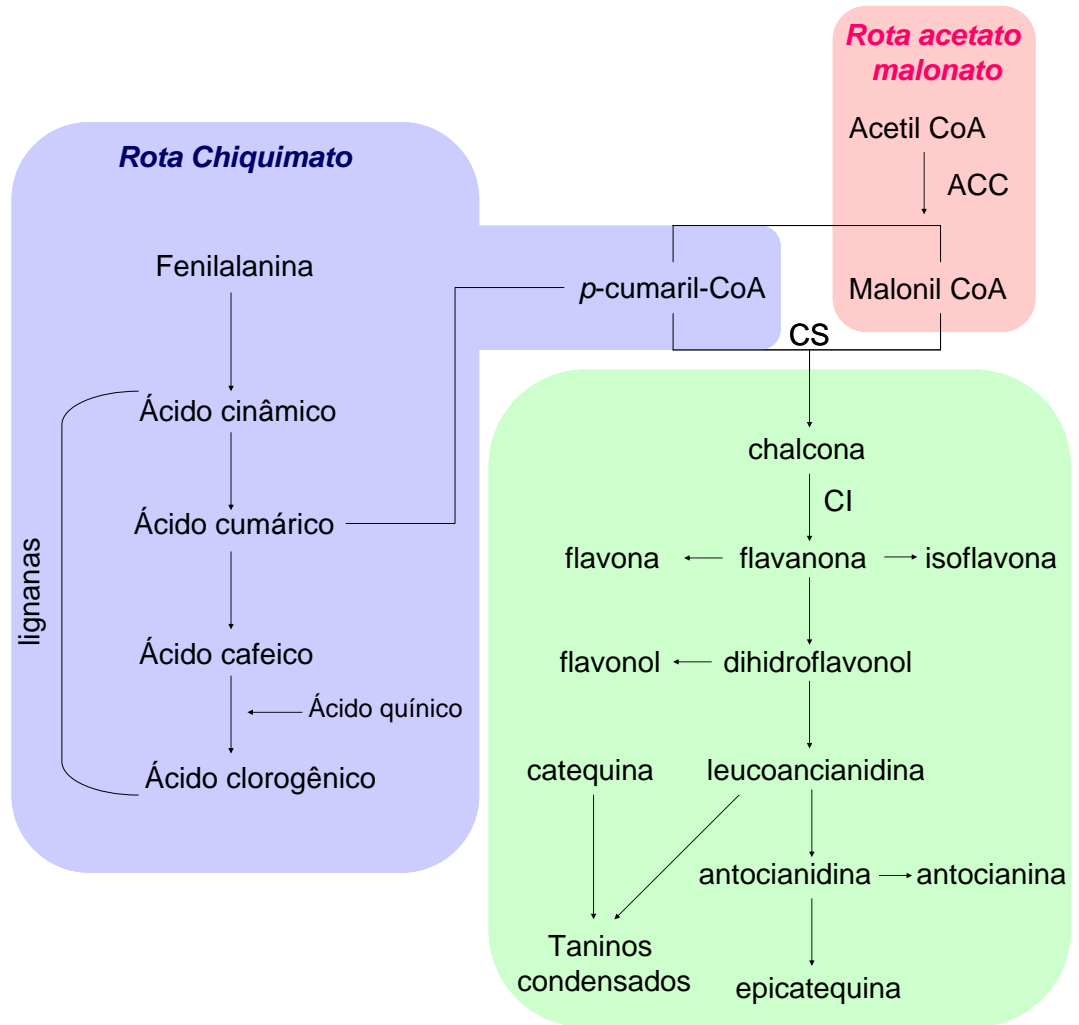

Figura 3 - Esquema geral da rota biossintética de flavonóides (ACC-acetil CoA-carboxilase, CSchalcona sintetase e CI-chalcona isomerase).

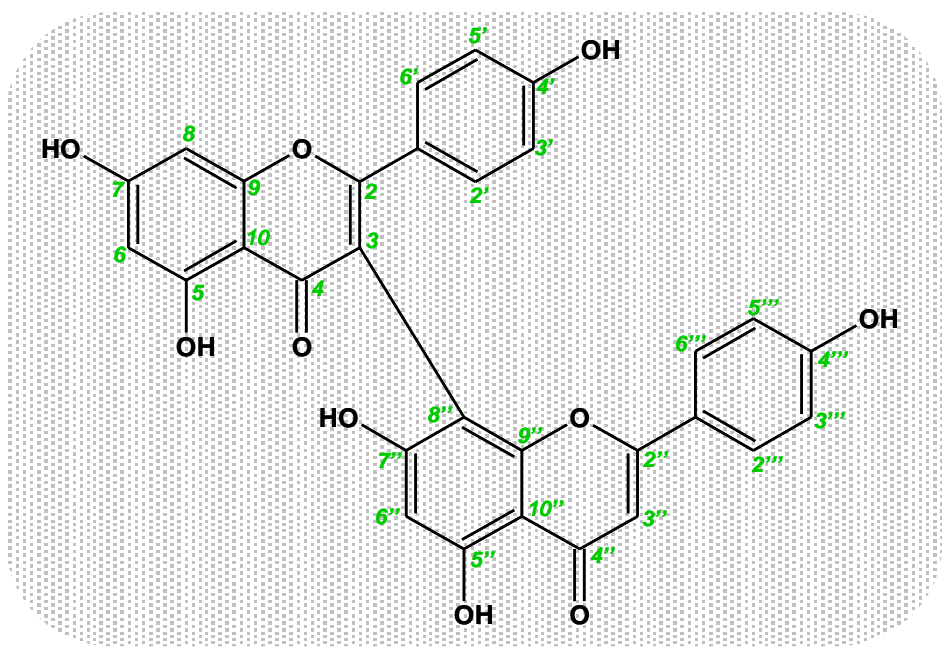

Figura 4 - Estrutura de biflavonóides tipo flavona-flavona. 
Estima-se que a quantidade de biflavonóides seja superior a duzentas substâncias, dispersas principalmente entre as plantas gimnospermas e angiospermas, das quais se destacam as famílias Clusiaceae, Ochnaceae e Anacardiaceae.

Os biflavonóides, quando comparados aos seus monômeros, frequentemente apresentam maior atividade, como por exemplo, em doenças espamódicas (HARBONE e WILLIAMS, 2000).

A biflavanona 7,7''-di- $O$-metiltetraidroamentoflavona isolada das folhas de $R h u s$ retinorrhoea apresentou moderada atividade frente às cepas W2 e D6 de $P$. falciparum com valores de $\mathrm{CI}_{50}$ de 0,98 e 2,80 $\mu \mathrm{g} \cdot \mathrm{mL}^{-1}$, respectivamente (AHMED et al., 2001). O fracionamento do extrato $n$ - $\mathrm{BuOH}$ da raiz de Wikstroemia indica permitiu o isolamento de sikokianina $\mathrm{B}$ e sikokianina $\mathrm{C}$ com valores de $\mathrm{CI}_{50}$ de 0,54 e $0,56 \mu \mathrm{g} \cdot \mathrm{mL}^{-1}$, respectivamente, frente à cepa cloroquina-resistente K1 de $P$. falciparum (NUNOME et al., 2004). Alguns biflavonóides apresentaram atividade antifúngica, como a amentoflavona, 6,6' '-bigenquanina e 7,7' '-dimetoxiagastisflavona que inibiu a produção de aflatoxina em Aspergillus flavus (GONCALEZ; FELICIO; PINTO, 2001). Atividades antivirais foram determinadas para os compostos amentoflavona, agatisflavona, rhusflavanona e robustaflavona, em ensaios frente aos vírus Myxovirus influenzae (gripe), Herpes simplex (LIN et al., 1999) e HIV (LIN et al., 1997). O potencial antineoplásico de alguns biflavonóides e análogos já foi avaliado com sucesso, em testes de citotoxicidade frente a linhagens de células tumorais (CHEN; DUH; CHEN, 2005), (LIN; KUO; CHOU, 2000), (SILVA et al., 1995), (LIN; CHEN; LEE, 1989) e mediante ensaios de inibição da enzima DNA topoisomerase (GRYNBERG et al., 2002). As biflavonas $6 \rightarrow 6^{\prime \prime}$-begenquanina e 7,7"-O-dimetilagatisflavona isoladas de Ouratea spectabilis apresentaram atividade inibitória sobre a enzima aldose redutase de cristalino bovino. O aumento da atividade dessa enzima está relacionado com a patogênese da maioria das complicações da diabetes, como cataratas, retinopatia, neuropatia (FELÍCIO et al., 1995).

\subsubsection{Atropoisomerismo}

O fenômeno conhecido como atropoisomerismo, denominação oriunda da palavra grega atropos (sem rotação), é atribuído a um tipo de estereoisomerismo característico de sistemas onde a rotação livre em torno de uma ligação simples é impedida, produzindo uma barreira energética suficientemente elevada, de modo a permitir o isolamento ou simplesmente a detecção dos diferentes rotâmeros, chamados atropoisômeros (FRAGA, et 
al., 2007). O atropoisomerismo ocorre quando os isômeros são separáveis com meia-vida de pelo menos $1000 \mathrm{~s}$ (16,7 $\mathrm{min})$, não depende do valor da barreira energética de interconversão e é variável com a temperatura (CANUTO, 2007).

A complexidade dos espectros de um biflavonóide, em que se observa duplicação e pareamento de sinais, é explicada pela atropoisomeria e ocorre frequentemente em estruturas cujas unidades estão interligadas através dos carbonos C-3 $\rightarrow$ C-8".

Li et al. (2002) mostrou que um experimento de RMN ${ }^{1} \mathrm{H}$ com os biflavonóides ( \pm )morelloflavona, ( \pm )-morelloflavona-7-sulfato e $( \pm)$-volkensiflavona-7-sulfato, isolados de Rheedia acuminata, realizado sob aquecimento de $80^{\circ} \mathrm{C}$ simplifica o espectro devido a alta energia da rotação, resultando assim, no desaparecimento das linhas espectrais duplicadas. À temperatura ambiente $\left(25^{\circ} \mathrm{C}\right)$ foram observados sinais pareados referente à mistura de rotâmeros (1a e 1b) em razão da lenta interconversão causada pela elevada barreira energética. Entretanto, em temperaturas superiores $\left(80^{\circ} \mathrm{C}\right)$ observa-se que os sinais duplos tendem a aproximar-se (alargamento dos picos), coalescem (pico único alargado) e por último obtem-se um sinal simples cuja absorção corresponde a uma freqüência central às duas existentes anteriormente. Isto acontece porque o aquecimento acelera a velocidade de interconversão, fazendo com que seja superada mais facilmente a barreira energética, favorecendo a formação exclusiva de um dos confôrmeros (Figura 5).

\subsection{Atividade antioxidante}

Doenças degenerativas do Sistema Nervoso Central (SNC) como Mal de Alzheimer e Mal de Parkinson estão associadas em parte com os efeitos deletérios que o desequilíbrio entre fatores pró e antioxidantes, decorrente da produção descontrolada de radicais livres, pode provocar nos sistemas biológicos.

A geração de radicais livres ocorre normalmente durante o metabolismo. Em condições fisiológicas, de todo o oxigênio molecular captado nas mitocôndrias e processado na cadeia respiratória, só 1 a $5 \%$ escapam e formam oxirradicais. Porém, esta mínima porcentagem é suficiente para dar origem a diversas espécies reativas, seja por absorção de energia ou por transferência de elétrons. Vale notar que nem todas as espécies reativas de oxigênio (EROs) são radicais, o peróxido de hidrogênio e o oxigênio singlete não possuem elétrons desemparelhados, e sua reatividade é atribuída ao fato de seus elétrons de valência estarem situados em órbitais mais distantes do núcleo, o que leva o 
átomo a um estado químico altamente reativo, com características diradicalares (CAO; SOFIC; PRIOR, 1997).
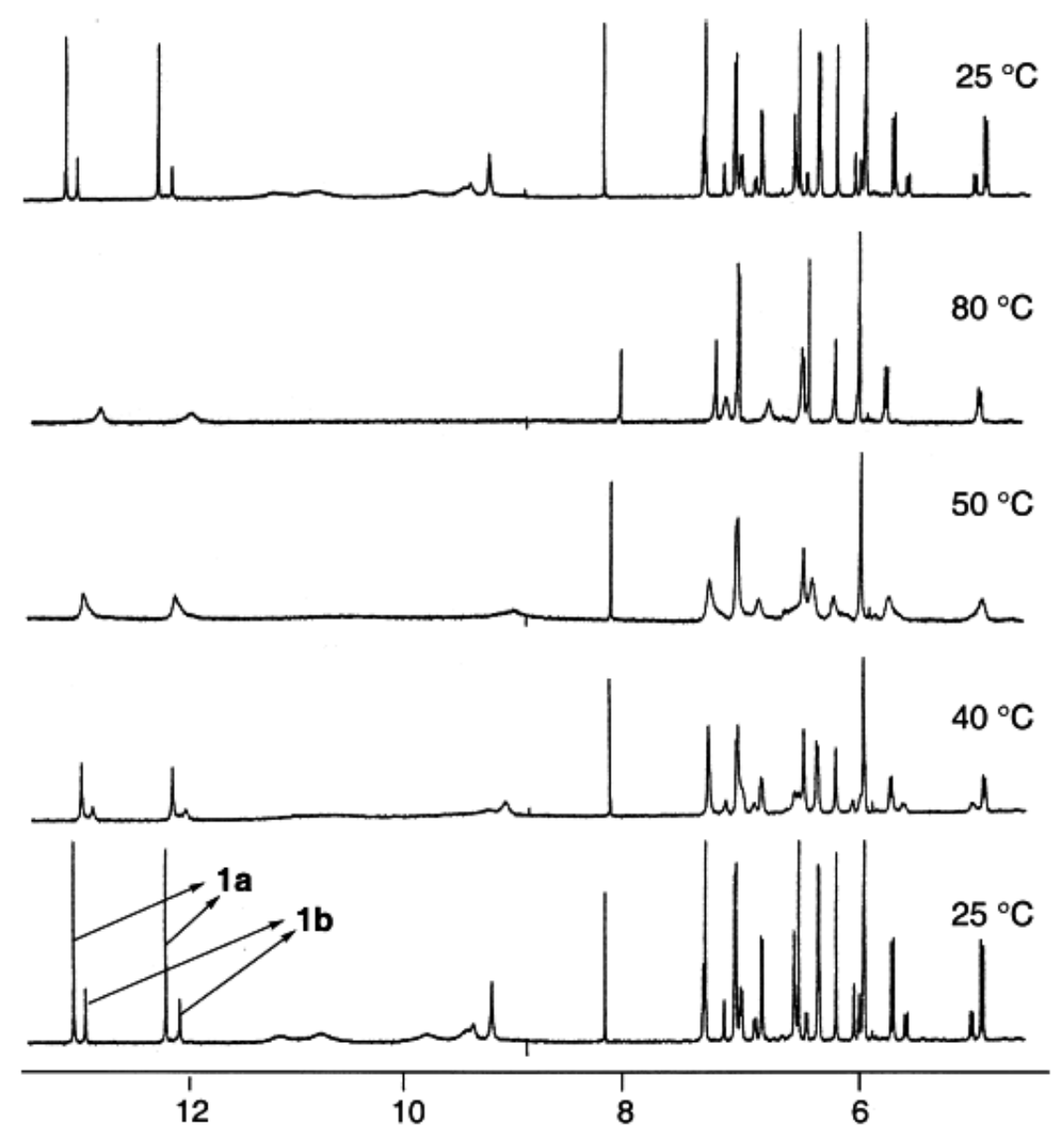

Figura 5 - Experimento de RMN ${ }^{1} \mathrm{H}$ para a ( \pm )-morelloflavona (Li et al., 2002) em temperaturas variáveis. O sinal 1a representa o confôrmero principal e $\mathbf{1 b}$ o confôrmero minoritário.

A produção dessas espécies de maneira desordenada provoca danos oxidativos em macromoléculas biológicas como lipídeos, proteínas, DNA, alterando suas propriedades, estruturas e as funções das membranas celulares e do material genético (POTTERAT, 1997).

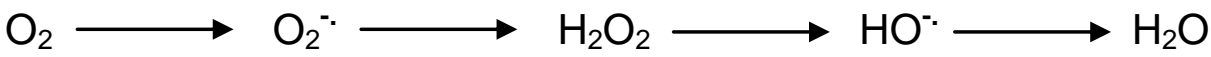

$\mathrm{Na}$ tentativa de minimizar os efeitos danosos dos radicais livres, organismos aeróbicos desenvolveram mecanismos de proteção antioxidante (Figura 6) que envolvem sistemas enzimáticos como a superóxido dismutase (SOD), catalase e glutationa peroxidase $(\mathrm{GSH})$ e sistemas antioxidantes compostos por micromoléculas como o ácido 
ascórbico (vitamina C), tocoferóis (vitamina E), carotenóides e flavonóides, entre outros (BARREIROS; DAVID; DAVID, 2006).

Embora o organismo tenha capacidade de prevenir reações indesejáveis e reparar moléculas e tecidos danificados, estes mecanismos de defesa não são suficientemente abrangentes para reparar todos os danos causados por tais reações, ocorrendo o acúmulo de substâncias prejudiciais ao nosso corpo. Esta situação de desequilíbrio entre a formação de espécie com poder oxidante e a sua destruição denomina-se estresse oxidativo e pode conduzir a um metabolismo anormal, disfunção celular, à perda de funções fisiológicas, a doenças e à morte.

Trabalhos sobre medicina preventiva mostram que as substâncias fenólicas são os antioxidantes naturais mais eficientes e enfatizam a importância da descoberta de novas substâncias que possam ser incluídas na dieta alimentar, visando à manutenção do equilíbrio pró-oxidante/antioxidante corporal, evitando assim o estresse oxidativo (RICEEVANS; MILEER; PAGANGA, 1996).

\subsection{Biflavonóides como agentes antioxidantes}

Os flavonóides/biflavonóides têm sido objeto de considerável interesse científico principalmente pela sua potencial ação antioxidante. De um modo geral, estes possuem estrutura ideal para o sequiestro de radicais, sendo antioxidantes mais efetivos que as vitaminas C e E em determinadas situações. A atividade antioxidante dos flavonóides depende da sua estrutura e pode ser determinada por cinco fatores: estabilidade do radical flavonoil formado, reatividade como agente doador de $\mathrm{H}^{\cdot}$ e elétrons, capacidade de quelar metais de transição e solubilidade e interação com as membranas (BARREIROS; DAVID; DAVID, 2006).

A atividade de seqüestro está diretamente ligada ao potencial de oxidação dos flavonóides e das espécies a serem seqüestradas. Quanto menor o potencial de oxidação do flavonóide, maior é a sua atividade como seqüestrador de radicais livres. 


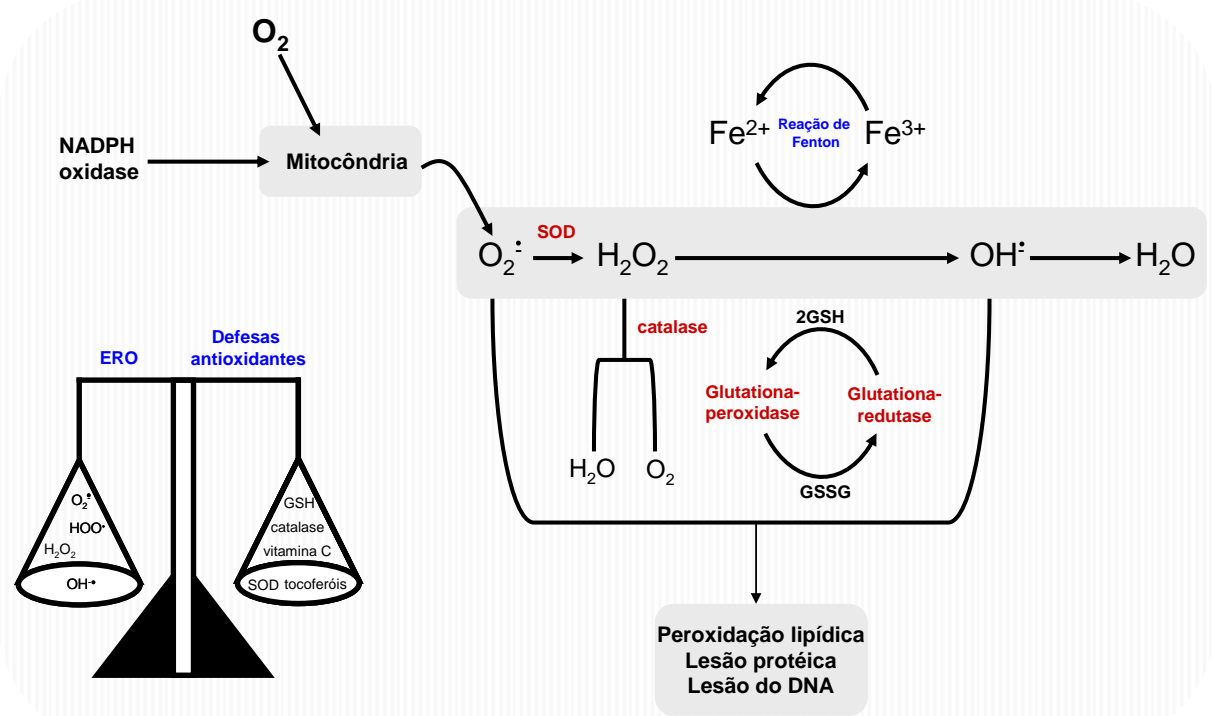

Figura 6 - Representação do equilíbrio entre as EROs e as defesas antioxidantes do nosso organismo (BARREIROS; DAVID; DAVID, 2006).

Quanto maior o número de hidroxilas, maior atividade como agente doador de $\mathrm{H}$ radicalar e de elétrons (CAO; SOFIC; PRIOR, 1997; YANG et al., 2001). Flavonóides monoidroxilados apresentam atividade muito baixa, por exemplo, a 5-hidroxi-flavona tem atividade abaixo dos limites de detecção. Entre os flavonóides diidroxilados, destacam-se aqueles que possuem o grupo catecol (3', 4' -diidroxi) no anel B. Os flavonóides com múltiplas hidroxilas como a miricetina, quercetina, luteolina, e taxifolina possuem forte atividade antioxidante quando comparados ao $\alpha$-tocoferol, ácido ascórbico, $\beta$-caroteno, glutationa, ácido úrico e bilirrubina (YANGet al., 2001).

A estabilidade do radical livre flavonoil formado depende da habilidade em deslocalizar o elétron desemparelhado. A presença de hidroxilas em orto e a insaturação em C2-C3 são os principais fatores que auxiliam nessa deslocalização. Os flavonóides, devido ao seu caráter fracamente ácido e à extensa conjugação, encontram-se, em geral, parcialmente ionizados, o que aumenta a estabilidade do radical formado na posição C-4 e favorece a deslocalização do elétron desemparelhado do radical formado entre os anéis A, $\mathrm{B}$ e C.

A remoção de metais de transição livres no meio biológico é fundamental para a proteção antioxidante do organismo, visto que esses catalisam as reações de Fenton (1) e de Haber-Weiss (2), produtoras de EROs. Para a atividade de quelação de metais é fundamental a presença de grupos orto-dioxigenados, onde o mais comum é o sistema 3', 4'-diidroxi, unidade catecol em B e/ou estruturas cetol com 4-ceto-3-hidroxi e 4-ceto-5- 
hidroxi. A substituição de qualquer uma das hidroxilas envolvidas na quelação de metais reduz essa atividade devida ao impedimento estérico provocado.

Outro fator importante que influencia a atividade antioxidante é a sua interação com as biomembranas. A lipofilicidade do flavonóide indica a incorporação deste pela membrana, que é alvo da grande parte dos radicais livres. Assim deve haver uma concentração mínima do flavonóide por ácido graxo, de modo a assegurar a presença de suas moléculas próximas aos sítios preferências de ataque do radical (VAN ACKEL et al., 1996). Flavonóides que possuem uma cadeia de açucares ligada em sua estrutura são muito polares, não sendo assimilados pela membrana, porém nesta forma eles podem ser armazenados em vesículas, possuindo um tempo maior de permanência no organismo. Os flavonóides que são assimilados pelas membranas exercem a função de moduladores de fluidez. Restringindo essa fluidez os flavonóides geram um impedimento físico pra a difusão dos radicais livres, de modo que decresce a cinética das reações responsáveis pelo estresse oxidativo.

Os biflavonóides apresentam significativa atividade antioxidante como a amentoflavona que é capaz de proteger membranas lipossômicas contra a degradação peroxidativa causada pelos raios UV (YAMAGUCHI et al., 2005). Recentemente, o biflavonóide morelloflavona mostrou-se ativo frente à inibição da oxidação de lipoproteínas de baixa densidade (HUTADILOCK-TOWATANA; KONGKACHUAY; MAHABUSARAKAM, 2007) e alguns biflavonóides como amentoflavona e hinokiflavona mostraram efeitos de proteção em estudos de morte celular induzida por estresse oxidativo com $\mathrm{H}_{2} \mathrm{O}_{2}$ (KANG et al., 2005).

\subsection{Agentes quimiopreventivos}

A quimioprevenção pode ser entendida como o uso de substâncias químicas a fim de prevenir, retardar ou reverter o processo de carcinogênese (WATTENBERG, 1985). Muitas substâncias quimiopreventivas potenciais estão presentes na dieta como polifenóis, isoflavonas, curcumina, fenetil isoiocianato, sulforafano, licopeno, ácidos salicílicos, cafeína entre outras. Tais substâncias tem-se mostrado grande aliadas no tratamento dos 
linfomas, dos tumores da infância e das neoplasias de células germinativas (KELLOFF et al., 2000; CHUANG et al., 2000).

Os elementos quimiopreventivos podem ser classificados em dois grupos de acordo com a etapa da carcinogênese química sobre a qual são eficazes. O primeiro grupo é composto por agentes bloqueadores, representados por compostos capazes de modular os processos de absorção intestinal, biotransformação e bioativação microssomal, excreção renal e interação com o material genético de substâncias cancerígenas. O segundo grupo de quimiopreventivos é composto por agentes supressores que interferem em alguns eventos celulares críticos à promoção e progressão da carcinogênese, prevenindo a evolução da malignização celular (WATTENBERG, 1985).

Algumas das estratégias para a proteção de células dos eventos iniciais da formação de tumores incluem a inibição de enzimas metabólicas responsáveis pela geração de espécies reativas (enzimas de fase I), ao passo que enzimas da fase II são estimuladas, promovendo a desativação de radicais e eletrófilos envolvidos nos processos celulares normais. Os agentes responsáveis por este acontecimento são denominados "indutores bifuncionais", onde os carcinógenos poderiam induzir a uma proteção contra seu próprio efeito tóxico. Além destes, existem os "indutores monofuncionais", que somente induzem enzimas de fase II seletivamente e ativam elementos de resposta antioxidante (CUENDET et al., 2006).

A redução de quinonas eletrofílicas pela quinona redutase se constitui numa via importante de detoxificação e o seu grau de atividade pode ser inferido através da indução em células da linhagem de hepatocarcinoma murino-Hepa 1c1c7. A indução de enzimas da fase II pode proteger os sistemas biológicos contra espécies químicas tóxicas e reativas, e estudos recentes demonstram que a elevação dessas enzimas, como a NADPH: quinonaredutase e GST (Glutationa $s$-transferase) estão correlacionadas com a proteção celular nos estágios iniciais e intermediários contra a carcinogênese induzida por agentes químicos em modelos animais (WATTENBERG, 1985; SONG et al., 1999; CUENDET et al., 2006). 


\section{JUSTIFICATIVA}

A obtenção de substâncias bioativas a partir de fontes naturais sofreu interesse renovado nos últimos anos, apesar do avanço acentuado de tecnologias competitivas como a química combinatória, análise de proteoma e metaboloma e a engenharia molecular (ROUHI, 2003; NEWMAN; CRAGG, 2007). A obtenção de moléculas de esqueleto inédito ou com atividades biológicas marcantes e/ou novos mecanismos de ação age como força matriz para esforços intensos e contínuos em atividades de bioprospecção e justificam os grandes investimentos realizados em escala mundial na busca por protótipos moleculares para o desenvolvimento de fármacos (CORDELL, 2000; YOUNES; VARELLA; SUFFREDINI, 2007).

O Brasil, com sua enorme biodiversidade apresenta motivos adicionais para intensificar essas atividades já que o conhecimento científico dos remanescentes da nossa flora podem despertar a consciência sobre as consequências da degradação dos nossos ecossistemas, com a perda de espécies desconhecidas ou não investigadas e consequentemente, de substâncias potencialmente úteis. Os projetos em andamento no NuBBE visando à conservação e uso sustentável da diversidade vegetal no Estado de São Paulo através de estudos sobre diversidade química e busca de drogas potenciais, incluem as atividades de bioprospecção e fazem parte da estratégia de exploração racional de nossa biodiversidade.

As substâncias presentes nos extratos vegetais pertencem a variadas classes de produtos naturais e podem apresentar atividades biológicas marcantes. A vasta gama de patologias decorrentes do estresse oxidativo permite uma abordagem que usa a detecção e avaliação das propriedades antioxidantes de extratos vegetais como etapa preliminar e indicativa de outros tipos de bioatividades. Assim, a detecção de atividade citotóxica seletiva para determinadas linhagens de células tumorais, por exemplo, através de mecanismos de apoptose e, no caso de plantas usadas por suas propriedades antiinflamatórias, os antioxidantes podem agir como redutores de estresse oxidativo que ocorre nas células sob ação dos mediadores químicos pró-inflamatórios.

Outras patologias associadas ao estresse oxidativo, como o câncer, podem ser evitados com o uso de agentes quiomiopreventivos, ou seja, extratos vegetais, frações semipurificadas ou substâncias isoladas que associam as propriedades antioxidantes com efeitos biológicos de indução sobre enzimas destoxificantes do organismo, por exemplo, a 
quinona redutase. Fica evidente, portanto, a complementariedade das informações obtidas na busca por substâncias naturais com atividade antioxidante, citotóxica e indutora de quinona redutase, justificando esta abordagem. 


\section{OBJETIVOS}

(A) Isolamento e determinação estrutural de substâncias dos frutos e folhas de Garcinia xanthochymus;

(B) Avaliação do potencial de bioatividade dos extratos brutos, frações semipurificadas e substâncias isoladas empregando ensaios para atividade antioxidante, indutora de quinona redutase, antifúngica, antimalárica e tripanocida. 


\section{MATERIAIS E EQUIPAMENTOS}

\subsection{Métodos cromatográficos}

\subsubsection{Cromatografia em camada delgada comparativa (CCDC)}

As cromatoplacas foram preparadas aplicando-se uma suspensão de sílica gel 60 PF254, com indicador de fluorescência em água destilada, na proporção de 1:2 (m:v) sobre placas de vidro, obtendo-se $25 \mathrm{~mm}$ de espessura de adsorvente através da utilização de espalhador Quickfitt ${ }^{\circledR}$. Após a preparação das cromatoplacas, estas foram ativadas em estufa por 30 minutos.

Revelação das cromatoplacas: cada cromatoplaca foi revelada por meio de um ou mais dos métodos físicos e químicos descritos abaixo:

(A) Inspeção em luz ultravioleta: as cromatoplacas foram expostas a luz ultravioleta, nos comprimentos de onda de 254 e $365 \mathrm{~nm}$.

(B) Solução de anisaldeído: aproximadamente 5,0 ml de solução de anisaldeído $(0,5 \mathrm{ml}$ de anisaldeído $+10,0 \mathrm{~mL}$ de ácido sulfúrico concentrado $+85,0 \mathrm{ml}$ de $\mathrm{MeOH}$ ) foi preparada com a adição dos reagentes em banho de gelo. Tal solução foi acondicionada em vidro âmbar e armazenada a $8^{\circ} \mathrm{C}$. Para a revelação de cromatoplacas, borrifaram-se pequenas alíquotas e então, estas foram colocadas em estufas a $120^{\circ} \mathrm{C}$.

(C) Solução de $\beta$-caroteno: Preparou-se uma solução de $0,02 \%$ de $\beta$-caroteno $\left(\right.$ Aldrich $^{\circledR}$ ) em metanol. Após a nebulização das cromatoplacas, essas foram expostas ao ar e luz natural, por cerca de 6 horas, a fim de catalisar a oxidação do $\beta$-caroteno.

\subsubsection{Cromatografia em coluna de fase normal (CC-FN)}

Para cromatografia em coluna de fase normal foi utilizado como fase estacionária sílica-gel 60-230 $\mu$ (Merck). O empacotamento da coluna se deu 24 horas antes do início da eluição. 


\subsubsection{Extração líquido-líquido (ELL)}

As amostras submetidas à ELL foram seletivamente separadas entre dois solventes imiscíveis. Para obter a mistura binária, empregaram-se os seguintes solventes: AcOEt, $n$ $\mathrm{BuOH}$ e solução hidroalcoólica de $\mathrm{MeOH}: \mathrm{H}_{2} \mathrm{O}$ otimizadas na proporção 6:4.

\subsubsection{Cromatografia de permeação em gel (CPG)}

Buscou-se por meio dessa técnica a separação de substâncias através dos seus diferentes tamanhos moleculares, empregando LH-20 (Sephadex ${ }^{\circledR}$ ) como suporte cromatográfico. Tal suporte foi mantido na fase eluente cerca de 48 horas antes do início da coluna para que o gel adquirisse porosidade homogênea.

\subsubsection{Cromatografia líquida de alta eficiência com detector de arranjo de diodos (CLAE-DAD)}

Para o delineamento do perfil cromatográfico dos extratos, frações e sufrações empregou-se um cromatógrafo líquido Varian, Pro star $240^{\circledR}$, detector de arranjo de diodos UV-VIS modelo Pro star 330, injetor automático modelo 410, e aquisição de dados via computador tipo Pentium III $550 \mathrm{MHz}$, utilizando software Star Chromatography Workstation, versão 5.31, e PV 2000 (tratamento de dados espectrais de ultravioleta).

\subsubsection{Cromatografia líquida de alta eficiência com detector UV (CLAE-UV)}

Utilizou-se um Cromatógrafo líquido Varian, modelo Pro star 230, injetor manual Rheodyne 7725, com detector UV-VIS modelo 310 e aquisição de dados via computador tipo Pentium II 300 MHz utilizando software Varian Star Chromatography Workstation, versão 5.31 . 


\subsubsection{Cromatografia líquida de alta eficiência preparativa (CLAE-UV-prep)}

Utilizou-se um Cromatógrafo líquido Varian, modelo Pro star SD1, injetor manual Rheodyne 7725, com detector UV-VIS modelo 320 e aquisição de dados via computador tipo Pentium III $550 \mathrm{MHz}$ utilizando software Varian Star Chromatography Workstation, versão 5.31 .

\subsubsection{Cromatografia gasosa $(C G)$}

Utilizou-se um cromatógrafo a gás Varian, modelo CP-3800, com injetor ajustado a temperatura de $260^{\circ} \mathrm{C}$ e detector de ionização em chama a $310^{\circ} \mathrm{C}$ para SPB-5 $(5 \%$ fenilmetil-silicone, $30 \mathrm{~m} \times 0,25 \mathrm{~mm} \times 0,25 \mu \mathrm{m})$ e $290^{\circ} \mathrm{C}$ para SPB-50 (50\% fenil-metilsilicone, $30 \mathrm{~m} \times 0,25 \mathrm{~mm} \times 0,25 \mu \mathrm{m})$. O volume injetado foi $2 \mu \mathrm{L}$, a temperatura da coluna SPB-50 foi de $280^{\circ} \mathrm{C}$ (isoterma) e a temperatura da coluna SPB-5 foi inicialmente de $250^{\circ} \mathrm{C}$, mantida por $12 \mathrm{~min}$, seguido por um aumento de temperatura de $6^{\circ} \mathrm{C} \cdot \mathrm{min}^{-1}$ até $280^{\circ} \mathrm{C}$. As retenções relativas (RR) de triterpenos e esteróis foram comparados com as RR de padrões (CREVELIN et al., 2006) utilizando colesterol como padrão interno.

\subsection{Espectrometria}

Para a identificação e elucidação estrutural das substâncias isoladas foram empregadas técnicas de ressonância magnética nuclear mono e bidimensionais. Os espectros de RMN foram obtidos nos espectrômetros Bruker AC $200^{\circledR}$, operando a 200 $\mathrm{MHz}$ na frequência do hidrogênio e a $50 \mathrm{MHz}$ na frequência do carbono e/ou em espectrômetro Varian Inova $500^{\circledR}$, operando a $500 \mathrm{MHz}$ na frequência do hidrogênio e em $125 \mathrm{MHz}$ na frequência do carbono. Os espectros dinâmicos de RMN foram feitos no Laboratório de Ressonância Magnética Nuclear (UFSCar), sob orientação do prof ${ }^{\mathrm{o}}$ Antonio Gilberto Ferreira.

Os espectros de Infravermelho (IV) foram obtidos no Laboratório de Fitoquímica (UNESP- Araraquara), sob supervisão do Prof ${ }^{o}$ Vagner Wilegas. Utilizou-se um espectrofotômetro Shimadzu FT-IR 8300.

As análises em CLAE-EM e CLAE-EM/EM foram realizadas na USP-RP em um cromatógrafo líquido de alta eficiência da marca Shimadzu, modelo Class Vp 20 equipado com duas bombas de solvente (LC-20AD), detector por arranjo de diodos (SPD-M20A) e 
sistema controlador (CBM-20A). Este cromatógrafo foi acoplado a um espectrômetro de massas da marca Bruker Daltonics (Billerica, MA), modelo UltroTOF-Q, equipado com uma fonte de ionização por electrospray (ESI) e analisador por tempo de vôo, operando nos modos negativo e positivo. As amostras foram injetadas utilizando-se um injetor Rheodyne, modelo 7125 equipado com um loop de $20 \mu \mathrm{L}$. Como calibração interna foi usada uma solução de NA-TFA a $10 \mathrm{mg} \cdot \mathrm{mL}^{-1}$.

Para os espectros de CG-EM utilizou-se um cromatógrafo da marca Shimadzu CG 17 A, EM DP5050A, IE: + $70 \mathrm{eV}$ (fixo), coluna DB-1 (30m x 0,25 mm), filme 0,1 mm, injeção $1 \mathrm{~mL}$ (split 1:20), temperatura do injetor: $280^{\circ} \mathrm{C}$, temperatura interface: $300^{\circ} \mathrm{C}$, gás de arraste $\mathrm{He}$ e temperaturas programadas: $50^{\circ} \mathrm{C}(3 \mathrm{~min})$, aquece a $2^{\circ} \mathrm{C} \cdot \mathrm{min}^{-1}$ até chegar a $290^{\circ} \mathrm{C}$, onde permanece por $20 \mathrm{~min}$.

A rotação óptica $\left([\alpha]_{D}\right)$ foi obtida em um polarímetro Polamat A Carl Zeiss Jena na temperatura de $26^{\circ} \mathrm{C}$.

As medidas de dicroísmo circular foram realizadas em um cromatógrafo da marca Jasco, bomba modelo PU-2089, acoplado a um detector de dicroísmo circular (CD-2095) e injetor automático AS-2055. A coluna utilizada foi ODS da marca Phenomenex $(25,0 \mathrm{~cm} \mathrm{x}$ 4,6 mm x 5 $\mu \mathrm{m})$ com fase móvel de $\mathrm{MeOH}: \mathrm{H}_{2} \mathrm{O}: \mathrm{HOAc}(55: 44,5: 0,5)$ e vazão de 1,0 $\mathrm{mL} / \mathrm{min}$.

Ambas as medidas $\left([\alpha]_{\mathrm{D}}\right.$ e dicroísmo circular) foram realizadas no Laboratório de Fitoquímica da UNESP de Araraquara.

\subsection{Solventes}

Como solvente para o preparo de amostras (análises de RMN) foi utilizado DMSO$d_{6}$ e $\mathrm{CDCl}_{3}$ e, como referência interna TMS, para os experimentos de $\mathrm{RMN}$ de ${ }^{13} \mathrm{C}$ e ${ }^{1} \mathrm{H}$. Os solventes utilizados na extração foram destilados no laboratório e no processo final de isolamento os solventes foram da marca JT Baker ${ }^{\circledR}$. 


\section{PROCEDIMENTO EXPERIMENTAL}

\subsection{Coleta do material botânico e preparação dos extratos e frações}

Os frutos e folhas de Garcinia xanthochymus foram coletados no Campus da Universidade Estadual Júlio de Mesquita Filho (UNESP)-Jaboticabal em maio de 2008, sendo identificados pelo Prof ${ }^{\circ}$ Antonio Baldo G. Martins. As folhas foram secas em estufa a $40^{\circ} \mathrm{C}$ e em seguida pulverizadas em moinho de facas. Já os frutos foram triturados com etanol a temperatura ambiente. Os produtos obtidos foram submetidos ao processo de extração por maceração em $n$-hexano (3x), com posterior remaceração em etanol (3x), fornecendo as soluções hexânica e etanólica. Essas soluções foram evaporadas a pressão reduzida e forneceram os extratos hexânicos (HEX) e etanólico (ETOH), respectivamente. O extrato etanólico foi solubilizado em uma mistura de água:metanol (6:4) e então submetido à extração líquido-líquido (ELL), empregando $n$-hexano, AcOEt e $n$-BuOH como contra-fase (Figura 7 e Figura 8).

Todos os extratos e/ou frações oriundas da ELL foram analisados por ensaios em cromatografia em camada delgada comparativa (CCDC), nebulizadas com solução de $\beta$ caroteno e anisaldeído. Estes também foram analisados via CLAE-UV-DAD, para obtenção do perfil cromatográfico de cada amostra.

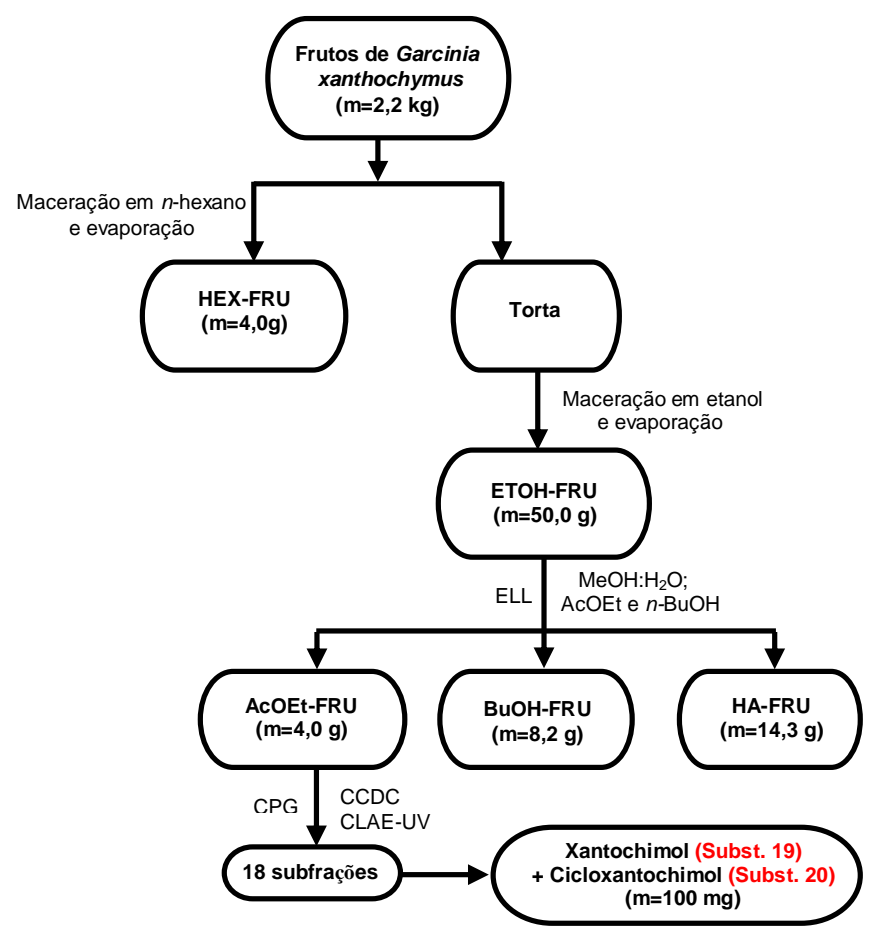

Figura 7 - Fracionamento cromatográfico dos frutos de Garcinia xanthochymus. 


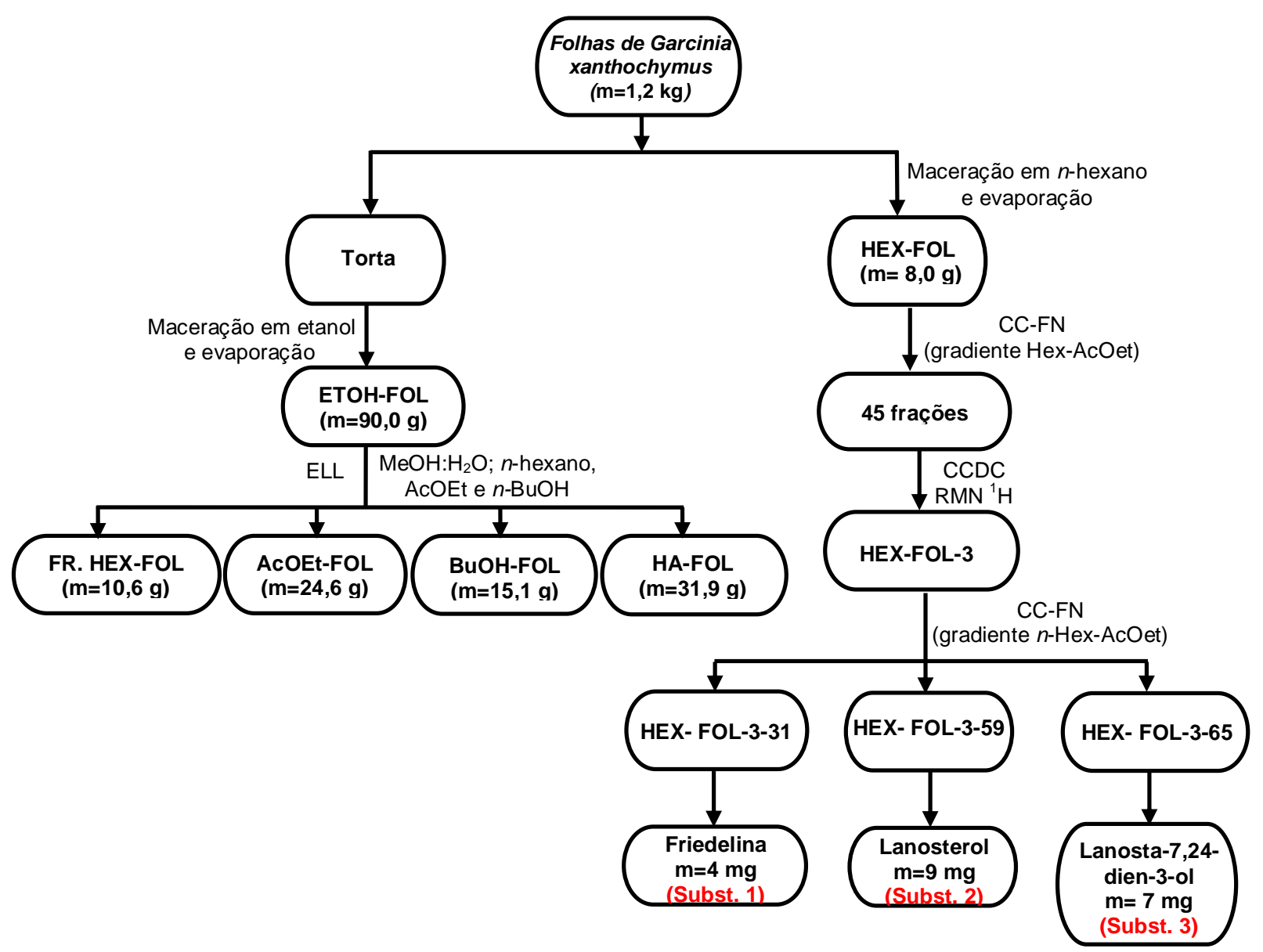

Figura 8 - Fracionamento cromatográfico das folhas de Garcinia xanthochymus.

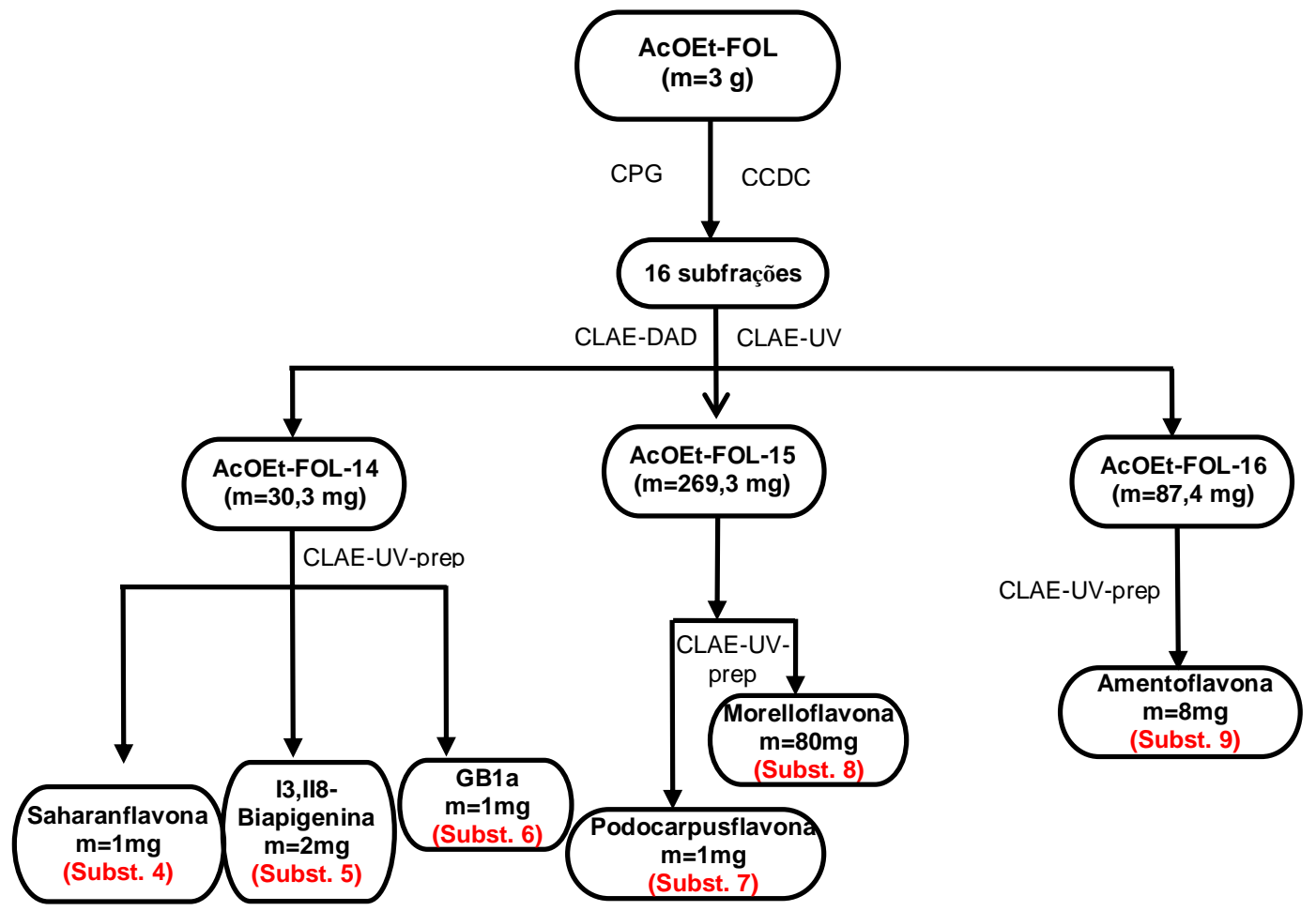

Figura 9 - Fracionamento cromatográfico da fração AcOEt-FOL de Garcinia xanthochymus em coluna de permeação em gel (LH-20, Sephadex $\left.{ }^{\circledR}\right)$. 


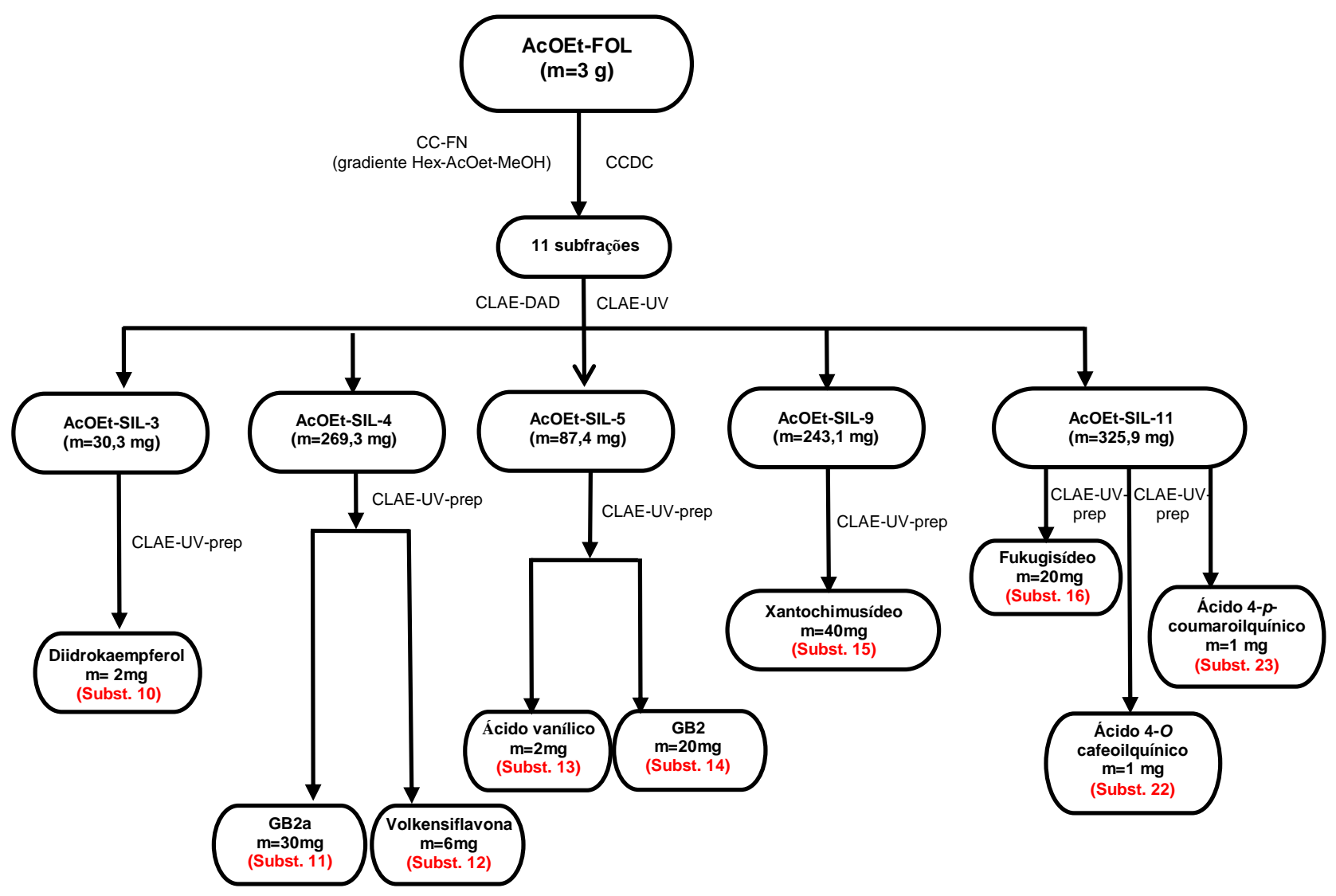

Figura 10 - Fracionamento cromatográfico da fração AcOEt-FOL de Garcinia xanthochymus em coluna de fase normal (sílica-gel 60-230 $\mu$ ).

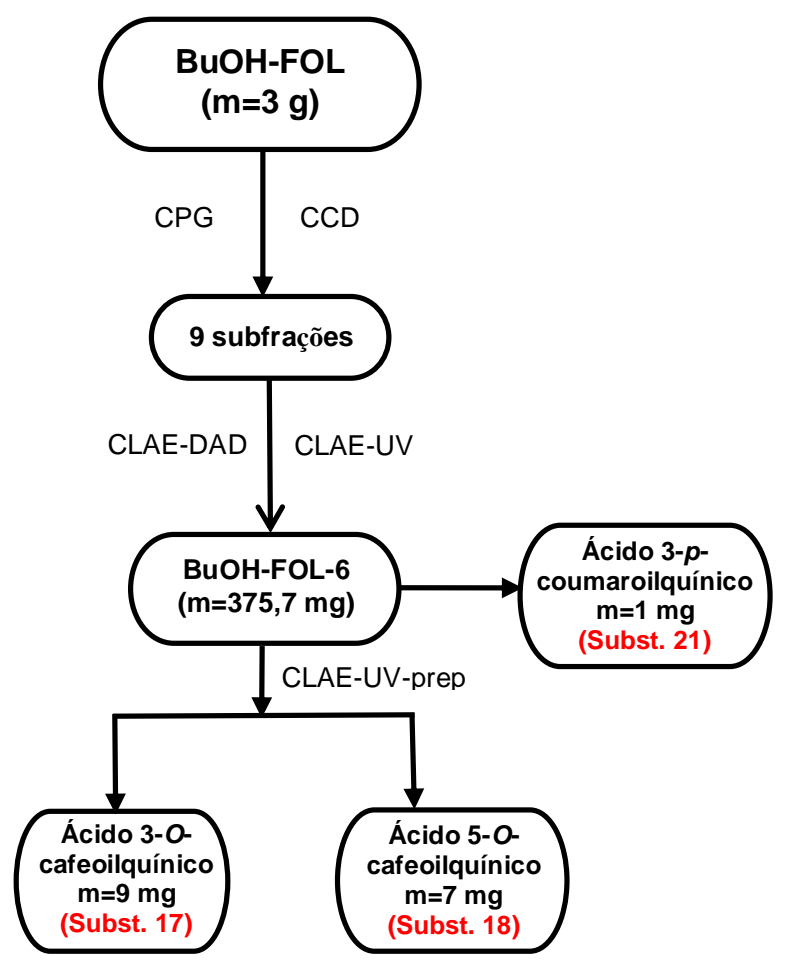

Figura 11 - Fracionamento cromatográfico da fração BuOH-FOL de Garcinia xanthochymus. 


\subsection{Pré-tratamento da amostra para CLAE-DAD e UV}

Antes de serem injetados no cromatógrafo, os extratos e frações de Garcinia xanthochymus foram submetidos a um tratamento preliminar, etapa que envolve a eliminação de grande parte dos pigmentos e constituintes de baixa polaridade. A extração em fase sólida de fase reversa foi utilizada por ser a técnica de escolha em pré-tratamentos de amostras para análises em CLAE fase reversa. Dessa maneira, seguiu-se o seguinte procedimento:

1. Pesagem de $1,5 \mathrm{~g}$ de ODS $(40-63 \mu \mathrm{m})$ e preparação de um cartucho com uma coluna de vidro $(0,9 \mathrm{~cm} \mathrm{di})$.

2. Condicionamento do cartucho com 3,0 mL do eluente $\mathrm{MeOH}: \mathrm{H}_{2} \mathrm{O}$ (95:05).

3. Solubilização do extrato ou fração em 1,0 mL do eluente.

4. Aplicação do extrato na coluna e eluição da amostra com 5,0 mL do eluente.

5. Filtração da amostra em membrana Millipore ${ }^{\circledR}(0,2 \mu \mathrm{m})$ e acondicionamento em frasco para injeção.

\subsection{Estudo químico do extrato hexânico das folhas de Garcinia xanthochymus (HEX-FOL)}

O extrato hexânico (HEX-FOL) foi submetido à cromatografia em coluna de fase normal (CC-FN), eluída no modo gradiente, utilizando misturas de HEX e AcOEt (Figura 8). Foram obtidas 45 frações, as quais foram analisadas por cromatografia em camada delgada comparativa (CCDC) e ressonância magnética nuclear de hidrogênio um (RMN de $\left.{ }^{1} \mathrm{H}\right)$. Assim, conseguiu-se um perfil cromatográfico e espectrométrico das frações obtidas, o qual revelou a presença de ácidos graxos, triterpenos e esteróides. Diante da simplicidade (menor número de substâncias reveladas em anisaldeído sulfúrico) e da presença de poucas substâncias adsorvidas fortemente nas cromatoplacas (alta polaridade), optou-se primeiramente pela fração HEX-FOL-3 para prosseguir o fracionamento cromatográfico. A fração HEX-FOL-3 foi submetida à CC-FN (gradiente HEX e AcOEt), culminando no isolamento da substância 1 (friedelina) e da substância 2 (lanosterol), inédita na literatura para essaa espécie. A subfração HEX-FOL-3-65 apresentou-se como uma mistura de dois esteróides: lanosterol e a substancia 3 (lanosta-7,24-dien-3-ol), também não identificada na espécie em estudo. 


\subsection{Fracionamento cromatográfico da fração AcOEt das folhas de Garcinia xanthochymus (AcOEt-FOL)}

Diante dos resultados preliminares da ação antioxidante e antimalárica dos extratos e frações obtidos das folhas de Garcinia xanthochymus (Tabela 18 e Tabela 19) optou-se inicialmente pelo estudo químico da fração AcOEt-FOL.

A fração AcOEt-FOL foi submetida à cromatografia de permeação em gel (CPG), empregando-se LH-20/Sephadex ${ }^{\circledR}$ e eluição isocrática com MeOH. Foram coletadas 45 subfrações, as quais foram analisadas por meio de CCDC, em placas de sílica gel eluídas com AcOEt: $\mathrm{H}_{2} \mathrm{O}$ (100:27) acidificadas com 11\% de ácido acético e 11\% de ácido fórmico (BLADT, 1996) e revelação com solução de anisaldeído, possibilitando reuní-las em 16 subfrações (Figura 9).

Em virtude da grande quantidade da massa $(24,6 \mathrm{~g})$ e baseando-se em referências da literatura na busca de xantonas preniladas (ZHONG; CHEN; YANG, 2008; CHANMAHASATHIEN et al., 2003; CHEN et al., 2008) a fração AcOEt-FOL também foi submetida à CC-FN (sílica-gel 60-230 $\mu \mathrm{m}$ ), utilizando misturas de HEX, AcOEt e MeOH no modo gradiente. Após análise comparativa por CCDC em placas de sílica gel e fase móvel 9:1 (AcOEt: MeOH) foi possível reunir as frações coletadas em 11 subfrações (Figura 10).

Todas as subfrações (AcOEt-FOL-1 a 16 e AcOEt-SIL-1 a 11) tiveram seu perfil químico analisado por CLAE-DAD (ODS, Phenomenex, 25,0 cm x 4,6 mm x $5 \mu \mathrm{m}$ ) e eluição gradiente em $\mathrm{H}_{2} \mathrm{O}: \mathrm{MeOH}$ (95:5) até $\mathrm{MeOH}$ (100).

Com isso, foi possível caracterizar o número de substâncias presentes em cada subfração, bem como selecionar as subfrações AcOEt-FOL-14-16, AcOEt-SIL-3-5, AcOEtSIL-9, AcOEt-SIL-11 para isolamento de seus constituintes químicos, baseando-se nas massas e perfil cromatográfico de cada matriz.

\subsection{Estudo químico da subfração AcOEt-FOL-14}

A otimização em CLAE para a subfração AcOEt-FOL-14 foi obtida com a fase móvel na composição de $57 \%$ metanol e $43 \%$ de água dopada com $0,5 \%$ de HOAc, em coluna Fenil-hexil (Phenomenex Luna 25,0 cm x 4,6), fluxo de $1 \mathrm{~mL} \cdot \mathrm{min}^{-1}$ e volume injetado de 20 $\mu \mathrm{L}$ (Figura 12). Quando submetida à CLAE-prep, com fluxo de $10 \mathrm{~mL} \cdot \mathrm{min}^{-1}, \mathrm{c}=10 \mathrm{mg} \cdot \mathrm{mL}^{-}$

${ }^{1}$ e detecção em $\lambda=254 \mathrm{~nm}$, a subfração AcOEt-FOL-14 (483,9 mg), apresentou cinco 
picos; o pico em $t_{r}=11,5$ min (Substância 4), o pico em $t_{r}=19,0$ min (Substância 5) e o pico em $t_{r}=27,0$ min (Substância 6) apresentaram-se puros e com sinais característicos de flavonóides, evidenciados pelos dados de UV e RMN de ${ }^{1} \mathrm{H}$.

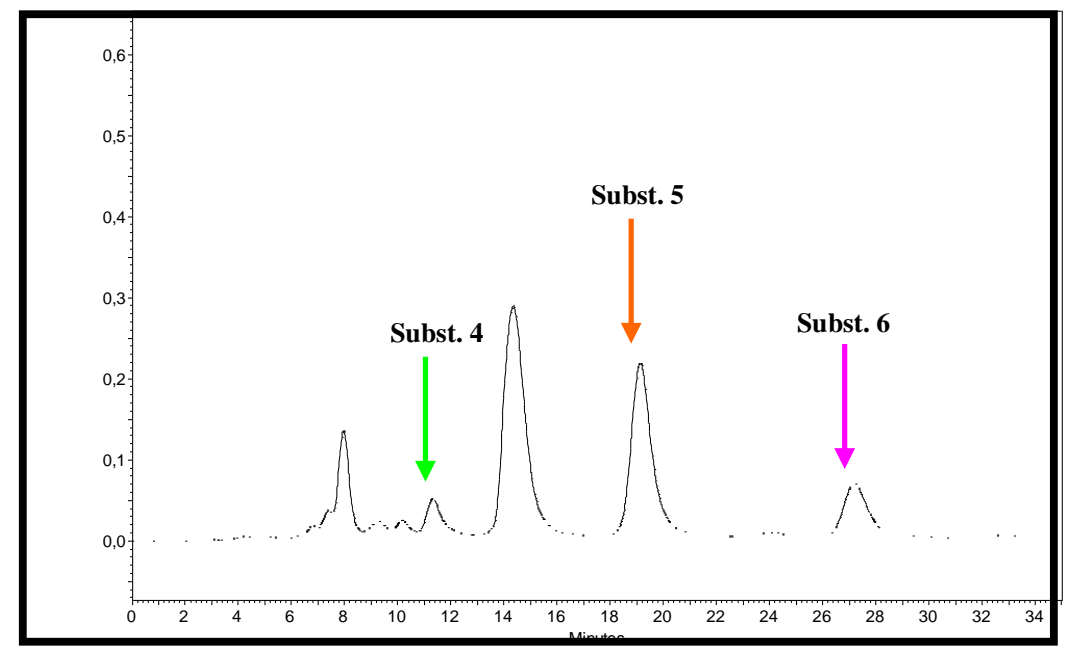

Figura 12 - Cromatograma analítico obtido via CLAE-UV da subfração AcOEt-FOL-14, eluída com MeOH: $\mathrm{H}_{2} \mathrm{O}$ : HOAc (57:42,5:0,5) e detecção em $\lambda=254 \mathrm{~nm}$.

\subsection{Estudo químico das subfrações AcOEt-FOL-15 e 16}

As subfrações AcOEt-FOL-15 e 16 também foram submetidas a experimentos de otimização em CLAE-UV para posterior utilização e separação por CLAE-prep. A melhor condição para tal separação foi obtida com a fase móvel na composição de $75 \%$ metanol e $25 \%$ de água dopada com 0,5\% de HOAc, em coluna Fenil-Hexil (Phenomenex Luna 25,0 $\mathrm{cm}$ x 4,6) com detecção em $\lambda=254 \mathrm{~nm}$, fluxo de $1 \mathrm{~mL} \cdot \mathrm{min}^{-1}$ e volume injetado de $20 \mu \mathrm{L}$ (Figura 13a e Figura 13b).

A subfração AcOEt-FOL-15 (61,2 mg) foi submetida à CLAE-prep, com fluxo de 10 mL.min ${ }^{-1}, c=10 \mathrm{mg} \cdot \mathrm{mL}^{-1} \mathrm{e}$ detecção em $\lambda=254 \mathrm{~nm}$, sendo que quatro picos foram separados. O segundo pico ( $t_{\mathrm{r}}$ em 4,0 min, Substância 7) e o quarto pico de interesse $\left(t_{\mathrm{r}}\right.$ em 7,7 min, Substância 8) apresentaram-se puros e com sinais característicos de flavonóides, evidenciados pelos dados de UV e RMN de ${ }^{1} \mathrm{H}$.

Nestas mesmas condições, a subfração AcOEt-FOL-16 (129,8 mg) apresentou dois picos, porém apenas o $2^{\circ}$ caracterizava-se como uma substância pura (Substância 9). 


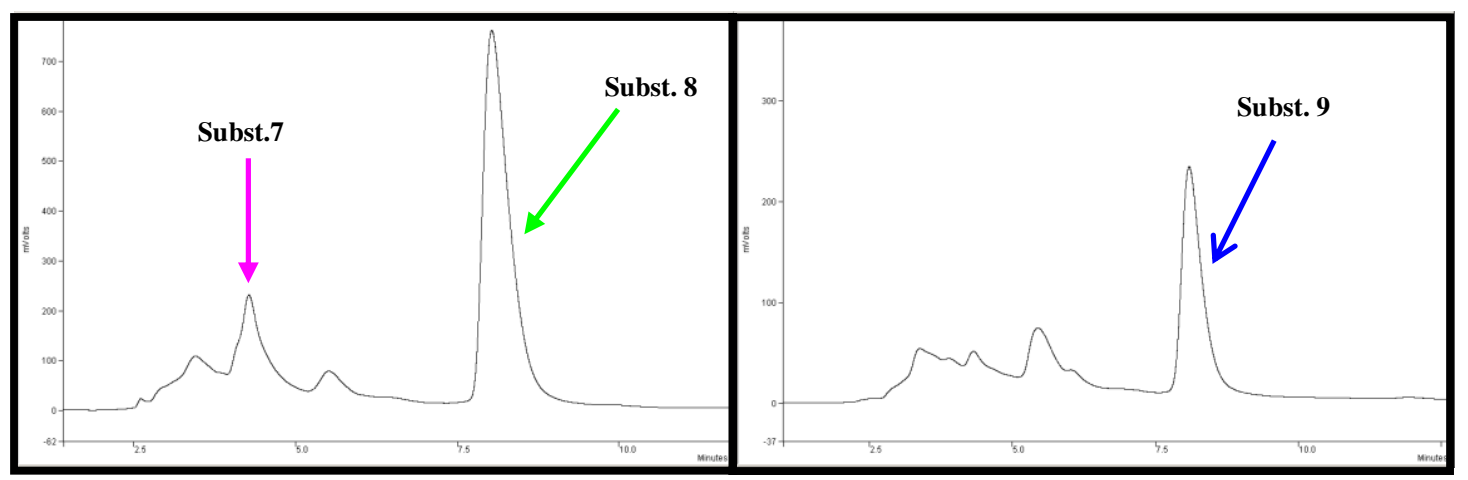

Figura 13 - Cromatogramas analíticos obtidos via CLAE-UV das subfrações (a) AcOEt-FOL-15 e (b) AcOEt-FOL-16, eluídas com MeOH: $\mathrm{H}_{2} \mathrm{O}: \mathrm{HOAc}(75: 24,5: 0,5)$ e detecção em $\lambda=254 \mathrm{~nm}$.

\subsection{Estudo químico da subfrações AcOEt-SIL-3 e 9}

As condições de separação das subfrações AcOEt-SIL-3 (m=30,3 mg) e AcOEt-SIL-9 $(\mathrm{m}=243,1 \mathrm{mg})$ foram otimizadas por CLAE-UV na condição de $45 \%$ metanol e $55 \%$ de água dopada com 0,5\% de HOAc, em coluna Fenil-hexil (Phenomenex Luna 25,0 cm x 4,6), fluxo de $1 \mathrm{~mL} \cdot \mathrm{min}^{-1}$ e volume injetado de $20 \mu \mathrm{L}$. Quando submetida ao fracionamento em escala preparativa em coluna Fenil-hexil (Phenomenex Luna 25,0 cm x 21), fluxo de 10 mL.min ${ }^{-1}, c=10$ mg.mL ${ }^{-1}$ e detecção em $\lambda=254$ nm, a subfração AcOEt-SIL-3 (Figura 14a) permitiu o isolamento da substância 10 ( $\left.\mathrm{t}_{\mathrm{r}}=17,5 \mathrm{~min}\right)$. A subfração AcOEt-SIL-9 (Figura 14b) apresentou dois picos, porém apenas o $2^{\circ}$ caracterizava-se como uma substância pura (Substância 15).

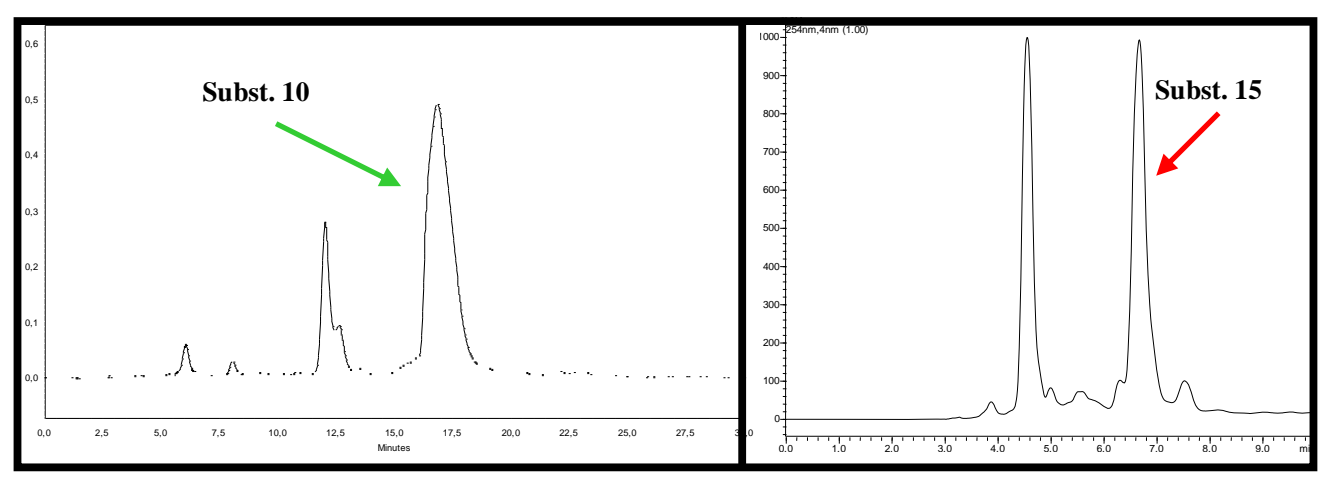

Figura 14 - Cromatogramas analíticos obtidos via CLAE-UV das subfrações (a) AcOEt-SIL-3 e (b) AcOEt-SIL-9, eluídas com MeOH: $\mathrm{H}_{2} \mathrm{O}$ : HOAc (45:54,5:0,5) e detecção em $\lambda=254 \mathrm{~nm}$. 


\subsection{Estudo químico das subfrações AcOEt-SIL-4 e 5}

A subfração AcOEt-SIL-4 (m=269,3 mg) apresentou dois picos de interesse na condição cromatográfica de $60 \%$ metanol e $40 \%$ de água dopada com $0,5 \%$ de HOAc, em coluna Fenil-hexil (Phenomenex Luna 25,0 $\mathrm{cm} \mathrm{x} \mathrm{4,6),} \mathrm{fluxo} \mathrm{de} 1 \mathrm{~mL} \cdot \mathrm{min}^{-1}$ e volume injetado de $20 \mu \mathrm{L}$ (Figura 15a). A posterior separação em CLAE-prep com fluxo de 10 mL.min ${ }^{-1}, c=10 \mathrm{mg} \cdot \mathrm{mL}^{-1}$ e detecção em $\lambda=254 \mathrm{~nm}$ permitiu o isolamento da substância 11 (pico em $\mathrm{t}_{\mathrm{r}}=11,2 \mathrm{~min}$ ) e da substância 12 (pico em $\mathrm{t}_{\mathrm{r}}=14,5 \mathrm{~min}$ ).

Já subfração AcOEt-SIL-5 $(\mathrm{m}=87,4)$ (Figura 15b) quando submetida à CLAE-UVprep com a fase móvel de $50 \%$ metanol e $50 \%$ de água dopada com 0,5\% de HOAc, em coluna Fenil-hexil (Phenomenex Luna 25,0 cm x 21), fluxo de $10 \mathrm{~mL} \cdot \mathrm{min}^{-1}$, c=10 mg.mL ${ }^{-1}$ e detecção em $\lambda=254 \mathrm{~nm}$, permitiu o isolamento do ácido vanílico (pico em $\mathrm{t}_{\mathrm{r}}=5,1 \mathrm{~min}$, Substância 13), do biflavonóide GB2 (pico em $\mathrm{t}_{\mathrm{r}}=15,1 \mathrm{~min}$, substância 14) e da substância 8, já isolada anteriormente da subfração AcOEt-FOL-15.

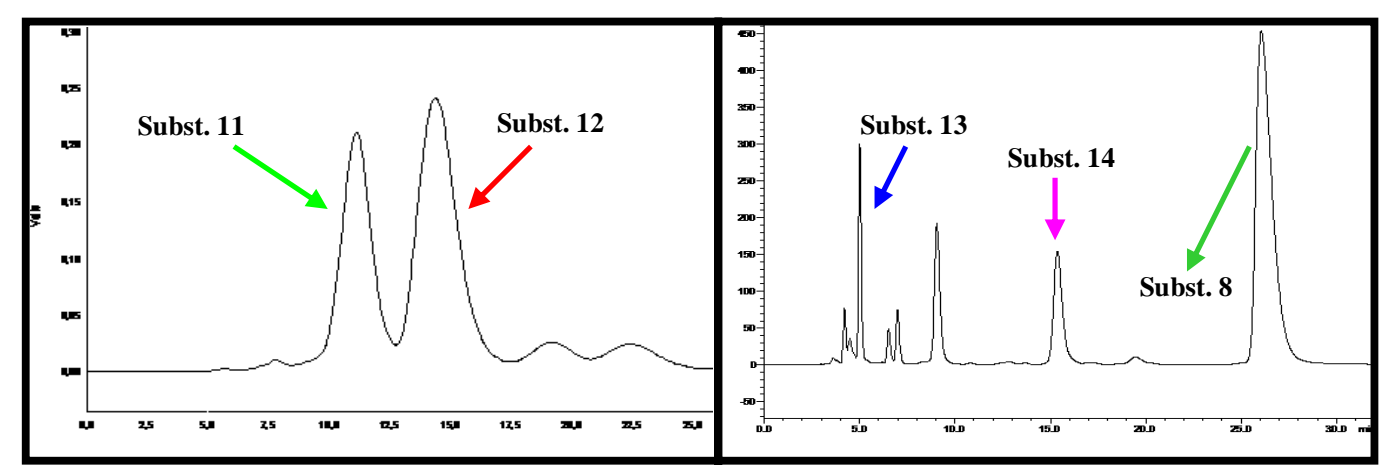

Figura 15 - Cromatogramas analíticos obtidos via CLAE-UV das subfrações (a) AcOEt-SIL-4, eluída com MeOH: $\mathrm{H}_{2} \mathrm{O}$ : HOAc (60:39,5:0,5) e (b) AcOEt-SIL-5, eluídas com MeOH: $\mathrm{H}_{2} \mathrm{O}: \mathrm{HOAc}$ $(50: 49,5: 0,5)$.

\subsection{Estudo químico da subfração AcOEt-SIL-11}

A otimização em CLAE para a subfração AcOEt-SIL-11 foi obtida com a fase móvel na composição de $35 \%$ metanol e $65 \%$ de água dopada com $0,5 \%$ de HOAc, em coluna Fenil-hexil (Phenomenex Luna 25,0 cm x 4,6), fluxo de $1 \mathrm{~mL} \cdot \mathrm{min}^{-1}$ e volume injetado de 20 $\mu \mathrm{L}$ (Figura 16). Quando submetida à CLAE-prep, com fluxo de $10 \mathrm{~mL} \cdot \mathrm{min}^{-1}, \mathrm{c}=10 \mathrm{mg} \cdot \mathrm{mL}^{-}$ ${ }^{1}$ e detecção em $\lambda=254 \mathrm{~nm}$, a subfração AcOEt-SIL-11 (325,9 mg), apresentou cinco picos; o segundo pico em $t_{r}=5,5$ min (Substância 16) apresentou-se com sinais característicos de 
flavonóides glicosilados, evidenciados pelos dados de UV e RMN de ${ }^{1} \mathrm{H}$. Já as substâncias 22 e 23 foram identificadas como derivadas de ácidos fenilpropanoídicos.

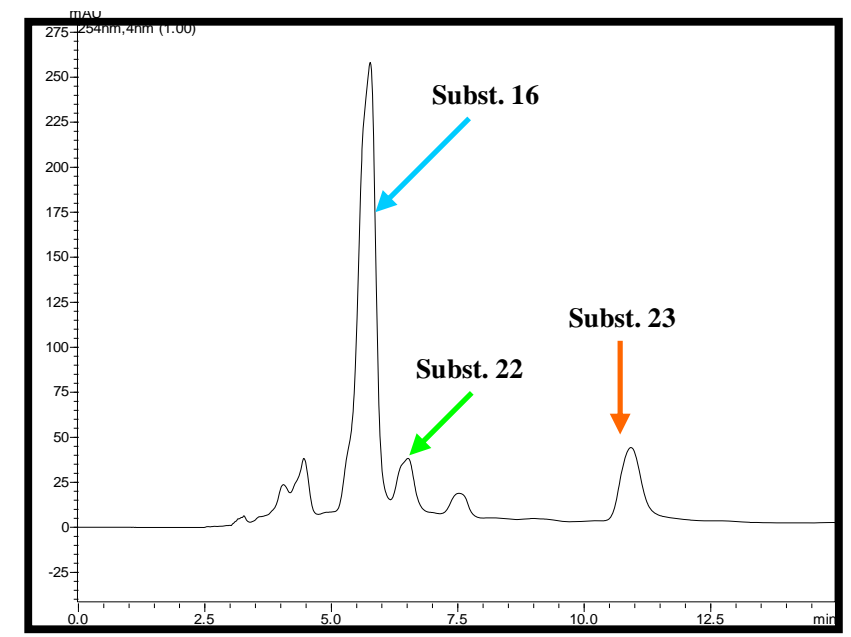

Figura 16 - Cromatograma analítico obtido via CLAE-UV da subfração AcOEt-SIL-11, eluída com $\mathrm{MeOH}: \mathrm{H}_{2} \mathrm{O}: \mathrm{HOAc}(35: 64,5: 0,5)$ e detecção em $\lambda=254 \mathrm{~nm}$.

\subsection{Fracionamento cromatográfico e estudo químico da fração $\mathrm{BuOH}$ das folhas de Garcinia xanthochymus (BuOH-FOL)}

A fase butanólica das folhas (BuOH-FOL) foi submetida à CPG (LH-20, Sephadex $\left.{ }^{\circledR}\right)$, eluída isocraticamente em MeOH. Foram coletadas 26 frações, as quais foram analisadas e reunidas em 9 subfrações por meio de CCDC (Figura 11), em placas de sílica gel eluídas com $\mathrm{H}_{2} \mathrm{O}: \mathrm{BuOH}: \mathrm{HOAc}$ (50:40:10) e revelação com solução de anisaldeído.

A análise das cromatoplacas, dos cromatogramas obtidos via CLAE-DAD e dos espectros de ressonância magnética nuclear de hidrogênio um (RMN de $\left.{ }^{1} \mathrm{H}\right)$ possibilitou a escolha da subfração BuOH-FOL-6 para posterior estudo fitoquímico. A melhor condição cromatográfica foi de $20 \%$ metanol e $80 \%$ de água dopada com $0,5 \%$ de HOAc, em coluna Fenil-hexil (Phenomenex Luna 25,0 cm x 4,6), fluxo de $1 \mathrm{~mL} \cdot \mathrm{min}^{-1}$ e volume injetado de 20 $\mu \mathrm{L}$ (Figura 17). Quando submetida à CLAE-prep, com fluxo de $10 \mathrm{~mL} \cdot \mathrm{min}^{-1}, \mathrm{c}=10 \mathrm{mg} \cdot \mathrm{mL}^{-}$ ${ }^{1}$ e detecção em $\lambda=254 \mathrm{~nm}$ a subfração BuOH-FOL-6 $(375,7 \mathrm{mg})$ apresentou três picos, sendo que o $1^{\circ}$ pico $\left(t_{r}=5,5 \mathrm{~min}\right)$ foi identificado como substância 17 , o $2^{\circ}$ pico $\left(t_{r}=7,0 \mathrm{~min}\right)$ como substância 18 e o $3^{\circ}$ pico $\left(\mathrm{t}_{\mathrm{r}}=7,6 \mathrm{~min}\right)$ como substância 21 . 


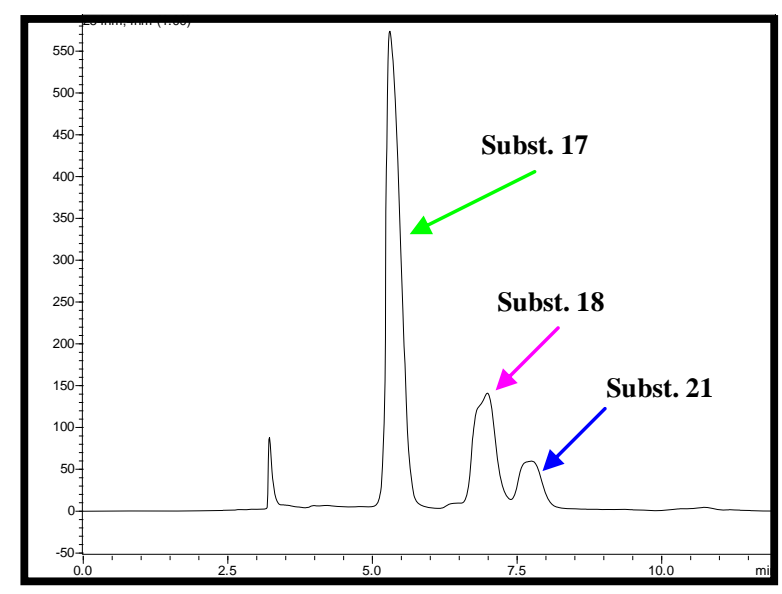

Figura 17 - Cromatograma analítico obtido via CLAE-UV da subfração BuOH-FOL-6, eluída com $\mathrm{MeOH}: \mathrm{H}_{2} \mathrm{O}: \mathrm{HOAc}(20: 79,5: 0,5)$ e detecção em $\lambda=254 \mathrm{~nm}$.

\subsection{Fracionamento cromatográfico e estudo químico da fração AcOEt dos frutos de Garcinia xanthochymus (AcOEt -FRU)}

Após análise das cromatoplacas em diversos tipos de eluentes e reveladores, a fração AcOEt-FRU foi selecionada para estudo fitoquímico por apresentar melhor resolução, um menor número de substâncias e maior massa.

Uma alíquota da fração AcOEt-FRU (4,0 g) foi dissolvida em $4 \mathrm{~mL}$ de $\mathrm{MeOH}$ e submetida a CC em LH-20/Sephadex ${ }^{\circledR}$. Utilizando metanol como eluente, foram coletadas 37 frações de $25 \mathrm{~mL}$, analisadas por CCDC, o que permitiu sua reunião em 18 subfrações.
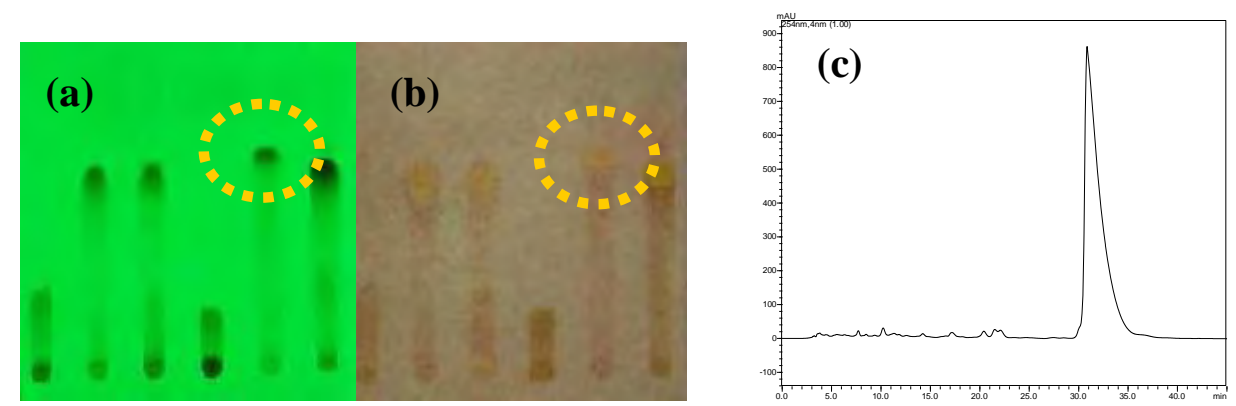

Figura 18 - Cromatoplaca da subfração AcOEt-FRU-7 com (a) revelação física em $\lambda=254 \mathrm{~nm}$ e (b) revelação química com anisaldeído sulfúrico (c) Cromatograma analítico da subfração AcOEt-FRU7, obtido em coluna ODS (Phenomenex, 25,0 cm x 4,6 mm x $5 \mu \mathrm{m}$ ) eluída com fase móvel de $\mathrm{MeOH}: \mathrm{H}_{2} \mathrm{O}: \mathrm{HOAc}(75: 24,5: 0,5)$ e detecção em $\lambda=254 \mathrm{~nm}$.

A cromatoplaca da subfração AcOEt-FRU-7 (100 mg) revelou a presença de apenas uma mancha amarela em revelação com anisaldeído sulfúrico, pureza também exibida em 
análise por CLAE-DAD (Figura 18). Porém quando submetida às análises espectroscópicas evidenciou-se a presença de uma mistura isomérica (Substâncias 19 e 20).

\subsection{Identificação por CLAE-DAD-EM dos constituintes de frações selecionadas de Garcinia xanthochymus-análise por desreplicação}

Após o pré-tratamento de amostras para CLAE, conforme descrito no item 5.2, algumas subfrações (provenientes da fração AcOEt dos frutos) e/ou substâncias puras foram analisadas e identificadas por CLAE-DAD-EM. As condições cromatográficas foram: AcOEt-FRU-13, 30\% metanol e 70\% de água dopada com 0,5\% de HOAc, em coluna Fenil-hexil (Phenomenex Luna 25,0 cm x 4,6), fluxo de $1 \mathrm{~mL} \cdot \mathrm{min}^{-1}$ e volume injetado de 20 $\mu \mathrm{L}$ e para a subfração AcOEt-FRU-17, $40 \%$ metanol e $60 \%$ de água dopada com 0,5\% de HOAc, em coluna Fenil-hexil (Phenomenex Luna 25,0 cm x 4,6), fluxo de $1 \mathrm{~mL} \cdot \mathrm{min}^{-1} \mathrm{e}$ volume injetado de $20 \mu \mathrm{L}$.

Por apresentar pequena quantidade de massa e/ou impurezas, algumas amostras (Substâncias 6, 7, 15, 16, 21, 22, 23 e a subfração AcOEt-FRU-7) foram analisadas por EM, injeção direta (sistema off), a fim de aumentar a concentração para um mesmo volume injetado. Estas também foram comparadas e identificadas através dos tempos de retenção, bandas de absorção e dados de RMN obtidos da literatura.

\subsection{Identificação de triterpenos e esteróides presentes nos extratos de baixa polaridade de Garcinia xanthochymus utilizando cromatografia gasosa (CG)}

Em virtude do extrato hexânico das folhas (HEX-FOL), a fração hexânica das folhas (FR. HEX-FOL) e o extrato hexânico dos frutos (HEX-FRU) apresentarem um perfil em CCDC bastante complexo e de difícil separação, essas matrizes foram analisadas por CG, conforme metodologia e equipamentos descritos no item 4.1.8. O pré-tratamento consistiu em solubilizar $10 \mathrm{mg}$ de cada amostra em clorofórmio $(3 \mathrm{~mL})$ e eluir as mesmas por uma coluna cromatográfica contendo celite:carvão ativo $(1: 1,100 \mathrm{mg})+$ sílica gel $(200 \mathrm{mg})$ e fase móvel $10 \mathrm{~mL}$ de clorofórmio. Após a evaporação à temperatura ambiente, o eluído foi então, solubilizado em $n$-hexano: AcOEt (7:3). 


\subsection{Ensaios antioxidantes}

\subsubsection{Descoloração de $\beta$-caroteno}

Preparou-se uma solução de $0,02 \%$ de $\beta$-caroteno $\left(\right.$ Aldrich $^{\circledR}$ ) em metanol e após a nebulização das cromatoplacas, essas foram expostas ao ar e luz natural, por cerca de 6 horas, a fim de catalisar a oxidação do $\beta$-caroteno (SILVA et al., 2001).

\subsubsection{Atividade seqüestradora de radicais livres: DPPH (1,1-difenil-2- picrilhidrazila)}

O radical DPPH apresenta absorção máxima em $531 \mathrm{~nm}$. Neste comprimento de onda avalia-se a absorbância na ausência e na presença das amostras-teste, sendo que na presença de agentes antioxidantes ocorre aumento da transmitância. A solução de DPPH $(200 \mu \mathrm{M})$ foi preparada em MeOH. Na placa de 96 poços foram adicionados: Amostra: $200 \mu \mathrm{L}$ de DPPH e $100 \mu \mathrm{L}$ de amostra em diversas diluições. Controle positivo: $200 \mu \mathrm{L}$ de DPPH e $100 \mu \mathrm{L}$ de antioxidante padrão. Controle negativo: $200 \mu \mathrm{L}$ de DPPH e $100 \mu \mathrm{L}$ de solvente. A placa foi mantida por 30 minutos no escuro. A avaliação da forma reduzida do DPPH gerado foi determinada através da diminuição da absorbância a 517 nm. (SON e LEWIS, 2002; PAULETTI et al., 2003).

Processamento dos dados:

Fórmula: \% de sequestro do radical livre DPPH

\% = (absorbância do CONTROLE DPPH- absorbância da AMOSTRA ou PADRÃO)*100 Absorbância do CONTROLE-DPPH

\subsection{Ensaio in vitro da polimerização de heme}

O ensaio foi baseado na metodologia de Baelmans e colaboradores, com algumas modificações. Este teste consistiu na incubação em microtubos de $1,5 \mathrm{~mL}$ por 24 horas a $37^{\circ} \mathrm{C}$ das seguintes soluções: $50 \mu \mathrm{L}$ de extratos dissolvidos em DMSO (à concentração final 
de $2,5 \mathrm{mg} / \mathrm{mL})$, DMSO $(50 \mu \mathrm{L})$ para os controles com $100 \mu \mathrm{L}$ de heme $(6,4 \mathrm{mM}$ de heme dissolvida em 0,2 N NaOH, 4,16 mg em $1000 \mu \mathrm{L}$, que foi preparada 60 minutos antes da execução do ensaio, incubada a $37^{\circ} \mathrm{C}$ e protegida da luz), $200 \mu \mathrm{L}$ de acetato de sódio $0,5 \mathrm{M}$ e $50 \mu \mathrm{L}$ de ácido acético. Após a incubação, os microtubos foram centrifugados por $10 \mathrm{~min}$ e o sobrenadante foi descartado. O precipitado foi lavado duas vezes, com $400 \mu \mathrm{L}$ de DMSO e $400 \mu \mathrm{L}$ de metanol, e dissolvido em $1000 \mu \mathrm{L}$ de $\mathrm{NaOH}$ 0,1 M. Aliquotas de $20 \mu \mathrm{L}$ da $\beta$-hematina dissolvida foram transferidas para uma placa de 96 poços com $180 \mu \mathrm{L}$ de $\mathrm{NaOH}$ 0,1 M, e as amostras foram lidas a $405 \mathrm{~nm}$ no leitor de microplacas. Quinina e cloroquina foram utilizadas como controle positivo. Os dados foram expressos como porcentagem de inibição da polimerização do heme e foram calculados pelo programa $\mathrm{KC} 4$ pelo emprego da fórmula a seguir. As análises foram feitas sempre em triplicata para o cálculo do desvio padrão.

\% inibição da formação de $\beta$-hematina $=\left(\mathrm{A}_{\text {controle }+}-\mathrm{A}_{\text {amostra }}\right) * 100 / \mathrm{A}_{\text {controle }+}$

\subsection{Atividade antifúngica}

O teste incluiu os organismos Candida albicans ATCC 90028, Candida krusei ATCC 6258, Candida parapsilosis ATCC 22019 e Cryptococcus neoformans ATCC 90012. Os testes foram realizados no Departamento de Análises Clínicas/Laboratório de Micologia Clínica, Araraquara-UNESP, sob supervisão da Dra. Maria José M. Giannini.

A atividade antifúngica foi realizada seguindo a metodologia de microdiluição e verificação de turbidez em leitor de microplacas descrita no documento M27-A2 do CLSI (Clinical and Laboratory Standards Institute) com algumas modificações. As análises foram feitas em triplicatas e o meio utilizado foi RPMI 1640 com L-glutamina e ácido morfolinopropanosulfônico $0,165 \mathrm{M}$ (pH: 7,0) acrescido com $2 \%$ glicose.

As amostras foram preparadas em DMSO numa concentração de $250 \mu \mathrm{g} / \mathrm{ml}$. A suspensão das células foram preparadas em uma solução $0,85 \%$ salina e inoculada numa placa de microtubos previamente preparada com as amostras diluídas numa concentração entre $250 \mu \mathrm{g} / \mathrm{mL}$ para $0,48 \mu \mathrm{g} / \mathrm{mL}$. As placas foram incubadas sob agitação a $37^{\circ} \mathrm{C}$ por $24 \mathrm{~h}$ para a espécie Candida e 48 h para Crytococcus neoformans. 
O controle positivo utilizado foi o fluconazol dissolvido em DMSO. Pelo método espectrofotométrico, a CIM foi definida como a concentração mais baixa em que a densidade ótica (OD) foi reduzida a $90 \%$ do OD do poço controle do crescimento.

\subsection{Atividade tripanocida}

O teste colorimétrico do MTT foi realizado no Laboratório de Imunologia e Biologia Molecular de Parasitos sob supervisão da Prof ${ }^{a}$ Regina M. B. Cicarelli no Departamento de Ciências Biológicas, Araraquara-UNESP. A forma epimastigota de Trypanosoma cruzi foi escolhida por ser uma forma não infectante e de fácil manutenção em cultura.

Os testes foram realizados em triplicata em placas de poliestireno com 96 poços estéreis e com tampa em fluxo laminar.

Após diluições em DMSO, $3 \mu \mathrm{L}$ de cada substância testada (concentrações finais de $100,50,25,10,5,2,5$ e $1 \mu \mathrm{g} / \mathrm{mL}$, respectivamente), foram adicionados a $95 \mu \mathrm{L}$ de meio LIT (Liver Infusion Tryptose) contendo 1,0 × $10^{7}$ parasitos/ml na forma epimastigota de $T$. cruzi (fase log). Para os extratos e frações, as concentrações das substâncias foram extrapoladas até valores de 200,300, 400 e $500 \mu \mathrm{g} / \mathrm{mL}$. A placa foi incubada em câmara úmida por 72 horas. Então, adicionou-se $10 \mu \mathrm{L}$ de solução MTT/PMS em todos os poços e a placa novamente foi incubada, ao abrigo de luz por 75 minutos a $28^{\circ} \mathrm{C}$. Neste momento, ocorre a redução do sal tetrazolium MTT 3-(4,5-dimetiltiazol-2-il)-2-5-difeniltetrazólio em um produto colorido, formazan, pela ação da enzima succinato desidrogenase das mitocôndrias. Após solubilização dos cristais de formazan e incubação a temperatura ambiente por 30 minutos, foi feita a leitura num espectrofotômetro a $595 \mathrm{~nm}$ (COTINGUIBA et al., 2009).

A porcentagem de citotoxicidade (\%C) foi calculada segundo a equação abaixo:

$$
\% \mathrm{C}=\left[\left(\mathrm{G}_{c}-\mathrm{G}_{\mathrm{p}}\right) / \mathrm{G}_{\mathrm{c}}\right]^{*} 100 \quad \mathrm{G}_{\mathrm{c}}=\mathrm{A}_{\mathrm{c}}-\mathrm{A}_{\mathrm{m}}, \mathrm{G}_{\mathrm{p}}=\mathrm{A}_{\mathrm{p}}-\mathrm{A}_{\mathrm{pm}}
$$

Sendo que, Gc representa o número de parasitos/mL nos poços controle e $\mathrm{G}_{\mathrm{p}}$, o número de parasitos/mL detectados em diferentes concentrações da substância. Ac corresponde ao valor de absorbância nos poços controle (na ausência da substância) sem parasito; $A_{p}$, o valor da absorbância nos testes e $A_{p m}$, o valor da absorbância das diferentes concentrações da substância na ausência do parasito. 
Foram realizados dois controles, um na ausência do parasito para cada poço teste, mas na presença da substância e outro na ausência desta, mas contendo parasitos.

\subsection{Atividade quimiopreventiva}

$\mathrm{O}$ ensaio da quinona redutase $(\mathrm{QR})$ constitui um método simples para detecção e avaliação da indução da enzima quinona redutase (enzima de fase II), que destoxifica carcinógenos por produtos naturais, baseado na medida direta da atividade da QR em células de hepatocarcinoma celular (KINGHORN et al., 2004). A quinona redutase catalisa a redução da menadiona (2-metil-1,4-naftoquinona), a menadiol mediada por NADPH como doador de elétrons. O MTT é então reduzido não-enzimaticamente pelo menadiol, resultando na formação do sal azul de formazan (FAHEY et al., 2004). A linhagem derivada de hepatocarcinoma celular murino-Hepa 1c1c7 contém quantidades de QR induzíveis facilmente mensuráveis que fornece um sistema confiável para detecção de indutores de enzimas de fase II (CUENDET et al., 2006).

A atividade de QR foi determinada em placas de 96 poços com células (1,5x $10^{4}$ células/cavidade) da linhagem de hepatocarcinoma murino-Hepa 1c1c7. A atividade específica foi definida como a concentração nanomolar de MTT formado por mg de proteína por minuto, monitorada em leitor de placas a $595 \mathrm{~nm}$. A indução da QR foi calculada pela comparação da atividade específica de células tratadas com aquelas expostas apenas ao solvente, sendo gerado um gráfico dessas razões.

$$
\mathrm{IQ}=\mathrm{CI}_{50} / \mathrm{CD}
$$

CD representa a concentração necessária para duplicar a indução de QR e o Índice de Quimioprevenção (IQ) é um valor gerado pela comparação de $\mathrm{CD}$ e $\mathrm{CI}_{50}$ (concentração para $50 \%$ de inibição da viabilidade celular). 


\section{RESULTADOS E DISCUSSÃO}

\subsection{Análise dos cromatogramas e espectros de absorção}

Nas condições empregadas, os cromatogramas dos extratos e frações das folhas e frutos de Garcinia xanthochymus mostraram que nos frutos os metabólitos secundários são minoritários e/ou se encontram em menores concentrações, com exceção do pico em $t_{r}=45$ min (Substs. 19 e 20, isoladas da fração AcOEt-FRU-7, Figura 18), que é majoritário no extrato ETOH e fração AcOEt dos frutos (Figura 19a e Figura 19b-acima). Similaridades nos tempos de retenção e nos espectros de UV foram encontradas para substâncias com $\mathrm{t}_{\mathrm{r}}=$ 12,5 e 28,0 min que estão presentes na fração $\mathrm{BuOH}$ das folhas e frutos. A substância com $\mathrm{t}_{\mathrm{r}}=12,5$ min também está presente na fração HA de ambos órgãos (Figura 19c e Figura 19d-acima e abaixo).

Nota-se também semelhanças entre o extrato ETOH e a fração AcOEt das folhas no que diz respeito à composição (bandas de absorção no UV) e tempos de retenção. Assim também para as frações $\mathrm{BuOH}$ e HA, que apresentam similaridades na região de menores tempos de retenção dos picos nos cromatogramas (relativo à composição da fase móvel com maior teor de água no gradiente exploratório), o que sugere um caráter mais polar das substâncias presentes nesta região do cromatograma.

Os picos majoritários da fração AcOEt-FOL (Figura 19b-abaixo) apresentam espectros de absorção no UV característicos de flavonóides (Figura 20). O espectro consiste de dois máximos de absorção, nos intervalos de comprimento de onda de 230-295 nm (banda II) e entre 300-560 nm (banda I). A posição precisa e as intensidades relativas desses máximos fornecem informações valiosas da natureza do flavonóide e de seu padrão de oxigenação (Tabela 2). Sendo assim, mudanças na substituição do anel A normalmente são evidenciadas por alteração na posição e/ou intensidade na banda II, enquanto alterações nos anéis B e C resultam em alterações na banda I (MABRY; MARKHAM; THOMAS, 1970; MERKEN; BEECHER, 2000).

As substâncias 11 e 15 isoladas da fração AcOEt-SIL-4 e 9, respectivamente (Figura 15a e Figura 14b), apresentaram uma banda em $293 \mathrm{~nm}$ e outra banda pouco intensa em $332 \mathrm{~nm}$, sugerindo a subclasse das flavanonas. A adição de uma unidade de açúcar, em C3, C-5, C-7 ou C-4', causa um deslocamento hipsocrômico na banda II das flavanonas. Assim, pode-se sugerir a presença de uma unidade de açúcar na substância 15. A 
substância 9 apresentou duas bandas (banda II em 268 nm e a banda I em 337 nm) evidenciando a subclasse das flavonas. Já as substâncias 8 e 16 apresentaram bandas características de flavanonas para o anel A (banda II em $290 \mathrm{~nm}$ ) e, para o anel B e C, apresentaram bandas características da subclasse das flavonas (banda I entre 310-350 nm), sugerindo a presença de duas subclasses distintas no esqueleto flavonoídico.

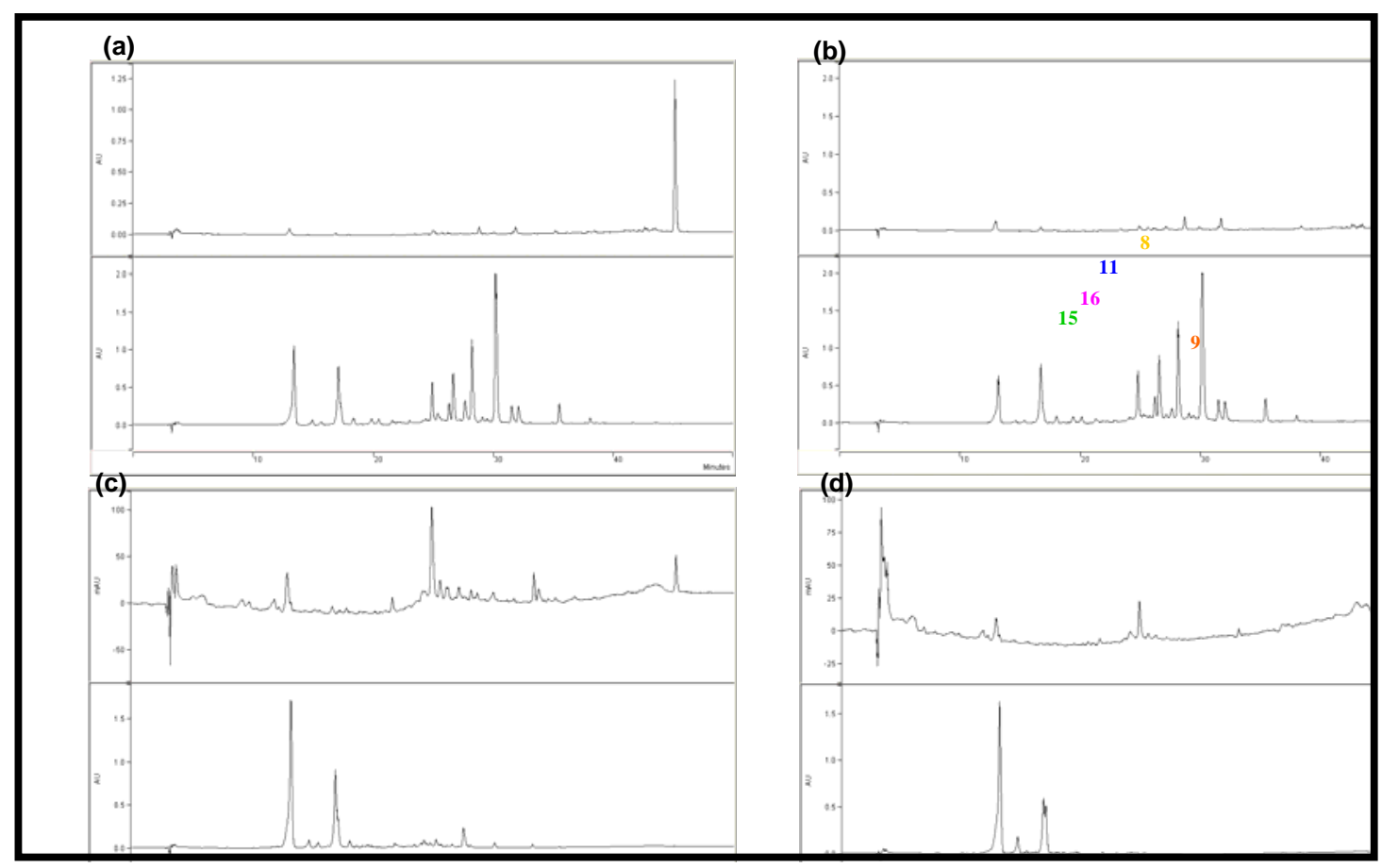

Figura 19 - Cromatograma analítico obtido via CLAE-UV do extrato ETOH (a) e das frações AcOEt (b), $\mathrm{BuOH}$ (c) e $\mathrm{HA}$ (d) dos frutos (acima) e das folhas (abaixo) de Garcinia xanthochymus no modo gradiente em $\mathrm{H}_{2} \mathrm{O}$ : $\mathrm{MeOH}$ (95:5) até $\mathrm{MeOH}$ (100) e suporte cromatográfico: ODS (Phenomenex, 25,0 $\mathrm{cm}$ x 4,6 mm x 5 $\mu \mathrm{m}$ ).

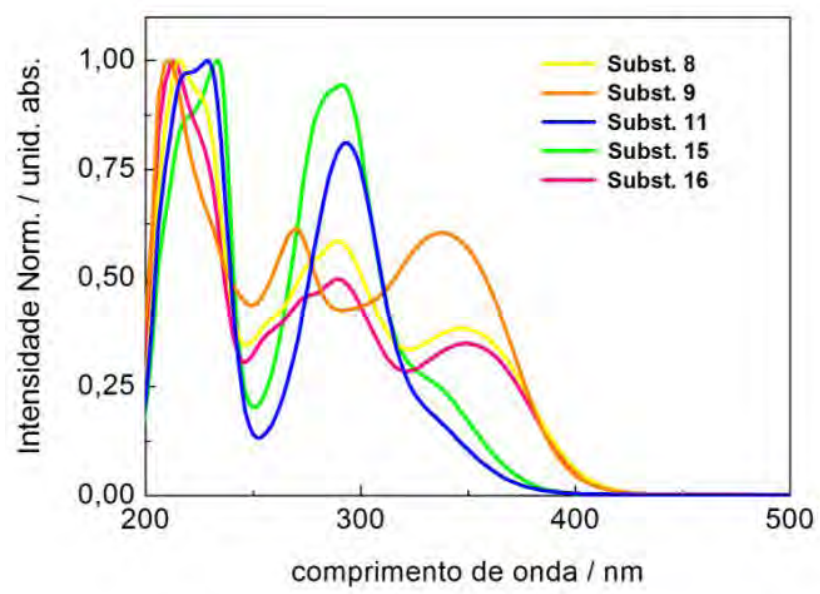

Figura 20 - Espectro no UV de algumas substâncias isoladas da fração AcOEt-FOL de Garcinia xanthochymus. 
Tabela 2 - Intervalos de absorção no UV para diferentes tipos de flavonóides.

\begin{tabular}{ccc}
\hline Banda II (nm) & Banda I (nm) & Tipo de flavonóide \\
\hline $250-280$ & $310-350$ & Flavona \\
$250-280$ & $330-360$ & Flavonol (3-OH substituído) \\
$250-280$ & $350-385$ & Flavonol (3-OH livre) \\
$245-275$ & $310-330$ (pouca intensa) & Isoflavona \\
$275-295$ & $300-330$ (pouca intensa) & Flavanona e Diidroflavonol \\
$230-270$ (pouco intensa) & $340-390$ & Chalcona \\
$230-270$ (pouco intensa) & $380-430$ & Aurona \\
$230-270$ & $465-560$ & Antocianidina e Antocianina \\
\hline
\end{tabular}

\subsection{Estudo químico das folhas}

As estruturas das substâncias isoladas foram elucidadas através da análise de dados espectrométricos, especialmente RMN uni e bi dimensional ( $g \mathrm{HMBC}, g \mathrm{HMQC}, \mathrm{COSY}$, DEPT, NOESY e HOMODEC), além dos dados de UV, IV e EM e comparação com dados encontrados na literatura.

\subsubsection{Caracterização espectrométrica da substância 1}

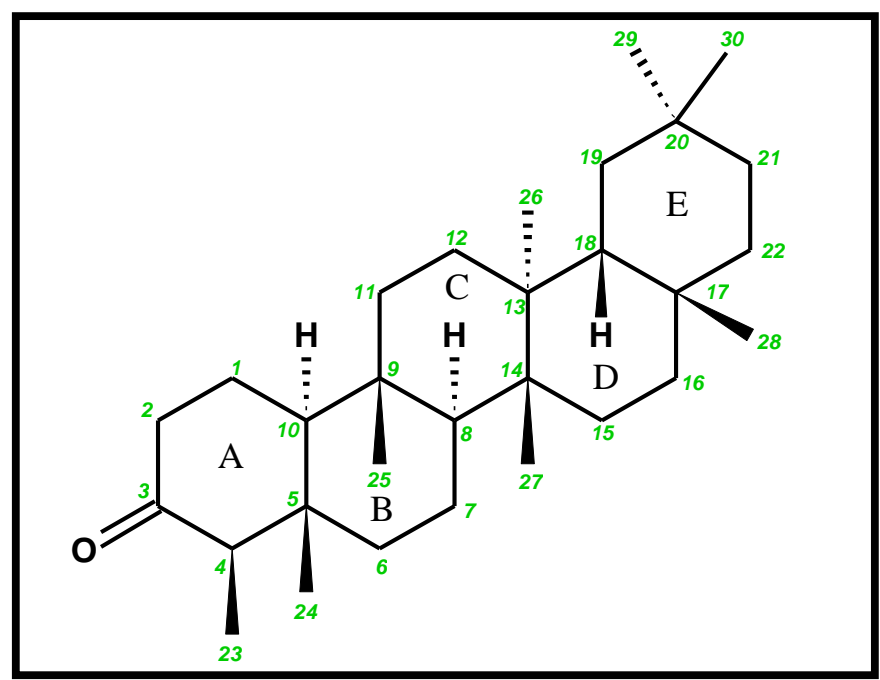

A substância 1 foi isolada do extrato HEX-FOL, conforme procedimento experimental em $\mathbf{5 . 3}$.

A análise dos espectros de $\mathrm{RMN}$ de ${ }^{1} \mathrm{H}$ e ${ }^{13} \mathrm{C}$, IV e EM, permitiu caracterizar a substância 1 como um triterpeno pentacíclico pertencente à classe dos friedelanos.

O espectro de IV (Figura 22) apresentou sinal de estiramento de carbonila em 1698 $\mathrm{cm}^{-1}\left(v_{\mathrm{C}=\mathrm{O}}\right.$ ), uma banda em $2925 \mathrm{~cm}^{-1}$ correspondente a deformação axial da ligação C-H 
de grupos metílicos e metilênicos $\left(v_{\mathrm{C}-\mathrm{H}}\right)$ e bandas entre 1450 e $1550 \mathrm{~cm}^{-1}$ correspondentes a vibrações de deformação angular de C-H $\left(\delta_{\mathrm{C}-\mathrm{H}}\right)$ (SILVERSTEIN; WEBSTER; KIEMLE, 1994).

$\mathrm{O}$ espectro de massas obtido por CG-EM (IE=+70 eV) apresentou o íon molecular em $\mathrm{m} / \mathrm{z} 426$ e um fragmento em $\mathrm{m} / \mathrm{z}$ 273, típicos de friedelanos saturados quando substituídos apenas nos anéis A ou E (Figura 21). Os fragmentos em $m / z 55$ e 69 podem ser resultantes da clivagem inicial, respectivamente, das ligações $\mathrm{C} 2-\mathrm{C} 3$ ou $\mathrm{C} 4-\mathrm{C} 3$, com posterior migração de um átomo de hidrogênio, conforme ilustrado na Figura 23, concomitante à clivagem das ligações $\mathrm{C} 1-\mathrm{C} 10$ ou C5-C10.

$\mathrm{O}$ espectro de $\mathrm{RMN}{ }^{13} \mathrm{C}$ apresentou sinal de carbono carbonílico em $\delta_{\mathrm{C}} 213,2$ e um sinal de um grupo metila em $\delta_{\mathrm{C}} 6,8$ protegido pelo efeito $\gamma$ do oxigênio da carbonila (Anexos 4 a 6). Através da análise dos espectros de RMN de ${ }^{13} \mathrm{C}$ e DEPT foi possível contabilizar 30 carbonos, dos quais 8 são carbonos metílicos, 11 são carbonos metilênicos, 4 metínicos e 7 quaternários (Anexos 7 a 9, Tabela 3).

$\mathrm{O}$ espectro de RMN de ${ }^{1} \mathrm{H}$ mostrou sinais de absorção entre $\delta_{\mathrm{H}} 1,36$ a 2,43 referentes aos grupos metilênicos e metínicos; e na região entre $\delta_{\mathrm{H}} 0,74$ a 1,20 , mostrou 8 sinais associados às 8 metilas da estrutura desta substância (Anexos 1 a 3).

A comparação dos dados espectrométricos de $\mathbf{1}$ com valores registrados na literatura permitiu identificar este triterpeno como 3-oxo-friedelano (friedelina) (GOTTIEB et al., 1985).

A friedelina foi isolada das folhas de Garcinia xanthochymus por Singh et al. em 1991. Este composto mostrou-se muito eficaz como agente antibacteriano. Há relatos que atribuem à friedelina atividade antiúlcera estomacal e contra gastrite (CORDEIRO; VILEGAS; LANCAS, 1999; RAMESH et al., 2002). A friedelina possui ainda efeito antiinflamatório quando administrada por via tópica, inclusive para inflamações oculares (DI STASI; GOMES; VILEGAS, 1999).

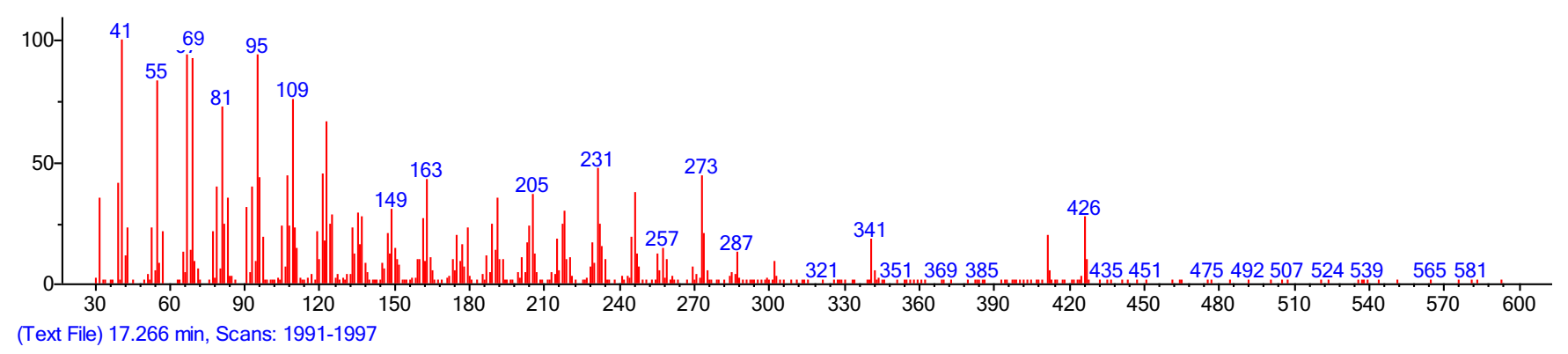

Figura 21 - Espectro de massas da substância 1 obtido por CG-EM (IE=+70 eV). 


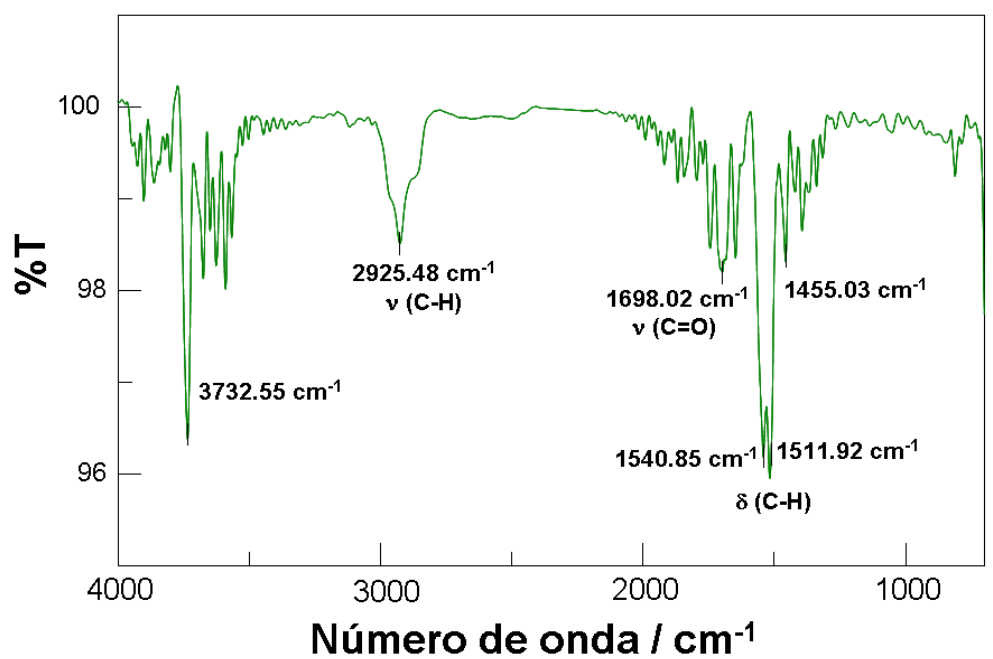

Figura 22 - Espectro vibracional na região do IV da substância 1.

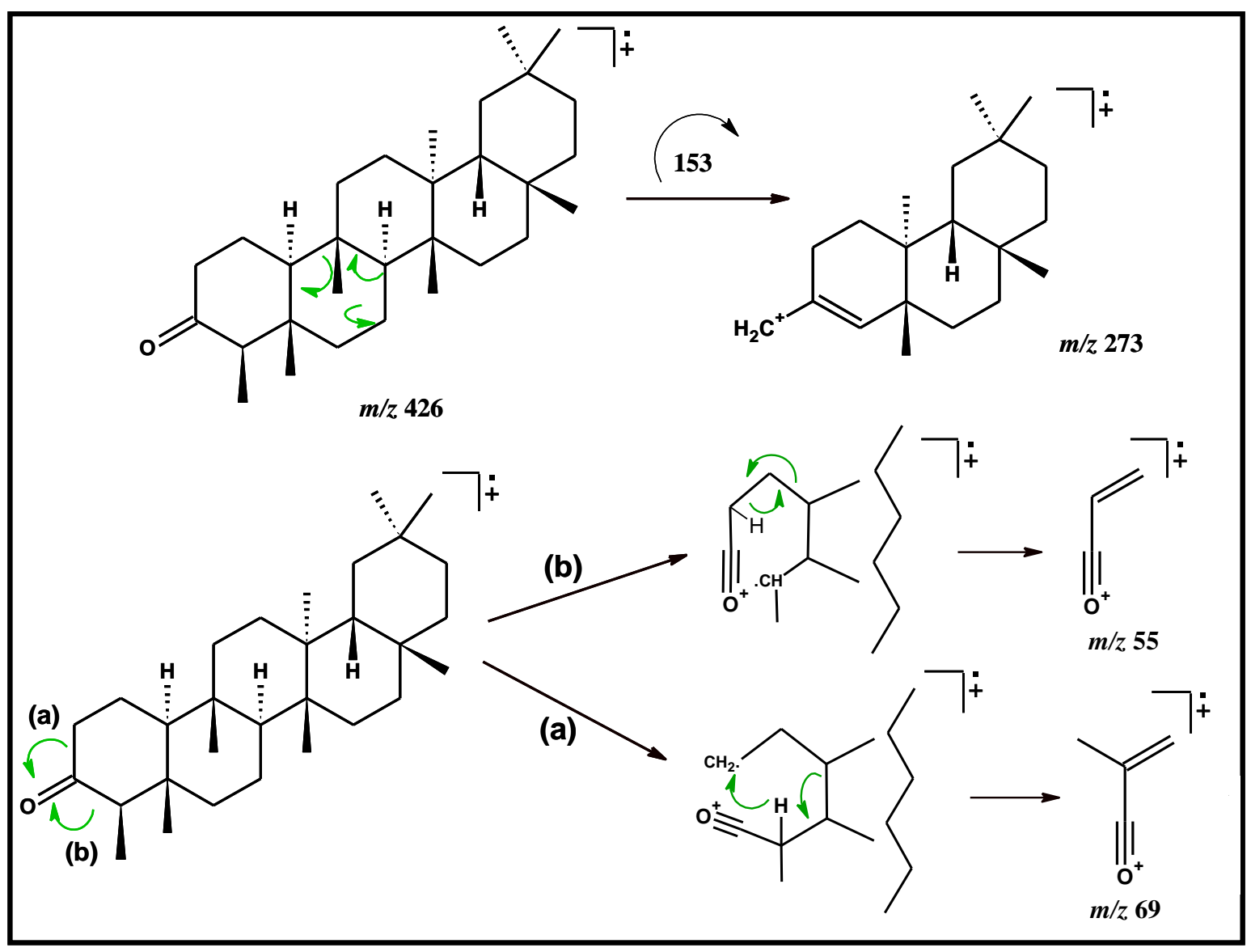

Figura 23 - Proposta de fragmentação da substância 1. 


\subsubsection{Caracterização espectrométrica da substância 2}

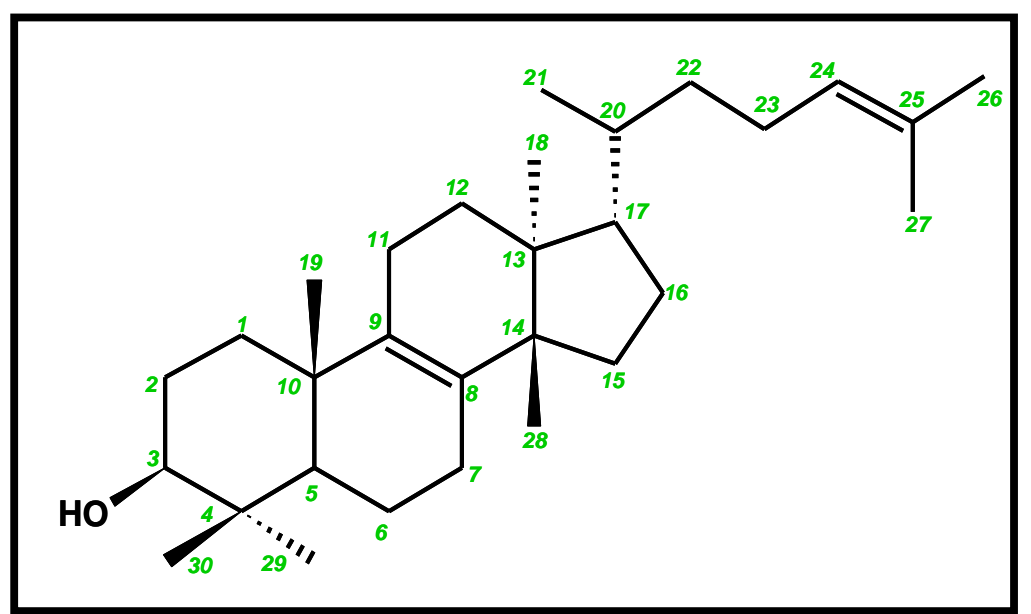

A substância 2 foi isolada do extrato HEX-FOL, conforme procedimento experimental em $\mathbf{5 . 3}$.

A análise dos espectros de RMN de ${ }^{1} \mathrm{H}$ e ${ }^{13} \mathrm{C}$, IV e EM, permitiu identificar a substância 2 como um esteróide.

O espectro na região do IV (Figura 24) apresentou uma banda larga de absorção em $3336 \mathrm{~cm}^{-1}$ característica do estiramento da ligação O-H ( $\left.v_{\mathrm{O}-\mathrm{H}}\right)$, bandas em 2935 e $2868 \mathrm{~cm}^{-}$ ${ }^{1}$ atribuídas aos estiramentos da ligação $\mathrm{C}-\mathrm{H}$ dos grupos metilênicos e metínicos $\left(v_{\mathrm{C}-\mathrm{H}}\right)$, uma banda em $1722 \mathrm{~cm}^{-1}$ referente à deformação axial de $\mathrm{C}=\mathrm{C}\left(v_{\mathrm{C}=\mathrm{C}}\right)$, absorções em 1455 $\mathrm{cm}^{-1}$ correspondentes a deformação angular da ligação C-H $\left(\delta_{\mathrm{C}-\mathrm{H}}\right)$. O espectro apresentou ainda uma banda em $1377 \mathrm{~cm}^{-1}$ referente à deformação angular da ligação $\mathrm{O}-\mathrm{H}\left(\delta_{\mathrm{O}-\mathrm{H}}\right)$ e uma banda em $1091 \mathrm{~cm}^{-1}$, atribuída ao estiramento C-O ( $\left.v_{\mathrm{C}-\mathrm{O}}\right)$ (SILVERSTEIN; WEBSTER; KIEMLE, 1994).

$\mathrm{O}$ espectro de massas obtido por CG-EM (IE=+70 ev) (Figura 25) mostrou o íon molecular em $\mathrm{m} / \mathrm{z}$ 426, o íon base em $\mathrm{m} / \mathrm{z}$ 393, referente à perda de uma metila, e um fragmento intenso em $\mathrm{m} / \mathrm{z}$ 411, referente à perda de uma molécula de água (Figura 26). É interessante notar que esqueletos de triterpenos com insaturação na posição C-12 (série ursano e oleano) e não substituídos, apresentam fragmentação típica denominada RetroDiels-Alder, que ocorre no anel C, provocando a formação de um íon em $m / z 218$. O íon m/ 218 não foi detectado no espectro da substância 2 , sugerindo que a mesma não possui insaturação em C-12. 


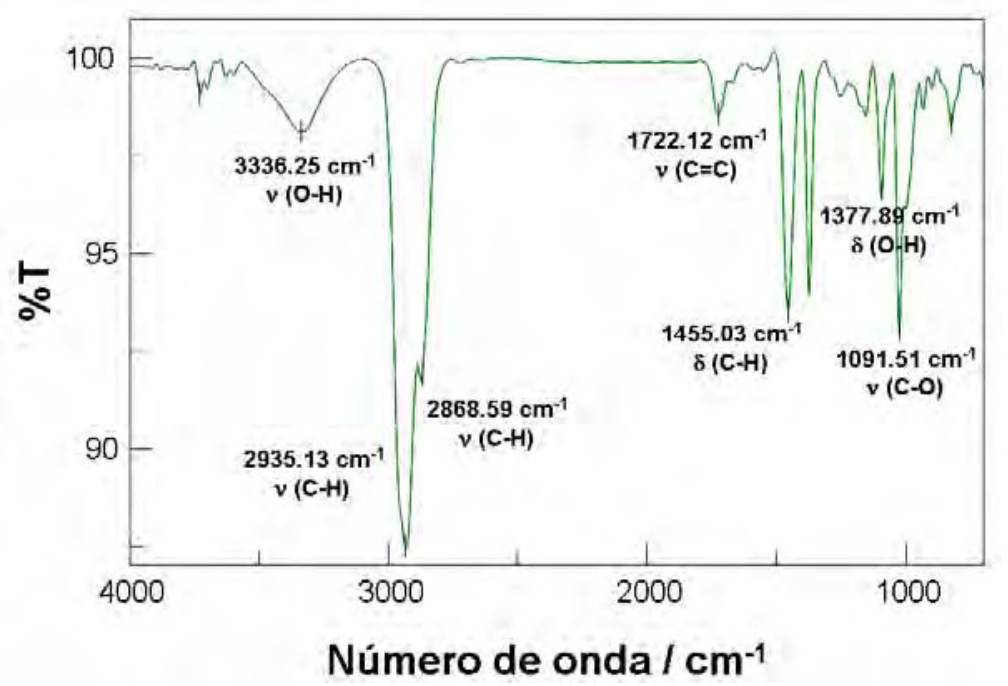

Figura 24 - Espectro vibracional na região do IV da substância 2.

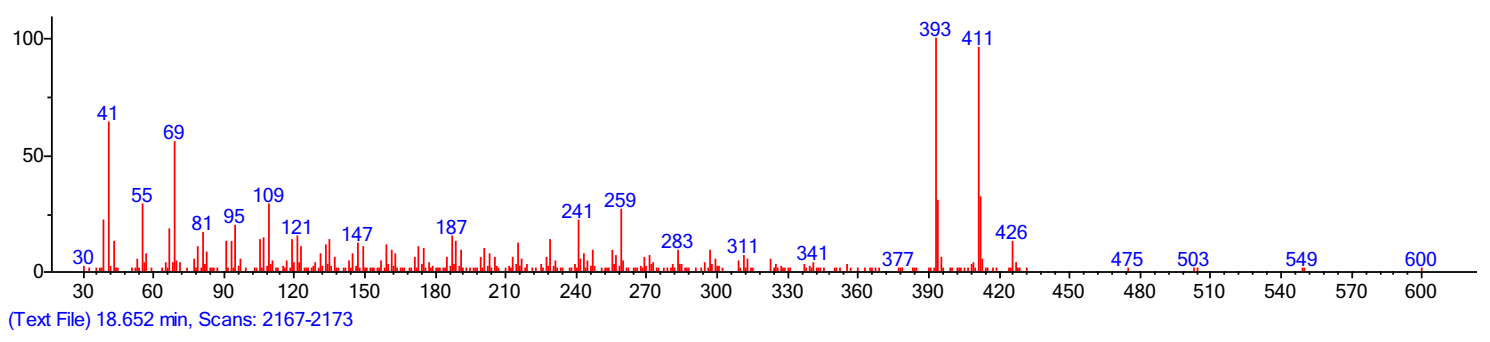

Figura 25 - Espectro de massas da substância 2 obtido por CG-EM $(\mathrm{IE}=+70 \mathrm{eV})$.

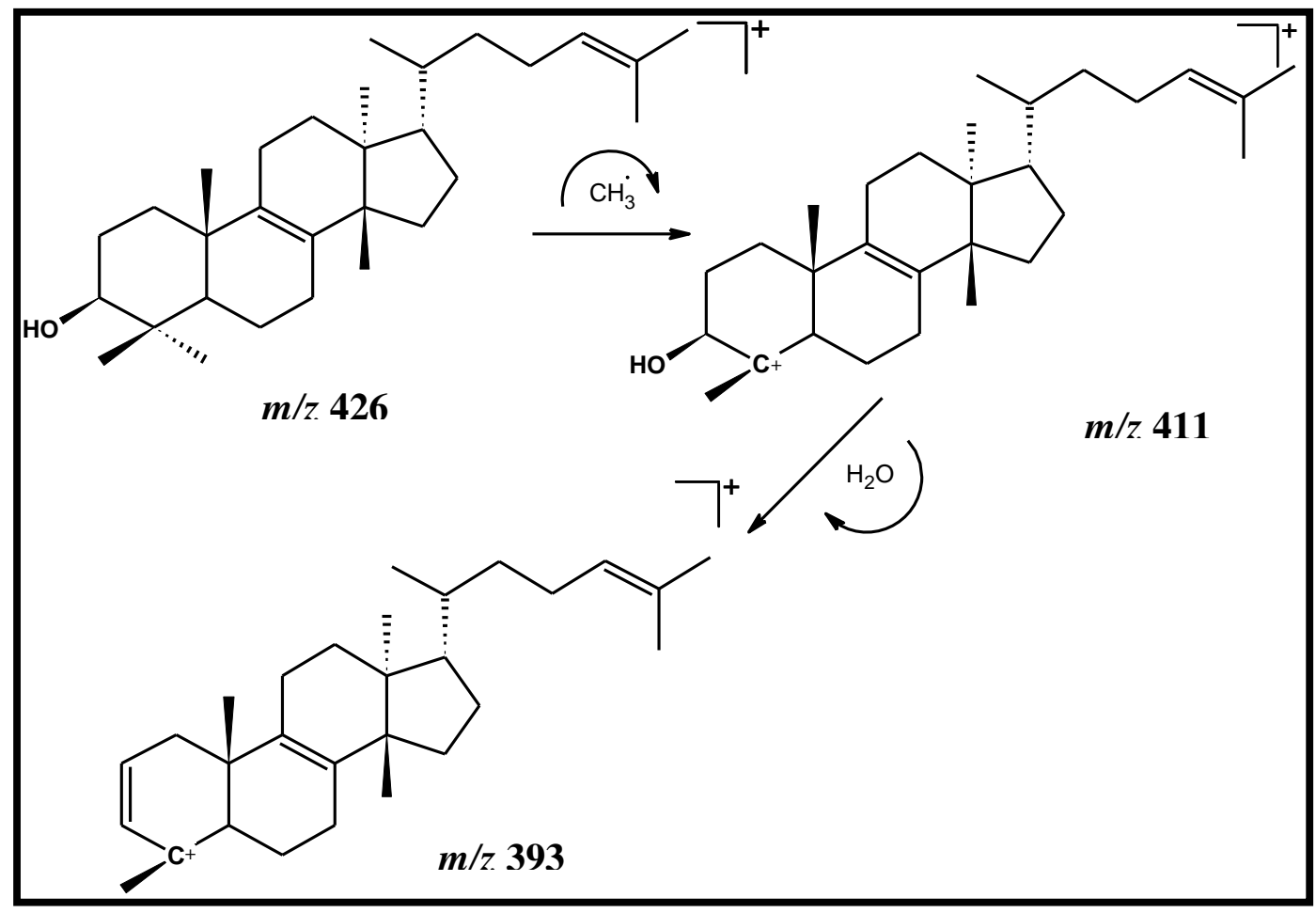

Figura 26 - Proposta de fragmentação da substância 2. 
$\mathrm{O}$ espectro de $\mathrm{RMN}$ de ${ }^{1} \mathrm{H}$ apresentou sinais de prótons olefínicos $\left(\delta_{\mathrm{H}} 5,02 ; m\right)$ e de prótons carbinólicos $\left(\delta_{\mathrm{H}} 3,17 ; d d ; J=12,0\right.$ e $\left.J=4,5 \mathrm{~Hz}\right)$. A região de $\delta_{\mathrm{H}} 0,69$ a 1,19 mostrou 8 sinais referentes às metilas da molécula, e entre $\delta_{\mathrm{H}} 1,30$ a 2,10, os sinais correspondentes aos grupos metilênicos e metínicos (Anexos 10 a 12).

Através da análise dos espectros de RMN de ${ }^{13} \mathrm{C}$ e DEPT, foi possível identificar 30 carbonos dos quais 8 são carbonos metílicos, 10 são carbonos metilênicos, 5 metínicos e 7 quaternários (Anexos 16 a 19, Tabela 3). Os sinais dos carbonos olefínicos no espectro de ${ }^{13} \mathrm{C}\left(\right.$ Anexos 13 a 15) em $\delta_{\mathrm{C}} 125,2(\mathrm{C}-24), \delta_{\mathrm{C}} 130,8(\mathrm{C}-25), \delta_{\mathrm{C}} 134,1(\mathrm{C}-8)$ e $\delta_{\mathrm{C}} 133,6(\mathrm{C}-$ 9), além do sinal de carbono carbinólico em $\delta_{\mathrm{C}} 79,0$ (C-3) e as observações citadas acima permitiram identificar a substância 2 como lanosta-8,24-dien-3-ol, conhecida como lanosterol (KNIGHT, 1973).

\subsubsection{Caracterização espectrométrica da substância 3}

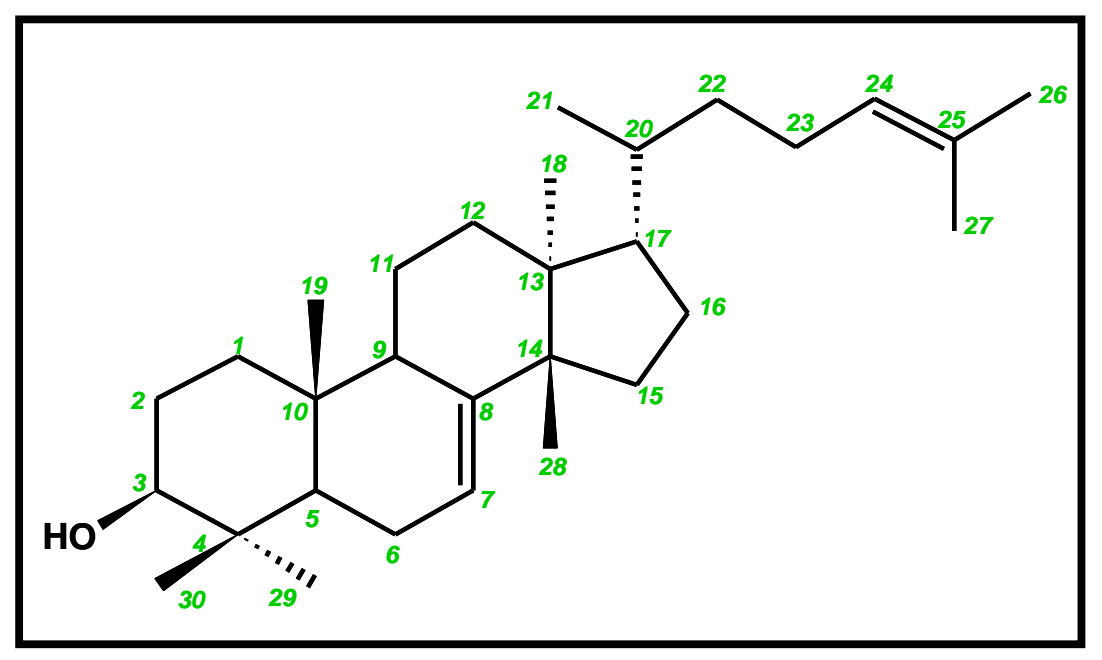

A estrutura da substância $\mathbf{3}$ foi determinada em mistura, conforme procedimento experimental em $\mathbf{5 . 3}$.

Nos espectros de $\mathrm{RMN}$ de ${ }^{13} \mathrm{C}$ e DEPT desta fração foi possível identificar 58 carbonos dos quais 30 foram atribuídos ao lanosterol, cuja elucidação foi discutida acima (Anexos 21 a 24). Os sinais restantes foram atribuídos ao esteróide lanosta-7,24-dien-3-ol (Tabela 3), que co-ocorre com a substância 2 em grande parte dos vegetais. Os espectros de IV e massas apresentaram características análogas às da substância 2, confirmando a presença dos isômeros de posição $\mathbf{2}$ e $\mathbf{3}$ na amostra.

Os sinais em $\delta_{\mathrm{C}} 117,8(\mathrm{C}-7), \delta_{\mathrm{C}} 145,8(\mathrm{C}-8), \delta_{\mathrm{C}} 125,1(\mathrm{C}-24)$ e $\delta_{\mathrm{C}} 130,9(\mathrm{C}-25)$ foram atribuídos aos carbonos olefínicos e o sinal em $\delta 79,3$ foi atribuído ao carbono 
hidroximetínico C-3. Estes dados, aliados à análise de $\mathrm{RMN}{ }^{1} \mathrm{H}$ da mistura (Anexo 20) e comparação com dados da literatura, permitiram identificar 3 como lanosta-7,24-dien-3-ol (OLEA; ROQUE, 1990).

Tabela 3 - Dados de RMN de ${ }^{13} \mathrm{C}(125 \mathrm{MHz})$ das substâncias $\mathbf{1}, 2$ e 3 em $\mathrm{CDCl}_{3}$.

\begin{tabular}{|c|c|c|c|}
\hline Posição & $\begin{array}{c}\delta_{c}(p p m) \\
1\end{array}$ & $\begin{array}{c}\delta_{\mathrm{c}}(\mathbf{p p m}) \\
\mathbf{2}\end{array}$ & $\begin{array}{c}\delta_{\mathrm{c}}(\mathbf{p p m}) \\
\mathbf{3}\end{array}$ \\
\hline 1 & $22,3 t$ & $35,3 t$ & $37,2 t$ \\
\hline 2 & $41,5 t$ & $27,7 t$ & $27,6 t$ \\
\hline 3 & $213,2 \mathrm{~s}$ & $79,0 d$ & $79,3 d$ \\
\hline 4 & $58,3 d$ & $38,9 s$ & $38,9 s$ \\
\hline 5 & $42,2 s$ & $50,9 d$ & $50,7 d$ \\
\hline 6 & $41,3 t$ & $18,9 t$ & $23,9 t$ \\
\hline 7 & $18,3 t$ & $27,9 t$ & $117,8 d$ \\
\hline 8 & $53,1 d$ & $134,1 \mathrm{~s}$ & $145,9 d$ \\
\hline 9 & $37,5 s$ & $133,6 s$ & $48,9 s$ \\
\hline 10 & $59,5 d$ & $37,3 s$ & $35,1 \mathrm{~s}$ \\
\hline 11 & $35,7 t$ & $21,5 t$ & $22,1 t$ \\
\hline 12 & $30,5 t$ & $28,1 t$ & $34,9 t$ \\
\hline 13 & $39,7 \mathrm{~s}$ & $44,1 s$ & $43,6 s$ \\
\hline 14 & $38,3 \mathrm{~s}$ & $50,0 \mathrm{~s}$ & $51,3 s$ \\
\hline 15 & $32,5 t$ & $30,9 t$ & $33,8 t$ \\
\hline 16 & $36,0 t$ & $29,8 t$ & $28,4 t$ \\
\hline 17 & $30,0 \mathrm{~s}$ & $49,7 d$ & $53,2 d$ \\
\hline 18 & $42,9 d$ & $15,6 q$ & $13,1 q$ \\
\hline 19 & $35,4 t$ & $20,1 q$ & $18,1 q$ \\
\hline 20 & $28,2 \mathrm{~s}$ & $35,4 d$ & $35,8 d$ \\
\hline 21 & $32,8 t$ & $18,9 q$ & $18,6 q$ \\
\hline 22 & $39,3 t$ & $35,9 t$ & $36,1 t$ \\
\hline 23 & $6,8 q$ & $24,8 t$ & $25,4 t$ \\
\hline 24 & $14,6 q$ & $125,2 d$ & $125,1 d$ \\
\hline 25 & $17,9 q$ & $130,8 \mathrm{~s}$ & $130,9 \mathrm{~s}$ \\
\hline 26 & $20,3 q$ & $17,7 q$ & $26,6 q$ \\
\hline 27 & $18,6 q$ & $25,7 q$ & * \\
\hline 28 & $32,1 q$ & $24,5 q$ & * \\
\hline 29 & $31,8 q$ & $28,1 q$ & $27,7 q$ \\
\hline 30 & $35,0 q$ & $15,5 q$ & $14,7 q$ \\
\hline
\end{tabular}

\subsubsection{Caracterização espectrométrica da substância 4}

A substância 4 foi isolada da subfração AcOEt-FOL-14, conforme procedimento experimental em $\mathbf{5 . 5}$.

$\mathrm{O}$ composto de fórmula $\mathrm{C}_{30} \mathrm{H}_{18} \mathrm{O}_{11}$ foi obtido como cristais amarelos e apresentou espectro de UV típico da subclasse das flavonas, com a banda II em $267 \mathrm{~nm}$ e a banda I em 
$343 \mathrm{~nm}$ (Figura 27). A fórmula molecular proposta foi obtida pela espectrometria de massas de alta resolução no modo negativo (ESI) (Figura 29), em que foi observado o pico referente ao íon molecular em $\mathrm{m} / z$ 553,0872 [M - H] $]^{-}$.

O espectro de absorção na região do IV (Figura 28) mostrou uma banda vibracional larga em $3421 \mathrm{~cm}^{-1}$ correspondente à deformação axial da ligação $\mathrm{O}-\mathrm{H}\left(v_{\mathrm{O}-\mathrm{H}}\right)$ e uma banda em $2952 \mathrm{~cm}^{-1}$ referente à deformação axial C-H de aromáticos $\left(v_{\mathrm{C}-\mathrm{H}}\right)$. Também mostrou uma banda em $1639 \mathrm{~cm}^{-1}$ referente à carbonila conjugada da molécula $\left(v_{\mathrm{C}-\mathrm{O}}\right)$, bandas entre 1500 e $1602 \mathrm{~cm}^{-1}$ atribuídas à deformação axial de C-C ( $\left.v_{\mathrm{C}-\mathrm{C}}\right)$ do anel aromático, absorção em $1258 \mathrm{~cm}^{-1}$ associada a deformações axiais C-O ( $\left.v_{\mathrm{C}-\mathrm{O}}\right)$, bandas referentes à deformação angular no plano de C-H $\left(\delta_{\mathrm{C}-\mathrm{H}}\right)$ entre 1072 e $1167 \mathrm{~cm}^{-1}$ e uma banda em $814 \mathrm{~cm}^{-1}$ relacionadas a deformações angulares fora do plano das ligações $\mathrm{C}-\mathrm{H}\left(\delta_{\mathrm{C}-\mathrm{H}}\right)$ do anel (SILVERSTEIN; WEBSTER; KIEMLE, 1994).

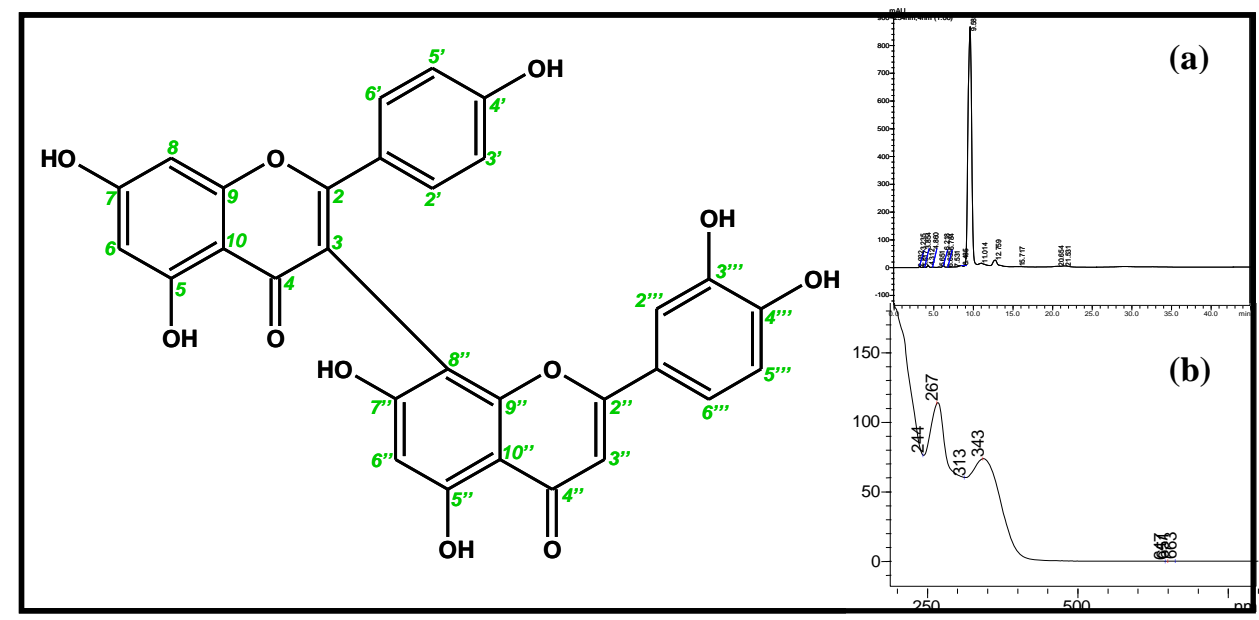

Figura 27 - Estrutura da substância 4. (a) Cromatograma analítico e (b) espectro de absorção da substância 4 obtido via CLAE-UV-DAD no modo isocrático 1:1 $\left(\mathrm{MeOH}: \mathrm{H}_{2} \mathrm{O}\right)$ e suporte

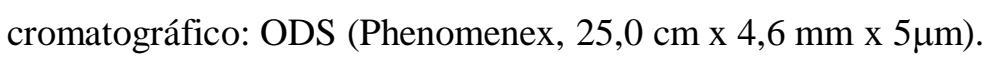

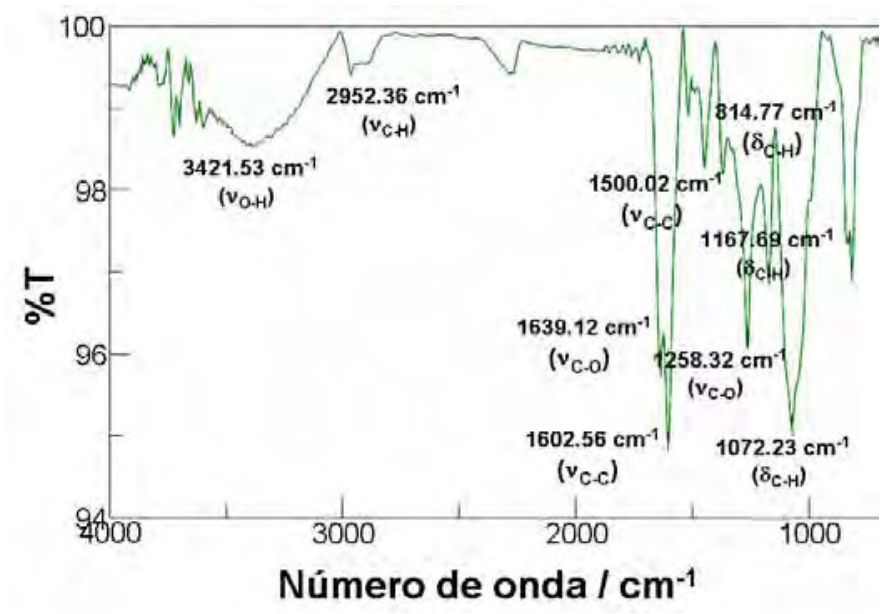

Figura 28 - Espectro vibracional na região do IV da substância 4. 
O espectro de RMN de ${ }^{1} \mathrm{H}$ (Anexos 25 e 26) mostrou a presença de dois singletos em $\delta_{\mathrm{H}} 12,82$ (unidade I) e $\delta_{\mathrm{H}} 13,04$ (unidade II), correspondentes a hidroxilas quelatadas que estabelecem ligação de hidrogênio intramolecular com os oxigênios carbonílicos situados em C-4 e C-4", respectivamente. Destaca-se a presença de dois dubletos em $\delta_{\mathrm{H}} 7,34(2 \mathrm{H}$, H-2'/6', $J=8,5 \mathrm{~Hz})$ e $\delta_{\mathrm{H}} 6,68\left(2 \mathrm{H}, \mathrm{H}-3^{\prime} / 5^{\prime}, J=8,5 \mathrm{~Hz}\right)$ caracterizando a presença de um padrão de substituição para-hidroxilado no anel B da unidade I. Sinais de um anel aromático trissubstituído contendo dois carbonos oxigenados foram observados em $\delta_{\mathrm{H}} 7,06$

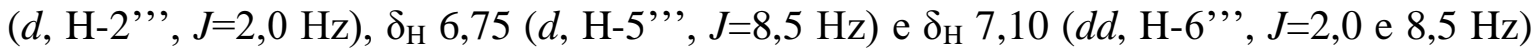
caracterizando o anel B da unidade II, fato também confirmado pelo espectro de gCOSY que mostrou a interação de H-2,", com H-6", , de H-5,", com H-6", e de H-6", com H2", " e H-5", (Anexos 27 e 28). Os dubletos em $\delta_{\mathrm{H}} 6,26$ e 6,51 ( $\mathrm{J=2,0}$ Hz) correspondentes a H-6 e H-8, respectivamente, demonstram a presença de apenas um par de hidrogênios em acoplamento meta, o que sugere a ligação interflavonoídica entre C3 da unidade I e C8' da unidade II. Esse espectro exibiu ainda um singleto em $\delta_{\mathrm{H}} 6,26$ (sobreposto ao dubleto em $\delta_{H} 6,26$ correspondente à H-6), atribuído ao hidrogênio H-6', e um singleto em $\delta_{H} 6,63$ correspondente a H-3', ambos atribuídos à unidade II do esqueleto flavonoídico.

O experimento de $g$ HMBC (Anexos 31 a 34) mostrou a interação a longa distância de $\delta_{\mathrm{H}}$ 6,26 (H-6"') com $\delta_{\mathrm{c}} 99,4$ (C-8') e 104,5 (C-10") confirmando que a ligação interflavonoídica ocorre em C-8', Também mostrou a interação de $\delta_{\mathrm{H}} 6,63\left(\mathrm{H}-3\right.$ '’) com $\delta_{\mathrm{c}}$ 163,8 ; de $\delta_{\mathrm{H}} 6,68\left(\mathrm{H}^{3} 3^{\prime} / 5^{\prime}\right)$ com $\delta_{\mathrm{c}} 122,9$; de $\delta_{\mathrm{H}} 6,75\left(\mathrm{H}-5^{\prime \prime \prime}\right)$ ) com $\delta_{\mathrm{c}} 122,0$ e 146,$0 ;$ de $\delta_{\mathrm{H}}$ 7,06 (H-2',') com $\delta_{\mathrm{c}} 149,8$ e de $\delta_{\mathrm{H}} 7,34\left(\mathrm{H}-2{ }^{\prime} / 6\right.$ ') com $\delta_{\mathrm{c}} 129,2$ e 159,9. Mostrou ainda interações $J 2$ e $J 3$ entre $\delta_{\mathrm{H}} 12,82$ e 13,04 com C-5, C-6 e C-10 de ambas as unidades, corroborando a proposta acima delineada (Tabela 4).

O experimento NOESY-1D (Anexo 36), com irradiação do singleto em $\delta_{\mathrm{H}} 6,26$, não mostrou efeito NOE com os hidrogênios presentes na molécula, confirmando a atribuição do respectivo sinal para H-6 e H-6', Pela análise do espectro de HOMODEC (Anexo 35) não houve alteração na multiplicidade e/ou presença dos sinais de hidrogênios quando ocorreu a eliminação do sinal em $\delta_{H} 6,63$, confirmando a atribuição deste singleto a H-6".

A partir desses dados, a substância 4 foi caracterizada como saharanflavona, uma biflavona ainda não encontrada como produto natural, sintetizada anteriormente a partir da oxidação da morelloflavona (PELTER et al., 1971). 


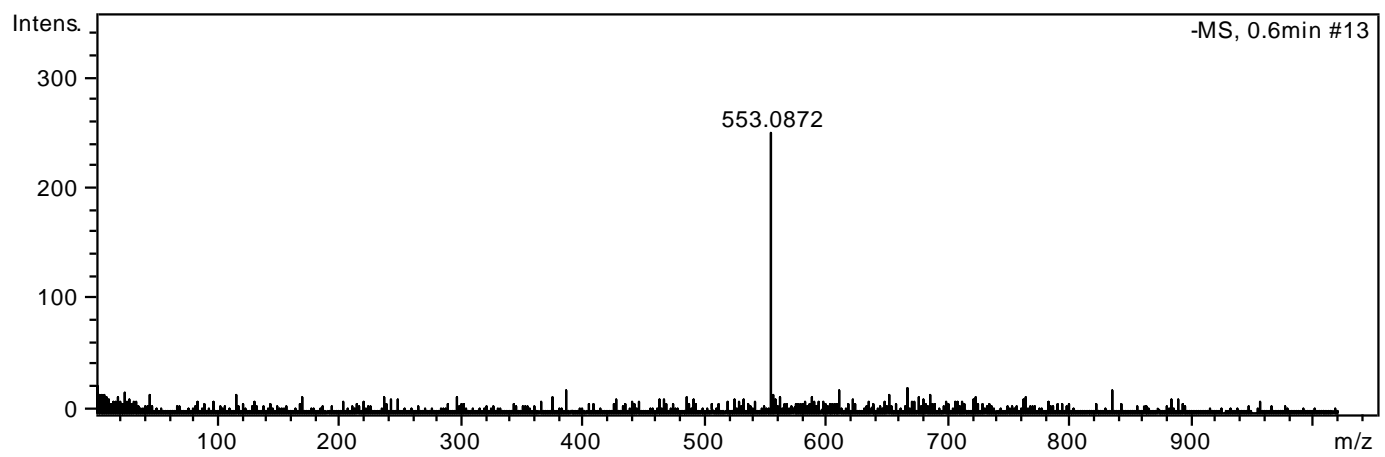

Figura 29 - Espectro de massas de primeira-ordem da substância 4 obtido no modo negativo (ESI).

Tabela 4 - Dados de RMN de ${ }^{1} \mathrm{H}(500 \mathrm{MHz})$ e RMN de ${ }^{13} \mathrm{C}(125 \mathrm{MHz})$ da substância 4 (DMSO- $\left.d_{6}\right)$.

\begin{tabular}{|c|c|c|c|c|}
\hline Posição & $\begin{array}{c}\delta_{\mathrm{H}}(\mathrm{ppm}) \\
\text { (multiplicidade; } J(\mathrm{~Hz}))\end{array}$ & $\begin{array}{c}\delta_{\mathrm{C}} \\
(\mathbf{p p m})\end{array}$ & $g \mathrm{HMBC}$ & $g \mathrm{COSY}$ \\
\hline 2 & - & $*$ & - & - \\
\hline 3 & - & $*$ & - & - \\
\hline 4 & - & $*$ & - & - \\
\hline 5 & - & 161,4 & - & - \\
\hline 6 & $6,26(d ; 2,0)$ & 98,4 & * & * \\
\hline 7 & - & $*$ & - & - \\
\hline 8 & $6,51(d ; 2,0)$ & 93,9 & $*$ & $*$ \\
\hline 9 & - & $*$ & - & - \\
\hline 10 & - & 103,1 & - & - \\
\hline 1 ' & - & 122,9 & - & - \\
\hline 2' 6' & $7,34(d ; 8,5)$ & 129,2 & 129,$2 ; 159,9$ & H-3' \\
\hline 3' 5' & $6,68(d ; 8,5)$ & 114,7 & 122,9 & $\mathrm{H}-2$ \\
\hline 4' & - & 159,9 & - & - \\
\hline 5-OH & $12,82(s)$ & - & 98,$4 ; 103,1 ; 161,4$ & - \\
\hline 2"' & & 163,8 & - & - \\
\hline 3"' & $6,63(s)$ & 102,3 & 163,8 & - \\
\hline 4"' & & * & - & - \\
\hline 5, & - & 161,0 & - & - \\
\hline $6^{\prime \prime}$ & $6,26(s)$ & 98,4 & 99,$4 ; 104,5$ & - \\
\hline 7 ' & 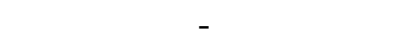 & $*$ & - & - \\
\hline 8', & - & 99,4 & - & - \\
\hline 9"' & - & $*$ & - & - \\
\hline $10 "$ & - & 104,5 & - & - \\
\hline $1 "$, & - & 122,0 & - & - \\
\hline 2", & $7,06(d ; 2,0)$ & 112,8 & 149,8 & H-6", \\
\hline 3"' & - & 149,8 & - & - \\
\hline 4"', & - & 146,0 & - & - \\
\hline $5, "$ & $6,75(d ; 8,5)$ & 114,8 & 122,$0 ; 146,0$ & H-6", \\
\hline 6", & $7,10(d d ; 2,0$ e 8,5$)$ & 118,3 & $*$ & H-2 "', H-5"', \\
\hline 5 '-ОН & $13,04(s)$ & - & 98,$4 ; 161,0$ & - \\
\hline
\end{tabular}

*valores não observados

Os valores de RMN de ${ }^{13} \mathrm{C}$ foram atribuídos através das interações observadas nos experimentos $g \mathrm{HMQC}$ e $g \mathrm{HMBC}$. 


\subsubsection{Caracterização espectrométrica da substância 5}

A substância 5 foi isolada da subfração AcOEt-FOL-14, conforme procedimento experimental em $\mathbf{5 . 5}$.

A substância 5 foi obtida como um sólido amarelo pálido amorfo com fórmula molecular $\mathrm{C}_{30} \mathrm{H}_{18} \mathrm{O}_{10}$. O espectro no UV sugeriu a subclasse das flavonas, fato evidenciado pelas bandas em $268 \mathrm{~nm}$ (banda II, anel A) e $333 \mathrm{~nm}$ (banda I, anéis B e C). A análise por CLAE mostrou $t_{r}=14,1$ min para $\mathbf{5}$, sugerindo um esqueleto com menor polaridade que $\mathbf{4}$, que apresentou $t_{r}=9,6$ min (Figura 31).

A análise do espectro de IV (Figura 31) mostrou uma banda vibracional larga atribuída à hidroxila $\left(v_{\mathrm{O}-\mathrm{H}}\right)$ em $3445 \mathrm{~cm}^{-1}$, bandas em 2920 e $2854 \mathrm{~cm}^{-1}$, referentes à deformação axial C-H de aromáticos $\left(v_{\mathrm{C}-\mathrm{H}}\right)$ e uma banda em $1690 \mathrm{~cm}^{-1}$ referente à carbonila conjugada da molécula $\left(v_{\mathrm{C}-\mathrm{O}}\right)$. Apresentou ainda, uma banda em $1458 \mathrm{~cm}^{-1}$ atribuída à deformação axial de $\mathrm{C}-\mathrm{C}\left(v_{\mathrm{C}-\mathrm{C}}\right)$ do anel aromático e bandas referentes à deformação angular no plano de C-H $\left(\delta_{\mathrm{C}-\mathrm{H}}\right)$ entre 1062 e $1377 \mathrm{~cm}^{-1}$ (SILVERSTEIN; WEBSTER; KIEMLE, 1994).

No espectro de massas no modo negativo (ESI) obtido para essa substância (Figura 33) foi observado o íon $\mathrm{m} / z 537[\mathrm{M}-\mathrm{H}]^{-}$que confirma a estrutura proposta.

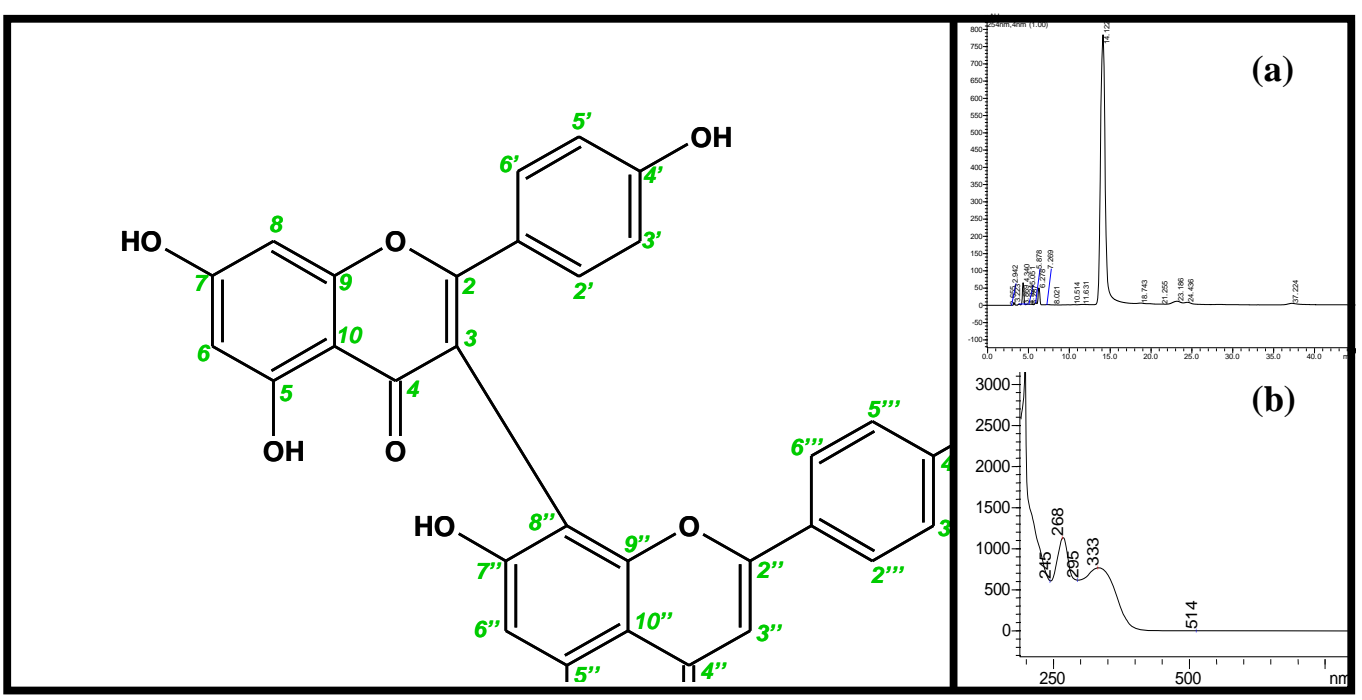

Figura 30 - Estrutura da substância 5. (a) Cromatograma analítico e (b) espectro de absorção da substância 5 obtido via CLAE-UV-DAD no modo isocrático 1:1 $\left(\mathrm{MeOH}: \mathrm{H}_{2} \mathrm{O}\right)$ e suporte cromatográfico: ODS (Phenomenex, 25,0 cm x 4,6 mm x 5 $\mu \mathrm{m}$ ) 
$\mathrm{O}$ espectro de $\mathrm{RMN}{ }^{13} \mathrm{C}$ mostrou sinais para dois carbonos com deslocamento químico característico de carbonilas de flavonas $\left(\delta_{\mathrm{c}} 181,7\right.$ e 180,4), sugerindo a presença de um núcleo flavonoídico na forma dimérica (Anexos 39 a 41).

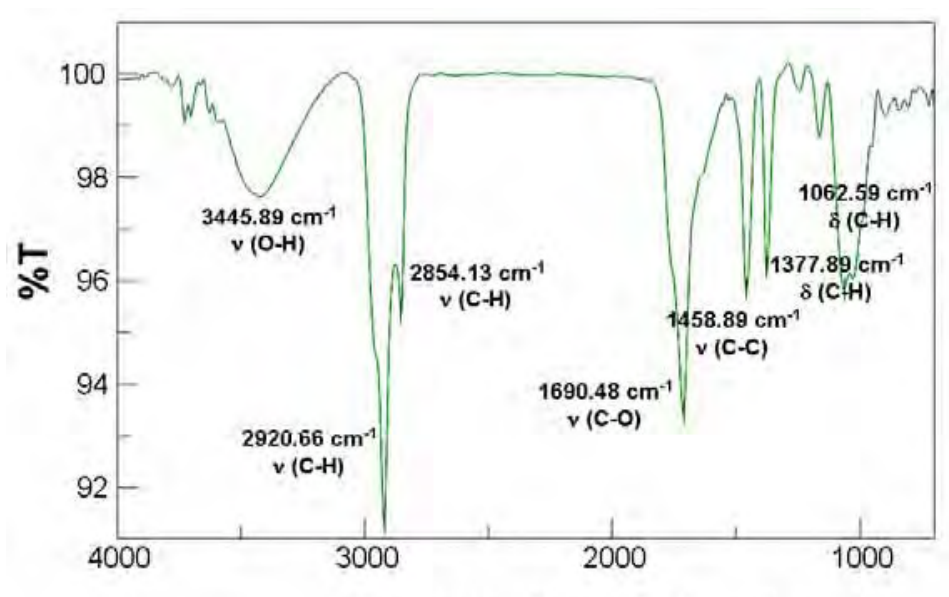

Número de onda $/ \mathrm{cm}^{-1}$

Figura 31 - Espectro vibracional na região do IV da substância 5.

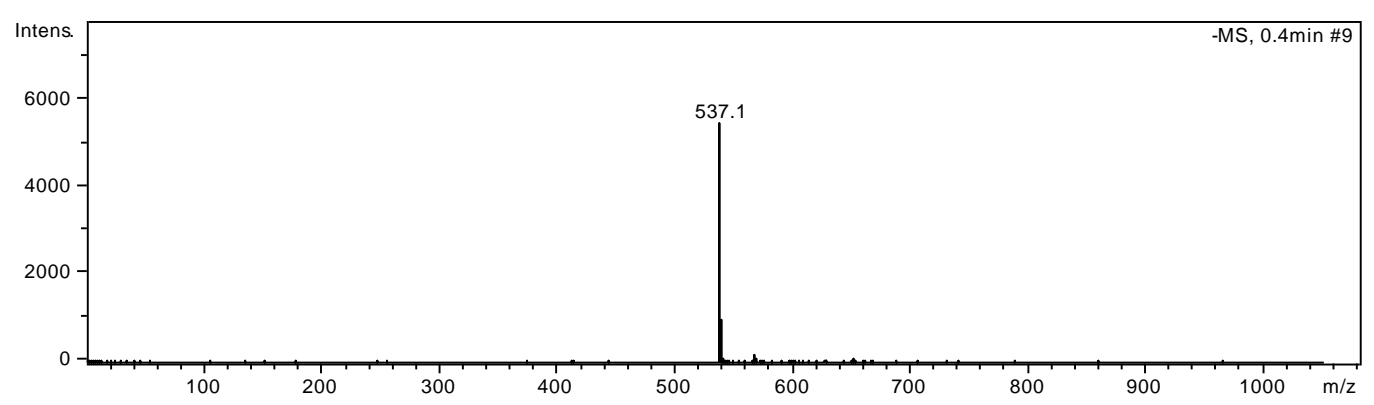

Figura 32 - Espectro de massas de primeira-ordem da substância 5 obtido no modo negativo (ESI).

Os quatro dubletos $(J=9,0 \mathrm{~Hz})$ no espectro de ${ }^{1} \mathrm{H}$ em $\delta_{\mathrm{H}} 7,34 ; 6,66$ e $\delta_{\mathrm{H}} 7,54 ; 6,76$, cada um correspondendo a $2 \mathrm{H}$, sugeriu a presença de um padrão de substituição parahidroxilado em ambos os anéis B. A análise dos dados de $g \mathrm{COSY}$ e $g \mathrm{HMBC}$ permitiu sua atribuição aos H-2'/H-6'; H-3'/H-5' e H-2','/H-6','; H-3','/H-5',', das unidades I e II respectivamente. $\mathrm{O}$ s dubletos em $\delta_{\mathrm{H}} 6,23$ e $6,49(J=2,0 \mathrm{~Hz})$ atribuídos a H-6 e H-8, respectivamente, demonstraram a presença de apenas um par de hidrogênios em acoplamento meta, sugerindo a ligação interflavonoídica entre C3 da unidade I e C8"' da unidade II (Anexos 37 e 38).

Os espectros de $g \mathrm{HMQC}$ permitiram estabelecer a correlação direta entre os hidrogênios e seus respectivos carbonos (Anexos 44 a 47). O experimento de gHMBC (Tabela 5) mostrou a interação a longa distância entre $\delta_{\mathrm{H}} 7,34$ (H-2') e $\delta_{\mathrm{c}} 163,3$ (C-2) mostrando e confirmando a atribuição dos sinais para o anel B; e ainda a interação de $\delta_{\mathrm{H}}$ 6,21 (H-6") e $\delta_{c} 98,9$ (C-8'), confirmando a ligação interflavonoídica na posição C-8"'. 
Mostrou também interações $J 2$ e $J 3$ entre $\delta_{\mathrm{H}} 12,81$ e 13,12 com as posições C-5, C-6 e C10 de ambas as unidades, corroborando a proposta apresentada (Anexos 48 a 53).

A partir dos resultados obtidos das análises espectroscópicas, concluiu-se que a substância 5 é o biflavonóide I3, II8-biapigenina, cujos dados espectroscópicos estão de acordo com os relatados na literatura (BERGHÖFER; HÖLZL, 1987). Esse biflavonóide foi isolado dos frutos de Garcinia xanthochymus por Baggett et al. (2005).

Tabela 5 - Dados de RMN de ${ }^{1} \mathrm{H}(500 \mathrm{MHz})$ e RMN de ${ }^{13} \mathrm{C}(125 \mathrm{MHz})$ da substância 5 (DMSO- $\left.d_{6}\right)$.

\begin{tabular}{|c|c|c|c|c|}
\hline Posição & $\begin{array}{c}\delta_{\mathrm{H}}(\mathrm{ppm}) \\
\text { (multiplicidade; } J(\mathrm{~Hz}))\end{array}$ & $\begin{array}{c}\delta_{\mathrm{C}} \\
(\mathbf{p p m})\end{array}$ & gНМBC & $g \mathrm{COSY}$ \\
\hline 2 & - & 163,3 & - & - \\
\hline 3 & - & 110,5 & - & - \\
\hline 4 & - & 181,7 & - & - \\
\hline 5 & - & 161,5 & - & - \\
\hline 6 & $6,23(d ; 2,0)$ & 99,2 & 93,$7 ; 102,8$ & - \\
\hline 7 & - & 164,5 & - & - \\
\hline 8 & $6,49(d ; 2,0)$ & 93,7 & 99,$2 ; 102,8 ; 157,3 ; 164,5$ & - \\
\hline 9 & 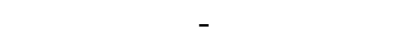 & 157,3 & the & - \\
\hline 10 & - & 102,8 & - & - \\
\hline 1 ' & - & 122,9 & - & - \\
\hline 2' 6' & $7,34(d ; 9,0)$ & 129,6 & 129,$6 ; 161,0 ; 163,3$ & H-3, \\
\hline 3' 5' & $6,66(d ; 9,0)$ & 115,1 & 115,$1 ; 122,9 ; 161,0$ & H-2' \\
\hline 4' & & 161,0 & 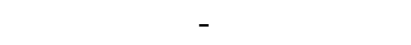 & - \\
\hline 5-OH & $12,81(s)$ & - & 99,$2 ; 102,8 ; 161,5$ & - \\
\hline 2"' & & 163,4 & - & - \\
\hline 3"' & $6,70(s)$ & 102,7 & 103,$8 ; 163,4$ & - \\
\hline 4"' & - & 180,4 & - & - \\
\hline 5 ' & - & 161,0 & - & - \\
\hline 6"' & $6,21(s)$ & 98,9 & 98,9 & - \\
\hline $7^{\prime \prime}$ & - & 164,5 & - & - \\
\hline 8', & - & 98,9 & - & - \\
\hline 9"' & - & 154,8 & - & - \\
\hline $10 "$ & - & 103,8 & - & - \\
\hline 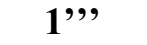 & - & 121,1 & - & - \\
\hline 2" 6" & $7,54(d ; 9,0)$ & 127,9 & 127,$9 ; 159,8 ; 163,4$ & $\mathrm{H}-3$, \\
\hline 3"' 5"', & $6,76(d ; 9,0)$ & 115,8 & 115,$8 ; 121,1 ; 159,8$ & $\mathrm{H}-2$ ', \\
\hline 4"', & - & 159,8 & - & - \\
\hline 5'-OH & $13,12(s)$ & - & 98,$9 ; 103,8 ; 161,0$ & - \\
\hline
\end{tabular}

\subsubsection{Caracterização espectrométrica da substância 8}

A substância 8 foi isolada da subfração AcOEt-FOL-15, conforme procedimento experimental em 5.6. 
A substância de fórmula $\mathrm{C}_{30} \mathrm{H}_{20} \mathrm{O}_{11}$ foi obtida como cristais amarelos e apresentou espectro de UV típico de flavona/flavanona, com a banda II em $289 \mathrm{~nm}$ e a banda I em 348 nm (Figura 33). A fórmula molecular de $\mathbf{8}$ foi obtida pelo espectro de massas no modo negativo (ESI) que apresentou íon molecular em $\mathrm{m} / z 555[\mathrm{M}-\mathrm{H}]^{-}$e um único fragmento em $m / z, 429$ [M-H] $]^{-}$justificado pela perda do floroglucinol (126 u) como mostrado na Figura 35 e Figura 36.

O espectro de absorção na região do IV (Figura 34) apresentou bandas em 3733 e $3621 \mathrm{~cm}^{-1}$ correspondentes à deformação axial da ligação $\mathrm{O}-\mathrm{H}\left(v_{\mathrm{O}-\mathrm{H}}\right)$. O espectro também exibiu uma banda em $2956 \mathrm{~cm}^{-1}$ referente à deformação axial C-H de aromáticos $\left(v_{\mathrm{C}-\mathrm{H}}\right)$, uma banda em $1641 \mathrm{~cm}^{-1}$ referente à carbonila conjugada da molécula $\left(v_{\mathrm{C}-\mathrm{O}}\right)$, bandas em 1509 e $1364 \mathrm{~cm}^{-1}$ atribuídas à deformação axial de C-C ( $\left.v_{\mathrm{C}-\mathrm{C}}\right)$ do anel aromático, absorção em $1263 \mathrm{~cm}^{-1}$ associada a deformações axiais C-O ( $\left.v_{\mathrm{C}-\mathrm{O}}\right)$ e ainda, uma banda em $821 \mathrm{~cm}^{-1}$ relacionadas a deformações angulares fora do plano das ligações $\mathrm{C}-\mathrm{H}\left(\delta_{\mathrm{C}-\mathrm{H}}\right)$ do anel (SILVERSTEIN; WEBSTER; KIEMLE, 1994).

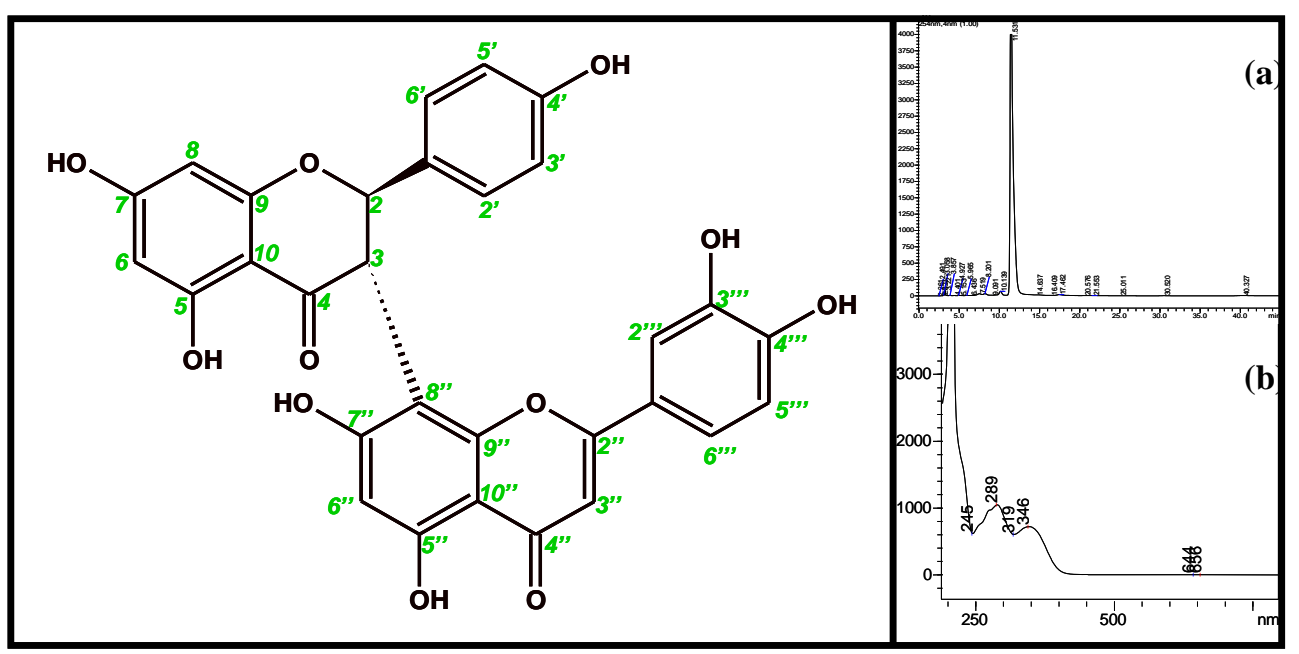

Figura 33 - Estrutura da substância 8. (a) Cromatograma analítico e (b) espectro de absorção da substância 8 obtido via CLAE-UV-DAD no modo isocrático 1:1 $\left(\mathrm{MeOH}: \mathrm{H}_{2} \mathrm{O}\right)$ e suporte

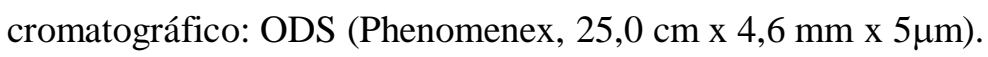




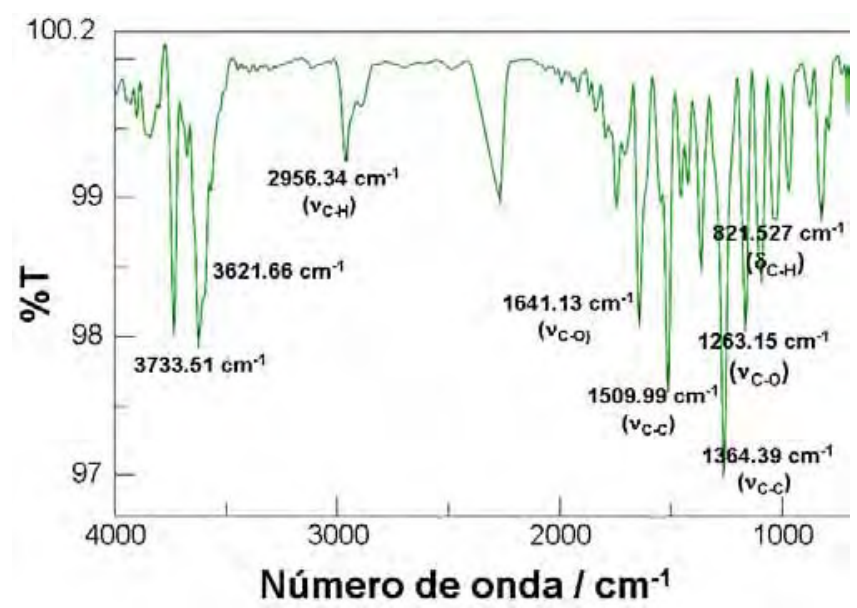

Figura 34 - Espectro vibracional na região do IV da substância 8.

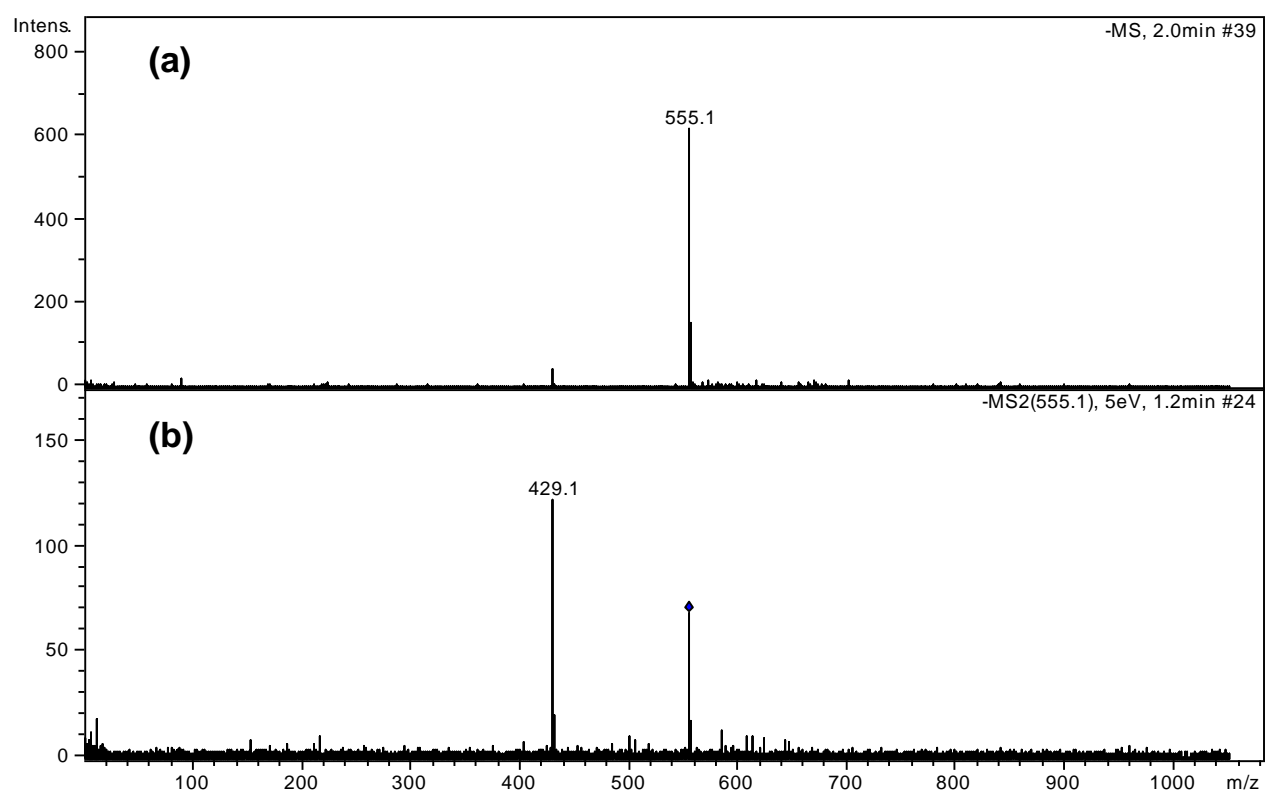

Figura 35 - Espectro de massas (a) de primeira e (b) segunda-ordem da substância 8, obtido em modo negativo com energia de colisão de 5\% para EM2 (ESI).

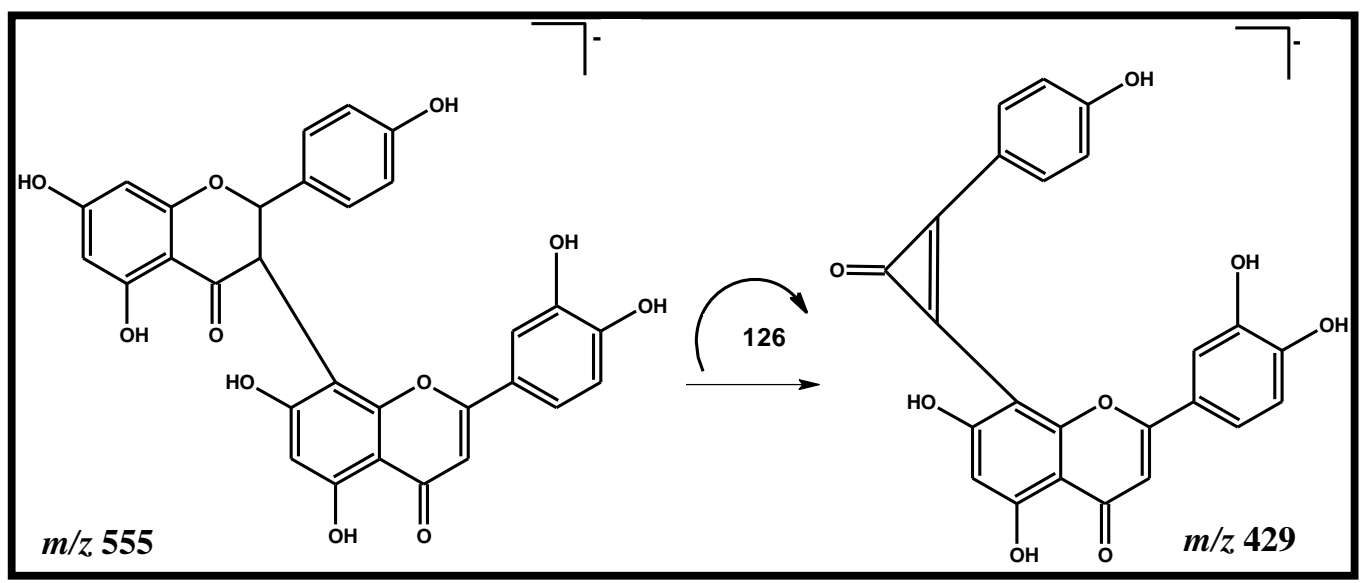

Figura 36 - Proposta de fragmentação da substância 8. 
$\mathrm{O}$ espectro de RMN de ${ }^{1} \mathrm{H}$ (Anexos 54 e 55) mostrou dois singletos largos em $\delta_{\mathrm{H}}$ 13,05 e 12,24, provavelmente relacionados a hidrogênios de hidroxilas quelatadas, capaz de estabelecer uma ligação de hidrogênio intramolecular com o oxigênio carbonílico em C4. Destacam-se os dubletos em $\delta_{\mathrm{H}} 5,71$ e 4,88 (J=12,0), atribuídos a H-2 e H-3, respectivamente, evidenciando a subclasse das flavanonas.

$\mathrm{O}$ espectro de RMN de ${ }^{1} \mathrm{H}$ apresentou ainda, dois dubletos em $\delta_{\mathrm{H}} 7,13(\mathrm{~J}=8,5 \mathrm{~Hz}$; $2 \mathrm{H})$ e $\delta_{\mathrm{H}} 6,38(\mathrm{~J}=8,5 \mathrm{~Hz} ; 2 \mathrm{H})$, os quais foram atribuídos aos hidrogênios H-2'/H-6' e H3'/H-5', respectivamente, para a unidade I. O multipleto em $\delta_{\mathrm{H}} 7,41$ foi atribuído aos hidrogênios H-6", ' e H-2,", e o dubleto $\delta_{\mathrm{H}} 6,90(\mathrm{~J}=8,5 \mathrm{~Hz}, 1 \mathrm{H})$ foi atribuído ao hidrogênio H-5", , para a unidade II. Este sistema foi confirmado por $g \mathrm{HMBC}$ através das correlações entre o sinal $\delta_{\mathrm{H}}$ 7,41 e $\delta_{\mathrm{C}}$ 113,4 (C-2"’'), 119,6 (C-6"',), 146,2 (C-3",'), 150,0 (C-4"',) e 164,0 (C-2'”). A correlação a longa distância também foi útil para designar a união interflavonoídica tipo $3 \rightarrow 8$ ', através da correlação do sinal em $\delta_{\mathrm{H}} 4,88(\mathrm{H}-3)$ com $\delta_{\mathrm{C}} 161,8(\mathrm{C}$ 7') e 155,8 (C-9''). Também confirmou a posição dos anéis B pela correlação do sinal em $\delta_{\mathrm{H}} 7,13\left(\mathrm{H}-2\right.$ ') $\operatorname{com} \delta_{\mathrm{C}} 81,0(\mathrm{C}-2)$ e $\delta_{\mathrm{H}} 7,41\left(\mathrm{H}-6\right.$ '”') com $\delta_{\mathrm{C}} 164,0(\mathrm{C}-2$ '”) (Anexos 62 a 70).

Observou-se um singleto intenso em $\delta_{\mathrm{H}} 5,97$ atribuído a H-6 e H-8, um singleto em $\delta_{\mathrm{H}} 6,23$ correspondente ao H-6" e um singleto em $\delta_{\mathrm{H}} 6,56$ associado ao H-3"'. Através de todos os dados espectroscópicos e comparação com dados da literatura (LI, 2002), pode-se definir a substância $\mathbf{8}$ como morelloflavona.

Este composto foi isolado de várias espécies de Garcinia (KONOSHIMA et al., 1969, 1970; MBWAMBO et al., 2006; VERDI et al., 2004) e a caracterização estrutural e análise conformacional proposta por Li et al. (2002) evidencia o efeito atropisomérico da morelloflavona, como discutido no item 1.4.1. No espectro de $\mathrm{RMN}{ }^{1} \mathrm{H}$ da morelloflavona os sinais principais são acompanhados por sinais de menor intensidade, fato explicado pela restrição na rotação C-3 $\rightarrow$ C-8', , confirmando a interligação das unidades flavonoídicas através desses carbonos. As estruturas mais estáveis são definidas a partir da correlação espacial (NOESY-1D) entre H-3 e H-6" ' do confôrmero principal, e entre H-2 e H-6" " do confôrmero minoritário, e mostra claramente que o confôrmero majoritário (8a) possui a unidade da flavona AIICIIBII estendida sob o plano dos anéis AICI da unidade da flavanona. O confôrmero minoritário (8b) apresenta os anéis AIICIIBII abaixo do plano dos anéis AICI da unidade da flavanona (Figura 38). 
Os dados de RMN ${ }^{1} \mathrm{H}$ do confôrmero principal e minoritário estão apresentados na Tabela 6. Para o confôrmero minoritário foram listados apenas os dados de $\mathrm{RMN}{ }^{1} \mathrm{H}$, pois os sinais de carbonos foram de baixa intensidade.

A substância 8 apresentou $[\alpha]_{D}^{T}=+170,8\left(\mathrm{c}=1,0 \mathrm{mg} \cdot \mathrm{mL}^{-1}\right)$ em MeOH. A análise da curva de dicroísmo circular indicou efeito Cotton positivo para as transições $n \rightarrow \pi^{*}$ e $\pi \rightarrow \pi^{*}$ em 345 e 285, respectivamente (Figura 37). Um efeito Cotton positivo sobre 285 nm para compostos semelhantes a $\mathbf{8}$, indica uma configuração absoluta $2 R$ (LI et al., 2002). Assim, fazendo uso da estereoquímica relativa inferida a partir do experimento de RMN, no qual os hidrogênios H-2 e H-3 apresentaram configuração trans $\left(J_{2,3}=12,0 \mathrm{~Hz}\right)$, pode-se concluir que a substância $\mathbf{8}$ apresenta configuração absoluta de $2 R, 3 S$.

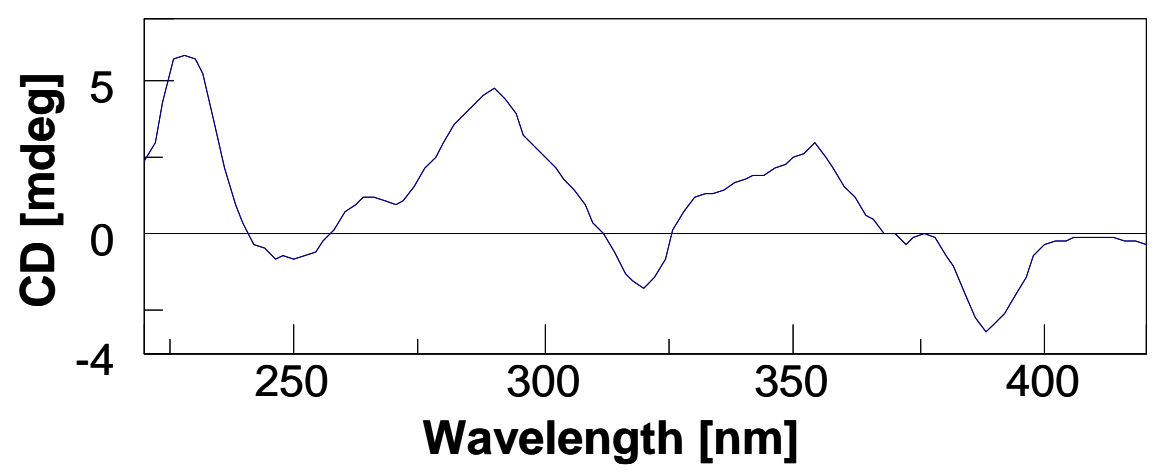

Figura 37 - Curva de dicroísmo circular (DC) da substância 8.
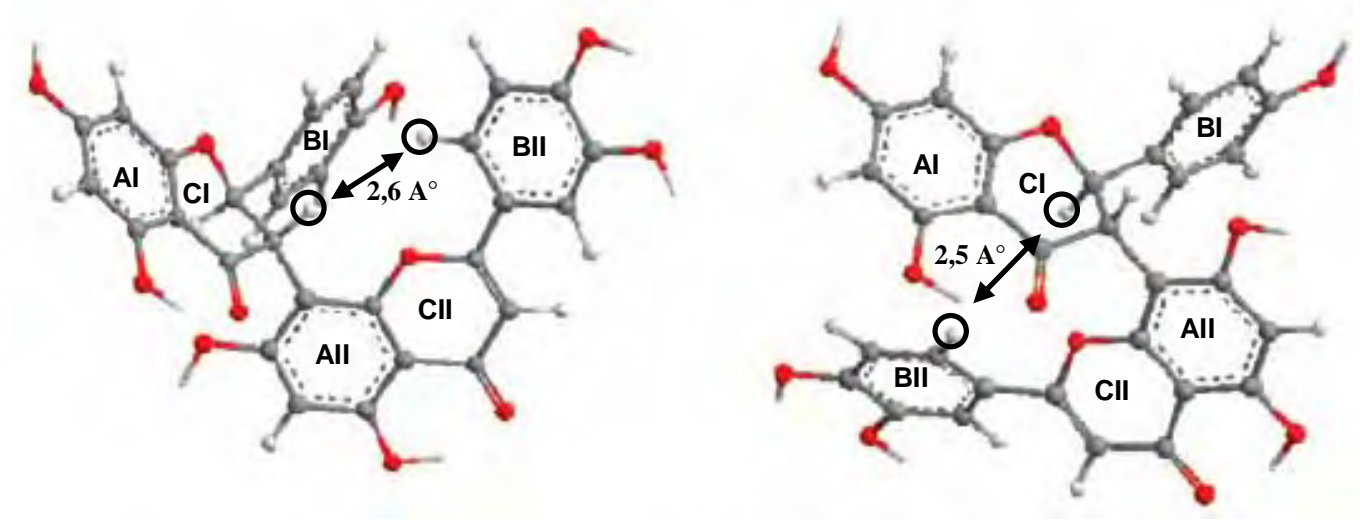

Figura 38 - Estruturas do confôrmero principal (8a) e minoritário (8b) da morelloflavona. 
Tabela 6 - Dados de RMN de ${ }^{1} \mathrm{H}(500 \mathrm{MHz})$ e RMN de ${ }^{13} \mathrm{C}(125 \mathrm{MHz})$ da substância 8 (DMSO- $\left.d_{6}\right)$.

\begin{tabular}{|c|c|c|c|c|c|}
\hline Posição & \multicolumn{2}{|c|}{$\begin{array}{c}\delta_{\mathrm{H}}(\mathrm{ppm}) \\
\text { (multiplicidade; } J(\mathrm{~Hz}))\end{array}$} & $\begin{array}{c}\boldsymbol{\delta}_{\mathbf{c}} \\
(\mathbf{p p m})\end{array}$ & gHМBC & $g \mathrm{COSY}$ \\
\hline 2 & $5,71(d ; 12,0)$ & $5,58(d ; 12,0)$ & 81,0 & 128,7 & $\mathrm{H}-3$ \\
\hline 3 & $4,88(d ; 12,0)$ & $4,98(d ; 12,0)$ & 48,8 & $\begin{array}{l}81,0 ; 101,1 ; 128,7 ; \\
155,8 ; 161,8 ; 196,0\end{array}$ & $\mathrm{H}-2$ \\
\hline 4 & - & - & 196,0 & - & - \\
\hline 5 & - & - & 164,0 & - & - \\
\hline 6 & $5,97(s)$ & $5,97(s)$ & 96,0 & 101,$1 ; 163,5$ & $*$ \\
\hline 7 & - & - & 163,5 & - & - \\
\hline 8 & $5,97(s)$ & $5,97(s)$ & 96,2 & 101,$1 ; 163,5 ; 166,6$ & $*$ \\
\hline 9 & - & - & 166,6 & - & - \\
\hline 10 & - & - & 101,1 & - & - \\
\hline 1 & - & - & 128,7 & - & - \\
\hline 2' 6', & $7,13(d ; 8,5)$ & $7,08(d ; 8,5)$ & 128,8 & 81,$0 ; 128,8 ; 158,0$ & $\mathrm{H}-3$, \\
\hline 3' 5' & $6,38(d ; 8,5)$ & $6,60(d ; 8,5)$ & 114,6 & 114,$6 ; 128,7 ; 158,0$ & $\mathrm{H}-2$ \\
\hline $4 ’$ & - & - & 158,0 & - & - \\
\hline 5-OH & $12,24(s)$ & $12,19(s)$ & - & 96,$0 ; 101,1 ; 164,0$ & - \\
\hline 2 & - & - & 164,0 & - & - \\
\hline 3 '" & $6,56(s)$ & $6,61(s)$ & 102,2 & $\begin{array}{c}103,6 ; 121,8 ; 164,0 ; \\
182,0\end{array}$ & - \\
\hline $4 "$ & - & - & 182,0 & - & - \\
\hline 5 & - & - & 161,0 & - & - \\
\hline $6 "$ & $6,23(s)$ & $6,06(s)$ & 99,0 & 100,$7 ; 103,6 ; 161,8$ & - \\
\hline 7, & - & - & 161,8 & - & - \\
\hline 8 & - & - & 100,7 & - & - \\
\hline 9", & - & - & 155,8 & - & - \\
\hline 10 "' & - & - & 103,6 & - & - \\
\hline $1 "$, & - & - & 121,8 & - & - \\
\hline 2", & $7,41(m)$ & $7,24(m)$ & 113,4 & 119,$6 ; 146,2 ; 150,0$ & H-6, \\
\hline $3, \%$ & - & - & 146,2 & - & - \\
\hline $4, \%$ & - & - & 150,0 & - & - \\
\hline 5, & $6,90(d ; 8,5)$ & $6,50(d ; 8,5)$ & 116,2 & 121,$8 ; 146,2$ & H-6,", \\
\hline $6, \%$ & $7,41(\mathrm{~m})$ & $6,96(m)$ & 119,6 & 113,$4 ; 150,0 ; 164,0$ & H-2,"'; H-5,", \\
\hline 5"'-OH & $13,05(s)$ & $12,89(s)$ & - & 99,$0 ; 103,6 ; 161,0$ & - \\
\hline
\end{tabular}

(8a) representa o confôrmero principal e a série $(\mathbf{8 b})$ o confôrmero minoritário.

*valores não observados

Os valores de RMN de ${ }^{13} \mathrm{C}$ foram atribuídos através das interações observadas nos experimentos $g \mathrm{HMQC}$ e $g \mathrm{HMBC}$. 


\subsubsection{Caracterização espectrométrica da substância 9}

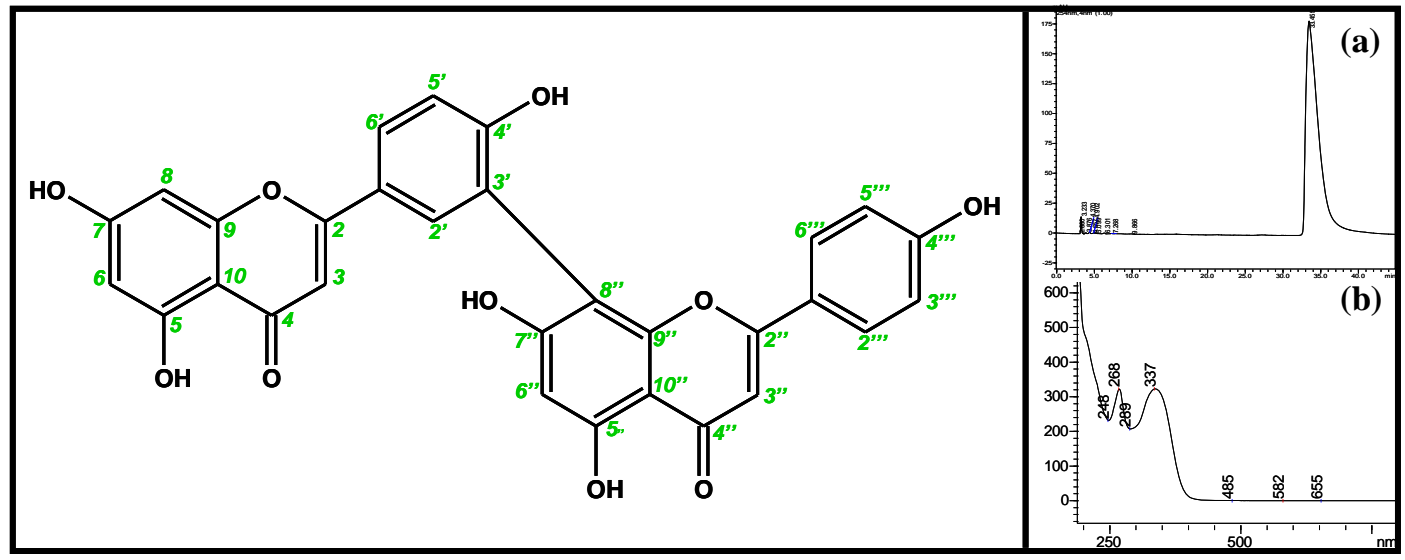

Figura 39 - Estrutura da substância 9. (a) Cromatograma analítico e (b) espectro de absorção da substância 9 obtido via CLAE-UV-DAD no modo isocrático 1:1 $\left(\mathrm{MeOH}: \mathrm{H}_{2} \mathrm{O}\right)$ e suporte cromatográfico: ODS (Phenomenex, 25,0 $\mathrm{cm}$ x 4,6 mm x 5 $\mu \mathrm{m}$ ).

A substância 9 foi isolada da subfração AcOEt-FOL-16, conforme procedimento experimental em $\mathbf{5 . 6}$.

Os resultados observados no espectro de $\mathrm{RMN}$ de ${ }^{13} \mathrm{C}$ e ${ }^{1} \mathrm{H}$, UV, IV e massas permitiram caracterizar 9 como sendo uma substância pertencente à classe dos biflavonóides tipo flavona-flavona.

$\mathrm{O}$ composto de estrutura $\mathrm{C}_{30} \mathrm{H}_{18} \mathrm{O}_{10}$ apresentou-se como um sólido amarelo amorfo e apresentou bandas de absorção no UV características de flavonas (268 e $337 \mathrm{~nm}$ ). A fórmula molecular foi obtida pelo espectro de massas no modo negativo (ESI) que apresentou o pico íon molecular em $\mathrm{m} / z 537$ [M-H] $]^{-}$(Figura 41). O tempo de retenção da substância 9 foi de $t_{r}=33,4$ min (Figura 39) mostrando que, sob mesmas condições de análise, uma mudança de posição da ligação inter-flavonoídica, faz com que a molécula apresente propriedades como polaridade bastante diferenciadas. A união entre as unidades I e II do flavonóide em 9 é do tipo $3^{\prime} \rightarrow 8$ " e para $\mathbf{5}$, ocorre tipo $3 \rightarrow 8$ '. Essa diferença na posição das ligações de união das unidades (isomeria de posição) faz com que $\mathbf{9}$ apresente uma polaridade significativamente menor que $\mathbf{5}\left(\mathrm{t}_{\mathrm{r}}=14,1 \mathrm{~min}\right)$.

O espectro de absorção na região do IV (Figura 40) mostrou uma banda larga em $3490 \mathrm{~cm}^{-1}$ correspondente à deformação axial da ligação $\mathrm{O}-\mathrm{H}\left(v_{\mathrm{O}-\mathrm{H}}\right)$, evidenciando a presença de hidroxila, uma banda em $2970 \mathrm{~cm}^{-1}$ referente à deformação axial C-H de aromáticos $\left(v_{\mathrm{C}-\mathrm{H}}\right)$, uma banda em $1648 \mathrm{~cm}^{-1}$ referente à carbonila conjugada da molécula 
$\left(v_{\mathrm{C}-\mathrm{O}}\right)$, bandas em $1485 \mathrm{~cm}^{-1}$ atribuída à deformação axial de $\mathrm{C}-\mathrm{C}\left(v_{\mathrm{C}-\mathrm{C}}\right)$ do anel aromático e ainda, bandas referentes à deformação angular no plano de C-H $\left(\delta_{\mathrm{C}-\mathrm{H}}\right)$ em $1062 \mathrm{~cm}^{-1}$ (SILVERSTEIN; WEBSTER; KIEMLE, 1994).

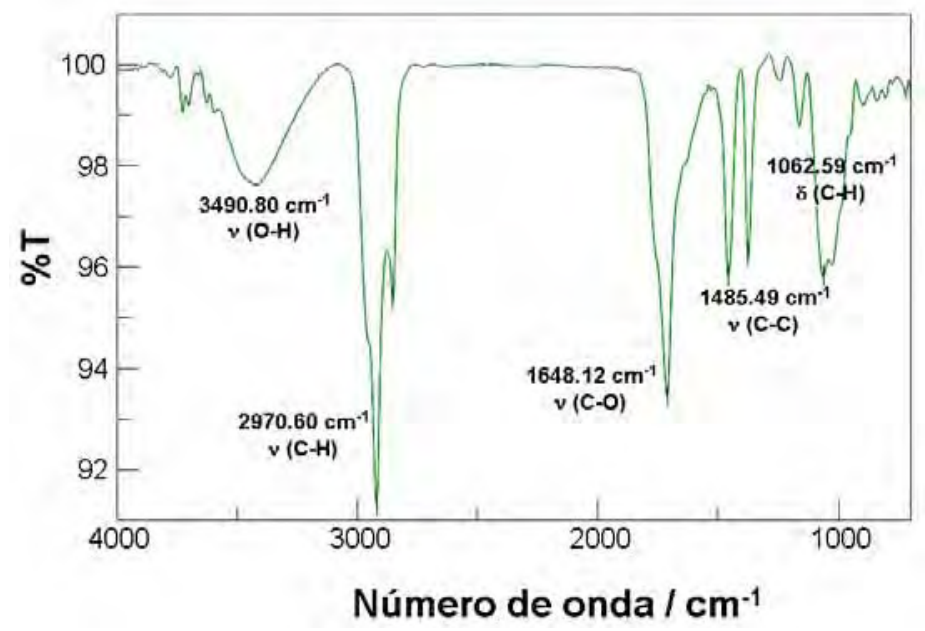

Figura 40 - Espectro vibracional na região do IV da substância 9.

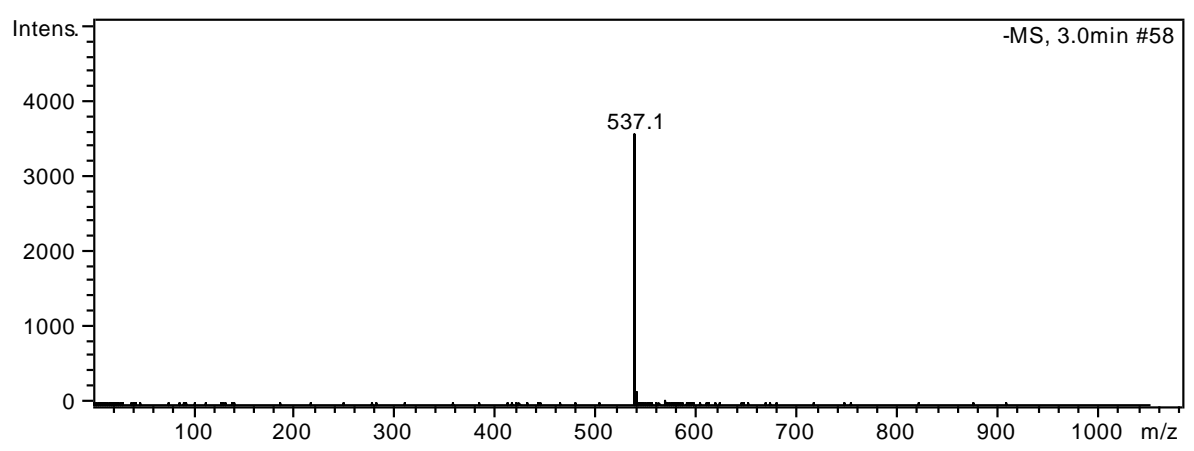

Figura 41 - Espectro de massas de primeira-ordem da substância 9 obtido no modo negativo (ESI).

No espectro de $\mathrm{RMN}$ de ${ }^{13} \mathrm{C}$ (Anexos 74 a 76) destacaram-se os sinais em $\delta_{\mathrm{C}} 163,9 \mathrm{e}$ $\delta_{\mathrm{C}} 102,4$ atribuídos a C-2 e C-3, respectivamente, evidenciando a subclasse das flavonas e os sinais em $\delta_{\mathrm{C}} 181,9$ e $\delta_{\mathrm{C}} 181,6$ correspondentes aos carbonos carbonílicos C-4 e C-4"' das unidades I e II (Tabela 7).

O espectro de RMN de ${ }^{1} \mathrm{H}$ (Anexos 71 a 73) mostrou a presença de dois singletos em $\delta_{\mathrm{H}} 12,98$ (unidade II) e $\delta_{\mathrm{H}} 13,10$ (unidade I), correspondentes a hidroxilas quelatadas com ligação de hidrogênio intramolecular com o oxigênio carbonílico situado em C-4 e C-4'. Destaca-se a presença de dois dubletos em $\delta_{\mathrm{H}} 7,58(2 \mathrm{H}, \mathrm{H}-2$ ','/6"', $J=9,0 \mathrm{~Hz})$ e $\delta_{\mathrm{H}} 6,66$ $(2 \mathrm{H}, \mathrm{H}-3$ '", $/ 5$ ', $, J=9,0 \mathrm{~Hz})$ correspondentes à unidade II. Sinais de um anel aromático trissubstituído contendo um carbono carbinólico foram observados em $\delta_{\mathrm{H}} 8,05(d, \mathrm{H}-2$ ', $J=2,0 \mathrm{~Hz}), \delta_{\mathrm{H}} 7,06\left(d, \mathrm{H}^{-5}{ }^{\prime}, J=9,0 \mathrm{~Hz}\right)$ e $\delta_{\mathrm{H}} 7,96(d d, \mathrm{H}-6$ ', $J=2,0 ; 9,0 \mathrm{~Hz})$, juntamente com 
os dubletos de um anel aromático tetrassubstituído em $\delta_{\mathrm{H}} 6,16(d, \mathrm{H}-6, J=2,0 \mathrm{~Hz})$ e $\delta_{\mathrm{H}} 6,40$ $(d, \mathrm{H}-8, J=2,0 \mathrm{~Hz})$.

Tabela 7 - Dados de RMN de ${ }^{1} \mathrm{H}(500 \mathrm{MHz})$ e RMN de ${ }^{13} \mathrm{C}(125 \mathrm{MHz})$ da substância 9 (DMSO- $\left.d_{6}\right)$.

\begin{tabular}{|c|c|c|c|c|}
\hline Posição & $\begin{array}{c}\delta_{\mathrm{H}}(\mathrm{ppm}) \\
\text { (multiplicidade; } J(\mathrm{~Hz}))\end{array}$ & $\delta_{c}(\mathbf{p p m})$ & $g \mathrm{HMBC}$ & $g \mathrm{COSY}$ \\
\hline 2 & - & 163,9 & - & - \\
\hline 3 & $6,74(s)$ & 102,4 & 103,$6 ; 163,9$ & - \\
\hline 4 & - & 181,9 & - & - \\
\hline 5 & - & 161,3 & - & - \\
\hline 6 & $6,16(d ; 2,0)$ & 98,7 & 93,$9 ; 103,6 ; 161,3 ; 165,2$ & - \\
\hline 7 & - & 165,2 & - & - \\
\hline 8 & $6,40(d ; 2,0)$ & 93,9 & 98,$7 ; 103,6 ; 157,3 ; 165,2$ & - \\
\hline 9 & - & 157,3 & - & - \\
\hline 10 & - & 103,6 & - & - \\
\hline 1 ' & - & 121,4 & - & - \\
\hline 2' & $8,05(d ; 2,0)$ & 131,3 & 104,$1 ; 127,4 ; 161,8$ & H-6 \\
\hline 3 ' & - & 120,1 & - & - \\
\hline 4 ' & - & 161,8 & - & - \\
\hline 5 & $7,06(d ; 9,0)$ & 116,9 & 120,1 & H-6' \\
\hline $6{ }^{\prime}$ & $7,96(d d ; 2,0$ e 9,0$)$ & 127,4 & 131,$3 ; 161,8 ; 163,9$ & H-2'; H-5'; \\
\hline 5-OH & $13,10(s)$ & - & 98,$7 ; 103,6 ; 161,3$ & - \\
\hline $2 "$ & - & 163,4 & - & - \\
\hline 3, & $6,79(s)$ & 102,6 & 102,$4 ; 121,4 ; 163,4$ & - \\
\hline 4', & - & 181,6 & - & - \\
\hline 5, & - & 160,4 & - & - \\
\hline $6 "$ & $6,28(s)$ & 99,4 & 104,1 & - \\
\hline 7, & - & $*$ & - & - \\
\hline 8, & - & 104,1 & - & - \\
\hline 9, & - & $*$ & - & - \\
\hline $10 "$ & - & 102,4 & - & - \\
\hline $1 \%$ & - & 121,4 & - & - \\
\hline $2, \% 6 \%$ & $7,58(d ; 9,0)$ & 128,1 & 128,$1 ; 160,8 ; 163,4$ & $\mathrm{H}-3$, \\
\hline 3"' 5"' & $6,66(d ; 9,0)$ & 115,6 & 121,$4 ; 160,8$ & $\mathrm{H}-2$, \\
\hline $4 \%$, & - & 160,8 & - & - \\
\hline 5',-OH & $12,98(s)$ & - & 99,$4 ; 102,4 ; 160,4$ & - \\
\hline
\end{tabular}

*valores não observados

A correlação a longa distância (Anexos 82 a 85) foi útil para designar a união interflavonoídica, tipo 3' $\rightarrow$ ', , através da correlação de $\delta_{\mathrm{H}} 8,05$ (H-2') com $\delta_{\mathrm{C}} 104,1$ (C-8' '), assim como o experimento de $g \operatorname{COSY}\left(\right.$ Anexos 77 e 78) que mostrou interação entre $\delta_{H}$ $8,05\left(\mathrm{H}-2^{\prime}\right)$ e com $\delta_{\mathrm{H}} 7,96\left(\mathrm{H}^{\prime} 6^{\prime}\right)$; de $\delta_{\mathrm{H}} 7,06\left(\mathrm{H}^{-5}{ }^{\prime}\right)$ e $\delta_{\mathrm{H}} 7,96\left(\mathrm{H}-6\right.$ ') e de $\delta_{\mathrm{H}}$ 7,96 (H-6') $\operatorname{com} \delta_{\mathrm{H}} 8,05\left(\mathrm{H}-2^{\prime}\right)$ e $\delta_{\mathrm{H}} 7,06(\mathrm{H}-5$ '). 
A análise destas informações em conjunto com os dados da literatura (CARBONEZI et al., 2007), permitiu identificar a substância 9 como amentoflavona, um biflavonóide já isolado dos frutos de Garcinia xanthochymus por Baggett et al. (2005).

\subsubsection{Caracterização espectrométrica da substância 10}

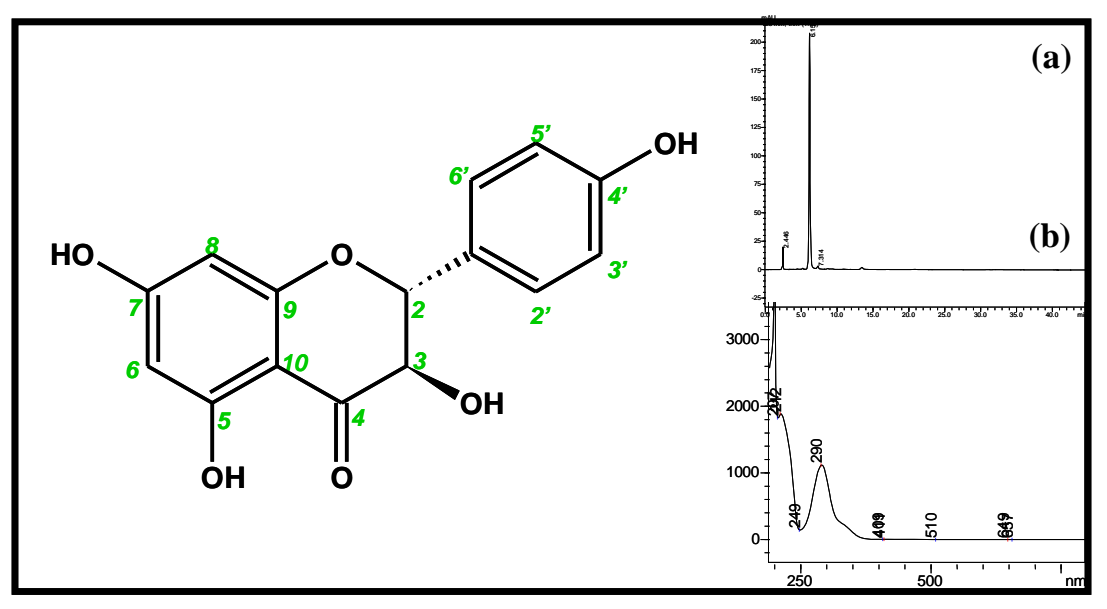

Figura 42 - Estrutura da substância 10. (a) Cromatograma analítico e (b) espectro de absorção da substância 10 obtido via CLAE-UV-DAD no modo isocrático 1:1 $\left(\mathrm{MeOH}: \mathrm{H}_{2} \mathrm{O}\right)$ e suporte

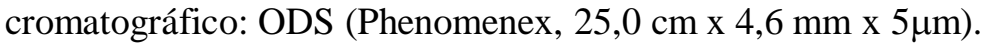

A substância 10 foi isolada da subfração AcOEt-SIL-3, conforme procedimento experimental em $\mathbf{5 . 7}$.

A substância 10 obtida como pó amorfo de coloração amarelada apresentou fórmula molecular de $\mathrm{C}_{15} \mathrm{H}_{12} \mathrm{O}_{6}$ correspondendo ao íon $\mathrm{m} / z, 287[\mathrm{M}-\mathrm{H}]^{-}$. Além do pico íon molecular $m / z 287[\mathrm{M}-\mathrm{H}]^{-}$, a substância 10 apresentou pico íon base de $\mathrm{m} / z, 259$, correspondendo à perda de $\mathrm{CO}[\mathrm{M}-\mathrm{H}-28]^{-}$e $m / z$ 243, correspondendo à perda de $\mathrm{CO}_{2}[\mathrm{M}$ H-44]' (Figura 44 e Figura 45).

O espectro de UV apresentou uma única banda em $290 \mathrm{~nm}$, podendo ser atribuída a uma flavanona ou diidroflavonol (Figura 42).

O espectro de absorção na região do IV de 10 apresentou bandas em 3733 e $3616 \mathrm{~cm}^{-}$ ${ }^{1}$ referentes à deformação axial da ligação O-H $\left(v_{\mathrm{O}-\mathrm{H}}\right)$, uma banda em $2995 \mathrm{~cm}^{-1}$ referente à deformação axial C-H de aromáticos $\left(v_{\mathrm{C}-\mathrm{H}}\right)$, uma banda em $1678 \mathrm{~cm}^{-1}$ referente à carbonila da molécula $\left(v_{\mathrm{C}-\mathrm{O}}\right)$ e bandas em 1631, 1509 e $1456 \mathrm{~cm}^{-1}$ atribuídas à deformação axial de C-C $\left(v_{\mathrm{C}-\mathrm{C}}\right)$ do anel aromático (Figura 43). Exibiu ainda, bandas com absorção em 1160 e $1083 \mathrm{~cm}^{-1}$ associada a deformações axiais C-O ( $\left.v_{\mathrm{C}-\mathrm{O}}\right)$ e uma banda em $821 \mathrm{~cm}^{-1}$ 
relacionada à deformação angular fora do plano das ligações $\mathrm{C}-\mathrm{H}\left(\delta_{\mathrm{C}-\mathrm{H}}\right)$ do anel (SILVERSTEIN; WEBSTER; KIEMLE, 1994).

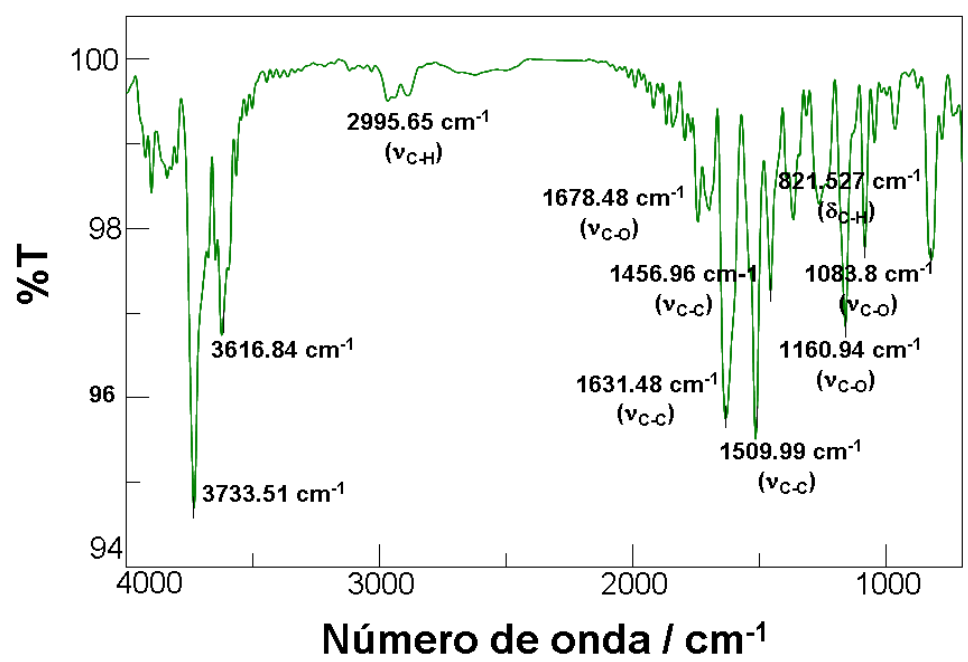

Figura 43 - Espectro vibracional na região do IV da substância 10.

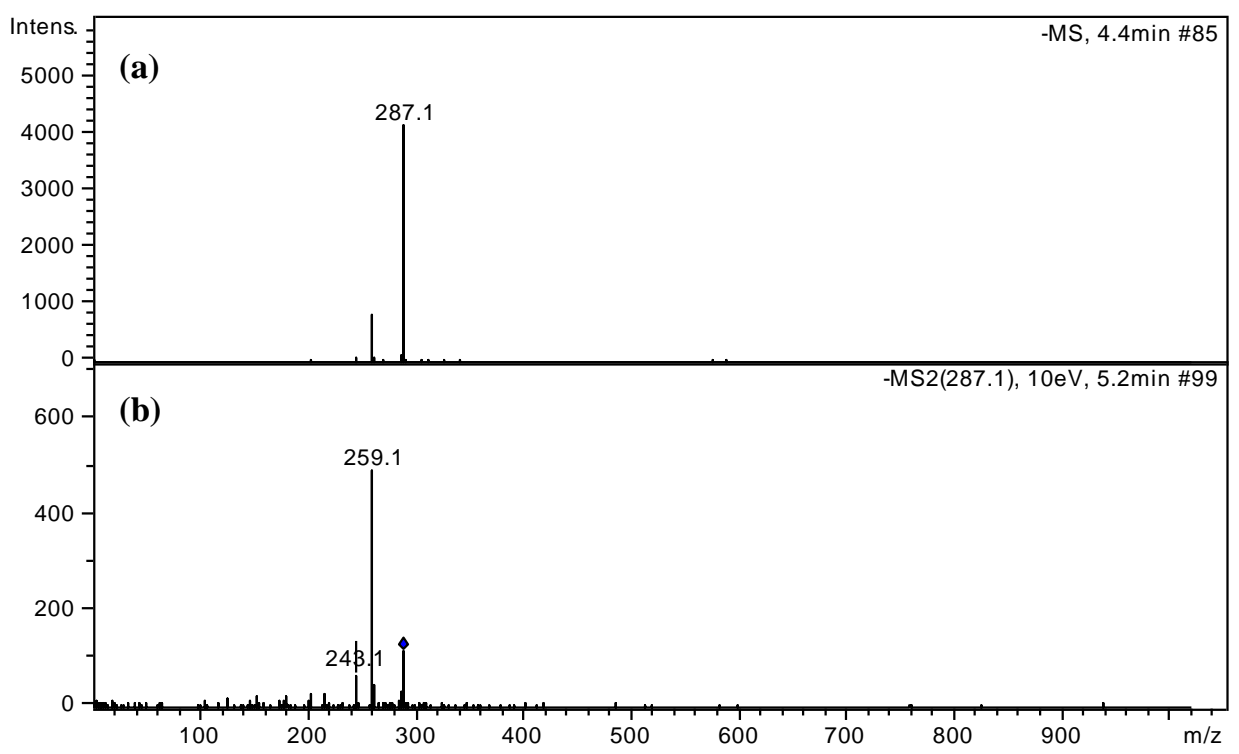

Figura 44 - Espectro de massas (a) de primeira e (b) segunda-ordem da substância 10, obtido em modo negativo com energia de colisão de $10 \%$ para EM2 (ESI).

Os espectros de $\mathrm{RMN}$ de ${ }^{1} \mathrm{H}$ e ${ }^{13} \mathrm{C}$, juntamente com os dados acima, permitiram inferir que a substância $\mathbf{1 0}$ pertence à subclasse dos diidroflavonol ou flavanonol.

$\mathrm{O}$ espectro de $\mathrm{RMN}{ }^{1} \mathrm{H}$ (Anexos 86 e 87) apresentou um par de dubletos em $\delta_{\mathrm{H}} 5,84 \mathrm{e}$ 5,90, sugerindo um anel A 5, 7, 9, 10-tetrassubstituído e 5, 7, 9-trioxigenado. Os sinais integrando para $2 \mathrm{H}$ em $\delta_{\mathrm{H}}$ 7,30 e 6,77 podem ser atribuídos aos hidrogênios $\mathrm{H}-2$ '/6' e H3'/5', sugerindo padrão de substituição 1,4-dissubstituído para o anel B. O espectro ainda 
mostrou dois dubletos em $\delta_{\mathrm{H}} 5,03(\mathrm{H}-2, J=11,5 \mathrm{~Hz})$ e 4,51 $(\mathrm{H}-3, J=11,5 \mathrm{~Hz})$, sugerindo um acoplamento do tipo axial-axial e a proposta de que o anel B e o grupo hidroxila em C-3 mantêm uma relação anti.

Entre outras feições, o espectro de $g \mathrm{HMQC}$ (Anexos 91 e 92) mostrou a correlação entre o sinal em $\delta_{\mathrm{H}} 5,03$ e $\delta_{\mathrm{C}} 82,0$; e entre o sinal $\delta_{\mathrm{H}} 4,51$ e $\delta_{\mathrm{C}} 71,0$, associados aos $\mathrm{C}$ e $\mathrm{H}$ nas posições 2 e 3, respectivamente, confirmando a proposta estrutural de um diidroflavonol.

O espectro de $g$ HMBC (Anexos 93 a 96) corrobora a proposição estrutural à medida que revela importantes acoplamentos a longa distância, entre eles, o acoplamento existente entre o hidrogênio H-2 $\left(\delta_{\mathrm{H}} 5,03\right)$ e os carbonos C-3, C-1', C-2'/6' e C-4; entre H-3 $\left(\delta_{\mathrm{H}}\right.$ $4,51)$ e C-2; entre H-2'/6' $\left(\delta_{\mathrm{H}} 7,30\right)$ e C-2 e C-4' e entre $\mathrm{H}-3^{\prime} / 5^{\prime}\left(\delta_{\mathrm{H}} 6,77\right)$ e os carbonos C1' e C-4' (Tabela 8).

A substância 10 apresentou $[\alpha]_{D}^{T}=+70,5\left(\mathrm{c}=1,0 \mathrm{mg} \cdot \mathrm{mL}^{-1}\right)$ em MeOH. A análise da curva de dicroísmo circular indicou efeito Cotton negativo para as transições $\pi \rightarrow \pi^{*}$ em aproximadamente $290 \mathrm{~nm}$ e efeito Cotton positivo para as transições $\mathrm{n} \rightarrow \pi^{*}$ em $330 \mathrm{~nm}$. (Figura 46). Assim, a partir de dados de DC da literatura para os estereoisômeros do diidrokaempferol (LI et al., 2002) foi possível identificar a substância 10 como $(2 R, 3 R)$ diidrokaempferol, um diidroflavonol ainda não identificado na espécie G. xanthochymus.

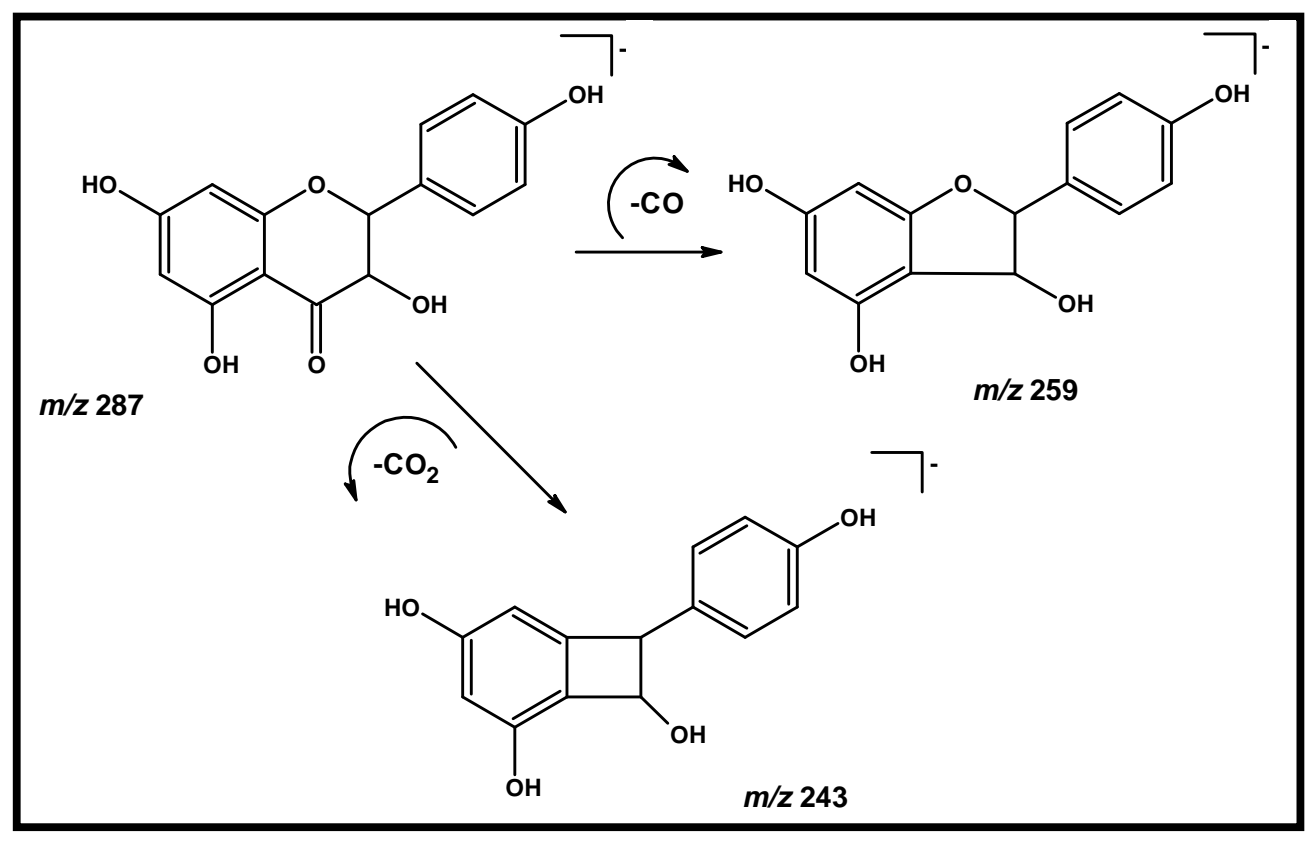

Figura 45 - Proposta de fragmentação da substância 10. 


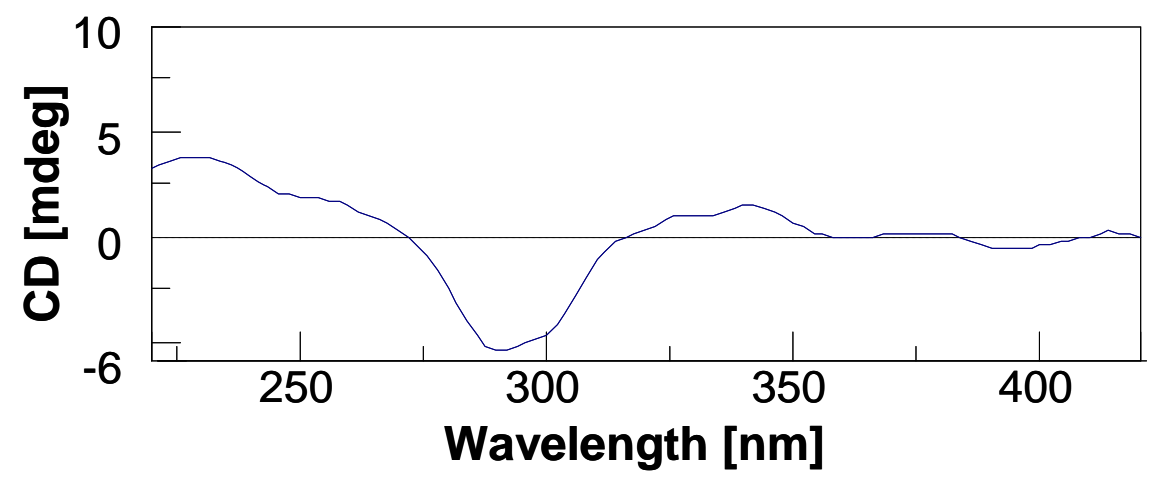

Figura 46 - Curva de dicroísmo circular (DC) da substância 10.

Tabela 8 - Dados de RMN de ${ }^{1} \mathrm{H}(500 \mathrm{MHz})$ e RMN de ${ }^{13} \mathrm{C}(125 \mathrm{MHz})$ da substância 10 (DMSO- $\left.d_{6}\right)$.

\begin{tabular}{|c|c|c|c|c|}
\hline Posição & $\begin{array}{c}\delta_{\mathrm{H}}(\mathrm{ppm}) \\
\text { (multiplicidade; } J(\mathrm{~Hz}))\end{array}$ & $\delta_{\mathrm{C}}(\mathbf{p p m})$ & gHМBC & $g \mathrm{COSY}$ \\
\hline 2 & $5,03(d ; 11,5)$ & 82,0 & 71,$0 ; 127,4 ; 129,0 ; 197,0$ & $\mathrm{H}-3$ \\
\hline 3 & $4,51(d ; 11,5)$ & 71,0 & 82,0 & $\mathrm{H}-2$ \\
\hline 4 & - & 197,0 & - & - \\
\hline 5 & - & 162,0 & - & - \\
\hline 6 & $5,84(d ; 2,0)$ & 94,0 & 96,$3 ; 100,2 ; 162,0 ; 167,0$ & - \\
\hline 7 & - & 167,0 & - & - \\
\hline 8 & $5,90(d ; 2,0)$ & 96,3 & 94,$0 ; 100,2 ; 163,0 ; 167,0$ & - \\
\hline 9 & - & 163,0 & - & - \\
\hline 10 & - & 100,2 & - & - \\
\hline 1 ' & - & 127,4 & - & - \\
\hline 2' 6' & $7,30(d ; 8,0)$ & 129,0 & 82,$0 ; 129,0 ; 158,1$ & $\mathrm{H}-3$ \\
\hline 3' 5', & $6,77(d ; 8,0)$ & 115,0 & 115,$0 ; 127,4 ; 158,1$ & $\mathrm{H}-2$ \\
\hline $4{ }^{\prime}$ & - & 158,1 & - & - \\
\hline 5-OH & $11,96(s)$ & - & $*$ & - \\
\hline
\end{tabular}

* valores não observados

Os valores de RMN de ${ }^{13} \mathrm{C}$ foram atribuídos através das interações observadas nos experimentos $g \mathrm{HMQC}$ e $g \mathrm{HMBC}$.

\subsubsection{Caracterização espectrométrica da substância 11}

A substância 11 foi isolada da subfração AcOEt-SIL-4, conforme procedimento experimental em $\mathbf{5 . 8}$.

A substância 11 obtida como cristais amarelos apresentou espectro de UV típico de flavanonas, com uma única banda em $291 \mathrm{~nm}$ (Figura 47).

O espectro de absorção na região do IV de 11 (Figura 48) foi bastante similar ao espectro de 8, com bandas correspondentes à deformação axial da ligação $\mathrm{O}-\mathrm{H}\left(v_{\mathrm{O}-\mathrm{H}}\right)$ em 3733 e $3621 \mathrm{~cm}^{-1}$. Também exibiu uma banda em $2954 \mathrm{~cm}^{-1}$ referente à deformação axial $\mathrm{C}-\mathrm{H}$ de aromáticos $\left(v_{\mathrm{C}-\mathrm{H}}\right)$, uma banda em $1626 \mathrm{~cm}^{-1}$ referente à carbonila da molécula $\left(v_{\mathrm{C}-}\right.$ 
o), uma banda em $1515 \mathrm{~cm}^{-1}$ atribuída à deformação axial de C-C ( $\left.v_{\mathrm{C}-\mathrm{C}}\right)$ do anel aromático, bandas com absorção em 1160 e 1078 cm$^{-1}$ associada a deformações axiais C-O ( $v_{\mathrm{C}-\mathrm{O}}$ ) e ainda, uma banda em $811 \mathrm{~cm}^{-1}$ relacionada à deformação angular fora do plano das ligações C-H $\left(\delta_{\mathrm{C}-\mathrm{H}}\right)$ do anel (SILVERSTEIN; WEBSTER; KIEMLE, 1994; JACKSON et al., 1966).

A fórmula molecular de $\mathrm{C}_{30} \mathrm{H}_{22} \mathrm{O}_{11}$ foi obtida a partir do íon molecular $\mathrm{m} / \mathrm{z} 557$ [M$\mathrm{H}]^{`}$, através do espectro de massa obtido no modo negativo e ionização por ESI. O padrão de fragmentação de 11 (Figura 49 e Figura 50) sugeriu sua natureza dimérica, através do íon em $m / z 431$ [M-H] $]^{-}$, referente à perda de floroglucinol (126 u) e o íon em $m / z, 295$ [M$\mathrm{H}^{\circ}$, referente à perda de 136 u por um mecanismo via Retro-Diels-Alder (RDA).

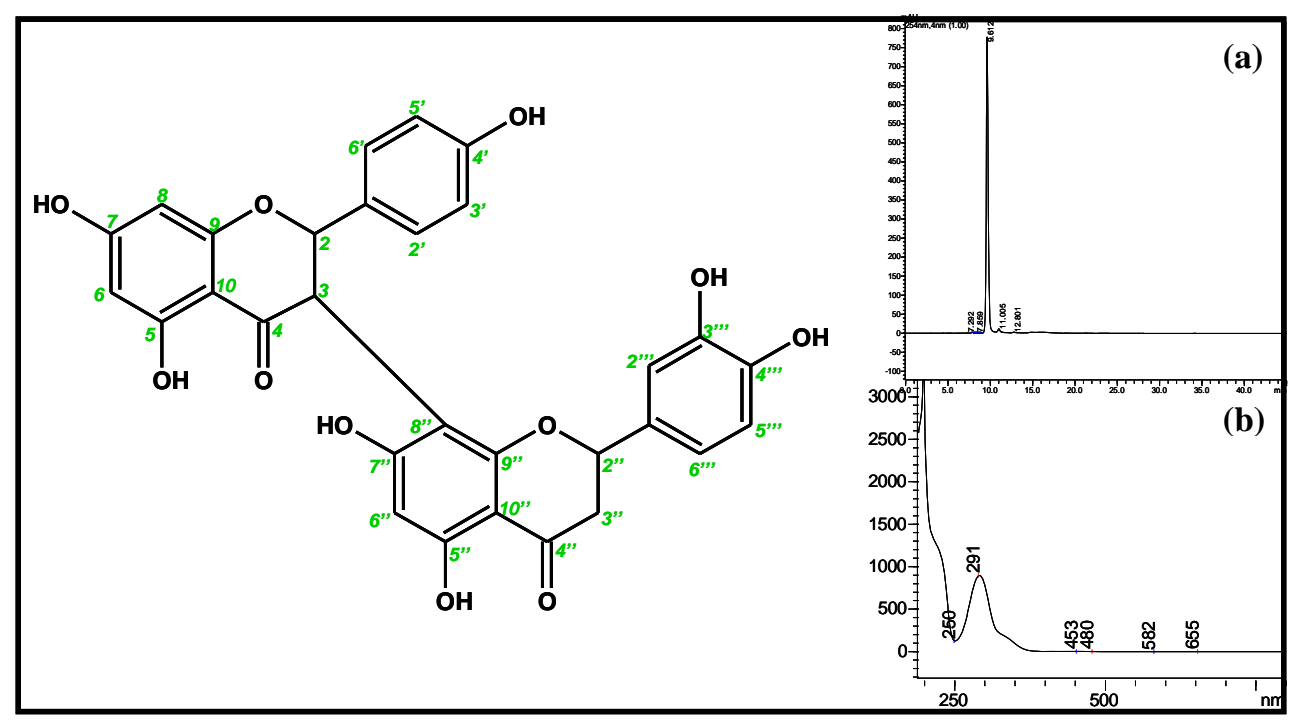

Figura 47 - Estrutura da substância 11. (a) Cromatograma analítico e (b) espectro de absorção da substância 11 obtido via CLAE-UV-DAD no modo isocrático 1:1 $\left(\mathrm{MeOH}: \mathrm{H}_{2} \mathrm{O}\right)$ e suporte cromatográfico: ODS (Phenomenex, 25,0 $\mathrm{cm}$ x 4,6 mm x 5 $\mu \mathrm{m}$ ).

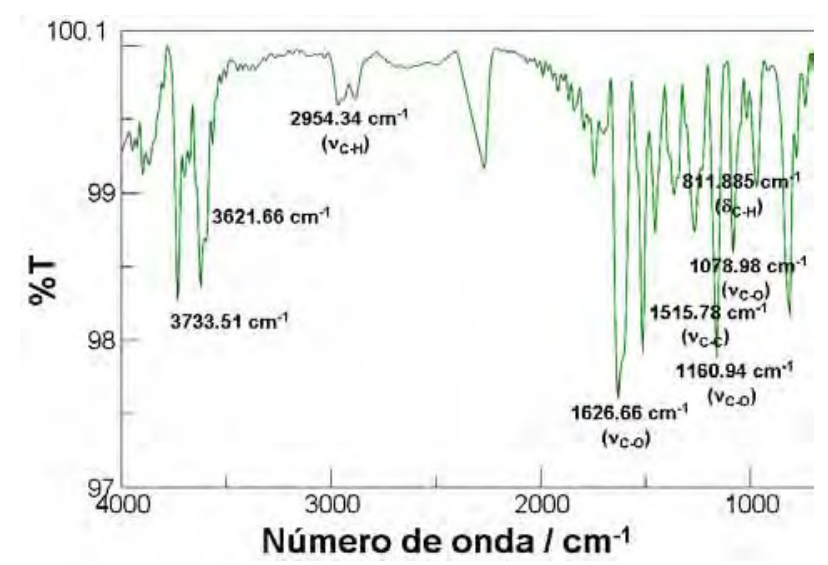

Figura 48 - Espectro vibracional na região do IV da substância 11. 


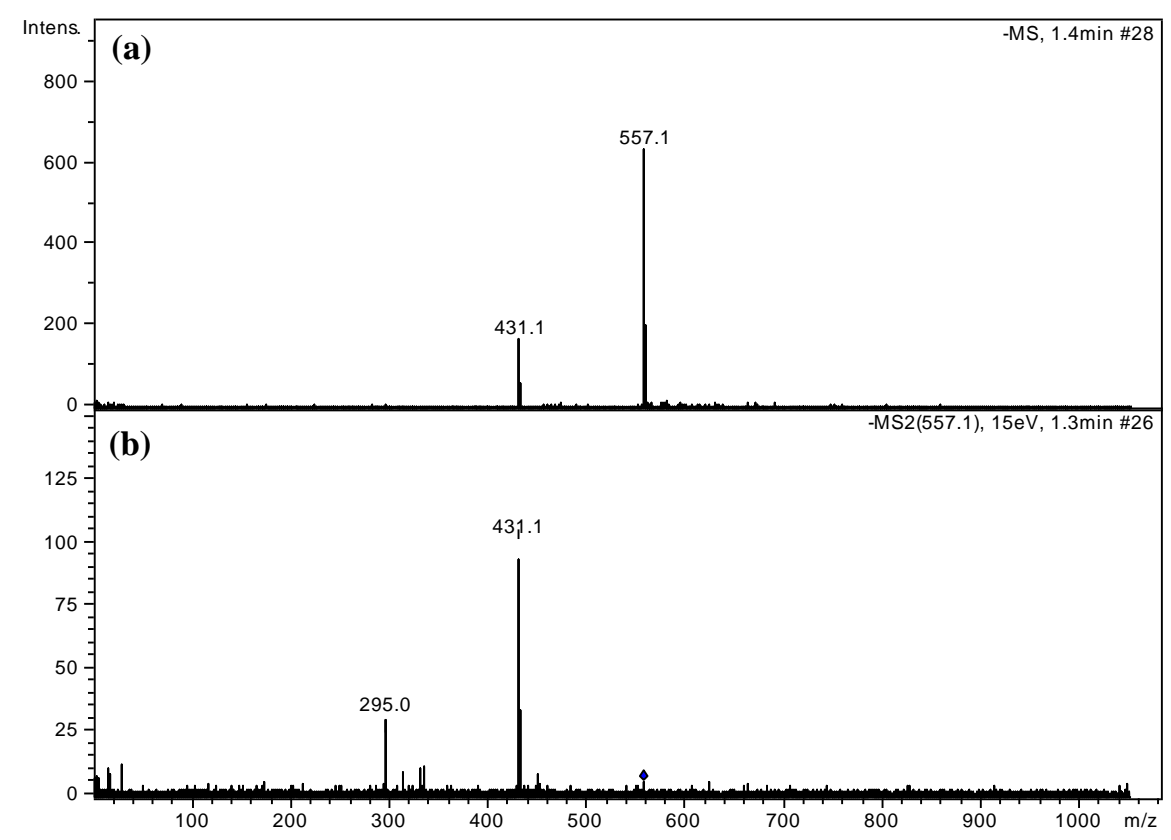

Figura 49 - Espectro de massas (a) de primeira e (b) segunda-ordem da substância 11, obtido em modo negativo com energia de colisão de 15\% para EM2 (ESI).

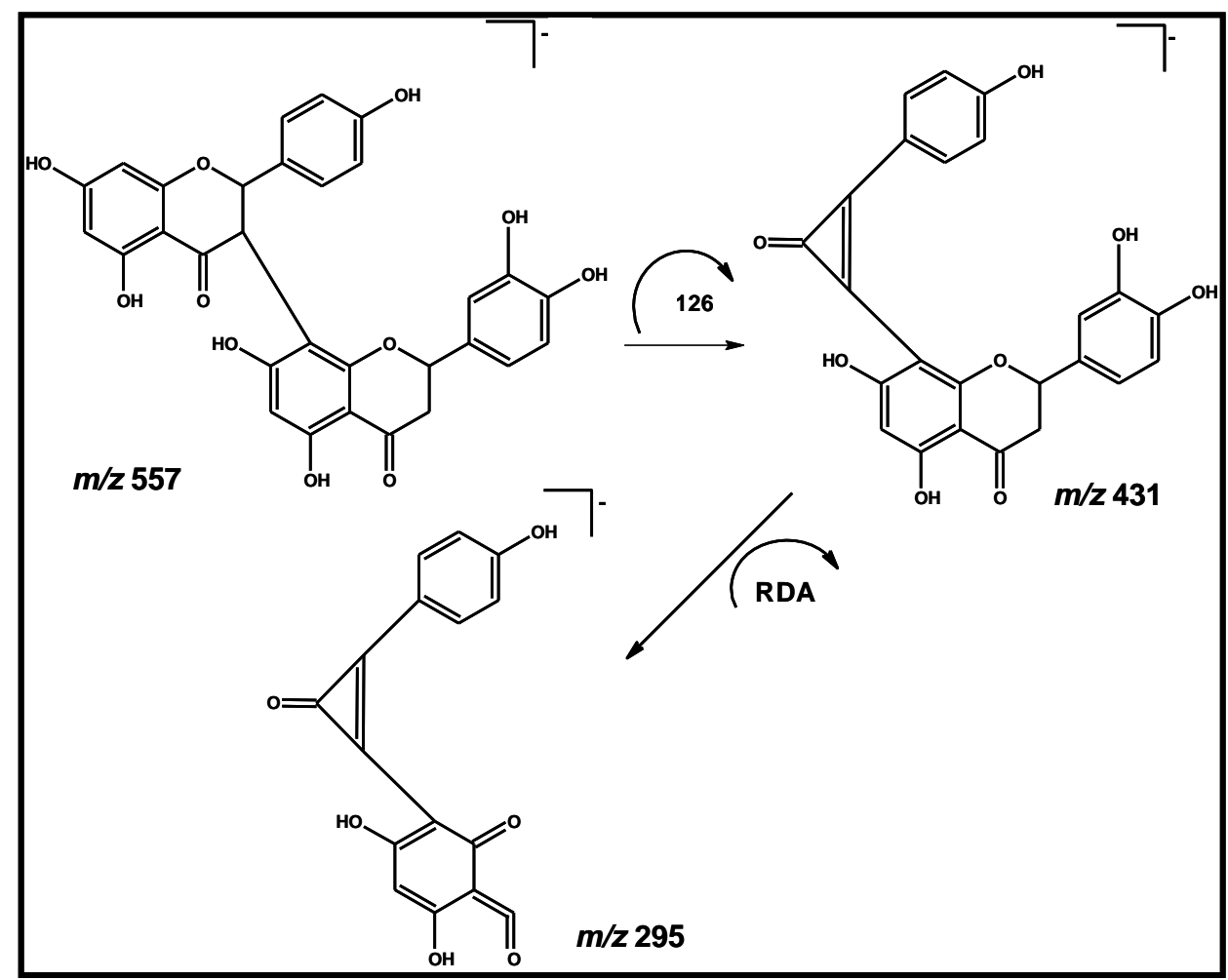

Figura 50 - Proposta de fragmentação da substância 11.

A substância 11 também apresentou duplicação dos sinais no espectro de RMN à temperatura ambiente, devido ao efeito de atropoisomerismo, evidenciando uma ligação tipo C3 $\rightarrow$ C8" " para o biflavonóide proposto (Anexos 97 a 99). 
Devido à complexidade dos espectros, principalmente nas regiões de atribuições aromáticas entre $\delta_{\mathrm{H}} 5,30$ a 7,12, realizou-se um experimento dinâmico de RMN de ${ }^{1} \mathrm{H}$ a $25^{\circ} \mathrm{C}, 45^{\circ} \mathrm{C}, 65^{\circ} \mathrm{C}$ e $90^{\circ} \mathrm{C}$. Observou-se, que em $45^{\circ} \mathrm{C}$ os sinais duplos coalesceram (pico único alargado), a $65^{\circ} \mathrm{C}$ começaram a desaparecer os sinais do confôrmero minoritário e por último a $90^{\circ} \mathrm{C}$, houve a predominância do confôrmero principal. O aquecimento acelerou a velocidade de interconversão, fazendo com que a barreira energética fosse superada mais facilmente e assim, favorecesse a formação exclusiva do confôrmero mais estável (Figura 51).

Tabela 9 - Dados de RMN de ${ }^{1} \mathrm{H}(500 \mathrm{MHz})$ e RMN de ${ }^{13} \mathrm{C}$ (125 MHz) da substância 11 (DMSO- $d_{6}$ ).

\begin{tabular}{|c|c|c|c|c|c|}
\hline \multirow[t]{2}{*}{ Posição } & \multicolumn{3}{|c|}{$\begin{array}{c}\delta_{\mathrm{H}}(\mathrm{ppm}) \\
\text { (multiplicidade; } J(\mathrm{~Hz}) \text { ) }\end{array}$} & \multirow{2}{*}{$\begin{array}{c}\delta_{\mathrm{C}}(\mathbf{p p m}) \\
\left(25^{\circ} \mathrm{C}\right)\end{array}$} & \multirow{2}{*}{$\begin{array}{c}g \mathrm{HMBC} \\
\left(25^{\circ} \mathrm{C}\right)\end{array}$} \\
\hline & $11 \mathrm{a}\left(25^{\circ} \mathrm{C}\right)$ & $11 \mathrm{~b}\left(25^{\circ} \mathrm{C}\right)$ & $11 \mathrm{a}\left(90^{\circ} \mathrm{C}\right)$ & & \\
\hline 2 & $5,71(d ; 12,0)$ & $5,44(m)$ & $5,70(d ; 12,0)$ & 81,4 & 129,0 \\
\hline 3 & $4,55(d ; 12,0)$ & $4,68(d ; 12,0)$ & $4,58(d ; 12,0)$ & 47,3 & 81,$4 ; 101,3 ; 160,7 ; 164,4 ; 196,6$ \\
\hline 4 & - & - & - & 196,6 & - \\
\hline 5 & - & - & - & 163,8 & - \\
\hline 6 & $5,90(s)$ & $5,90(s)$ & $5,90(s)$ & 96,1 & 95,$0 ; 101,2 ; 162,8$ \\
\hline 7 & - & - & - & 162,8 & 然 \\
\hline 8 & $5,90(s)$ & $5,90(s)$ & $5,90(s)$ & 95,0 & 96,$1 ; 101,2 ; 166,4$ \\
\hline 9 & - & - & - & 166,4 & - \\
\hline 10 & - & - & - & 101,2 & - \\
\hline 1 ' & - & - & - & 129,8 & - \\
\hline 2' 6 ' & $7,12(m)$ & $7,12(m)$ & $7,09(d ; 8,8)$ & 129,0 & 81,$4 ; 129,0 ; 157,7$ \\
\hline 3' 5 & $6,59-6,87(\mathrm{~m})$ & $6,59-6,87(\mathrm{~m})$ & $6,63(d ; 8,8)$ & 114,8 & * \\
\hline 4' & - & - & - & 157,7 & - \\
\hline 5-OH & $12,16(s)$ & $12,18(s)$ & $12,17(s)$ & - & 96,$1 ; 101,2 ; 163,8$ \\
\hline 2 & $5,44(m)$ & $5,30(d ; 12,0)$ & $5,35(d d ; 2,8$ e 12,8$)$ & 78,5 & 129,0 \\
\hline & $2,67(m)$ & $2,67(\mathrm{~m})$ & $2,64(d d ; 2,8$ e 17,2$)$ & & 78,$5 ; 196,1$ \\
\hline $3 "$ & $2,93(m)$ & $2,93(m)$ & $3,01(d d ; 12,8$ e 17,2$)$ & 43,2 & 78,$5 ; 196,1$ \\
\hline 4", & - & - & - & 196,1 & - \\
\hline $5 "$ & - & - & - & 162,0 & - \\
\hline 6" & $5,86(s)$ & $5,86(s)$ & & 95,0 & 101,$1 ; 101,3 ; 162,0$ \\
\hline 7 & - & - & - & 164,4 & - \\
\hline 8" & - & - & - & 101,3 & - \\
\hline 9 ", & - & - & - & 160,7 & - \\
\hline $10 "$ & - & - & - & 101,1 & - \\
\hline 1", & - & - & - & 129,0 & - \\
\hline 2"', & $6,59-6,87(\mathrm{~m})$ & $6,59-6,87(\mathrm{~m})$ & $6,84(d ; 1,6)$ & 113,5 & * \\
\hline 3", & - & - & - & 145,3 & - \\
\hline 4", & - & - & - & 145,7 & - \\
\hline $5, "$ & 6,59-6,87 (m) & 6,59-6,87 (m) & $6,72(d ; 8,8)$ & 115,3 & * \\
\hline 6", & $7,12(\mathrm{~m})$ & $7,12(\mathrm{~m})$ & $7,11(d d ; 1,6$ e 8,8$)$ & 117,5 & 129,0 \\
\hline $5 "-\mathrm{OH}$ & $12,13(s)$ & $12,05(s)$ & $12,09(s)$ & - & 95,$0 ; 101,1 ; 162,0$ \\
\hline
\end{tabular}

(11a) representa o confôrmero principal e a série (11b) o confôrmero minoritário.

* sinais sobrepostos

Com o desaparecimento das linhas espectrais duplicadas, os sinais espectrais foram atribuídos inequivocamente para a substância 11, de maneira consistente com esqueleto 
carbônico descrito acima. Os sinais de $\mathrm{RMN}{ }^{1} \mathrm{H}$ do confôrmero principal foram listados na Tabela 9, assim como dados do experimento de RMN ${ }^{13} \mathrm{C}$ (Anexos 100 a 104) e $g \mathrm{HMBC}$ (Anexos 116 a 125). Para o confôrmero minoritário, só foram descritos os sinais de RMN ${ }^{1} \mathrm{H}$, pois os sinais de $\mathrm{RMN}{ }^{13} \mathrm{C}$ foram de baixa intensidade.

$\mathrm{O}$ espectro de $\mathrm{RMN}{ }^{1} \mathrm{H}$ a $90^{\circ} \mathrm{C}$ mostrou dois singletos referentes a hidrogênios de hidroxilas quelatadas bastante desprotegidos em $\delta_{\mathrm{H}} 12,09$ e 12,17, capaz de estabelecer uma ligação intramolecular com o oxigênio carbonílico em C-4. O espectro mostrou ainda um sinal em $\delta_{\mathrm{H}} 7,09\left(2 \mathrm{H}, d, J=8,8 \mathrm{~Hz}, \mathrm{H}-2^{\prime} / 6^{\prime}\right)$ e um sinal em $\delta_{\mathrm{H}} 6,63(2 \mathrm{H}, d, J=8,8 \mathrm{~Hz}, \mathrm{H}-$ sinal 3'/5'), correspondendo à unidade I e $\delta_{\mathrm{H}} 7,11\left(1 \mathrm{H}, d d, J=8,8 \mathrm{~Hz}, \mathrm{H}-6\right.$ ', '), $\delta_{\mathrm{H}} 6,72(1 \mathrm{H}$, $d, J=8,8 \mathrm{~Hz}, \mathrm{H}-5^{\prime}$ ' ') e $\delta_{\mathrm{H}} 6,84(1 \mathrm{H}, d, J=1,6 \mathrm{~Hz}, \mathrm{H}-2$ ', '), correspondendo à unidade II.

Baseando-se nos espectros de $g$ COSY (Anexos 108 a 111), gHMQC (Anexos 112 a 115) e DEPT (Anexos 105 a 107), dois dubletos em $\delta_{H} 5,70$ e 4,58 com constante igual a $J=12,0 \mathrm{~Hz}$ foram atribuídos aos hidrogênios H-2 e H-3, respectivamente. Os sinais em $\delta_{\mathrm{H}}$ 2,64 $(d d, J=17,2$ e 2,8) e 3,01 ( $d d, J=17,2$ e 12,8) foram atribuídos ao carbono metilênico em $\delta_{C} 43,2$ (C-3'), evidenciando a presença de hidrogênios geminais no anel B da unidade II da flavanona.

A correlação a longa distância foi útil para designar a união inter-flavonoídica, tipo $3 \rightarrow 8$ ', através da correlação do sinal em $\delta_{\mathrm{H}} 4,58$ (H-3) e $\delta_{\mathrm{C}} 101,3$ (C-8'); 160,7 (C-9'”) e 164,4 (C-7'’). Também mostrou importantes correlações entre o sinal em $\delta_{\mathrm{H}} 4,58$ (H-3) com $\delta_{\mathrm{C}} 81,4$ (C-2) e 196,6 (C-4) e entre $\delta_{\mathrm{H}} 2,64$ e 3,01 e $\delta_{\mathrm{C}} 78,5$ (C-2'”) e 196,1 (C-4'”), confirmando a proposta do esqueleto flavanoídico.

A substância 11 apresentou $[\alpha]_{D}^{T}=+7,8\left(\mathrm{c}=1,0 \mathrm{mg} \cdot \mathrm{mL}^{-1}\right)$ em MeOH.

A partir dos experimentos espectrométricos, analisados em conjunto com os dados da literatura (COMPAGNONE, et al., 2008; KONOSHIMA et al., 1970), pode-se inferir que a substância 11 é o biflavonóide GB2a, uma biflavanona isolada dos frutos de $G$. xanthochymus por Konoshima et al. em 1970. 


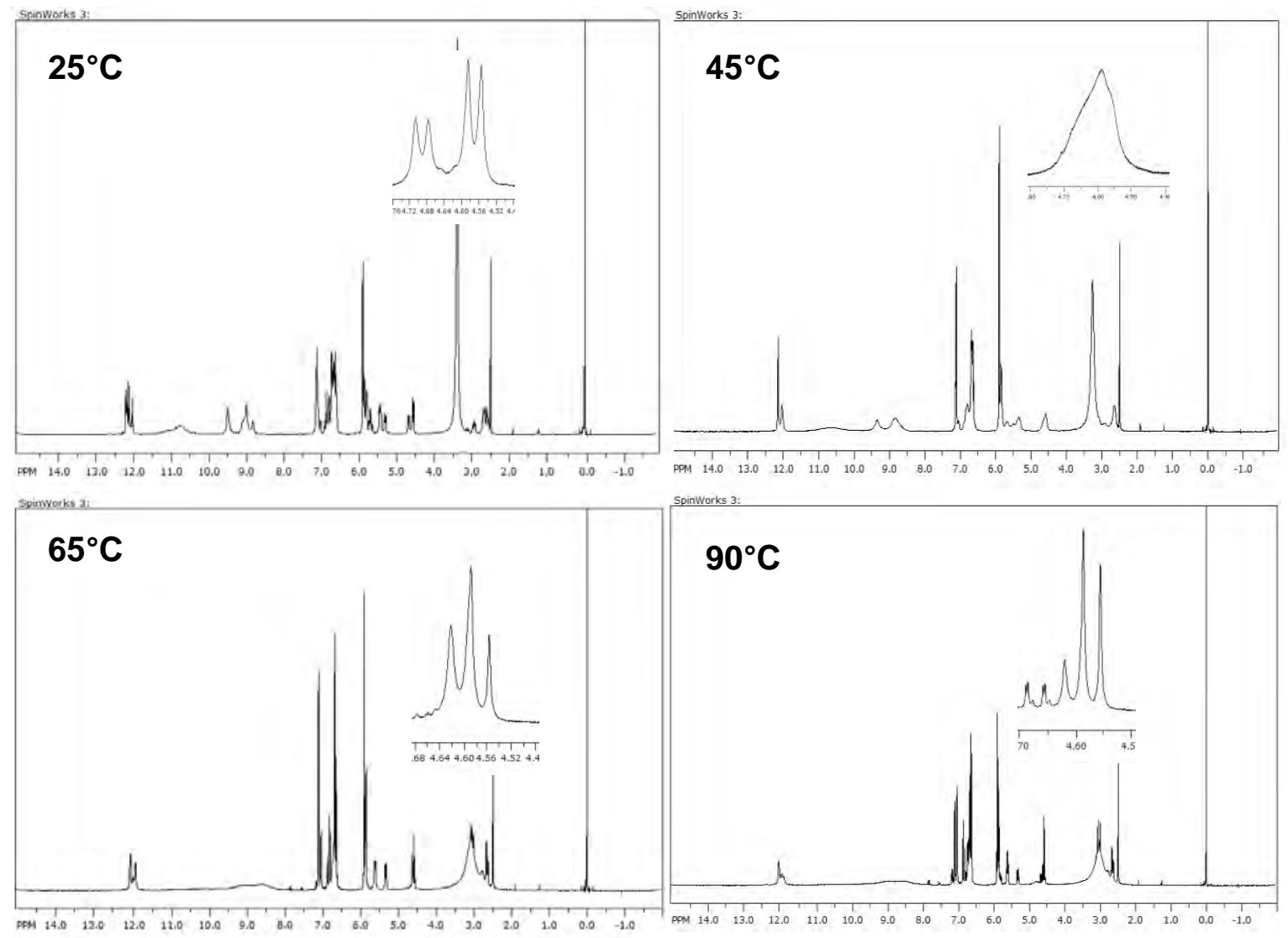

Figura 51 - Experimento de $\mathrm{RMN}{ }^{1} \mathrm{H}$ com temperatura variável da substância 11.

\subsubsection{Caracterização espectrométrica da substância 12}

A substância 12 foi isolada da subfração AcOEt-SIL-4, conforme procedimento experimental em $\mathbf{5 . 8}$.

A substância 12 obtida como cristais amarelos apresentou fórmula molecular de $\mathrm{C}_{30} \mathrm{H}_{20} \mathrm{O}_{10}$, obtida pelo espectro de massas no modo negativo (ESI), no qual apresentou íon molecular em $m / z 539$ [M-H] $]^{-}$e um único fragmento em $m / z 413[\mathrm{M}-\mathrm{H}]^{-}$, justificado pela perda do floroglucinol (126 u), como mostrado nas Figura 54 e Figura 55.

O espectro de absorção no UV apresentou bandas em $289 \mathrm{~nm}$ e $330 \mathrm{~nm}$, características da subclasse flavona/flavanona. Pode-se notar também, um deslocamento hipsocrômico da banda I de 12 (330 nm) em relação à banda I de 8 (348 nm), sugerindo menor grau de oxigenação em 12 nos anéis B ou C (Figura 52).

O espectro de absorção na região do IV (Figura 53) mostrou bandas correspondentes à deformação axial da ligação $\mathrm{O}-\mathrm{H}\left(v_{\mathrm{O}-\mathrm{H}}\right)$ em 3733,3592 e $3621 \mathrm{~cm}^{-1}$. O espectro também exibiu uma banda em $2927 \mathrm{~cm}^{-1}$ referente à deformação axial C-H de aromáticos $\left(v_{\mathrm{C}-\mathrm{H}}\right)$, uma banda em $1645 \mathrm{~cm}^{-1}$ referente à carbonila conjugada da molécula $\left(v_{\mathrm{C}-\mathrm{O}}\right)$, bandas em 
1509 e $1452 \mathrm{~cm}^{-1}$ atribuídas à deformação axial de C-C ( $\left.v_{\mathrm{C}-\mathrm{C}}\right)$ do anel aromático, absorção em $1170 \mathrm{~cm}^{-1}$ associada a deformações axiais C-O ( $\left.v_{\mathrm{C}-\mathrm{O}}\right)$ e ainda, uma banda em $816 \mathrm{~cm}^{-1}$ relacionadas a deformações angulares fora do plano das ligações $\mathrm{C}-\mathrm{H}\left(\delta_{\mathrm{C}-\mathrm{H}}\right)$ do anel (SILVERSTEIN; WEBSTER; KIEMLE, 1994).

O espectro de RMN ${ }^{1} \mathrm{H}$ de 12 (Anexos 126 e 127) apresentou igual complexidade de 8 e 11, fenômeno caracterizado pela união interflavonoídica tipo C3 $\rightarrow$ C-8 ", (atropoisomerismo). No entanto, a substância 12 apresentou padrão de substituição parahidroxilado em ambos os anéis $\mathrm{B}$, com um sinal em $\delta_{\mathrm{H}} 7,11\left(2 \mathrm{H}, d, J=8,5 \mathrm{~Hz}, \mathrm{H}-2^{\prime} / 6^{\prime}\right)$ e um sinal em $\delta_{\mathrm{H}} 6,36\left(2 \mathrm{H}, d, J=8,5 \mathrm{~Hz}, \mathrm{H}-3^{\prime} / 5^{\prime}\right)$, correspondendo à unidade I e sinais em $\delta_{\mathrm{H}}$ 7,92 (2H, $d, J=8,5 \mathrm{~Hz}, \mathrm{H}-2$ ','/6',') e $\delta_{\mathrm{H}} 6,94(2 \mathrm{H}, d, J=8,5 \mathrm{~Hz}, \mathrm{H}-3$ ','/5','), associados à unidade II. Mostrou ainda, dois dubletos em $\delta_{\mathrm{H}}$ 5,67 e 4,97 com constante de acoplamento de $J=12,0 \mathrm{~Hz}$, atribuídos aos hidrogênios H-2 e H-3, evidenciando a subclasse das flavanonas.

$\mathrm{O}$ espectro de $\mathrm{RMN}{ }^{13} \mathrm{C}$ (Anexos 128 a 131) mostrou sinais para dois carbonos com deslocamento químico característico de carbonilas de flavona $\left(\delta_{\mathrm{c}} 181,6\right)$ e flavanona $\left(\delta_{\mathrm{c}}\right.$ 196,3), como também apresentou sinais em $\delta_{c} 47,3$ e 80,8, confirmando o esqueleto flavanoídico proposto para a unidade I.

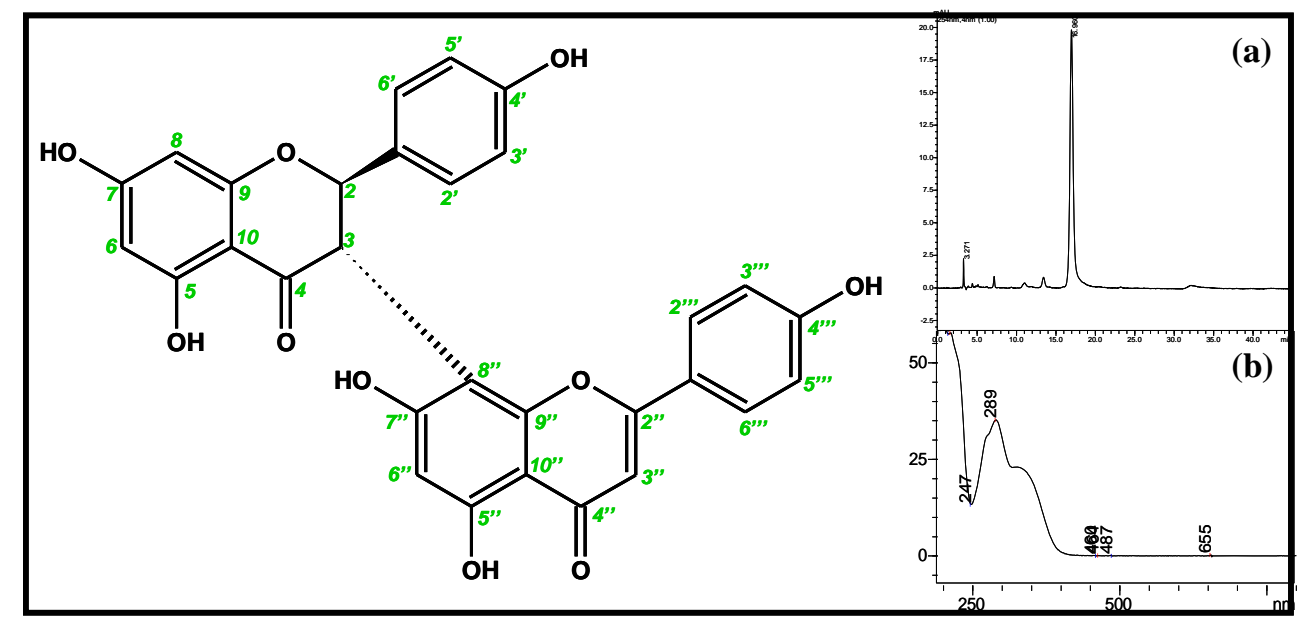

Figura 52 - Estrutura da substância 12. (a) Cromatograma analítico e (b) espectro de absorção da substância 12 obtido via CLAE-UV-DAD no modo isocrático 1:1 $\left(\mathrm{MeOH}: \mathrm{H}_{2} \mathrm{O}\right)$ e suporte cromatográfico: ODS (Phenomenex, 25,0 cm x 4,6 mm x 5 $\mu \mathrm{m}$ ). 


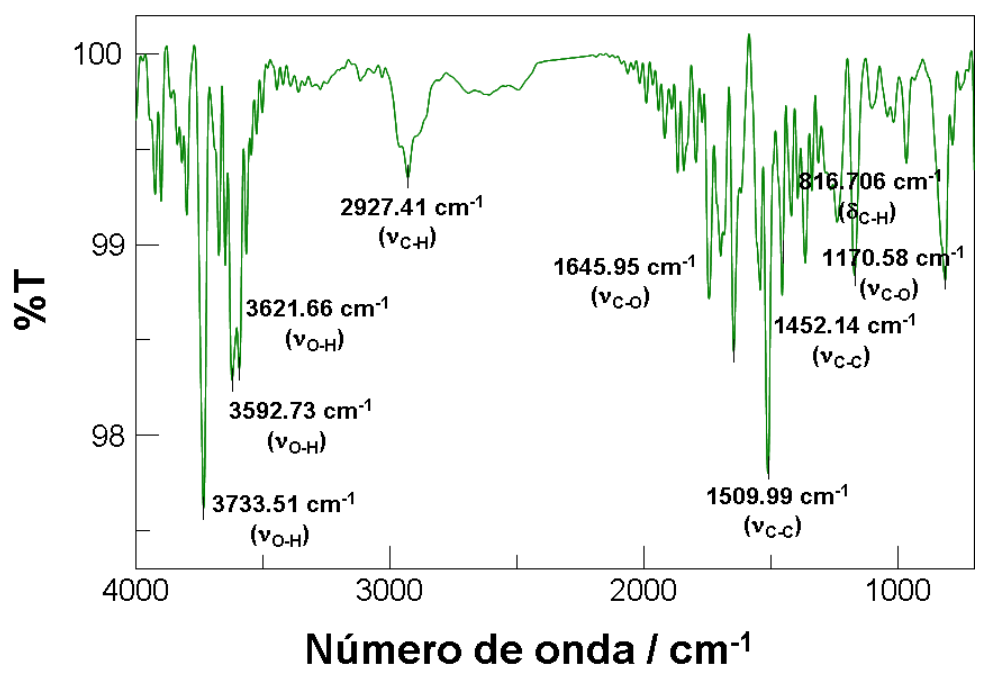

Figura 53 - Espectro vibracional na região do IV da substância 12.

O experimento de $g$ HMBC (Anexos 141 a 146) foi útil para estabelecer a posição da ligação dimérica, através da correlação entre H-3 $\left(\delta_{\mathrm{H}} 4,97\right)$ com C- ${ }^{\prime \prime}\left(\delta_{\mathrm{c}} 100,7\right)$ comprovando que a união das unidades ocorre tipo $3 \rightarrow 8$ ". Também mostrou interação entre $\delta_{\mathrm{H}} 13,01$ com $\delta_{\mathrm{c}} 95,1 ; 101,5$ e 163,6 e $\delta_{\mathrm{H}} 12,32$ com $\delta_{\mathrm{c}} 98,6 ; 103,0$ e 160,5 , sugerindo a presença de um núcleo flavonoídico na forma dimérica, oxigenado nas posições C-5 e C5" em ambas as unidades (Tabela 10).

A substância 12 apresentou $[\alpha]_{D}^{T}=+157,2\left(\mathrm{c}=1,0 \mathrm{mg} \cdot \mathrm{mL}^{-1}\right)$ em MeOH. A análise da curva de dicroísmo circular (Figura 56) mostrou semelhante efeito Cotton que 8 (positivo para as transições $\mathrm{n} \rightarrow \pi^{*}$ e $\pi \rightarrow \pi^{*}$ em 345 e $285 \mathrm{~nm}$, respectivamente), chegando a conclusão de uma configuração absoluta de $2 R, 3 S$ para 12.

Diante de todos esses dados e comparação com os existentes na literatura (HERBIN et al., 2007) pode-se identificar a substância 12 como $(2 R, 3 S)$-volkensiflavona, isolada de várias espécies de Garcinia (HERBIN et al., 1970; Konoshima et al., 1970; PELTER et al., 1971; VERDI et al., 2004). 


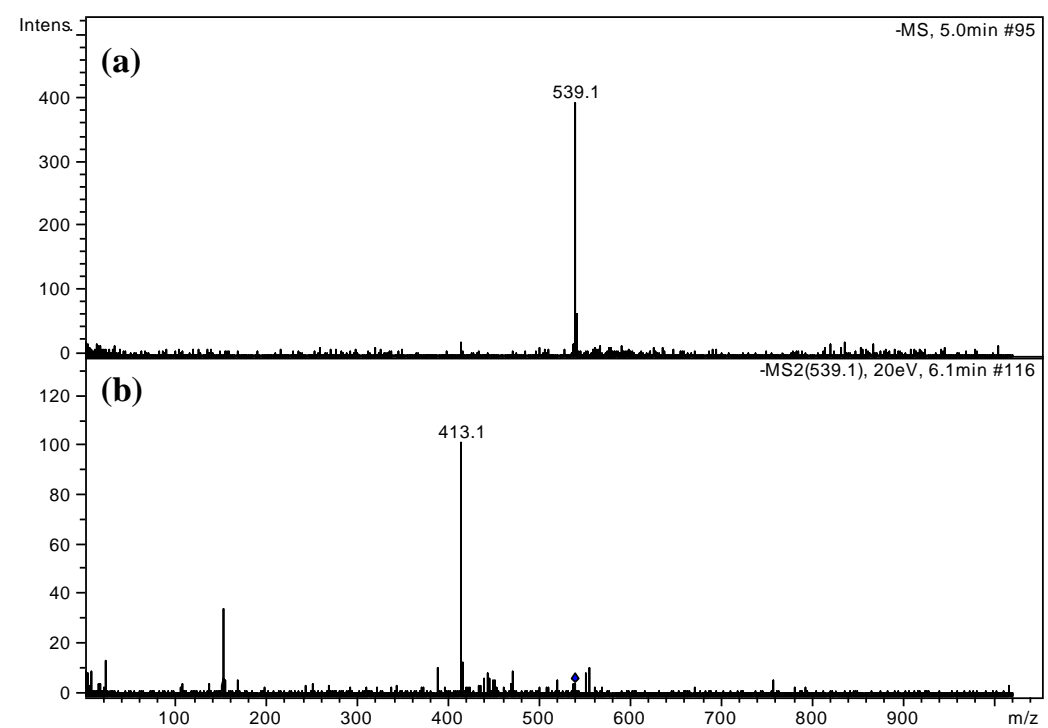

Figura 54 - Espectro de massas (a) de primeira e (b) segunda-ordem da substância 12, obtido em modo negativo com energia de colisão de 10\% para EM2 (ESI).

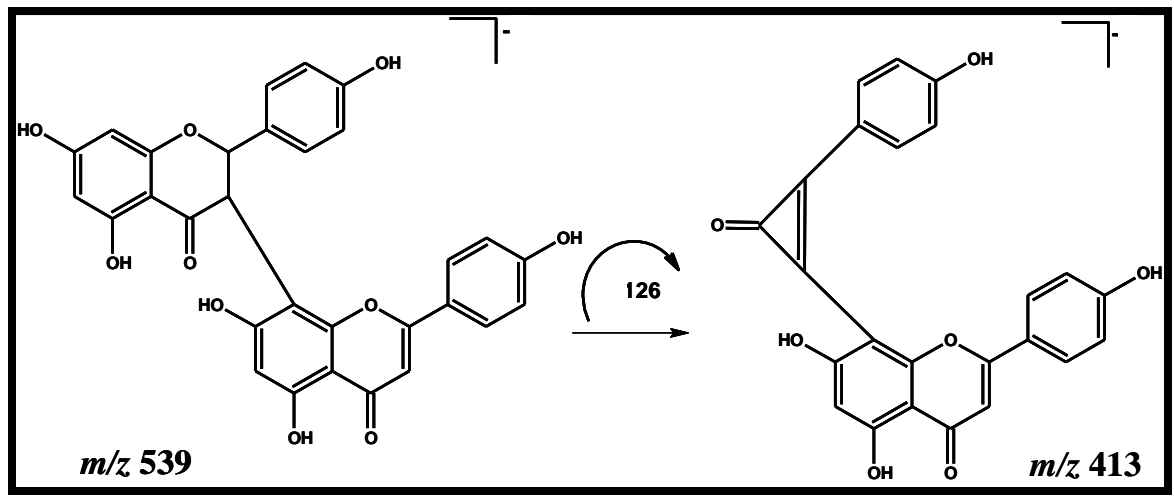

Figura 55 - Proposta de fragmentação da substância 12.

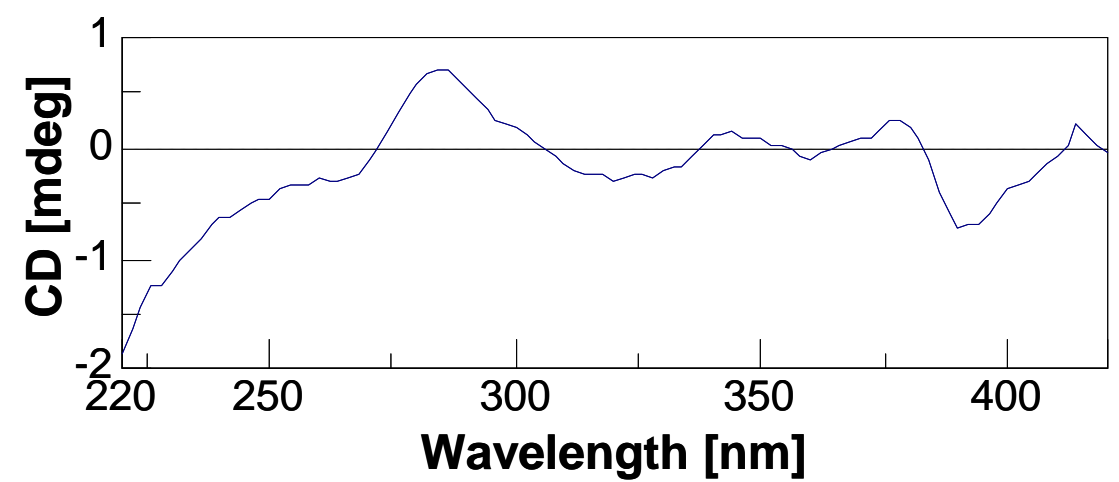

Figura 56 - Curva de dicroísmo circular (DC) da substância 12. 
Tabela 10 - Dados de RMN de ${ }^{1} \mathrm{H}(500 \mathrm{MHz})$ e RMN de ${ }^{13} \mathrm{C}\left(125 \mathrm{MHz}\right.$ ) da substância 12 (DMSO- $d_{6}$ ).

\begin{tabular}{|c|c|c|c|c|c|}
\hline Posição & \multicolumn{2}{|c|}{$\begin{array}{c}\delta_{\mathrm{H}}(\mathrm{ppm}) \\
\text { (multiplicidade; } J(\mathrm{~Hz}))\end{array}$} & $\delta_{\mathrm{C}}(\mathbf{p p m})$ & gНМBC & $g \mathrm{COSY}$ \\
\hline 2 & $5,67(d ; 12,0)$ & $5,55(d ; 12,0)$ & 80,8 & 128,4 & $\mathrm{H}-3$ \\
\hline 3 & $4,97(d ; 12,0)$ & $4,99(d ; 12,0)$ & 47,3 & 80,$8 ; 100,7 ; 196,3$ & $\mathrm{H}-2$ \\
\hline 4 & - & - & 196,3 & - & - \\
\hline 5 & - & - & 163,6 & - & - \\
\hline 6 & $5,96(s)$ & $5,96(s)$ & 95,1 & 101,$5 ; 166,4$ & - \\
\hline 7 & - & - & 166,4 & - & - \\
\hline 8 & $5,96(s)$ & $5,96(s)$ & 96,0 & 163,7 & - \\
\hline 9 & - & - & 163,7 & - & - \\
\hline 10 & - & - & 101,5 & - & - \\
\hline 1 ' & - & - & 128,4 & - & - \\
\hline 2' 6' & $7,11(d ; 8,5)$ & $7,10(d ; 8,5)$ & 128,7 & 80,$8 ; 128,7 ; 157,2$ & H-3' \\
\hline 3' 5' & $6,36(d ; 8,5)$ & $6,60(d ; 8,5)$ & 114,3 & 114,$3 ; 128,4$ & H-2' \\
\hline 4' & - & - & 157,2 & - & - \\
\hline 5-OH & $13,01(s)$ & $12,97(s)$ & - & 95,$1 ; 101,5 ; 163,6$ & - \\
\hline $2 "$, & - & - & 163,9 & - & - \\
\hline $3 "$, & $6,64(s)$ & $6,77(s)$ & 102,2 & 103,$0 ; 121,1 ; 163,9$ & - \\
\hline $4 "$, & - & - & 181,6 & - & - \\
\hline $5^{\prime \prime}$ & - & - & 160,5 & - & - \\
\hline 6"' & $6,22(s)$ & $6,05(s)$ & 98,6 & 100,$7 ; 103,0 ; 160,9$ & - \\
\hline $7^{\prime \prime}$ & - & - & 160,9 & - & - \\
\hline 8', & - & - & 100,7 & - & - \\
\hline 9"' & - & - & 157,5 & - & - \\
\hline $10 "$ & - & - & 103,0 & - & - \\
\hline $1 " \%$ & - & - & 121,1 & - & - \\
\hline 2"" 6"" & $7,92(d ; 8,5)$ & $7,61(d ; 8,5)$ & 128,8 & 128,$8 ; 161,1 ; 163,9$ & H-3,', \\
\hline 3"' 5"' & $6,94(d ; 8,5)$ & $6,61(d ; 8,5)$ & 115,9 & 121,1 & H-2,", \\
\hline 4"' & - & - & 161,1 & - & - \\
\hline 5"-OH & $12,32(s)$ & $12,28(s)$ & - & 98,$6 ; 103,0 ; 160,5$ & - \\
\hline
\end{tabular}

(12a) representa o confôrmero principal e a série (12b) o confôrmero minoritário.

\subsubsection{Caracterização espectrométrica da substância 13}

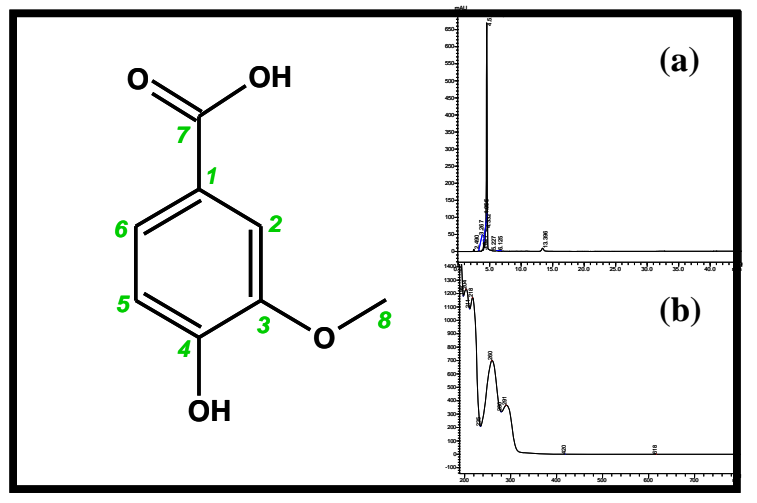

Figura 57 - Estrutura da substância 13. (a) Cromatograma analítico e (b) espectro de absorção da substância 13 obtido via CLAE-UV-DAD no modo isocrático 1:1 $\left(\mathrm{MeOH}: \mathrm{H}_{2} \mathrm{O}\right)$ e suporte

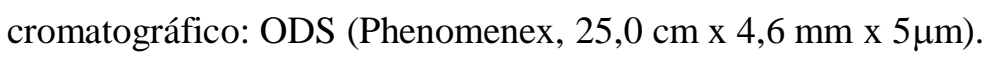


A substância 13 foi isolada da subfração AcOEt-SIL-5, conforme procedimento experimental em $\mathbf{5 . 8}$.

A substância 13 apresentou bandas em 260 e 291 nm (Figura 57), evidenciando a presença de derivados do ácido protocatecuico (AO et al., 2009).

Os grupos funcionais presentes na estrutura da substância $\mathbf{1 3}$ foram caracterizados pelas freqüências das bandas observadas no espectro de absorção na região do IV (Figura 58). O espectro mostrou uma banda em $3476 \mathrm{~cm}^{-1}$, característica da deformação axial da ligação $\mathrm{O}-\mathrm{H}\left(v_{\mathrm{O}-\mathrm{H}}\right)$, uma banda em $1666 \mathrm{~cm}^{-1}$ referente à carbonila conjugada da molécula anel $\left(v_{\mathrm{C}-\mathrm{O}}\right)$, bandas em 1589 e $1501 \mathrm{~cm}^{-1}$ atribuídas à deformação axial de $\mathrm{C}-\mathrm{C}\left(v_{\mathrm{C}-\mathrm{C}}\right)$ do anel aromático, absorção em 1277 e $1202 \mathrm{~cm}^{-1}$ associada a deformações axiais C-O ( $v_{\mathrm{C}-\mathrm{O}}$ ) e ainda uma banda em $821 \mathrm{~cm}^{-1}$ relacionadas a deformações angulares fora do plano das ligações C-H $\left(\delta_{\mathrm{C}-\mathrm{H}}\right)$ do anel (SILVERSTEIN; WEBSTER; KIEMLE, 1994).

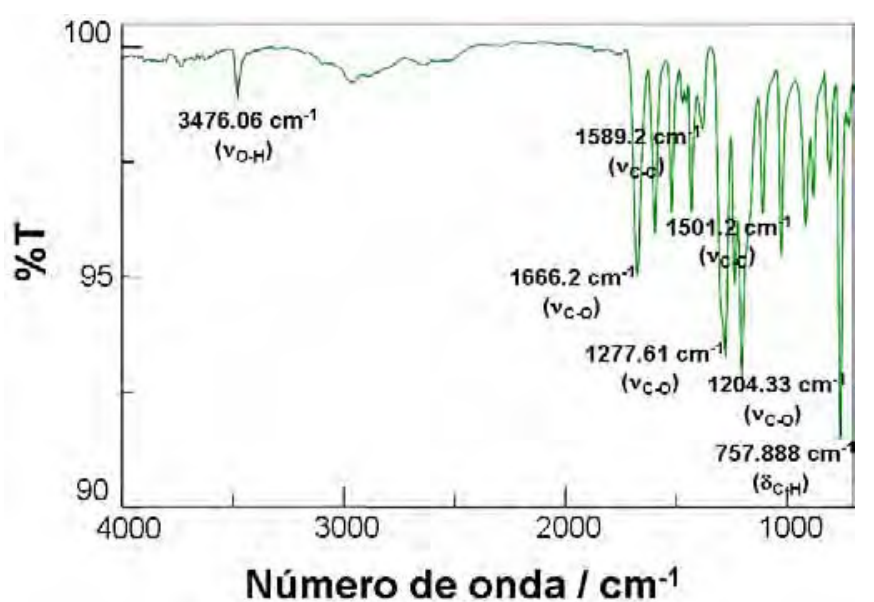

Figura 58 - Espectro vibracional na região do IV da substância 13.

O espectro de massas de 13 (Figura 59 e Figura 60) obtido no modo negativo (ESI) exibiu fragmentos de $m / z \quad 167$ [M-H, pico íon molecular]', m/z 152 [M-H-15, desmetilação] ${ }^{-}, 123$ [M-H-44, descarboxilação] e m/z 108 [M-H-15-44]'. A partir da composição elementar $\mathrm{C}_{8} \mathrm{H}_{8} \mathrm{O}_{4}$, fornecida pelo pico íon molecular, foram sugeridos três análogos metilados do ácido protocatecuico: um éster (a) e dois éteres metílicos, sendo um alquilado na posição 3 (b) e outro na posição 4 (c). 


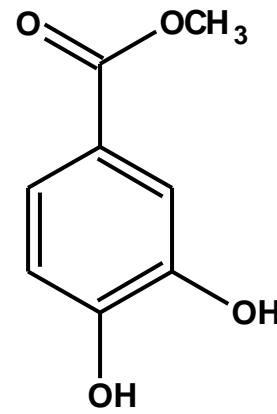

(a)

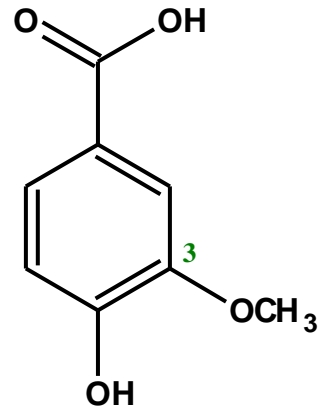

(b)

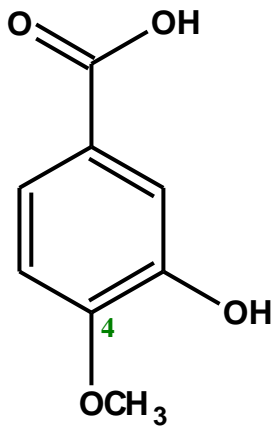

(c)

Para definir a estrutura correta da molécula foram analisados, juntamente com os espectros de $\mathrm{RMN}$ de ${ }^{1} \mathrm{He}$ e ${ }^{13} \mathrm{C}$, dados de interação à longa distância.

O espectro de ${ }^{1} \mathrm{H}$ (Anexos 147 e 148) forneceu um dubleto de $J=8,5 \mathrm{~Hz}$ em $\delta_{\mathrm{H}} 6,81$ correspondente a H-5 $(1 \mathrm{H})$, um multipleto em $\delta_{\mathrm{H}}$ 7,42 $(2 \mathrm{H})$, correspondente a H-2 e H-6 e um singleto em $\delta_{\mathrm{H}} 3,79(3 \mathrm{H})$ relacionados a hidrogênios metoxílicos. Já o espectro de gHMQC (Anexos 151 e 152) mostrou a presença de um sinal em $\delta_{\mathrm{C}} 168,0$ (típico de carbonila), dois sinais em $\delta_{\mathrm{C}}$ 147,2 e 151,0, característicos de carbonos aromáticos oxigenados e um sinal em $\delta_{\mathrm{C}} 55,6$, confirmando a presença da metoxila no esqueleto da molécula.

O espectro de $g \mathrm{HMBC}$ (Anexos 153 e 154) exibiu uma correlação entre o sinal em $\delta_{\mathrm{H}}$ 7,42 e o sinal em $\delta_{\mathrm{C}} 168,0$, confirmando a posição da carbonila em C-1. Também mostrou a correlação de H-2 com os sinais em $\delta_{C} 123,4 ; 147,2$; 151,0 e 168,0, de H-6 com os sinais $\delta_{C} 112,8 ; 151,0 ; 168,0$ e de $\mathrm{H}-5$ com os sinais $\delta_{C} 123,4 ; 147,2 ; 151,0$ (Tabela 11).

$\mathrm{O}$ espectro de $g \mathrm{HMBC}$ mostrou ainda, o acoplamento entre os hidrogênios metílicos $\left(\delta_{\mathrm{H}} 3,79\right)$ com o carbono aromático C-3 $\left(\delta_{\mathrm{C}} 147,2\right)$, evidenciando a presença de um grupamento éter alquil-aril e justificando a proposta (b). Além disso, no espectro de massas não foram observados picos em $\mathrm{m} / z 149$ e $\mathrm{m} / z$ 135, característicos de moléculas que possuem grupos contendo hidrogênio na posição orto em relação ao grupo carboxílico. Este "efeito orto" ocorre, pois tais substituintes podem formar um estado de transição de seis átomos que facilita a eliminação de moléculas neutras como $\mathrm{H}_{2} \mathrm{O}(18 \mathrm{u})$ ou $\mathrm{CH}_{3} \mathrm{OH}$ $(32 \mathrm{u})$.

Baseando-se nas informações espectrais e comparando-as com os dados da literatura (SCOTT, 1972; SOUZA FILHO et al., 2006) concluiu-se que a substância 13 é descrita pela proposta (b) e identificada como ácido vanílico. 


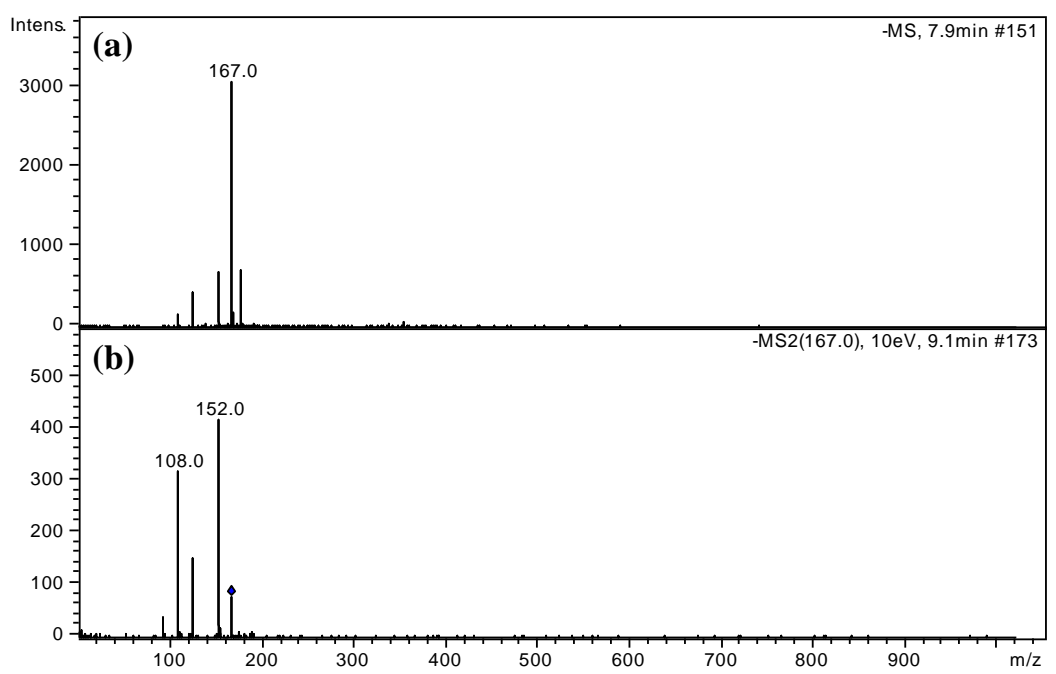

Figura 59 - Espectro de massas (a) de primeira e (b) segunda-ordem da substância 13, obtido em modo negativo com energia de colisão de 10\% para EM2 (ESI).

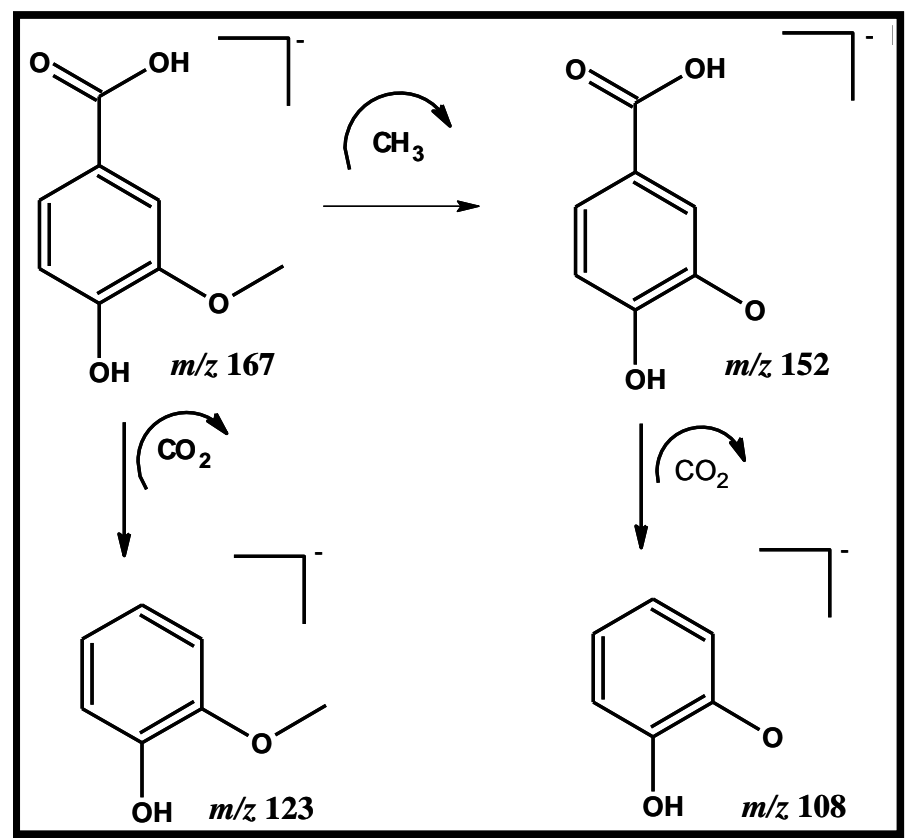

Figura 60 - Proposta de fragmentação da substância 13.

Tabela 11 - Dados de RMN de ${ }^{1} \mathrm{H}(500 \mathrm{MHz})$ e RMN de ${ }^{13} \mathrm{C}(125 \mathrm{MHz})$ da substância 13 (DMSO- $\left.d_{6}\right)$.

\begin{tabular}{ccccc}
\hline Posição & $\boldsymbol{\delta}_{\mathbf{H}}(\mathbf{p p m})(\mathbf{m u l t i p l i c i d a d e} ;$ & $\boldsymbol{\delta}_{\mathbf{C}}(\mathbf{p p m})$ & $\boldsymbol{g H M B C}$ & $\boldsymbol{g} \mathbf{C O S Y}$ \\
\hline $\mathbf{1}$ & $\boldsymbol{J}(\mathbf{H z}))$ & $*$ & - & - \\
$\mathbf{2}$ & - & 112,8 & 123,$4 ; 147,2 ; 151,0 ; 168,0$ & $*$ \\
$\mathbf{3}$ & $7,42(m)$ & 147,2 & - & - \\
$\mathbf{4}$ & - & 151,0 & - & - \\
$\mathbf{5}$ & - & 115,0 & 123,$4 ; 147,2 ; 151,0$ & $\mathrm{H}-6$ \\
$\mathbf{6}$ & $6,81(d ; 8,5)$ & 123,4 & 112,$8 ; 151,0 ; 168,0$ & $\mathrm{H}-5$ \\
$\mathbf{7}$ & $7,42(m)$ & 168,0 & - & - \\
$\mathbf{8}$ & - & 55,6 & 147,2 & - \\
\hline
\end{tabular}

*valores não observados

Os valores de RMN de ${ }^{13} \mathrm{C}$ foram atribuídos através das interações observadas nos experimentos $g \mathrm{HMQC}$ e $g \mathrm{HMBC}$. 


\subsubsection{Caracterização espectrométrica da substância 14}

A substância 14 foi isolada da subfração AcOEt-SIL-5, conforme procedimento experimental em $\mathbf{5 . 8}$.

A substância $\mathbf{1 4}$ foi isolada como cristais amarelos e apresentou fórmula molecular $\mathrm{C}_{30} \mathrm{H}_{22} \mathrm{O}_{12}$, confirmada pela espectro de massas obtido no modo negativo (ESI), através do íon molecular $m / z, 573$ [M-H] $]^{-}$e pelos fragmentos em $m / z 447$ [M-H-126] $]^{-} m / z 429$ [M-H126- $\left.\mathrm{H}_{2} \mathrm{O}\right]^{-}$e $m / z \quad 419$ [M-H-126-CO] (Figura 63 e Figura 64). Apresentou perfil espectral similar ao de 11 na região do IV e, em relação às bandas no UV apresentou características da subclasse das flavanonas (Figura 61). Salienta-se, o deslocamento batocrômico da banda II em relação a 11, sugerindo hidroxila adicional em 14, consistente também com a redução no tempo de retenção observado: $t_{r}=6,1 \min$ para 14 e $t_{r}=9,8$ min para 11.

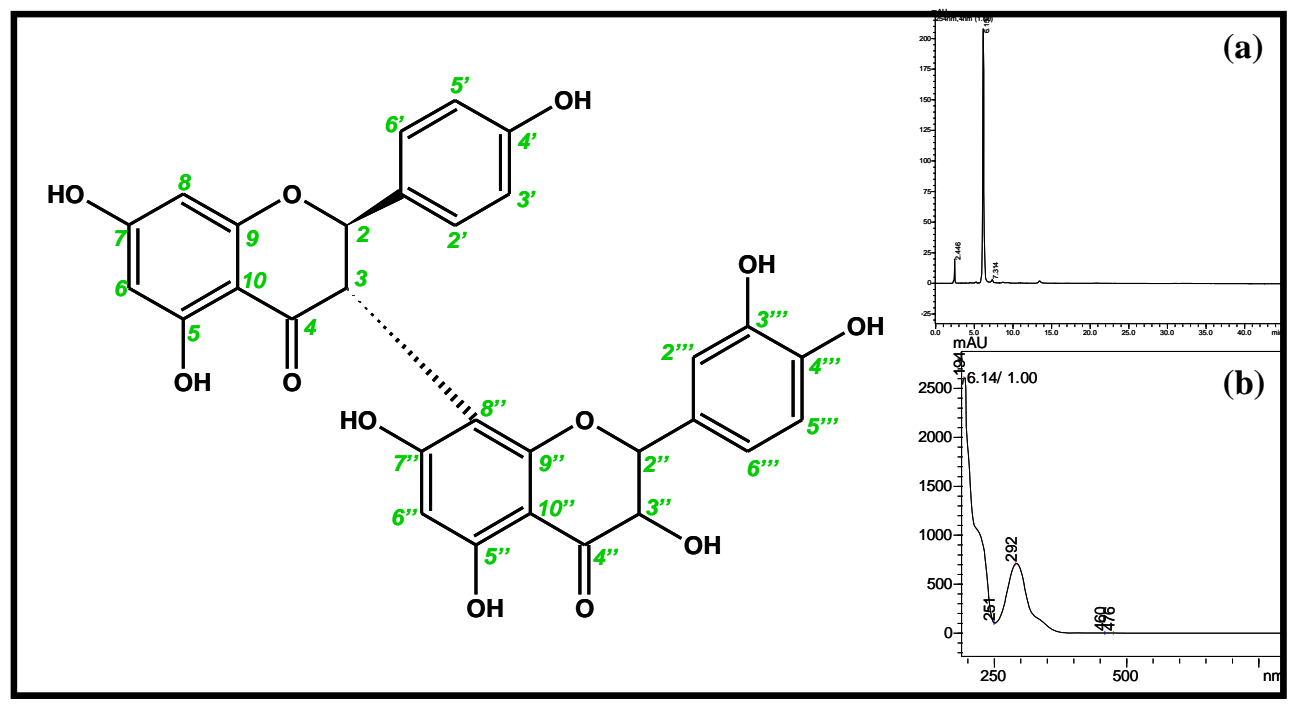

Figura 61 - Estrutura da substância 14. (a) Cromatograma analítico e (b) espectro de absorção da substância 14 obtido via CLAE-UV-DAD no modo isocrático 1:1 $\left(\mathrm{MeOH}: \mathrm{H}_{2} \mathrm{O}\right)$ e suporte cromatográfico: ODS (Phenomenex, 25,0 $\mathrm{cm}$ x 4,6 mm x 5 $\mu \mathrm{m}$ ).

De uma maneira geral, os espectros de RMN das substâncias 11 e 14 apresentaram-se muito semelhantes. Basicamente, a diferença refere-se aos sinais em $\delta_{\mathrm{H}} 4,13(\mathrm{~J}=12,0 \mathrm{~Hz}) \mathrm{e}$ 4,92 ( $J=12,0 \mathrm{~Hz}$ ), atribuídos aos hidrogênios H-3', e H-2', respectivamente (Anexos 155 a 157), o que elimina a possibilidade de hidrogênios geminais no anel $\mathrm{C}$, como ocorre em 11. Este fato também foi confirmado pelo espectro de RMN de ${ }^{13} \mathrm{C}$ (Anexos 158 a 161), que exibiu sinais em $\delta_{\mathrm{C}} 82,7$ (C-2') e 71,9 (C-3'), típicos da subclasse dos diidroflavonois (Tabela 12). 
A substância 14 apresentou $[\alpha]_{D}^{T}=+187,6\left(\mathrm{c}=1,0 \mathrm{mg} \cdot \mathrm{mL}^{-1}\right) \mathrm{em} \mathrm{MeOH}$.

A partir dos dados espectrométricos, incluindo a análise das correlações nos mapas gHMQC (Anexos 165 a 167) e $g$ HMBC (Anexos 168 a 172), associados à comparação com dados da literatura pode-se identificar 14 como o biflavonóide GB2, já isolado dos caules de Garcinia xanthochymus (KONOSHIMA et al., 1970).

GB2 apresentou efeito Cotton positivo para as transições $n \rightarrow \pi^{*}$ em $345 \mathrm{~nm}$ e efeito Cotton negativo para as transições $\pi \rightarrow \pi^{*}$ em $285 \mathrm{~nm}$ (Figura 62). Há poucos relatos sobre a estereoquímica de biflavonóides do tipo GB, ora porque a magnitude do sinal da curva de

Tabela 12 - Dados de RMN de ${ }^{1} \mathrm{H}(500 \mathrm{MHz})$ e RMN de ${ }^{13} \mathrm{C}$ (125 MHz) da substância 14 (DMSO- $\left.d_{6}\right)$.

\begin{tabular}{|c|c|c|c|c|c|}
\hline \multirow[t]{2}{*}{ Posição } & \multicolumn{3}{|c|}{$\begin{array}{c}\delta_{\mathrm{H}}(\mathrm{ppm}) \\
\text { (multiplicidade; } J(\mathrm{~Hz}))\end{array}$} & \multirow{2}{*}{$\begin{array}{c}\delta_{\mathrm{C}}(\mathbf{p p m}) \\
\left(25^{\circ} \mathrm{C}\right)\end{array}$} & \multirow[t]{2}{*}{ gHMBC } \\
\hline & $16 \mathbf{a}\left(25^{\circ} \mathrm{C}\right)$ & $16 \mathrm{~b}\left(25^{\circ} \mathrm{C}\right)$ & $16 \mathbf{a}\left(90^{\circ} \mathrm{C}\right)$ & & \\
\hline 2 & $5,66(m)$ & $5,35(d ; 12,0)$ & $5,62(d ; 12,0)$ & 81,2 & 129,4 \\
\hline 3 & $4,45(d ; 12)$ & $4,65(d ; 12,0)$ & $4,53(d ; 12,0)$ & 47,2 & $\begin{array}{c}81,2 ; 101,0 ; 160,1 ; 164,4 ; \\
196,5\end{array}$ \\
\hline 4 & - & - & - & 196,5 & - \\
\hline 5 & - & - & - & 164,4 & - \\
\hline 6 & $5,88(s)$ & $5,88(s)$ & $5,90(d ; 2,0)$ & 96,0 & 95,$3 ; 101,0 ; 166,3$ \\
\hline 7 & - & - & - & 166,3 & - \\
\hline 8 & $5,88(s)$ & $5,88(s)$ & $5,90(d ; 2,0)$ & 95,3 & 101,$0 ; 163,3$ \\
\hline 9 & - & - & - & 163,3 & - \\
\hline 10 & - & - & - & 101,0 & - \\
\hline 1 & - & - & - & 129,4 & - \\
\hline 2' 6' & $7,10(m)$ & $7,10(m)$ & $7,10(d ; 8,5)$ & 128,8 & 81,$2 ; 128,8 ; 157,7$ \\
\hline 3' 5', & $6,60-6,84(m)$ & $6,60-6,84(\mathrm{~m})$ & $6,74(d ; 8,5)$ & 115,3 & $*$ \\
\hline 4 & - & - & - & 157,7 & - \\
\hline 5-OH & $12,17(s)$ & $12,19(s)$ & $12,09(s)$ & - & 96,$0 ; 101,0 ; 164,4$ \\
\hline $2 \%$ & $4,87(d ; 12,0)$ & $4,99(d ; 12,0)$ & $4,92(d ; 12,0)$ & 82,7 & 118,$9 ; 128,0 ; 197,5$ \\
\hline 3 "' & $3,95(m)$ & $4,19(m)$ & $4,13(d ; 12,0)$ & 71,9 & 82,7 \\
\hline $4 "$ & - & - & - & 197,5 & - \\
\hline 5, & - & - & - & 162,7 & - \\
\hline 6"' & $5,88(s)$ & $5,88(s)$ & $5,88(s)$ & 95,7 & 100,2 \\
\hline $7 "$ & - & - & - & 164,4 & - \\
\hline 8', & - & - & - & 100,2 & - \\
\hline 9', & - & - & - & 160,1 & - \\
\hline 10 ' & - & - & - & 99,7 & - \\
\hline $1 \%$ & - & - & - & 128,0 & - \\
\hline 2, & $6,60-6,84(m)$ & $6,60-6,84(m)$ & $6,82(d ; 1,6)$ & 114,8 & $*$ \\
\hline $3^{\prime \prime \prime}$ & - & - & - & 144,5 & - \\
\hline $4, "$, & - & - & - & 145,8 & - \\
\hline $5, \%$ & $6,60-6,84(m)$ & $6,60-6,84(\mathrm{~m})$ & $6,75(m)$ & 115,3 & $*$ \\
\hline $6, "$ & $6,60-6,84(m)$ & $6,60-6,84(m)$ & $\begin{array}{c}6,64(d d ; 1,6 \mathrm{e} \\
8,8)\end{array}$ & 118,9 & $*$ \\
\hline 5',-OH & $11,82(s)$ & $12,79(s)$ & $11,62(s)$ & - & 95,$7 ; 99,7 ; 162,7$ \\
\hline
\end{tabular}

(16a) representa o confôrmero principal e a série (16b) o confôrmero minoritário. 
dicroísmo é muito baixa, ora pelo efeito atropisomérico da ligação $3 \rightarrow 8$ '. Ferrrari e seus colaboradores (2003) fizeram uma revisão sobre a configuração absoluta dos biflavonóides GB1, GB2, GB4 e GB4a e propuseram os sinais dos efeitos Cottons de cada estereoisômero. Para GB2, a configuração absoluta de $2 R, 3 S, 2$ '' $R, 3$ '' $R$ é caracterizada pelo efeito Cotton positivo em $345 \mathrm{~nm}$ e efeito Cotton negativo em $285 \mathrm{~nm}$, semelhante à curva de DC mostrada por 14. Conclui-se afinal, que a substância 14 é o biflavonóide $(2 R, 3 S, 2$ '’R, 3',R)-5,7,4',5', 7',,3', 3',',4','-octaidroxi-(3,8'))-biflavanona.

Em relação às biflavanonas (livres na posição C-3"') GB1a e GB2a, isoladas da fração AcOEt-FOL, a curva de DC foi similar a da substância 14 (Figura 62), porém, para uma atribuição completa e inequívoca dos sinais do efeito Cotton, serão necessários experimentos adicionais, visto que ainda não há relato sobre a configuração absoluta dos possíveis estereoisômeros.
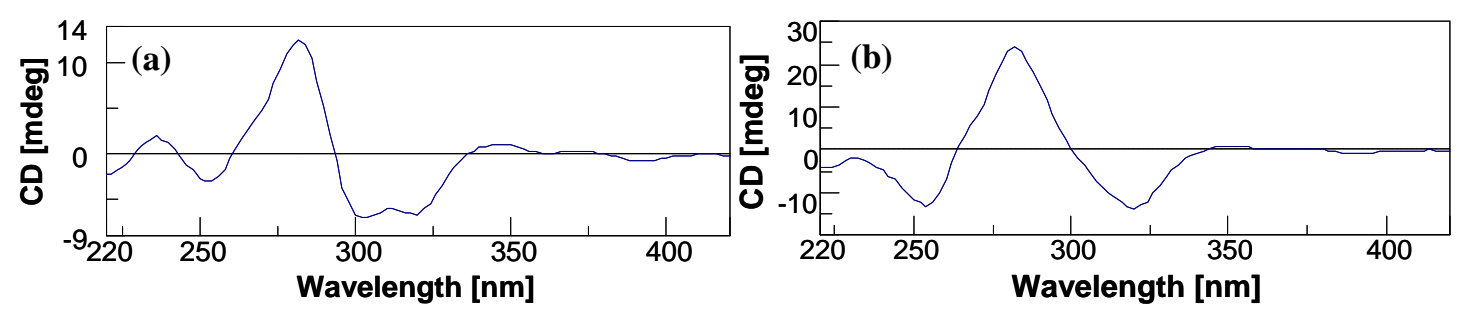

Figura 62 - Curva de dicroísmo circular (DC) das substâncias (a) 11 e (b) 14.

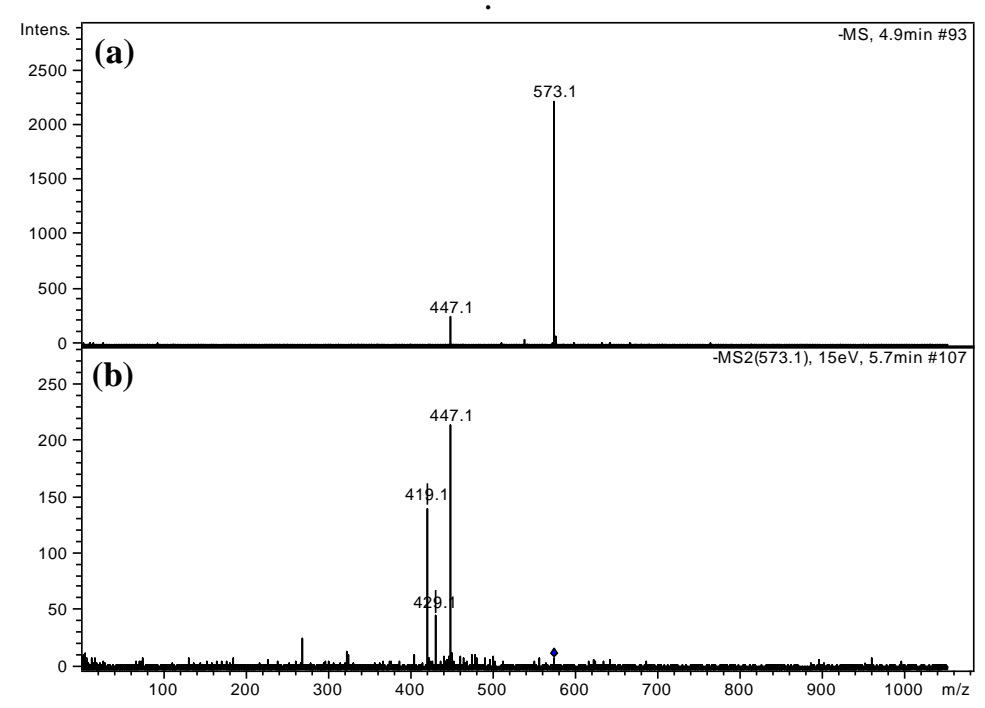

Figura 63 - Espectro de massas (a) de primeira e (b) segunda-ordem da substância 14, obtido em modo negativo com energia de colisão de $15 \%$ para EM2 (ESI). 


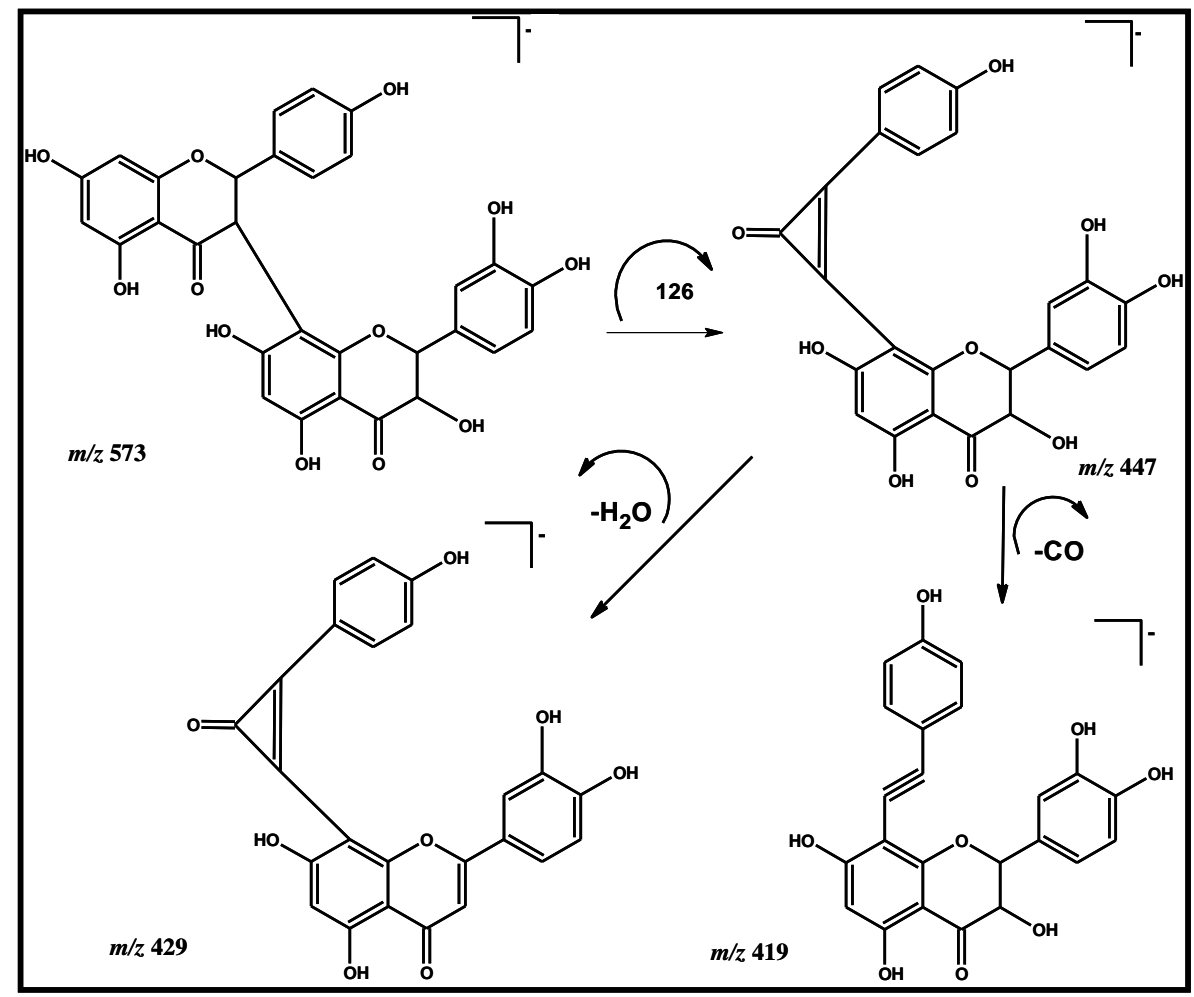

Figura 64 - Proposta de fragmentação da substância 14.

\subsubsection{Caracterização espectrométrica das substâncias 17 e 18}

As substâncias $\mathbf{1 7}$ e $\mathbf{1 8}$ foram isoladas da subfração BuOH-FOL-6, conforme procedimento experimental em $\mathbf{5 . 1 0}$.

A substância 17 isolada como um sólido amarelo claro amorfo apresentou fórmula molecular de $\mathrm{C}_{16} \mathrm{H}_{18} \mathrm{O}_{9}$ correspondendo à massa molecular de 354 g.mol ${ }^{-1}$. Em análise por CLAE-UV-DAD a substância mostrou um caráter bastante polar, eluindo com $\mathrm{t}_{\mathrm{r}}=4,4$ min com fase móvel de $75 \%$ de água. No espectro na região do UV (Figura 65) apresentou bandas com comprimentos de onda de absorção máxima em 329 nm e um ombro em 290 nm, típico de moléculas com unidades cafeoíla em sua estrutura (MAISUTHISAKUL et al., 2007).

A análise do espectro de absorção na região do IV (Figura 66) conduziu à identificação de alguns grupos funcionais como: hidroxila, devido a uma banda larga em $3374 \mathrm{~cm}^{-1}$ característica da deformação axial da ligação O-H $\left(v_{\mathrm{O}-\mathrm{H}}\right)$; carbonila conjugada, evidenciada por uma banda em $1698 \mathrm{~cm}^{-1}\left(v_{\mathrm{C}-\mathrm{O}}\right)$; anel aromático, devido a bandas em 1500 e $1597 \mathrm{~cm}^{-1}$ atribuídas à deformação axial de C-C $\left(v_{\mathrm{C}-\mathrm{C}}\right)$ e as bandas em 814 e $976 \mathrm{~cm}^{-1}$ relacionadas a deformações angulares fora do plano das ligações $\mathrm{C}-\mathrm{H}\left(\delta_{\mathrm{C}-\mathrm{H}}\right)$, e ainda, carbonos oxigenados, reconhecidos através das absorções em 1263 e $1158 \mathrm{~cm}^{-1}$ associadas 


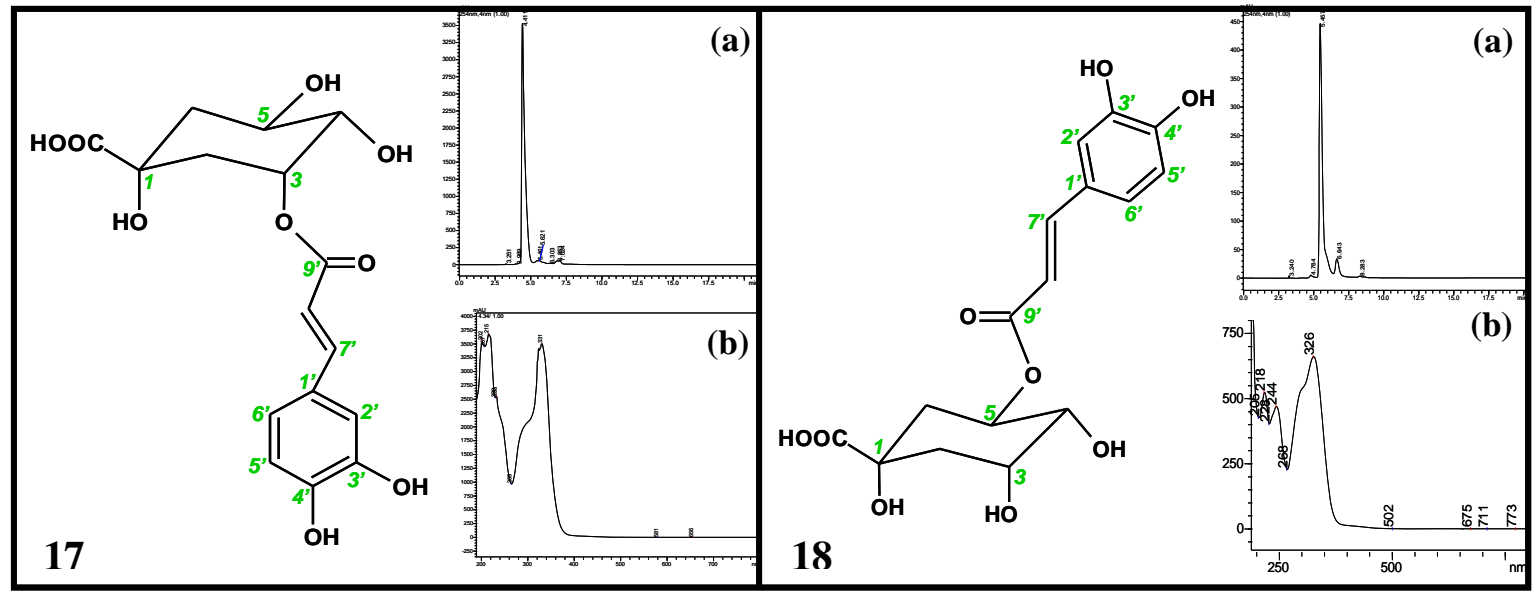

Figura 65 - Estruturas das substâncias 17 e 18. (a) Cromatogramas analíticos e (b) espectros de absorção das substâncias $\mathbf{1 7}$ e $\mathbf{1 8}$ obtido via CLAE-UV-DAD no modo isocrático 35:75 $\left(\mathrm{MeOH}: \mathrm{H}_{2} \mathrm{O}\right.$ ) e suporte cromatográfico: ODS (Phenomenex, 25,0 cm x 4,6 mm x 5 $\mu \mathrm{m}$ ).

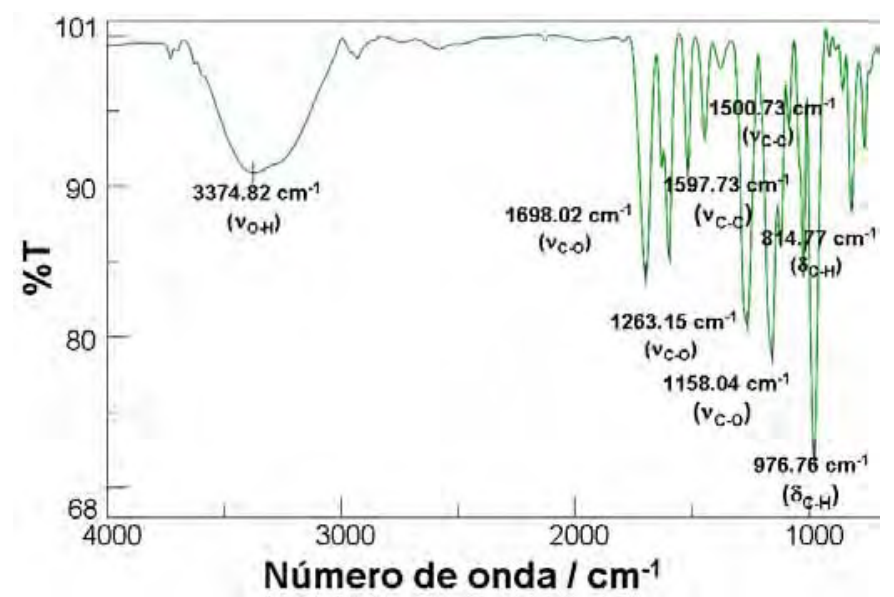

Figura 66 - Espectro vibracional na região do IV da substância 17.

Tabela 13 - Dados de RMN de ${ }^{1} \mathrm{H}(500 \mathrm{MHz})$ e RMN de ${ }^{13} \mathrm{C}(125 \mathrm{MHz})$ da substância 17 (DMSO- $\left.d_{6}\right)$.

\begin{tabular}{|c|c|c|c|c|}
\hline Posição & 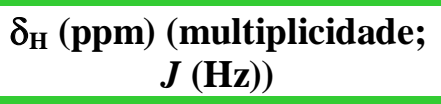 & $\delta_{\mathrm{C}}(\mathbf{p p m})$ & gНМBC & $g \mathrm{COSY}$ \\
\hline $1^{\prime}$ & - & 125,7 & - & - \\
\hline 2 & $7,00(d ; 2,0)$ & 114,5 & 121,$0 ; 144,3 ; 148,9$ & H-6' \\
\hline 3' & - & 145,5 & - & - \\
\hline 4 ' & - & 148,9 & - & - \\
\hline 5 , & $6,75(d ; 8,0)$ & 115,7 & 145,$5 ; 148,9$ & H-6 \\
\hline 69 & $6,95(d d ; 8,0$ e 2,0$)$ & 121,0 & 114,$5 ; 144,3 ; 148,9$ & $\mathrm{H}-2^{\prime} ; \mathrm{H}-5^{\prime}$ \\
\hline 7 & $7,44(d ; 16,0)$ & 144,3 & 114,$5 ; 125,7 ; 166,0$ & H-8, \\
\hline 8 & $6,19(d ; 16,0)$ & 115,0 & 125,$7 ; 166,0$ & $\mathrm{H}-7$ \\
\hline 9' & - & 166,0 & - & - \\
\hline 1 & - & 72,9 & - & - \\
\hline 2 & $1,97-2,01(m)$ & 35,1 & 39,$0 ; 70,9$ & $\mathrm{H}-3$ \\
\hline 3 & $5,17(\mathrm{~m})$ & 70,9 & 166,0 & $\mathrm{H}-2 ; \mathrm{H}-4$ \\
\hline 4 & $3,53(d ; 4,0)$ & 71,2 & $*$ & $\mathrm{H}-5 ; \mathrm{H}-3$ \\
\hline 5 & $3,85(m)$ & 67,2 & 70,$9 ; 72,9$ & H-6; H-4 \\
\hline 6 & $1,83-1,91(m)$ & 39,0 & 67,$2 ; 72,9$ & H-5 \\
\hline 7 & - & 176,1 & - & - \\
\hline
\end{tabular}

* sinal não observado 
a deformações axiais C-O (v $\left.v_{\mathrm{C}-\mathrm{O}}\right)$ (SILVERSTEIN; WEBSTER; KIEMLE, 1994).

$\mathrm{O}$ espectro de RMN de ${ }^{1} \mathrm{H}$ (Anexos 173 a 176) da substância 17 apresentou sinais característicos de substância aromática. Os sinais em $\delta_{\mathrm{H}} 7,00(d, 1 \mathrm{H}, 2,0 \mathrm{~Hz}), 6,95(d d, 1 \mathrm{H}$, $8,0$ e $2,0 \mathrm{~Hz})$ e $6,75(d, 1 \mathrm{H}, 8,0 \mathrm{~Hz})$ indicaram a presença de anel aromático 1,3,4trissubstituído (Tabela 13). Foram observados ainda sinais em $\delta_{\mathrm{H}} 7,44(d, 1 \mathrm{H}, 16,0 \mathrm{~Hz}) \mathrm{e}$ $6,19(d, 1 \mathrm{H}, 16,0 \mathrm{~Hz})$ que indicaram a presença de ligação dupla trans-dissubstituída. A análise do conjunto destes sinais evidenciou a presença da porção do ácido cafeico. $\mathrm{O}$ espectro de $\mathrm{RMN}$ de ${ }^{1} \mathrm{H}$ exibiu ainda os sinais em $\delta_{\mathrm{H}} 5,17$ e 3,85, característicos de hidrogênios oximetínicos.

A análise do espectro de RMN de ${ }^{13} \mathrm{C}$ (Anexo 177, Tabela 13) confirmou a presença da unidade do ácido cafeico pelos sinais em $\delta_{\mathrm{C}} 166,0 ; 148,9 ; 145,5 ; 144,3 ; 125,7 ; 121,0$; 115,7 e 114,5. Foram observados sinais de carbonos carbinólicos em $\delta_{\mathrm{C}} 72,9 ; 71,2 ; 70,9$ e 67,2 e sinais de carbonos metilênicos em $\delta_{C} 35,1$ e 39,0. O espectro mostrou ainda, sinal para carbono de carboxila em $\delta_{\mathrm{C}} 176,1$, sugerindo a estrutura do ácido quínico.

Os acoplamentos observados no mapa de correlação gHMBC (Anexos 185 a 190) entre os hidrogênios em $\delta_{\mathrm{H}}$ 7,44 (H-7') e $\delta_{\mathrm{H}} 6,19$ (H-8') com o carbono em $\delta_{\mathrm{C}} 166,0$ (atribuída a carbonila de éster em C-9'), confirmaram o sistema carbonílico $\alpha, \beta$-insaturado conjugado ao anel. A localização do ácido quínico na estrutura foi determinada pela existência de acoplamento a longa distância entre o sinal do hidrogênio em $\delta_{\mathrm{H}} 5,17$ (H-3) do ácido quínico e o sinal do carbono carboxílico do ácido cafeico em $\delta_{\mathrm{C}} 166,0$, indicando a esterificação do ácido cafeico pelo ácido quínico.

Essas observações, associadas aos dados da literatura, permitiram identificar a substância 17 como ácido 3-O-cafeoilquínico ou ácido clorogênico (3-ACQ).

A substância 18 apresentou um mesmo perfil espectral (Anexos 191 a 209), porém em análise por CLAE-UV-DAD (Figura 65) o tempo de retenção foi de 5,1 min, diferente de 17, que mostrou tempo de retenção igual a 4,4 min, nas mesmas condições. Essa diferença nos levou a investigar a ocorrência de um possível isômero do ácido clorogênico.

Os derivados do ácido clorogênico são resultantes de esterificações de um ou mais tipos de ácidos trans-cinâmicos (cinâmico, cumárico, cafeico, ferúlico e dimetoxicinâmico) com as hidroxilas do ácido quínico, gerando uma série de isômeros de posição. Os derivados com esterificações nas posições 3, 4 e 5 são de ocorrência comum, ao contrário dos derivados com esterificação na posição 1 , de ocorrência rara. 
Pela análise dos espectros de $\mathrm{RMN}{ }^{1} \mathrm{H}$, nota-se uma grande similaridade estrutural entre 17 e 18, com pequenas variações nos deslocamentos químicos e nas constantes de acoplamento. A diferenciação se dá principalmente, pela estereoquímica dos substituintes, observadas a partir dos núcleos de $\mathrm{H}$ do ácido quínico. As hidroxilas do ácido quínico nas posições 1,3 e 4 devem estar em posição $\alpha$ relativas ao plano do anel, enquanto a carboxila e hidroxila em C-5, devem estar em posição $\beta$ (DEWICK, 2002). Assim, a conformação cadeira mais estável é aquela em que o grupo carboxílico ocupa a posição equatorial (Figura 67a), minimizando a interação do tipo 1,3-diaxial entre carboxila e hidroxila que ocorreria conforme ilustrado na Figura 67b (CORSE et al., 1966).

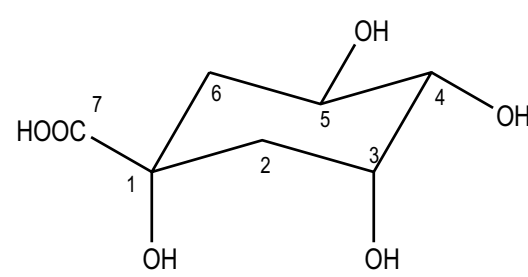

(a)

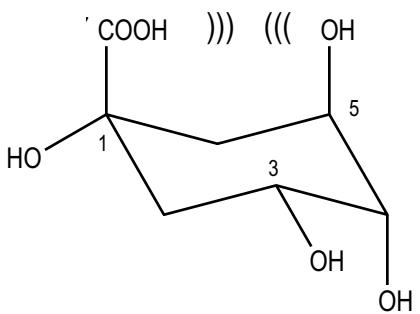

(b)

Figura 67 - Estrutura do ácido quínico. (a) conformação de maior estabilidade. (b) conformação de menor estabilidade evidenciando interação 1,3-diaxial entre a carboxila e a hidroxila em C5.

A atribuição dos hidrogênios H-2, H-3, H-4, H-5 e H6 é dificultada pelo fato dos sinais estarem sobrepostos em uma estreita região espectral e por possuírem constantes de acoplamento múltiplas (PAULI.; POETSCH; NAHRSTEDT, 1998). Porém, é possível contornar este problema levando em consideração a largura total dos multipletos e comparando-se os deslocamentos, com o ácido quínico não substituído. Desta forma, a largura total encontrada para o hidrogênio $\mathrm{H}-3$ é de no máximo $15,0 \mathrm{~Hz}$, enquanto que para o H-5 esta constante é de no máximo 25,0 Hz (GE et al., 2007).

Diante desta sistemática, a substância 17 apresentou um multipleto em $\delta_{\mathrm{H}} 3,85$ atribuído a H-5 (largura da constante de acoplamento de $J=17,5 \mathrm{~Hz}$ ) e um multipleto em $\delta_{\mathrm{H}}$ 5,17 atribuído a H-3 (largura da constante de acoplamento de $J=14,5 \mathrm{~Hz}$ ) (Anexo 174). Como o sinal em $\delta_{\mathrm{H}} 5,17$ deslocou-se para região paramagnética do espectro em relação ao padrão ácido quínico não substituído (deslocamento em $\delta_{\mathrm{H}} 4,00$ para $\mathrm{H}-5$ e $\delta_{\mathrm{H}} 4,10$ para H3) e o sinal em $\delta_{H} 3,85$ permaneceu inalterado, conclui-se que a esterificação ocorre pela hidroxila em C-3 do ácido quínico. Essas observações confirmaram a estrutura proposta para 17, conforme discutido acima. 
Já para a substância 18, a largura da constante de acoplamento para o sinal em $\delta_{\mathrm{H}}$ 3,85 foi de $J=7,0 \mathrm{~Hz}$ (H-3) e o deslocamento permaneceu inalterado (Anexo 192). O sinal em $\delta_{\mathrm{H}} 5,17$ mostrou uma largura de $J=18,5 \mathrm{~Hz}(\mathrm{H}-5)$ e deslocou-se para região desprotegida do espectro, indicando que a esterificação do ácido cafeico ocorre pela hidroxila em C-5 do ácido quínico. Conclui-se que 18 é o ácido 5-O-cafeoilquínico ou ácido isoclorogênico (5-ACQ).

Tabela 14 - Fragmentos obtidos dos analitos isolados de G. xanthochymus a partir da análise por EM e EM2 obtido em modo negativo com energia de colisão de $15 \%$.

\begin{tabular}{|c|c|c|c|c|c|c|}
\hline \multirow{3}{*}{ Compostos } & \multirow{3}{*}{$\begin{array}{c}\text { EM1 } \\
\text { (ion molecular) } \\
\mathrm{m} / z\end{array}$} & \multicolumn{5}{|c|}{ EM2 } \\
\hline & & \multirow{2}{*}{$\begin{array}{c}\text { Pico base } \\
m / z\end{array}$} & \multicolumn{4}{|c|}{ Fragmentos secundários } \\
\hline & & & $m / z$ & intensidade* & $\mathrm{m} / \mathrm{z}$ & intensidade $^{*}$ \\
\hline 3-ACQ & 353,1 & 191,7 & 179,7 & 45 & 135,6 & 22 \\
\hline 4-ACQ & 353,1 & 173,0 & 191,0 & 49 & 179,0 & 38 \\
\hline 5-ACQ & 353,1 & 191,1 & - & - & - & - \\
\hline 3-ApCoQ & 337,1 & 163,0 & 191,1 & 32 & - & - \\
\hline 4- $\mathrm{ApCoQ}$ & 337,1 & 173,0 & 163,0 & 82 & 119,0 & 25 \\
\hline
\end{tabular}

* abundância relativa do fragmento

Pela análise do espectro de massas obtido no modo negativo (ESI), observa-se que o padrão de fragmentação dos isômeros 3-ACQ e 5-ACQ é bastante similar (Tabela 14, Figura 68-Figura 71). A diferenciação foi possível a partir da fragmentação EM2, onde os fragmentos secundários em $\mathrm{m} / z$ 179,7 $[\mathrm{M}-\mathrm{H}]^{-}$e $\mathrm{m} / z$ 135,6 [M-H] $]^{-}$foram identificados exclusivamente no espectro de massas do 3-ACQ (substância 17), como relatado para tal composto por CLIFFORD et al. (2003) e GOBBO-NETO; LOPES (2008).

A facilidade da perda de uma unidade de um ácido trans-cinâmico (como o ácido cafeico) esterificada em uma posição específica do ácido quínico é influenciada principalmente pela sua proximidade espacial com carboxila ou hidroxila no C-1 do ácido quínico, fator que influencia o mecanismo e consequente perfil de fragmentação destes derivados. No caso do isômero 3-ACQ, um hidrogênio é abstraído da $\mathrm{OH}$ em C-1 e no caso do 5-ACQ, um hidrogênio da carboxila do ácido quínico é abstraído para a eliminação da porção cafeica. Estas diferenças na fragmentação ocasionam consideráveis diferenças na intensidade, e às vezes na natureza dos íons produtos nos espectros de segunda geração 
EM2, o que possibilita a diferenciação entre os isômeros de posição (CLIFFORD et al., 2003, 2006).

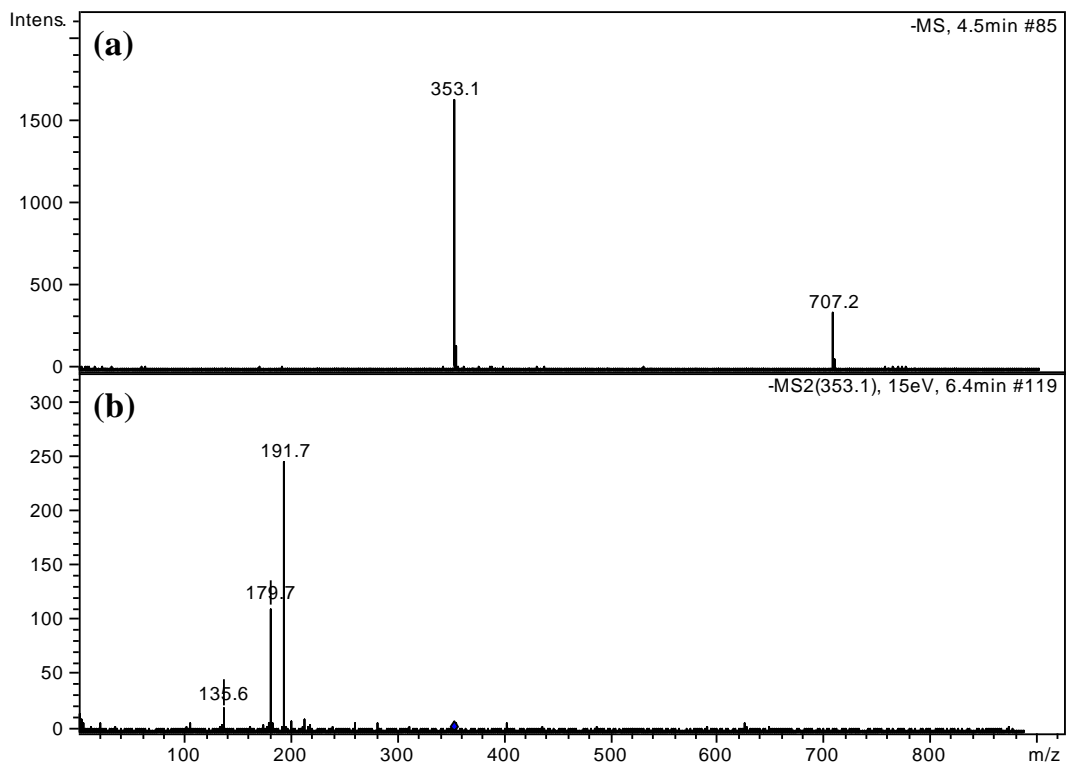

Figura 68 - Espectro de massas (a) de primeira e (b) segunda-ordem da substância 17, obtido em modo negativo com energia de colisão de 15\% para EM2 (ESI).

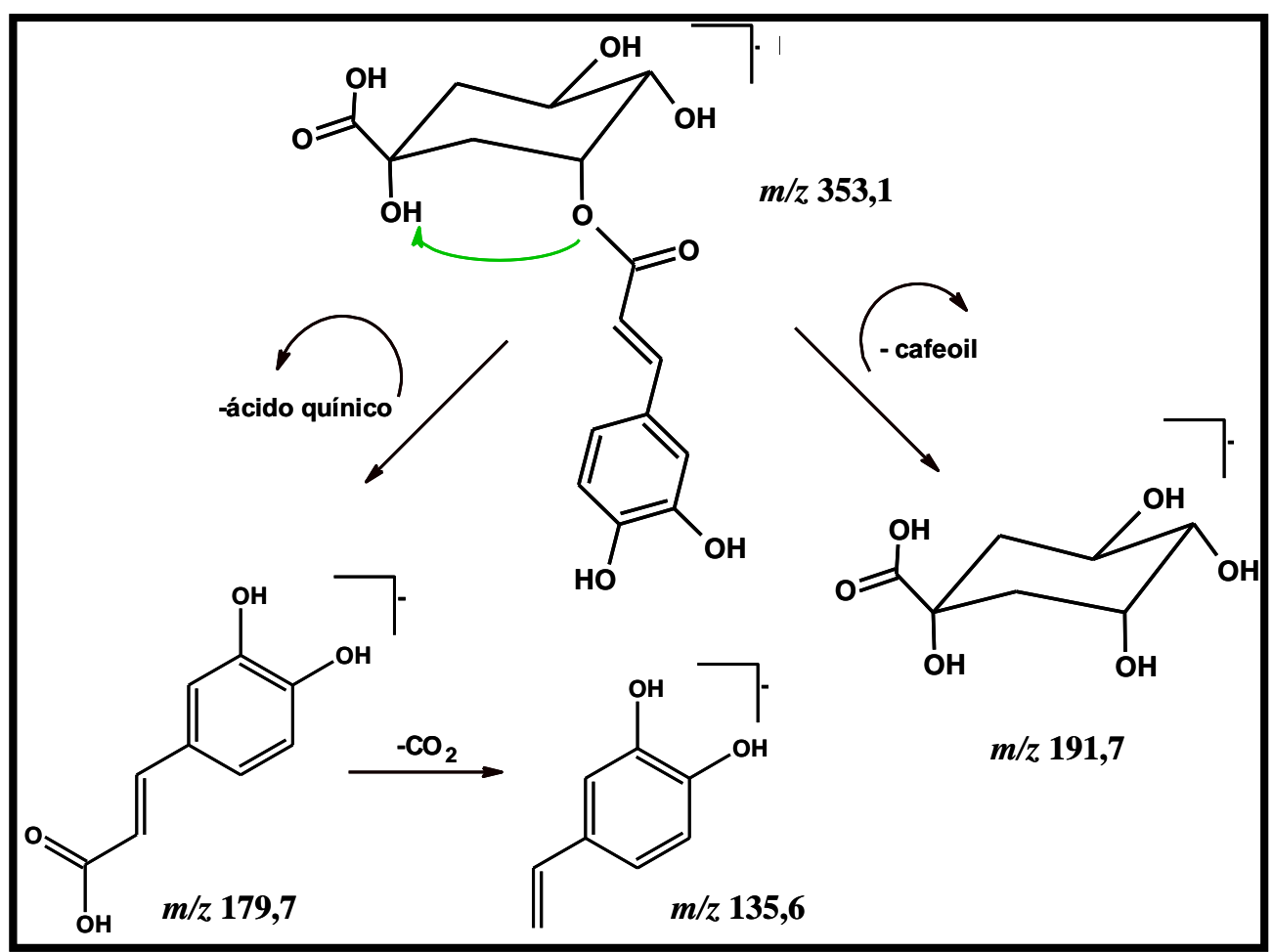

Figura 69 - Proposta de fragmentação da substância 17. 


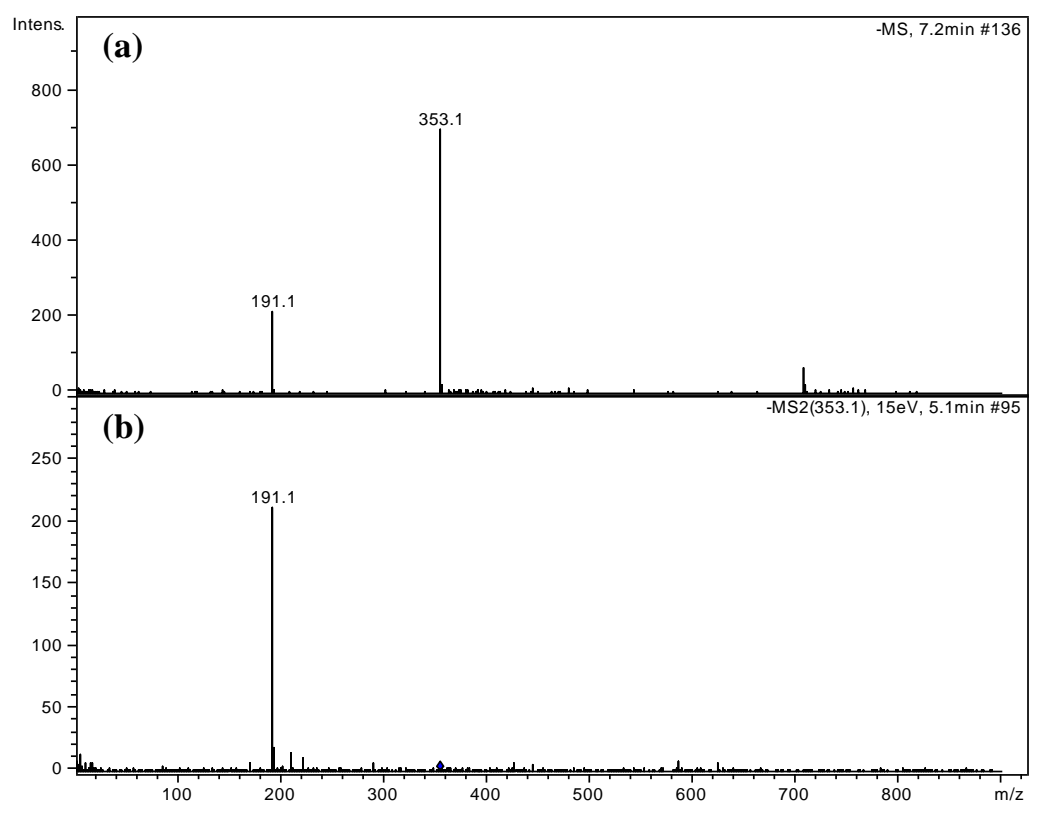

Figura 70 - Espectro de massas (a) de primeira e (b) segunda-ordem da substância 18, obtido em modo negativo com energia de colisão de 15\% para EM2 (ESI).

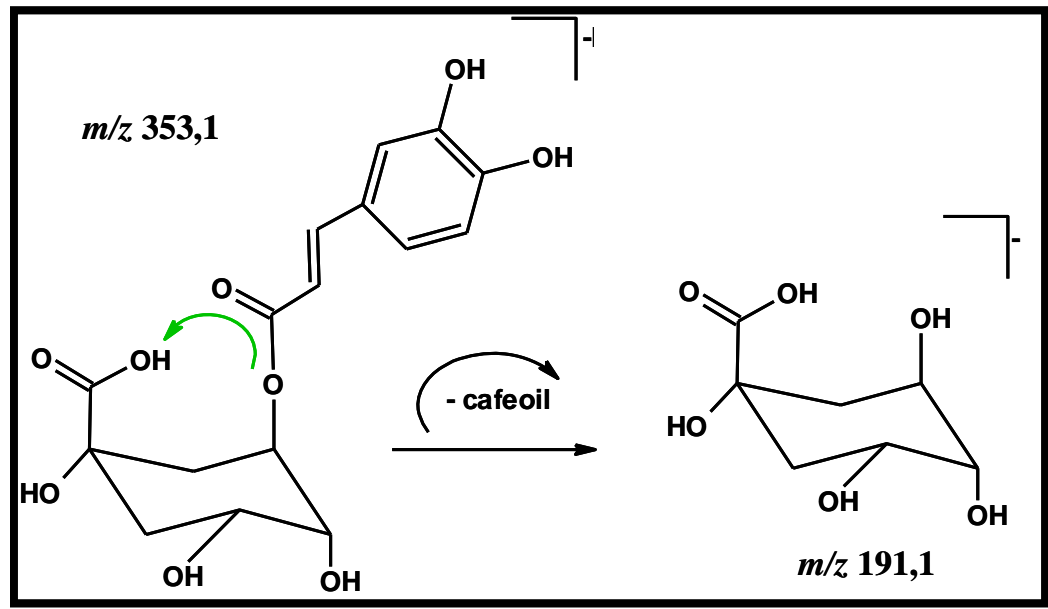

Figura 71 - Proposta de fragmentação da substância 18.

\subsection{A desreplicação em estudos de bioprospecção}

Desreplicação é uma estratégia de análise na procura de novos medicamentos, onde o foco é a identificação rápida de novas substâncias, frequentemente em mistura, ativas biologicamente, a partir de fontes naturais. O desenvolvimento da técnica começou com a necessidade de se priorizar a obtenção de substâncias inéditas com ou sem atividade biológica, uma vez que o trabalho fitoquímico pode ser muitas vezes dispendioso e levar geralmente a compostos já conhecidos. Estima-se um gasto de $\$ 50.000$ e um trabalho de 3 meses para isolar e identificar um composto como bioativo (CORDELL e SHIN, 1999). 
A desreplicação utiliza várias técnicas de análise tais como a CLAE-UV-DAD, CG, CG-EM, CLAE-RMN e CLAE-EM ou uma combinação dessas. O equipamento de CLAEEM consiste de um sistema eletrospray e um espectrômetro contendo um detector quadrupolar e consiste de duas fases distintas. A primeira etapa consiste na coleta e separação de dados (parâmetros cromatográficos, manipulação da amostra, testes biológicos) e a segunda consiste na análise de dados (RODRIGUES et al., 2006).

O uso da desreplicação nos mostra uma linha de pesquisa muito promissora, bastando lembrar a riqueza de nossa flora, para se ter uma idéia da abrangência que pode ser alcançada nos estudos de extratos de plantas e em curto espaço de tempo (CORDELL e SHIN, 1999).

\subsubsection{Identificação por CLAE-UV-DAD-EM dos constituintes de Garcinia xanthochymus}

A fração AcOEt-FRU de Garcinia xanthochymus apresentou um perfil químico bastante diversificado (um maior número de picos com diferentes bandas de absorção no UV), por isso a escolha de tal matriz para análise e identificação de seus metabólitos por CLAE-DAD-EM.

A análise conjunta de algumas subfrações (selecionadas com base em seus perfis cromatográficos, Figura 72) originárias da fração AcOEt-FRU por CPG, de substâncias purificadas durante esse trabalho e comparação com dados da literatura, permitiu a localização de substâncias já isoladas e/ou isoladas em trabalhos anteriores, assim como foi possível identificar classes diferentes daquelas já isoladas, tais como as xantonas.

Os fragmentogramas dos metabólitos presentes na subfração AcOEt-FRU-13 (Figura 73 e Figura 74) mostrou padrão de fragmentação semelhante aos encontrados para algumas xantonas, isoladas em trabalhos anteriores de diversas espécies do gênero Garcinia (PANTHONG, et al., 2006; HARRISON, et al., 2005; IINUMA, et al., 1996; ZHOU, et al., 2008; MOREAU, et al., 2002; SCHIEBER; BERARDINI; CARLE, 2003).

O íon $\mathrm{m} / z 303[\mathrm{M}-\mathrm{H}]^{-}$, verificado no espectro de massas obtido no modo negativo (ESI) de 24, pode ser atribuído a fórmula molecular $\mathrm{C}_{15} \mathrm{H}_{12} \mathrm{O}_{7}$. A fragmentação de xantonas metoxiladas é caracterizada pela presença do fragmento [M-H-15]', referente à perda de uma metila, tal como é observado no EM de 24. Os íons $\mathrm{m} / \mathrm{z} 288$ e $\mathrm{m} / \mathrm{z} 273$ correspondentes a [M-H-15] e [M-H-30]', respectivamente, evidenciam a presença de um 


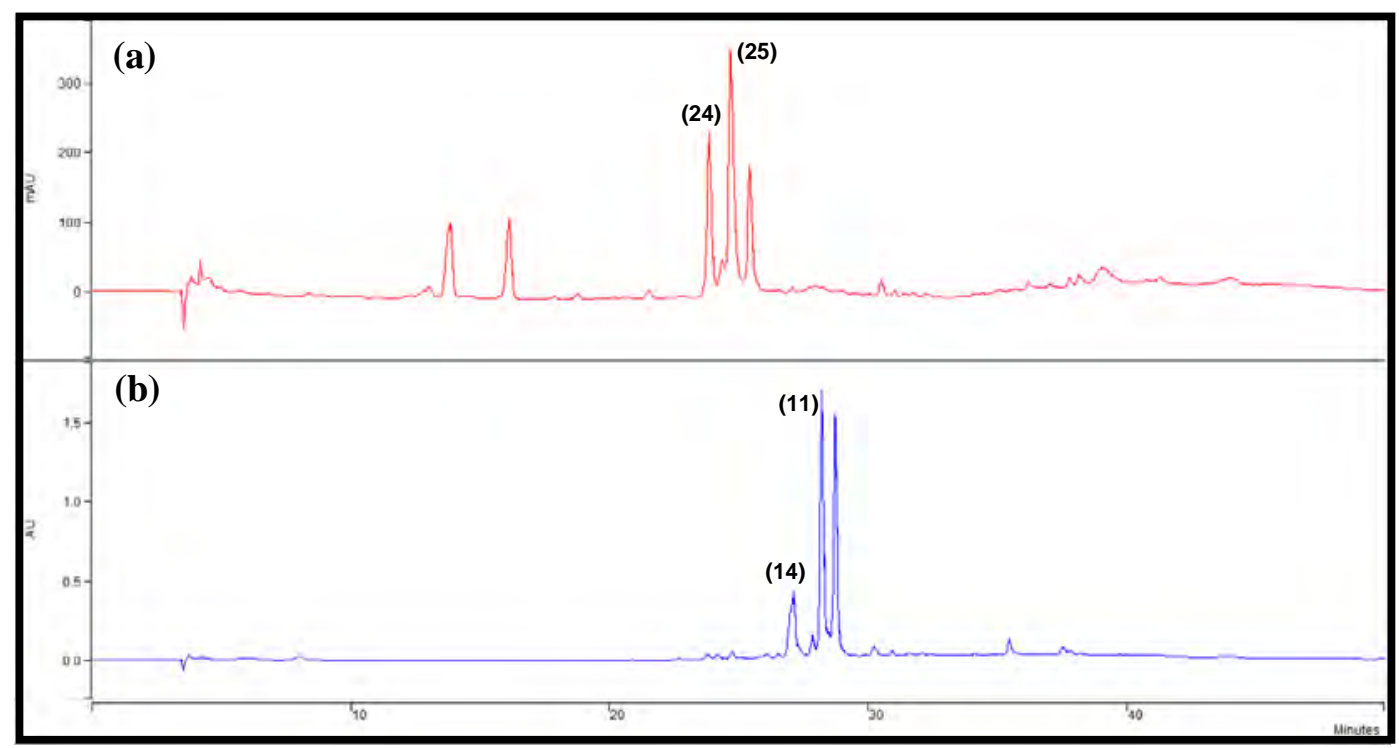

Figura 72 - Cromatograma analítico de alguns constituintes majoritários obtido via CLAE-UVDAD das subfrações (a) AcOEt-FRU-13 (b) e AcOEt-FRU-17, no modo gradiente em $\mathrm{H}_{2} \mathrm{O}: \mathrm{MeOH}$ (95:5) até $\mathrm{MeOH}$ (100) e suporte cromatográfico: ODS (Phenomenex, 25,0 cm x 4,6 mm x 5 $\mu \mathrm{m}$ ).

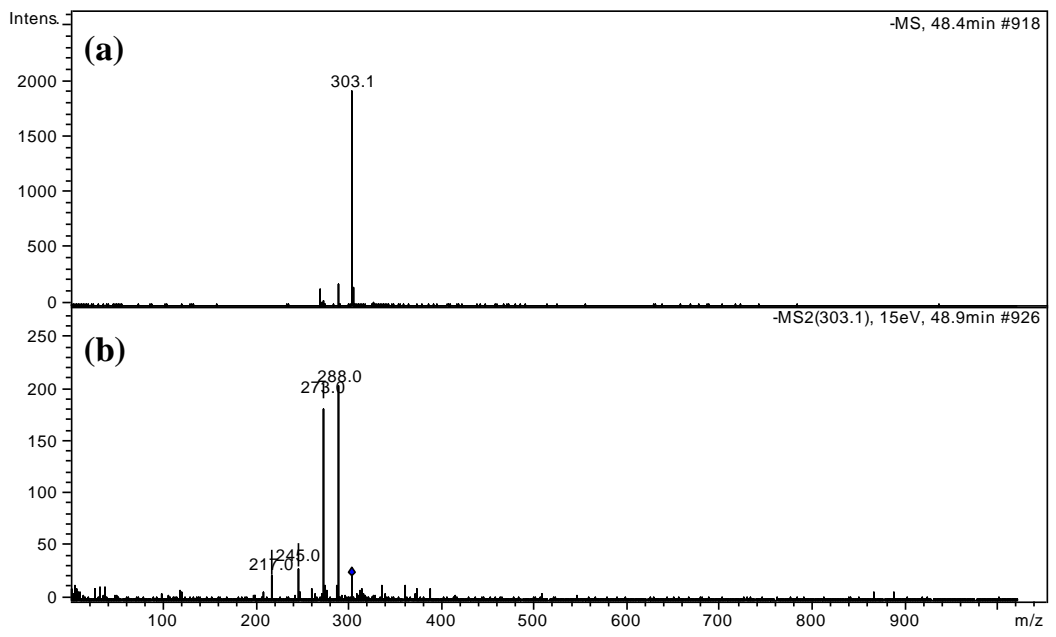

Figura 73 - Espectro de massas (a) de primeira e (b) segunda-ordem da substância 24, obtido em modo negativo com energia de colisão de 15\% para EM2 (ESI).

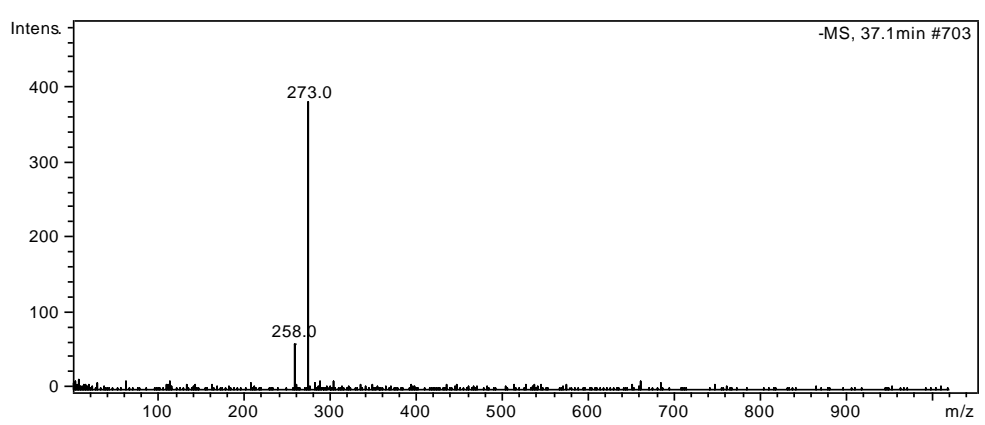

Figura 74 - Espectro de massas de primeira-ordem da substância 25 obtido no modo negativo (ESI). 
esqueleto xantônico triidroxilado e dimetoxilado, como relatado para xantonas isoladas em trabalhos anteriores (BASHIR et al., 1992; FUJITA et al., 1992; IKEYA et al., 1991). A unidade fundamental de uma xantona também poder ser caracterizada pela presença dos íons $m / z 245$ [M-H-30-28] e $m / z 217$ [M-H-30-56]', referentes à perda de duas metilas com subseqüente perda de CO (Figura 73 e Figura 75).

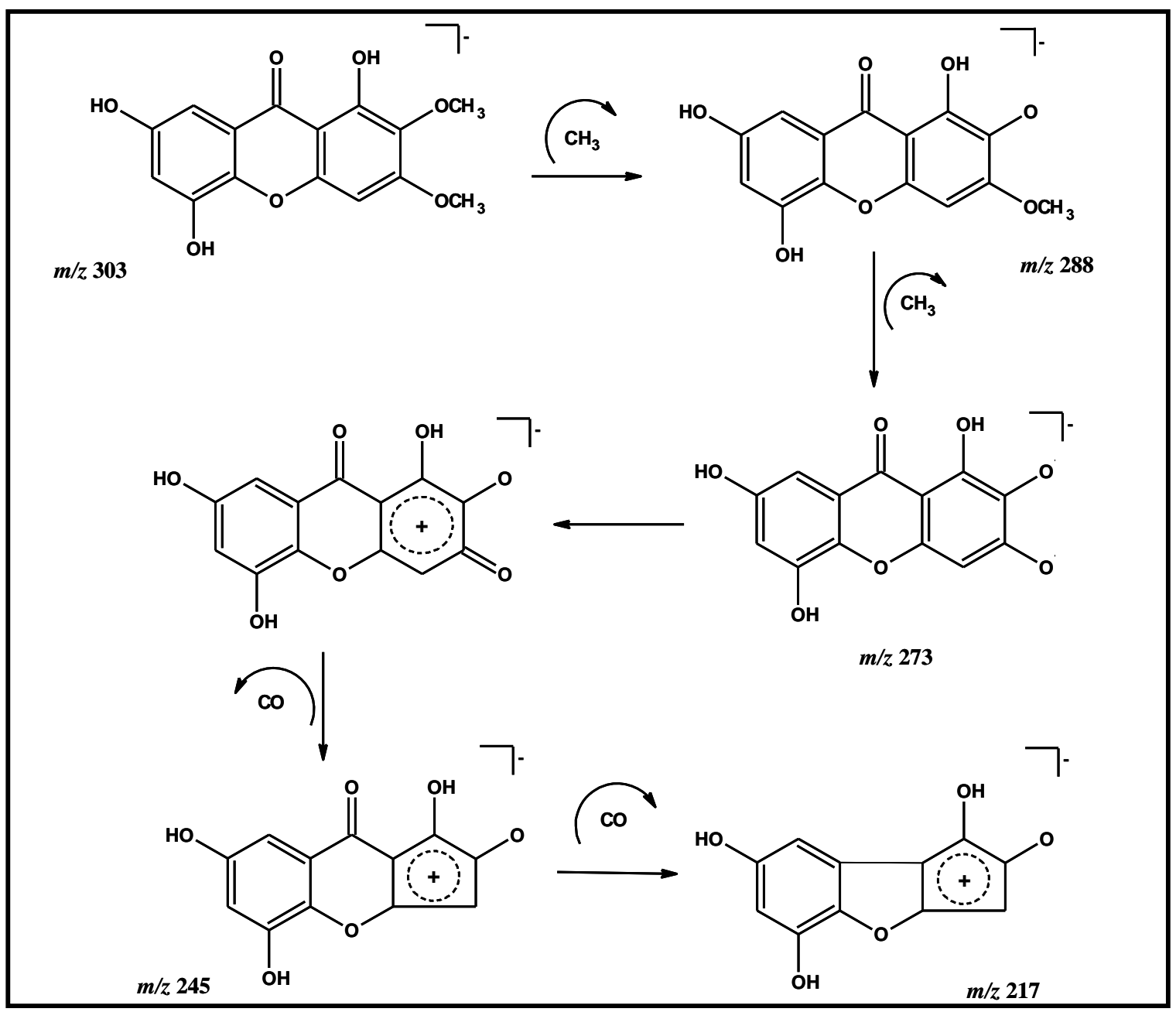

Figura 75 - Proposta de fragmentação da substância 24.

$m / z 273$<smiles>COc1cc(O)cc2c(=O)c3c(O)cc(O)cc3oc12</smiles><smiles>O=c1c2cc(O)cc(O)c2oc2cc(O)cc(O)c12</smiles>

Figura 76 - Proposta de fragmentação da substância 25. 
O íon molecular $m / z, 273[\mathrm{M}-\mathrm{H}]^{-}$apresentado pela substância 25 sugere a fórmula $\mathrm{C}_{14} \mathrm{H}_{10} \mathrm{O}_{6}$ e pode ser atribuído a esqueletos xantônicos triidroxilados e metoxilados. Esse fato também é confirmado pela presença do íon $\mathrm{m} / \mathrm{z}, 258$ referente à perda de uma metila [M-H-15] (Figura 74 e Figura 76). Este tipo de xantona é muito comum e vários isômeros já foram isolados da espécie G. xanthochymus (BAGGETT et al., 2005; ZHONG; CHEN; YANG, 2008). É importante salientar que a identificação sugere apenas o esqueleto básico do metabólito secundário e que a posição dos substituintes só é realmente comprovada com o auxílio de técnicas de RMN mono e bidimensionais e/ou cuidadosa análise do perfil de fragmentação por EM1 e EM2 para as amostras e padrões.

A análise através de CLAE fase reversa confirmou essas informações através da comparação de espectros de UV e dos tempos de retenção obtidos para essas duas subfrações e amostra padrão (Figura 77). As substâncias 24 e 25 apresentaram $t_{r}=24,1$ min e $t_{r}=25,9$ min, respectivamente (Figura 72) semelhante aos tempos de retenção de amostras autênticas de xantonas [1,5,7-triidroxi-2,3-dimetoxixantona (xantona 1), $\mathrm{t}_{\mathrm{r}}=24,0$ min; 1,3,7-triidroxi-5-metoxixantona (xantona 2), $\mathrm{t}_{\mathrm{r}}=25,8 \mathrm{~min}$ ] analisadas nas mesmas condições por CLAE (Figura 78).<smiles>COc1cc2oc3c(O)cc(O)cc3c(=O)c2c(O)c1OC</smiles>

xantona 1<smiles>COc1cc(O)cc2c(=O)c3c(O)cc(O)cc3oc12</smiles>

xantona 2

Figura 77 - Estruturas das xantonas padrão utilizadas no processo de desreplicação das substâncias 24 e 25.

A subfração AcOEt-FRU-17 apresentou dois picos com tempos de retenção e bandas no UV semelhantes aos das substâncias 11 e 14 (Figura 79). No espectro de massas obtido no modo negativo observou-se sinais em $m / z 573[\mathrm{M}-\mathrm{H}]^{-}$e $m / z 557$ [M-H] $]^{-}$, que foram atribuídos aos íons moleculares de GB2 (subst. 14) e GB2a (subst. 11), respectivamente. Os íons de segunda-ordem (EM2) $m / z 431$ [M-H-126] e $m / z 295$ [M-H-126-136]

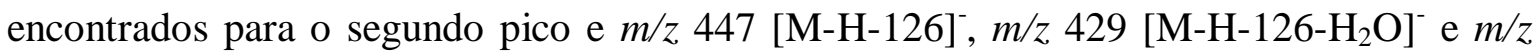
419 [M-H-126-CO]', para o primeiro pico, corroboram a proposta apresentada para essas duas substâncias (Figura 80). 


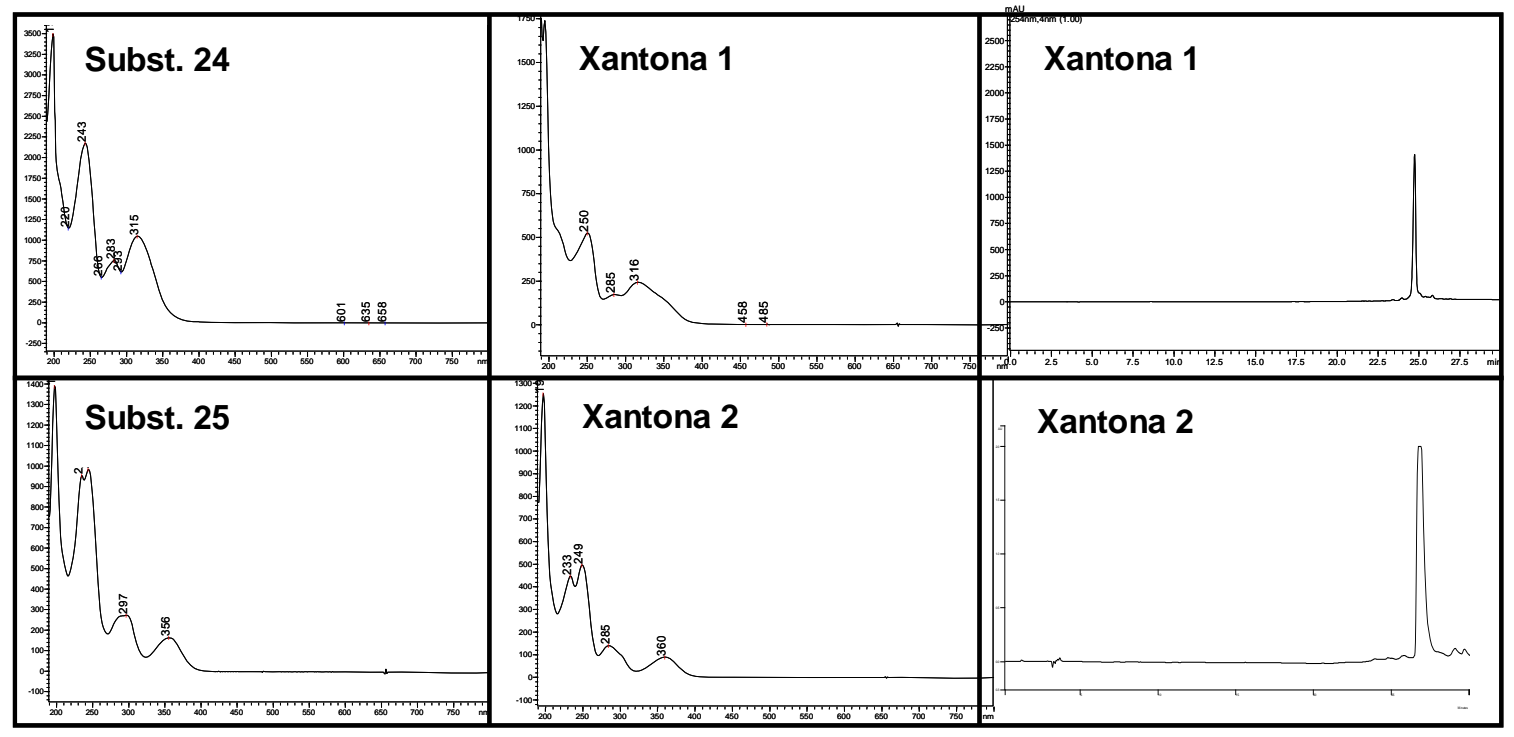

Figura 78 - (a) Espectro de absorção da substância 24, da xantona 1 e cromatograma analítico da xantona 1 (b) Espectro de absorção da substância 25, xantona 2 e cromatograma analítico da xantona 2. Modo gradiente em $\mathrm{H}_{2} \mathrm{O}: \mathrm{MeOH}$ (95:5) até $\mathrm{MeOH}$ (100) e suporte cromatográfico: ODS (Phenomenex, 25,0 cm x 4,6 $\mathrm{mm} \times 5 \mu \mathrm{m}$ ).
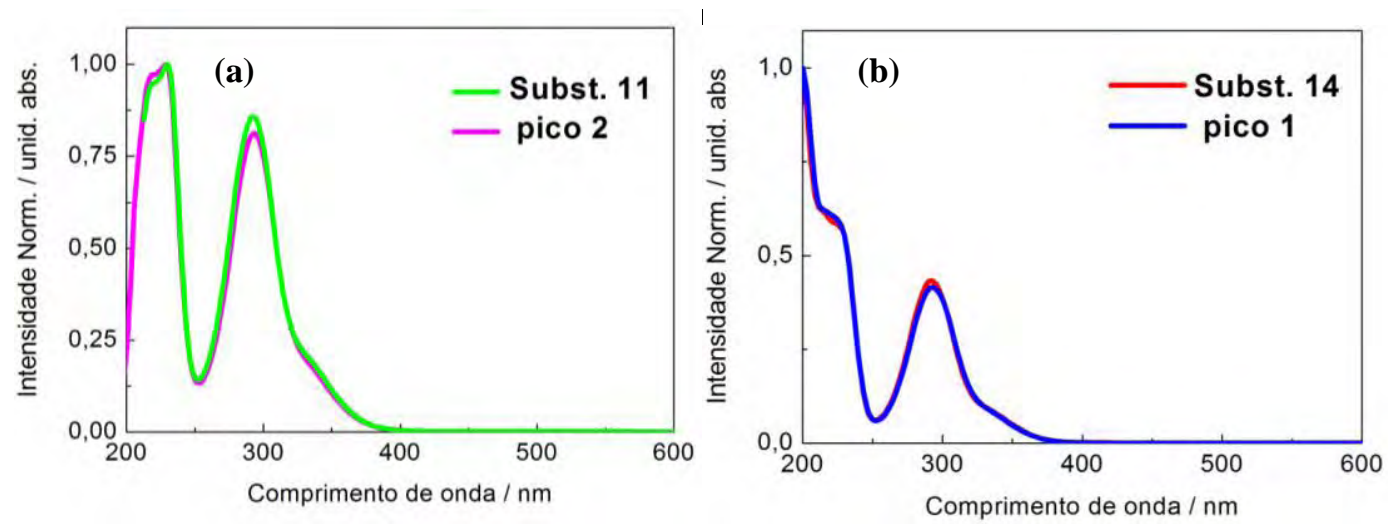

Figura 79 - Espectro de absorção no UV comparativo (a) da substância 11 e o pico 2 da fração AcOEt-FRU-17 e (b) da substância 14 e o pico 1 da fração AcOEt-FRU-17.

As substâncias 6, 7, 15 e 16 apresentaram espectro de absorção no UV, sinais de RMN ${ }^{1} \mathrm{H}$ e padrão de fragmentação característicos de biflavonóides e a subfração AcOEtFRU-7 mostrou-se como uma mistura de benzofenonas (Substs. 19 e 20). As substâncias 21, 22 e 23 mostraram-se semelhantes, quando comparados com dados de UV e massas, aos derivados de ácidos fenilpropanoídicos já isolados e identificados na fração BUOHFOL.

A substância 6, isolada da subfração AcOEt-FOL-14 (procedimento experimental 5.5), apresentou banda de absorção no UV em $\lambda=293 \mathrm{~nm}$ atribuída à banda II de uma flavanona (Figura 81). O espetro de $\mathrm{RMN}{ }^{1} \mathrm{H}$ apresentou sinais entre $\delta_{\mathrm{H}} 2,65$ e 5,70, 

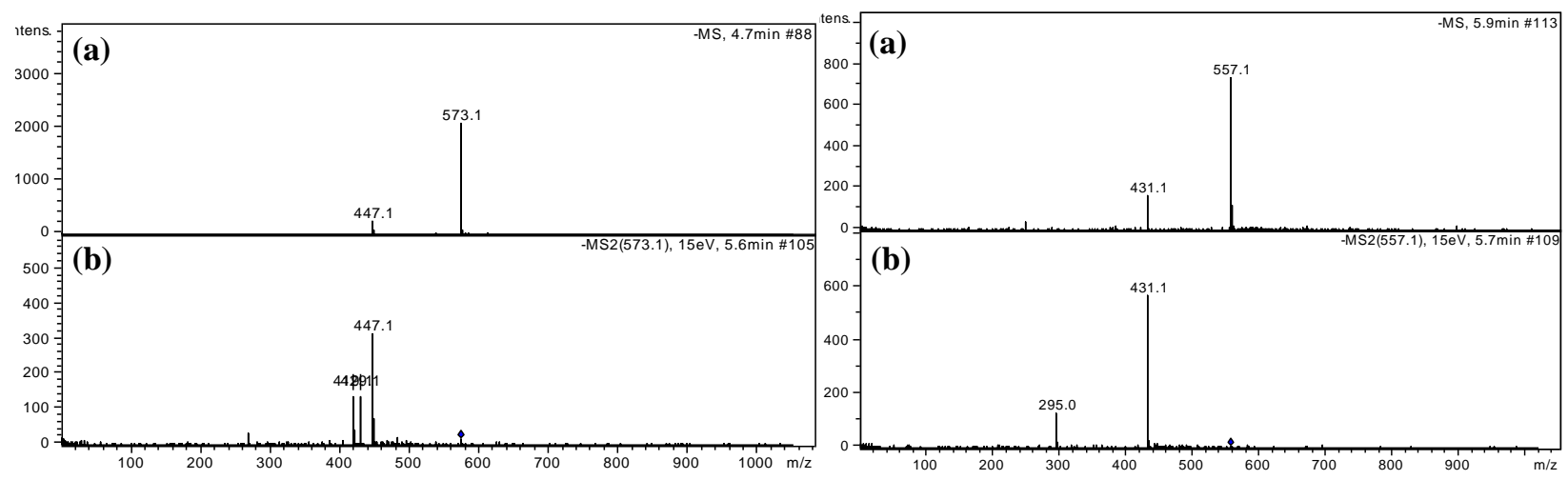

Figura 80 - Espectro de massas (a) de primeira e (b) segunda-ordem dos picos 1 (esquerda) e 2 (direita) da subfração AcOEt-FRU-17, obtido em modo negativo com energia de colisão de $15 \%$ para EM2 (ESI).

atribuídos aos hidrogênios H-2, H-3, H-2" e H-3', sinais entre $\delta_{\mathrm{H}} 5,82$ e 5,94, atribuídos a hidrogênios do anel A e sinais entre $\delta_{\mathrm{H}} 6,23$ e 7,25 atribuídos a hidrogênios do anel $\mathrm{B}$ (Figura 82). Todavia, em virtude da pequena quantidade de massa e complexidade do espectro em função da existência de atropoisomerismo, não foi possível atribuir satisfatoriamente os sinais, assim como também não foi possível adquirir os espectros de ${ }^{13} \mathrm{C}$ e bidimensionais. Assim, a identificação foi realizada a partir da comparação dos íons precursores de $\mathbf{6}$ e de seus produtos de fragmentação com dados da literatura, pelo uso da EM. No modo de ionização negativa (ESI), o espectro exibiu íon molecular $m / z 541$ [M$\mathrm{H}]^{-}$e fragmentos em m/z 415 [M-H-126] e 295 [M-H-126-120]', correspondendo à perda de floroglucinol (126 u) e subseqüente perda de 120 u por um mecanismo Retro-DielsAlder (Figuras 83 e 84). Nota-se por fim, que a substância 6 é muito semelhante a 11, diferindo apenas no padrão de substituição do anel B (livre de hidroxila na posição C-3"') podendo ser identificada com GB1a, um biflavonóide isolado dos frutos de $G$. xanthochymus (KONOSHIMA et al., 1970; BASLAS; KUMAR, 1979).

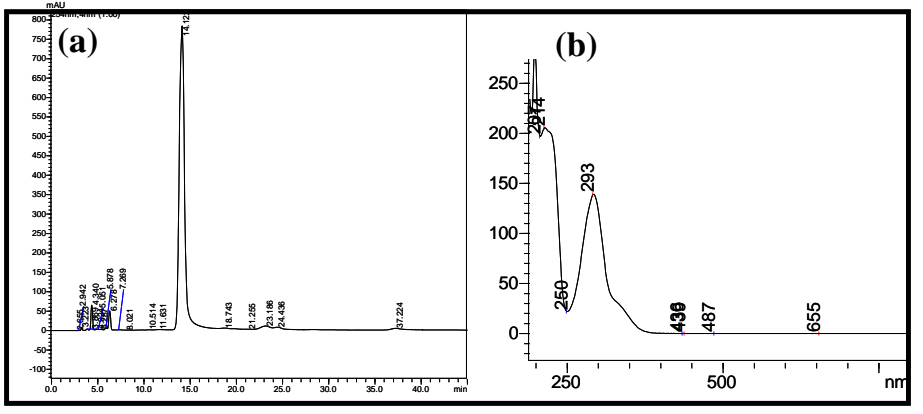

Figura 81 - (a) Cromatograma analítico e (b) espectro de absorção da substância 6 obtido via CLAE-UV-DAD no modo isocrático 1:1 (MeOH: $\left.\mathrm{H}_{2} \mathrm{O}\right)$ e suporte cromatográfico: ODS (Phenomenex, 25,0 cm x 4,6 mm x 5 $\mu \mathrm{m}$ ). 


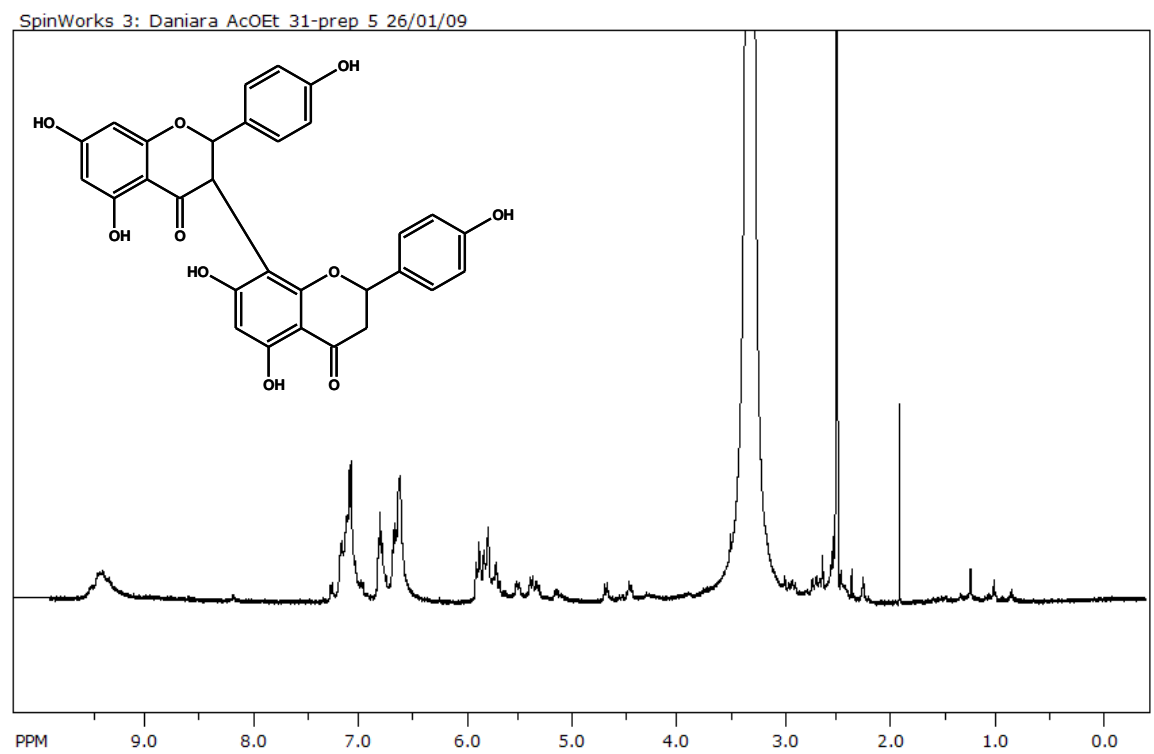

Figura 82 - Espectro de RMN de ${ }^{1} \mathrm{H}(500 \mathrm{MHz})$ da substância 6 (DMSO- $d_{6}$ ).

Do mesmo modo a substância 7, isolada da subfração AcOEt-FOL-15 (procedimento experimental 5.6) foi identificada através dos dados de EM pelo íon em $\mathrm{m} / z 551[\mathrm{M}-\mathrm{H}]^{-}$ (Figura 86), além da análise do espectro de $\mathrm{RMN}$ de ${ }^{1} \mathrm{H}$, em que se nota uma grande semelhança dos deslocamentos químicos e constantes de acoplamento entre 7 e 9, diferindo apenas no singleto em $\delta_{\mathrm{H}} 3,67$ integrando para três hidrogênios, que pode ser atribuído a presença de uma metila na estrutura de 7 (Figura 85). A partir dos dados da literatura para substâncias já isoladas de G. xanthochymus, pode-se identificar a substância 7 como 7-O-metilamentoflavona, um derivado metoxilado da amentoflavona isolado das folhas de G. xanthochymus (PARVEEN et al., 1994).

A substância 15, isolada da subfração AcOEt-SIL-9 (procedimento experimental 5.7), apresentou uma única banda de absorção no UV ( $\lambda=293 \mathrm{~nm})$, sugerindo a subclasse das flavanonas. Já a substância 16, isolada da subfração AcOEt-SIL-11 (procedimento experimental 5.9), apresentou bandas de absorção características de flavanonas/flavonas, com a banda I em $\lambda=348 \mathrm{~nm}$ e a banda II em $\lambda=289 \mathrm{~nm}$ (Figura 20). 


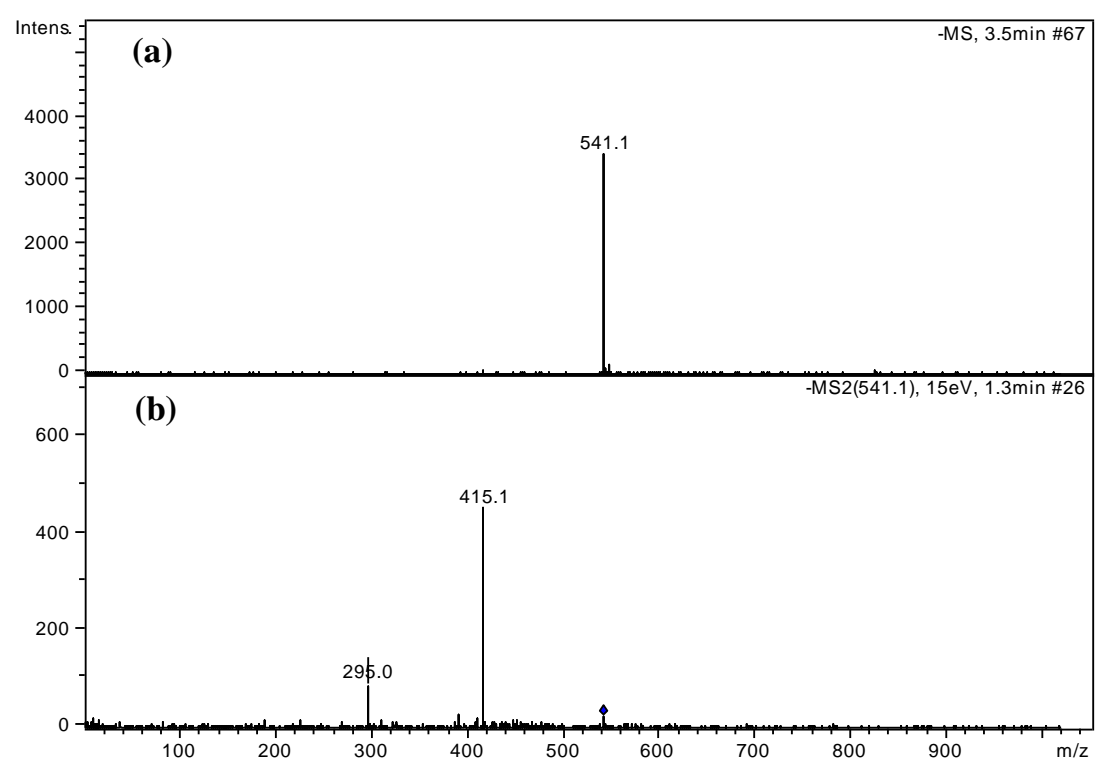

Figura 83 - Espectro de massas (a) de primeira e (b) segunda-ordem da substância 6, obtido em modo negativo com energia de colisão de 15\% para EM2 (ESI).

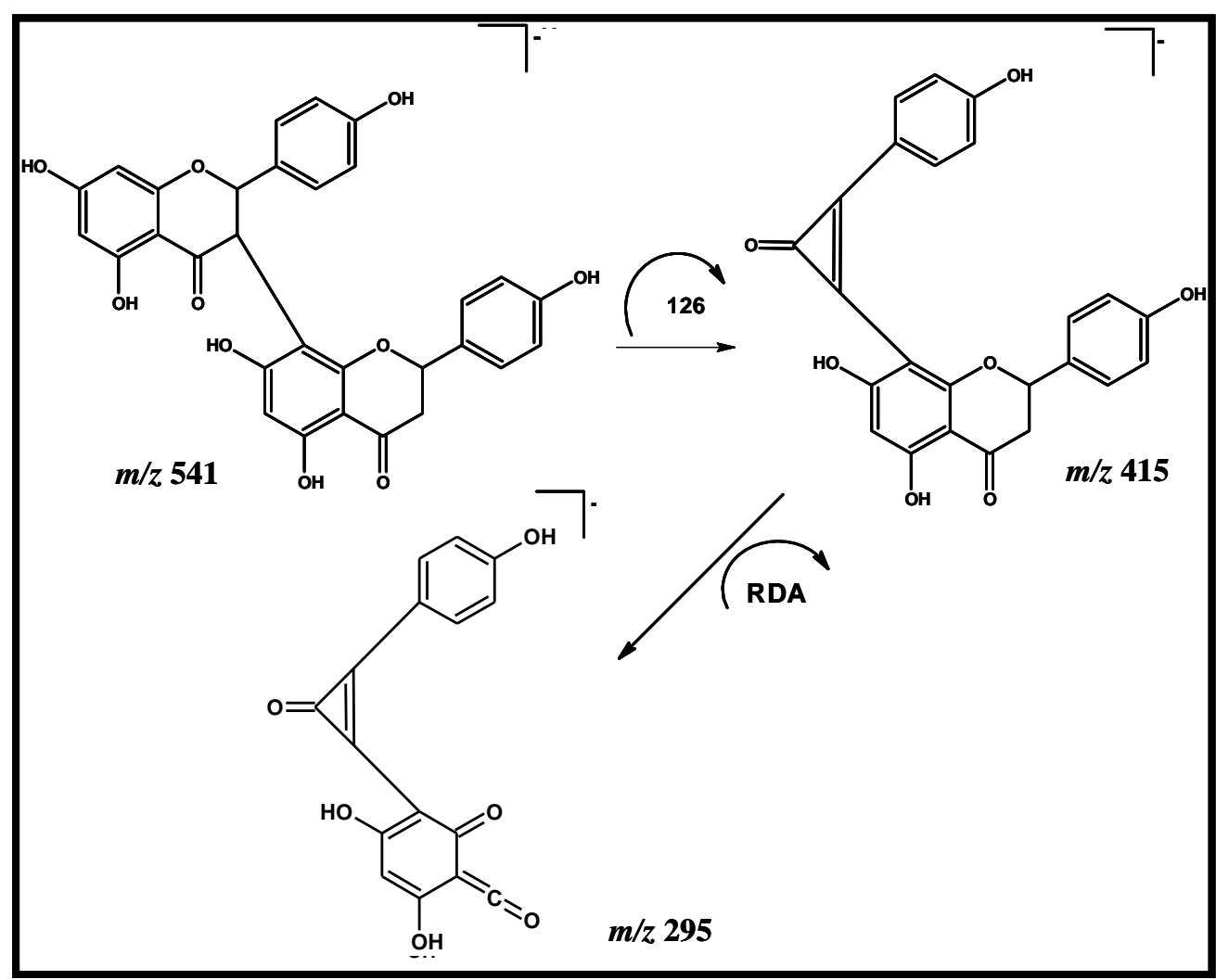

Figura 84 - Proposta de fragmentação da substância 6. 


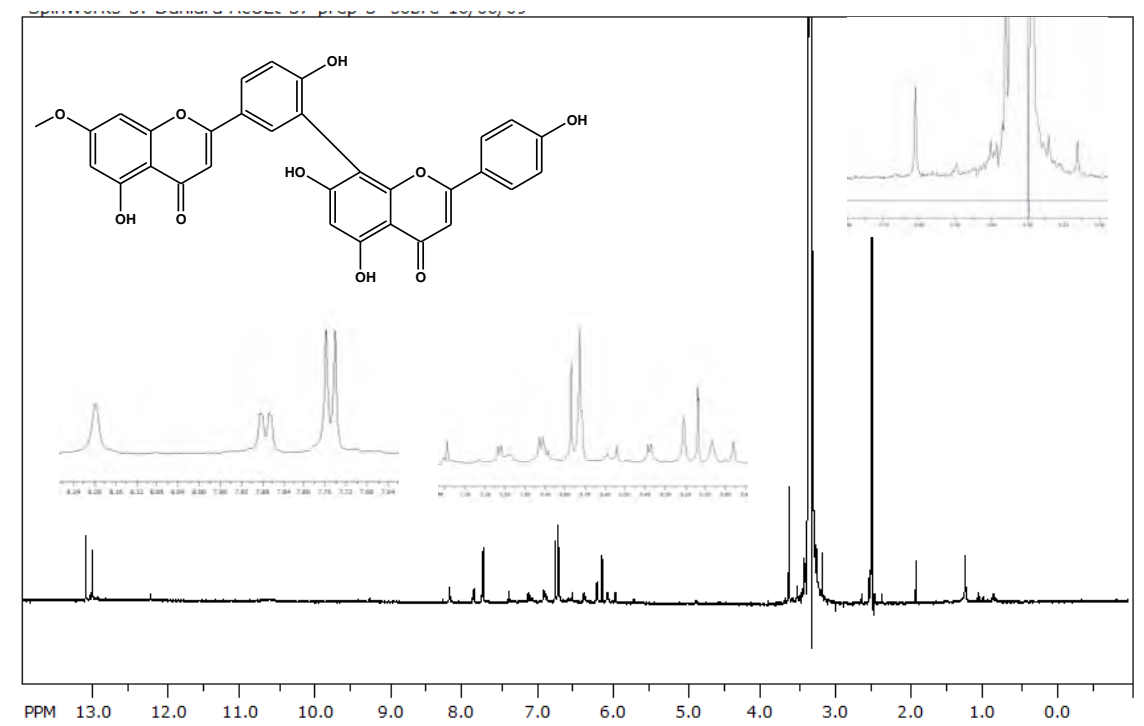

Figura 85 - Espectro de RMN de ${ }^{1} \mathrm{H}(500 \mathrm{MHz})$ da substância 7 (DMSO- $d_{6}$ ).

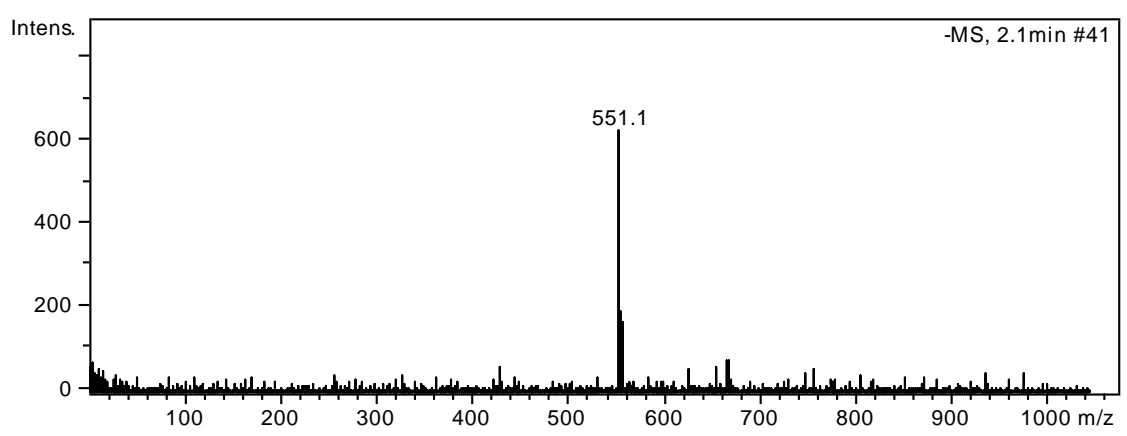

Figura 86 - Espectro de massas de primeira-ordem da substância 7 obtido no modo negativo (ESI).

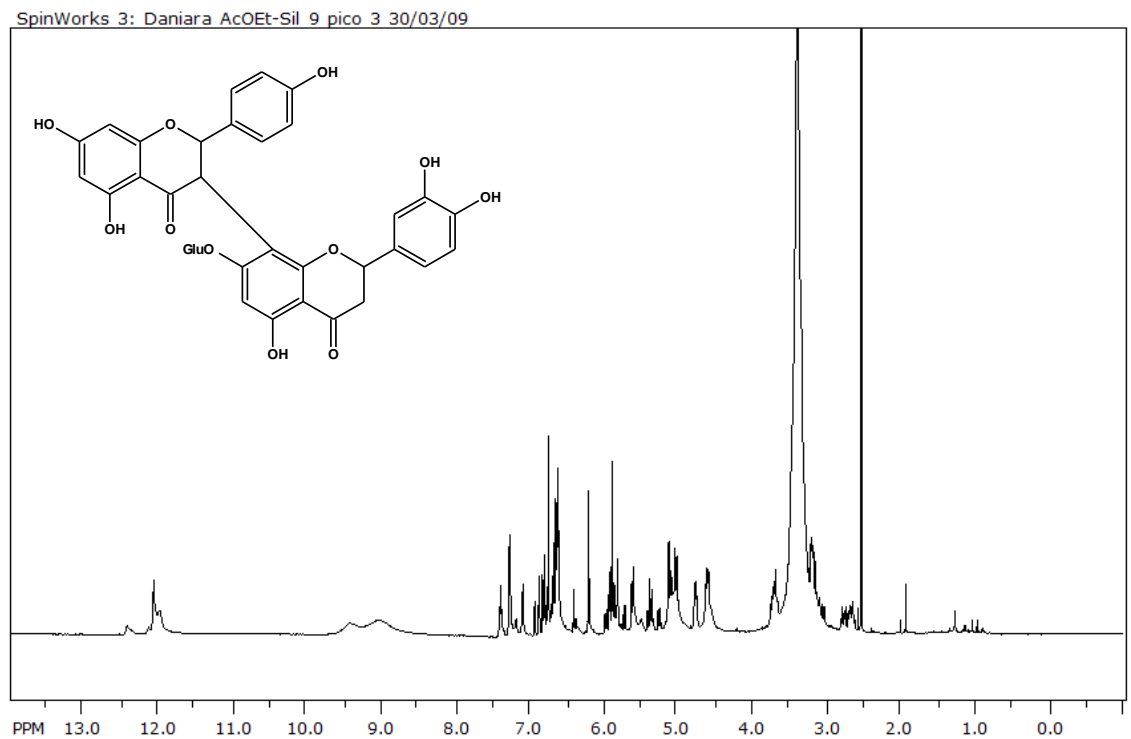

Figura 87 - Espectro de RMN de ${ }^{1} \mathrm{H}(500 \mathrm{MHz})$ da substância 15 (DMSO- $d_{6}$ ). 
A complexidade dos espectros de $\mathrm{RMN}$ de ${ }^{1} \mathrm{H}$ e duplicação de sinais pode ser explicada pelo efeito atropisomérico de ambas as substâncias, indicando a presença de biflavonóides do tipo $\mathrm{C} 3 \rightarrow \mathrm{C} 8$ ', Observa-se a presença de sinais em $\delta_{\mathrm{H}} 12,03$, relacionados a hidrogênios de hidroxilas quelatadas, capaz de estabelecer uma ligação intramolecular com o oxigênio carbonílico em C-4. O espectro também apresentou sinais entre $\delta_{\mathrm{H}} 2,54 \mathrm{e}$ 5,12, sugerindo a presença de uma unidade de açúcar ligada à aglicona (Figura 87 e Figura 88). Esses dados permitiram a identificação das substâncias 15 e 16, associados à análise por EM, que apresentou íon molecular de $m / z, 719$ [M-H] $]^{-}$para a substância 15 (Figura 89) e $m / z, 717[\mathrm{M}-\mathrm{H}]^{-}$para a substância 16 (Figura 90).

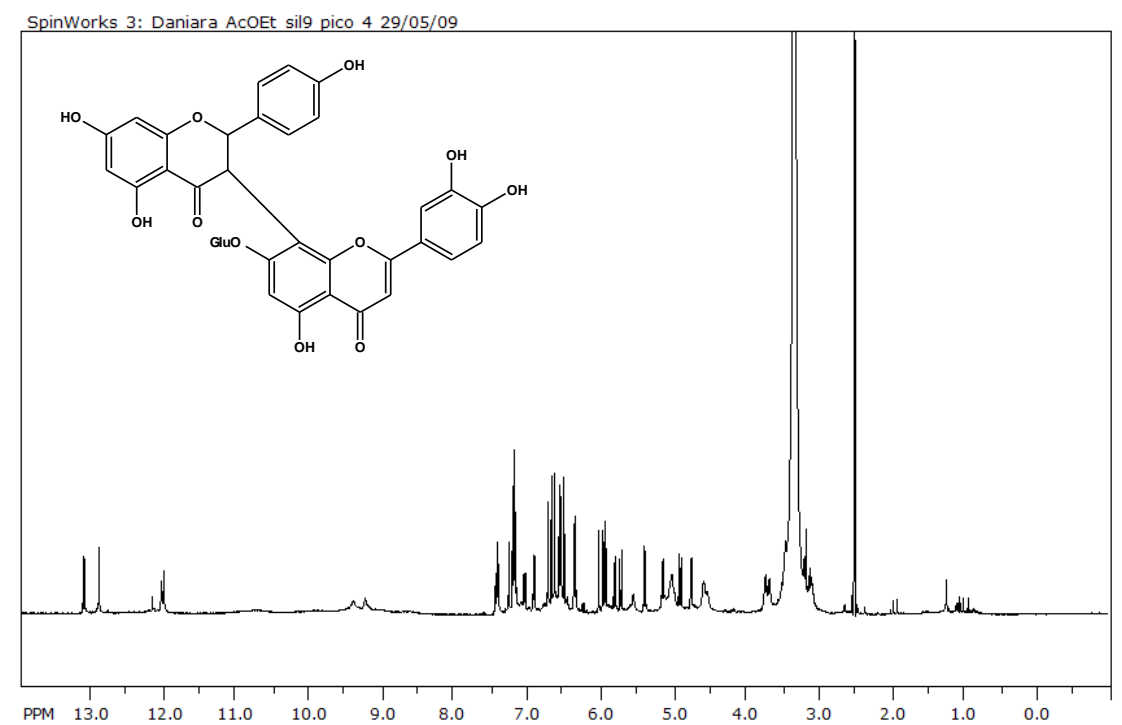

Figura 88 - Espectro de RMN de ${ }^{1} \mathrm{H}(500 \mathrm{MHz})$ da substância 16 (DMSO- $d_{6}$ ).

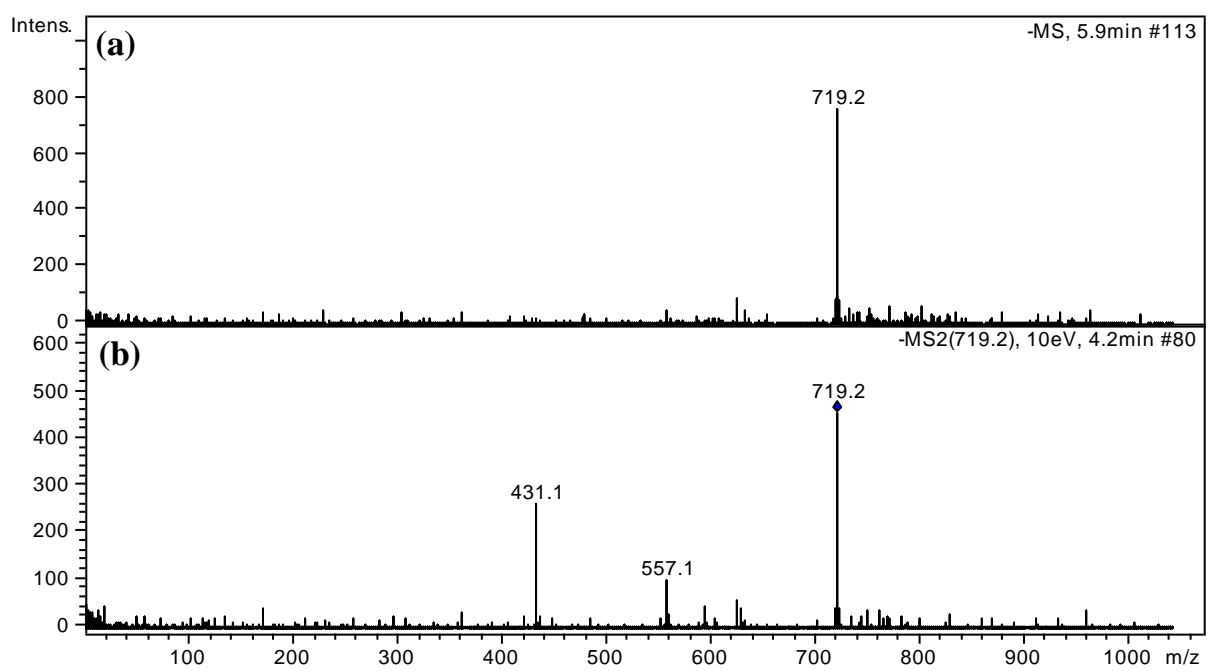

Figura 89 - Espectro de massas (a) de primeira e (b) segunda-ordem da substância 15, obtido em modo negativo com energia de colisão de 10\% para EM2 (ESI). 
Através do espectro de segunda ordem obtido no modo negativo (ESI) de 15 (EM2) pode-se sugerir a presença de uma unidade de hexose no esqueleto flavonoídico, representada pelo íon $m / z 557$ [M-H-162] e $m / z$, 431 [M-H-162-126]'. Aliados a esses dados e comparando o padrão de fragmentação com o apresentado pela substância 11, pode-se inferir que a substância 15 é o biflavonóide xantochimusídeo, um derivado glicosilado do GB2a já isolado dos caules de G. xanthochymus (KONOSHIMA et al., 1970). Já a substância 16 não apresentou fragmentos secundários que caracterizassem a presença de uma unidade de açúcar, sugerindo a necessidade de energia de colisão maior que $15 \%$. Todavia, o espectro de $g \mathrm{HMBC}$ mostrou a interação entre o hidrogênio anomérico em $\delta_{\mathrm{H}}$ $5,12(J=7,5 \mathrm{~Hz})$ com o sinal em $\delta_{\mathrm{C}} 160,8$, sugerindo a presença da glicose em C-7'. Comparando esses dados com a literatura, pode-se identificar a substância $\mathbf{1 6}$ como fukugisídeo, um derivado glicosilado da morelloflavona isolado dos frutos de $G$. xanthochymus (KONOSHIMA et al., 1970; BAGGETT et al., 2005).

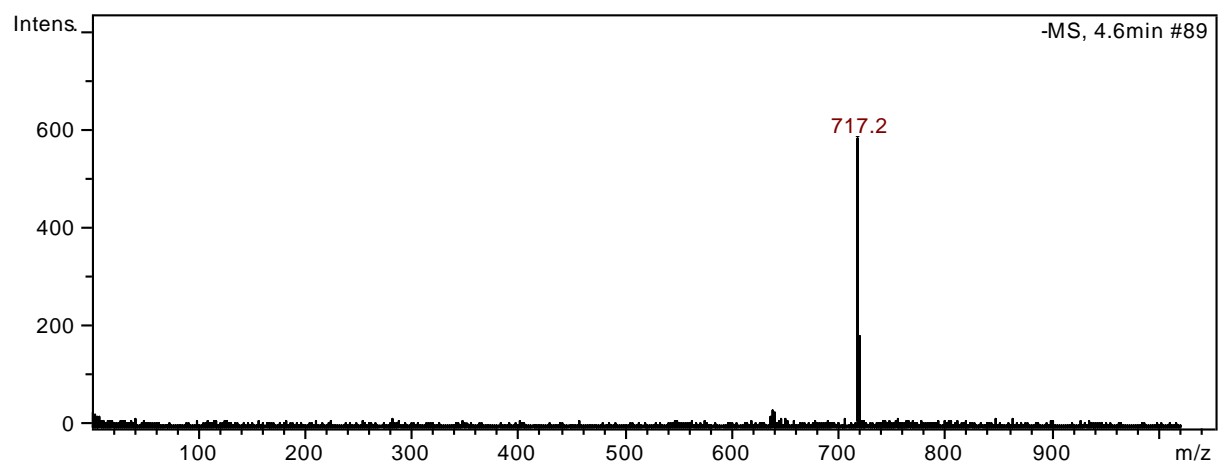

Figura 90 - Espectro de massas de primeira-ordem da substância 16 obtido no modo negativo (ESI).

A subfração AcOEt-FRU-7, obtida do fracionamento cromatográfico da fração AcOEt-FRU (procedimento experimental 5.11), apresentou duas bandas no UV em $\lambda=251$ e $356 \mathrm{~nm}$, características de benzofenonas (Figura 91). O espectro de RMN de ${ }^{1} \mathrm{H}$ (Figura 92) mostrou sinais entre $\delta_{H} 0,75$ e 2,90 característicos de grupos metílicos, metilênicos e metínicos, e entre $\delta_{\mathrm{H}} 4,47$ e 4,91 característicos de hidrogênios olefínicos. Exibiu também sinais em $\delta_{\mathrm{H}} 6,65(d, J=8,5 \mathrm{~Hz}), \delta_{\mathrm{H}} 6,91(m)$ e 7,18 $(d, J=2,5 \mathrm{~Hz})$ sugerindo a presença de um grupo aromático trissubstituído (Tabela 15). Esses dados são consistentes com os relatados para a classe das benzofenonas, porém a integração dos sinais de RMN de hidrogênio sugeriu que se tratava de uma mistura composta por dois isômeros, fato confirmado pela EM que apresentou um único sinal referente ao íon molecular em $\mathrm{m} / \mathrm{z} 601$ 
Tabela 15 - Dados de RMN de ${ }^{1} \mathrm{H}(500 \mathrm{MHz})$ das substâncias 19 e 20 (DMSO- $\left.d_{6}\right)$.

\begin{tabular}{|c|c|c|}
\hline & xantochimol (19) & cicloxantochimol (20) \\
\hline Posição & $\begin{array}{c}\delta_{\mathrm{H}}(\mathbf{p p m}) \\
\text { (multiplicidade; } J(\mathrm{~Hz}))\end{array}$ & $\begin{array}{c}\delta_{\mathrm{H}}(\mathrm{ppm}) \\
\text { (multiplicidade; } J(\mathrm{~Hz}))\end{array}$ \\
\hline 1 & - & - \\
\hline 2 & - & - \\
\hline 3 & - & - \\
\hline 4 & - & - \\
\hline 5 & - & - \\
\hline 6 & $1,49(m)$ & $1,50(\mathrm{~m})$ \\
\hline \multirow[t]{2}{*}{7} & $2,05(\mathrm{~m})$ & $1,97(\mathrm{~m})$ \\
\hline & $2,25(d ; 14,2)$ & $2,13(d ; 14,6)$ \\
\hline 8 & - & - \\
\hline 9 & - & - \\
\hline 10 & - & - \\
\hline 11 & - & - \\
\hline 12 & $7,18(d ; 2,0)$ & $7,16(d ; 2,0)$ \\
\hline 13 & - & - \\
\hline 14 & - & - \\
\hline 15 & $6,65(d ; 8,5)$ & $6,64(d ; 6,8)$ \\
\hline 16 & $6,91(\mathrm{~m})$ & $6,91(\mathrm{~m})$ \\
\hline \multirow[t]{2}{*}{17} & $2,58(m)$ & $2,33(\mathrm{~m})$ \\
\hline & $2,70(d d ; 13,9$ e 8,8$)$ & $2,49(m)$ \\
\hline 18 & $4,90(\mathrm{~m})$ & $4,88(m)$ \\
\hline 19 & - & - \\
\hline 20 & $1,73(s)$ & $1,60(s)$ \\
\hline 21 & $1,69(s)$ & $1,52(s)$ \\
\hline 22 & $1,16(s)$ & $1,05(s)$ \\
\hline 23 & $1,00(s)$ & $0,91(s)$ \\
\hline \multirow[t]{2}{*}{24} & $2,03(\mathrm{~m})$ & $2,04(\mathrm{~m})$ \\
\hline & $2,11(\mathrm{~m})$ & $2,56(m)$ \\
\hline 25 & $4,86(m)$ & $4,91(m)$ \\
\hline 26 & - & - \\
\hline 27 & $1,65(s)$ & $1,65(s)$ \\
\hline 28 & $1,50(s)$ & $1,60(s)$ \\
\hline \multirow[t]{2}{*}{29} & $1,92(d d ; 13,9$ e 5,6$)$ & $1,01(d ; 13,1)$ \\
\hline & $2,02(m)$ & $2,90(d d ; 14,2$ e 3,4$)$ \\
\hline 30 & $2,55(m)$ & $1,24(m)$ \\
\hline 31 & - & - \\
\hline 32 & $4,47(m)$ & $0,75(s)$ \\
\hline 33 & $1,61(s)$ & $1,17(s)$ \\
\hline 34 & $1,46(m)$ & $1,47(m)$ \\
\hline 35 & $1,85(m)$ & $4,91(m)$ \\
\hline 36 & - & - \\
\hline 37 & $4,63(d ; 6,4)$ & $1,64(s)$ \\
\hline 38 & $1,58(s)$ & $1,61(s)$ \\
\hline
\end{tabular}

[M-1] (Figura 93). Das benzofenonas isoladas de G. xanthochymus apenas cinco

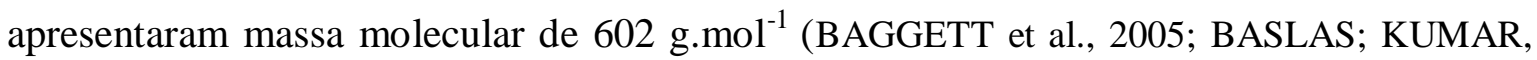
1979 e 1981; KARANJGOAKAR, et al., 1973; RAMA RAO; VENKATSWAMY; YEMUL, 1980) como mostra a Tabela 16. De acordo com os dados de RMN ${ }^{1} \mathrm{H}$, padrão de 
fragmentação de cada substância e sinais apresentados através da EM2 pela subfração AcOEt-FRU-7 (m/z 465, 409 e 273) pode-se inferir que a mesma constitui-se do xantochimol e cicloxantochimol, identificados como substâncias $\mathbf{1 9}$ e 20, respectivamente.

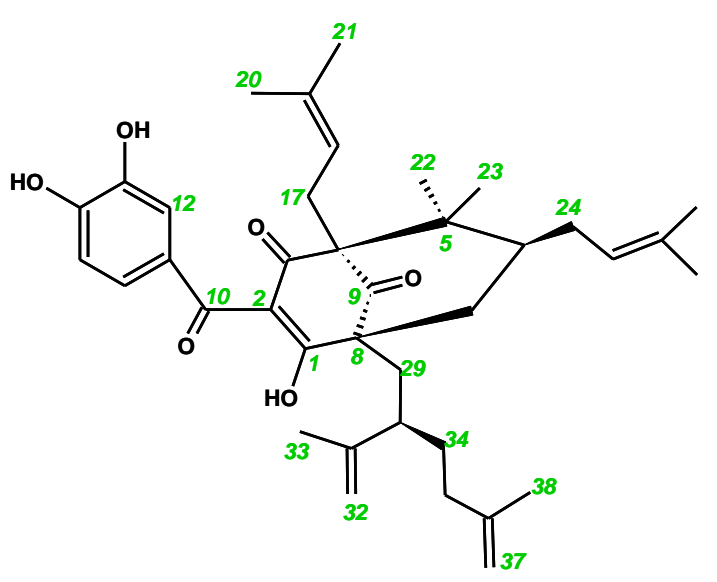

Xanthochymol (19)

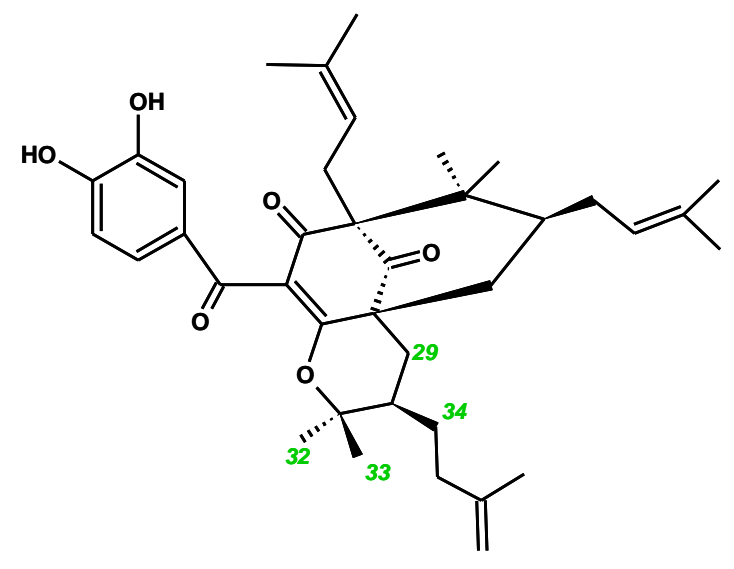

Cicloxanthochymol (20)

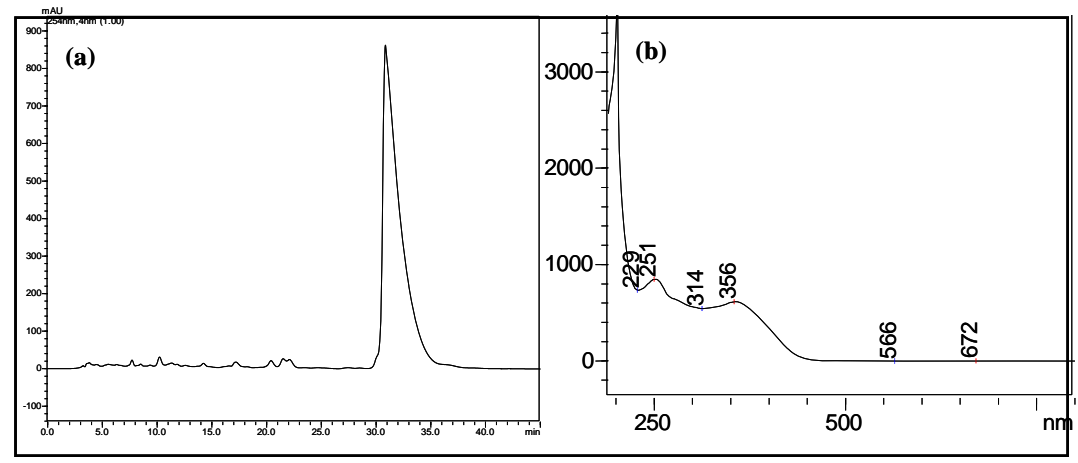

Figura 91 - Cromatograma analítico e (b) espectro de absorção da subfração AcOEt-FRU-7 obtido via CLAE-UV-DAD no modo isocrático $\mathrm{MeOH}: \mathrm{H}_{2} \mathrm{O}: \mathrm{HOAc}(75: 24,5: 0,5)$, suporte cromatográfico: ODS (Phenomenex, 25,0 cm x 4,6 mm x $5 \mu \mathrm{m}$ ) e detecção em $\lambda=254 \mathrm{~nm}$.

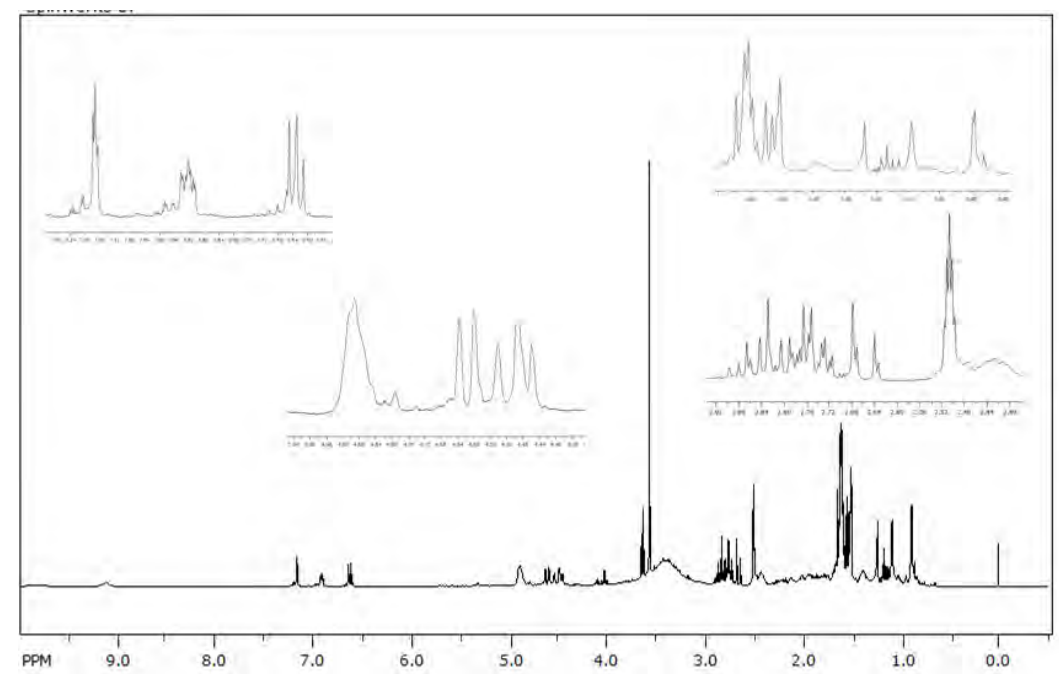

Figura 92 - Espectro de RMN de ${ }^{1} \mathrm{H}(500 \mathrm{MHz})$ das substâncias 19 e 20 (DMSO- $d_{6}$ ). 
Tabela 16 - Fragmentos obtidos de benzofenonas isoladas de G. xanthochymus através de EM e EM2.

\begin{tabular}{c|c|c|c}
\hline Compostos & $\begin{array}{c}\boldsymbol{E M} \\
\text { (ion molecular) }\end{array}$ & \multicolumn{2}{|c}{$\begin{array}{c}\text { EM2 } \\
\text { (principais fragmentos) }\end{array}$} \\
\cline { 3 - 4 } & $\boldsymbol{m} / \boldsymbol{z}$ & $\boldsymbol{m} / \boldsymbol{z}$ & $\boldsymbol{m} / \boldsymbol{z}$ \\
\hline cicloxantochimol & 601,4 & 465 & - \\
isoxantochimol & 601,4 & 433 & 203 \\
Gutiferona E & 601,4 & 449 & 177 \\
Gutiferona H & 601,4 & $*$ & $*$ \\
xantochimol & 601,4 & 409 & 273 \\
\hline
\end{tabular}

* dados não encontrados na literatura

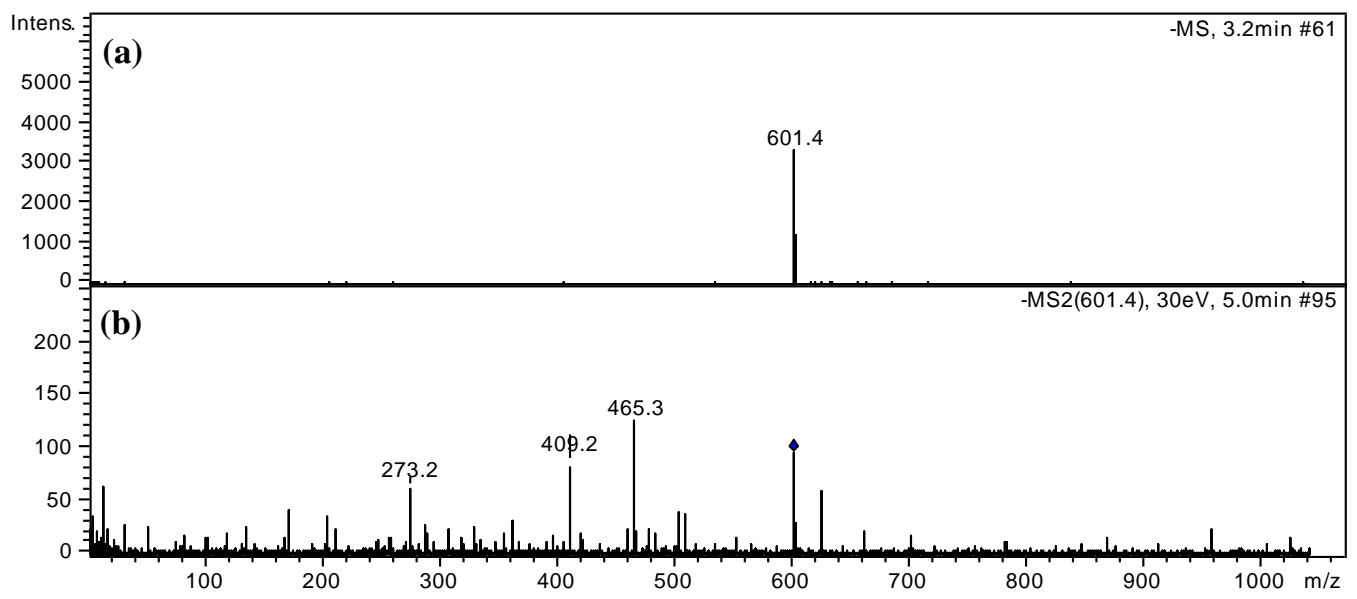

Figura 93 - Espectro de massas (a) de primeira e (b) segunda-ordem da subfração AcOEt-FRU-7, obtido em modo negativo com energia de colisão de 30\% para EM2 (ESI).

As substâncias 21, 22 e 23 (derivados de ácidos fenilpropanoídicos), isoladas da subfração BuOH-FOL-6 (procedimento experimental 5.10) e da subfração AcOEt-SIL-11 (procedimento experimental 5.9), apresentou pequena quantidade de massa, o que inviabilizou o processo de elucidação estrutural por técnicas convencionais de RMN mono e bidimensionais. Assim, a identificação foi realizada a partir da comparação dos íons precursores e de seus produtos de fragmentação (razão $\mathrm{m} / \mathrm{z}$ e intensidade dos fragmentos em relação ao pico base, em porcentagem), de acordo com dados da literatura (CLIFFORD et al., 2003 e 2006). Como apresentado na tabela 14, o ácido 4-cafeoilquínico (4-ACQ) apresenta pico base em $\mathrm{m} / z 173[\mathrm{M}-\mathrm{H}]^{-}$, diferentemente dos isômeros 3-ACQ e 5-ACQ, que apresentam pico base em $m / z 191$ [M-1]. Comparando-se o espectro de primeira e segunda-ordem da substância 22 (Figura 94) com o padrão de fragmentação apresentado pelo 4-ACQ, pode-se identificar 22 como ácido 4-cafeoilquínico. De maneira análoga, as substâncias 21 e 23 foram identificadas como ácidos 3-p-coumaroilquínico (3-ApCoQ) e 4-p-coumaroilquínico (4-A $p \mathrm{CoQ})$, respectivamente (Figura 95). 

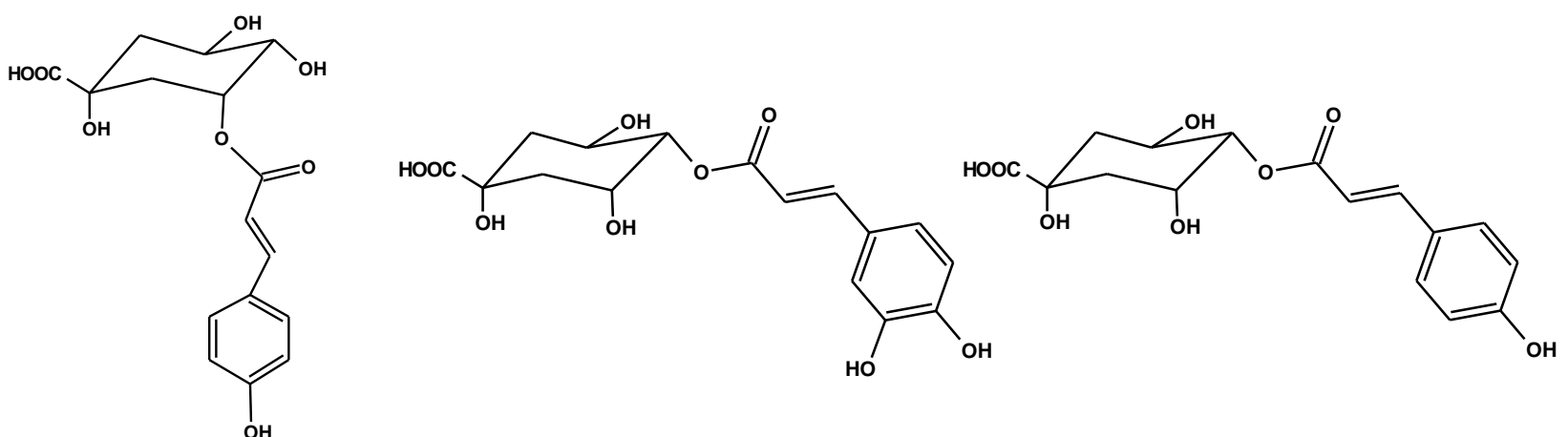

(21)

(22)

(23)

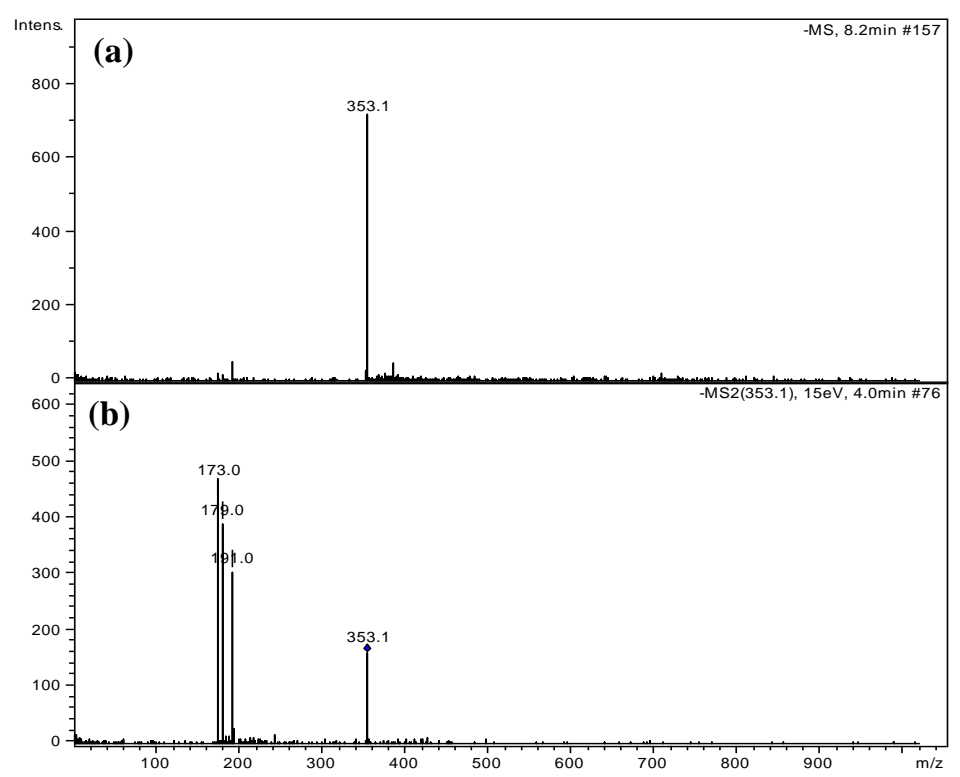

Figura 94 - Espectro de massas (a) de primeira e (b) segunda-ordem da substância 22, obtido em modo negativo com energia de colisão de $15 \%$ para EM2 (ESI).

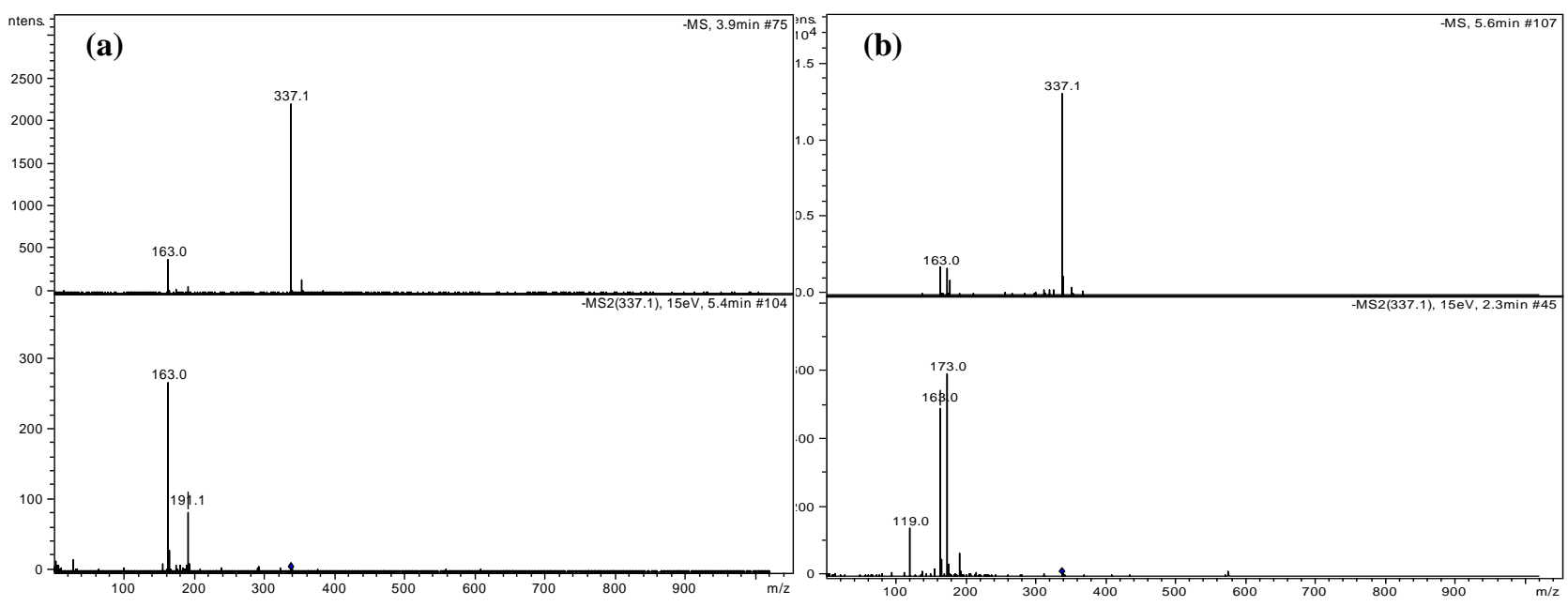

Figura 95 - Espectro de massas de primeira e segunda-ordem obtido em modo negativo com energia de colisão de 15\% para EM2 (ESI) da (a) substância 21 e da (b) substância 23. 


\subsection{Identificação de triterpenos e esteróides presentes nos extratos de baixa polaridade de Garcinia xanthochymus utilizando cromatografia gasosa (CG)}

A bioatividade de extratos de baixa polaridade tem sido frequentemente associada a misturas complexas de triterpenóides e/ou esteróides, sem no entanto, uma análise mais aprofundada de identificação dos componentes da mistura. Isso acontece, em primeiro lugar, porque os procedimentos de fitoquímica tradicional, que incluem isolamento dos componentes de misturas de diversos componentes, icluindo isômeros, podem ser afanosos e relativamente caros. Em segundo lugar, devido à sua complexidade estrutural, a análise

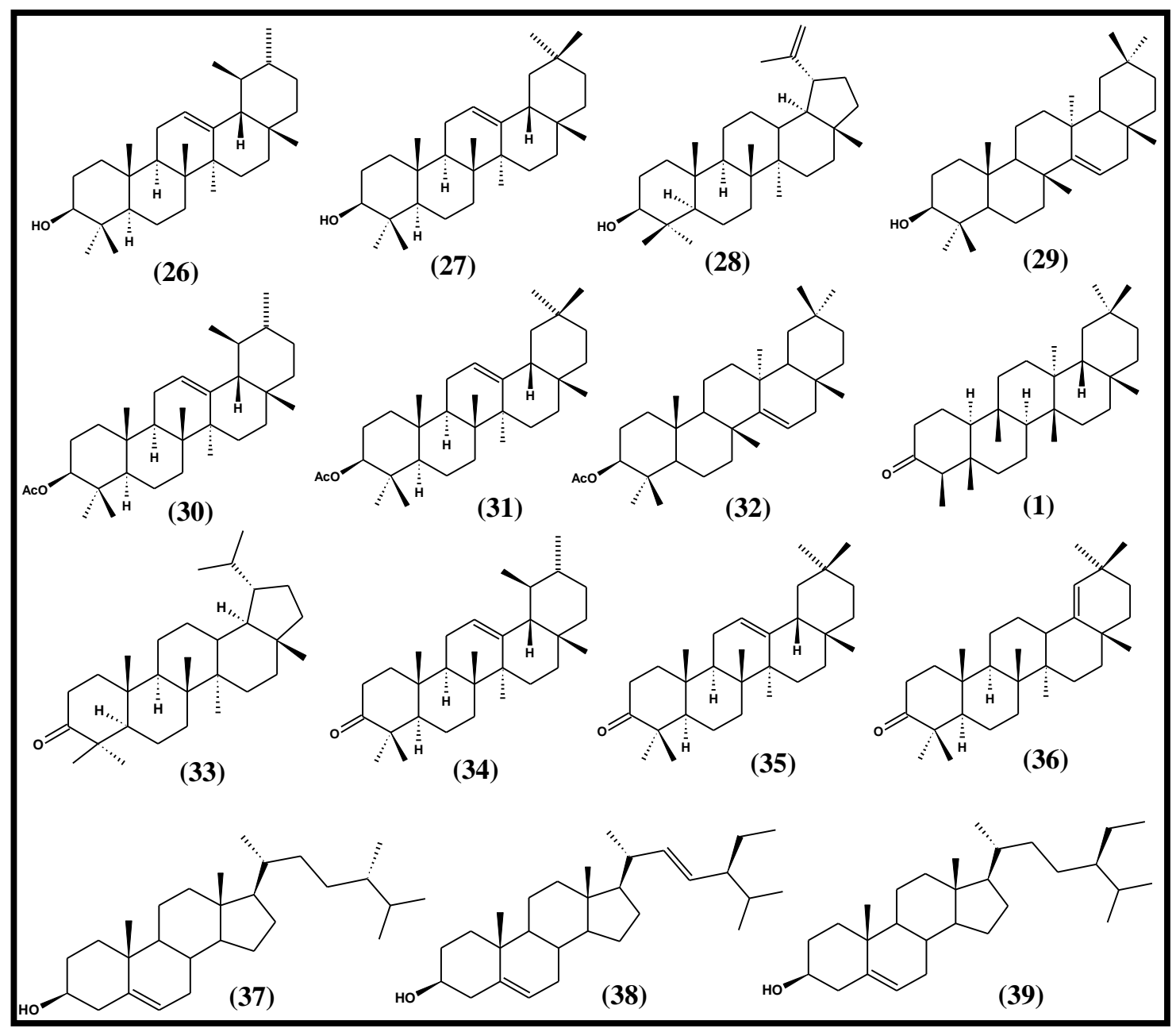

Figura 96 - Estruturas dos triterpenos e esteróides identificados nos extratos e frações de baixa polaridade de Garcinia xanthochymus.

de triterpenos e esteróides por técnicas espectroscópicas, tem se mostrado difícil em muitos casos. A Cromatografia gasosa (CG) surgiu como uma das melhores técnicas analíticas 
para caracterização rápida, simples e relativamente barata de compostos apolares de extratos de plantas (REGASINI et al., 2009).

Tabela 17 - Valores da retenção relativa das amostras com o colesterol.

\begin{tabular}{|c|c|c|c|c|c|c|c|c|}
\hline \multirow{2}{*}{ Compostos } & \multicolumn{2}{|c|}{$H E X-F O L$} & \multicolumn{2}{|c|}{$\begin{array}{c}\text { FR. HEX- } \\
\quad \text { FOL }\end{array}$} & \multicolumn{2}{|c|}{$H E X-F R U$} & \multirow{2}{*}{$S P B-5$} & \multirow{2}{*}{$S P B-50$} \\
\hline & $a$ & $b$ & $a$ & $b$ & $a$ & $\boldsymbol{b}$ & & \\
\hline (26) $\alpha$-Amirina & 1,36 & - & 1,37 & - & - & - & 1,38 & 2,02 \\
\hline (27) $\beta$-Amirina & - & - & 1,31 & 1,78 & 1,31 & 1,82 & 1,32 & 1,80 \\
\hline (28) Lupeol & - & - & 1,39 & - & 1,39 & - & 1,39 & 2,16 \\
\hline (29) Taraxerol & - & - & - & 1,74 & - & - & 1,29 & 1,75 \\
\hline (30) Acetato de $\alpha$-amirina & 1,55 & - & - & - & - & - & 1,57 & 2,25 \\
\hline (31) Acetato de $\beta$-amirina & - & - & - & 1,93 & - & 1,92 & 1,49 & 1,93 \\
\hline Acetato de lupeol & - & - & - & - & - & - & $\mathbf{1 , 5 8}$ & 2,27 \\
\hline Acetato de bauerenila & - & - & - & - & - & - & - & 2,54 \\
\hline (32) Acetato de taraxerol & 1,46 & - & 1,44 & 1,93 & 1,44 & 1,92 & 1,46 & 1,93 \\
\hline Acetato de friedelanoíla & - & - & - & - & - & - & 1,82 & 2,95 \\
\hline (1) Friedelina & - & 2,76 & - & - & - & - & 1,58 & 2,78 \\
\hline (33) Lupenona & 1,36 & - & - & - & - & - & 1,34 & 2,01 \\
\hline (34) $\alpha$-Amirenona & 1,36 & 1,95 & - & - & - & - & 1,34 & 1,94 \\
\hline (35) $\beta$-Amirenona & 1,28 & - & 1,28 & 1,74 & 1,28 & 1,73 & 1,28 & 1,73 \\
\hline (36) Germanicona & - & - & 1,26 & - & 1,26 & - & 1,26 & 1,66 \\
\hline (37) Campesterol & 1,12 & 1,21 & - & - & 1,13 & - & 1,13 & 1,23 \\
\hline (38) Estigmasterol & 1,18 & - & 1,19 & - & 1,19 & 1,30 & 1,18 & 1,30 \\
\hline (39) $\beta$-Sitosterol & - & - & 1,26 & 1,48 & 1,26 & 1,45 & 1,26 & 1,48 \\
\hline Estigmas-4en-3-ona & - & - & - & - & - & - & - & - \\
\hline Colesterol & 1 & 1 & 1 & 1 & 1 & 1 & 1,00 & 1,00 \\
\hline
\end{tabular}

" $\boldsymbol{a}$ " significa que a análise foi realizada em SBP-5 e " $\boldsymbol{b}$ " realizada em SPB-50.

Diante deste contexto, o extrato hexânico das folhas (HEX-FOL), a fração hexânica das folhas (FR. HEX-FOL) e o extrato hexânico dos frutos (HEX-FRU) foram analisados por cromatografia gasosa $(\mathrm{CG})$ em comparação às retenções relativas $(\mathrm{RR})$ de triterpenos e esteróis padrões relatadas por Crevelin (2006). A Tabela 17 e as Figura 96Figura 98 apresentam a composição química de cada amostra, realizadas nas duas colunas capilares especificadas no item 4.1.8.

A exatidão do método é maior quando ocorre reprodutibilidade entre as colunas capilares e, para maior confiabilidade do método, define-se que o erro não pode ultrapassar duas casas decimais. Assim, pode-se inferir que a $\beta$-amirina, acetato de taraxerol, $\beta$ amirenona e $\beta$-sitosterol estão presentes na FR. HEX-FOL e HEX-FRU com maior 
confiabilidade. Também para $\alpha$-amirenona e campesterol, presentes no HEX-FOL, e estigmasterol, detectado somente no HEX-FRU, os dados apresentam alta confiabilidade.

Com menor reprodutibilidade, pode-se dizer que estão presentes no HEX-FOL a $\alpha$ amirina, acetato de $\alpha$-amirina, acetato de taraxerol, friedelina, lupenona, $\beta$-amirenona e estigmasterol. Adicionalmente, foram também detectados na FR. HEX-FOL, a $\alpha$-amirina, lupeol, germanicona e estigmasterol, e no HEX-FRU, o lupeol, acetato de $\beta$-amirina, germanicona e campesterol.

Estes resultados mostram claramente que os extratos e frações de baixa polaridade de dois diferentes órgãos de Garcinia xanthochymus apresentam grande similaridade em seus perfis químicos, corroborando ainda mais a importância da desreplicação, etapa crucial, que imprime maior agilidade a estudos de bioprospecção.

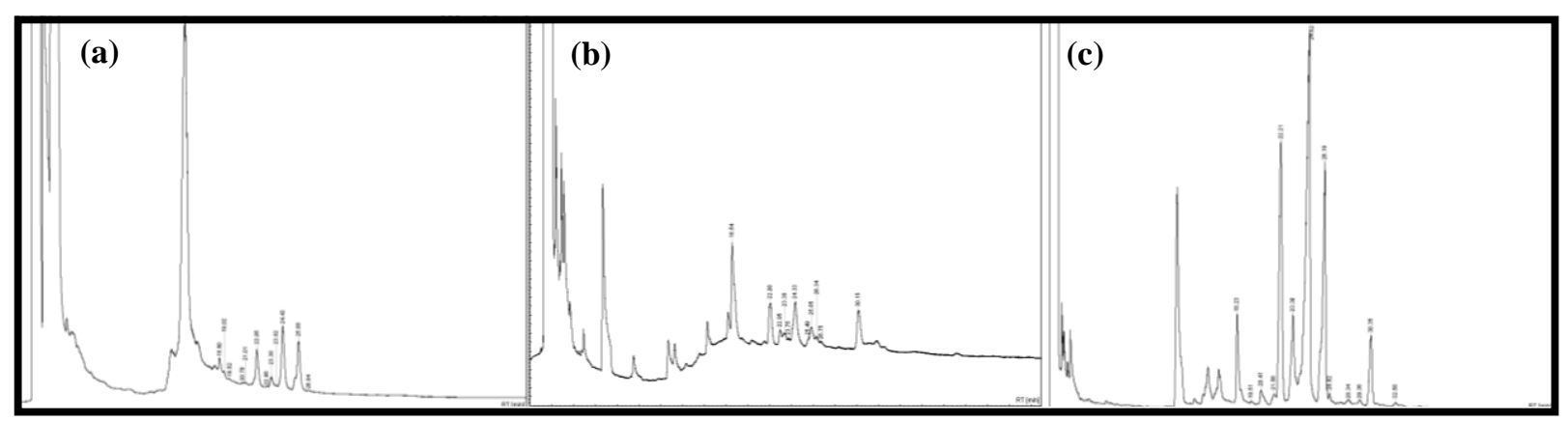

Figura 97 - Perfil cromatográfico (CG-DIC) em SPB-5 (a) do HEX-FRU [38 $t_{1}=22,05 ; 39$ $\mathrm{t}_{\mathrm{r}}=23,38 ; \mathbf{3 5} \mathrm{t}_{\mathrm{r}}=23,82 ; \mathbf{2 7} \mathrm{t}_{\mathrm{r}}=24,43$ e $\left.32 \mathrm{t}_{\mathrm{r}}=26,84\right]$ (b) da FR. HEX-FOL [39 $\mathrm{t}_{\mathrm{r}}=23,38 ; \mathbf{3 5} \mathrm{t}_{\mathrm{r}}=23,75$; $27 t_{1}=24,33$ e $\left.32 t_{1}=26,75\right]$ (c) e do EXT-FOL [37 $t_{1}=20,41$ e $\left.34 t_{1}=24,82\right]$, em presença de colesterol (padrão interno).

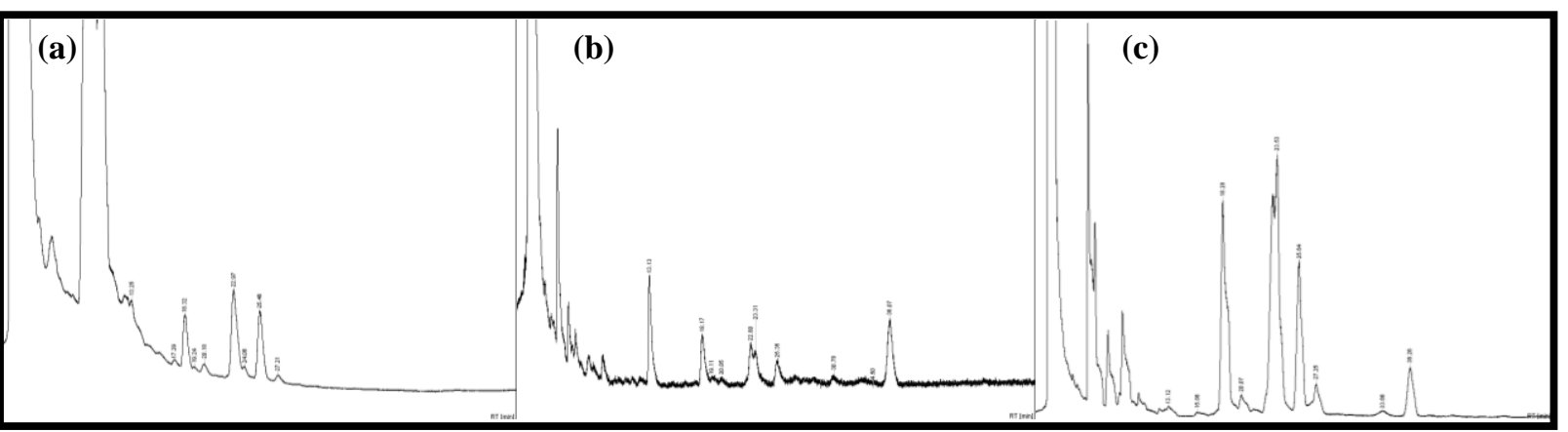

Figura 98 - Perfil cromatográfico (CG-DIC) em SPB-50 (a) do HEX-FRU [38 $t_{1}=17,29 ; 39$ $\mathrm{t}_{\mathrm{r}}=19,24 ; \mathbf{3 5} \mathrm{t}_{\mathrm{r}}=22,97 ; \mathbf{2 7} \mathrm{t}_{\mathrm{r}}=24,06$ e $\left.32 \mathrm{t}_{\mathrm{r}}=25,46\right]$ (b) da FR. HEX-FOL [39 $\mathrm{t}_{\mathrm{r}}=19,11 ; \mathbf{3 5} \mathrm{t}_{\mathrm{r}}=22,80$; $27 t_{1}=23,31$ e $\left.32 t_{1}=25,35\right]$ (c) e do EXT-FOL [37 $t_{1}=15,86$ e $\left.34 t_{1}=25,64\right]$, em presença de colesterol (padrão interno). 


\subsection{Atividade biológica dos extratos, frações e substâncias isoladas de Garcinia xanthochymus}

\subsubsection{Atividade antioxidante}

As folhas de G. xanthochymus apresentaram melhores resultados de $\mathrm{CI}_{50}$ quando comparadas com os frutos da mesma espécie. Segundo a tabela abaixo, o Extrato Bruto Etanólico das folhas (ETOH-FOL) mostrou-se bastante ativo com valor de $\mathrm{CI}_{50}=12$ $\mu \mathrm{g} / \mathrm{mL}$ ). Após o fracionamento por ELL, destacaram-se as frações AcOEt-FOL e BuOHFOL, com $\mathrm{CI}_{50}$ de $11 \mu \mathrm{g} / \mathrm{mL}$ e $18 \mu \mathrm{g} / \mathrm{mL}$, respectivamente, próximos ou menores aos apresentados pelos controles positivos $\operatorname{Trolox}^{\circledR}\left(\mathrm{CI}_{50}=10 \mu \mathrm{g} / \mathrm{mL}\right)$ e quercetina $\left(\mathrm{CI}_{50}=17\right.$ $\mu \mathrm{g} / \mathrm{mL})$.

Os resultados observados no gráfico (Figura 99) a na Tabela 18 corroboram a importância de substâncias com unidades fenólicas e/ou núcleos catecólicos (presentes em sua maioria em extratos polares) em antioxidantes em potencial.

Tabela 18 - Atividade antioxidante dos extratos e frações de Garcinia xanthochymus frente ao radical DPPH.

\begin{tabular}{|c|c|c|}
\hline \multicolumn{2}{|c|}{ Extratos e frações de Garcinia xanthochymus } & $\mathrm{CI}_{50}(\mu \mathrm{g} / \mathrm{mL})$ \\
\hline \multirow{6}{*}{ 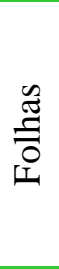 } & ETOH-FOL & 12 \\
\hline & HEX-FOL & $\mathrm{n}^{*}$ \\
\hline & FR. HEX-FOL & $\mathrm{n}^{*}$ \\
\hline & AcOEt-FOL & 11 \\
\hline & BuOH-FOL & 18 \\
\hline & HA-FOL & 19 \\
\hline \multirow{7}{*}{ 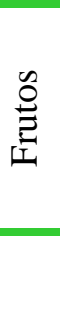 } & ETOH-FRU & $\mathrm{n}^{*}$ \\
\hline & HEX-FRU & $\mathrm{n}^{*}$ \\
\hline & AcOEt-FRU & $\mathrm{n}^{*}$ \\
\hline & BuOH-FRU & $\mathrm{n}^{*}$ \\
\hline & HA-FRU & $n^{*}$ \\
\hline & Trolox $^{\circledR}$ & 10 \\
\hline & Quercetina & 17 \\
\hline
\end{tabular}

As substâncias 5, 8, 10-20 foram avaliadas a fim de verificar se alguma delas seria a responsável pela forte atividade antioxidante apresentada nos extratos e/ou frações de $G$. xanthochymus (Tabela 21).

As substâncias $\mathbf{8}$ e $\mathbf{1 6}$ apresentaram os melhores resultados com valores de $\mathrm{CI}_{50}$ iguais 
a $8 \mu \mathrm{g} / \mathrm{mL}$ e $6 \mu \mathrm{g} / \mathrm{mL}$, respectivamente.
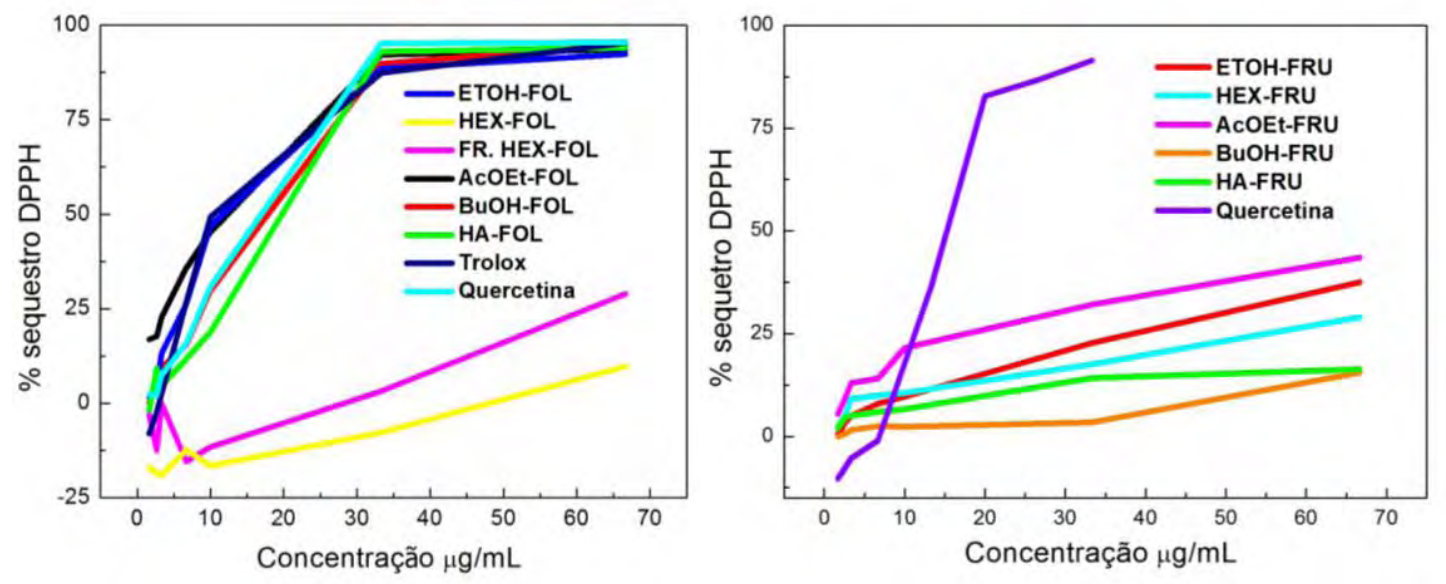

Figura 99 - Gráfico da curva de concentração dos extratos e frações (a) das folhas e dos (b) frutos de G. xanthochymus versus a \% de seqüestro de DPPH.

As substâncias 11, 14, 15, 17-20 apresentaram valores igualmente promissores, com valores de $\mathrm{CI}_{50}$ entre 9 e $12 \mu \mathrm{g} / \mathrm{mL}$. As menores atividades foram observadas para as substâncias 5, 10, 12 e 13, com valores de $\mathrm{CI}_{50}$ maior que $100 \mu \mathrm{g} / \mathrm{mL}$, consideradas inativas por comparação com as outras substâncias citadas acima.

Como discutido no item 1.6 a combinação de substituição 3',4'-diidroxi no anel B, com insaturação em C-2-C-3 e uma função carbonila em C-4, são requisitos estruturais que contribuem de maneira destacada para estabilização do radical flavonoídico, formado após a doação de hidrogênio radicalar pelas substâncias antioxidantes em potencial (FURUNO; AKASAKO; SUGIHARA, 2002). Os resultados encontrados estão de acordo com tais observações, pois: 5, 10 e 12 são biflavonas monoidroxildas no anel B; 13 é um monoaromático (menor número de estruturas mesoméricas); 11, 14 e 15 são biflavonóides com grupos catecólicos em B, porém saturadas em C-2 e C-3; e 8 e 16 são biflavonas (com insaturação em C-2-C-3) com um núcleo catecólico no anel B, corroborando as diferenças de potencial sequestrador de radicais livres observados para as substâncias fenólicas de $G$. xanthochymus.

\subsubsection{Ensaio in vitro da polimerização de heme}

A malária é considerada uma doença infecto-parasitária grave, transmitida por protozoários do gênero Plasmodium, aflige mais de 500 milhões de pessoas causando, pelo menos, 1 milhão de óbitos anuais, tendo como agravantes a resistência crescente do 
parasita à quimioterapia e a falta de uma vacina eficaz. No Brasil, a região amazônica concentra mais de $99 \%$ da transmissão da malária, representando um dos maiores problemas de saúde pública, vindo figurar entre as grandes epidemias que assolam o país. (KRETTLI et al., 2001; ALECRIM, 2000; ALSHAWSH et al., 2007)

Uma das mais importantes estratégias na busca de novos fármacos é a identificação de novos alvos e a subseqüente descoberta de substâncias que sejam capazes de agir nestes alvos. No caso da malária um destes alvos é a polimerização de heme (ROSENTHAL, 2003). No vacúolo digestivo ácido, o Plasmodium degrada $75 \%$ da hemoglobina do hospedeiro e utiliza os seus aminoácidos para a síntese de proteínas. Nesse processo, heme tóxica é liberada, armazenando-se na forma de um polímero inerte chamado hemozoína ou pigmento malárico, onde o grupo propionato do heme liga-se ao $\mathrm{Fe}^{3+}$ do outro heme. Sendo assim, substâncias capazes de inibir a síntese de hemozoína podem servir de modelos para a terapia da malária.

Ensaios empregando os extratos e frações das folhas de Garcinia xanthochymus evidenciaram uma forte interação com o grupo heme, com valores de inibição da polimerização do heme de $91 \pm 1,5 \%$ a $2.5 \mathrm{mg} / \mathrm{mL}$. Após a partição do extrato bruto, a fração AcOEt-FOL mostrou a maior atividade, com inibição de $84 \pm 0,7 \%$ a $2.5 \mathrm{mg} / \mathrm{mL}$, sugerindo a presença de substâncias com potencial atividade antimalárica nesta fração. Os frutos apresentaram valores moderados de inibição da formação do polímero hemozoína, com valores de $62 \pm 2,5 \%$ a $2.5 \mathrm{mg} / \mathrm{mL}$ para o ETOH-FRU, e $71 \pm 3,5 \%$ a $2.5 \mathrm{mg} / \mathrm{mL}$ para a AcOEt-FRU (Tabela 19).

Tabela 19 - Atividade inibitória in vitro no ensaio de formação de $\beta$-Hematina para os extratos e frações de Garcinia xanthochymus.

\begin{tabular}{|c|c|c|}
\hline \multicolumn{2}{|c|}{ Extratos e frações de Garcinia xanthochymus } & $\begin{array}{c}\text { \% inibição } \\
(2,5 \mathrm{mg} / \mathrm{mL})\end{array}$ \\
\hline \multirow{6}{*}{$\begin{array}{l}\text { בै } \\
\bar{\Xi} \\
0 \\
\text { I }\end{array}$} & ETOH-FOL & 91 \\
\hline & HEX-FOL & 53 \\
\hline & FR. HEX-FOL & 47 \\
\hline & AcOEt-FOL & 84 \\
\hline & $\mathrm{BuOH}-\mathrm{FOL}$ & $\mathrm{n}^{*}$ \\
\hline & HA-FOL & $\mathrm{n}^{*}$ \\
\hline \multirow{7}{*}{$\stackrel{\overbrace{}}{\stackrel{0}{*}}$} & ETOH-FRU & 62 \\
\hline & HEX-FRU & 23 \\
\hline & AcOEt-FRU & 71 \\
\hline & $\mathrm{BuOH}-\mathrm{FRU}$ & 5 \\
\hline & HA-FRU & 10 \\
\hline & Quinina & 88 \\
\hline & Cloroquina & 82 \\
\hline
\end{tabular}

$\mathrm{n}^{*}$ : não apresentaram atividade significativa. 


\subsubsection{Atividade antifúngica}

Os resultados dos ensaios antifúngicos das amostras provenientes de folhas de $G$. xanthochymus evidenciaram uma moderada atividade do HEX-FOL frente aos fungos patogênicos humanos Candida krusei, Candida parapsilosis e Cryptococcus neoformans usando o método de microdiluição e verificação da inibição em leitor automático de microplacas (HOLETZ, 2002). Já as FR. HEX-FOL e AcOEt-FOL apresentaram uma maior atividade frente aos fungos Candida parapsilosis e Candida krusei, respectivamente, com valor de CIM igual a 31,3 $\mu \mathrm{g} / \mathrm{mL}$, valor próximo ao padrão comercial fluconazol $(\mathrm{CIM}=16 \mu \mathrm{g} / \mathrm{mL})$. Em relação aos frutos de Garcinia xanthochymus, os resultados foram bastante promissores. Frente ao fungo Candida krusei os ETOH-FRU e HEX-FRU apresentaram CIM de $1,95 \mu \mathrm{g} / \mathrm{mL}$, resultado 8 vezes menor que o apresentado pelo padrão comercial fluconazol (CIM=16 $\mu \mathrm{g} / \mathrm{mL})$. O HEX-FRU também foi bastante ativo frente ao fungo Candida parapsilosis e Candida albicans, com CIM de 3,9 e 31,3 $\mu \mathrm{g} / \mathrm{mL}$, respectivamente (Tabela 20).

Tabela 20 - Atividade antifúngica in vitro dos extratos e frações de G. xanthochymus frente a fungos patogênicos humanos.

\begin{tabular}{|c|c|c|c|c|c|}
\hline & & \multicolumn{4}{|c|}{ CIM $(\mu \mathrm{g} / \mathrm{mL})$} \\
\hline & $\begin{array}{l}\text { Extratos e frações de } \\
\text { Garcinia xanthochymus }\end{array}$ & $\begin{array}{c}\text { Candida } \\
\text { krusei }\end{array}$ & $\begin{array}{c}\text { Candida } \\
\text { parapsilosis }\end{array}$ & $\begin{array}{l}\text { Candida } \\
\text { albicans }\end{array}$ & $\begin{array}{c}\text { Cryptococcus } \\
\text { neoformans }\end{array}$ \\
\hline \multirow{6}{*}{ 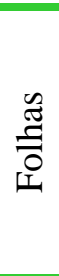 } & ETOH-FOL & 62,5 & 125 & 250,0 & 62,5 \\
\hline & HEX-FOL & 62,5 & 62,5 & 250,0 & 62,5 \\
\hline & FR. HEX-FOL & 125 & 31,3 & 250,0 & 125,0 \\
\hline & AcOEt-FOL & 31,3 & 250 & 250,0 & 62,5 \\
\hline & BuOH-FOL & 125 & 125 & 250,0 & 125,0 \\
\hline & HA-FOL & 250 & 250 & 250,0 & 250,0 \\
\hline \multirow{6}{*}{ 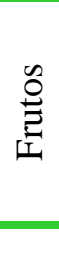 } & ETOH-FRU & 1,95 & $>250,0$ & 62,5 & $>250,0$ \\
\hline & HEX-FRU & 1,95 & 3,9 & 31,3 & $>250,0$ \\
\hline & AcOEt-FRU & 7,8 & $>250,0$ & 125,0 & $>250,0$ \\
\hline & BuOH-FRU & $>250,0$ & $>250,0$ & $>250,0$ & $>250,0$ \\
\hline & HA-FRU & $>250,0$ & $>250,0$ & $>250,0$ & 250,0 \\
\hline & Fluconazol & \multicolumn{4}{|c|}{16,0} \\
\hline
\end{tabular}

As substâncias isoladas da fração AcOEt-FOL de G. xanthochymus (Substs. 5, 8, 10, 11, 14-16) apresentaram atividade antifúngica fraca (CIM de $62,5 \mu \mathrm{g} / \mathrm{mL}$ ), resultados coerentes com o apresentado pela fração AcOEt-FOL, que apresentou fraca atividade frente ao fungo Cryptococcus neoformans (CIM de $62,5 \mu \mathrm{g} / \mathrm{mL}$ ) e moderada atividade 
frente ao fungo Candida krusei (CIM de 31,3 $\mu \mathrm{g} / \mathrm{mL}$ ). As substâncias 17 e 18 não apresentaram atividade fungitóxica, também concordante com a fração de origem $\mathrm{BuOH}$ FOL. A mistura de substâncias majoritárias nos frutos de G. xanthochymus (Substs. 19 e 20) parece não ser a responsável pela forte atividade antifúngica apresentada pelo ETOHFRU (CIM de 1,95 $\mu \mathrm{g} / \mathrm{mL}$ ), pois apresentou valor de CIM maior que $250 \mu \mathrm{g} / \mathrm{mL}$ (Tabela 21), sugerindo a presença de outros metabólitos minoritários mais ativos.

Tabela 21 - Atividade biológica dos constituintes isolados das folhas e frutos de Garcinia xanthochymus.

\begin{tabular}{|c|c|c|c|c|c|c|}
\hline \multirow[b]{2}{*}{ Substâncias } & \multirow{2}{*}{$\begin{array}{l}\text { antioxidante } \\
\mathrm{CI}_{50}(\mu \mathrm{g} / \mathrm{mL})\end{array}$} & \multicolumn{4}{|c|}{ antifúngica } & \multirow{2}{*}{$\begin{array}{c}\text { tripanocida } \\
\qquad \begin{array}{c}\mathrm{CI}_{50} \\
(\mu \mathrm{g} / \mathrm{mL})\end{array}\end{array}$} \\
\hline & & $\begin{array}{c}\text { Candida } \\
\text { krusei } \\
\text { CIM } \\
(\mu \mathrm{g} / \mathrm{mL})\end{array}$ & $\begin{array}{c}\text { Candida } \\
\text { parapsilosis } \\
\text { CIM } \\
(\mu \mathrm{g} / \mathrm{mL})\end{array}$ & $\begin{array}{c}\text { Candida } \\
\text { albicans } \\
\text { CIM } \\
(\mu \mathrm{g} / \mathrm{mL})\end{array}$ & $\begin{array}{c}\text { Cryptococcus } \\
\text { neoformans } \\
\text { CIM } \\
(\mu \mathrm{g} / \mathrm{mL})\end{array}$ & \\
\hline 1 & - & - & - & - & - & $\mathrm{n}^{*}$ \\
\hline 2 & - & $>250$ & $>250$ & $>250$ & $>250$ & $\mathrm{n}^{*}$ \\
\hline 3 & - & $>250$ & $>250$ & $>250$ & $>250$ & $\mathrm{n}^{*}$ \\
\hline 4 & - & - & - & - & - & $\mathrm{n}^{*}$ \\
\hline 5 & $\mathrm{n}^{*}$ & - & - & 125 & 62,5 & $\mathrm{n}^{*}$ \\
\hline 6 & - & - & - & - & - & $\mathrm{n}^{*}$ \\
\hline 7 & - & - & - & - & - & $\mathrm{n}^{*}$ \\
\hline 8 & 8 & 62,5 & 250 & 125 & 62,5 & $\mathrm{n}^{*}$ \\
\hline 9 & - & - & - & $>250$ & 250 & $\mathrm{n}^{*}$ \\
\hline 10 & $\mathrm{n}^{*}$ & - & - & 62,5 & 62,5 & $\mathrm{n}^{*}$ \\
\hline 11 & 11 & 62,5 & 125 & 125 & 62,5 & $\mathrm{n}^{*}$ \\
\hline 12 & $\mathrm{n}^{*}$ & $>250$ & - & - & 250 & $\mathrm{n}^{*}$ \\
\hline 13 & $\mathrm{n}^{*}$ & - & - & 125 & 250 & 75,6 \\
\hline 14 & 9 & 250 & 62,5 & 125 & 62,5 & $n^{*}$ \\
\hline 15 & 11 & 62,5 & 125 & 125 & 250 & $\mathrm{n}^{*}$ \\
\hline 16 & 6 & - & - & 62,5 & 250 & $\mathrm{n}^{*}$ \\
\hline 17 & 12 & 125 & 250 & 125 & 62,5 & $\mathrm{n}^{*}$ \\
\hline 18 & 12 & 125 & 250 & 125 & 62,5 & $\mathrm{n}^{*}$ \\
\hline 19 e 20 & 9 & $>250$ & $>250$ & $>250$ & $>250$ & 36,9 \\
\hline $\begin{array}{c}\text { Benzonidazol } \\
\text { Fluconazol } \\
\text { Quercetina }\end{array}$ & 17 & & & & & 9,7 \\
\hline
\end{tabular}

\subsubsection{Atividade tripanocida}

A atividade tripanocida foi mais pronunciada nas amostras provenientes dos frutos do que as folhas de G. xanthochymus com $\mathrm{CI}_{50}$ de $21,2 \mu \mathrm{g} / \mathrm{mL}$ para o HEX-FRU. Este resultado, quando comparado com a droga usada atualmente contra a Doença de Chagas, o 
benzonidazol $\left(\mathrm{CI}_{50}\right.$ de 9,7 $\left.\mu \mathrm{g} / \mathrm{mL}\right)$, incentiva o estudo na busca de micromoléculas antiparasitárias nesta matriz para servirem de modelos no desenvolvimento de novos agentes terapêuticos para o tratamento da Doença de Chagas (Tabela 22).

Conforme dados da tabela 20, somente a substância 13 e a mistura de 19 e 20 exibiram dados de $\mathrm{CI}_{50}$, com valores de $75,6 \mu \mathrm{g} / \mathrm{mL}$ e $36,9 \mu \mathrm{g} / \mathrm{mL}$, respectivamente. A baixa atividade antiparasitária dos biflavonóides em questão está de acordo com as publicações anteriores (MBWAMBO, et al., 2006; WENIGER, et al., 2006). Diversos tipos estruturais de biflavonóides já foram testados frente aos parasitas Trypanosoma brucei brucei, Trypanosoma cruzi, Leishmania infantum e Plasmodium falciparum e em quase todos os casos, biflavonóides do tipo $3 \rightarrow 8$ "' apresentaram-se inativos.

Tabela 22 - Atividade tripanocida dos extratos e frações de G. xanthochymus.

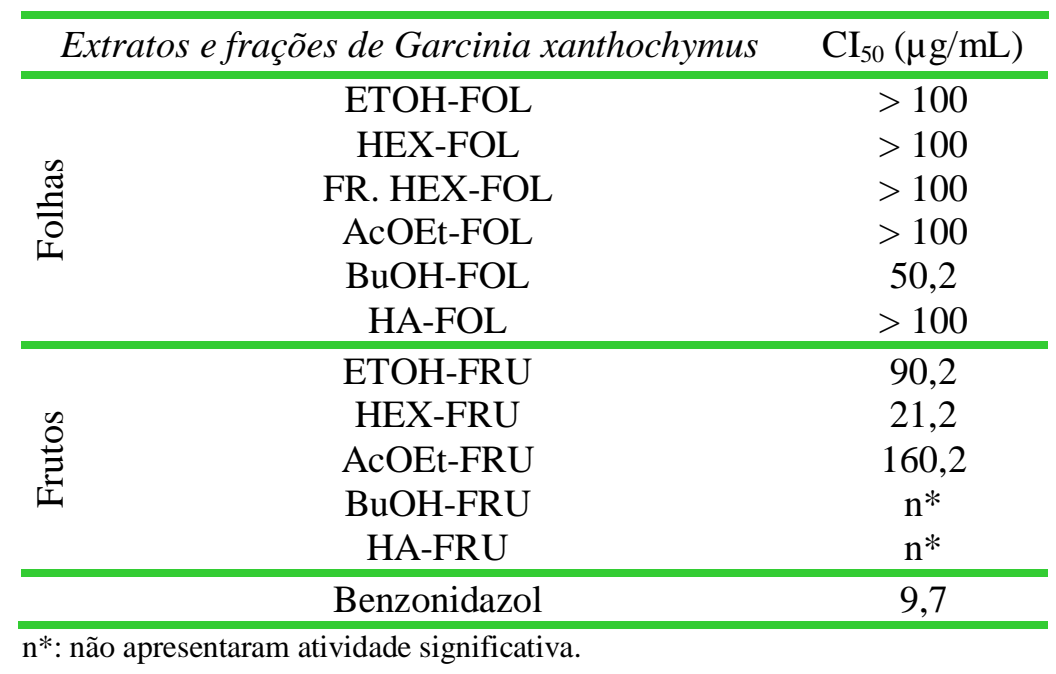

\subsubsection{Atividade quimiopreventiva}

O experimento para avaliação do potencial de quimioprevenção(item 5.18), através da indução da enzima quinonaredutase $(\mathrm{QR})$ empregando-se a linhagem celular hepa1c1c7 em teste espectrofotométrico realizado com os extratos e frações de $G$. xanthochymus, indicaram potencial quimiopreventivo moderado. Porém, a (+)morelloflavona (Subs. 8) mostrou-se com uma elevada capacidade de indução da atividade da enzima QR, como é observado na Tabela 23. Há uma duplicação da atividade indutora, sugerindo que substâncias com estruturas semelhantes a da 4'-bromoflavona (4'-BF, padrão comercial) podem ser protótipos para agentes quimiopreventivos, contribuindo para inibir a instalação de eventos iniciais associados à etiologia do câncer. 
Tabela 23 - Avaliação da taxa de indução (IR) da atividade de QR em linhagem Hepa1c1c7 para 8.

\begin{tabular}{ccccc}
\hline & IR & $\mathbf{C I}_{\mathbf{5 0}}(\boldsymbol{\mu M})$ & $\mathbf{C D}(\boldsymbol{\mu M})$ & IQ \\
\hline Morelloflavone & $2,15 \pm 0,5$ & $84,2 \pm 4,5$ & $28,7 \pm 1,4$ & $2,93 \pm 2,1$ \\
4'-BF & $3,0 \pm 0,6$ & $>166$ & $0,01^{*}$ & $>17,000^{*}$ \\
\hline
\end{tabular}




\section{CONCLUSÕES}

O estudo químico e biológico das folhas e frutos da espécie Garcinia xanthochymus, através do isolamento e/ou identificação de 25 substâncias, demonstrou coerência com relatos encontrados na literatura no que concerne a química da família Clusiaceae.

Dentre as substâncias isoladas, podemos destacar 3 triterpenos obtidos do extrato hexânico das folhas: friedelina (1), lanosta-8,24-dien-3-ol (2) e lanosta-7,24-dien-3-ol (3), sendo que as substâncias $\mathbf{2}$ e $\mathbf{3}$ foram relatadas pela primeira vez na literatura da espécie. A prospecção química da fase acetato de etila das folhas revelou uma abundante presença de biflavonóides, sendo as substâncias saharanflavona (4), I3,II8-biapigenina (5), GB1a (6), (+) morelloflavona (8), GB2a (11), volkensiflavona (12), GB2 (14), xantochimusídeo (15) e fukugisídeo (16), caracterizadas pela ligação interflavonoídica do tipo $3 \rightarrow 8^{\prime}$ ', e as substâncias podocarpusflavona (7) e amentoflavona (9), pela ligação do tipo $3^{\prime} \rightarrow 8^{\prime}$ '. Merece destaque a substância 4, isolada pela primeira vez de fontes naturais. Este biflavonóide foi sintetizado por Pelter et al. em 1970 e depois só obtido novamente de forma sintética. A composição química de G. xanthochymus constituiu-se ainda das substâncias diidrokaempferol (10), ácido vanílico (13), cinco derivados de ácidos fenilpropanoídicos: ácido 3-O-cafeoilquínico (17), ácido 5-O-cafeoilquínico (18), ácido 3p-coumaroilquínico (21), ácido 4-O-cafeoilquínico (22) e ácido 4-p-coumaroilquínico (23); e ainda a mistura binária das benzofenonas xantochimol (19) e cicloxantochimol (20). Todas as substâncias foram relatadas pela primeira vez nas folhas de G. xanthochymus, com exceção da substância 7, isolada anteriormente por PARVEEN et al. (1994) e as substâncias 10, 13, 17, 18, 21, 22 e 23, ainda não identificadas na espécie.

No estudo biológico realizado com os extratos, frações e substâncias puras isoladas dos frutos e folhas de G. xanthochymus, foram avaliados o potencial antioxidante, antimalárico, antifúngico, tripanocida e quimiopreventivo em testes in vitro espectrofotométricos e/ou enzimáticos. Os resultados observados para o ensaio de sequestro de radicais livres utilizando o radical DPPH evidenciaram a importância dos grupos catecólicos como essenciais para uma ação antioxidante potencializada. Os biflavonóides comportaram-se como potentes seqüestradores de radical livre com $\mathrm{CI}_{50}$ compreendidos entre 6 e $12 \mu \mathrm{g} / \mathrm{mL}$, configurando-se como promissores modelos para aplicação no desenvolvimento de novos protótipos antioxidantes. A fração AcOEt-FOL evidenciou uma forte interação com o grupo heme, com inibição de $84 \pm 1 \%$ a $2.5 \mathrm{mg} / \mathrm{mL}$, 
sugerindo a presença de substâncias com potencial atividade antimalárica nesta fração. Em relação à atividade antifúngica, a fração HEX-FOL e a fração AcOEt-FOL mostraram-se moderadamente ativas frente aos fungos patogênicos humanos Candida parapsilosis e $C$. krusei, enquanto os extratos ETOH-FRU e HEX-FRU dos frutos de Garcinia xanthochymus apresentaram resultados muito atrativos, com CIM de 1,95 $\mu \mathrm{g} / \mathrm{mL}$, cerca de oito vezes menor que o apresentado pelo padrão comercial fluconazol (CIM=16,0 $\mu \mathrm{g} / \mathrm{mL}$ ). Também a atividade tripanocida foi mais pronunciada nas amostras provenientes dos frutos do que das folhas de G. xanthochymus com $\mathrm{CI}_{50}$ de $21,2 \mu \mathrm{g} / \mathrm{mL}$ para o HEX-FRU, o que incentiva seu estudo na busca de micromoléculas antiparasitárias ou de protótipos para o desenvolvimento de agentes terapêuticos para o tratamento da Doença de Chagas. A (+)morelloflavona (8) mostrou elevada capacidade de indução da atividade da enzima quinona-redutase, confirmando o potencial quimiopreventivo atrativo de flavonóides, em especial de flavonas e seus derivados, incluindo biflavonóides com pelo menos uma unidade de flavona, como apresentado na estrutura da substância 8. Esses resultados indicam G. xanthochymus como uma fonte rica de substâncias quimiopreventivas que sejam potencialmente úteis para inibir a instalação dos eventos iniciais associados à etiologia do câncer.

De maneira global, os resultados de bioatividade dos extratos, frações semipurificadas e substâncias isoladas de G. xanthochymus confirmaram a importância de estudos de bioprospecção planejados e conduzidos de maneira adequada, mostrando-se indispensáveis para as etapas desenvolvidas neste trabalho. Dessa forma, foi possível a obtenção de um conjunto de dados de alto valor agregado, a partir do qual podem ser selecionadas frações ou substâncias puras para estudos mais aprofundados, incluindo o preparo de derivados, visando a potencialização de bioatividade ou ajuste de propriedades farmacocinéticas e/ou toxicológicas durante o processo de desenvolvimento de potenciais agentes terapêuticos.

A técnica CG-DIC mostrou-se eficiente e rápida na detecção de esteróides e triterpenos em misturas complexas. Foram identificados 15 compostos lipofílicos sem a necessidade de etapas demoradas e caras que são características do processo em escala preparativa. A utilização das técnicas hifenadas CLAE-UV e CLAE-EM foi imprescindível não somente para obter dados espectrométricos das substâncias isoladas, mas também para localizar substâncias já isoladas neste estudo e/ou isoladas em trabalhos anteriores, evitando-se a replicação de resultados. Fica evidente o grande potencial dessas técnicas na localização e identificação de substâncias de interesse em matrizes complexas, como 
extratos vegetais, que são fundamentais para atender à crescente demanda, decorrente da intensificação das atividades de bioprospecção, que se configuram como um dos principais focos das pesquisas realizadas pelo NuBBE. 


\section{REFERÊNCIAS}

AHMED, M. S. et al. A weakly antimalarial biflavanone from Rhus retinorrhoea. Phytochemistry, v. 58, n. 4, p. 599-602, 2001.

ALECRIM, M. das G. C. Tratamento da malária com artesunate (retocaps) em crianças da Amazônia Brasileira. Revista da Sociedade Brasileira de Medicina Tropical, v. 33, n. 2, p. $163-168,2000$.

ALSHAWSH, M. A. et al. Assessment of antimalarial activity against Plasmodium falciparum and phytochemical screening of some Yemeni medicinal plants. Evidencebased Complementary and Alternative Medicine, v. 6, n. 4, p. 453-456, 2007.

AO, C. et al. Biological activity and composition of extract from aerial root of Ficus microcarpa L. fil. International Journal of Food Science and Technology, v. 44, n. 2, p. 349-358, 2009.

BAELMANS, R. et al. A search for natural bioacte compounds in Bolivia through a multidiciplinar approach. Part IV. Is a new haem polymerization inhibition test pertinent for the detection of antimalarial natural products? Journal Ethnopharmacol, v. 73, p. $271-275,2000$.

BAGGETT, S. et al. Bioactive benzophenones from Garcinia xanthochymus fruits. Journal of Natural Products, v. 68, n. 3, p. 354-360, 2005.

BARREIROS, A. L. B. S.; DAVID, J. M.; DAVID, J. P. Estresse oxidativo: relação entre geração de espécies reativas e defesa do organismo. Química Nova, v. 29, n. 1, p. 113-123, 2006.

BASHIR, A. et al. Isoflavones and xanthones from Polygala virgata. Phytochemistry, v. 31, n. 1, p. 309-311, 1992.

BASLAS, R. K.; KUMAR, P. Chemical examination of the fruits of Garcinia xanthochymus. Current Science, v. 48, n. 18, p. 814-815, 1979.

BASLAS, R. K.; KUMAR, P. Isolation and characterization of biflavanone and xanthones in the fruits of Garcinia xanthochymus. Acta Ciencia Indica, v. 7, n. 1, p. 31-34, 1981. 
BERGHÖFER, R.; HÖLZL, J. Biflavonoids in Hypericum perforatum. 1. Isolation of I3,II8-biapigenin. Planta Medica, v. 53, n. 2, p. 216-217, 1987.

BLADT, W. A plant drug analysis: a thin layer chromatography atlas. 2nd ed. Berlin: Springer, 1996.

CALIXTO, J. B. Biodiversidade como fonte de medicamentos. Ciência \& Cultura, v. 55, n. 3, p. 37-39, 2003.

CANUTO, K. M. Aspectos químicos do estudo interdisciplinar (química-agronomiafarmacologia) de Amburana cearensis A. C. Smith. 2007. 303 f. Tese (Doutorado em Química Orgânica) - Centro de Ciências, Departamento de Orgânica e Inorgânica, Universidade Federal do Ceará, Fortaleza, 2007.

CAO, G. H.; SOFIC, E.; PRIOR, R. L. Antioxidant and prooxidant behavior of flavonoids: structure-activity relationships. Free Radical Biology and Medicine, v. 22, n. 5, p. 749$760,1997$.

CARBONEZI, C. A. et al. Bioactive flavone dimers from Ouratea multiflora (Ochnaceae). Revista Brasileira de Farmacognosia, v. 17, n. 3, p. 319-324, 2007.

CHANMAHASATHIEN, W. et al. Prenylated xanthones from Garcinia xanthochymus. Chemical and Pharmaceutical Bulletin, v. 51, n. 11, p. 1332-1334, 2003 a.

CHANMAHASATHIEN, W. et al. Prenylated xanthones with NGF-potentiating activity from Garcinia xanthochymus. Phytochemistry, v. 64, n. 5, p. 981-986, 2003 b.

CHEN, J. J.; DUH, C. Y.; CHEN, J. F. New cytotoxic biflavonoids from Selaginella delicatula. Planta Medica, v. 71, n. 7, p. 659-665, 2005.

CHEN, Y. et al. Structure elucidation and NMR spectral assignment of five new xanthones from the bark of Garcinia xanthochymus. Magnetic Resonance in Chemistry, v. 46, n. 12, p. 1180-1184, 2008.

CHENG, W. et al. Study on the antioxidant constituents from the barks of Garcinia xanthochymus. Tianran Chanwu Yanjiu Yu Kaifa, v. 20, n. 5, p. 836-838, 2008.

CHUANG, S. E. et al. Curcumin-containing diet inhibits diethylnitrosamine-induced murine hepatocarcinogenesis. Carcinogenesis, v. 21, n. 2, p. 331-335, 2000. 
CLIFFORD, M. N. et al. Hierarchical scheme for LC-MSn identification of chlorogenic acids. Journal of Agricultural and Food Chemistry, v. 51, n. 10, p. 2900-2911, 2003.

CLIFFORD, M. N. et al. Characterization by LC-MSn of four new classes of chlorogenic acids in green coffee beans: dimethoxycinnamoylquinic acids, diferuloylquinic acids, caffeoyl-dimethoxycinnamoylquinic acids, and feruloyl-dimethoxycinnamoylquinic acids. Journal of Agricultural and Food Chemistry, v. 54, n. 6, p. 1957-1969, 2006.

COMPAGNONE, R. S. et al. Flavonoids, benzophenones and a new euphane derivative from Clusia columnaris Engl. Brazilian Journal of Pharmacognosy, v. 18, n. 1, p. 6-10, 2008.

CORDEIRO, P. J. M.; VILEGAS, J. H. Y.; LANCAS, F. M. HRGC-MS analysis of terpenoids from Maytenus ilicifolia and Maytenus aquifolium ("espinheira santa"). Journal of the Brazilian Chemical Society, v. 10, n. 6, p. 523-526, 1999.

CORDELL, G. A. Biodiversity and drug discovery - a symbiotic relationship. Phytotherapy, v. 55, n. 6, p. 463-480, 2000.

CORDELL, G. A.; SHIN, Y. G. Finding the needle in the haystack. The dereplication of natural product extracts. Pure and Applied Chemistry, v. 71, n. 6, p. 1089-1094, 1999.

CORSE, J. et al. Conformation analyses of D-(-)-quinic acid and some of its derivatives by nuclear magnetic resonance. Phytochemistry, v. 5, n. 4, p. 767-776, 1966.

COTINGUIBA, F. et al. Piperamides and their derivatives as potential anti-trypanosomal agents. Medicinal Chemistry Research, v. 18, n. 9, p. 703-711, 2009.

CREVELIN, E. J. et al. Identification of biologically active triterpenes and sterols present in hexane extracts from Miconia species using high-resolution gas chromatography.

Biomedical Chromatography, v. 20, n. 8, p. 827-830, 2006.

CROTEAU, R.; KUTCHAN, T. M.; LEWIS, N. G. Natural products (secondary metabolites). In: BUCHANAN, B.; GRUISSEM, W.; JONES, R. (Ed.). Biochemistry \& molecular biology of plants. New York: Elsevier, 2000. Cap. 24, p. 1308-1311.

CRUZ, F. G. et al. Coumarins from Kielmeyera reticulate. Phytochemistry, v. 47, n. 7, p. 1363-1366, 1998. 
CUENDET, M. et al. Quinone reductase induction as a biomarker for cancer chemoprevention. Journal of Natural Products, v. 69, n. 3, p. 460-463, 2006.

DEWICK, P. M. The shikimate pathway: aromatic amino acids and phenylpropanoids. In:_ Medicinal natural products: a biosynthetic approach. 2 nd ed. New York: John Wiley \& Sons, 2002. Cap. 4, p. 121-131.

DI STASI, L. C.; HIRUMA-LIMA, C. A. Guttiferales medicinais. In: Plantas medicinais na Amazônia e na Mata Atlântica. 2. ed. São Paulo: Ed. UNESP, 2002. Cap. 14, p. 259-261.

DI STASI, L. C.; GOMES, J. C.; VILEGAS, W. Studies on anti-allergic constituints in the leaves and stems of Anchientia salutaris var. martiana (Violaceae). Chemical and Pharmaceutical Bulletin, v. 47, n. 6, p. 890-893, 1999.

FAHEY, J. W. et al. The "Prochaska" microtiter plate bioassy for inducers of NQ01. Methods Enzymol, v. 382, p. 243-258, 2004.

FELICIO, J. D. et al. Inhibition of lens aldose reductase by biflavones from Ouratea spectabilis. Planta Medica, v. 61, n. 3, p. 217-220, 1995.

FERRARI, J. et al. Isolation and on-line LC/CD analysis of 3,8 "-linked biflavonoids from Gnidia involucrate. Helvética Chimica Acta, v. 86, n. 8, p. 2768-2778, 2003.

FRAGA, C. A. M. et al. Atropoisomerismo: o efeito da quiralidade axial em substâncias bioativas. Química Nova, v. 30, n. 1, p. 125-135, 2007.

FUJITA, T. et al. Xanthones from Polygala tenuifolia. Phytochemistry, v. 31, n. 11, p. 3997-4000, 1992.

FURUNO, K.; AKASAKO, T.; SUGIHARA, N. The contribution of the pyrogallol moiety to the superoxide radical scavenging activity of flavonoids. Biological \& Pharmaceutical Bulletin, v. 25, n. 1, p. 19-23, 2002.

GE, F. et al. Isolation of chlorogenic acids and their derivatives from Stemona japonica by preparative HPLC and evaluation of their anti-AIV (H5N1) activity in vitro.

Phytochemical Analysis, v. 18, n. 3, p. 213-218, 2007. 
GOBBO-NETO, L.; LOPES, N. P. Online identification of chlorogenic acids, sesquiterpene lactones, and flavonoids in the brazilian arnica Lychnophora ericoides Mart. (Asteraceae) leaves by HPLC-DAD-MS and HPLC-DAD-MS/MS and a validated HPLCDAD method for their simultaneous analysis. Journal of Agricultural and Food Chemistry, v. 56, n. 4, p. 1193-1204, 2008.

GONCALEZ, E.; FELICIO, J. D.; PINTO, M. M. Biflavonoids inhibit the production of aflatoxin by Aspergillus flavus. Brazilian Journal of Medical and Biological Research, v. 34, p. 1453-1456, 2001.

GOTTLIEB, H. E.; RAMAIAH, P. A.; LAVIE, D. C-13 NMR signal assignment of friedelin and 3-alpha-hydroxyfriedelan-2-one. Magnetic Resonance in Chemistry, v. 23, n. 8, p. 616-620, 1985.

GREENWOOD, B.; MUTABINGWA, T. Malaria in 2002. Nature, v. 415, n. 6872, p. 670-672, 2002.

GRYNBERG, N. F. et al. DNA topoisomerase inhibitors: biflavonoids from Ouratea species. Brazilian Journal of Medical and Biological Research, v. 35, n. 7, p. 819-822, 2002.

HAN, Q. B. et al. Cytotoxic prenylated phenolic compounds from the twig bark of Garcinia xanthochymus. Chemistry and Biodiversity, v. 4, p. 940-946, 2007.

HARBORNE, J. H.; WILLIAEM, C. A. Advances in flavonoid research since 1992. Phytochemistry, v. 55, n. 6, p. 481-504, 2000.

HARRISON, L. J. et al. Xanthones and benzophenones from Garcinia griffithii and Garcinia mangostana. Phytochemistry, v. 66, n. 14, p. 1718-1723, 2005.

HERBIN, G. A. et al. Extractives from Guttiferae. 15. Biflavonoids of Garcinia-volkensii (Guttiferae). Phytochemistry, v. 9, n. 1, p. 221-226, 1970.

HOLETZ, F. B. et al. Screening of some plants used in the Brazilian folk medicine for the treatment of infectious diseases. Memórias Instituto Oswaldo Cruz, v. 97, n. 7, p. 1027-1031, 2002.

HUTADILOK-TOWATANA, N.; KONGKACHUAY, S.; MAHABUSARAKAM, W. Inhibition of human lipoprotein oxidation by morelloflavone and camboginol from Garcinia dulcis. Natural Product Research, v. 21, n. 7, p. 655-652, 2007. 
IINUMA, M. J. et al. Five new xanthones from Garcinia dulcis. Journal Natural Product, v. 59, n. 5, p. 472-475, 1996.

IKEYA, Y. et al. Two Xanthones from Polygala tenuifolia. Phytochemistry, v. 30, n. 6, p. 2061-2065, 1991.

JACKSON, B. et al. Isolation of a new series of biflavanones from heartwood of Garcinia buchananii. Tetrahedron Letters, n. 9, p. 787-792, 1967.

KANG, S. S. et al. Neuroprotective effects of naturally occurring biflavonoids. Bioorganic and Medicinal Chemistry Letters, v. 15, n. 15, p. 3588-3591, 2005.

KARANJGOAKAR, C. G. et al. Constitution of xanthochymol and isoxanthochymol Tetrahedron Letters, v. 50, p. 4977-4980, 1973.

KELLOFF, G. J. et al. Progress in cancer chemoprevention: development of diet-derived chemopreventive agents. Journal of Nutrition, v. 130, n. 2, p. 467-471, 2000.

KIRBY, G. C. Medicinal plants and the control of protozoal disease, with particular reference to malaria. Transactions of the Royal Society of Tropical Medicine and Hygiene, v. 90, n. 6, p. 605-609, 1996.

KINGHORN, A. D. et al. Induction of the phase II enzyme, quinone reductase, by withanolides and norwithanolides from solanaceous species. Mini-Reviews in Organic Chemistry, v. 1, n. 1, p. 115-123, 2004.

KNIGHT, S. A. C-13 NMR - Spectra of lanostenol - euphadienol and euphenol. Tetrahedron Letters, n. 1, p. 83-86, 1973.

KONOSHIMA, M. et al. The constitution of flavonoids from Garcinia spicata Hook. Tetrahedron Letters, n. 10, p. 121-124, 1969.

KONOSHIMA, M. et al. The constitution of biflavonoids from Garcinia plants. Tetrahedron Letters, n. 48, p. 4203-4206, 1970.

KRETTLI, A. U. et al. Searching new antimalarials from plants used to treat fever and malaria or plants randomly select: a review. Memórias do Instituto Oswaldo Cruz, v. 96, p. 1033-1042, 2001. 
LI, X. C. et al. Absolute configuration, conformation, and chiral properties of flavanone(3 $\rightarrow$ "')-flavone biflavonoids from Rheedia acuminate. Tetrahedron, v. 58, n. 43, p. 8709-8717, 2002.

LIN, L. C.; KUO, Y. C.; CHOU, C. J. Cytotoxic biflavonoids from Selaginella delicatula. Journal of Natural Products, v. 63, n. 5, p. 627-630, 2000.

LIN, Y. et al. In vitro anti-HIV activity of biflavonoids isolated from Rhus succedanea and Garcinia multiflora. Journal of Natural Products, v. 60, n. 9, p. 884-888, 1997.

LIN, Y. et al. Antiviral activities of biflavonoids. Planta Medica, v. 65, n. 2, p. 120-125, 1999.

LIN, Y. M.; CHEN, F. C.; LEE, K. H. Antitumor agents. 102. Hinokiflavone, a cytotoxic principle from Rhus succedanea and the cytotoxicity of the related biflavonoids. Planta Medica, v. 55, p. 166-168, 1989.

MABRY, T. J.; MARKHAM, K. R.; THOMAS, M. B. The ultraviolet spectra of flavones and flavonols. In: .The systematic identification of flavonoids. New York: Springer Verlag, 1970. p. 41-57.

MBWAMBO, Z. H. et al. Antiparasitic activity of some xanthones and biflavonoids from the root bark of Garcinia livingstonei. Journal of Natural Products, v. 69, n. 3, p. 369372, 2006.

MERKEN, H. M.; BEECHER, G. R. Measurement of food flavonoids by highperformance liquid chromatography: a review. Journal of Agricultural and Food Chemistry, v. 48, n. 3, p. 577-599, 2000.

MOREAU, S. et al. (2-arylhydrazonomethyl)-substituted xanthones as antimycotics: synthesis and fungistatic activity against Candida species. European Journal of Medicinal Chemistry, v. 37, n. 3, p. 237-253, 2002.

NEWMAN, D. J.; CRAGG, G. M. Natural products as sources of new drugs over the last 25 years. Journal of Natural Products, v. 70, n. 3, p. 461-477, 2007.

NUNOME, S. et al. In vitro antimalarial activity of biflavonoids from Wikstroemia indica. Planta Medica, v. 70, n. 1, p. 76-78, 2004. 
OLEA, R. S. G.; ROQUE, N. F. Análise de misturas de triterpenos por RMN de ${ }^{13} \mathrm{C}$. Química Nova, v. 13, n. 4, p. 278-281, 1990.

PANTHONG, K. et al. Tetraoxygenated xanthones from the fruits of Garcinia cowa. Phytochemistry, v. 67, n. 10, p. 999-1004, 2006.

PARVEEN, N. et al. Flavonoid constituents of Garcinia xanthochymus leaves.

Fitoterapia, v. 65, n. 1, p. 89-90, 1994.

PAULETTI, P. M. et al. New antioxidant C-glucosylxanthones from the stems of Arrabidaea samydoides. Journal of Natural Products, v. 66, n. 10, p. 1384-1387, 2003.

PAULI, G. F.; POETSCH, F.; NAHRSTEDT, A. Structure assignment of natural quinic acid derivatives using proton nuclear magnetic resonance techniques. Phytochemical Analysis, v. 9, n. 4, p. 177-185, 1998.

PELTER, A. et al. Biflavonyls from Guttifereae - Garcinia livingstonii. Tetrahedron, v. 27, n. 8, p. 1625-1634, 1971.

PINTO, A. C. et al. Produtos naturais: atualidade, desafios e perspectivas. Química Nova, v. 25, n. 1, p. 45-61, 2002.

POTTERAT, O. Antioxidants and free radical scavengers of natural origin. Current Organic Chemistry, v. 1, n. 4, p. 415-440, 1997.

RAMESH, N. et al. Phytochemical and antimicrobial studies of Begonia malabarica. Journal of Ethnopharmacology, v. 79, n. 1, p. 129-132, 2002.

RAMA RAO, A. V.; VENKATSWAMY, G.; YEMUL, S. S. Xanthochymol and isoxanthochymol, two novel polyisoprenylated benzophenones from Garcinia xanthochymus. Indian Journal of Chemistry, v. 19B, n. 8, p. 627-633, 1980.

REGASINI, L. O. et al. Identification of triterpenes and sterols from Pterogyne nitens (Fabaceae-caesalpinioideae) using high-resolution gas chromatography. Journal of the Chilean Chemical Society, v. 54, n. 3, p. 218-221, 2009.

RICE-EVANS, C. A.; MILEER, N. J.; PAGANGA, G. Structure-antioxidant activity relationships of flavonoids and phenolic acids. Free Radical Biology and Medicine, v. 20, n. 7, p. 933-956, 1996. 
RODRIGUES, M. V. N. et al. O emprego de técnicas hifenadas no estudo de plantas medicinais. Multi Ciência: Construindo a história dos Produtos Naturais, n. 7, 2006.

ROSENTHAL, P. J. Antimalarial drug discovery: old and new approaches. Journal of Experimental Biology, v. 206, n. 21, p. 3735-3744, 2003.

ROUHI, A. M. Betting on natural products for cures. Chemical and Engineering News, v. 81, n. 41, p. 77-78, 2003.

SCHIEBER, A.; BERARDINI, N.; CARLE, R. Identification of flavonol and xanthone glycosides from mango (Mangifera indica L. cv. "Tommy Atkins") peels by highperformance liquid chromatography-electrospray ionization mass spectrometry. Journal of Agricultural and Food Chemistry, v. 51, n. 17, p. 5006-5011, 2003.

SCOTT, K. N. C-13 Nuclear magnetic-resonance of biologically important aromatic acids. 1. Chemical-shifts of benzoic-acid and derivatives. Journal of the American Chemical Society, v. 94, n. 24, p. 8564-8568, 1972.

SILVA, D. H. S. et al. Lipophyllic antioxidants from Iryanthera juruensis fruits. Phytochemistry, v. 57, n. 3, p. 437-442, 2001.

SILVA, G. L. et al. Cytotoxic biflavonoids from Selaginella-willdenowii. Phytochemistry, v. 40, n. 1, p. 129-134, 1995.

SILVERSTEIN, R. M.; WEBSTER, X.; KIEMLE, D. J. Espectroscopia no infravermelho. In: _ Identificação espectrométrica de compostos orgânicos. 5. ed. Rio de Janeiro: Guanabara Koogan, 1994.

SIMÕES, C. M. O. et al. Farmacognosia: da planta ao medicamento. 4. ed. Porto Alegre: Ed. UFRGS, 2002.

SINGH, M. P. et al. Constituents of Garcinia xanthochymus. Fitoterapia, v. 62, n. 3, p. 286, 1991.

SON, S.; LEWIS, B. A. Free radical scavenging and antioxidative activity of caffeic acid amide and ester analogues: structureactivity relationship. Journal of Agricultural and Food Chemistry, v. 50, n. 3, p. 468-472, 2002. 
SONG, L. L. et al. Cancer chemopreventive activity mediated by 4'-bromoflavone, a potent inducer of phase II detoxification enzymes. Cancer Research, v. 59, n. 3, p. 578-585, 1999.

SOUZA FILHO, A. P. S. et al. Potencial alelopático de Myrcia guianensi. Planta

Daninha, v. 24, n. 4, p. 649-656, 2006.

SOYAMA, P. Plantas medicinais são pouco exploradas pelos dentistas. Ciência \& Cultura, v. 59, n.1, p. 12-13, 2007.

SULTANBAWA, M. U. S. Xanthonoids of tropical plants. Tetrahedron, v. 36, n. 11, p. 1465-1506, 1980.

SUZART, L. R. et al. Biodiversidade flavonoídica e aspectos farmacológicos em espécies dos gêneros Ouratea e Luxemburgia (Ochnaceae). Química Nova, v. 30, n. 4, p. 984-987, 2007.

TANDON, R. N. et al. Preliminary investigation on the anti-microbial activity of a phytochemical, xanthochymol from the fruits of Garcinia xanthochymus Hook f. Current Science, v. 49, n. 12, p. 472-473, 1980.

VAN ACKER, S. A. B. E. et al. Structural aspects of antioxidant activity of flavonoids. Free Radical Biology and Medicine, v. 20, n. 3, p. 331-342, 1996.

VERDI, L. G. et al. Antibacterial and brine shrimp lethality tests of biflavonoids and derivatives of Rheedia gardneriana. Fitoterapia, v. 75, n. 3, p. 360-363, 2004.

WATTENBERG, L.W. Chemoprevention of cancer. Cancer Research, v. 45, n. 1, p. 1-8, 1985.

WENIGER, B. et al. Comparative antiplasmodial, leishmanicidal and antitrypanosomal activities of several biflavonoids. Phytomedicine, v. 13, n. 3, p. 176-180, 2006.

XIE, D. Y.; DIXON, R. A. Proanthocyanidin biosynthesis - still more questions than answers? Phytochemistry, v. 66, n. 18, p. 2127-2144, 2005.

YAMAGUCHI, L. F. et al. Biflavonoids from Brazilian pine Araucaria angustifolia as potentials protective agents against DNA damage and lipoperoxidation. Phytochemistry, v. 66, n. 18, p. 2238-2247, 2005. 
YANG, B. et al. Relationship of electrochemical oxidation of catechins on their antioxidant activity in microsomal lipid peroxidation. Chemical and Pharmaceutical Bulletin, v. 49, n. 6, p. 747-751, 2001.

YOUNES, R. N.; VARELLA, A. D.; SUFFREDINI, I. B. Discovery of new antitumoral and antibacterial drugs from Brazilian plant extracts using high throughput screening. Clinics, v. 62, n. 6, p. 763-768, 2007.

ZHONG, F. F.; CHEN, Y.; YANG, G. Z. Chemical constituents from the bark of Garcinia xanthochymus and their 1,1-diphenyl-2-picrylhydrazyl (DPPH) radical-scavenging activities. Helvetica Chimica Acta, v. 91, n. 9, p. 1695-1703, 2008.

ZHONG, F. F. et al. Xanthones from the bark of Garcinia xanthochymus. Chinese Chemical Letters, v. 18, n. 7, p. 849-851, 2007.

ZHOU, Y. et al. Analysis of caged xanthones from the resin of Garcinia hanburyi using ultra-performance liquid chromatography/electrospray ionization quadrupole time-of-flight tandem mass spectrometry. Analytica Chimica Acta, v. 629, n. 1, p. 104-118, 2008. 


\section{Qnesces}




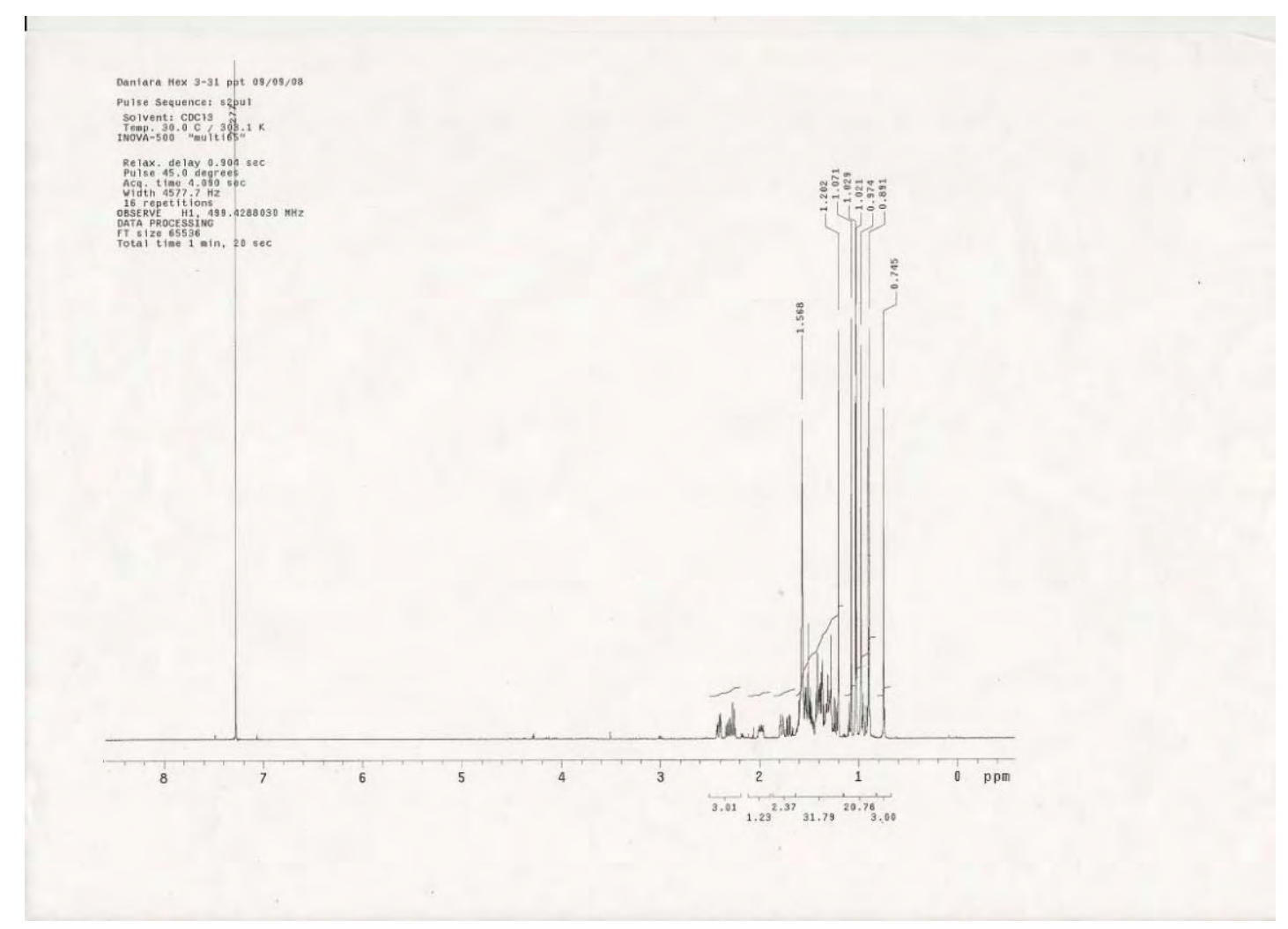

Anexo 1. Espectro de RMN de ${ }^{1} \mathrm{H}$ da substância 1.

$\left(500 \mathrm{MHz}-\mathrm{CDCl}_{3}\right)$

Daniara Hex $3-31$ ppt 09/09/08

Pulse soguences: s2pur

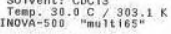

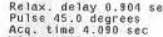

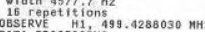

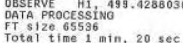

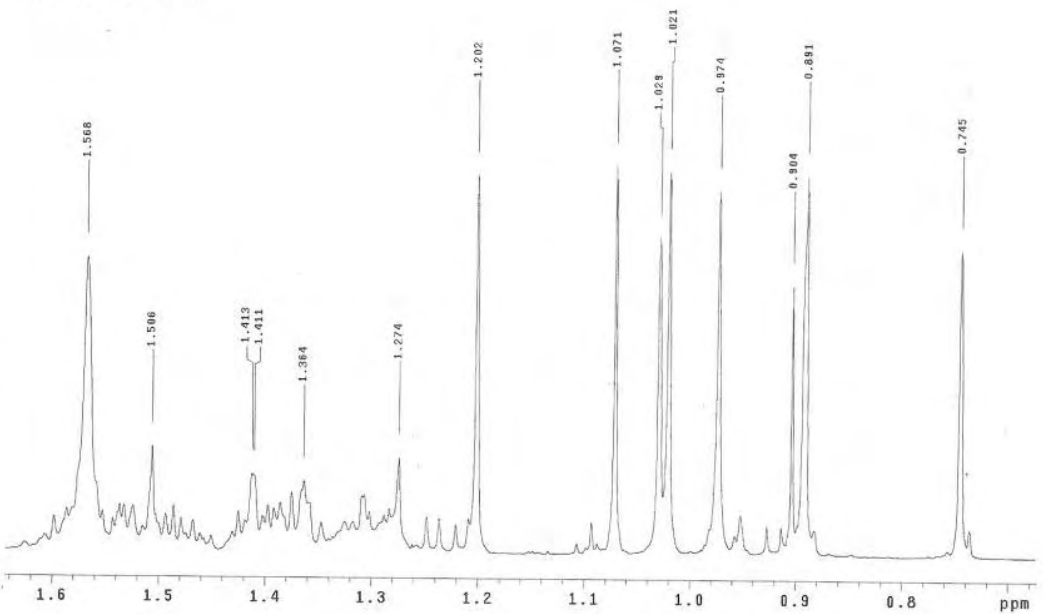

Anexo 2. Ampliação do espectro de RMN de ${ }^{1} \mathrm{H}$ da substância 1.

$\left(500 \mathrm{MHz}-\mathrm{CDCl}_{3}\right)$ 
Daniara Hex $3-31$ ppt $09 / 09 / 08$

Pulse Sequence: :2pul

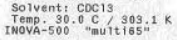

Relax. ${ }^{\text {delay }} 0.904 \mathrm{sec}$
Pulse 45.0 degrees

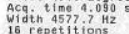

16 repetitions
OSSERVE

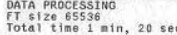

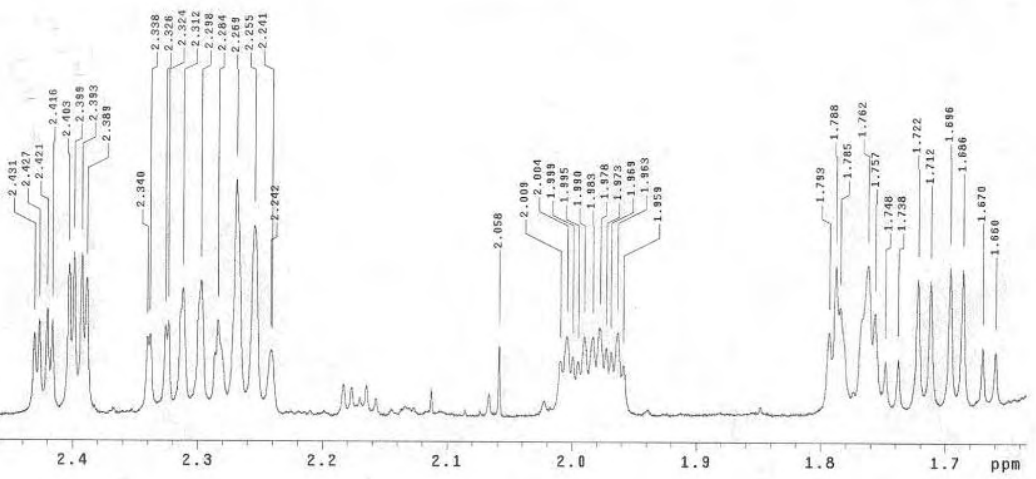

Anexo 3. Ampliação do espectro de RMN de ${ }^{1} \mathrm{H}$ da substância 1 .

$\left(500 \mathrm{MHz}-\mathrm{CDCl}_{3}\right)$

Dantara Hex 3-31 ppt 09/09/08

Pulse Sequence: s2put

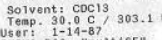

Relax. delay $0.957 \mathrm{sec}$

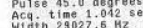

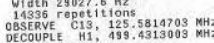

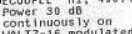

WAT $2-16$ modulated
DATA PROCESSTHO

tine broadenting $1.0 \mathrm{~Hz}$
$\mathrm{FT}$
$\mathrm{T}$
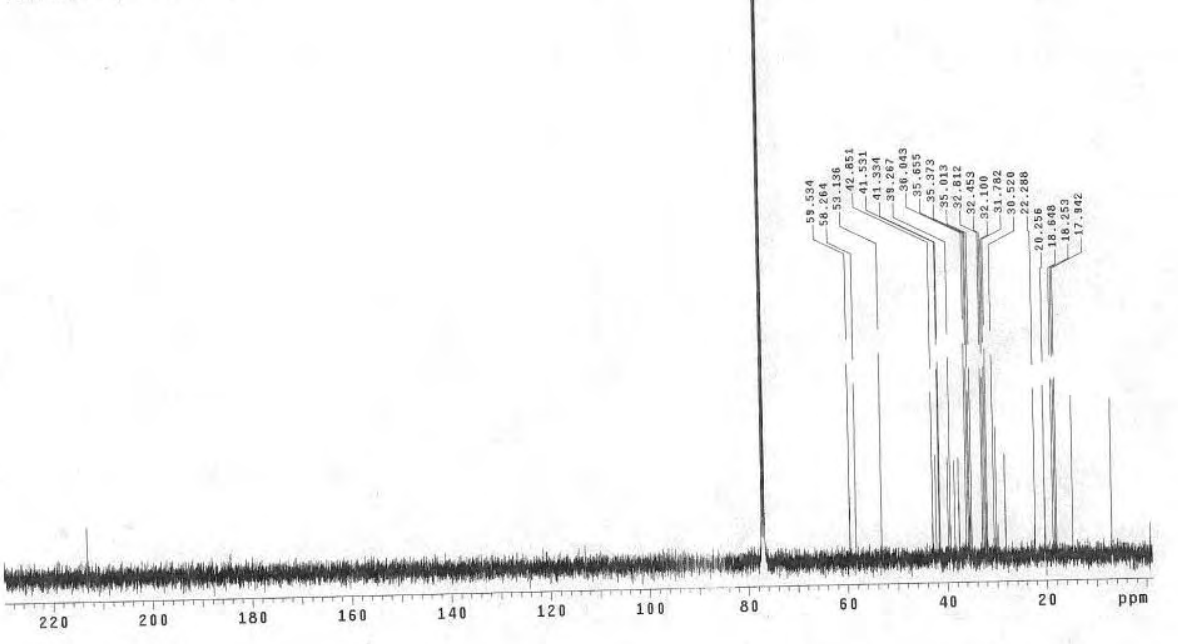

Anexo 4. Espectro de RMN de ${ }^{13} \mathrm{C}$ da substância 1.

$\left(125 \mathrm{MHz}-\mathrm{CDCl}_{3}\right)$ 


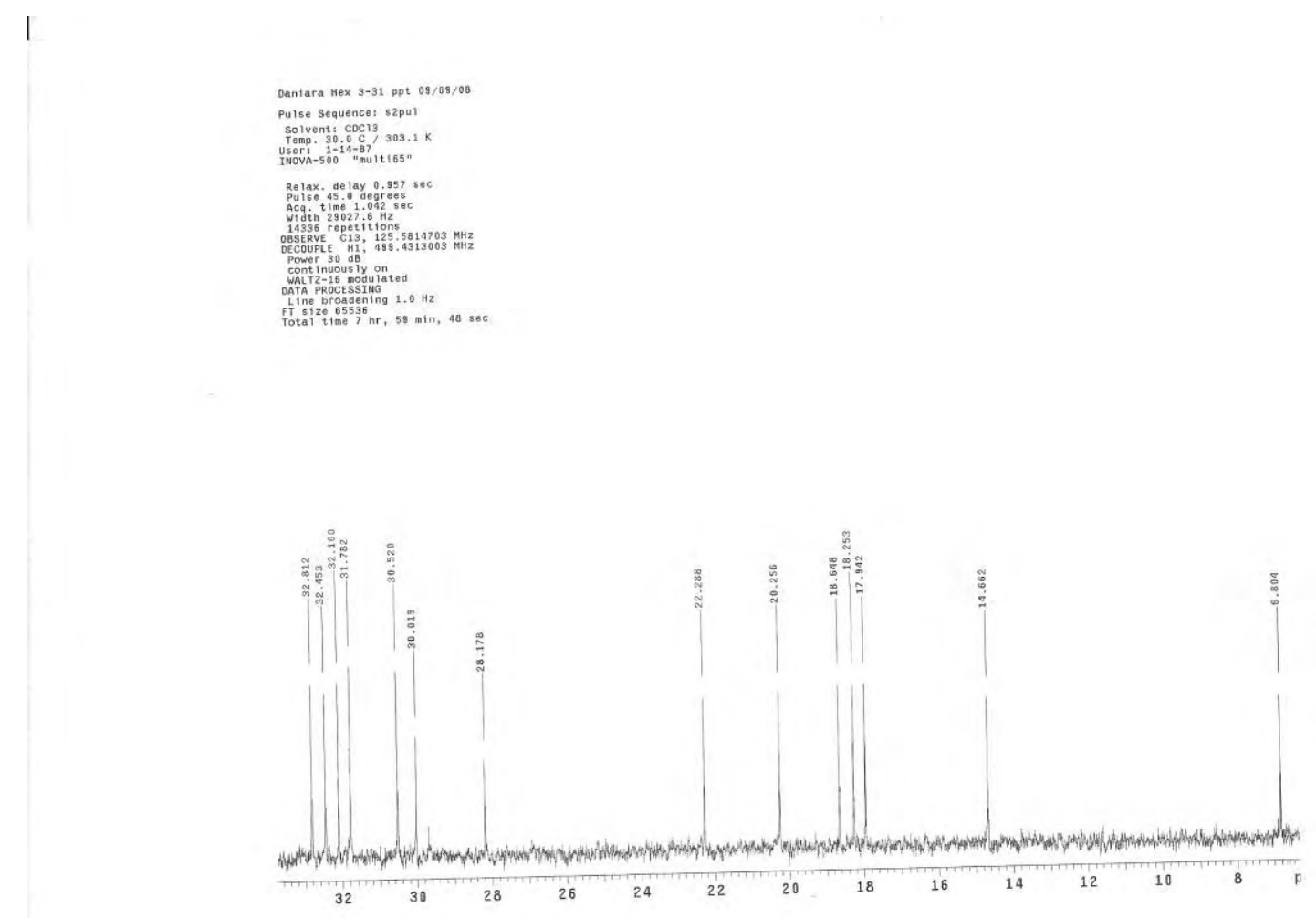

Anexo 5. Ampliação do espectro de RMN de ${ }^{13} \mathrm{C}$ da substância 1.

$\left(125 \mathrm{MHz}-\mathrm{CDCl}_{3}\right)$

Dantara Hex 3-91 ppt 09/09/08

Puise Sequence: s2pul

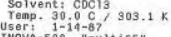

Relax. Delay 0.957 sec

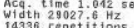

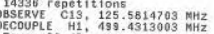

continuous 1 on
walt
wal -16 modulated

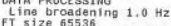

fT 58 ize $65536 \mathrm{~s}, 59 \mathrm{~Hz}$
Total time $7 \mathrm{hr}, 58 \mathrm{~min}, 48 \mathrm{sec}$

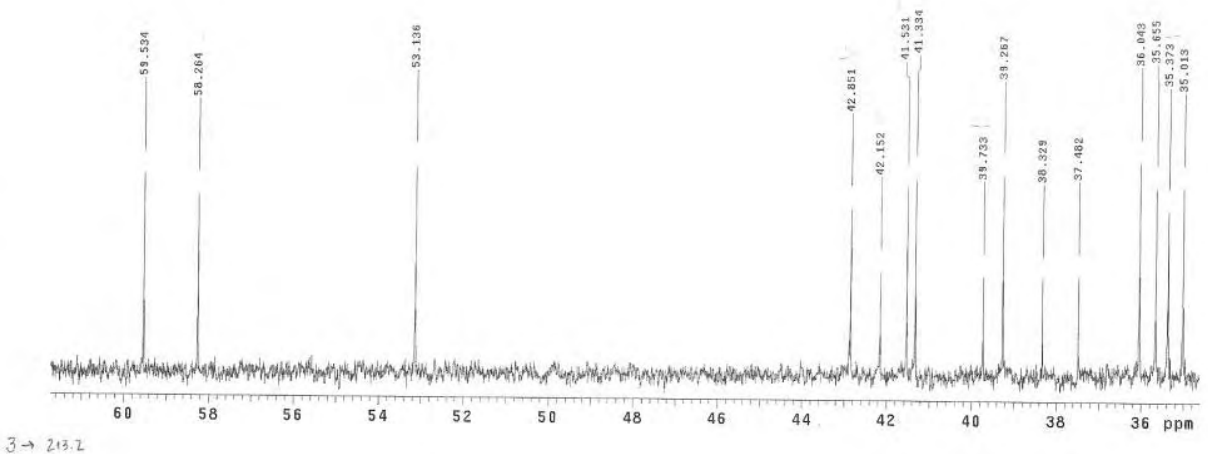

Anexo 6. Ampliação do espectro de RMN de ${ }^{13} \mathrm{C}$ da substância 1.

$\left(125 \mathrm{MHz}-\mathrm{CDCl}_{3}\right)$ 
ppt 09/09/00

Pulse Sequence: DEPT

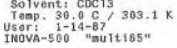

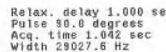

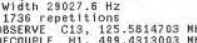

DECoupL
Power
H1
dB

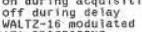

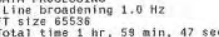

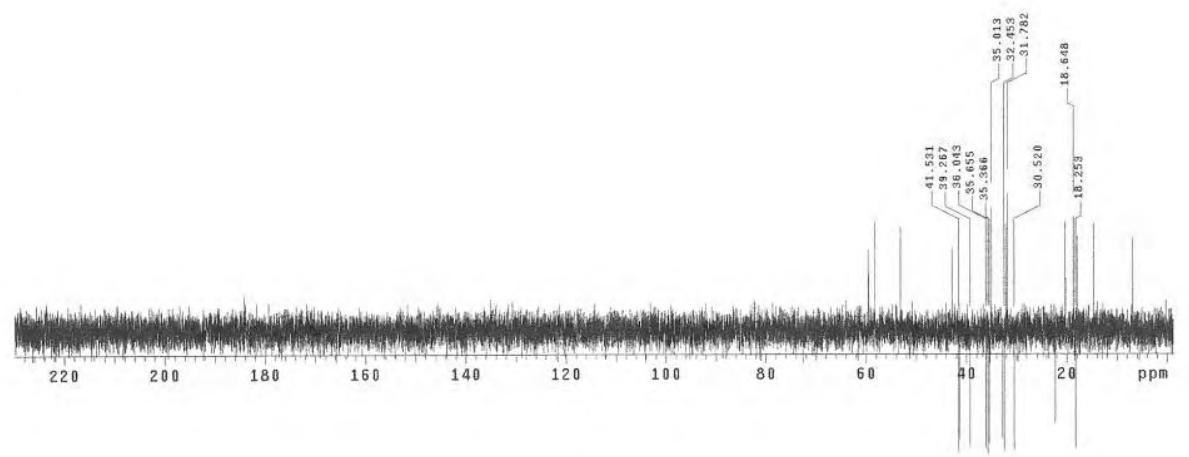

Anexo 7. Espectro de DEPT $135^{\circ}$ da substância 1.

$\left(125 \mathrm{MHz}-\mathrm{CDCl}_{3}\right)$

Daniara Hex $3-31$ ppt $09 / 09 / 00$

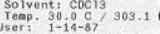

Relax. delay 1.000 se
pulse 90.0 degrees
act

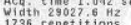

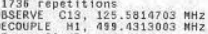

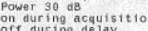

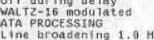

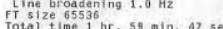

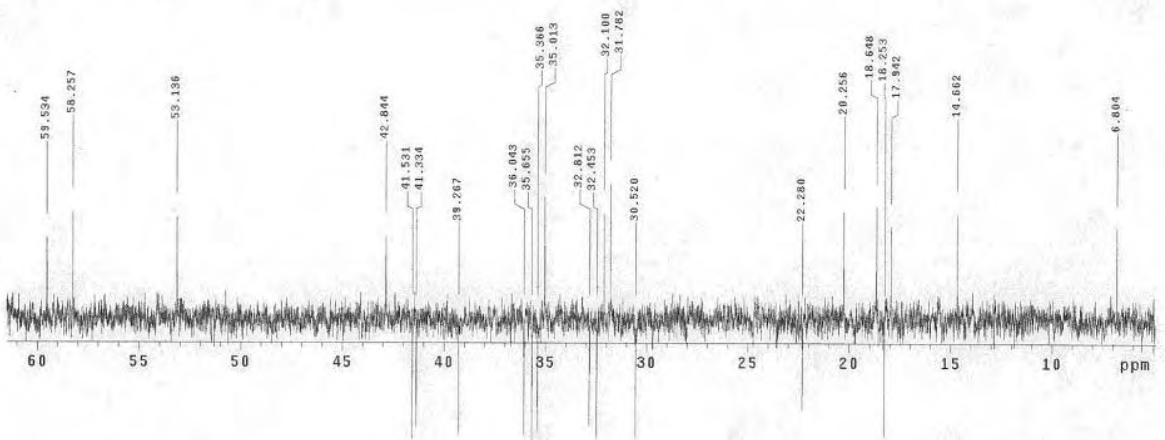

Anexo 8. Ampliação do espectro de DEPT $135^{\circ}$ da substância 1.

$\left(125 \mathrm{MHz}-\mathrm{CDCl}_{3}\right)$ 
Oaniara Hex 3-31 ppt 09/09/08

Sulse Sequence: DEPTIP

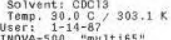

Relax. delay $1.000 \mathrm{sec}$
pulise 90.0 degress
but

Yidith $29027.6 \mathrm{~Hz}$

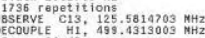

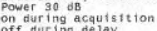

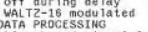

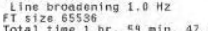

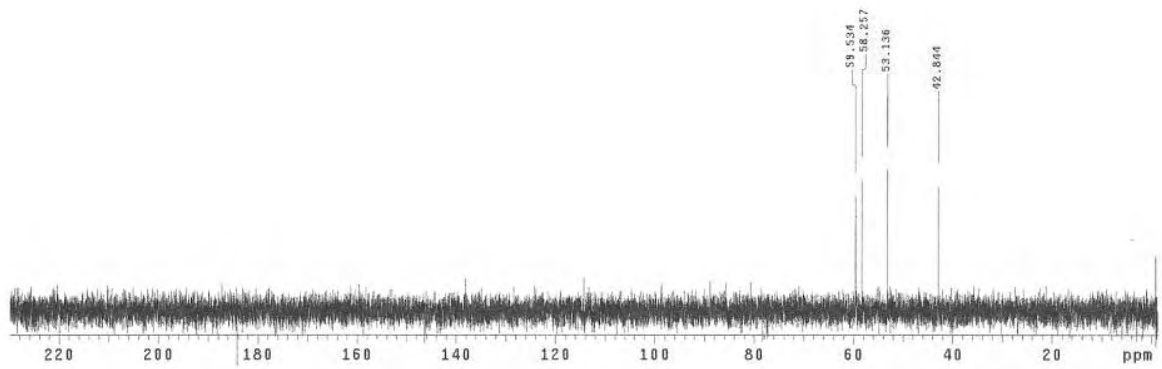

Anexo 9. Espectro de DEPT $90^{\circ}$ da substância 1.

$\left(125 \mathrm{MHz}-\mathrm{CDCl}_{3}\right)$

Daniara Hex 3-59 17/11/00

Pulse Sequence: stpur
Solvent: coc13

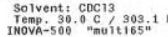

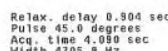

(⿻一丿)

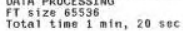

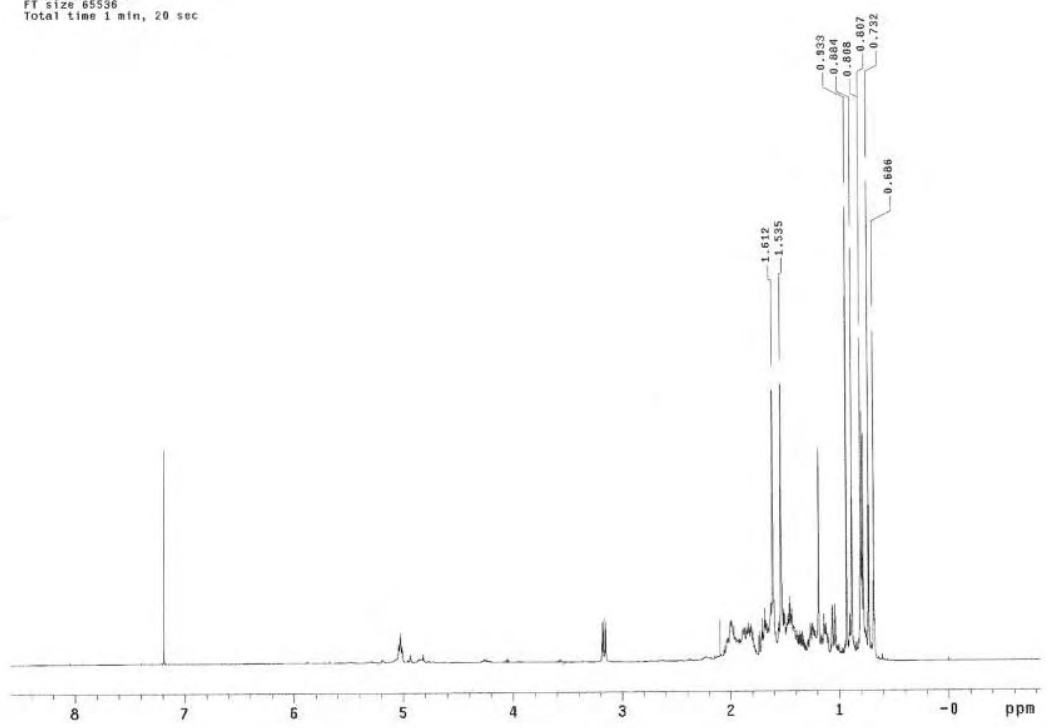

Anexo 10. Espectro de RMN de ${ }^{1} \mathrm{H}$ da substância 2.

$\left(500 \mathrm{MHz}-\mathrm{CDCl}_{3}\right)$ 
Dantara Hex 3-59 17/11/0

solvent: $\operatorname{CDC} 13$

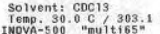

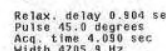

IS repetitions $98.4219825 \mathrm{NHZ}$

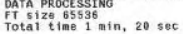

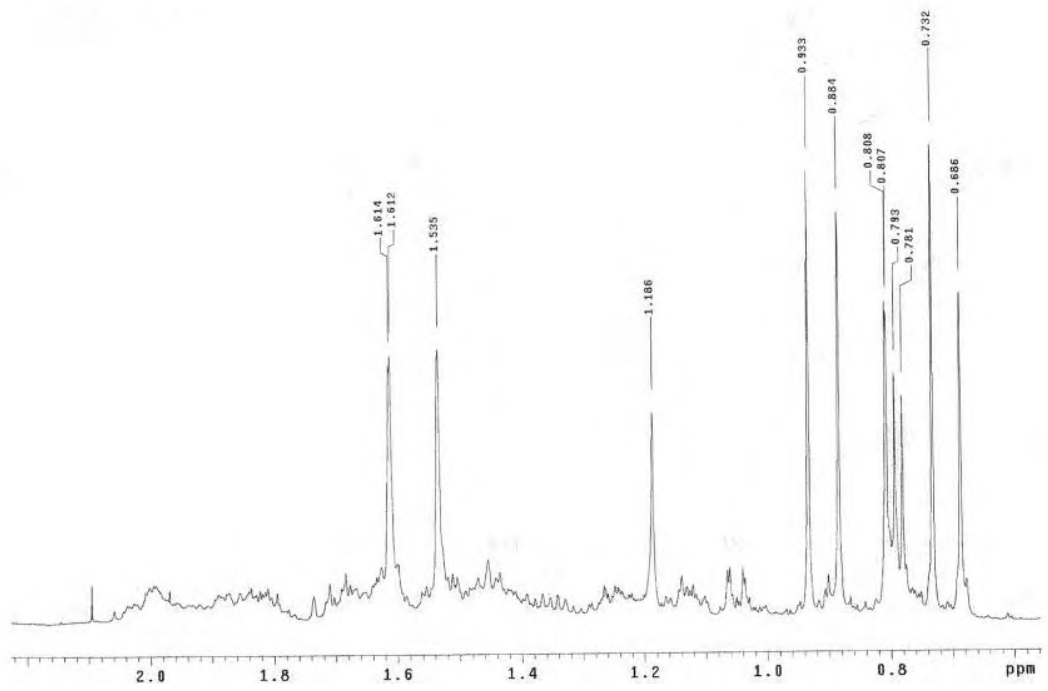

Anexo 11. Ampliação do espectro de RMN de ${ }^{1} \mathrm{H}$ da substância 1.

$\left(500 \mathrm{MHz}-\mathrm{CDCl}_{3}\right)$

Dantara Hex 3-59 $17 / 11 / 0$

Pulse sequence: s2pur

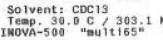

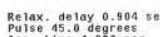

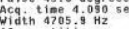

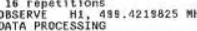

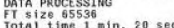

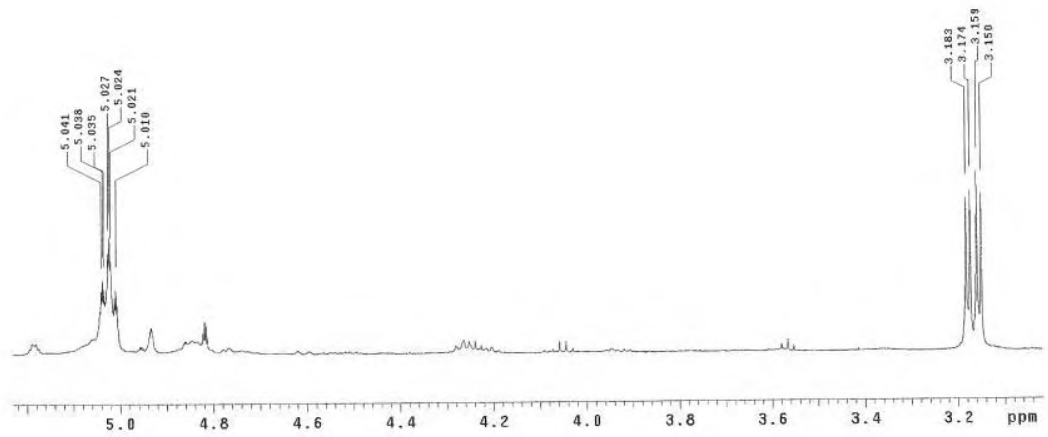

Anexo 12. Ampliação do espectro de RMN de ${ }^{1} \mathrm{H}$ da substância 2.

$\left(500 \mathrm{MHz}-\mathrm{CDCl}_{3}\right)$ 
Danlara Hex $3-59$ 19/08/08

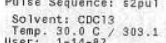

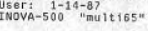

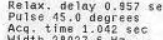

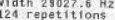

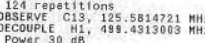

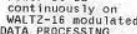

FT size 65535 sing $1.0 \mathrm{~Hz}$

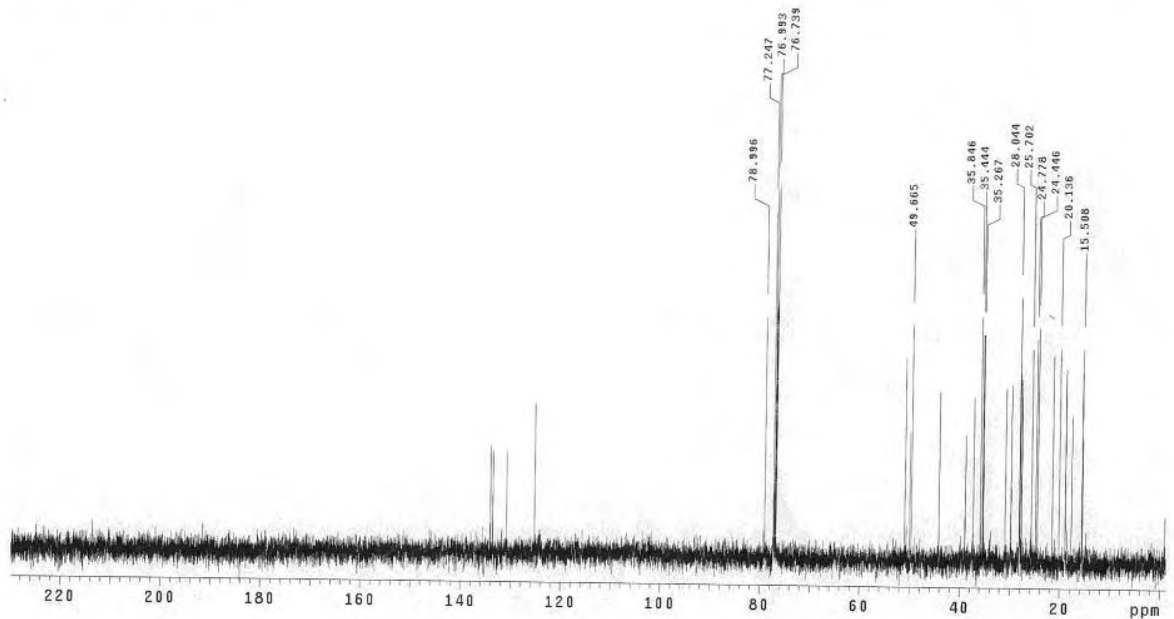

Anexo 13. Espectro de $\mathrm{RMN}$ de ${ }^{13} \mathrm{C}$ da substância 2

$\left(125 \mathrm{MHz}-\mathrm{CDCl}_{3}\right)$

Daniara Hex $3-59$ 19/08/08

unlse Sequence: $82 \mathrm{pur}$

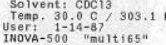

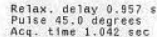

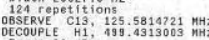

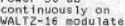

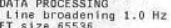

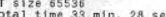

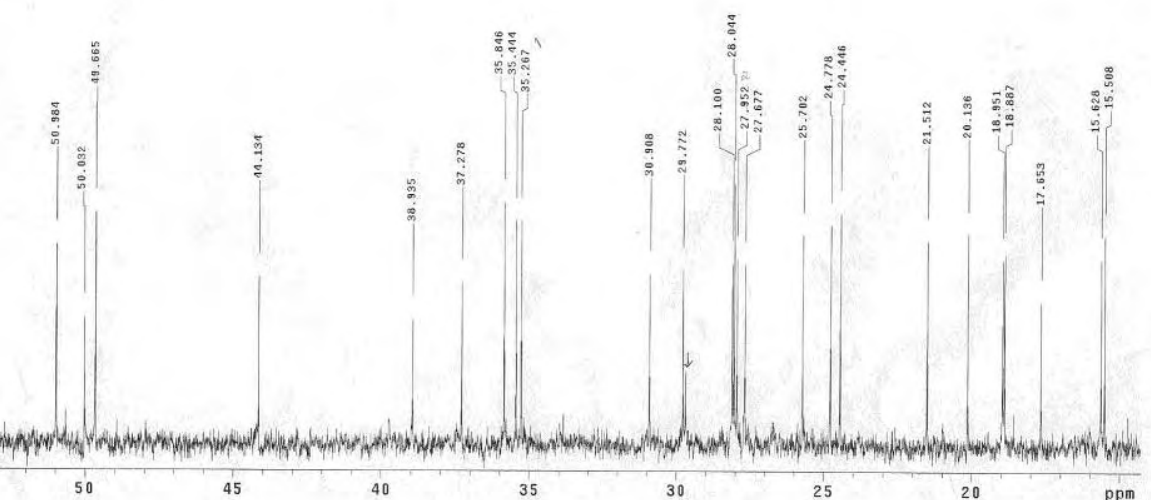

Anexo 14. Ampliação do espectro de RMN de ${ }^{13} \mathrm{C}$ da substância 2.

$\left(125 \mathrm{MHz}-\mathrm{CDCl}_{3}\right)$ 
Daniara Hex $3-59$ 19/00/00

Pulse Sequence: 52 pur

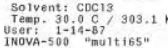

Relax, delay o.957 sec
Pulse 45.0 degriees
Acq t tine

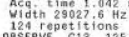

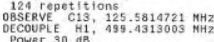

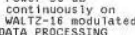

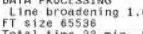

thal time 33

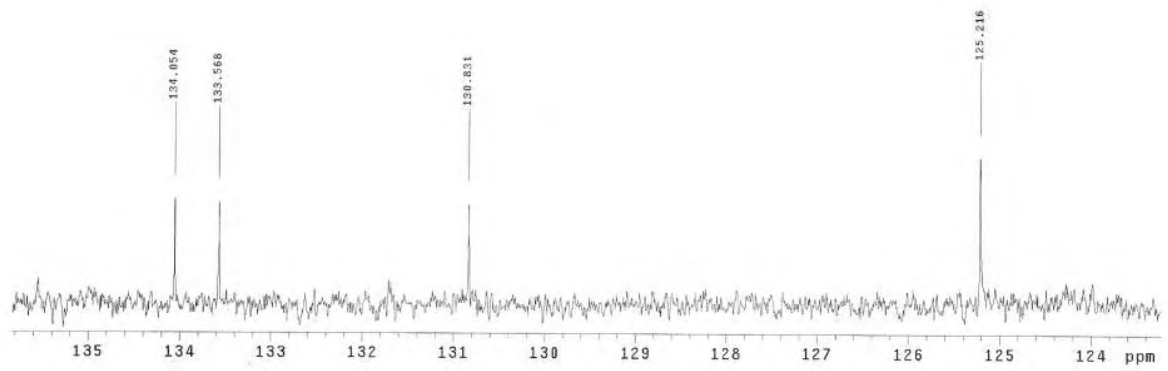

Anexo 15. Ampliação do espectro de $\mathrm{RMN}$ de ${ }^{13} \mathrm{C}$ da substância 2.

$\left(125 \mathrm{MHz}-\mathrm{CDCl}_{3}\right)$
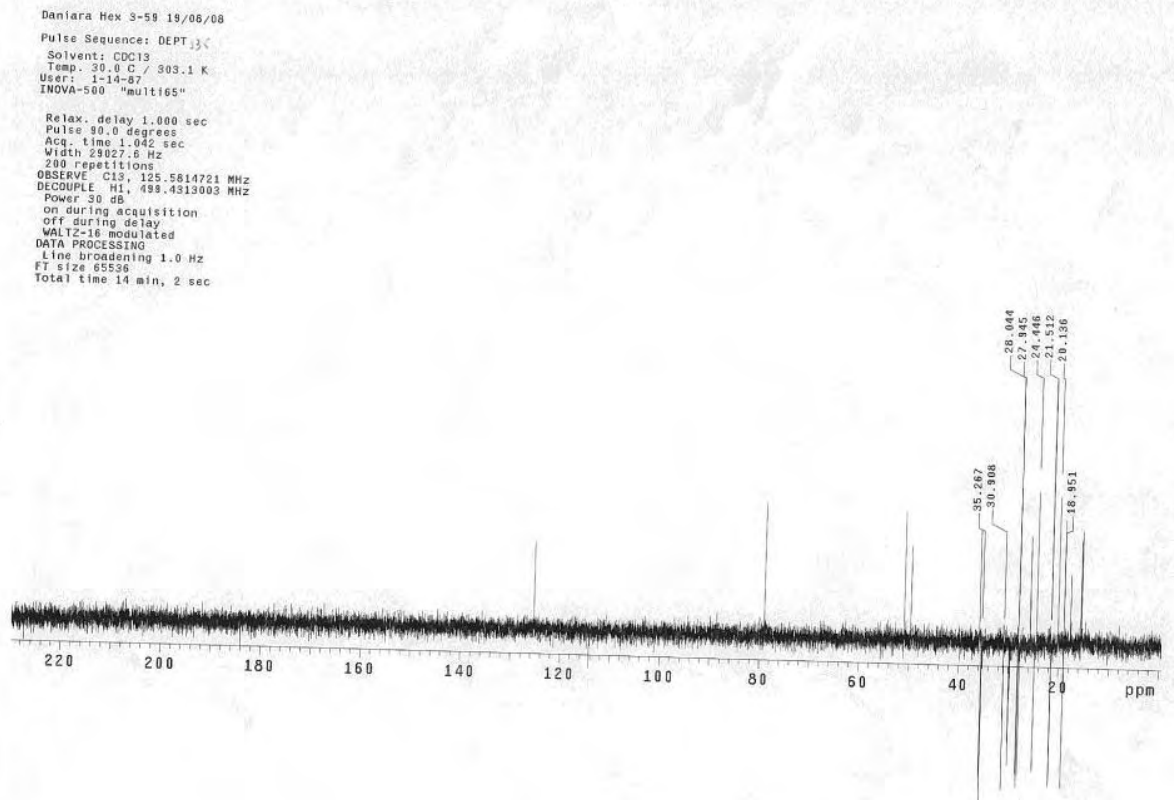

Anexo 16. Espectro de DEPT $135^{\circ}$ da substância 2.

$\left(125 \mathrm{MHz}-\mathrm{CDCl}_{3}\right)$ 
Daniara Hex 3-59 19/08/08

Pulse Sequence: DEPT j3i

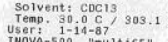

Relax. Delay $1,000 \mathrm{sec}$
Pulse 90.0 degrees

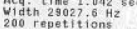

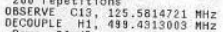

ond durng acquisit
off during delay

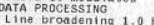

Line broadening $1.0 \mathrm{~Hz}$
FT size 65536 .
Total time 14

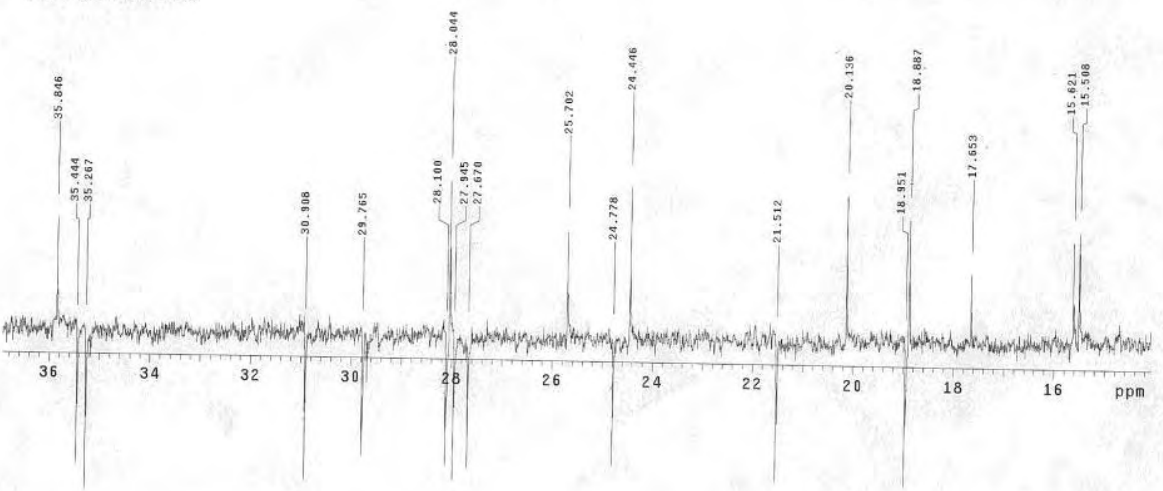

Anexo 17. Ampliação do espectro de DEPT $135^{\circ}$ da substância 2.

$\left(125 \mathrm{MHz}-\mathrm{CDCl}_{3}\right)$

Daniara Hex $3-59$ 19/08/00

Pulse Sequence: DEPT

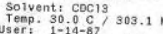

Relax. delay 1,000 sec

Act time 1.042 sec

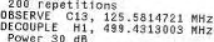

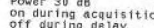

2
PROCESSIMG

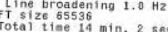

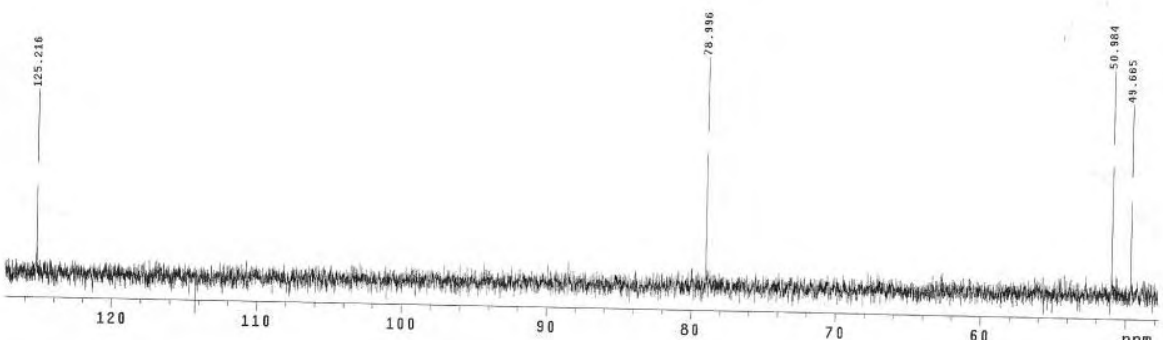

Anexo 18. Ampliação do espectro de DEPT $135^{\circ}$ da substância 2.

$$
\left(125 \mathrm{MHz}-\mathrm{CDCl}_{3}\right)
$$


Daniara Hex 3-59 19/08/08

Pulse Sequence: DEPT ID

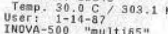

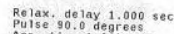

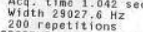

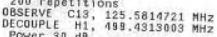

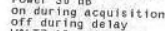

DATA PRocESSIHIG

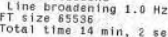

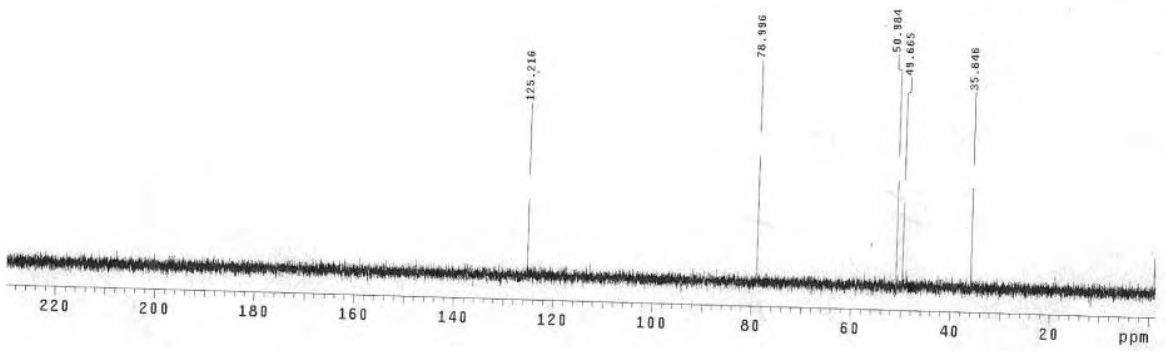

Anexo 19. Espectro de DEPT $90^{\circ}$ da substância 2.

$\left(125 \mathrm{MHz}-\mathrm{CDCl}_{3}\right)$

Daniara Hex $3-65$ 18/08/00

Pulse Sequence: 82 pu

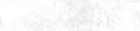
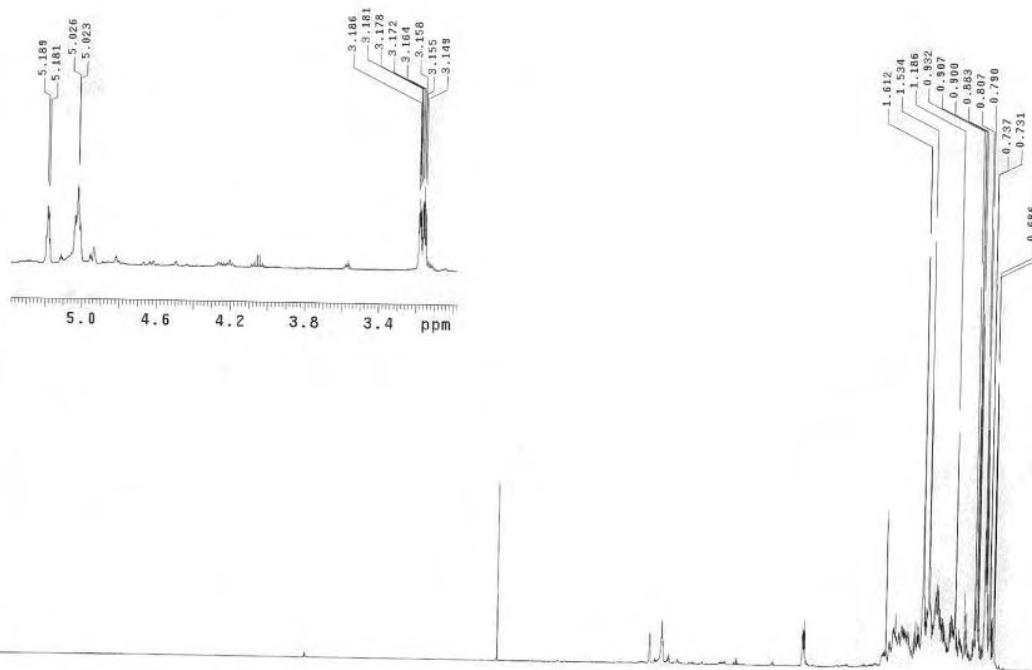

13
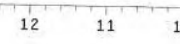

Anexo 20. Espectro de RMN de ${ }^{1} \mathrm{H}$ da mistura 2 e 3.

$\left(500 \mathrm{MHz}-\mathrm{CDCl}_{3}\right)$ 
Daniara Hex $3-65$ 21/08/08

Pulse Sequence: 52 pur
solve

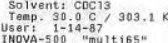

Relax. de lay $0.957 \mathrm{sec}$
pus se 45.0 degrees
Acs o t

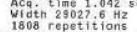

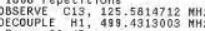

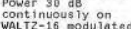

ine brosdening 1.0

Total time $1 \mathrm{hr}, 59 \mathrm{~min}, 57 \mathrm{sec}$

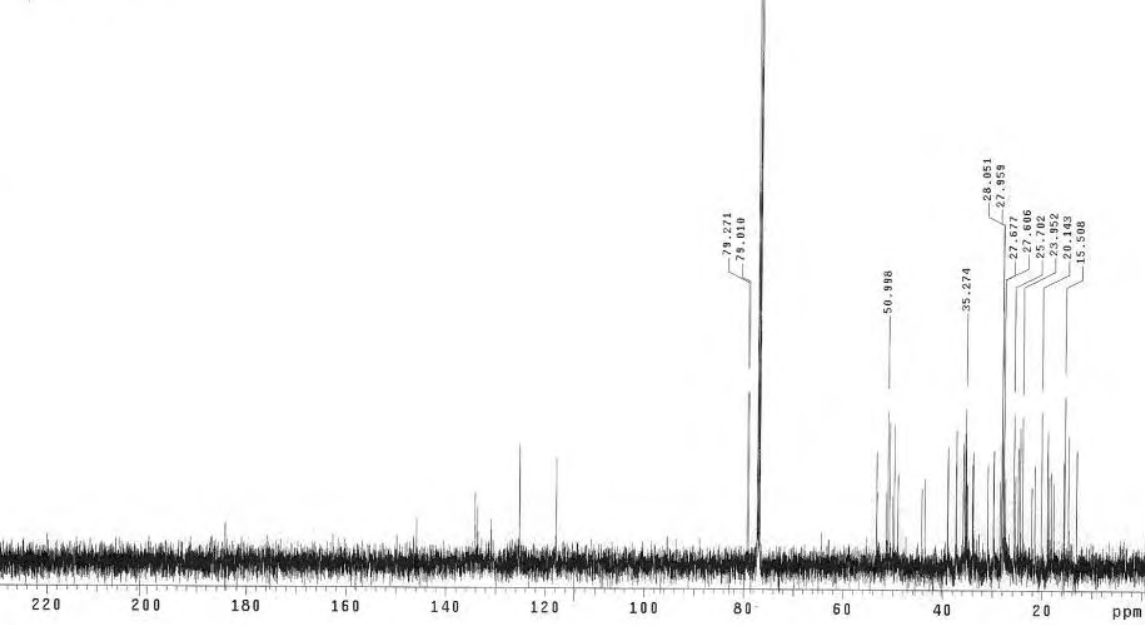

Anexo 21. Espectro de RMN de ${ }^{13} \mathrm{C}$ da mistura 2 e 3.

$\left(125 \mathrm{MHz}-\mathrm{CDCl}_{3}\right)$

Dantara Hex 3-55 21/00/00

Pulse Sequence: s2pul

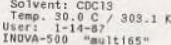

Relax. delay 0.957
Puise 45.0 degages

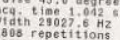

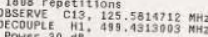

continuous iy on

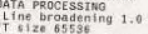

年

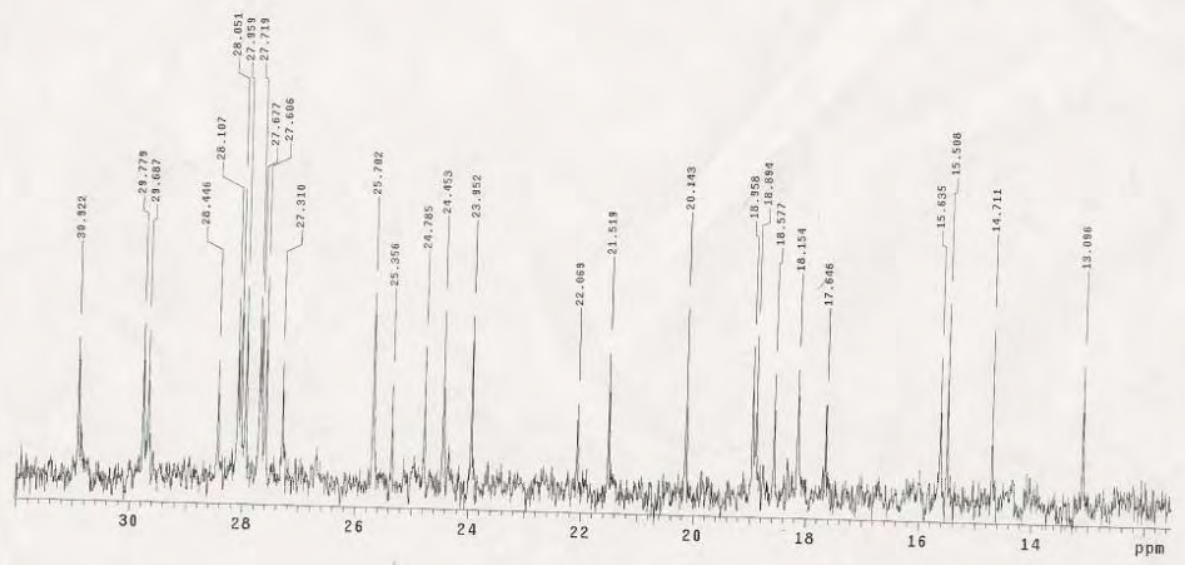

Anexo 22. Ampliação do espectro de RMN de ${ }^{13} \mathrm{C}$ da mistura 2 e 3.

$\left(125 \mathrm{MHz}-\mathrm{CDCl}_{3}\right)$ 
Daniara Hex 3-65 21/08/00

Pulse Sequence: 52 pur

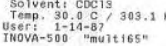

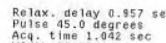

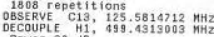

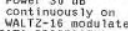

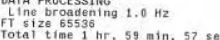

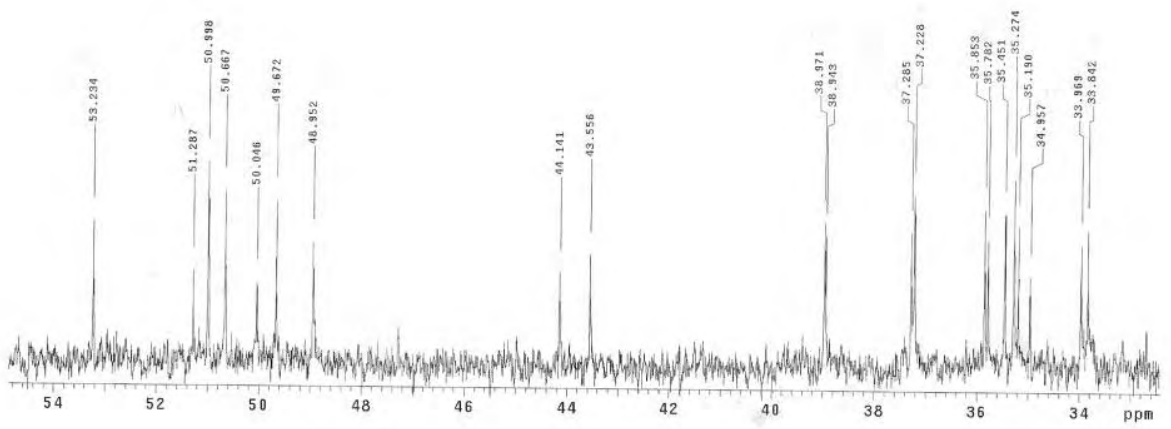

Anexo 23. Ampliação do espectro de RMN de ${ }^{13} \mathrm{C}$ da mistura 2 e 3. $\left(125 \mathrm{MHz}-\mathrm{CDCl}_{3}\right)$

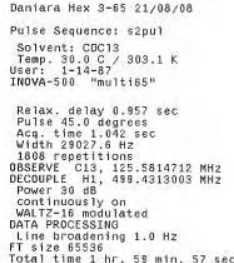

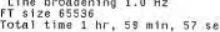

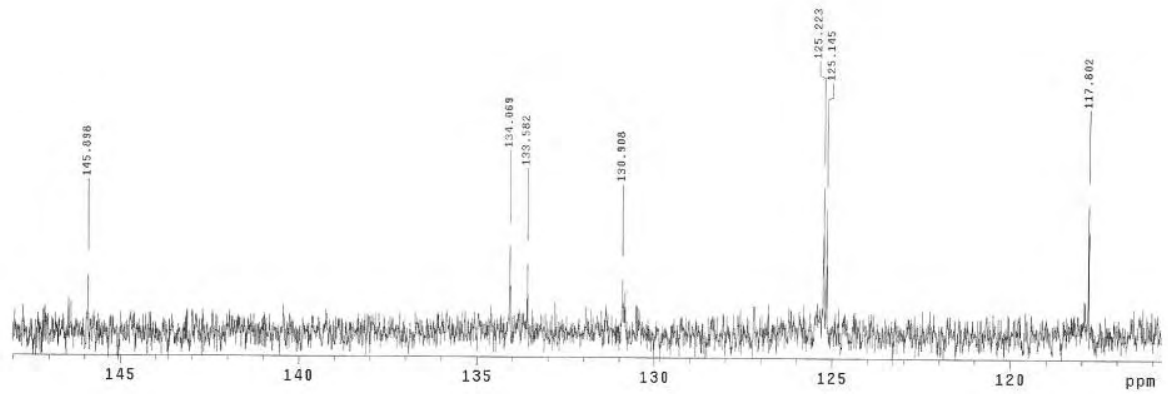

Anexo 24. Ampliação do espectro de RMN de ${ }^{13} \mathrm{C}$ da mistura 2 e 3.

$\left(125 \mathrm{MHz}-\mathrm{CDCl}_{3}\right)$ 
Daniara ACOEt 32 Pico 2 07/04/09

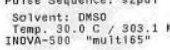

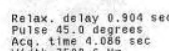

64 repettitions
ogservet

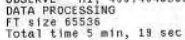

.

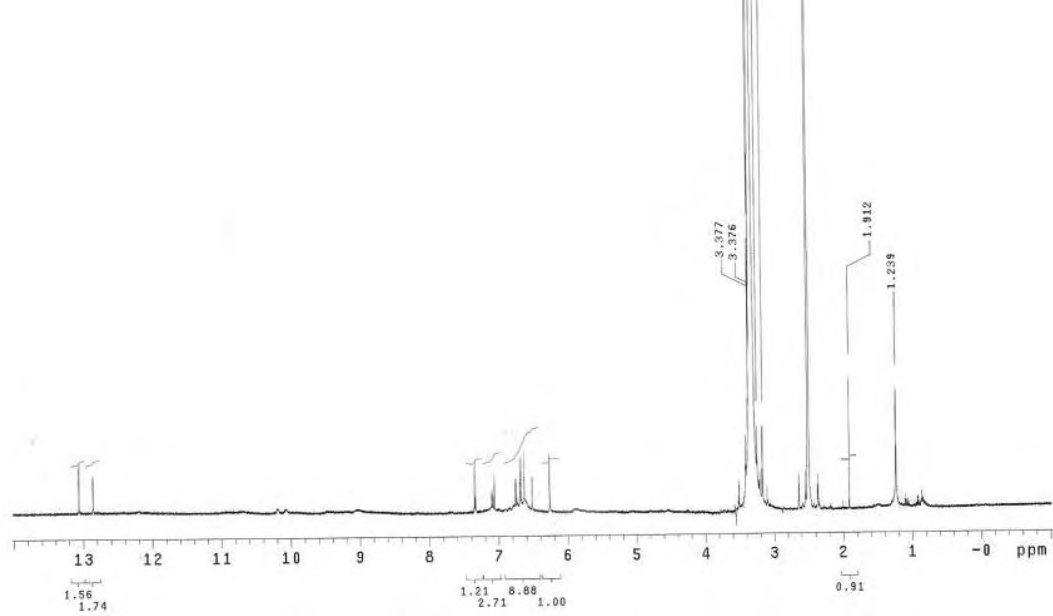

Anexo 25. Espectro de RMN de ${ }^{1} \mathrm{H}$ da substância 4.

$\left(500 \mathrm{MHz}-\mathrm{DMSO}-d_{6}\right)$

Pulse Sequence: 52pul

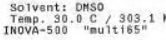

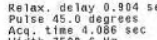

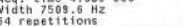

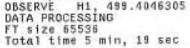

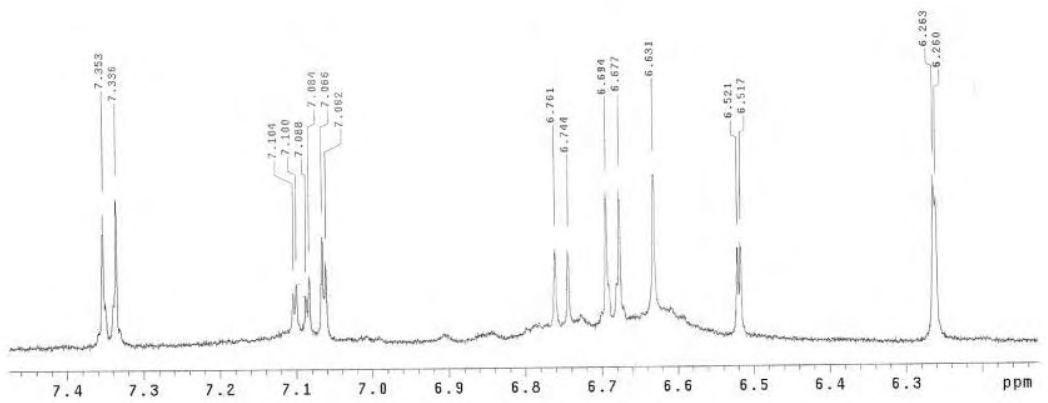

Anexo 26. Ampliação do espectro de RMN de ${ }^{1} \mathrm{H}$ da substância 4.

$\left(500 \mathrm{MHz}-\mathrm{DMSO}-d_{6}\right)$ 
Daniara Acost 32 Pico $207 / 04 / 09$

Pulse Sequence: gCosY

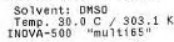

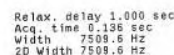

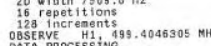

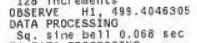

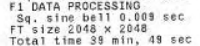

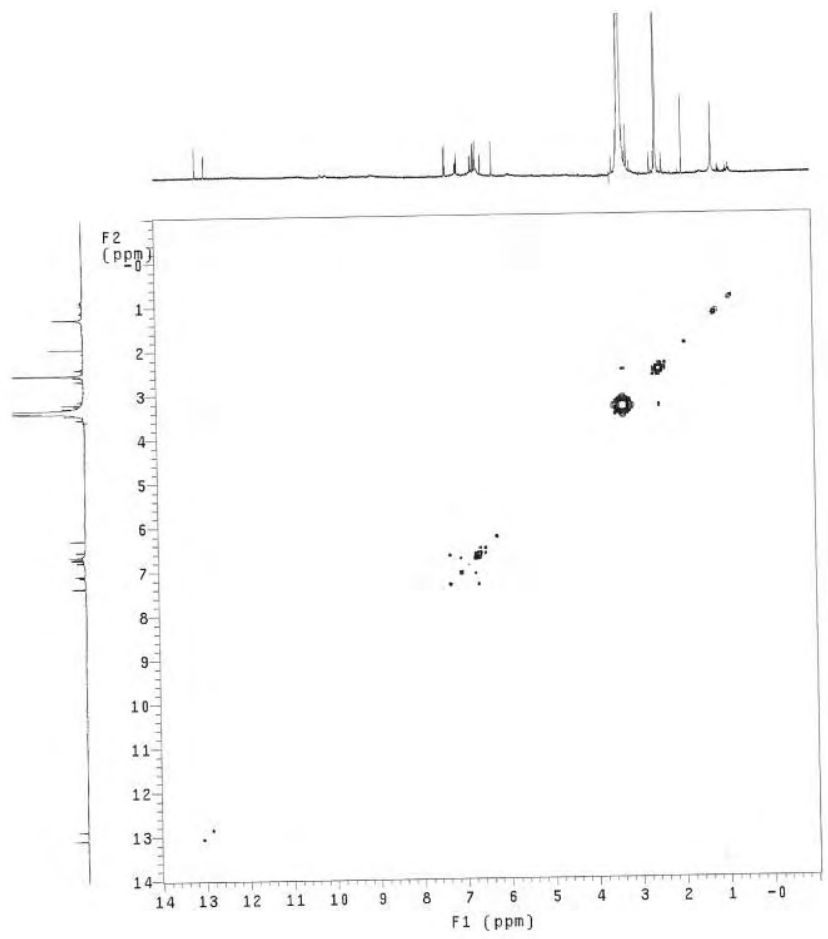

Anexo 27. Mapa de contorno ${ }^{1} \mathrm{H}-{ }^{1} \mathrm{H} g \mathrm{COSY}$ da substância 4.

$\left(500 \mathrm{MHz}-\mathrm{DMSO}-d_{6}\right)$

Daniara ACOEt 32 Pico $207 / 04 / 00$ Pulse Sequence: gcosr

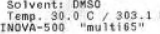

Relax. delay 1.000 sec
Acg.

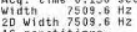

128 increment
OBSERE

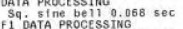

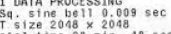
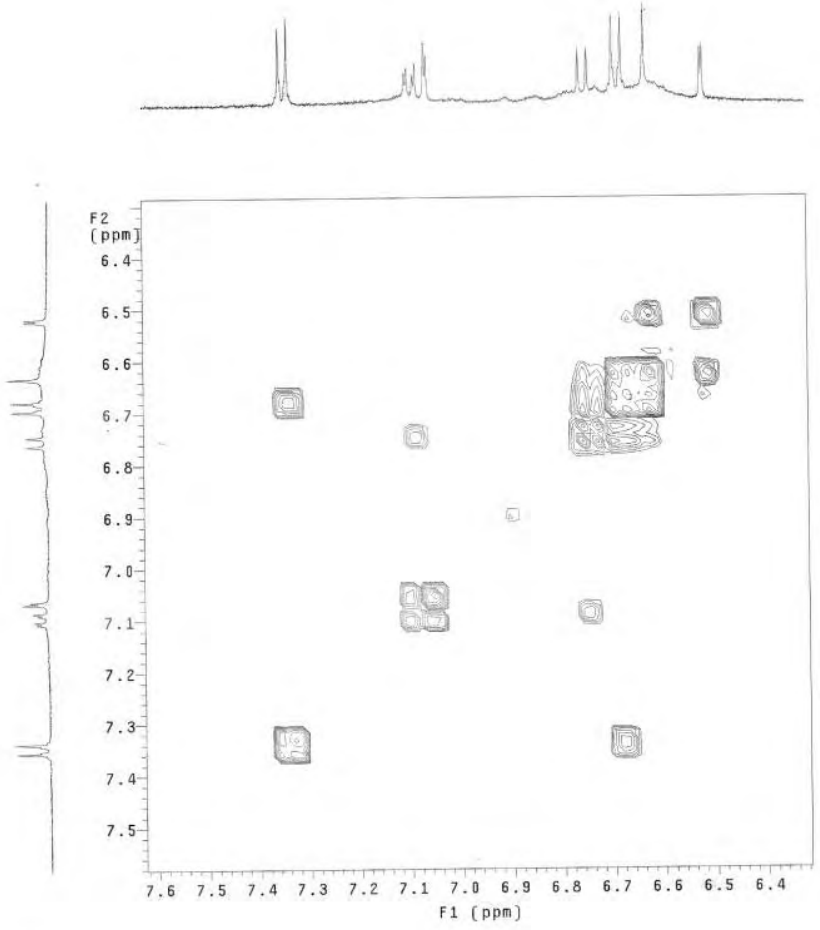

Anexo 28. Ampliação do mapa de contorno ${ }^{1} \mathrm{H}-{ }^{1} \mathrm{H} g \operatorname{COSY}$ da substância 4.

$$
\left(500 \mathrm{MHz}-\text { DMSO- } d_{6}\right)
$$




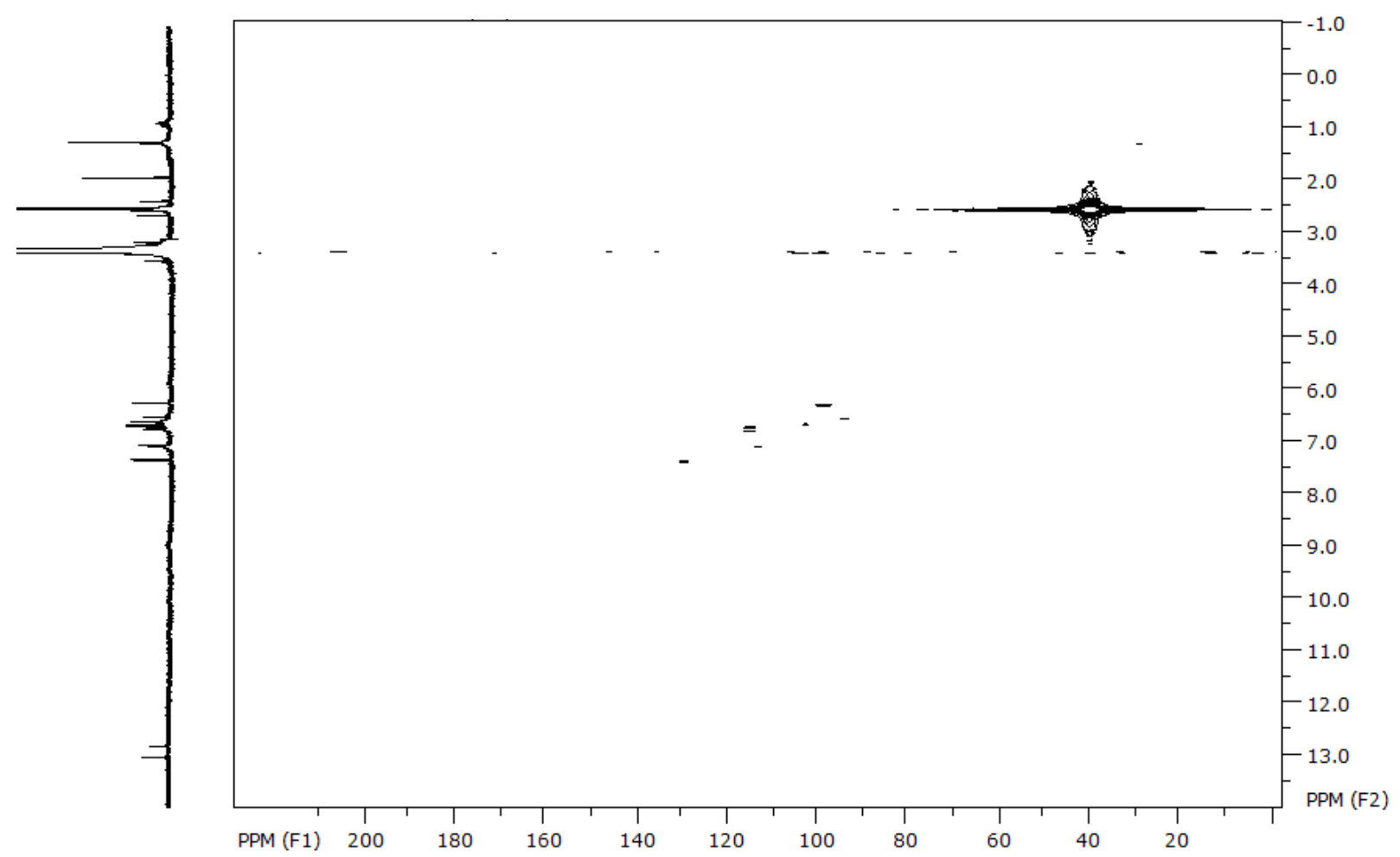

Anexo 29. Mapa de contorno ${ }^{1} \mathrm{H}^{13} \mathrm{C} g \mathrm{HMQC}$ da substância 4.

$$
\left(500 \mathrm{MHz}-\mathrm{DMSO}-d_{6}\right)
$$

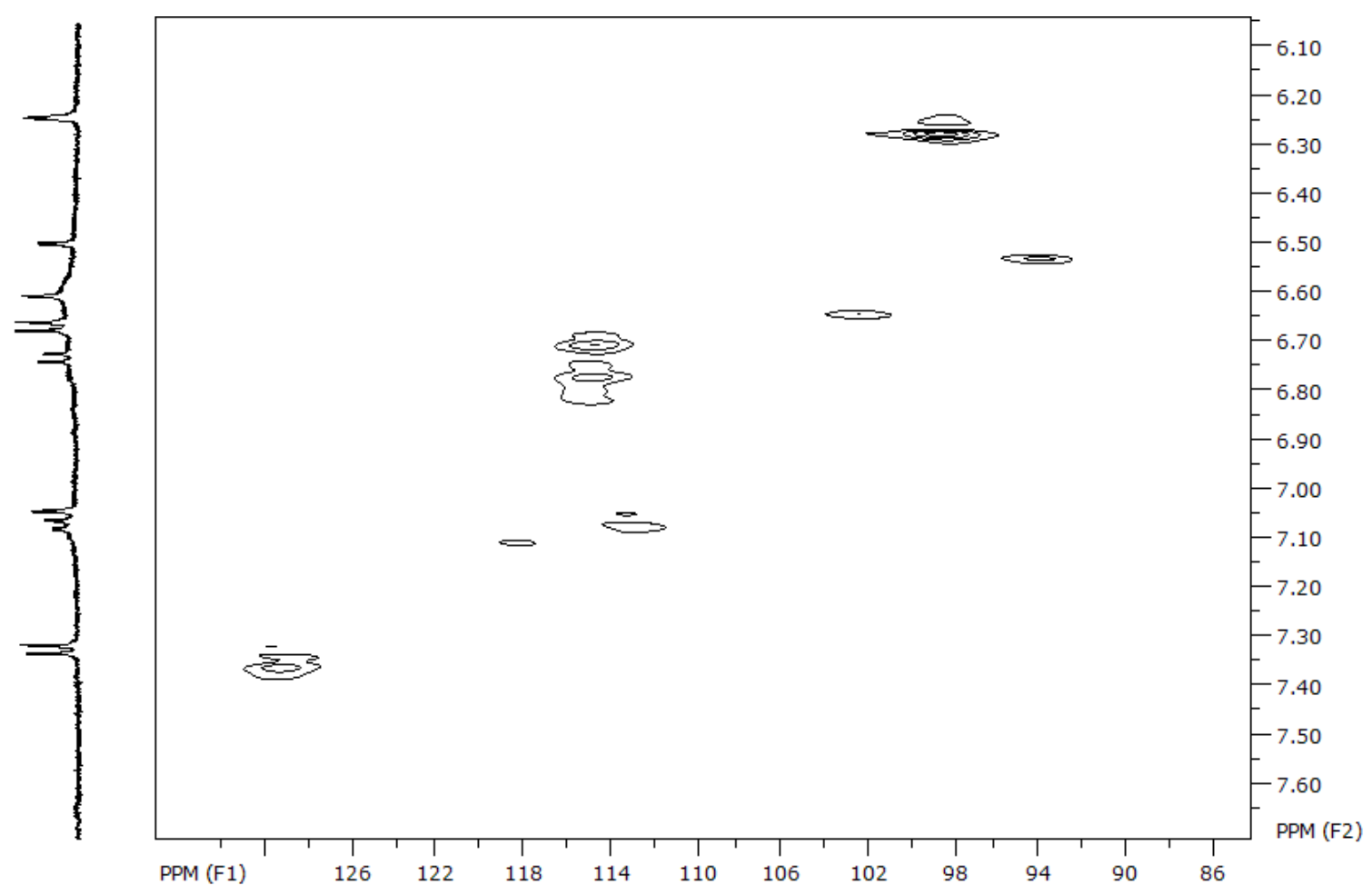

Anexo 30. Ampliação do mapa de contorno ${ }^{1} \mathrm{H}-{ }^{13} \mathrm{C} g \mathrm{HMQC}$ da substância 4

$$
\left(500 \mathrm{MHz}-\mathrm{DMSO}-d_{6}\right)
$$




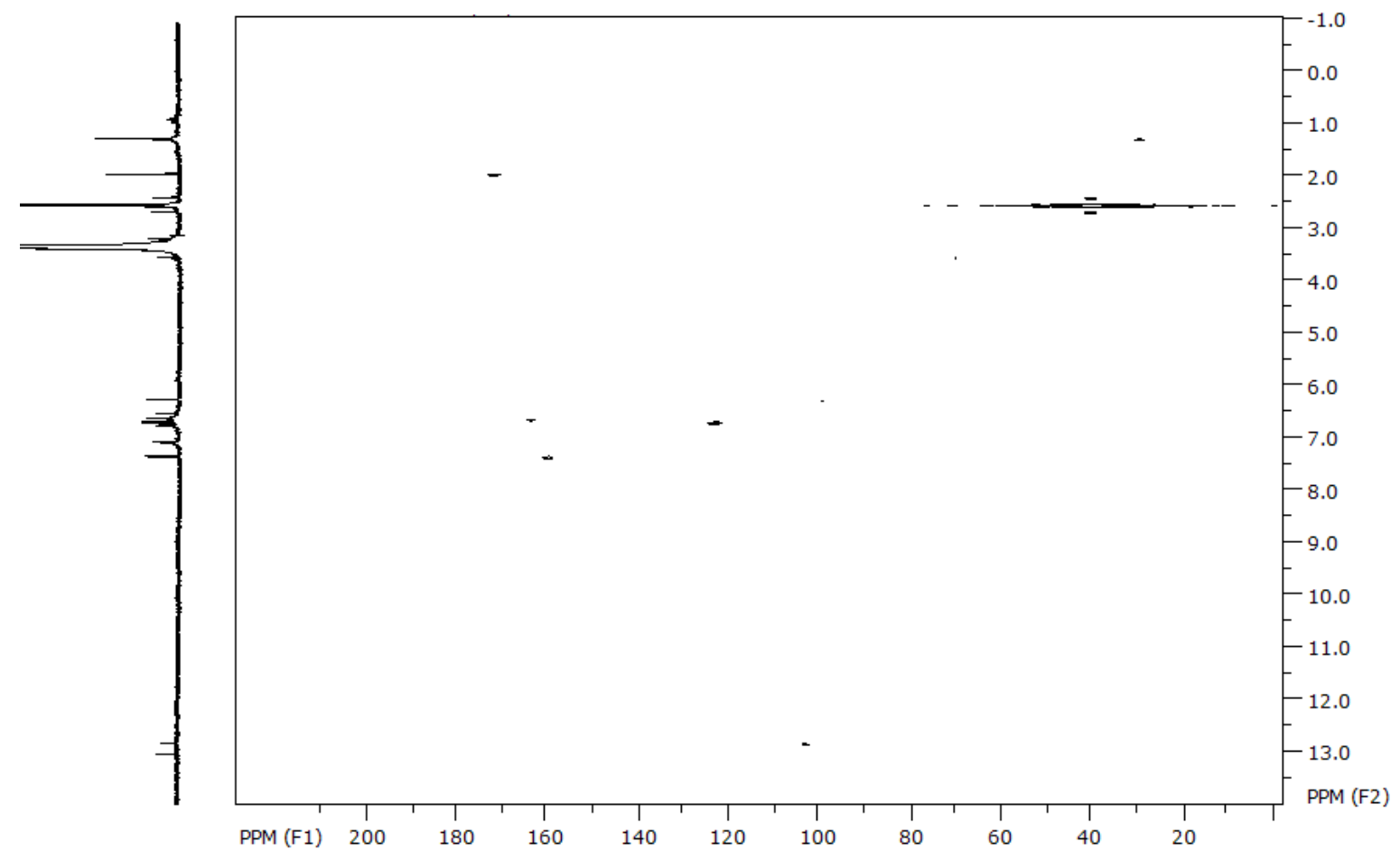

Anexo 31. Mapa de contorno ${ }^{1} \mathrm{H}^{-13} \mathrm{C} g \mathrm{HMBC}$ da substância 4.

$\left(500 \mathrm{MHz}-\mathrm{DMSO}-d_{6}\right)$

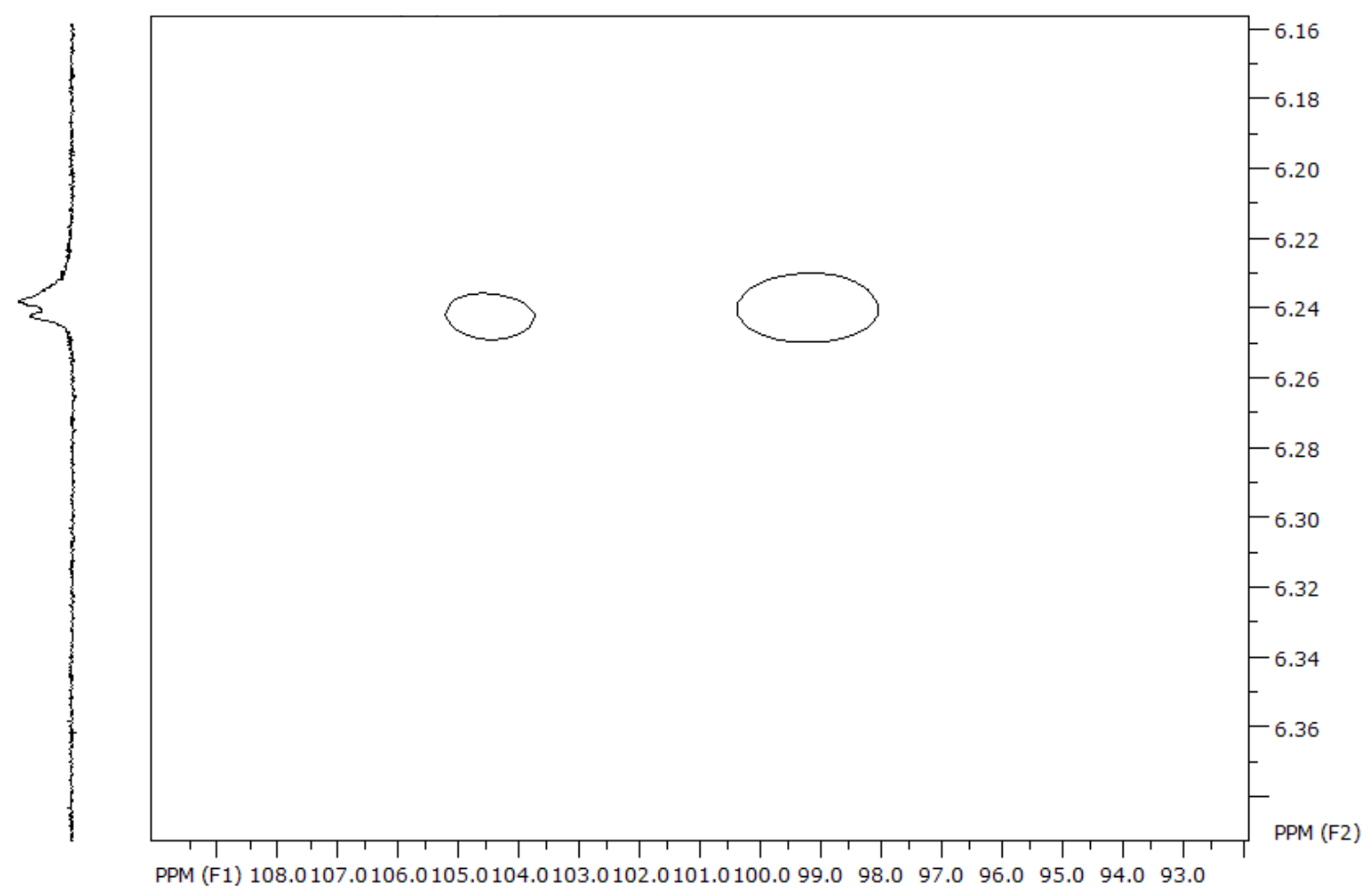

Anexo 32. Ampliação do mapa de contorno ${ }^{1} \mathrm{H}_{-}{ }^{13} \mathrm{C} g \mathrm{HMBC}$ da substância 4.

$$
\left(500 \mathrm{MHz}-\mathrm{DMSO}-d_{6}\right)
$$




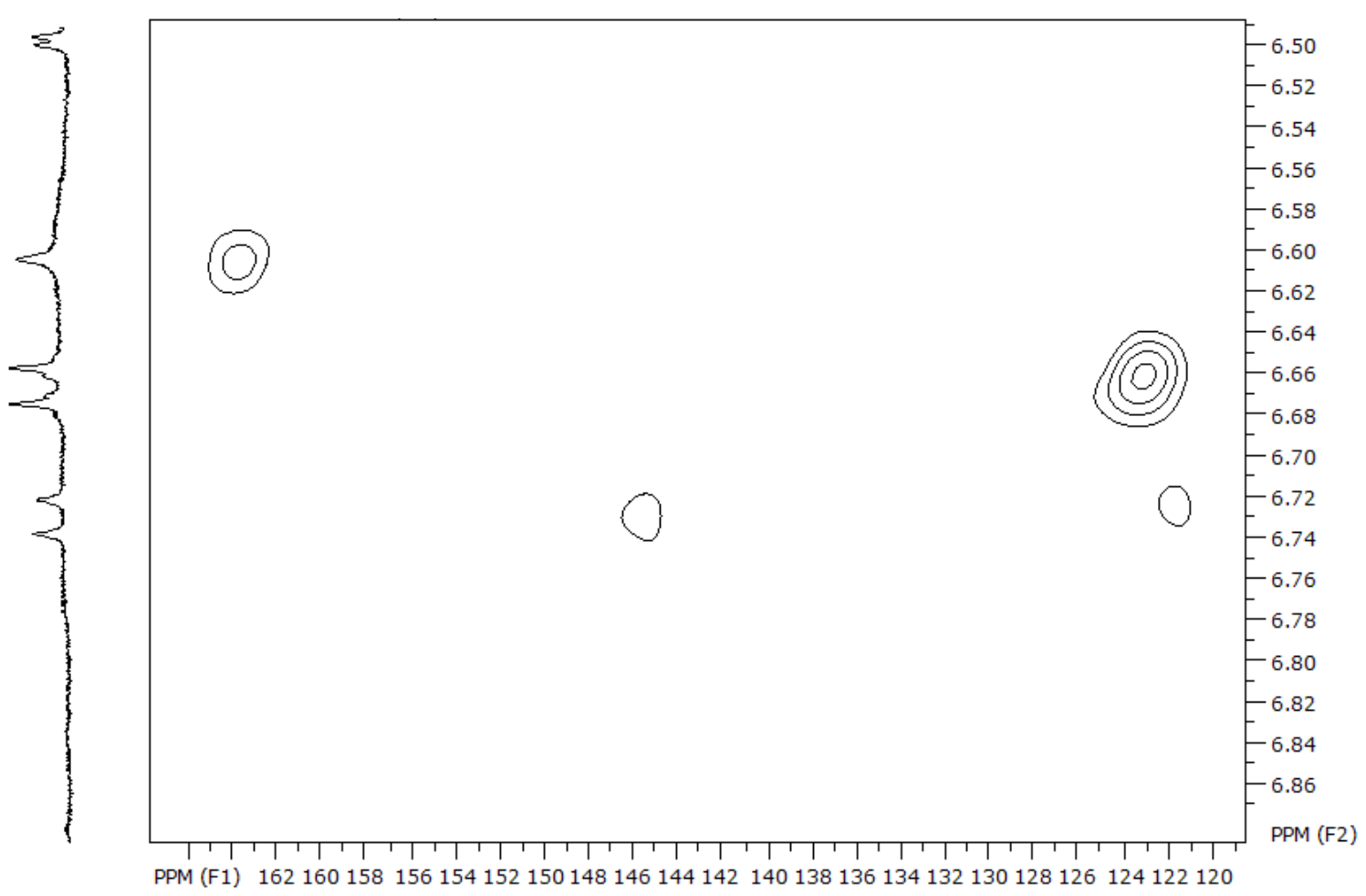

Anexo 33. Ampliação do mapa de contorno ${ }^{1} \mathrm{H}_{-}{ }^{13} \mathrm{C} g \mathrm{HMBC}$ da substância 4.

$$
\left(500 \mathrm{MHz}-\mathrm{DMSO}-d_{6}\right)
$$

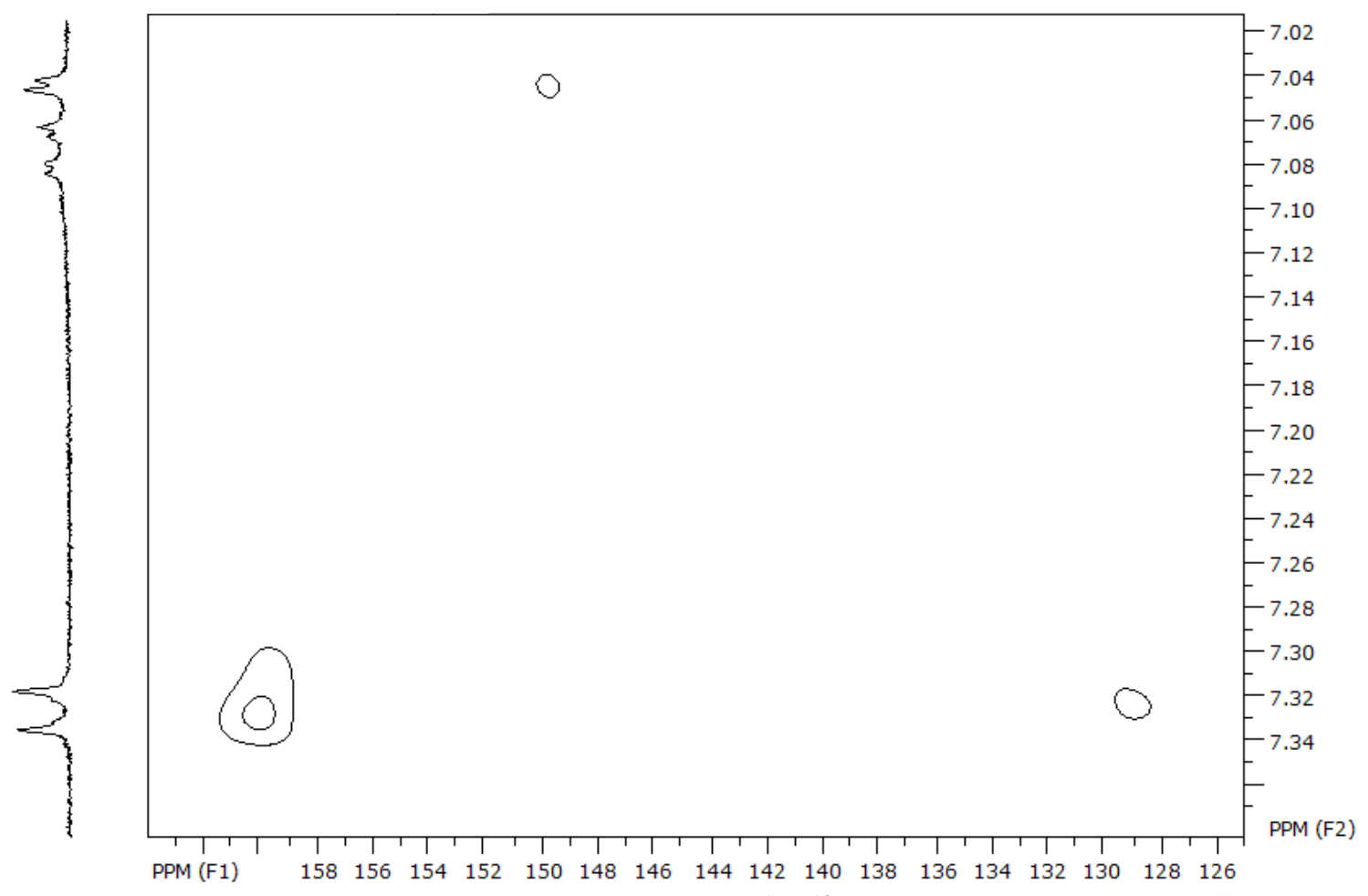

Anexo 34. Ampliação do mapa de contorno ${ }^{1} \mathrm{H}_{-}{ }^{13} \mathrm{C} g \mathrm{HMBC}$ da substância 4.

$\left(500 \mathrm{MHz}-\right.$ DMSO- $\left.d_{6}\right)$ 
Daniara ACOEt 32 pico 2 29/05/09

Pulse Sequences HonDoEc i pwn :Y
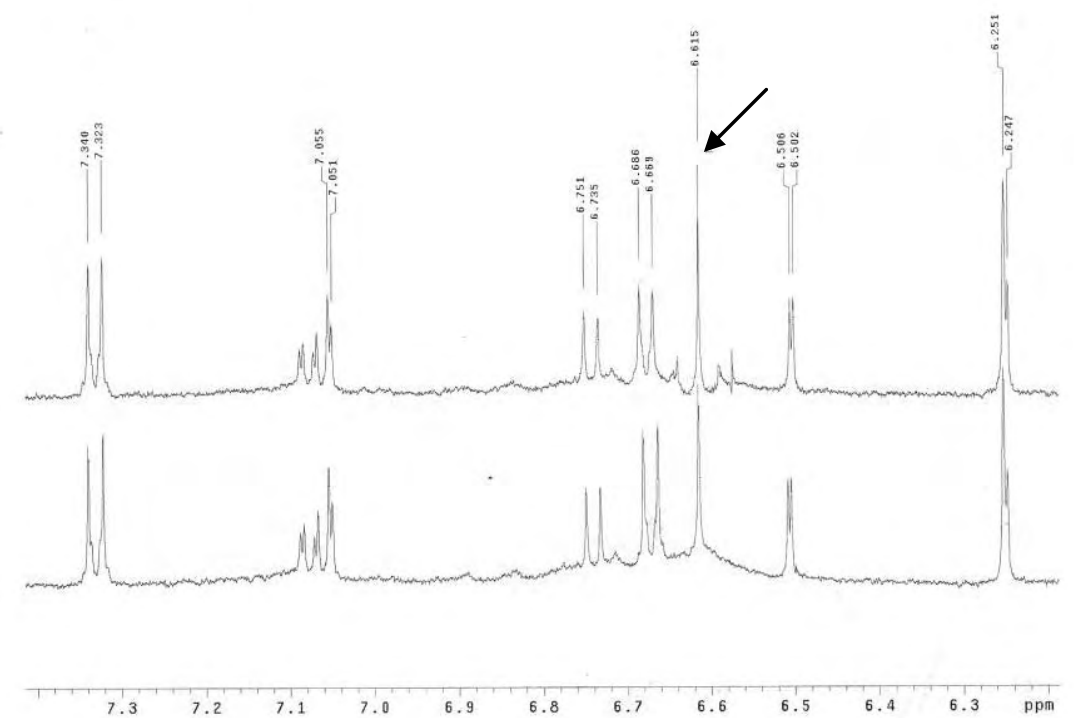

Anexo 35. Espectro de HOMODEC da substância 4 $\left(500 \mathrm{MHz}-\mathrm{DMSO}-d_{6}\right)$

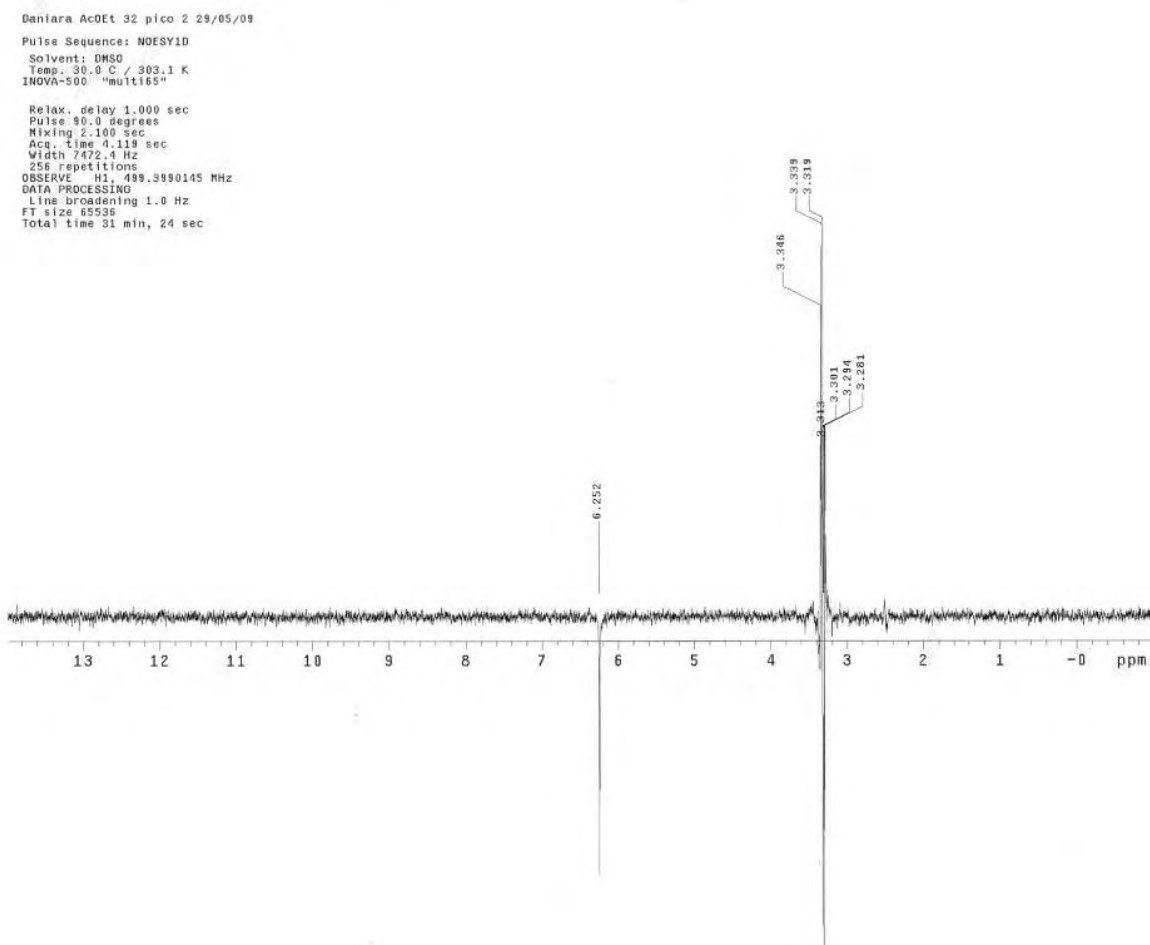

Anexo 36. Espectro de NOESY 1D (irradiação em $\delta_{H} 6,25$ ) da substância 4. $\left(500 \mathrm{MHz}-\mathrm{DMSO}-d_{6}\right)$ 
Dantara AcoEt 30. Picos 26/03/09

Pulse Sequence: : s2put

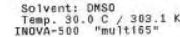

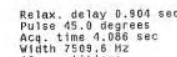

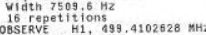

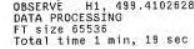

$\left(500 \mathrm{MHz}-\mathrm{DMSO}-d_{6}\right)$

Dantara Acoet 32 , pico $504 / 03 / 09$

Pulse Sequence: s2pu1

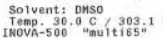

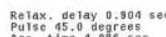

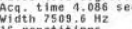

OBSERVE OH1. $199.4102628 \mathrm{n}$

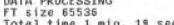

Anexo 37. Espectro de RMN de ${ }^{1} \mathrm{H}$ da substância 5

$\left(500 \mathrm{MHz}-\mathrm{DMSO}-d_{6}\right)$
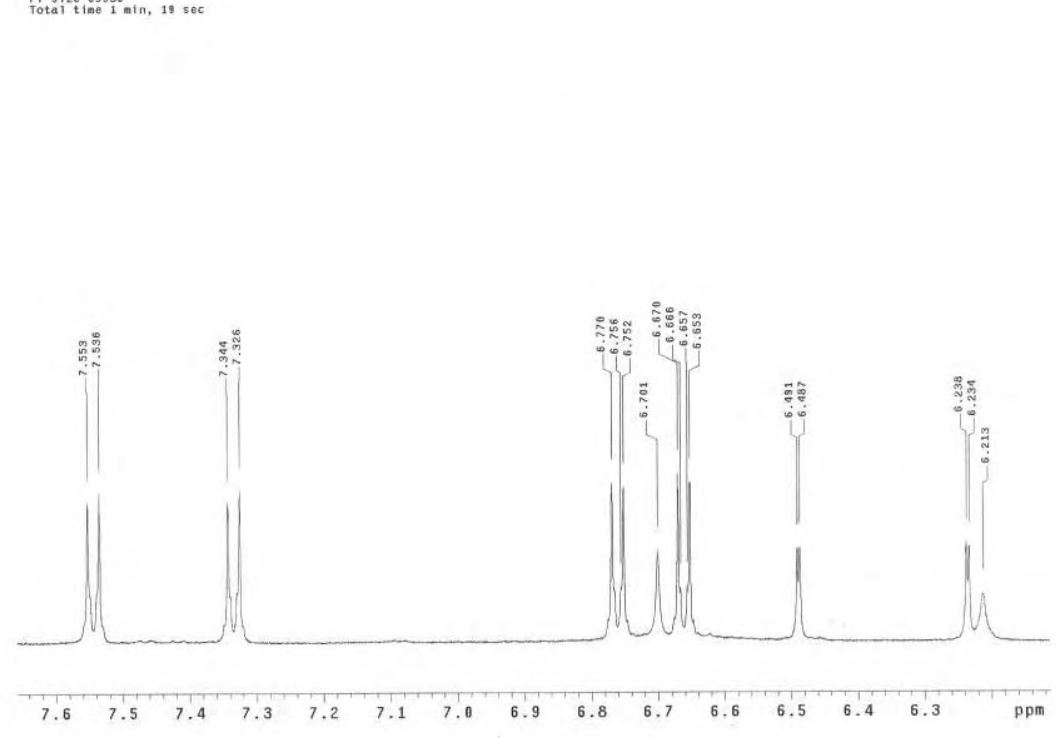

Anexo 38. Ampliação do espectro de RMN de ${ }^{1} \mathrm{H}$ da substância 5.

$$
\left(500 \mathrm{MHz}-\mathrm{DMSO}-d_{6}\right)
$$


Daniara Acoet sil 4 grep \& 11/05/09

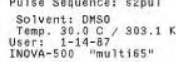

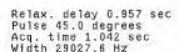

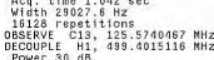

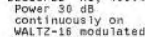

PATA ProceEsSTNG

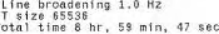
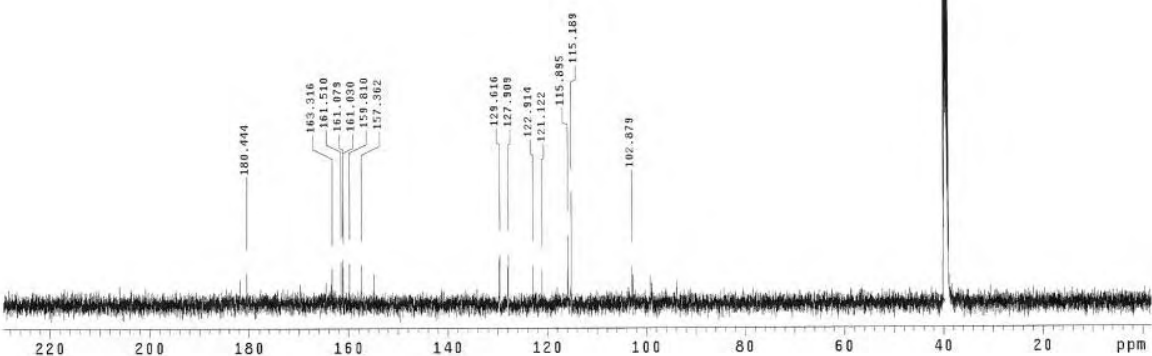

Anexo 39. Espectro de RMN de ${ }^{13} \mathrm{C}$ da substância 5 .

$$
\left(125 \mathrm{MHz}-\mathrm{DMSO}-d_{6}\right)
$$

Dantara Acoet s11 4 prep 8 11/05/09

Pulse Sequence: s2pu 1
solvent: DNSO

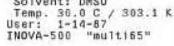

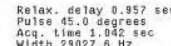

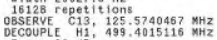

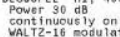

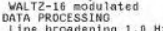

Fretsize

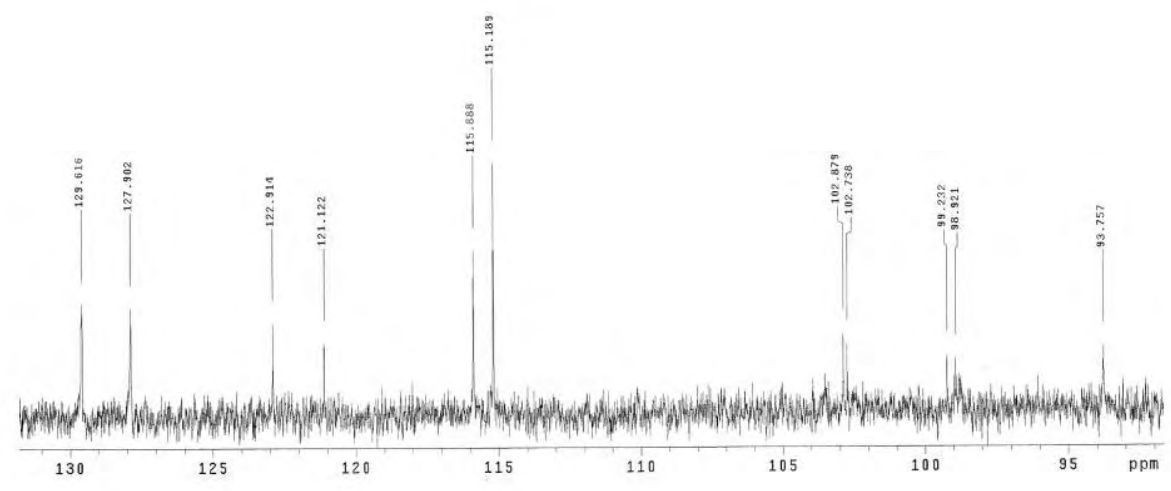

Anexo 40. Ampliação do espectro de RMN de ${ }^{13} \mathrm{C}$ da substância 5 .

$\left(125 \mathrm{MHz}-\mathrm{DMSO}-d_{6}\right)$ 
Danlara ACOEt s11 4 prep B 11/05/09

Pulse Sequence: s2put

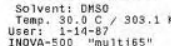

Re lax. delay 0.957 sec
Pulas

Ach time 1.0425

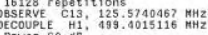

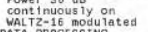

tine broadenting $1.0 \mathrm{~Hz}$

in, $47 \mathrm{sec}$

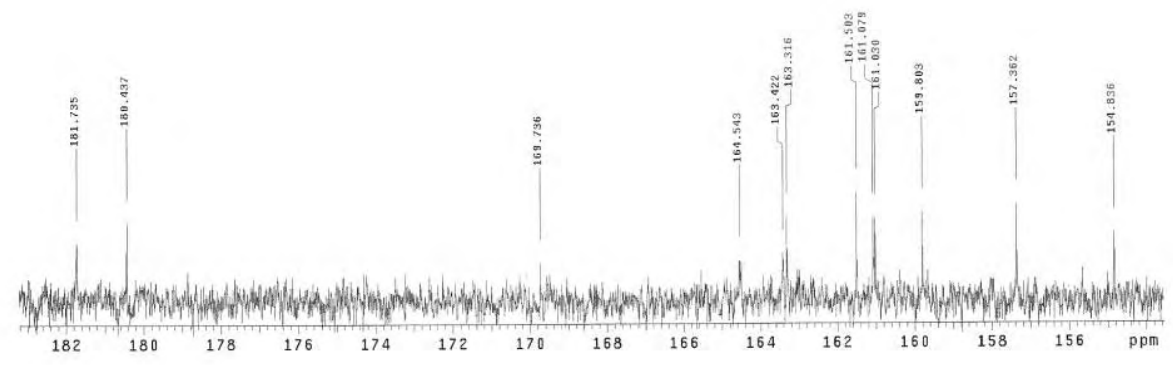

Anexo 41. Ampliação do espectro de RMN de ${ }^{13} \mathrm{C}$ da substância 5. $\left(125 \mathrm{MHz}-\mathrm{DMSO}-d_{6}\right)$

Daniara Acoet 30 Picos 26/03/0 Pulse Sequence: $g \cos Y$

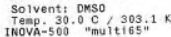

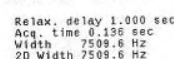

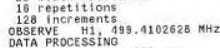

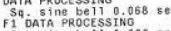

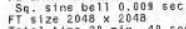

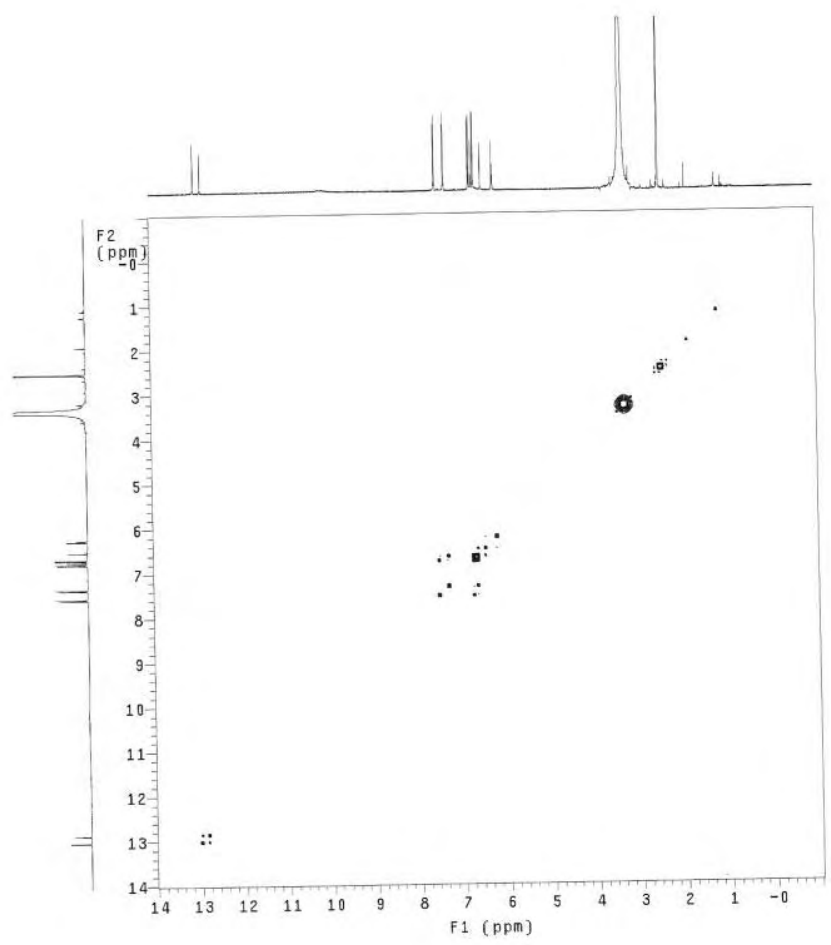

Anexo 42. Mapa de contorno ${ }^{1} \mathrm{H}-{ }^{1} \mathrm{H} g \operatorname{COSY}$ da substância 5.

$$
\left(500 \mathrm{MHz}-\mathrm{DMSO}-d_{6}\right)
$$


Daniara Acoet 30 Picos $26 / 03 / 09$ Pulse Sequence: gcosY

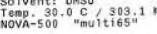

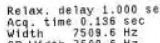

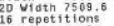
SERVE H1: 499,4102628 HHZ sq. $\operatorname{sinteb6} 110.068 \mathrm{sec}$

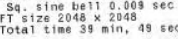

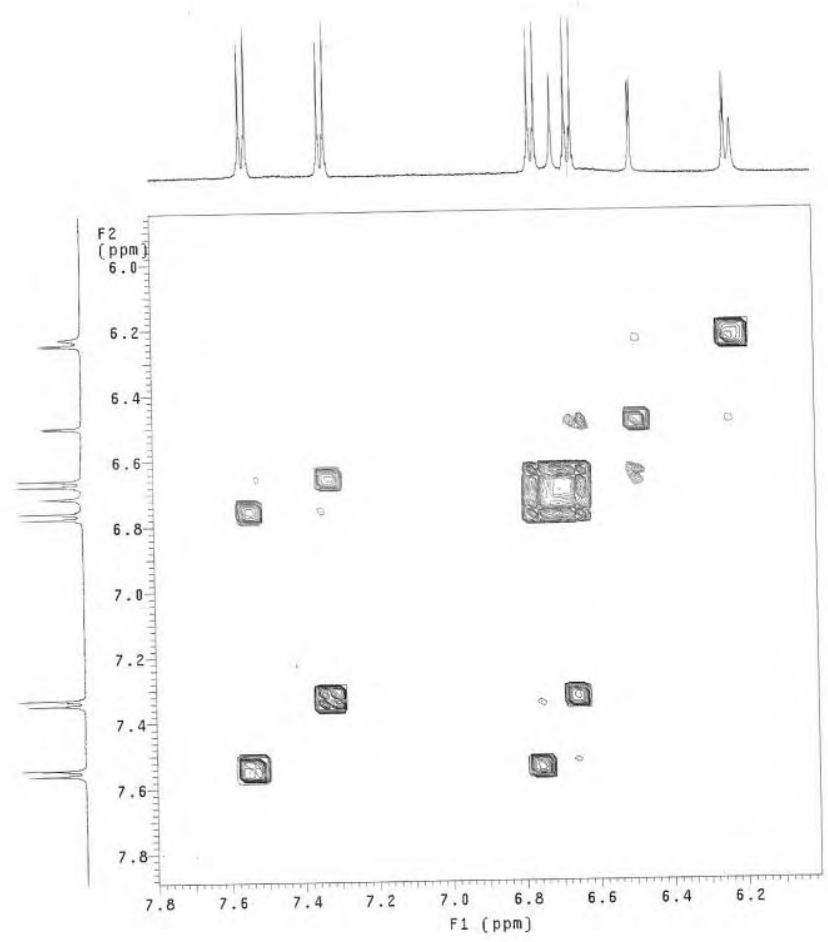

Anexo 43. Ampliação do mapa de contorno ${ }^{1} \mathrm{H}-{ }^{1} \mathrm{H} g \operatorname{COSY}$ da substância 5.

$$
\left(500 \mathrm{MHz}-\mathrm{DMSO}-d_{6}\right)
$$

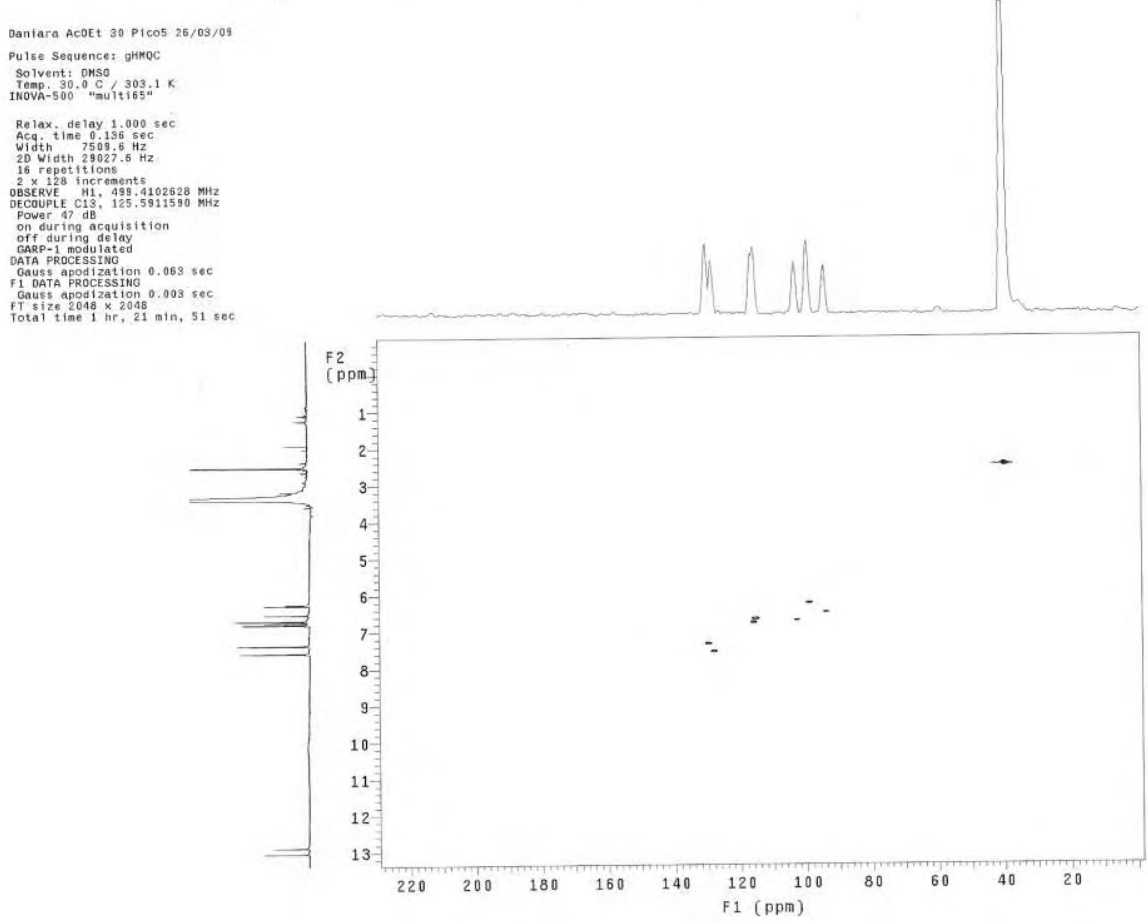

Anexo 44. Mapa de contorno ${ }^{1} \mathrm{H}^{-13} \mathrm{C} g \mathrm{HMQC}$ da substância 5.

$$
\left(500 \mathrm{MHz}-\mathrm{DMSO}-d_{6}\right)
$$


Dantara Acoet 30 Picos 26/03/09

Pulse Sequence: aHroc

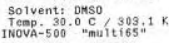

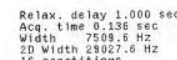

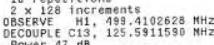

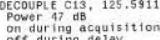

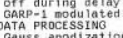

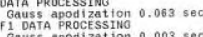

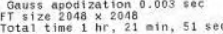

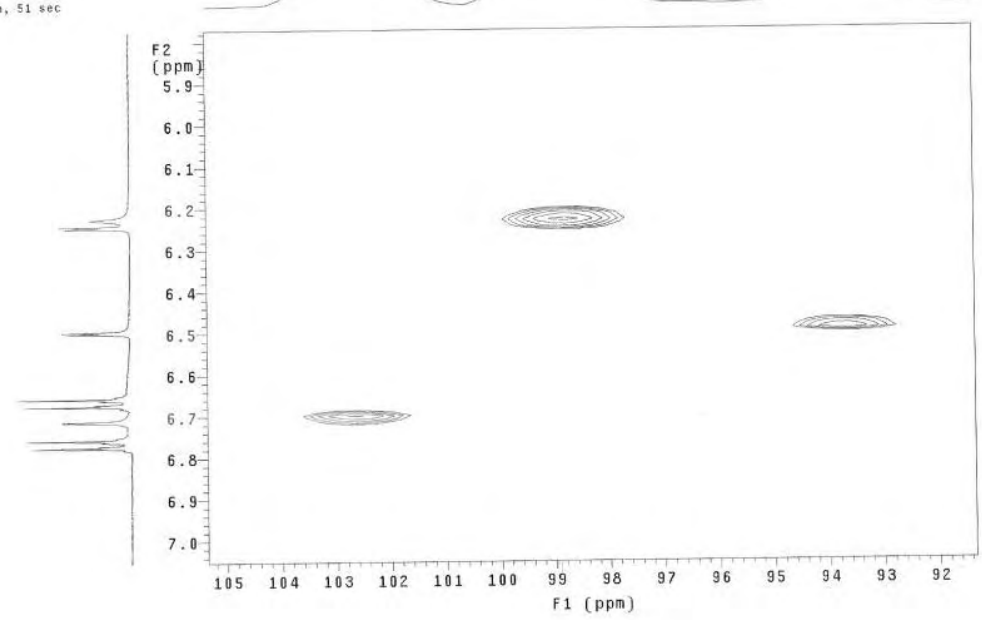

Anexo 45. Ampliação do mapa de contorno ${ }^{1} \mathrm{H}^{-13} \mathrm{C} g \mathrm{HMQC}$ da substância 5 .

$\left(500 \mathrm{MHz}-\mathrm{DMSO}-d_{6}\right)$

Daniara ACOEt 30 Picos 26/03/09

Pulse Sequence: ghHoc
solvent: Duso

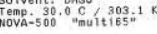

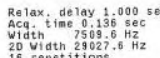

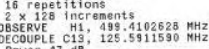

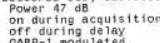

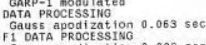

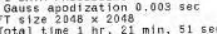

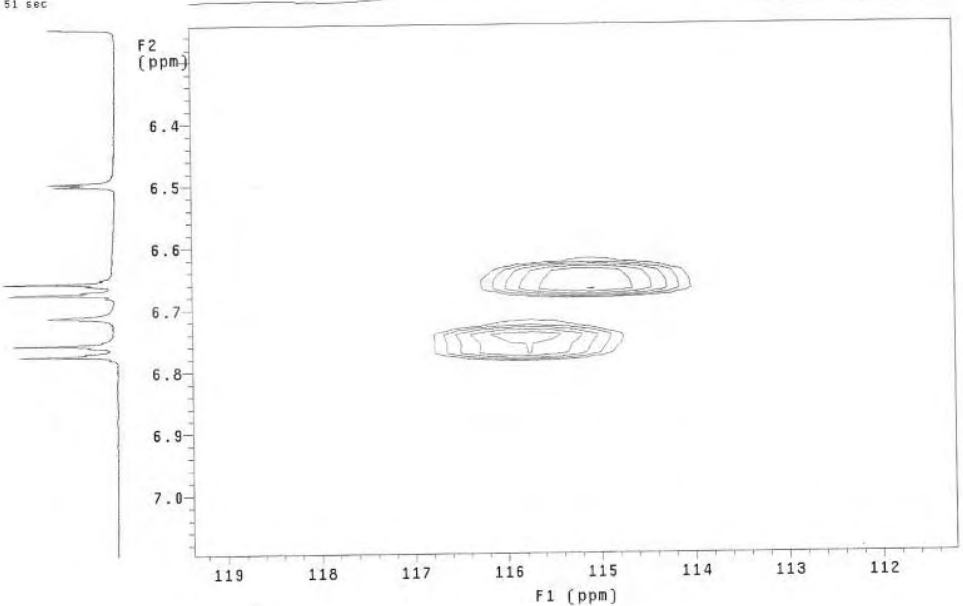

Anexo 46. Ampliação do mapa de contorno ${ }^{1} \mathrm{H}-{ }^{13} \mathrm{C} g \mathrm{HMQC}$ da substância 5.

$$
\left(500 \mathrm{MHz}-\mathrm{DMSO}-d_{6}\right)
$$


Dantara ACOEt 30 Pico5 $26 / 03 / 09$

Pulse Sequence: ghнос

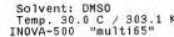

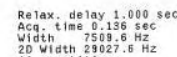

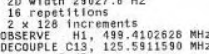

Power 4 C13, 125.5911

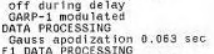

Gaush apodization $0.003 \mathrm{sec}$
GT

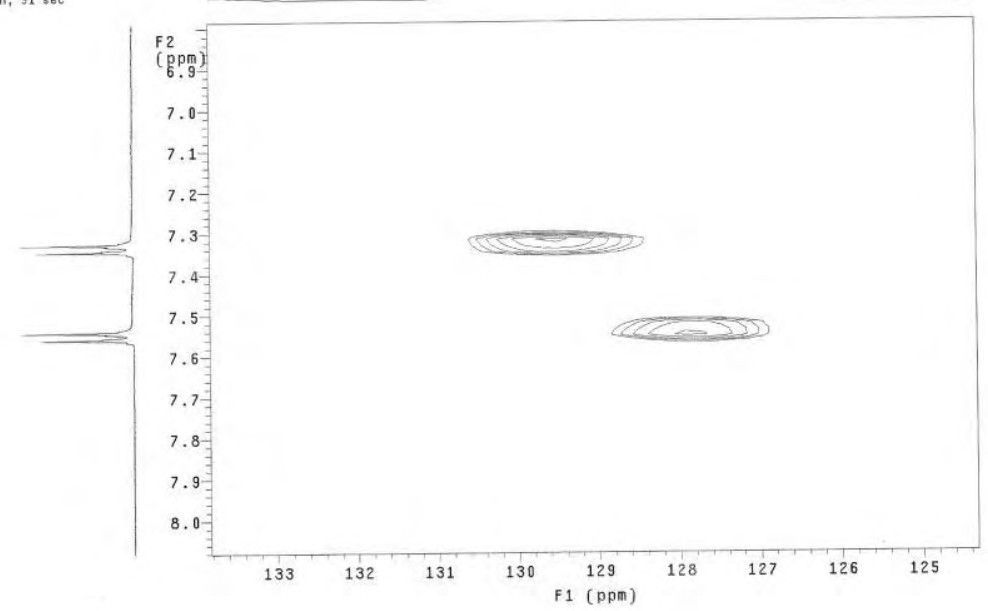

Anexo 47. Ampliação do mapa de contorno ${ }^{1} \mathrm{H}-{ }^{13} \mathrm{C} g \mathrm{HMQC}$ da substância 5.

$\left(500 \mathrm{MHz}-\mathrm{DMSO}-d_{6}\right)$

iara ACOEt 30 Picos 26/03/09

Pulse Sequence: ghrBC

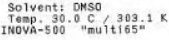

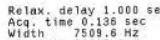

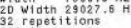

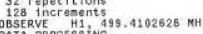

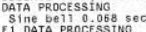

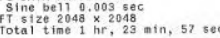

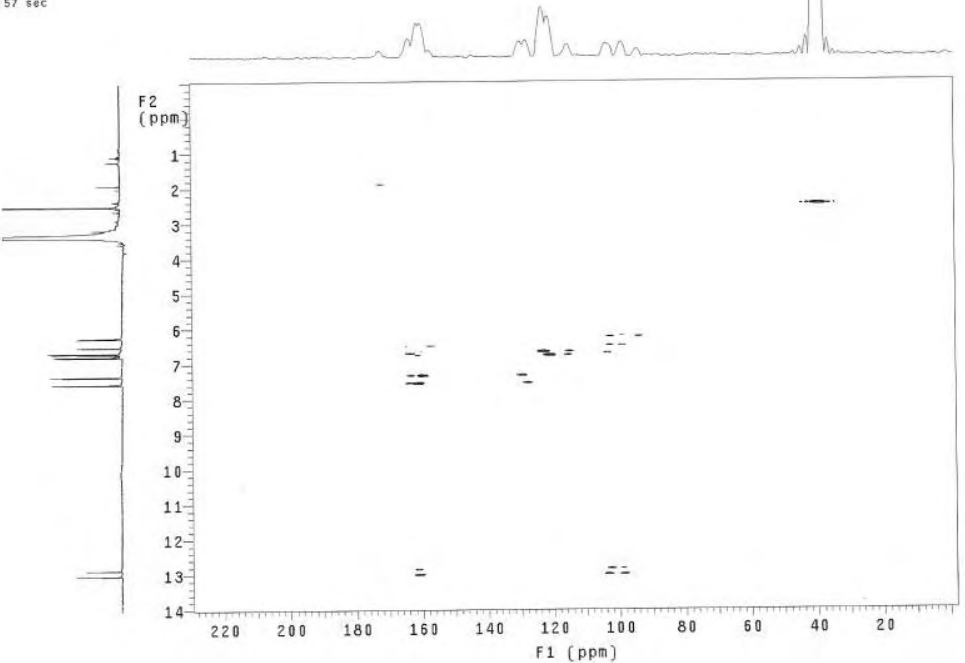

Anexo 48. Mapa de contorno ${ }^{1} \mathrm{H}-{ }^{13} \mathrm{C} g \mathrm{HMBC}$ da substância 5 .

$$
\left(500 \mathrm{MHz}-\mathrm{DMSO}-d_{6}\right)
$$


Daniara Acoft 30 Picos 26/03/09

Pulse Sequence: grmBC
Solvent: OHSO

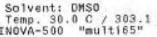

Relax. delay 1 , 000 sec

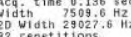

128
increanents
BSSRVE

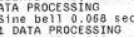

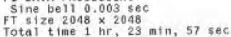

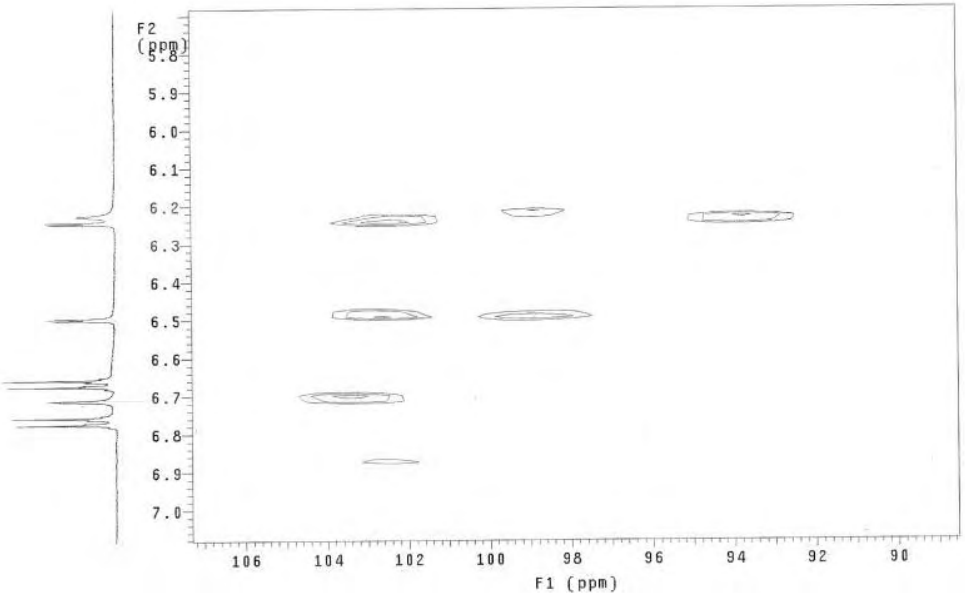

Anexo 49. Ampliação do mapa de contorno ${ }^{1} \mathrm{H}-{ }^{13} \mathrm{C} g \mathrm{HMBC}$ da substância 5. $\left(500 \mathrm{MHz}-\mathrm{DMSO}-d_{6}\right)$

Daniara ACOEt 30 Pico5 26/03/09

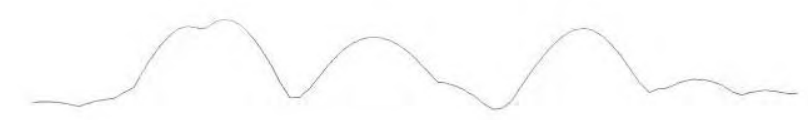

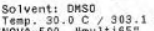

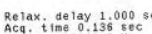

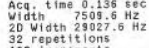

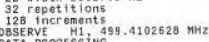

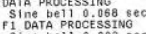

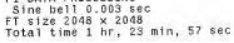
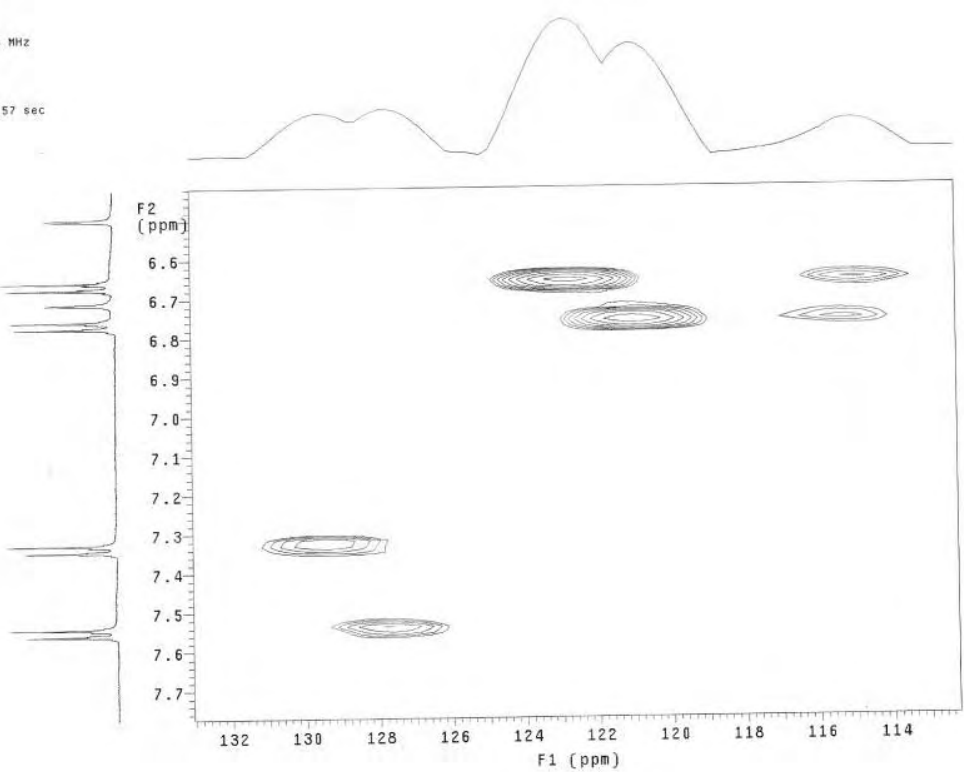

Anexo 50. Ampliação do mapa de contorno ${ }^{1} \mathrm{H}_{-}{ }^{13} \mathrm{C} g \mathrm{HMBC}$ da substância 5.

$$
\left(500 \mathrm{MHz}-\mathrm{DMSO}-d_{6}\right)
$$


Daniara ACOEt 30 Picos 26/03/09

Pulse Sequence: gHнBC

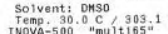

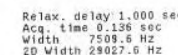

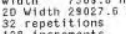

128 increment
BSREVE

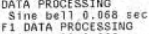

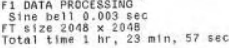
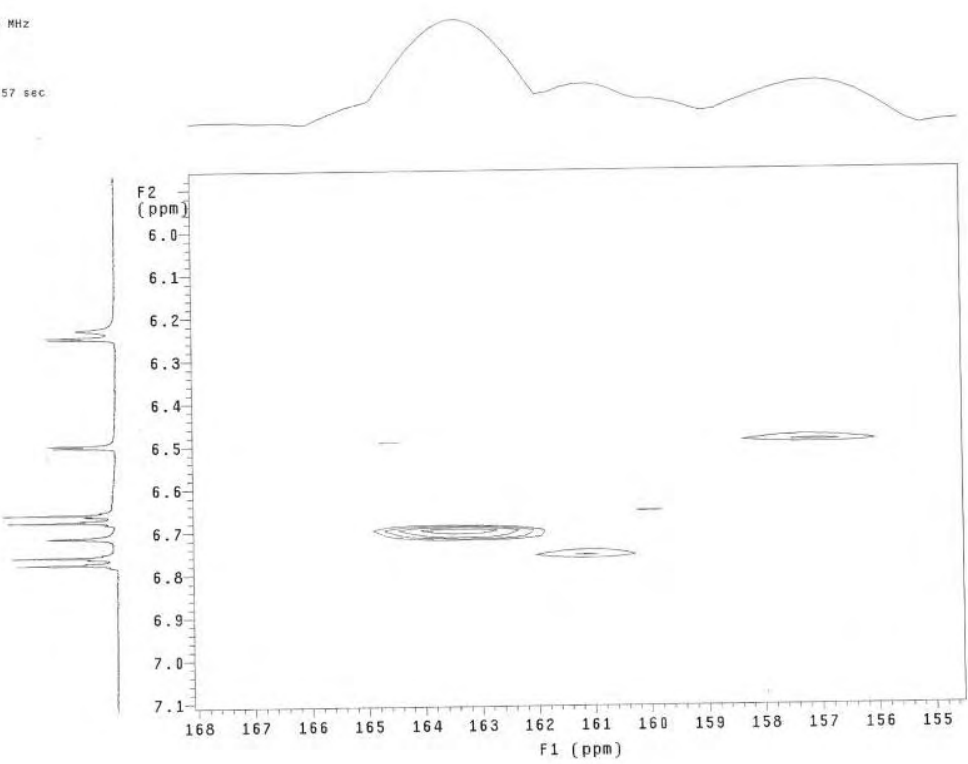

Anexo 51. Ampliação do mapa de contorno ${ }^{1} \mathrm{H}_{-}{ }^{13} \mathrm{C} g \mathrm{HMBC}$ da substância 5.

$$
\left(500 \mathrm{MHz}-\mathrm{DMSO}-d_{6}\right)
$$

Daniara AcoEt 30 Picos 26/03/09

Pulse Sequence: grimBC
solvent, onso

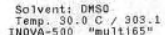

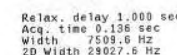

20. Wiath $29027,6 \mathrm{~Hz}$

28
128
SERE

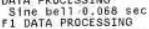

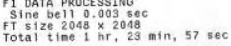
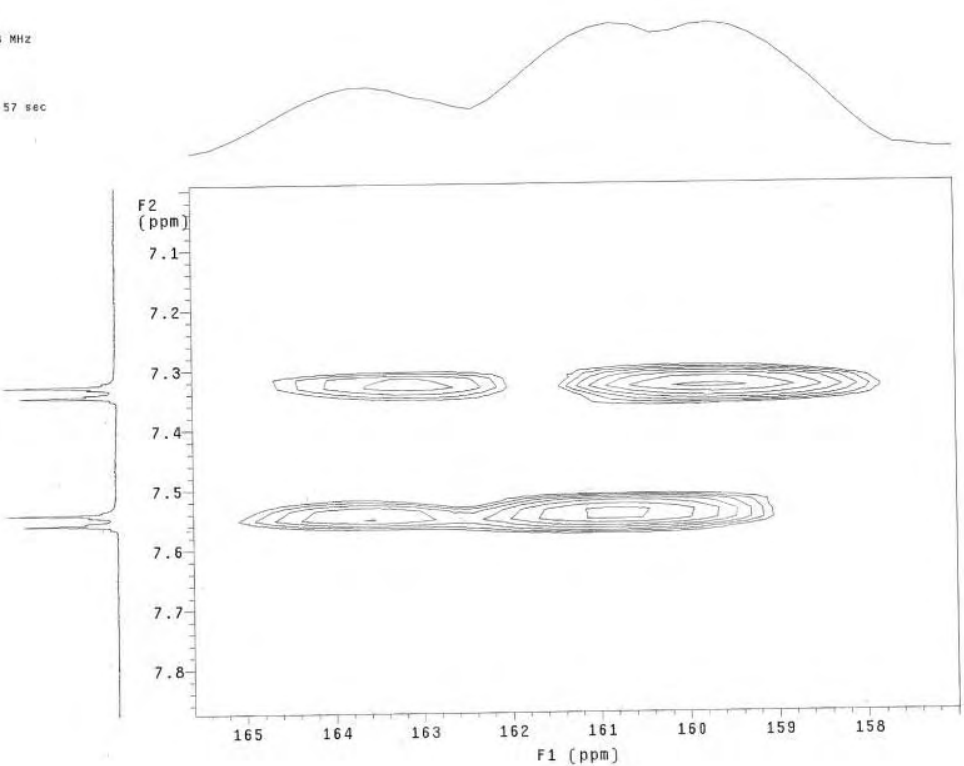

Anexo 52. Ampliação do mapa de contorno ${ }^{1} \mathrm{H}^{-13} \mathrm{C} g \mathrm{HMBC}$ da substância 5.

$$
\left(500 \mathrm{MHz}-\mathrm{DMSO}-d_{6}\right)
$$


Pulse Sequence: ghMBC

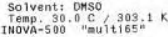

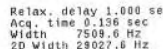

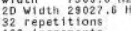

128 increments
BSERVE

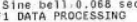

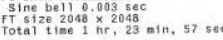

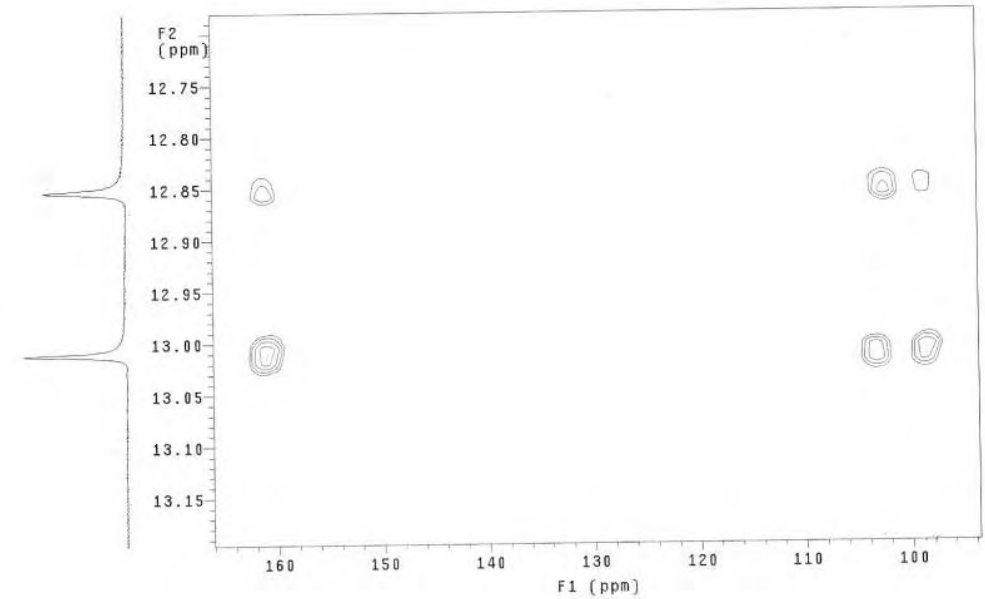

Anexo 53. Ampliação do mapa de contorno ${ }^{1} \mathrm{H}^{-13} \mathrm{C} g \mathrm{HMBC}$ da substância 5 .

$$
\left(500 \mathrm{MHz}-\mathrm{DMSO}-d_{6}\right)
$$

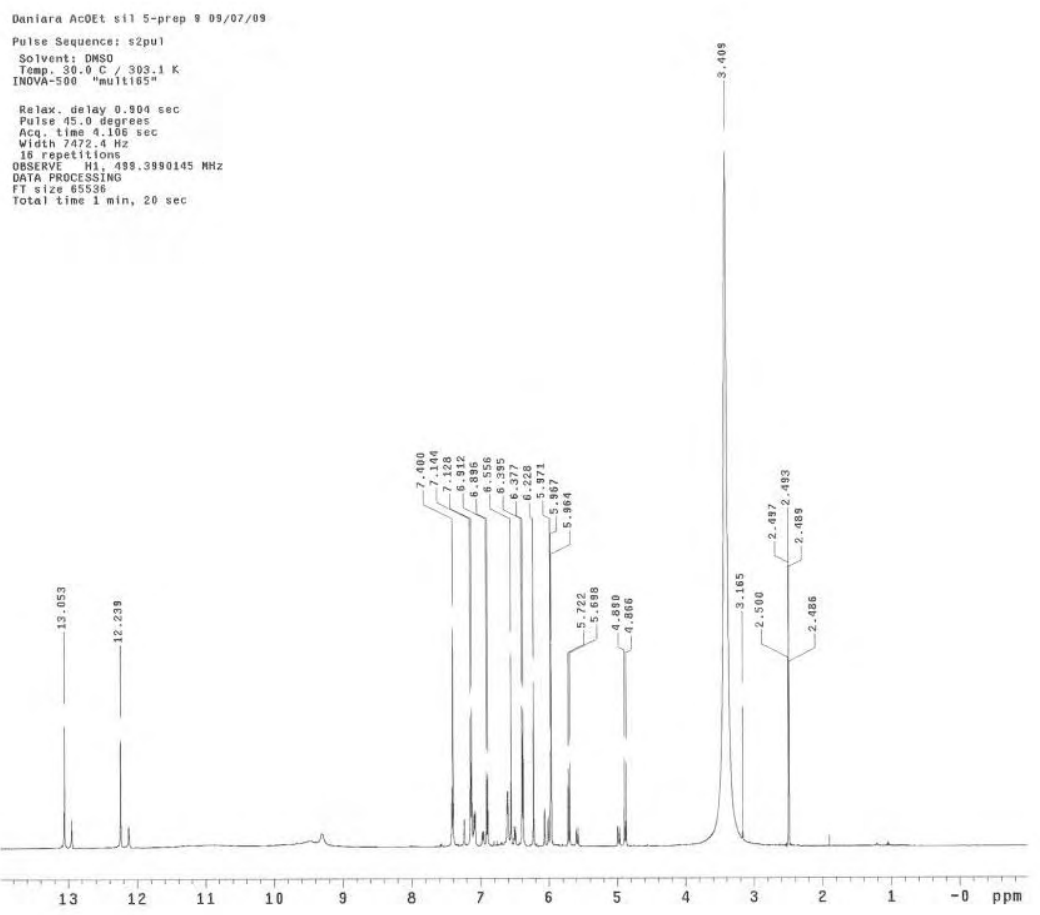

Anexo 54. Espectro de RMN de ${ }^{1} \mathrm{H}$ da substância 8.

$$
\left(500 \mathrm{MHz}-\mathrm{DMSO}-d_{6}\right)
$$


Daniara ACoEt s11 5-prep 9 09/07/09

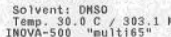

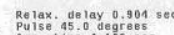

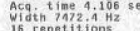

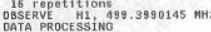

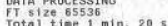

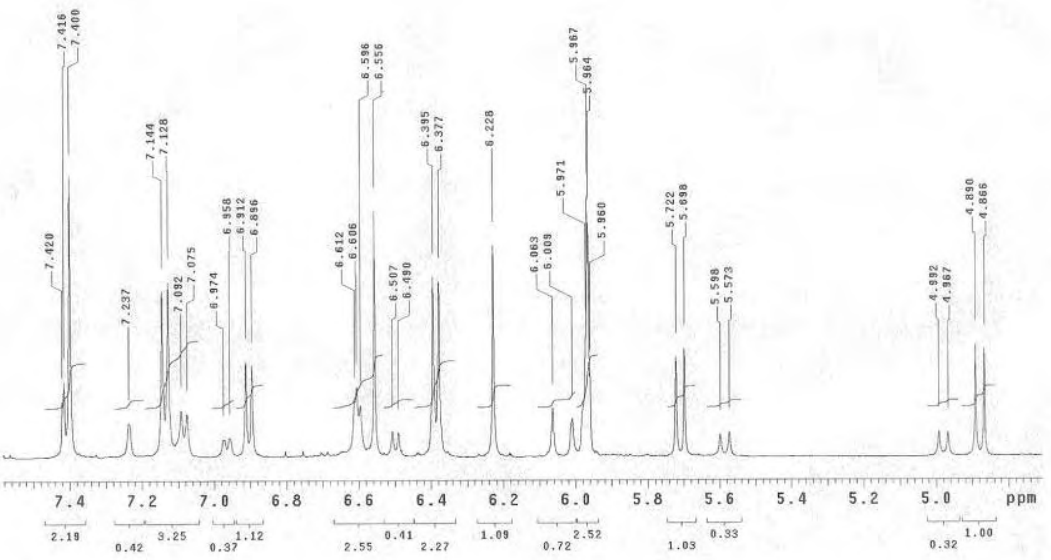

Anexo 55. Ampliação do espectro de $\mathrm{RMN}$ de ${ }^{1} \mathrm{H}$ da substância 8 .

$\left(500 \mathrm{MHz}-\mathrm{DMSO}-d_{6}\right)$

Daniara Acoet sil 5-prep 9 09/07/0 Pu1se Sequence: gcosy

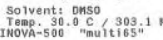

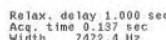
Gith 20 W $7972.49 \mathrm{~Hz}$
20 with $7472.4 \mathrm{~Hz}$

128
OBSERE

Sa vinectssing

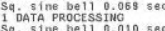

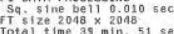

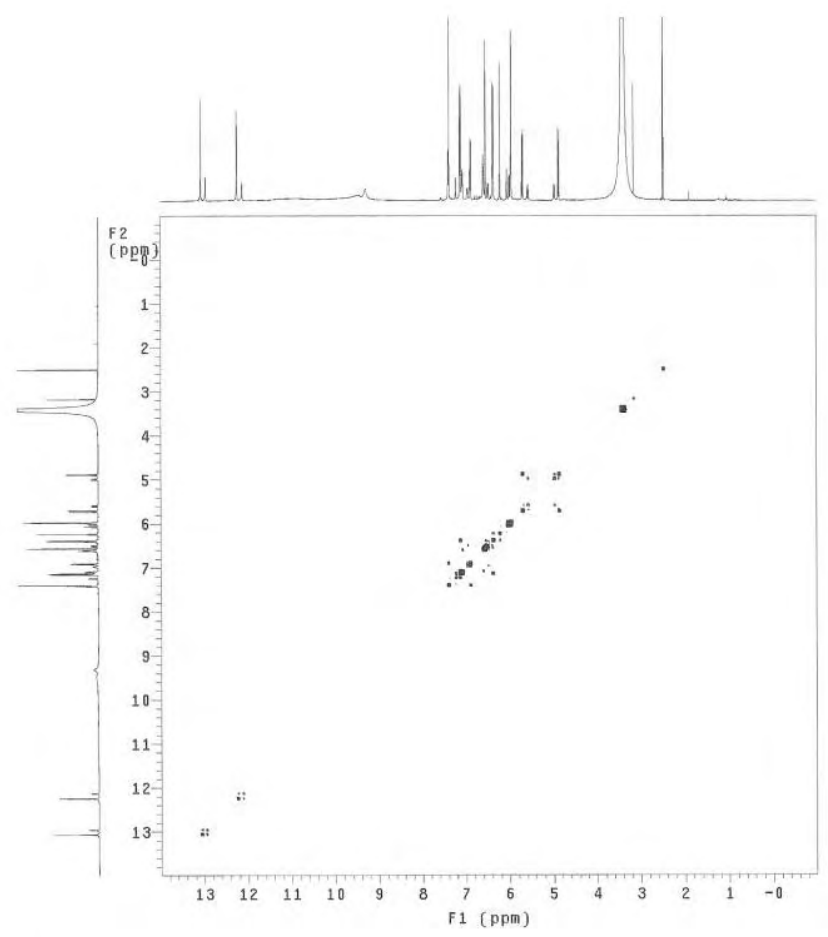

Anexo 56. Mapa de contorno ${ }^{1} \mathrm{H}-{ }^{1} \mathrm{H} g \operatorname{COSY}$ da substância 8.

$\left(500 \mathrm{MHz}-\mathrm{DMSO}-d_{6}\right)$ 
Daniara Acott sil 5-prep 9 03/07/00

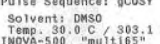

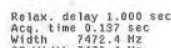

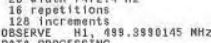

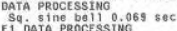

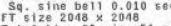

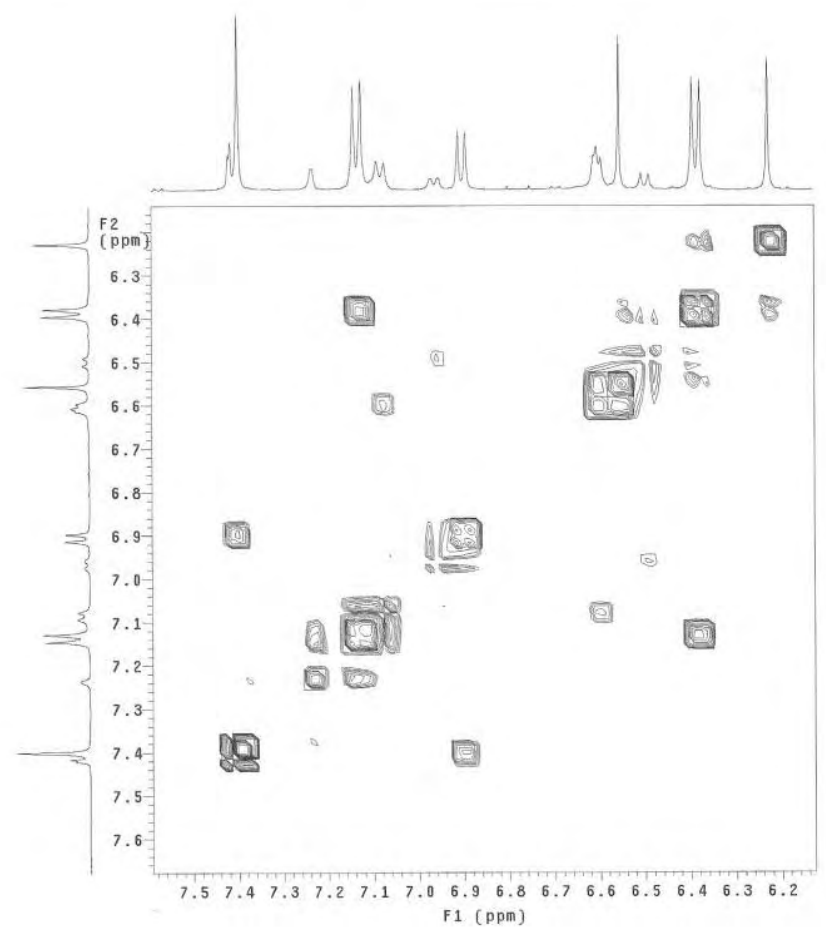

Anexo 57. Ampliação do mapa de contorno ${ }^{1} \mathrm{H}-{ }^{1} \mathrm{H} g \operatorname{COSY}$ da substância 8.

$\left(500 \mathrm{MHz}-\mathrm{DMSO}-d_{6}\right)$

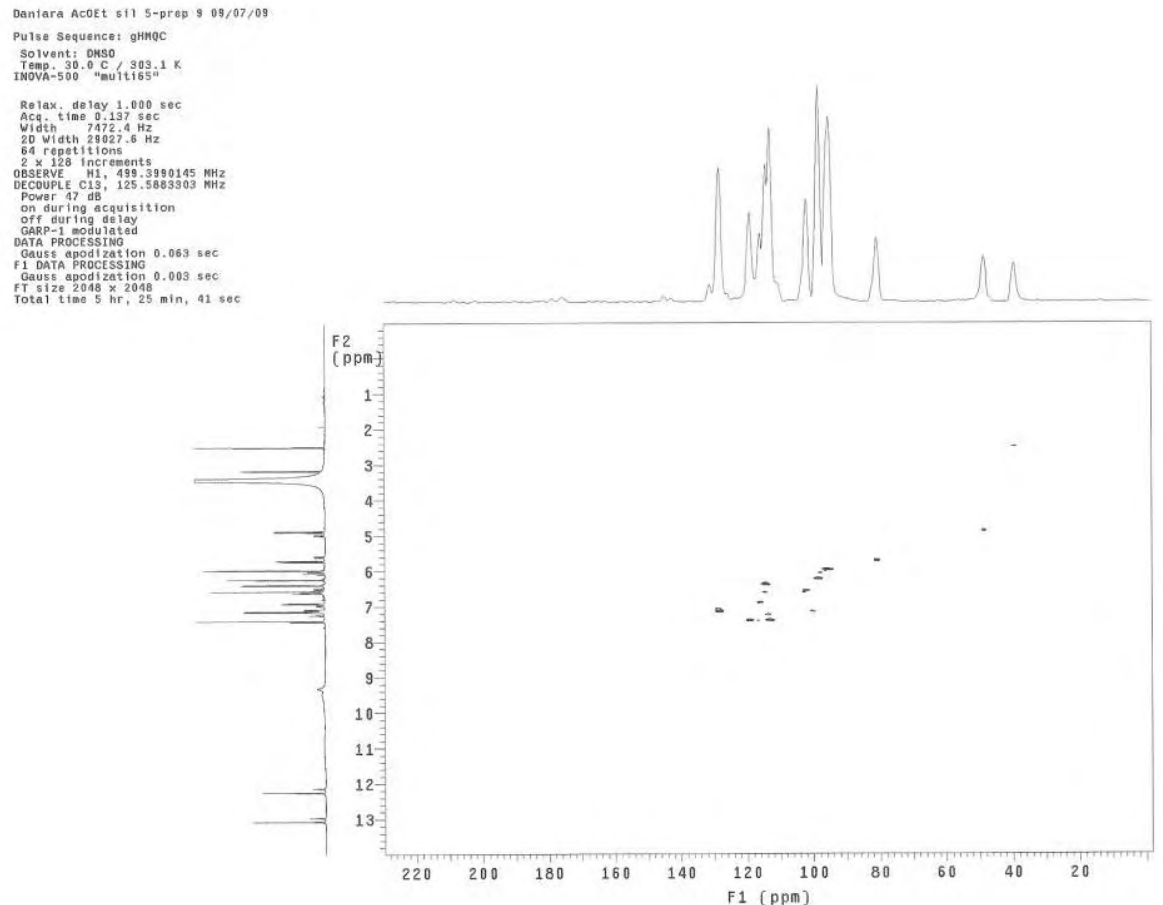

Anexo 58. Mapa de contorno ${ }^{1} \mathrm{H}^{-13} \mathrm{C} g \mathrm{HMQC}$ da substância 8.

$\left(500 \mathrm{MHz}-\mathrm{DMSO}-d_{6}\right)$ 
Daniara Acokt s11 5-prep \& 09/07/09

Pulse Sequence: gHnoc
Solvent: Drso

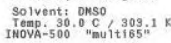

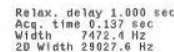

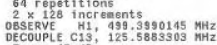

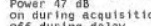

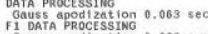

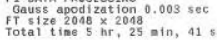

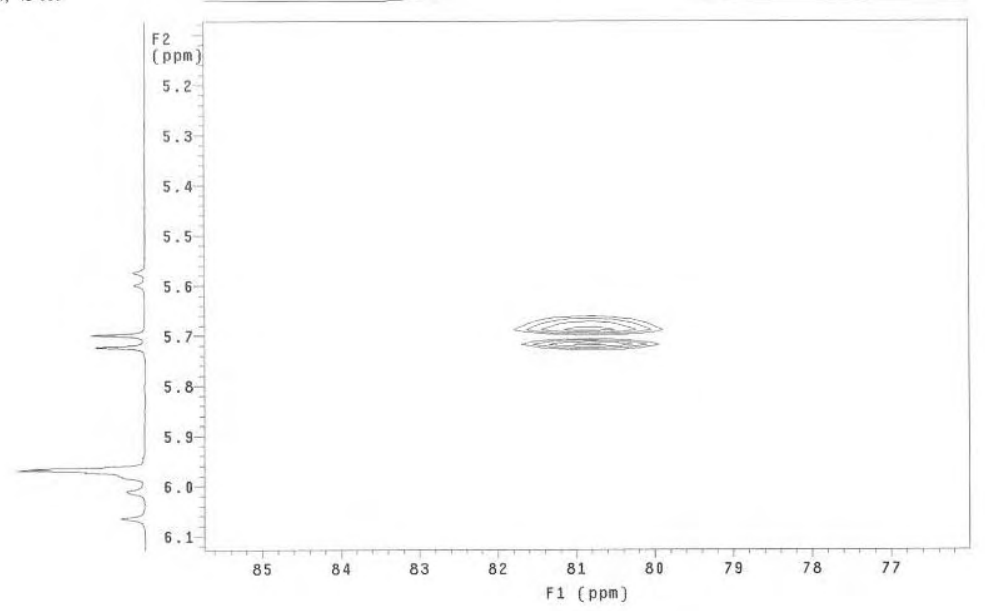

Anexo 59. Ampliação do mapa de contorno ${ }^{1} \mathrm{H}-{ }^{13} \mathrm{C} g \mathrm{HMQC}$ da substância 8.

$\left(500 \mathrm{MHz}-\mathrm{DMSO}-d_{6}\right)$

Daniara ACOEt st1 5-prep 9 09/07/09

Pulse Sequence: ghноc

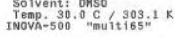

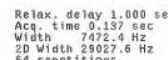

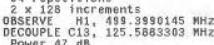

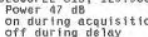

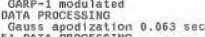

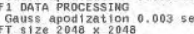

To $512 \mathrm{ze} 2040 \times 201040$
rotal time $5 \mathrm{hr}, 25 \mathrm{~min}, 41 \mathrm{sec}$

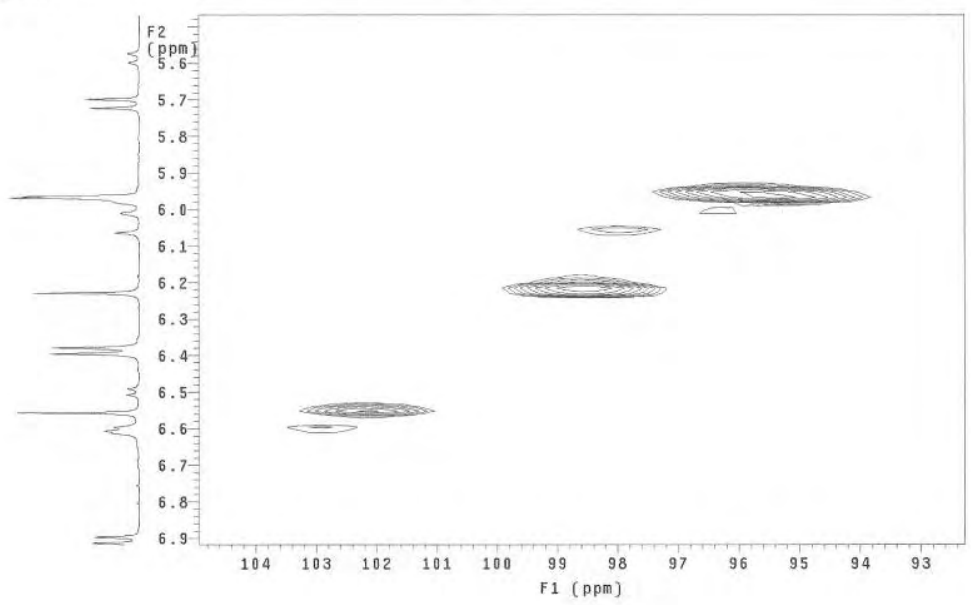

Anexo 60. Ampliação do mapa de contorno ${ }^{1} \mathrm{H}_{-}{ }^{13} \mathrm{C}$ gHMQC da substância 8.

$\left(500 \mathrm{MHz}-\mathrm{DMSO}-d_{6}\right)$ 
Dantara Acoet sil 5-prep 9 09/07/09

Puise Sequence: 9 gHKOC
solvent: Doso

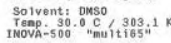

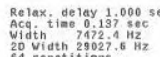

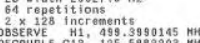

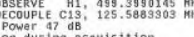

on dur ing acquisition
off dur ing elay
GRPP -1 modulate

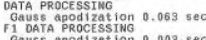

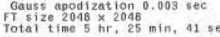

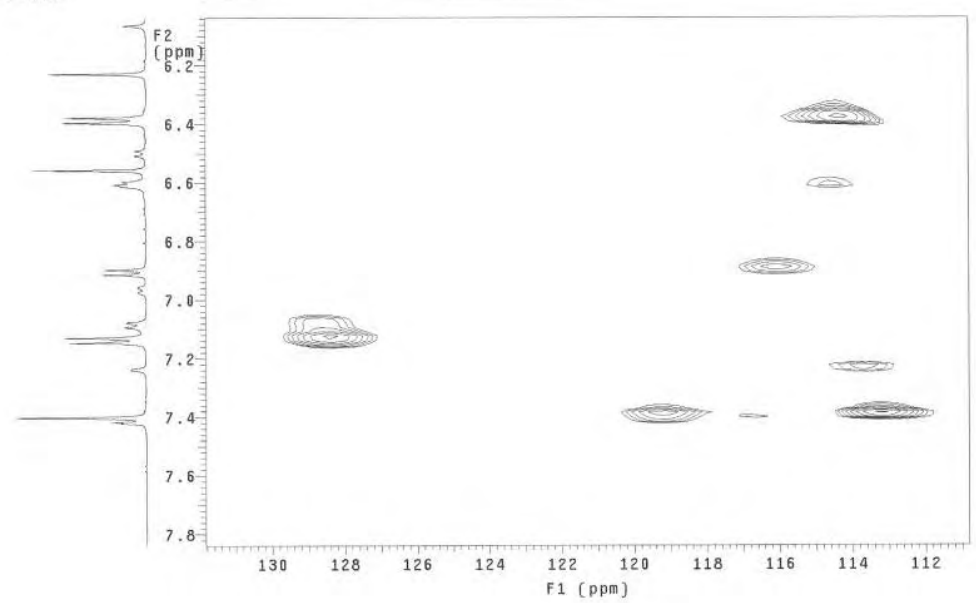

Anexo 61. Ampliação do mapa de contorno ${ }^{1} \mathrm{H}^{-13} \mathrm{C} g \mathrm{HMQC}$ da substância 8.

$\left(500 \mathrm{MHz}-\mathrm{DMSO}-d_{6}\right)$

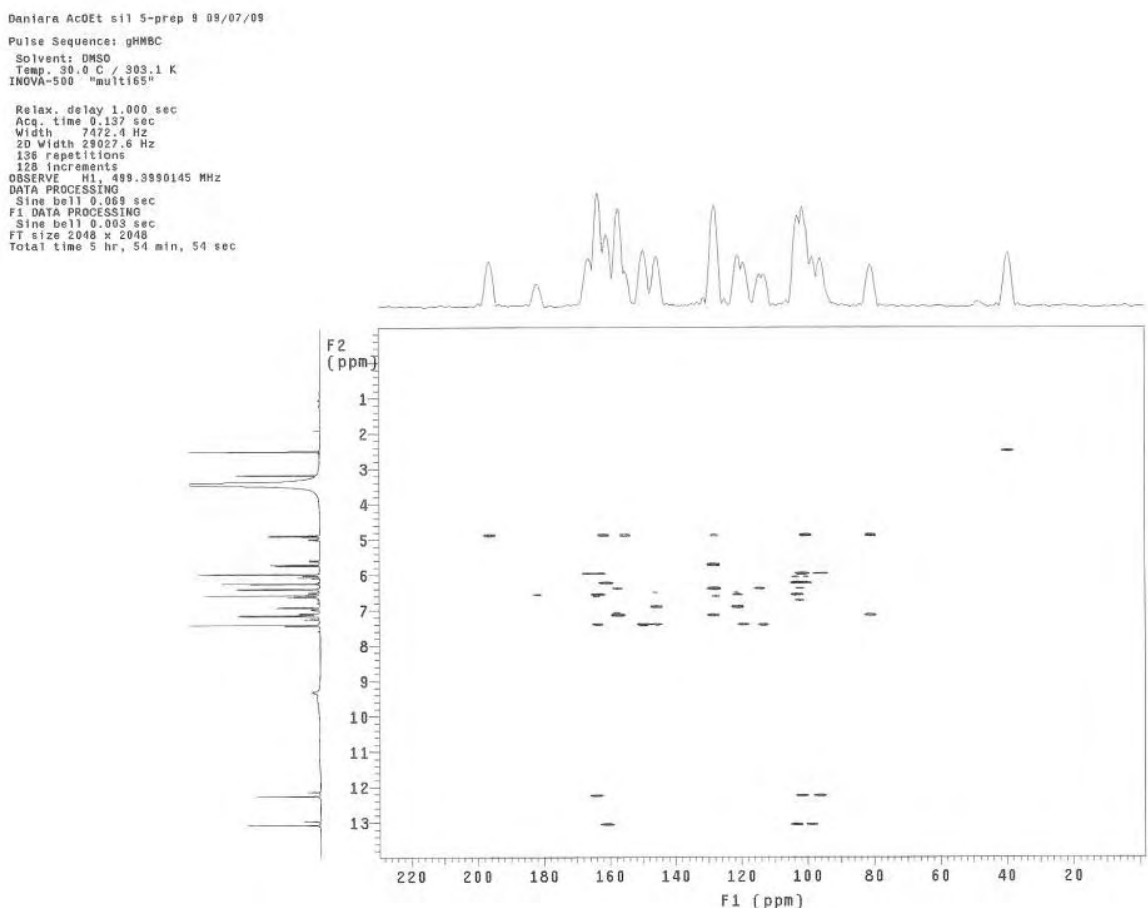

Anexo 62. Mapa de contorno ${ }^{1} \mathrm{H}_{-}{ }^{13} \mathrm{C} g \mathrm{HMBC}$ da substância 8

$$
\left(500 \mathrm{MHz}-\mathrm{DMSO}-d_{6}\right)
$$


Daniara Acoet sil 5-prep $909 / 07 / 09$

Pulse Sequence: gHMOC

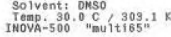

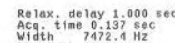

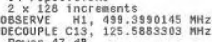

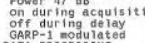

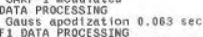

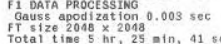

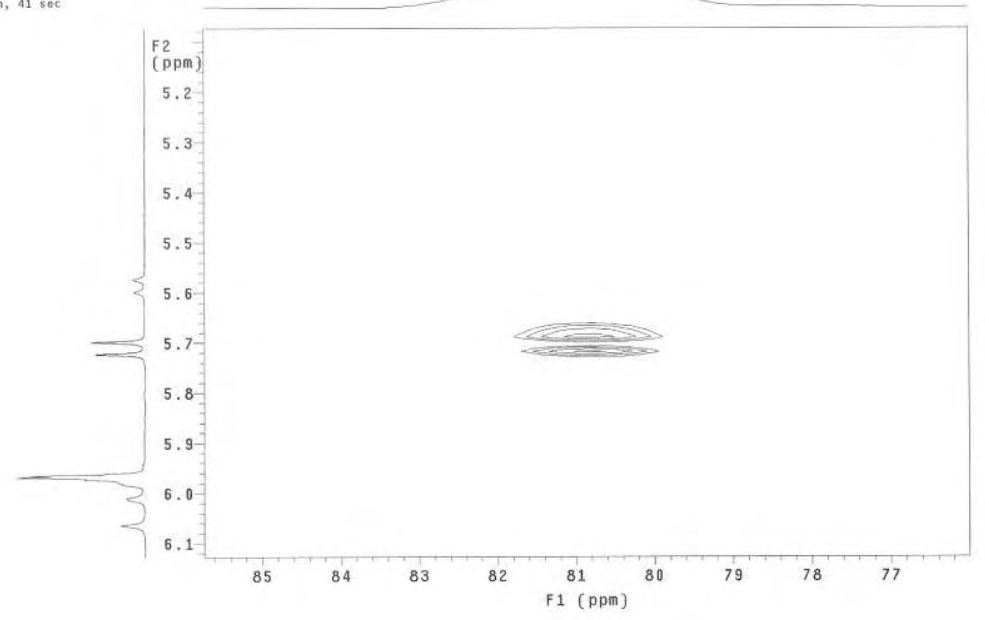

Anexo 63. Ampliação do mapa de contorno ${ }^{1} \mathrm{H}^{13}{ }^{13} \mathrm{C} g \mathrm{HMBC}$ da substância 8 . $\left(500 \mathrm{MHz}-\mathrm{DMSO}-d_{6}\right)$

Dantara Acott s11 5-prep 9 09/07/09

Pulse Sequence: gннвс

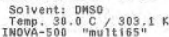
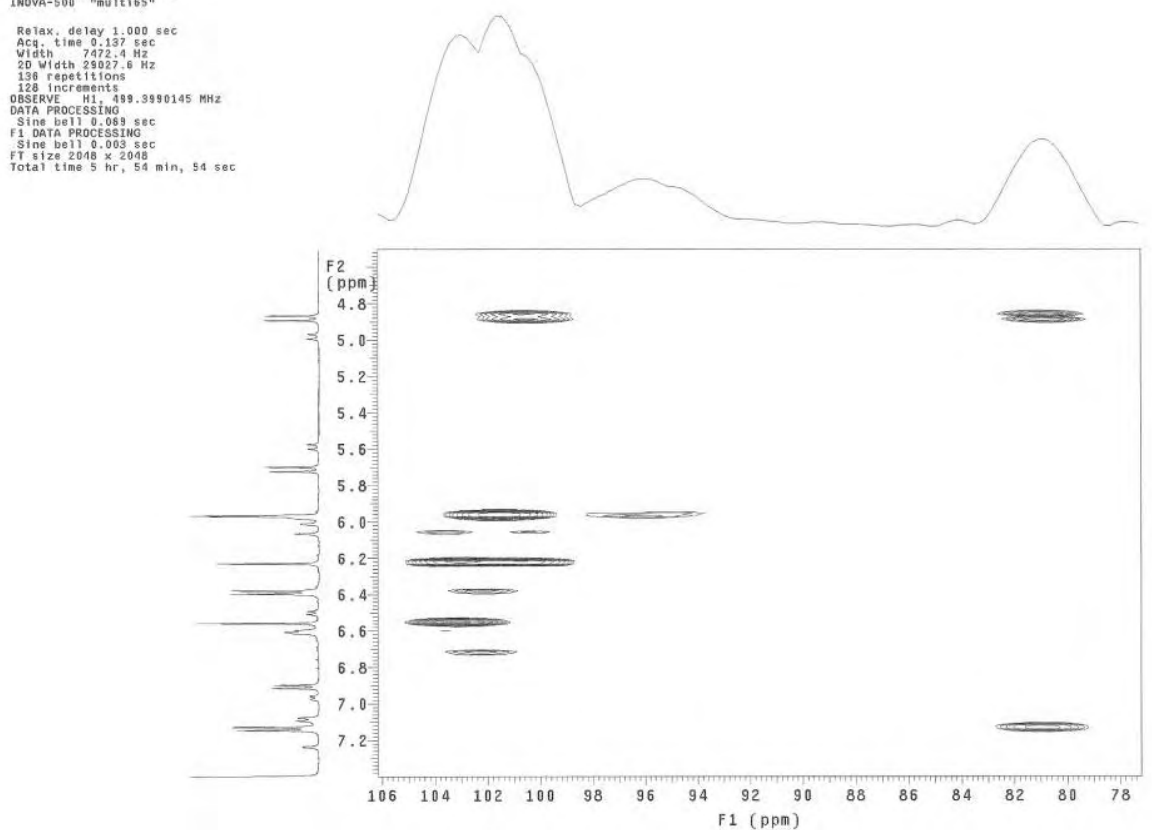

Anexo 64. Ampliação do mapa de contorno ${ }^{1} \mathrm{H}^{13}{ }^{13} \mathrm{C} g \mathrm{HMBC}$ da substância 8.

$$
\left(500 \mathrm{MHz}-\mathrm{DMSO}-d_{6}\right)
$$


Daniare AcoEt sil 5-prep \& 09/07/09

Pulse Sequence: gHMBC

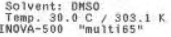

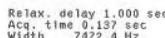

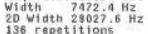

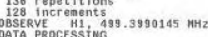

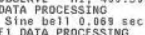

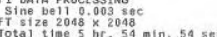

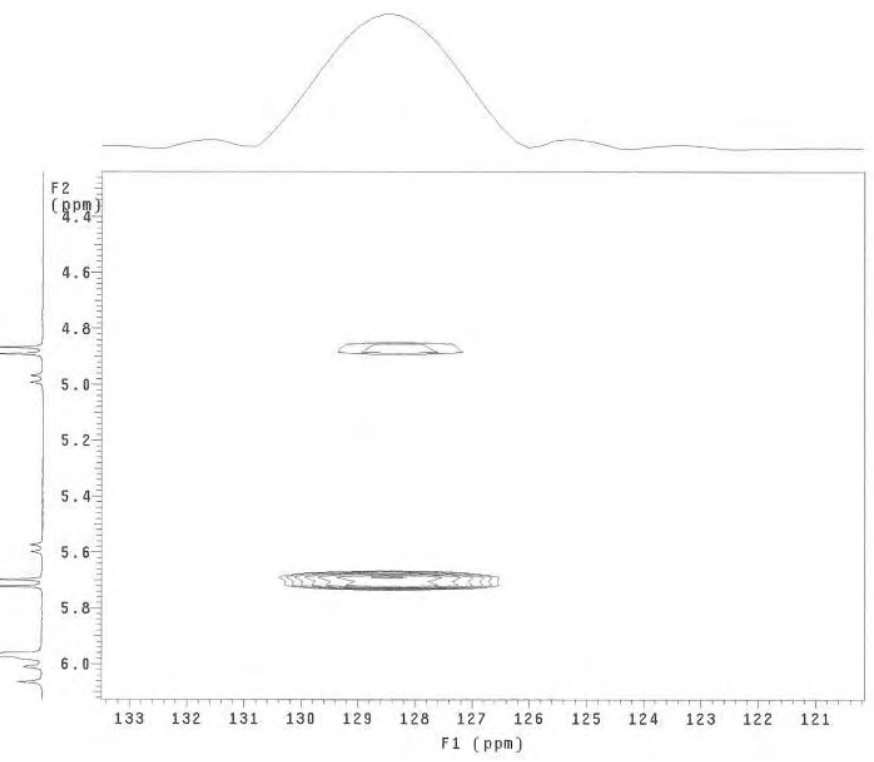

Anexo 65. Ampliação do mapa de contorno ${ }^{1} \mathrm{H}^{13}{ }^{13} \mathrm{C} g \mathrm{HMBC}$ da substância 8. $\left(500 \mathrm{MHz}-\mathrm{DMSO}-d_{6}\right)$

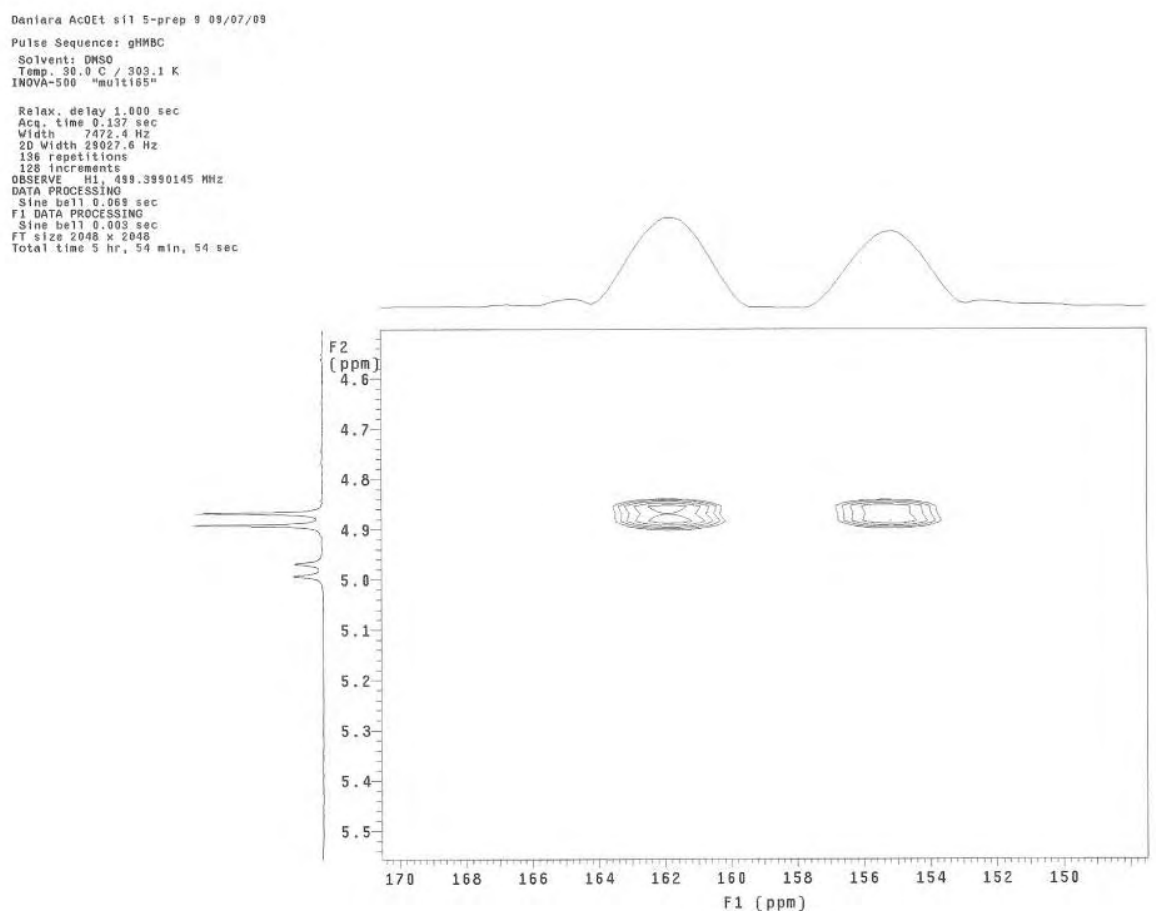

Anexo 66. Ampliação do mapa de contorno ${ }^{1} \mathrm{H}^{1}{ }^{13} \mathrm{C} g \mathrm{HMBC}$ da substância 8.

$$
\left(500 \mathrm{MHz}-\mathrm{DMSO}-d_{6}\right)
$$


Dantara Acoet s11 5-prep o 09/07/09

Pulse Sequence: oHrBC

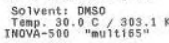

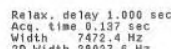

20
136
136 repetititions

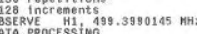

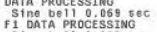

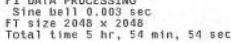

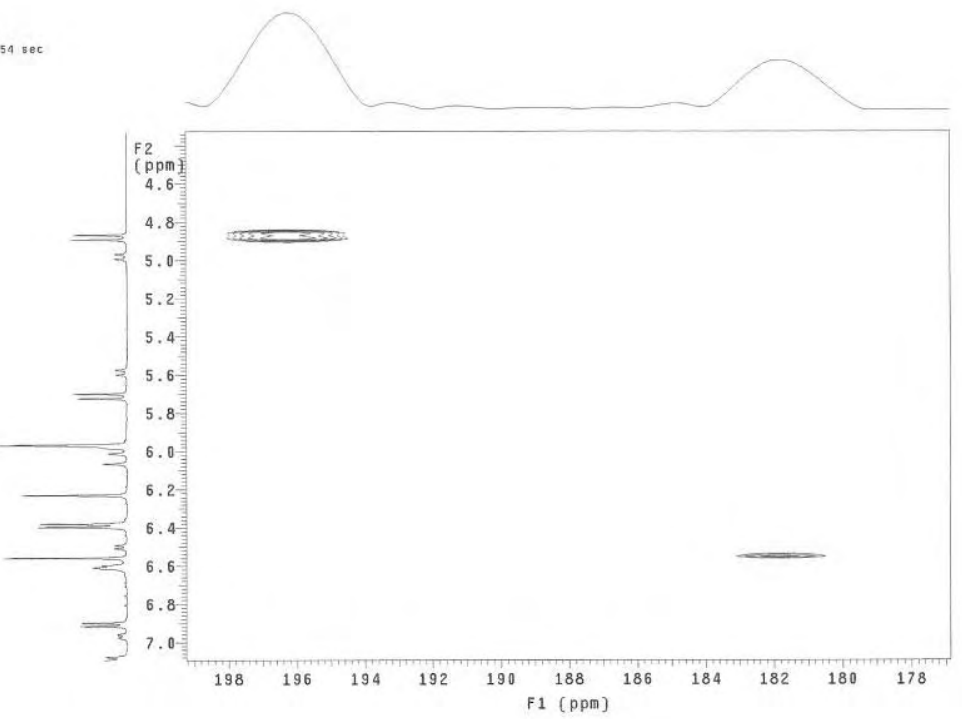

Anexo 67. Ampliação do mapa de contorno ${ }^{1} \mathrm{H}^{13} \mathrm{C} g \mathrm{HMBC}$ da substância 8. $\left(500 \mathrm{MHz}-\mathrm{DMSO}-d_{6}\right)$

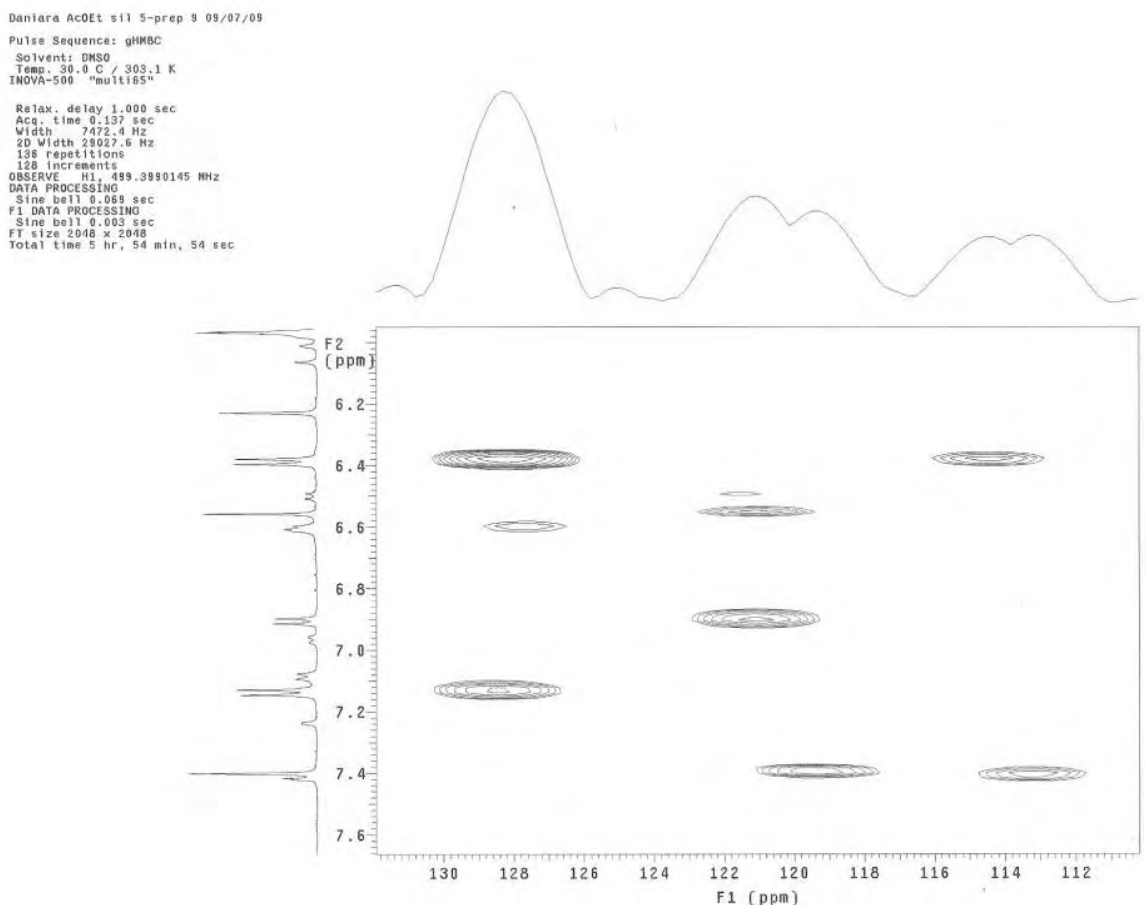

Anexo 68. Ampliação do mapa de contorno ${ }^{1} \mathrm{H}^{13}{ }^{13} \mathrm{C} g \mathrm{HMBC}$ da substância 8. $\left(500 \mathrm{MHz}-\mathrm{DMSO}-d_{6}\right)$ 
Daniara ACOEt sil 5-prep 9 09/07/09

Pulse Sequente: ghrsc

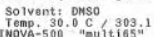

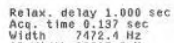

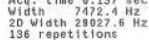

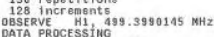

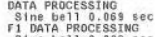

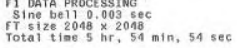
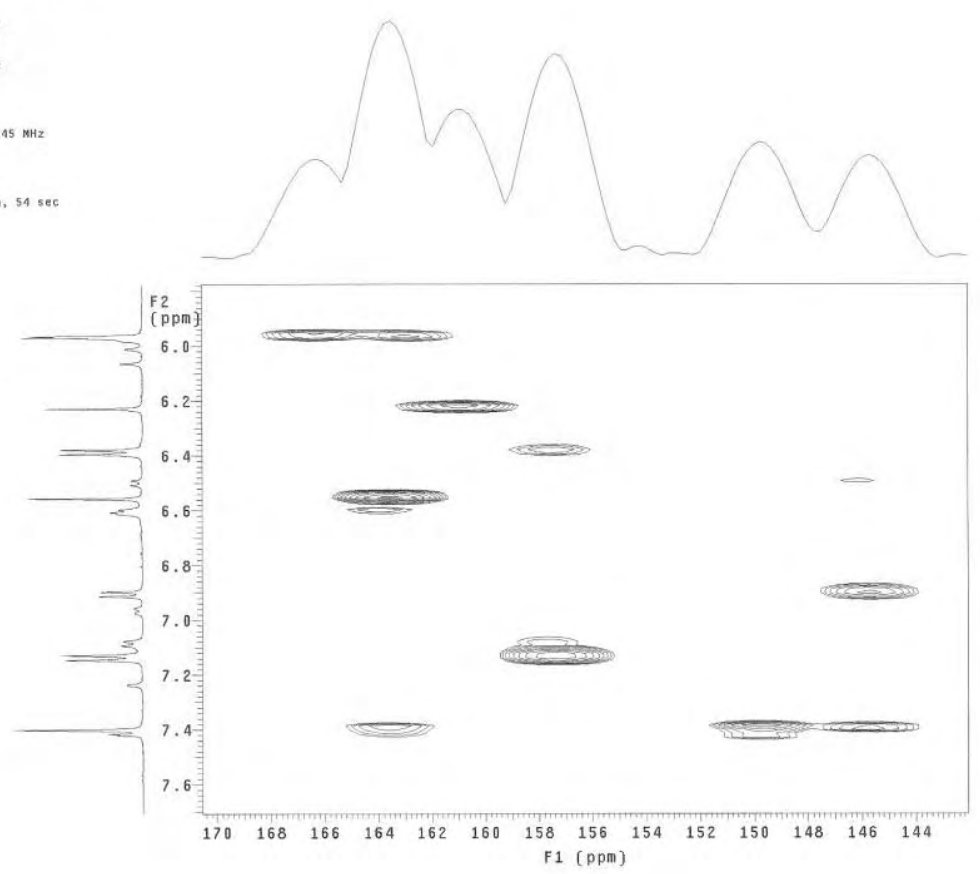

Anexo 69. Ampliação do mapa de contorno ${ }^{1} \mathrm{H}-{ }^{13} \mathrm{C} g \mathrm{HMBC}$ da substância 8.

$\left(500 \mathrm{MHz}-\mathrm{DMSO}-d_{6}\right)$

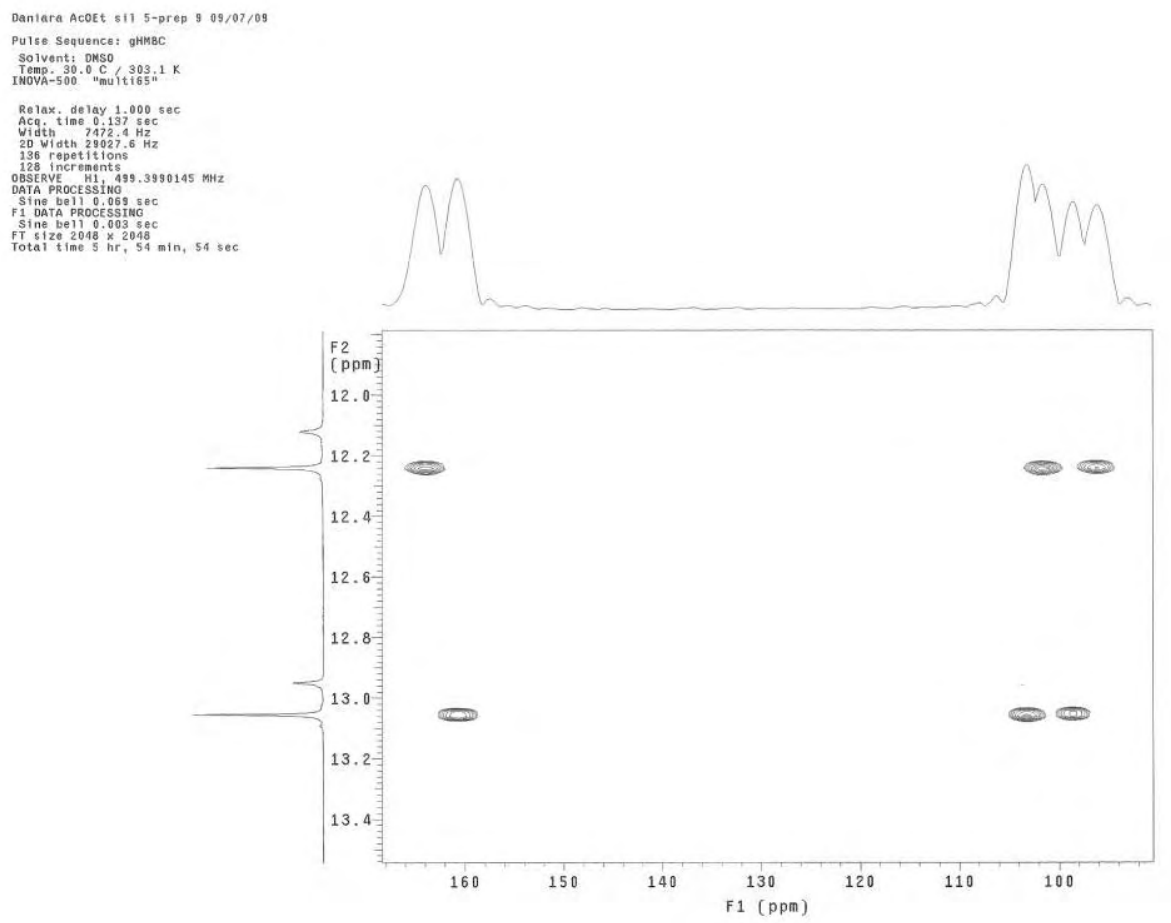

Anexo 70. Ampliação do mapa de contorno ${ }^{1} \mathrm{H}_{-}{ }^{13} \mathrm{C} g \mathrm{HMBC}$ da substância 8.

$$
\left(500 \mathrm{MHz}-\mathrm{DMSO}-d_{6}\right)
$$




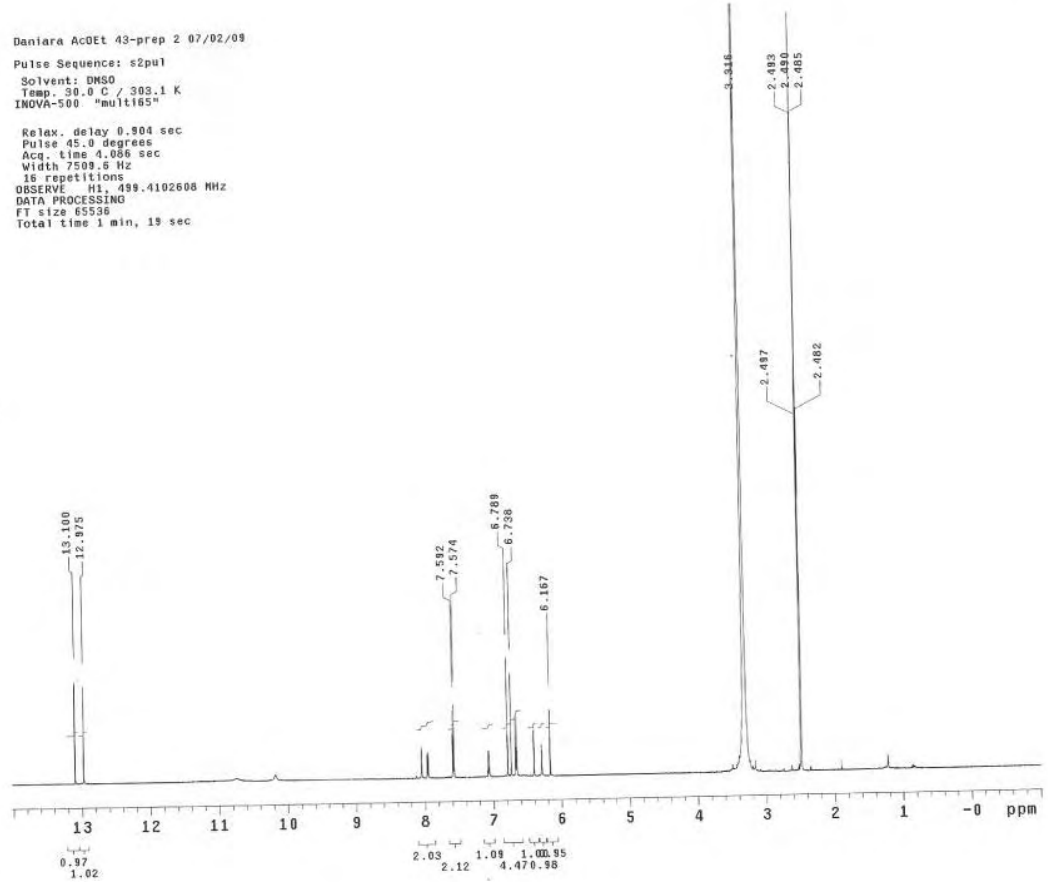

Anexo 71. Espectro de RMN de ${ }^{1} \mathrm{H}$ da substância 9. $\left(500 \mathrm{MHz}-\mathrm{DMSO}-d_{6}\right)$

Daniara ACOEt 43-prep 2 07/02/09

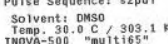

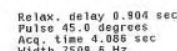

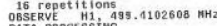

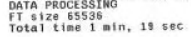

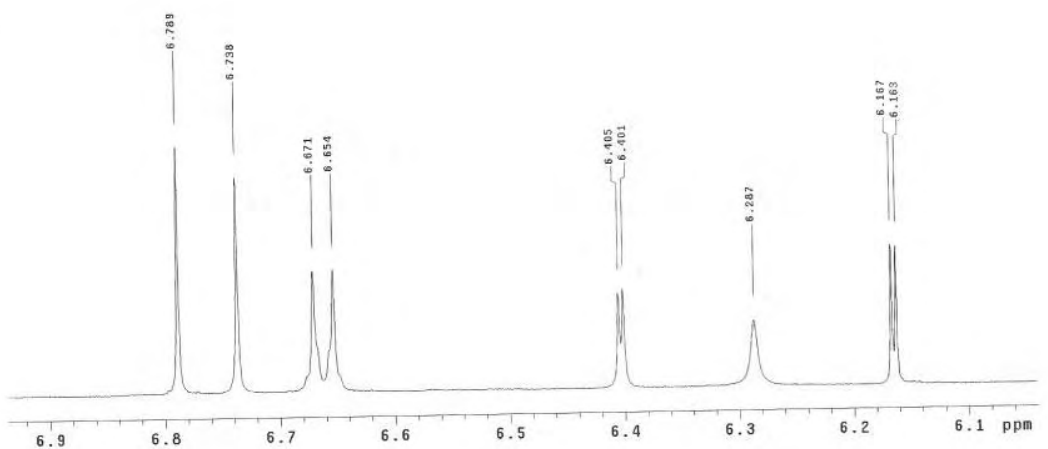

Anexo 72. Ampliação do espectro de RMN de ${ }^{1} \mathrm{H}$ da substância 9.

$\left(500 \mathrm{MHz}-\mathrm{DMSO}-d_{6}\right)$ 
Daniara ACOEt 43-prep $207 / 02 / 09$

Pu1se Sequence: $52 \mathrm{pu} 1$

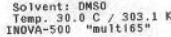

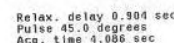

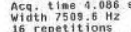

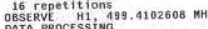

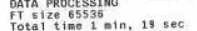

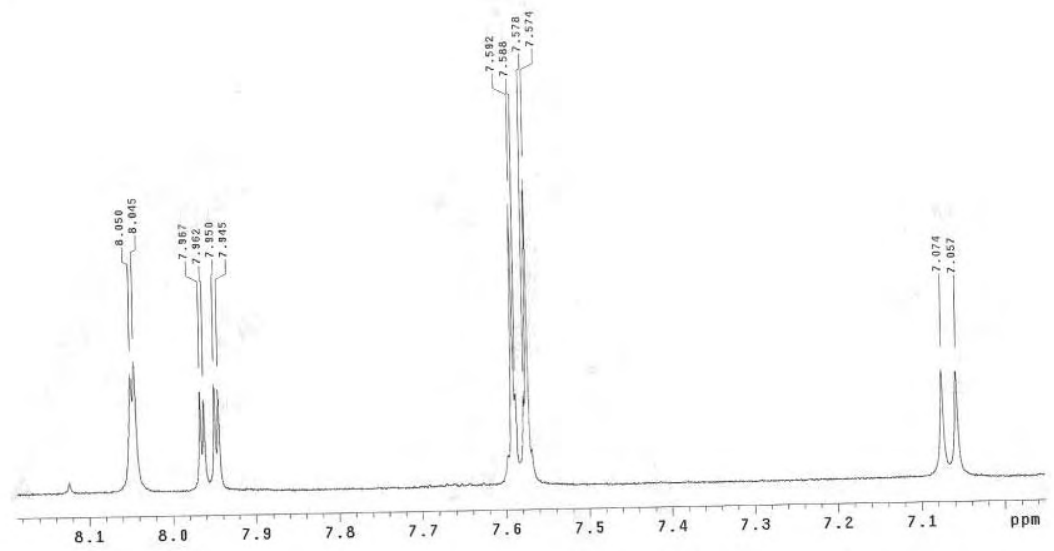

Anexo 73. Ampliação do espectro de RMN de ${ }^{1} \mathrm{H}$ da substância 9.

$$
\left(500 \mathrm{MHz}-\mathrm{DMSO}-d_{6}\right)
$$

Daniara Acott 43-prep 2 07/02/09

Pulse Sequence: s2pui

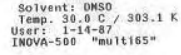

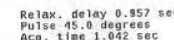

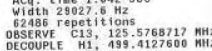

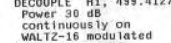

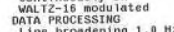

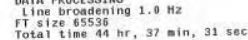

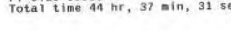

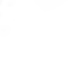


Daniara Acott 43-prep 2 07/02/09

Pulse Sequence: $82 \mathrm{pu} 1$
Solvent: Dnso

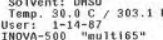

Relax, de lay 0.955 sec
Pulse 45.0 degrees

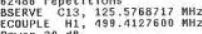

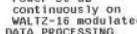

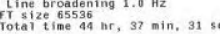

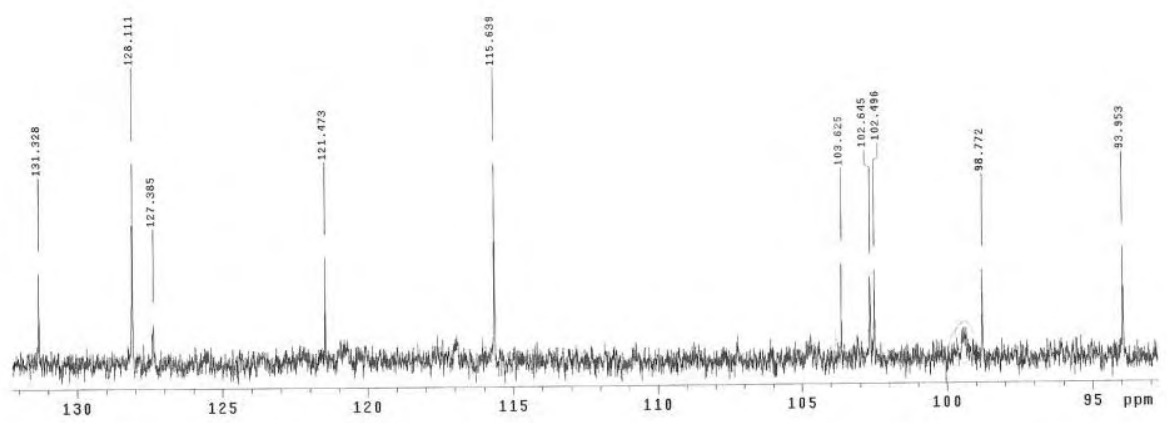

Anexo 75. Ampliação do espectro de RMN de ${ }^{13} \mathrm{C}$ da substância 9. $\left(125 \mathrm{MHz}-\mathrm{DMSO}-d_{6}\right)$

Daniara ACOEt 43-prep 2 07/02/09

Pulse sequence: 52pur

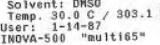

Relax. Gelay $0.952 \mathrm{sec}$
pultse

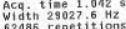

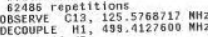

Cont inous ly on
watrz-15 modulated

FT

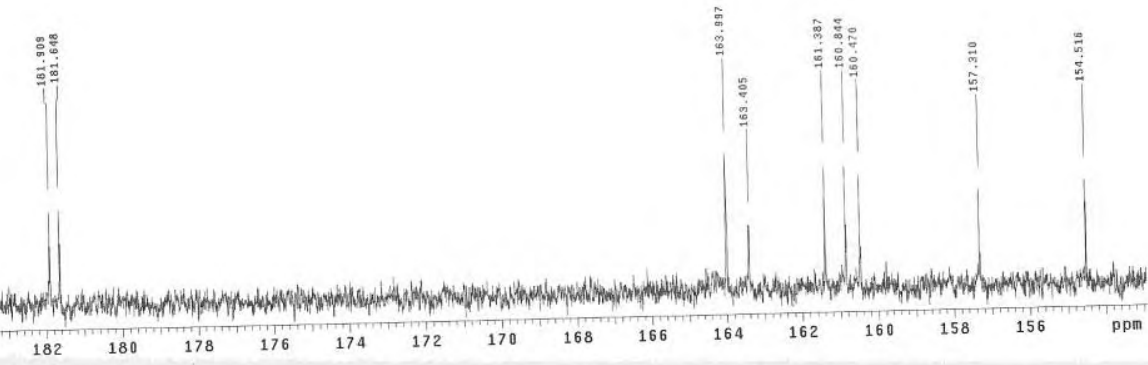

Anexo 76. Ampliação do espectro de RMN de ${ }^{13} \mathrm{C}$ da substância 9.

$\left(125 \mathrm{MHz}-\mathrm{DMSO}-d_{6}\right)$ 
Dantara Ac0Et 43-prep $207 / 02 / 08$ Pulse Sequence: gcosy

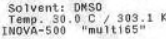

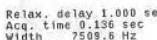
vidth $2509.6 \mathrm{~Hz}$
20 Width $509.6 \mathrm{~Hz}$
16 repetitions

DBSERE

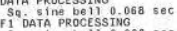

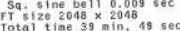

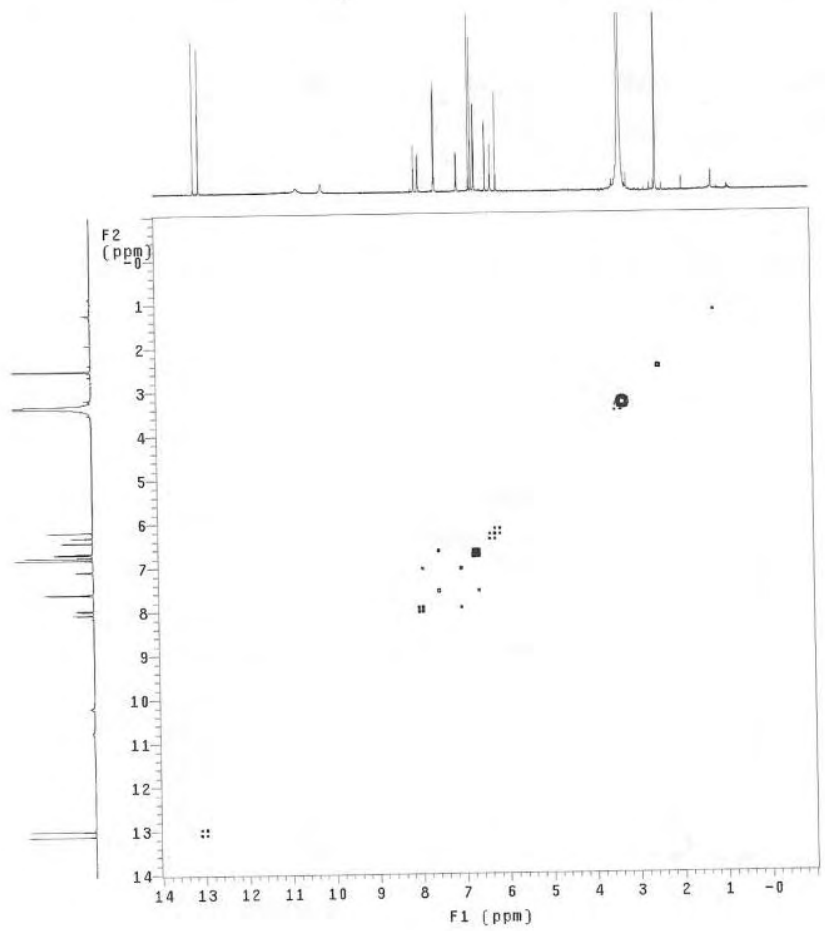

Anexo 77. Mapa de contorno ${ }^{1} \mathrm{H}-{ }^{1} \mathrm{H} g \mathrm{COSY}$ da substância 9. $\left(500 \mathrm{MHz}-\mathrm{DMSO}-d_{6}\right)$

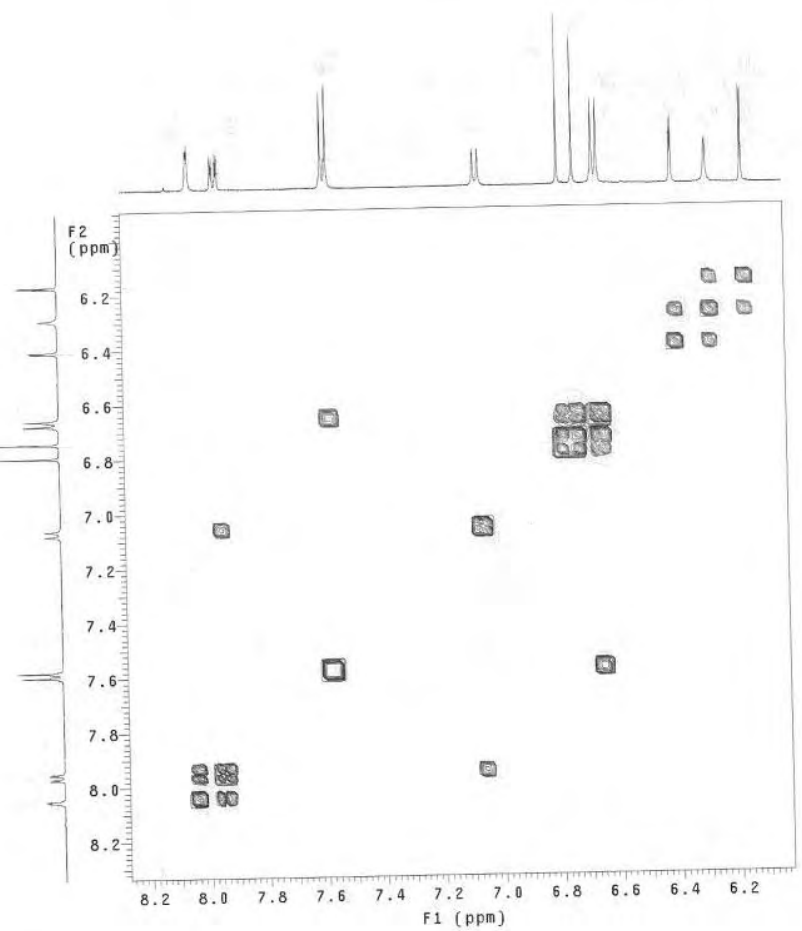

Anexo 78. Ampliação do mapa de contorno ${ }^{1} \mathrm{H}-{ }^{1} \mathrm{H} g \operatorname{COSY}$ da substância 9.

$$
\left(500 \mathrm{MHz}-\mathrm{DMSO}-d_{6}\right)
$$




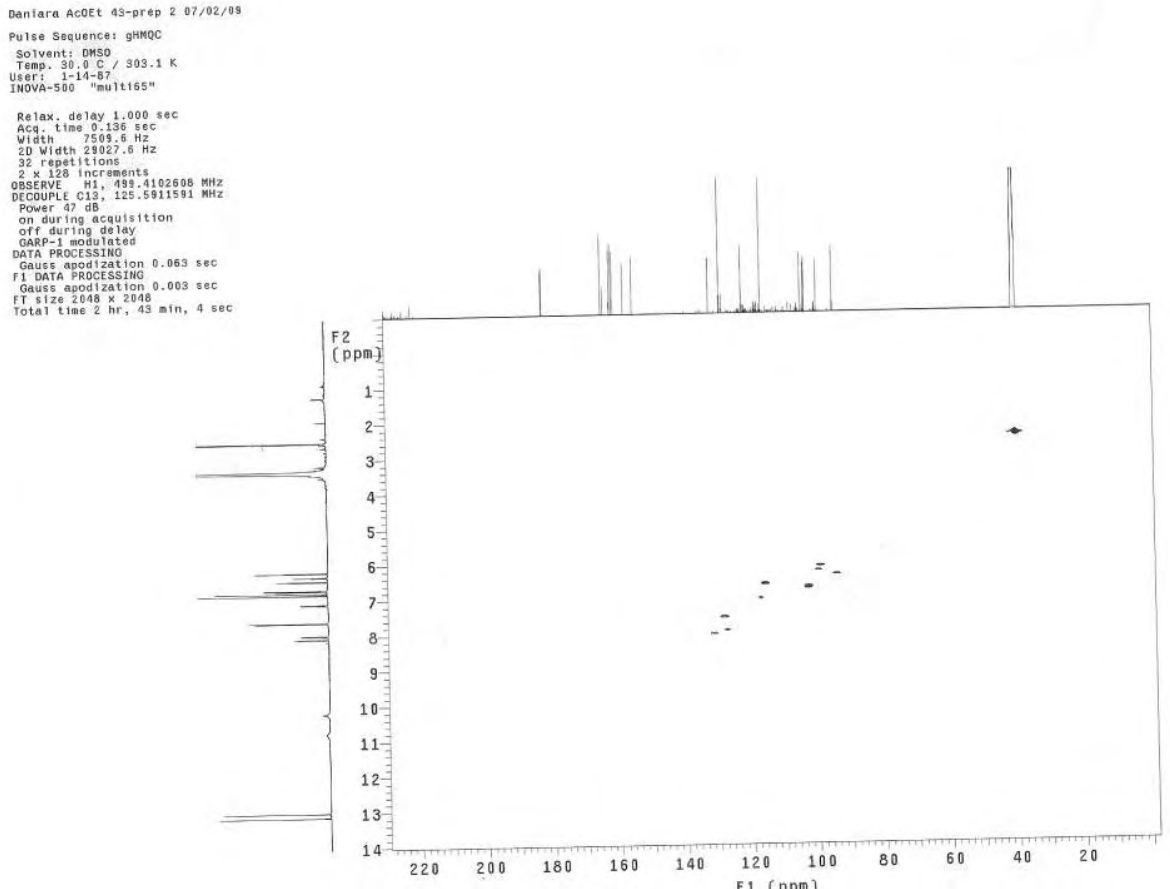

Anexo 79. Mapa de contorno ${ }^{1} \mathrm{H}-{ }^{13} \mathrm{C} g \mathrm{HMQC}$ da substância 9.

$$
\left(500 \mathrm{MHz}-\mathrm{DMSO}-d_{6}\right)
$$

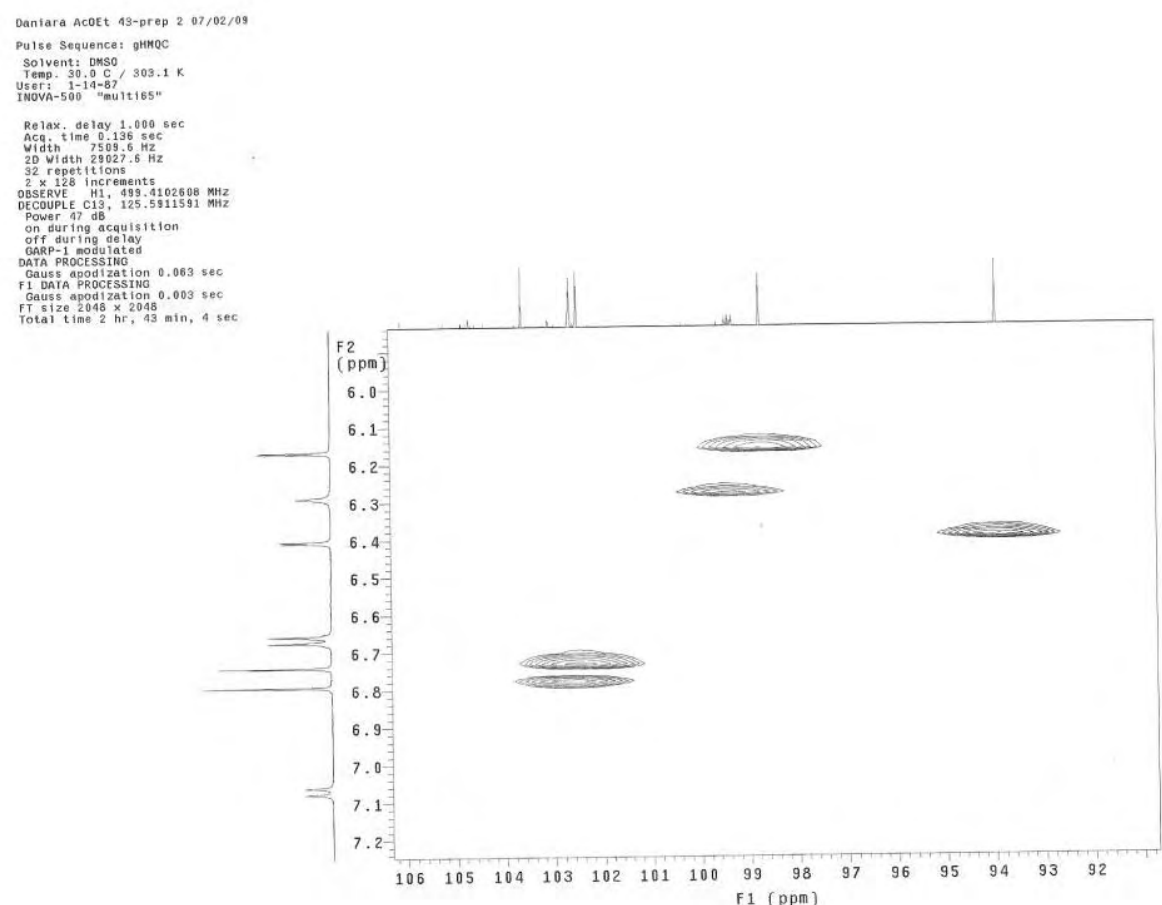

Anexo 80. Ampliação do mapa de contorno ${ }^{1} \mathrm{H}_{-}{ }^{13} \mathrm{C} g \mathrm{HMQC}$ da substância 9.

$$
\left(500 \mathrm{MHz}-\mathrm{DMSO}-d_{6}\right)
$$




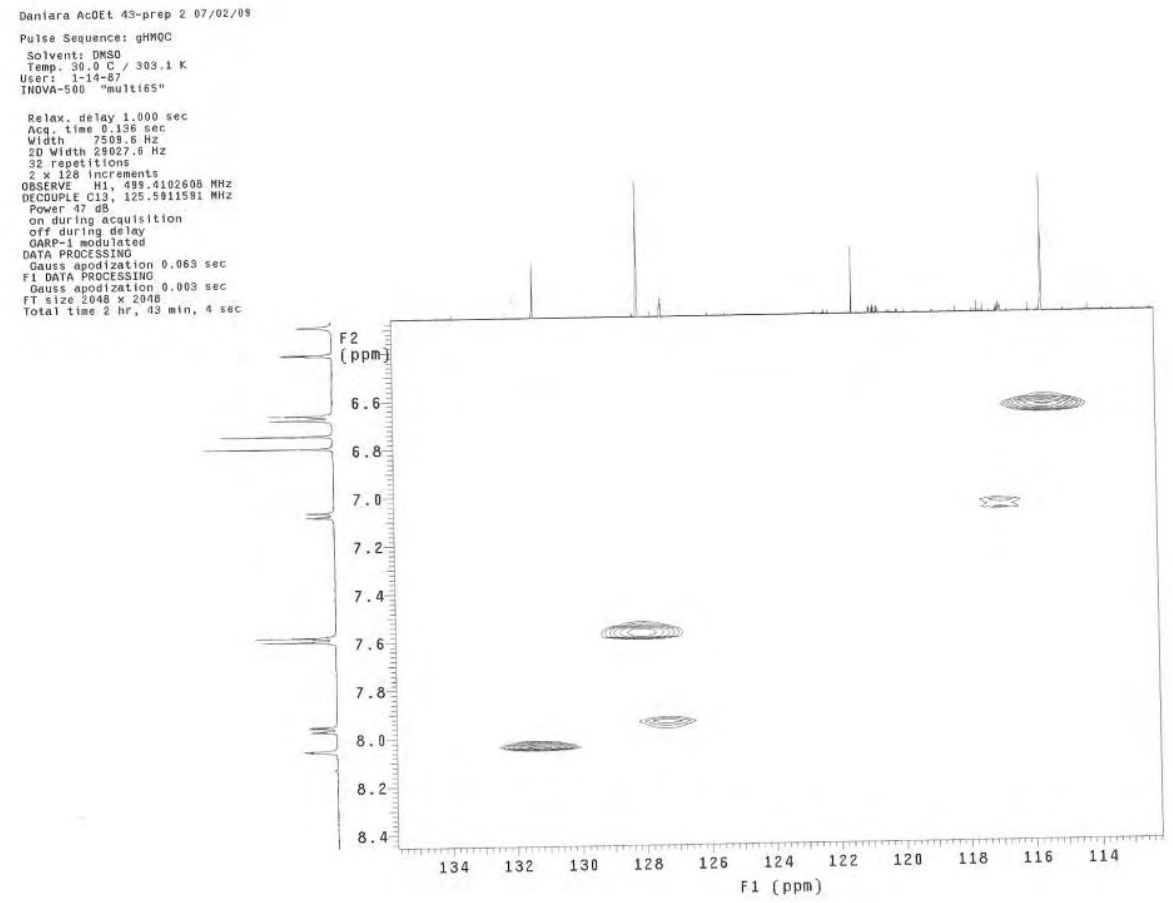

Anexo 81. Ampliação do mapa de contorno ${ }^{1} \mathrm{H}^{-}{ }^{13} \mathrm{C} g \mathrm{HMQC}$ da substância 9.

$$
\left(500 \mathrm{MHz}-\mathrm{DMSO}-d_{6}\right)
$$

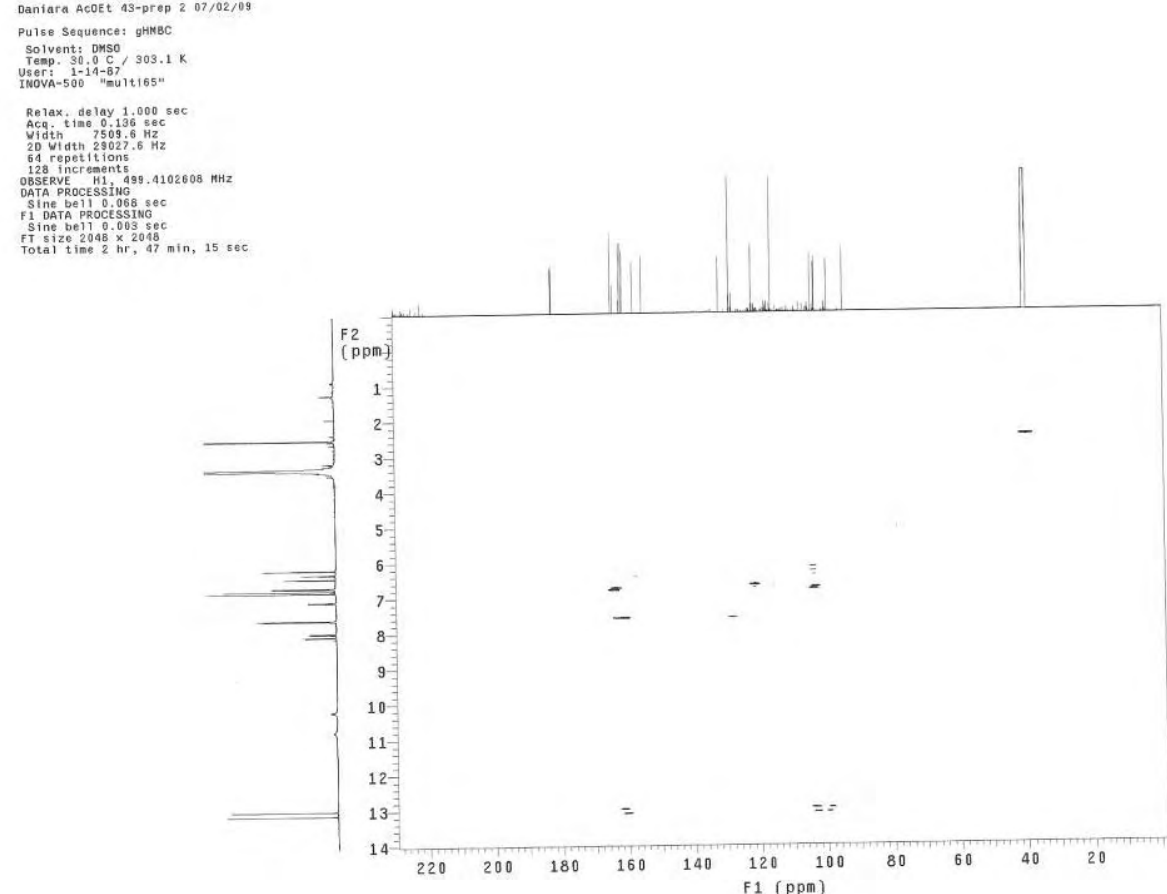

Anexo 82. Mapa de contorno ${ }^{1} \mathrm{H}^{-13} \mathrm{C} g \mathrm{HMBC}$ da substância 9.

$$
\left(500 \mathrm{MHz}-\mathrm{DMSO}-d_{6}\right)
$$


Daniara Acoet 43-prep $207 / 02 / 09$

Pulse sequence: ghrBb

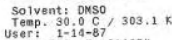

Re lax telay 1.000 sec

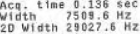

128
BSERE

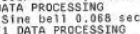

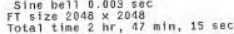

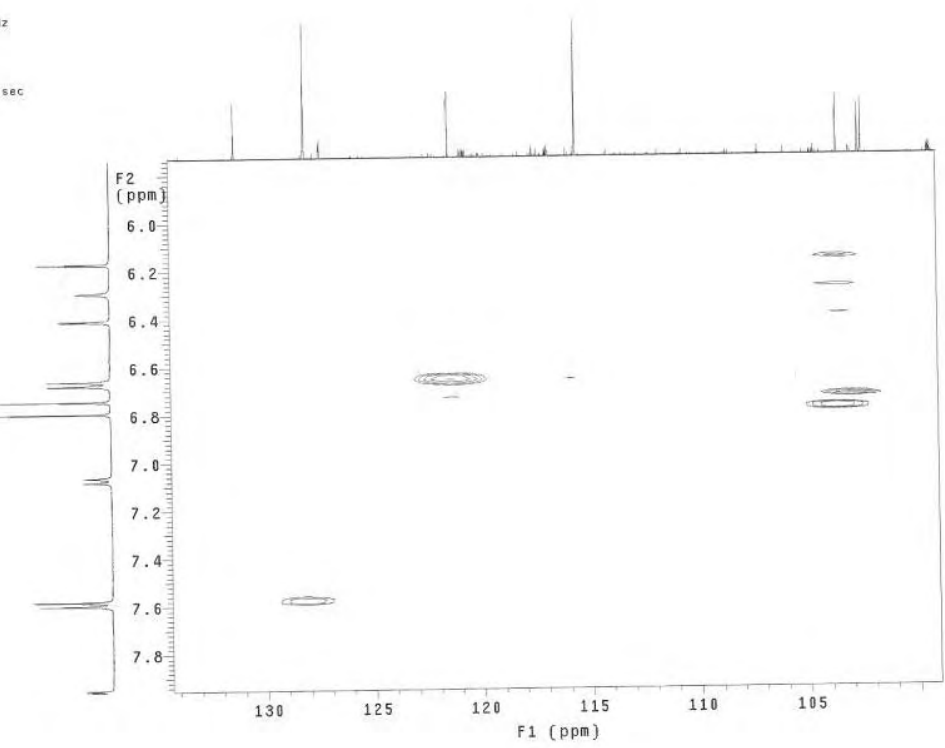

Anexo 83. Ampliação do mapa de contorno ${ }^{1} \mathrm{H}_{-}{ }^{13} \mathrm{C} g \mathrm{HMBC}$ da substância 9. $\left(500 \mathrm{MHz}-\mathrm{DMSO}-d_{6}\right)$

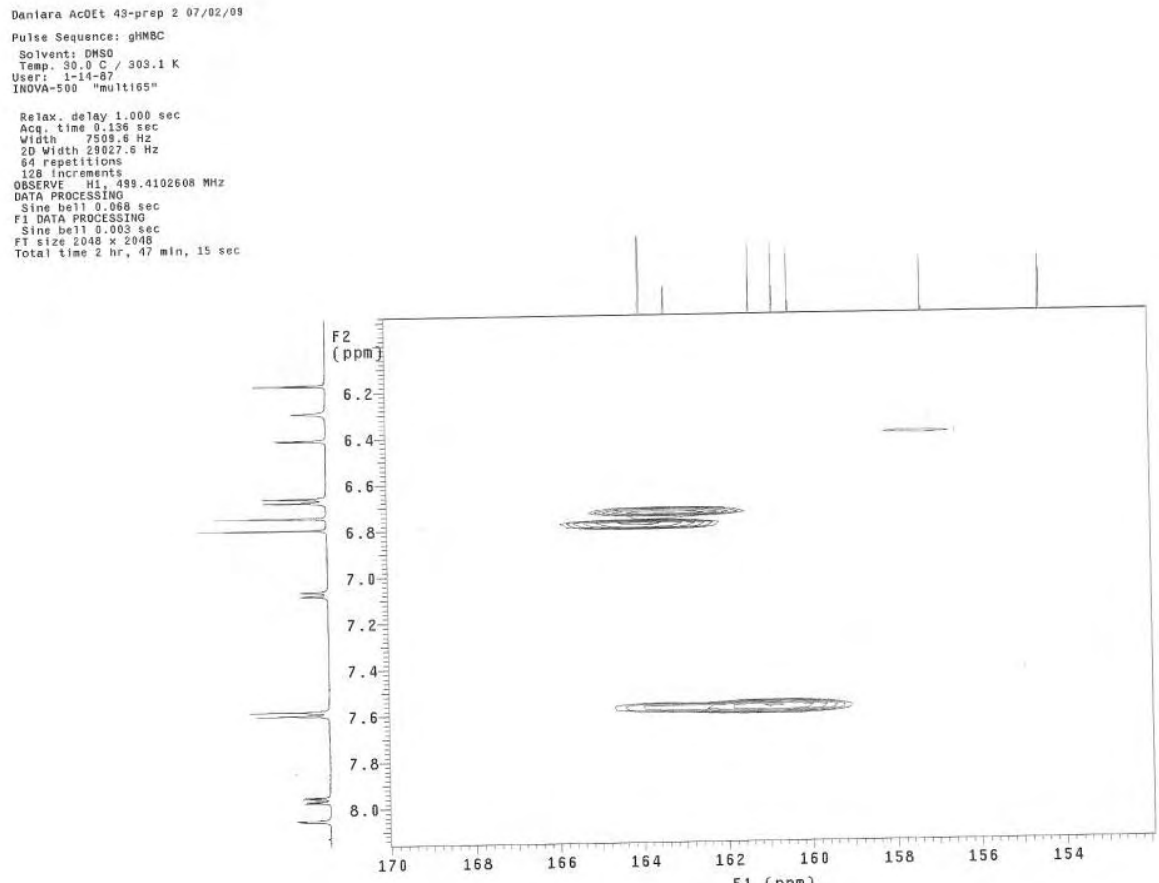

Anexo 84. Ampliação do mapa de contorno ${ }^{1} \mathrm{H}_{-}{ }^{13} \mathrm{C} g \mathrm{HMBC}$ da substância 9. $\left(500 \mathrm{MHz}-\mathrm{DMSO}-d_{6}\right)$ 


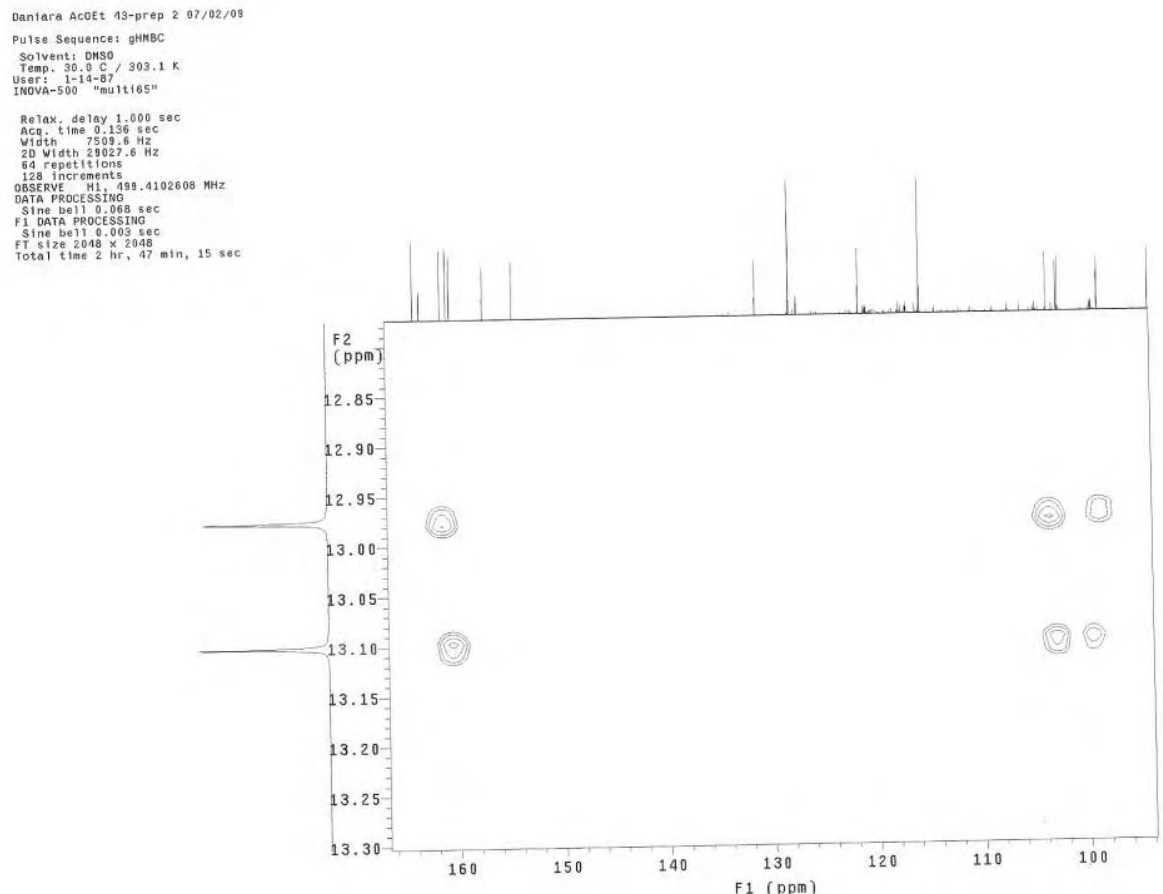

Anexo 85. Ampliação do mapa de contorno ${ }^{1} \mathrm{H}_{-}{ }^{13} \mathrm{C} g \mathrm{HMBC}$ da substância 9. $\left(500 \mathrm{MHz}-\mathrm{DMSO}-d_{6}\right)$

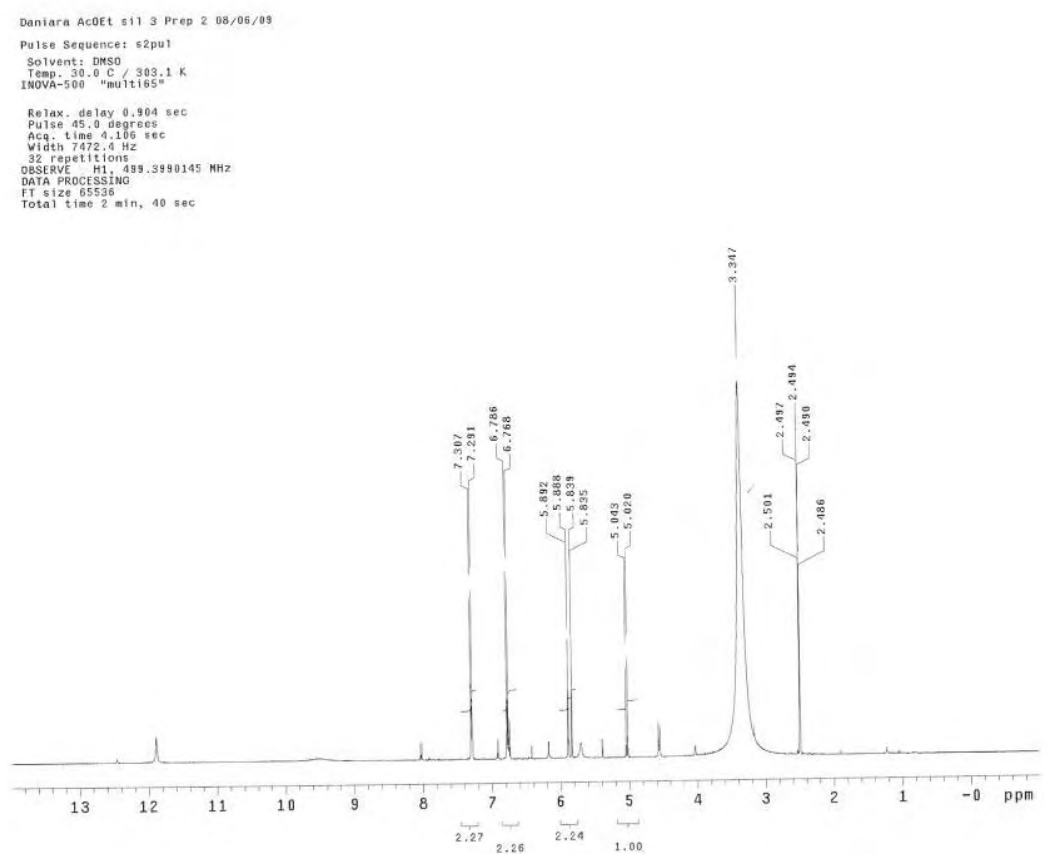

Anexo 86. Espectro de RMN de ${ }^{1} \mathrm{H}$ da substância 10.

$\left(500 \mathrm{MHz}-\mathrm{DMSO}-d_{6}\right)$ 
Daniara Acoet sil 3 Prep $208 / 06 / 09$

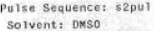

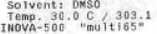

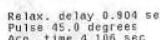

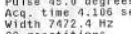

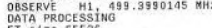

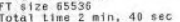

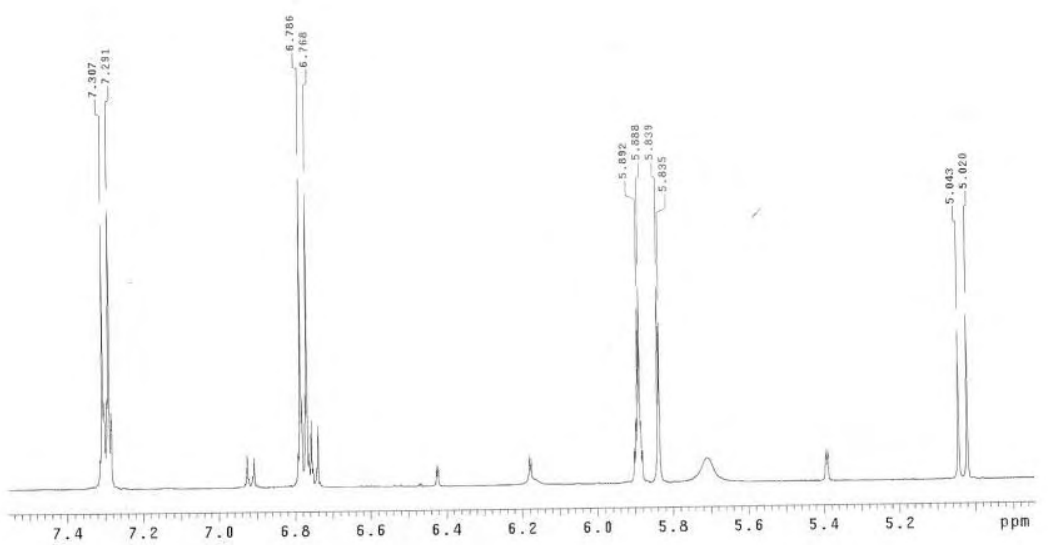

Anexo 87. Ampliação do espectro de RMN de ${ }^{1} \mathrm{H}$ da substância 10.

$\left(500 \mathrm{MHz}-\mathrm{DMSO}-d_{6}\right)$
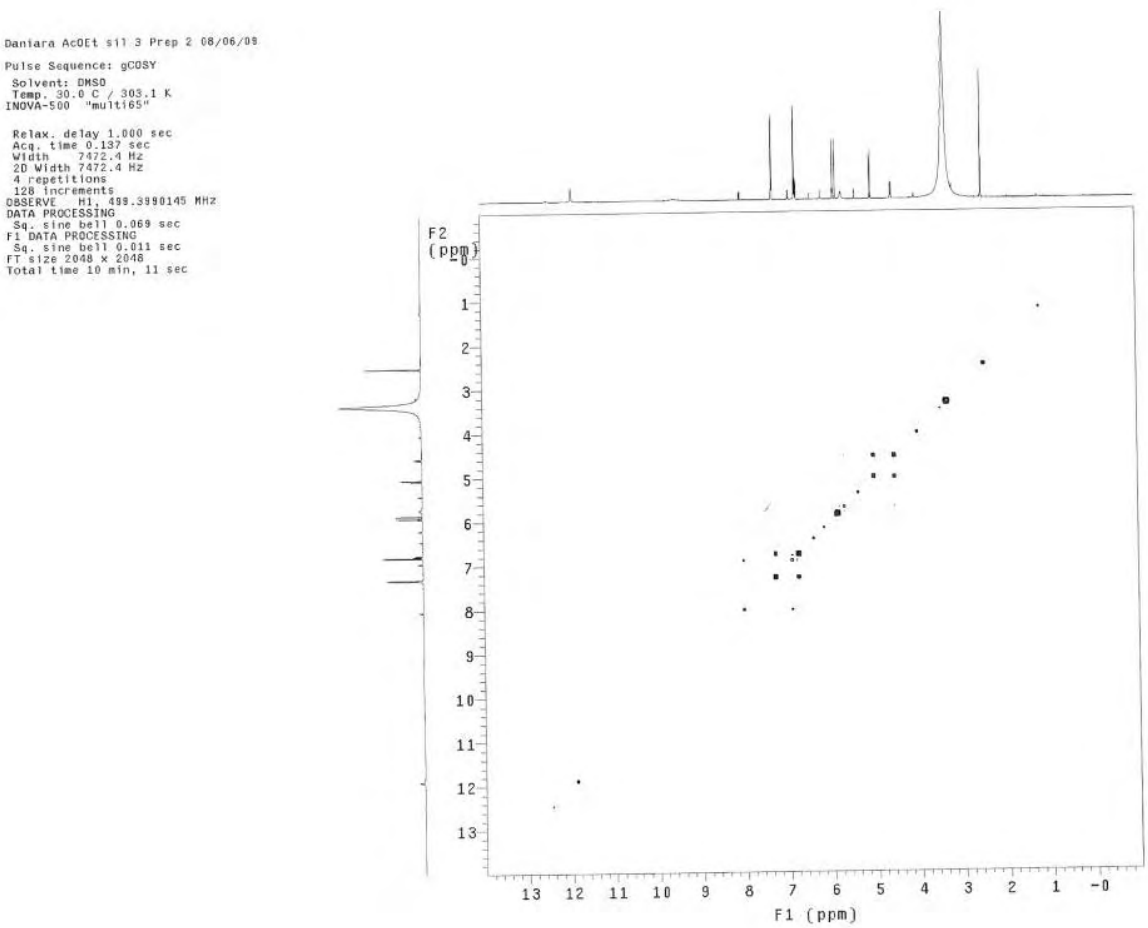

Anexo 88. Mapa de contorno ${ }^{1} \mathrm{H}-{ }^{1} \mathrm{H} g \operatorname{COSY}$ da substância 10.

$$
\left(500 \mathrm{MHz}-\mathrm{DMSO}-d_{6}\right)
$$


Daniara ACOEt s11 3 Prep $208 / 06 / 09$ Pulse sequence: gcost

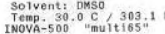

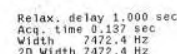

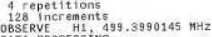

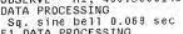

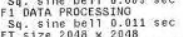

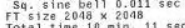

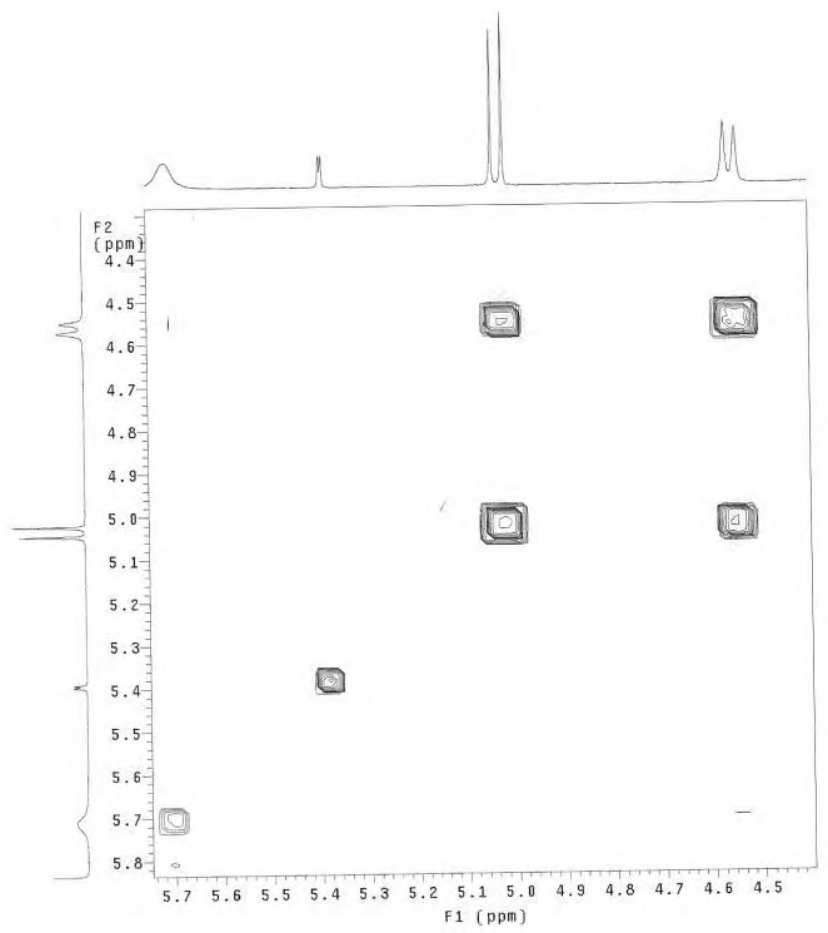

Anexo 89. Ampliação do mapa de contorno ${ }^{1} \mathrm{H}-{ }^{1} \mathrm{H} g \mathrm{COSY}$ da substância 10.

$\left(500 \mathrm{MHz}-\mathrm{DMSO}-d_{6}\right)$ Pulse Sequence: $g \cos \gamma$

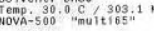

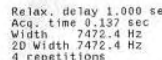

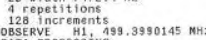

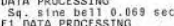

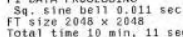

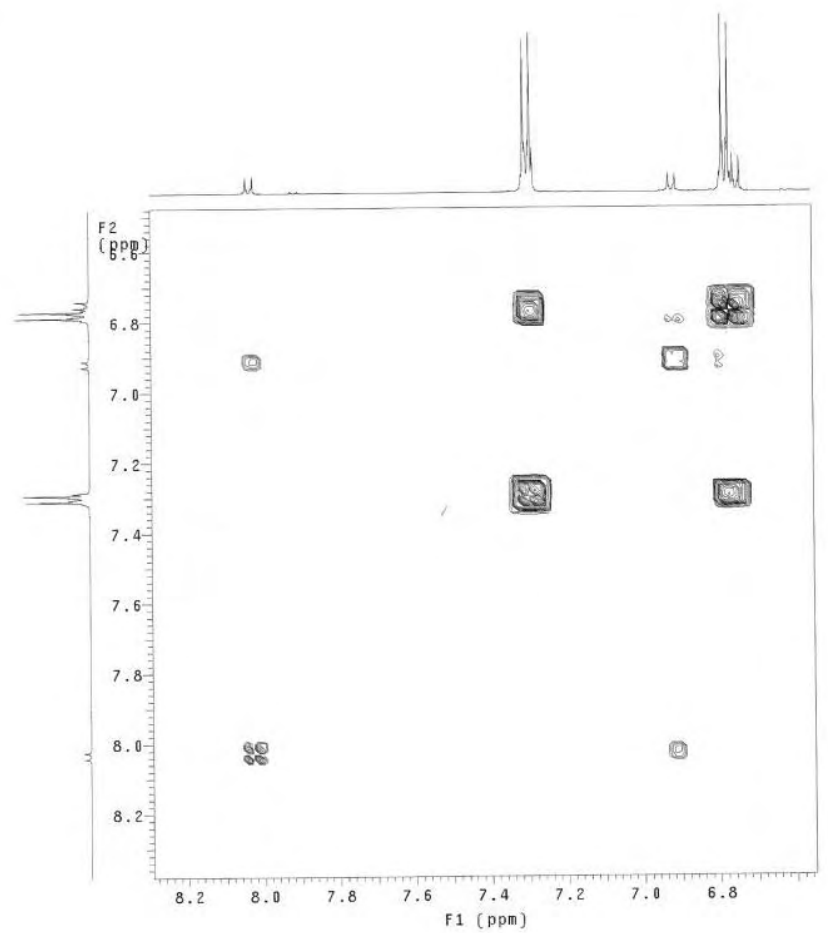

Anexo 90. Ampliação do mapa de contorno ${ }^{1} \mathrm{H}-{ }^{1} \mathrm{H} g \mathrm{COSY}$ da substância 10.

$$
\left(500 \mathrm{MHz}-\mathrm{DMSO}-d_{6}\right)
$$




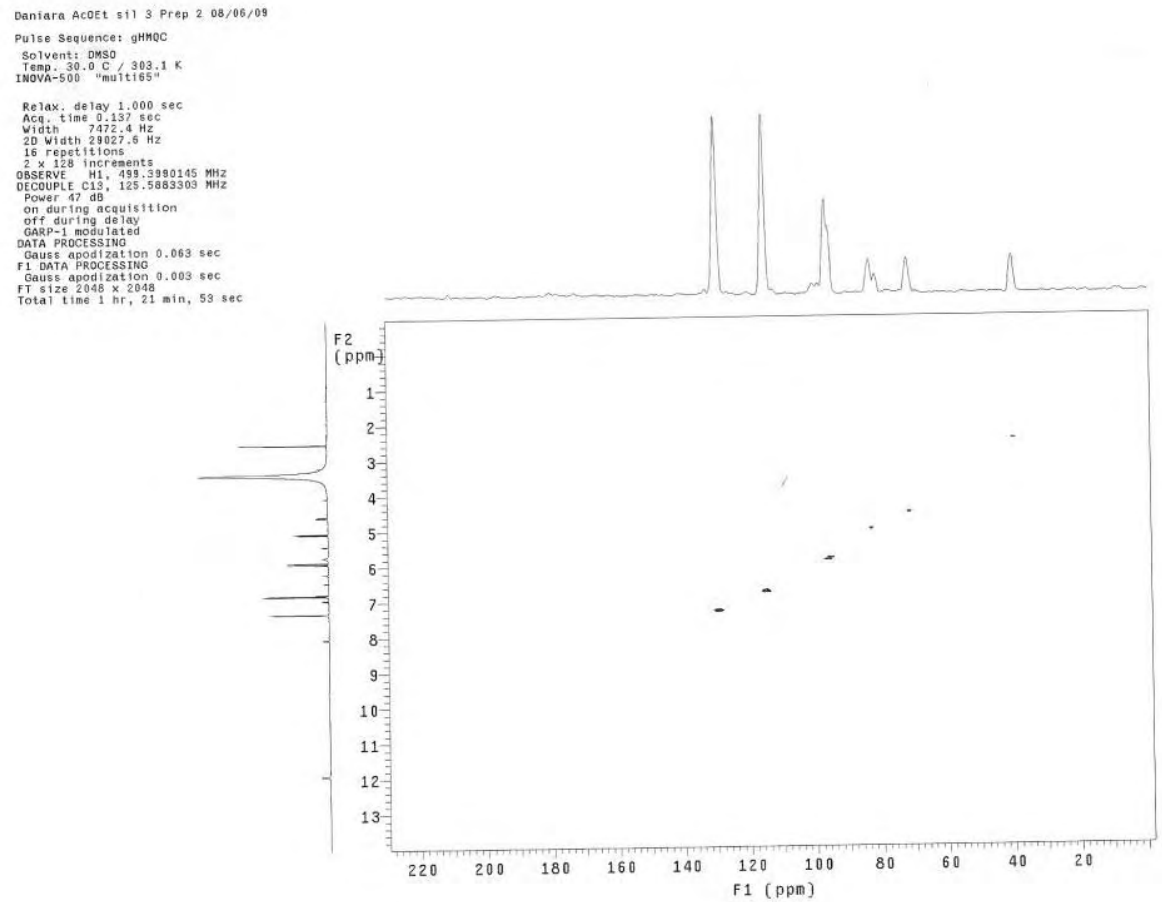

Anexo 91. Mapa de contorno ${ }^{1} \mathrm{H}_{-}{ }^{13} \mathrm{C} g \mathrm{HMQC}$ da substância 10.

$$
\left(500 \mathrm{MHz}-\mathrm{DMSO}-d_{6}\right)
$$

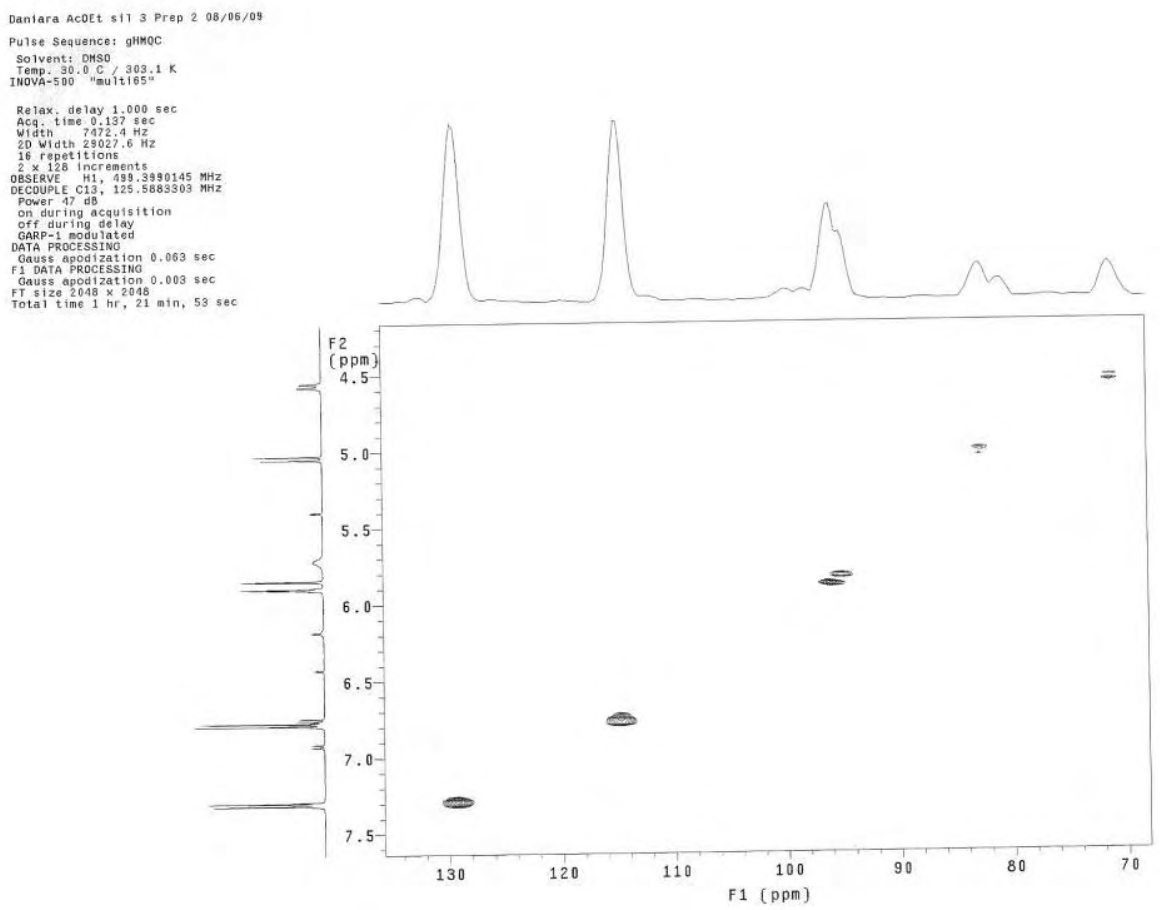

Anexo 92. Ampliação do mapa de contorno ${ }^{1} \mathrm{H}-{ }^{13} \mathrm{C} g \mathrm{HMQC}$ da substância 10.

$$
\left(500 \mathrm{MHz}-\mathrm{DMSO}-d_{6}\right)
$$




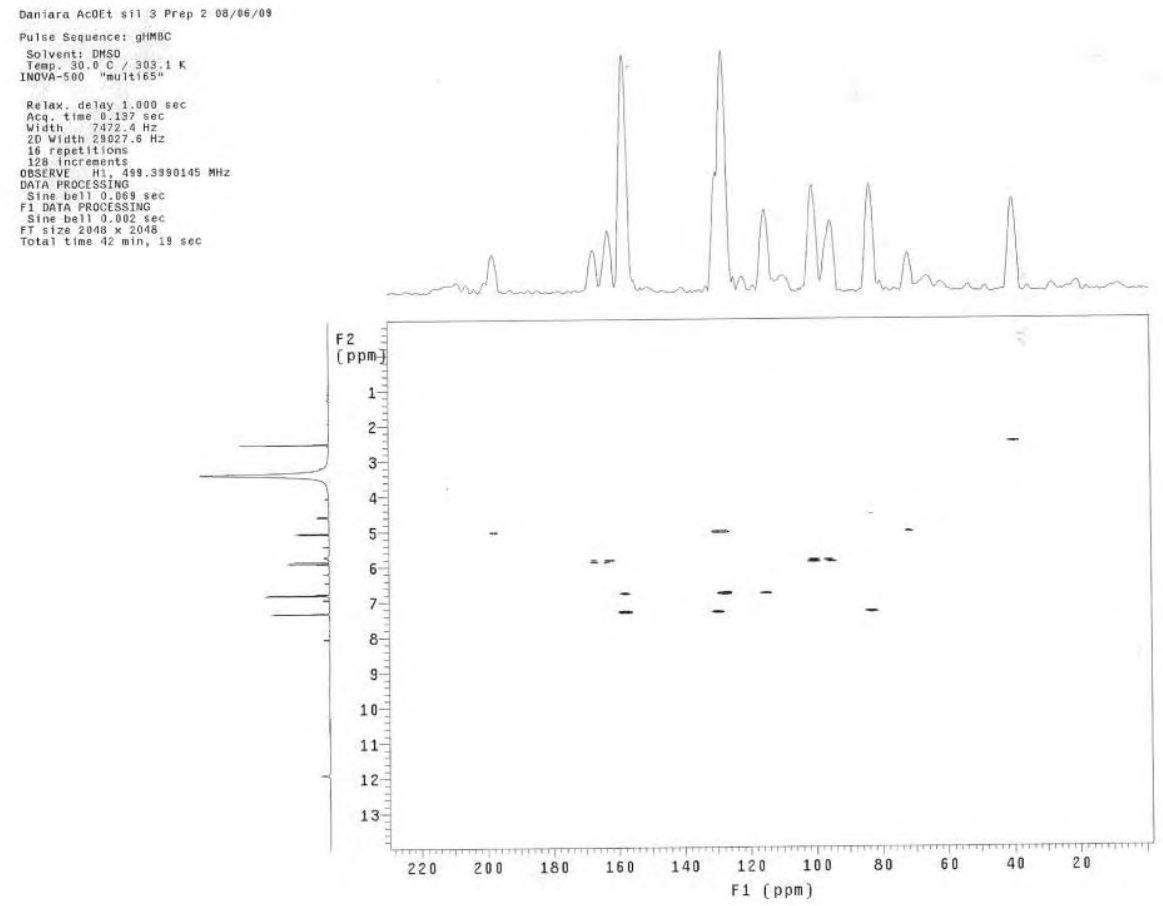

Anexo 93. Mapa de contorno ${ }^{1} \mathrm{H}-{ }^{13} \mathrm{C} g \mathrm{HMBC}$ da substância 10.

$\left(500 \mathrm{MHz}-\mathrm{DMSO}-d_{6}\right)$

Dantara ACOEt s11 3 Prep $208 / 06 / 05$

solvents onsto

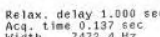

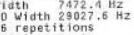

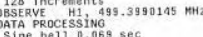

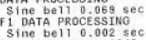

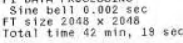

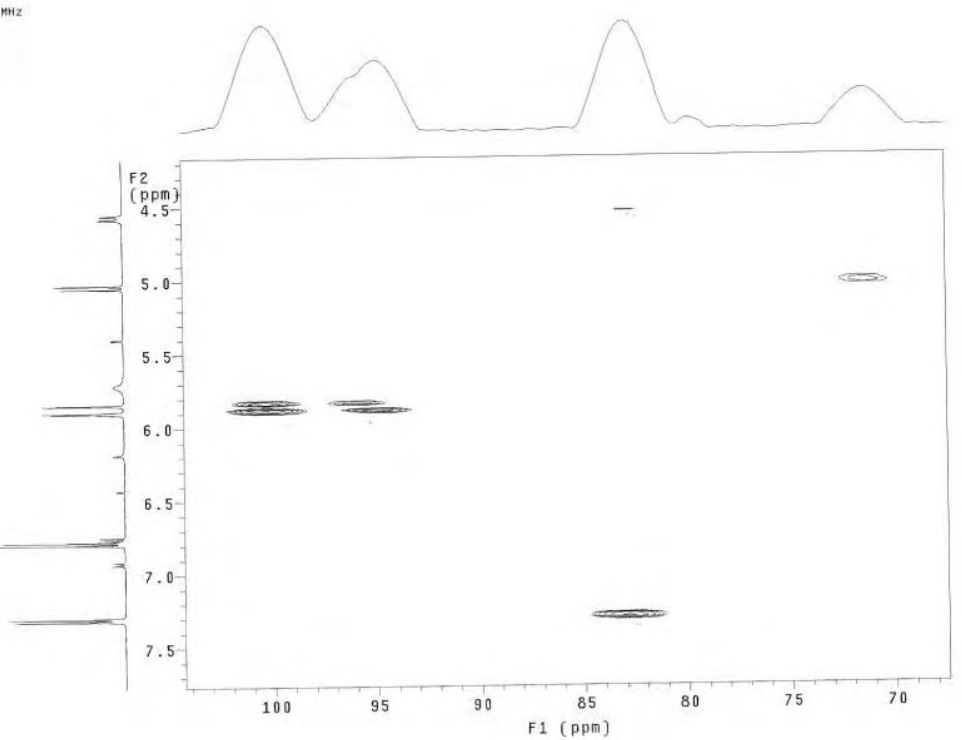

Anexo 94. Ampliação do mapa de contorno ${ }^{1} \mathrm{H}^{13} \mathrm{C} g \mathrm{HMBC}$ da substância 10.

$$
\left(500 \mathrm{MHz}-\mathrm{DMSO}-d_{6}\right)
$$


Dantara ACOEt s11 3 Prep 2 08/06/09

Pulse Sequence: ohrBC
Solvent: DHSO

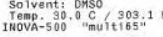

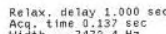

Width $7472,4 \mathrm{~Hz}$
20 Vidth $29027.6 \mathrm{~Hz}$
16 repetitions

政ERVE

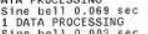

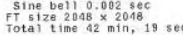

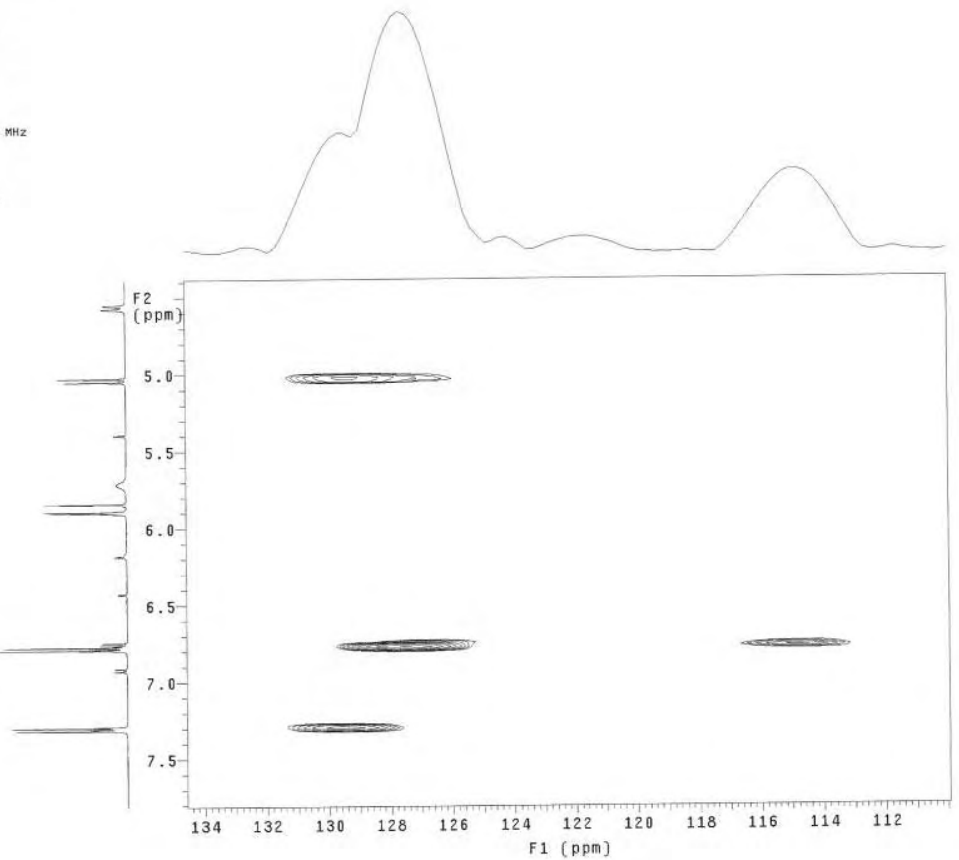

Anexo 95. Ampliação do mapa de contorno ${ }^{1} \mathrm{H}-{ }^{13} \mathrm{C} g \mathrm{HMBC}$ da substância 10.

$\left(500 \mathrm{MHz}-\mathrm{DMSO}-d_{6}\right)$

Daniara AcoEt sil 3 Prep $208 / 06 / 09$

Pulse Sequence: ghнBC

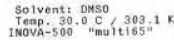

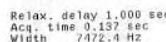

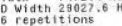

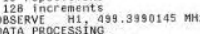

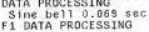

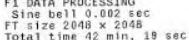

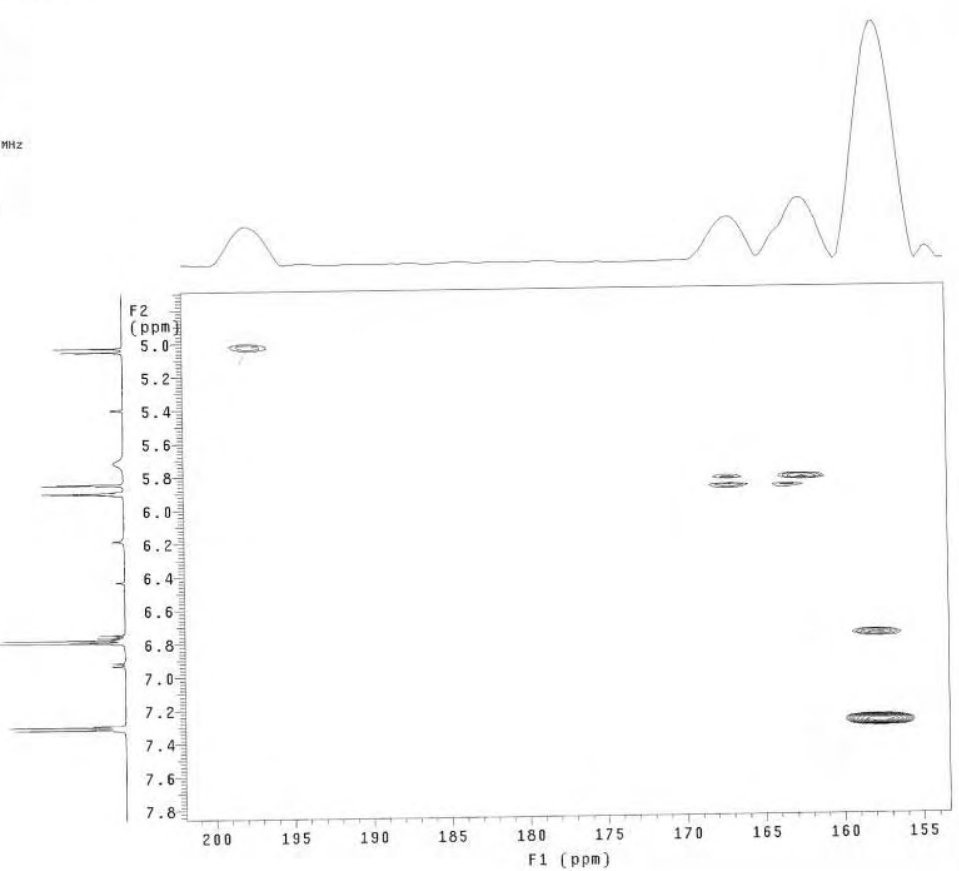

Anexo 96. Ampliação do mapa de contorno ${ }^{1} \mathrm{H}-{ }^{13} \mathrm{C} g \mathrm{HMBC}$ da substância 10. $\left(500 \mathrm{MHz}-\mathrm{DMSO}-d_{6}\right)$ 


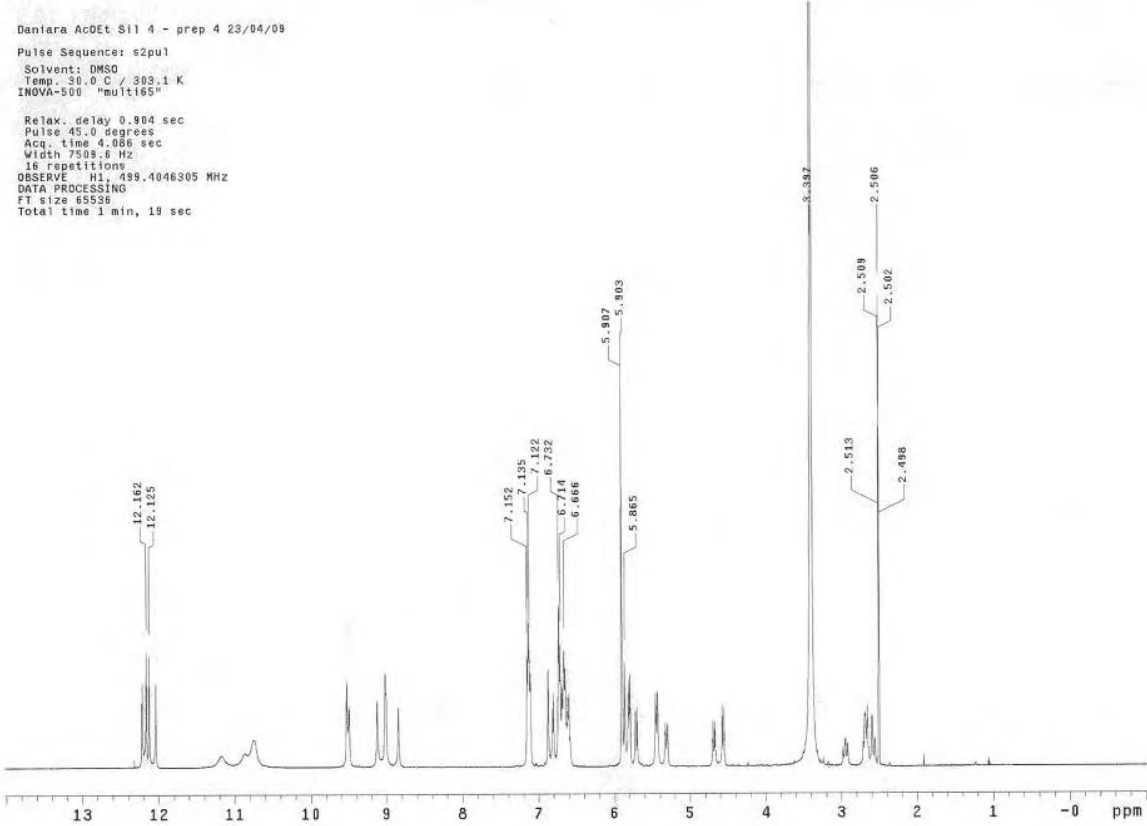

Anexo 97. Espectro de RMN de ${ }^{1} \mathrm{H}$ da substância 11.

$\left(500 \mathrm{MHz}-\mathrm{DMSO}-d_{6}\right)$

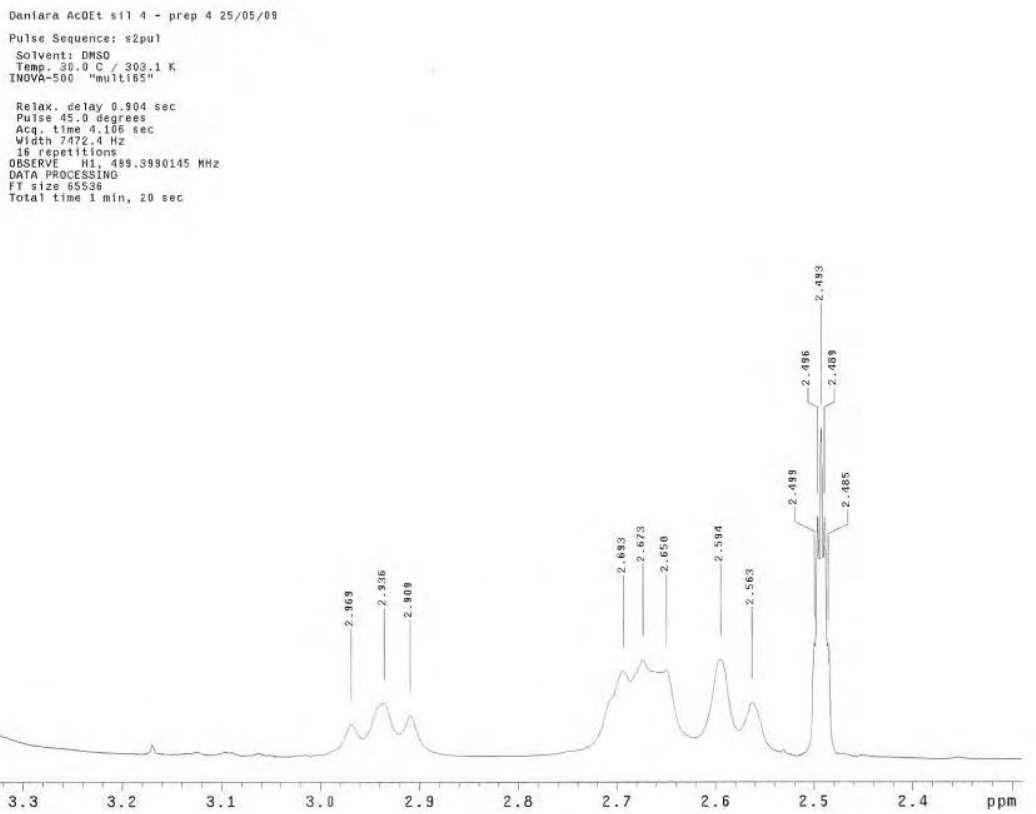

Anexo 98. Ampliação do espectro de RMN de ${ }^{1} \mathrm{H}$ da substância 11

$$
\left(500 \mathrm{MHz}-\mathrm{DMSO}-d_{6}\right)
$$


Dantara AcoEt s11 4 - prep 4 25/05/09

Pulse Sequence: s2pur

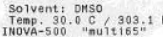

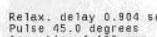

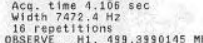

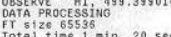
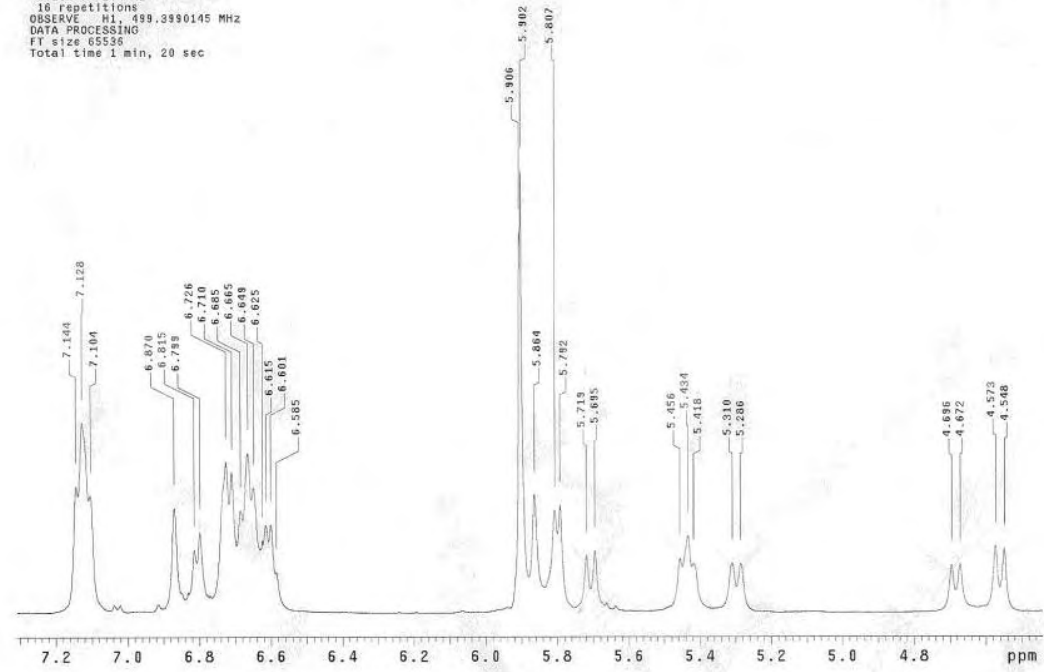

Anexo 99. Ampliação do espectro de RMN de ${ }^{1} \mathrm{H}$ da substância 11.

$\left(500 \mathrm{MHz}-\mathrm{DMSO}-d_{6}\right)$

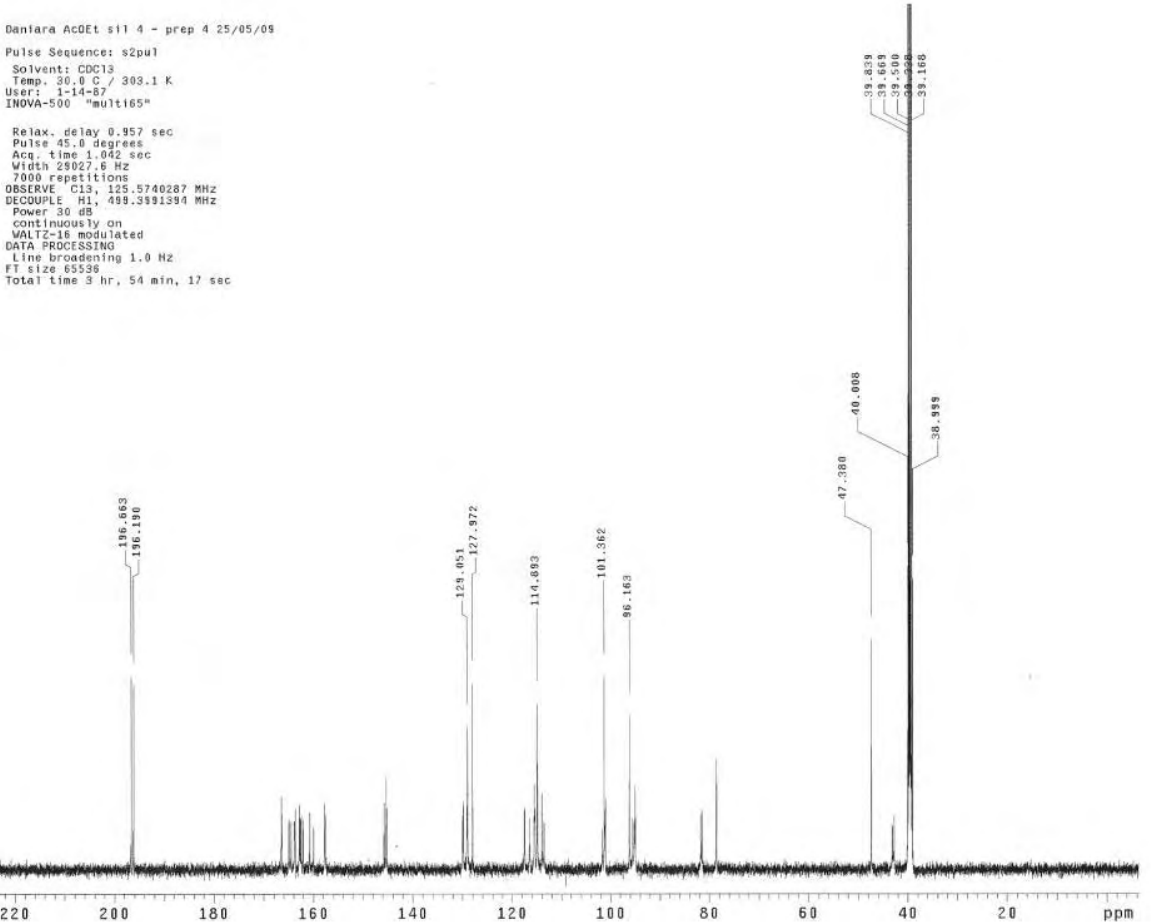

Anexo 100. Espectro de RMN de ${ }^{13} \mathrm{C}$ da substância 11.

$\left(125 \mathrm{MHz}-\mathrm{DMSO}-d_{6}\right)$ 
Daniara AcoEt s11 4 - prep 4 25/05/09

Sulse Sequences: 2 pul

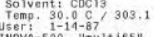

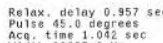

000 repetition

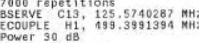

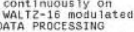

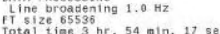

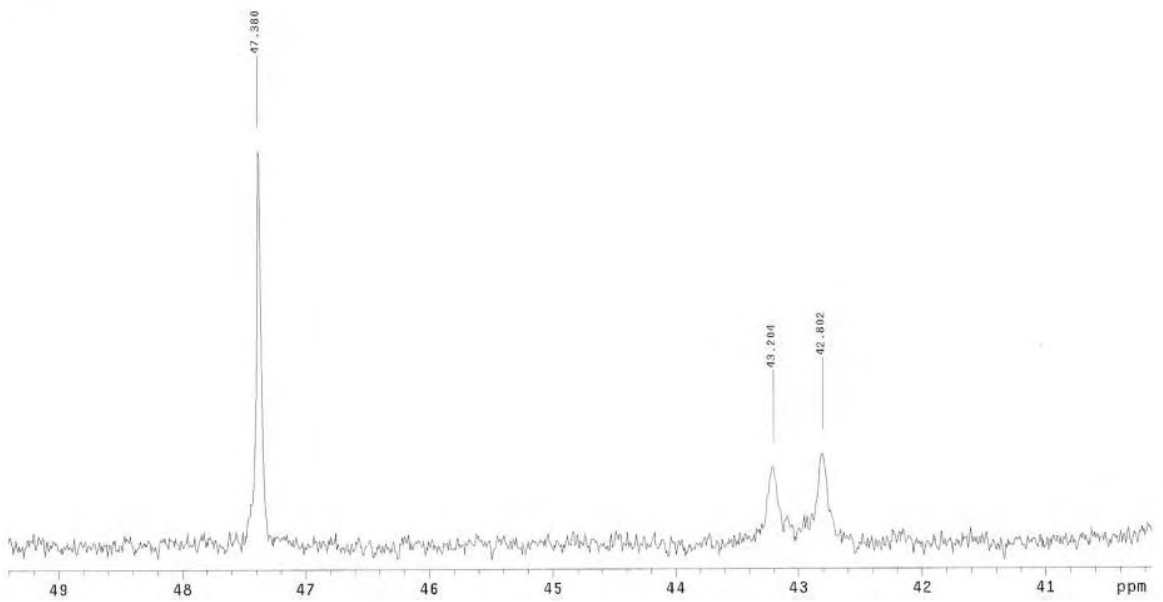

Anexo 101. Ampliação do espectro de RMN de ${ }^{13} \mathrm{C}$ da substância 11. $\left(125 \mathrm{MHz}-\mathrm{DMSO}-d_{6}\right)$

Dantara Acoet sit 4 - prep 4 25/05/09

Puise Sequence: s2pul 1

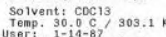

Relax. de lay $0.957 \mathrm{sec}$
Pulse

Pulse 45.0 degres
Acy time 1.042 sec
Vidith $29027.6 \mathrm{~Hz}$

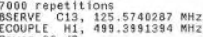

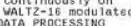

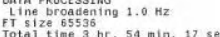

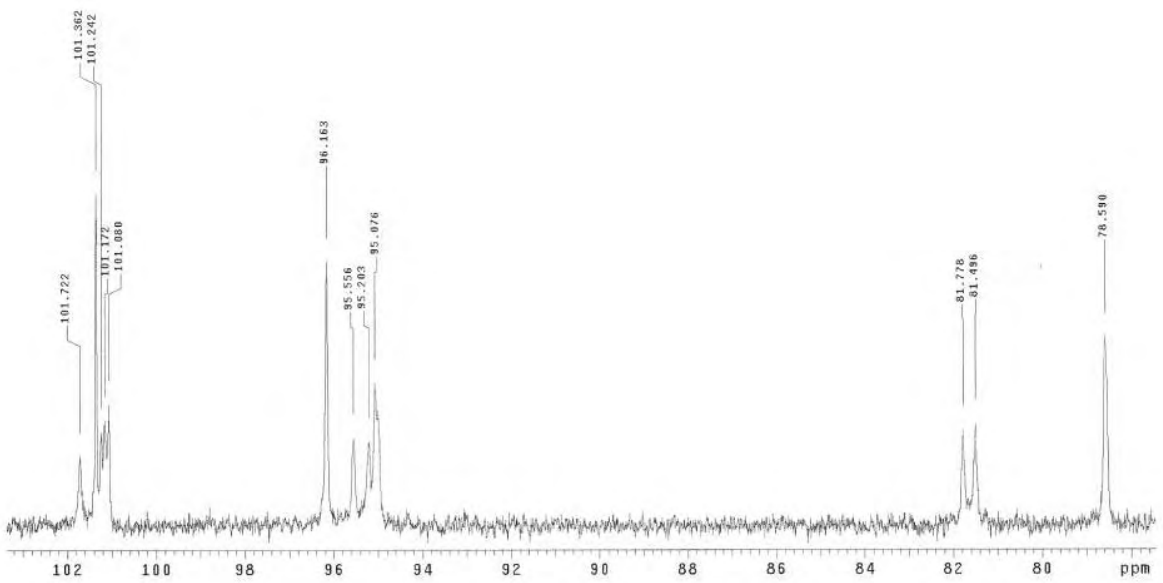

Anexo 102. Ampliação do espectro de RMN de ${ }^{13} \mathrm{C}$ da substância 11. $\left(125 \mathrm{MHz}-\mathrm{DMSO}-d_{6}\right)$ 
Daniara AcoEt s11 4 - prep 4 25/05/09

Pulse Sequence: 52pu1

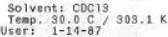

Hova-500 "mult t65"

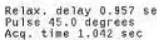

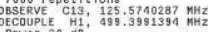

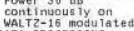

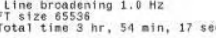

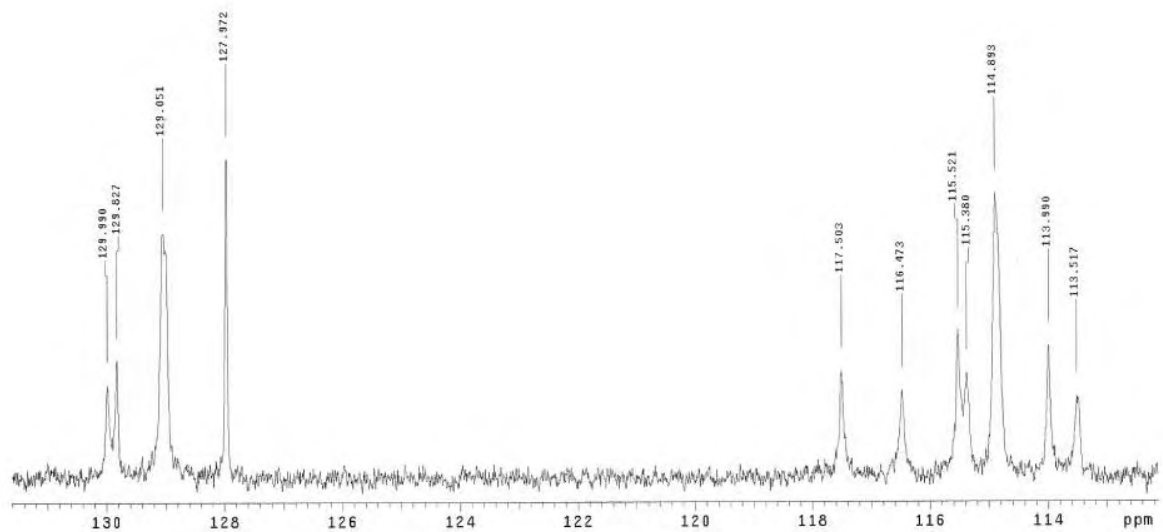

Anexo 103. Ampliação do espectro de RMN de ${ }^{13} \mathrm{C}$ da substância 11. $\left(125 \mathrm{MHz}-\mathrm{DMSO}-d_{6}\right)$

Daniara Acoet s11 4 - prep 1 25/05/0

Pulse Sequence: 82 put

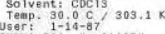

Relax. de lay 0.957 s.

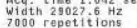

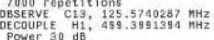

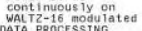

1T.

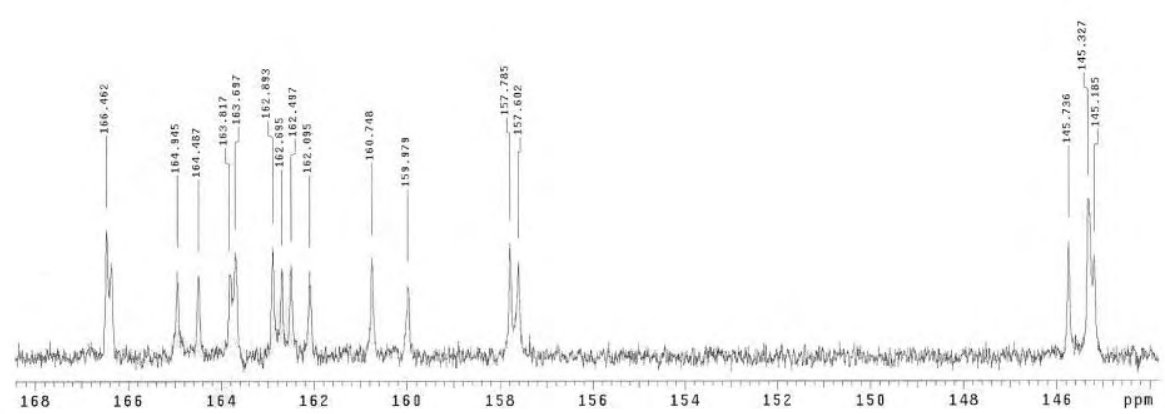

Anexo 104. Ampliação do espectro de RMN de ${ }^{13} \mathrm{C}$ da substância 11. $\left(125 \mathrm{MHz}-\mathrm{DMSO}-d_{6}\right)$ 
Daniara Acott s11 4 - prep 4 25/05/03

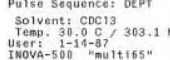

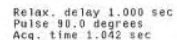

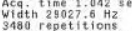

OBSERVE C13, 125.5740287
DECOUPLE

on dur ing acquitsition
off uring delay

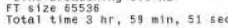

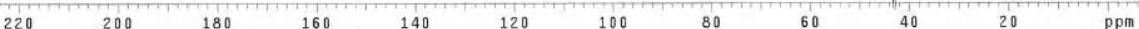

Anexo 105. Espectro de DEPT $135^{\circ}$ da substância 11

$\left(125 \mathrm{MHz}-\mathrm{DMSO}-d_{6}\right)$

Dantara AcoEt s11 4 - prep $425 / 05 / 09$

Pulse Sequence: DEPT

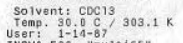

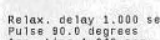

Wuidn $23027.6 \mathrm{~Hz}$

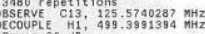

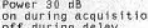

WALTZ -16 modulated
DATA PROCESINO

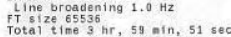

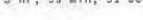

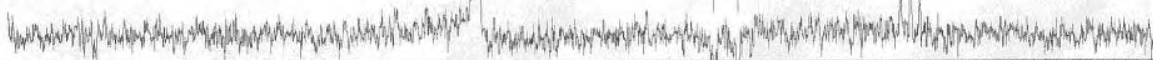

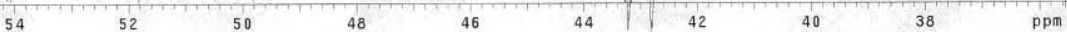

Anexo 106. Ampliação do espectro de DEPT $135^{\circ}$ da substância 11.

$\left(125 \mathrm{MHz}-\mathrm{DMSO}-d_{6}\right)$ 
Daniara AcoEt $\$ 11$ - prep 4 25/05/09

Pulse Sequence: DEPT

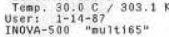

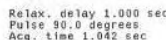

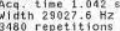

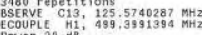

ond

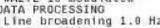

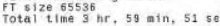

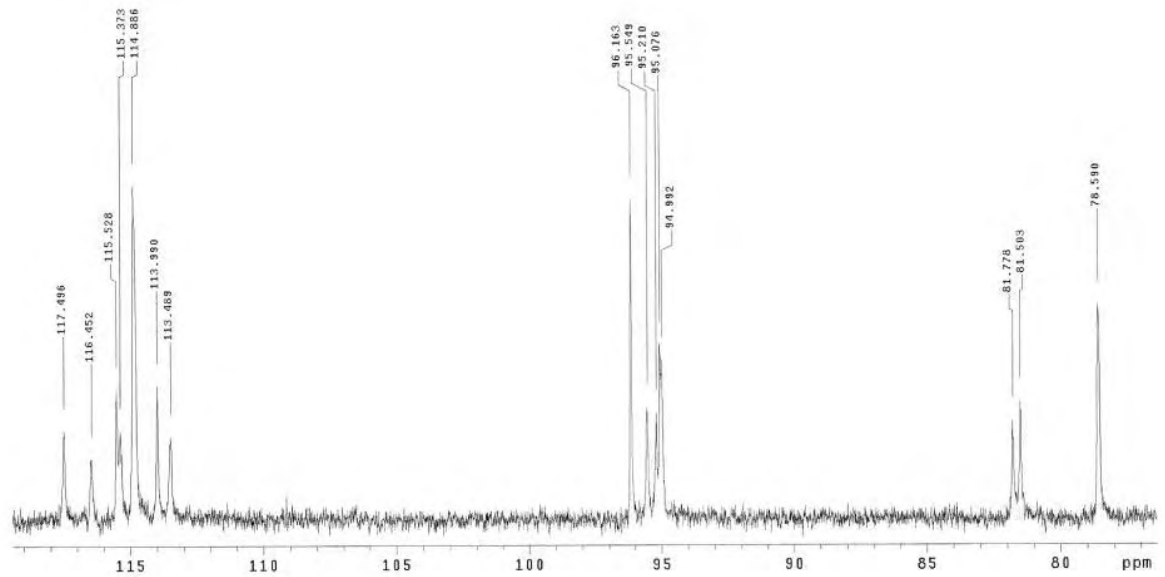

Anexo 107. Ampliação do espectro de DEPT $135^{\circ}$ da substância 11. $\left(125 \mathrm{MHz}-\mathrm{DMSO}-d_{6}\right)$

Dantara ACOEt 511 - Prep 4 25/05/00 Pulse Sequence: gcosy
Solvent: Dhso
Jomo A-500 "multi65"

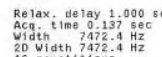

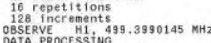

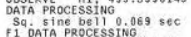

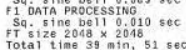

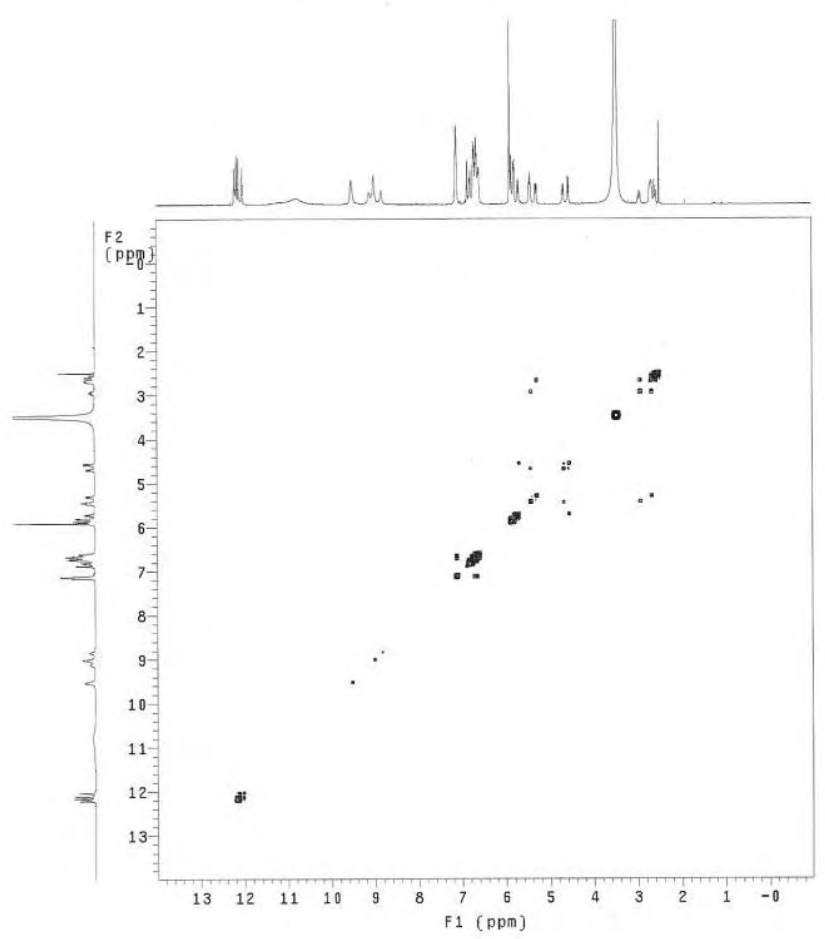

Anexo 108. Mapa de contorno ${ }^{1} \mathrm{H}-{ }^{1} \mathrm{H} g \operatorname{COSY}$ da substância 11. $\left(500 \mathrm{MHz}-\mathrm{DMSO}-d_{6}\right)$ 
Dantara AcoEt s11 4 - prep 4 25/05/09 Pulse Sequence: gcosy
Solvent: Duso

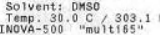

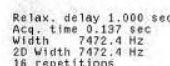
ISERVE

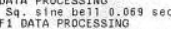

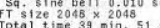

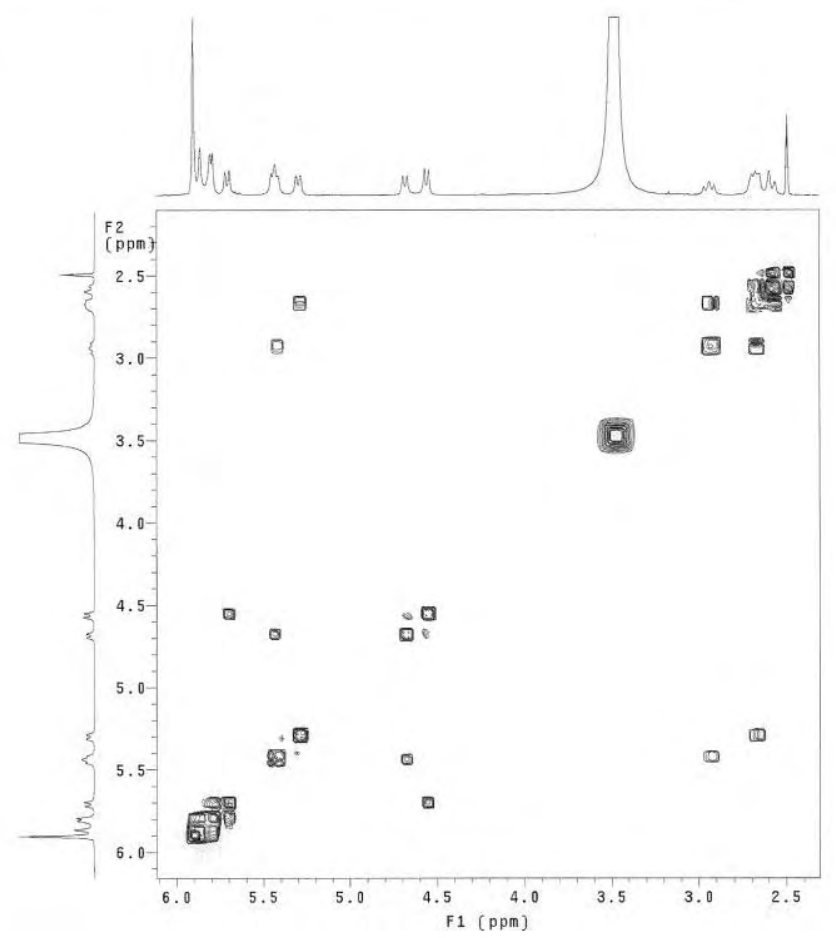

Anexo 109. Ampliação do mapa de contorno ${ }^{1} \mathrm{H}-{ }^{1} \mathrm{H} g \mathrm{COSY}$ da substância 11. $\left(500 \mathrm{MHz}-\mathrm{DMSO}-d_{6}\right)$
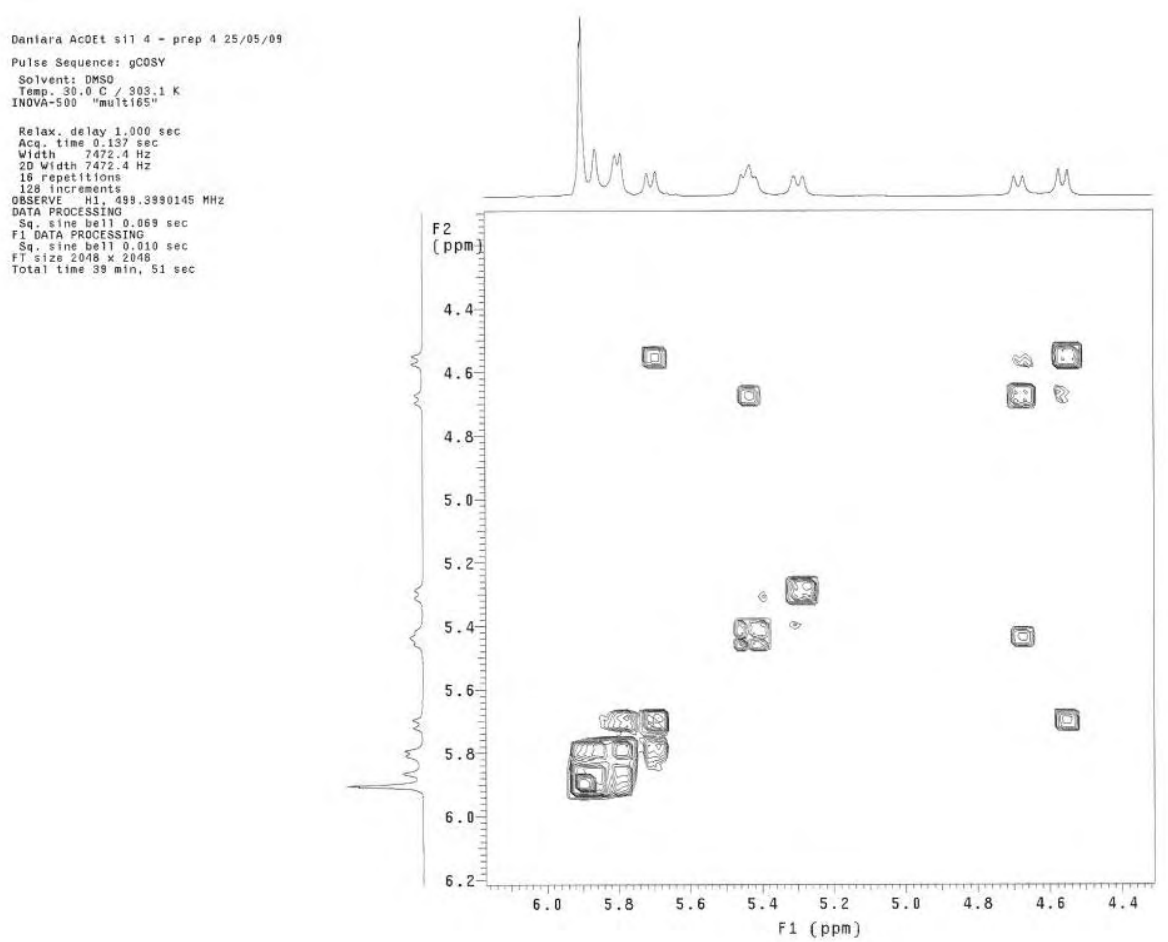

Anexo 110. Ampliação do mapa de contorno ${ }^{1} \mathrm{H}-{ }^{1} \mathrm{H} g \mathrm{COSY}$ da substância 11. $\left(500 \mathrm{MHz}-\mathrm{DMSO}-d_{6}\right)$ 
Daniara ACOEt sil 4 - prep 4 25/05/09 Pulse Sequence: gCosY

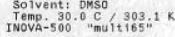
Relax. delay $1,000 \mathrm{sec}$
Acg. time $0.137 \mathrm{sec}$ Widin $7472.4 \mathrm{~Hz}$

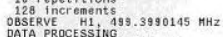

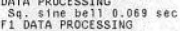

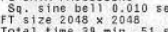

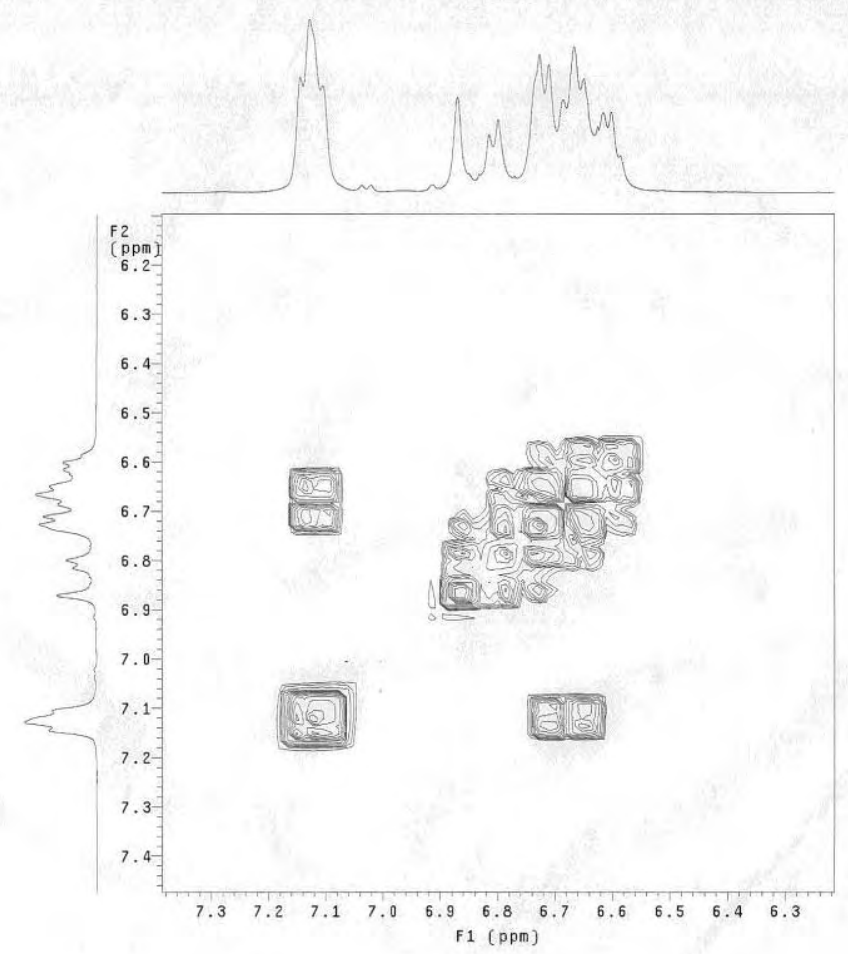

Anexo 111. Ampliação do mapa de contorno ${ }^{1} \mathrm{H}-{ }^{1} \mathrm{H} g \mathrm{COSY}$ da substância 11. $\left(500 \mathrm{MHz}-\mathrm{DMSO}-d_{6}\right)$

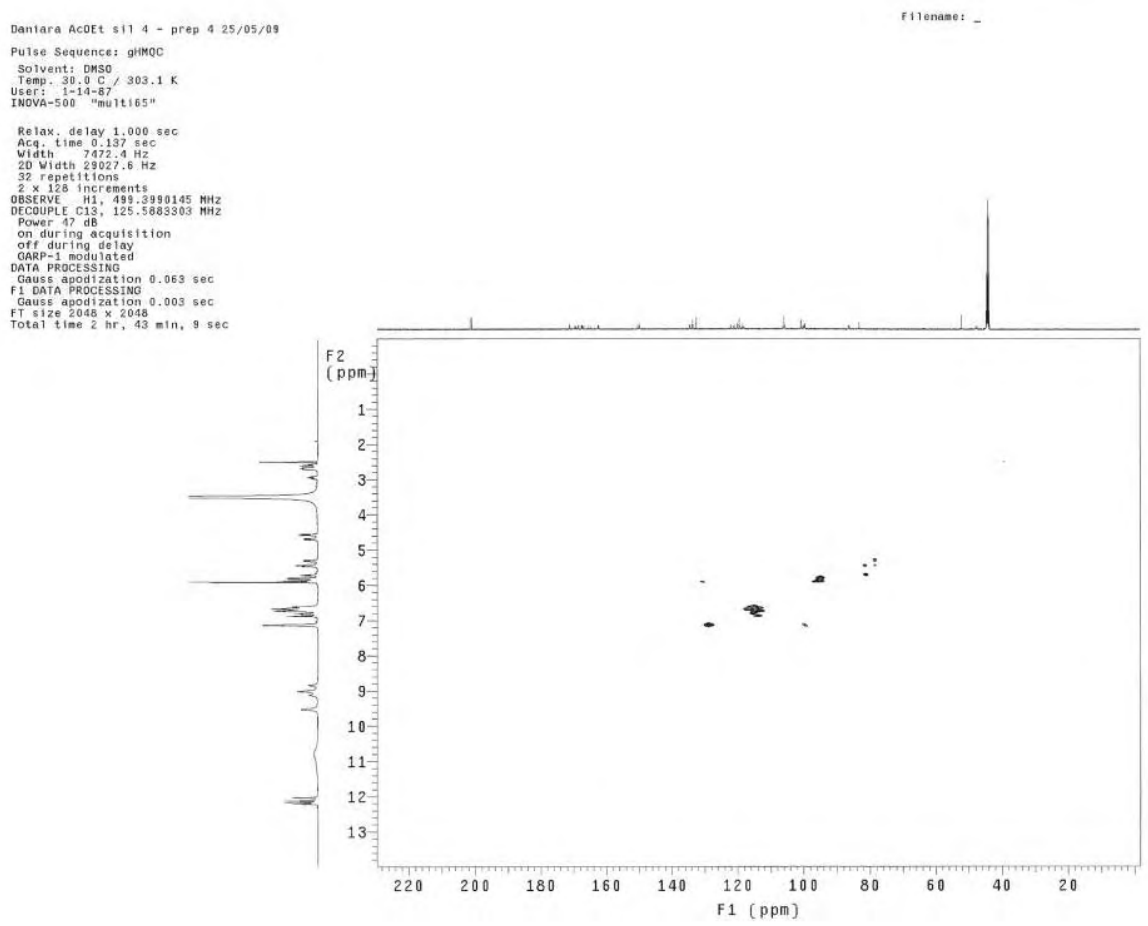

Anexo 112. Mapa de contorno ${ }^{1} \mathrm{H}^{13} \mathrm{C} g \mathrm{HMQC}$ da substância 11.

$$
\text { (500 MHz - DMSO- } d_{6} \text { ) }
$$


Dantara ACOEt s11 4- prep 4 25/05/0

Pulse Sequencer grmoc

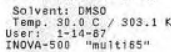

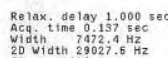

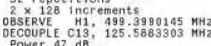

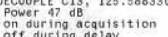

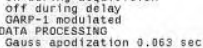

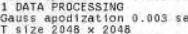

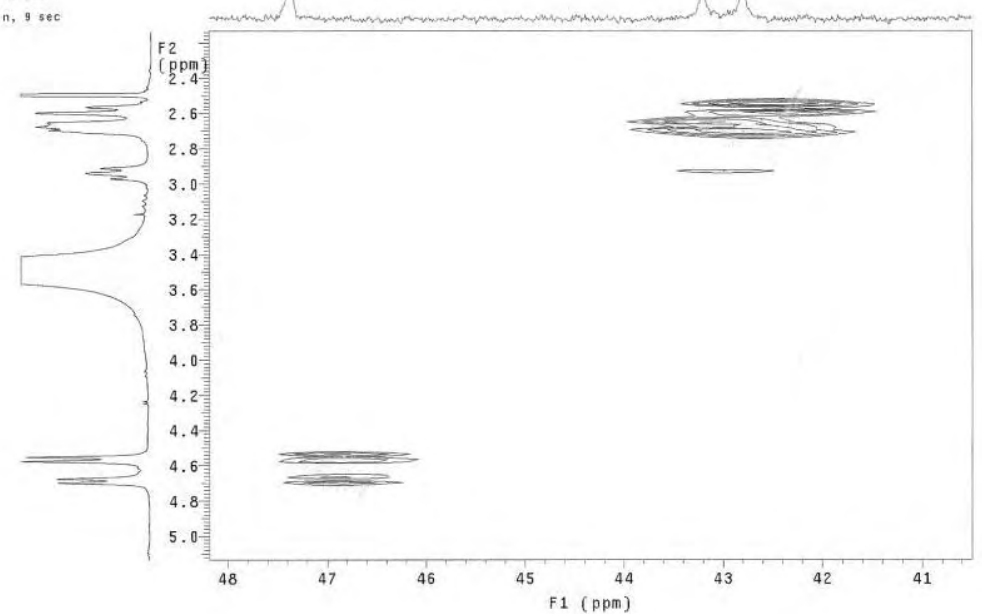

Anexo 113. Ampliação do mapa de contorno ${ }^{1} \mathrm{H}-{ }^{13} \mathrm{C} g \mathrm{HMQC}$ da substância 11 $\left(500 \mathrm{MHz}-\mathrm{DMSO}-d_{6}\right)$

Daniara ACOEt sil 4 - prep 4 25/05/09

Pulse Sequence: ghroc

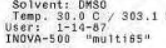

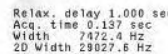

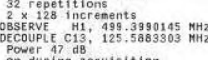

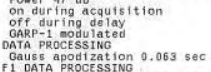

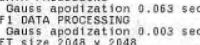

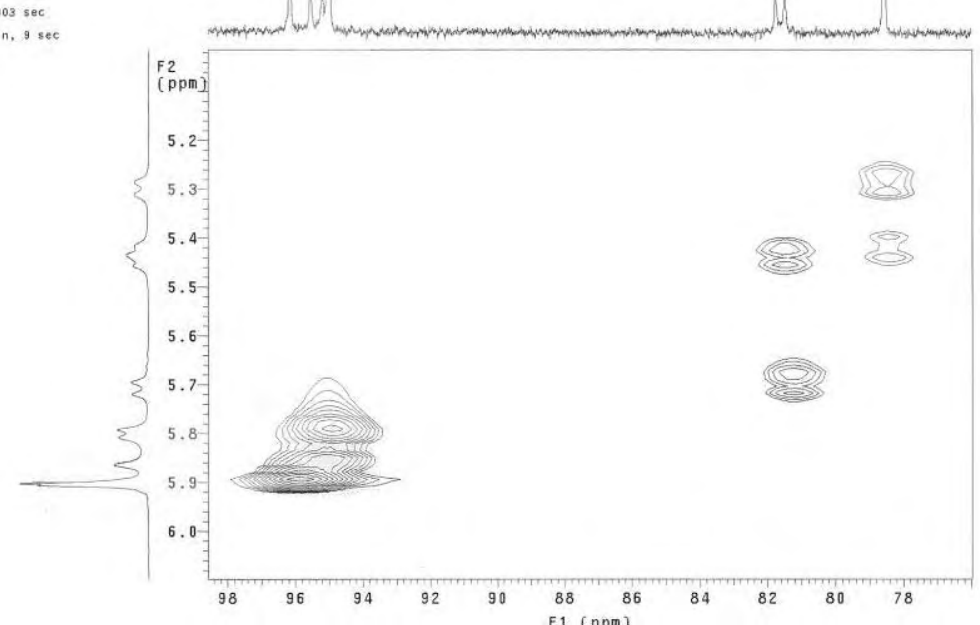

Anexo 114. Ampliação do mapa de contorno ${ }^{1} \mathrm{H}-{ }^{13} \mathrm{C} g \mathrm{HMQC}$ da substância 11.

$\left(500 \mathrm{MHz}-\mathrm{DMSO}-d_{6}\right)$ 
Danlara Acott s11 4 - prep 4 25/05/09

Pulse Sequence: ghrroc
Solvent: onso

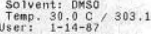

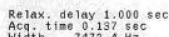

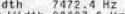

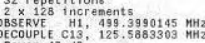

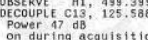

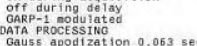

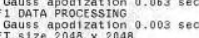

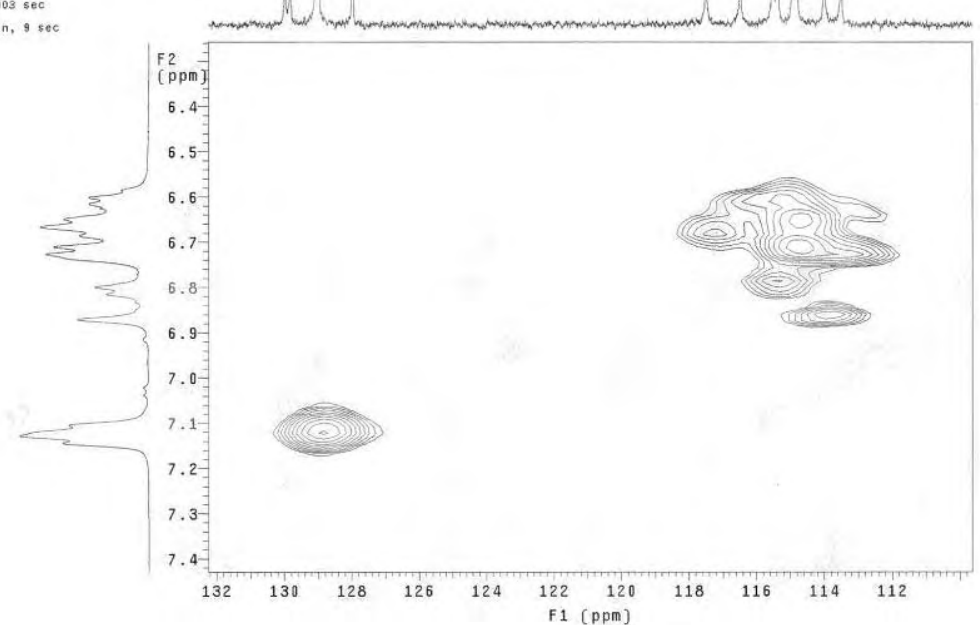

Anexo 115. Ampliação do mapa de contorno ${ }^{1} \mathrm{H}-{ }^{13} \mathrm{C} g \mathrm{HMQC}$ da substância 11. $\left(500 \mathrm{MHz}-\mathrm{DMSO}-d_{6}\right)$

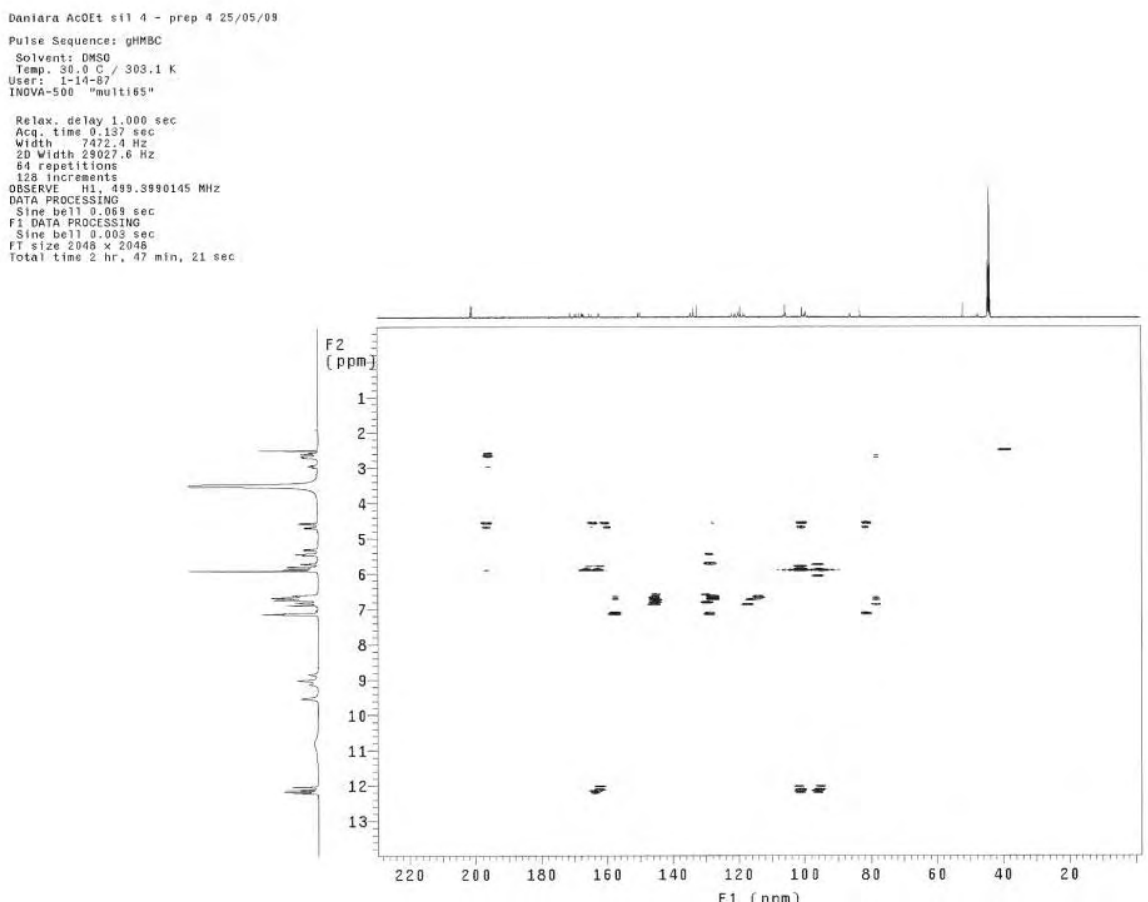

Anexo 116. Mapa de contorno ${ }^{1} \mathrm{H}-{ }^{13} \mathrm{C} g \mathrm{HMBC}$ da substância 11.

$$
\left(500 \mathrm{MHz}-\text { DMSO- } d_{6}\right)
$$




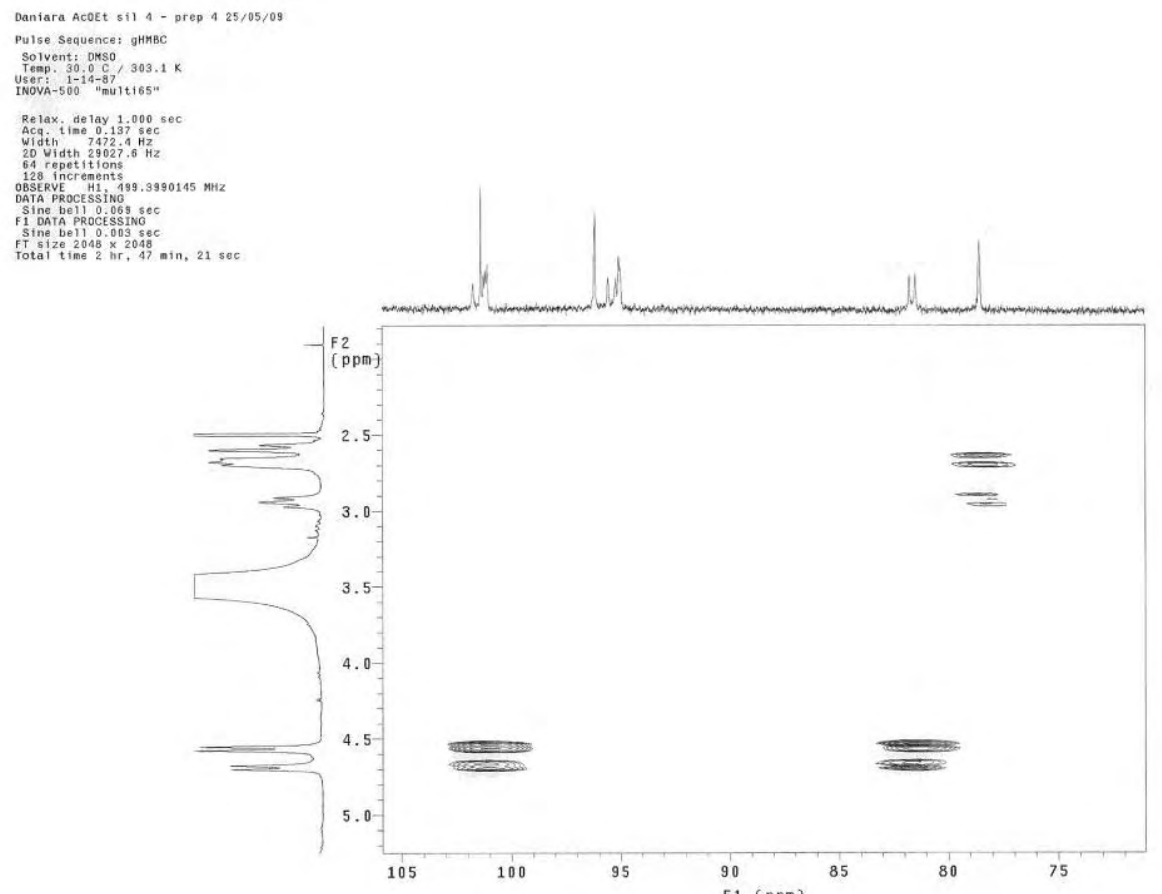

Anexo 117. Ampliação do mapa de contorno ${ }^{1} \mathrm{H}_{-}{ }^{13} \mathrm{C} g \mathrm{HMBC}$ da substância 11. $\left(500 \mathrm{MHz}-\mathrm{DMSO}-d_{6}\right)$

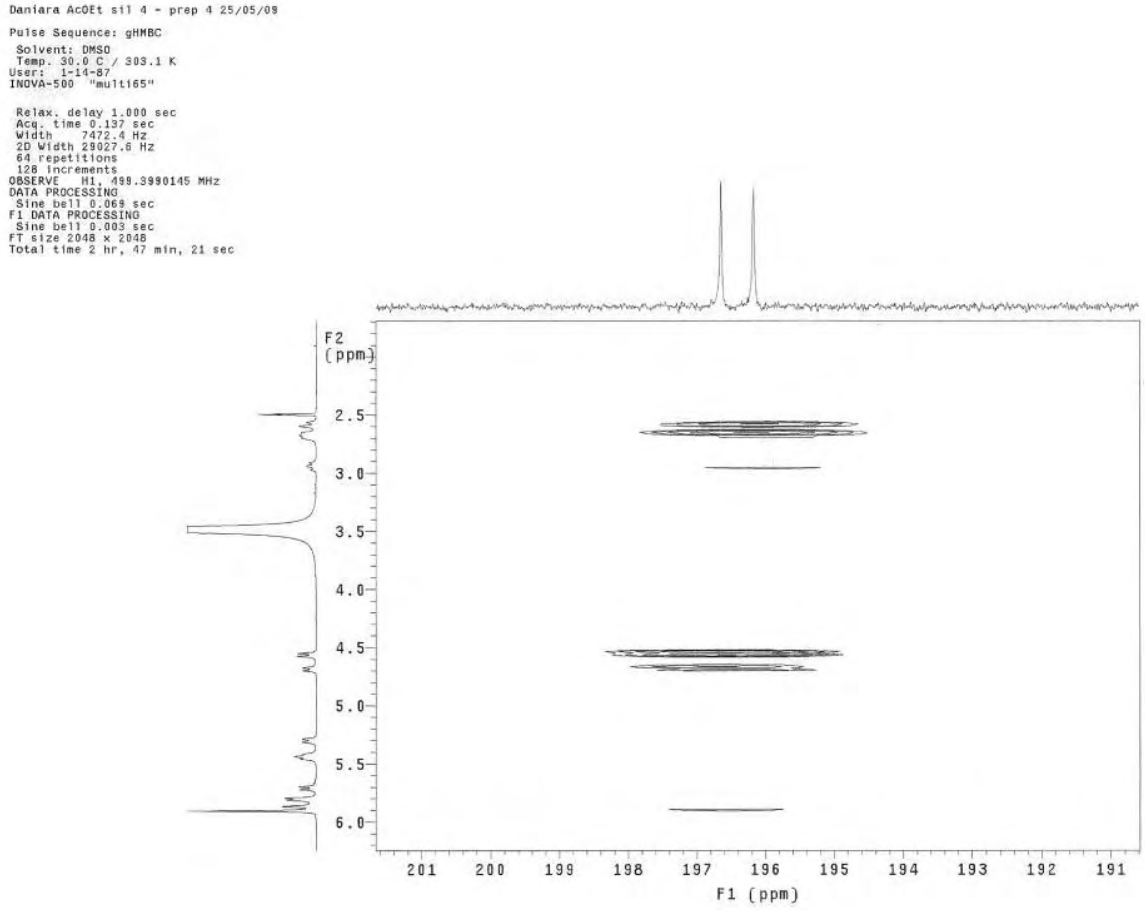

Anexo 118. Ampliação do mapa de contorno ${ }^{1} \mathrm{H}_{-}{ }^{13} \mathrm{C} g \mathrm{HMBC}$ da substância 11. $\left(500 \mathrm{MHz}-\mathrm{DMSO}-d_{6}\right)$ 
Daniara ACOEt sil 4 - prep 4 25/05/09

Puise Sequence: gHMBC
Solvent: 0 MHSO

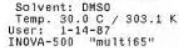

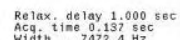

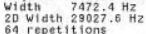

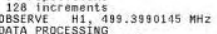

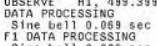

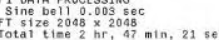

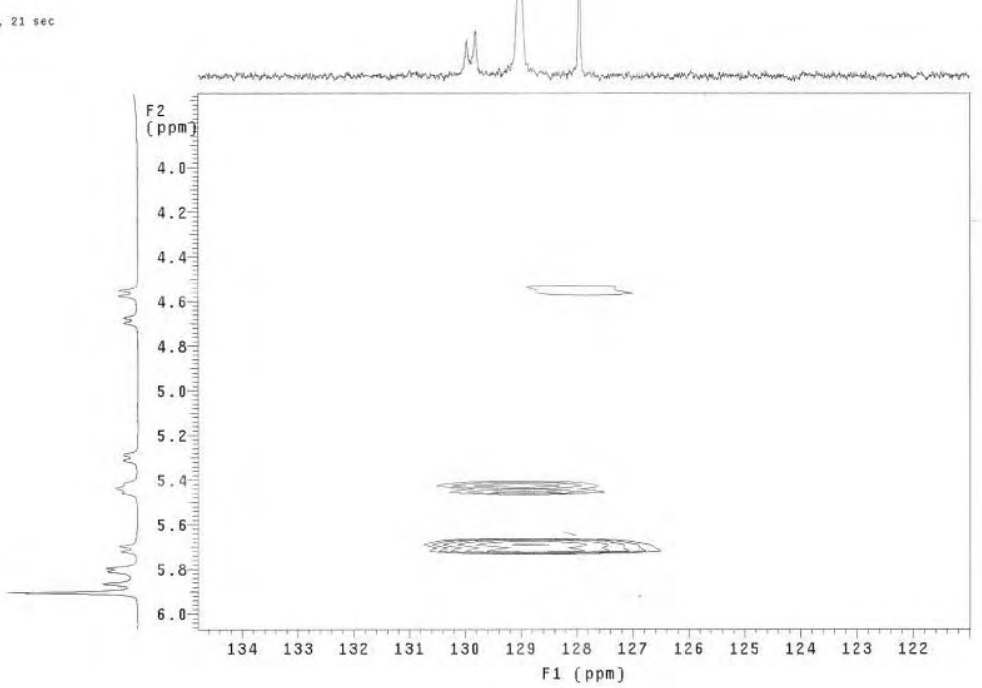

Anexo 119. Ampliação do mapa de contorno ${ }^{1} \mathrm{H}-{ }^{13} \mathrm{C} g \mathrm{HMBC}$ da substância 11.

$$
\left(500 \mathrm{MHz}-\mathrm{DMSO}-d_{6}\right)
$$

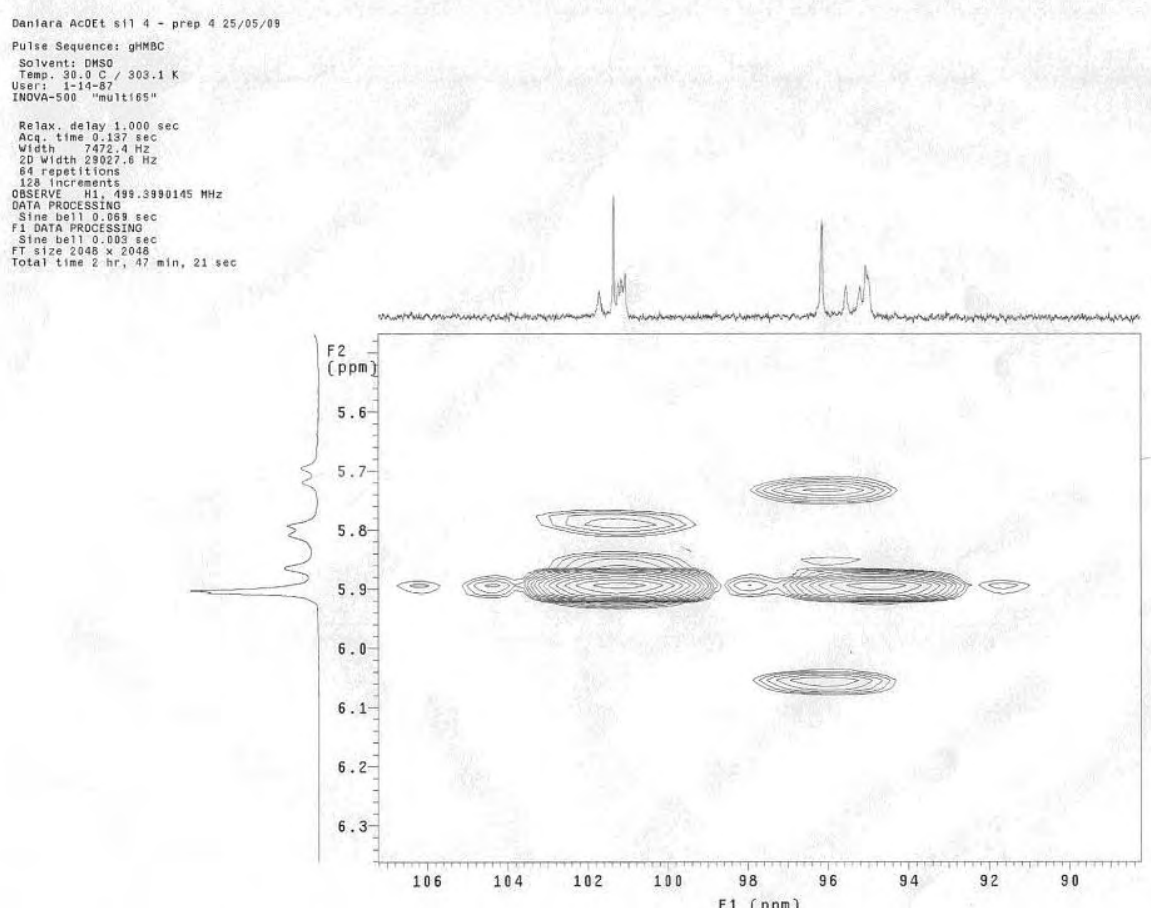

Anexo 120. Ampliação do mapa de contorno ${ }^{1} \mathrm{H}-{ }^{13} \mathrm{C} g \mathrm{HMBC}$ da substância 11.

$$
\left(500 \mathrm{MHz}-\mathrm{DMSO}-d_{6}\right)
$$


Dantara Acoet sil 4 - prep 4 25/05/09

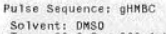

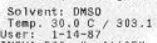

-

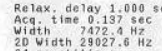

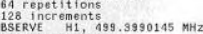

D.
Sine

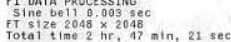

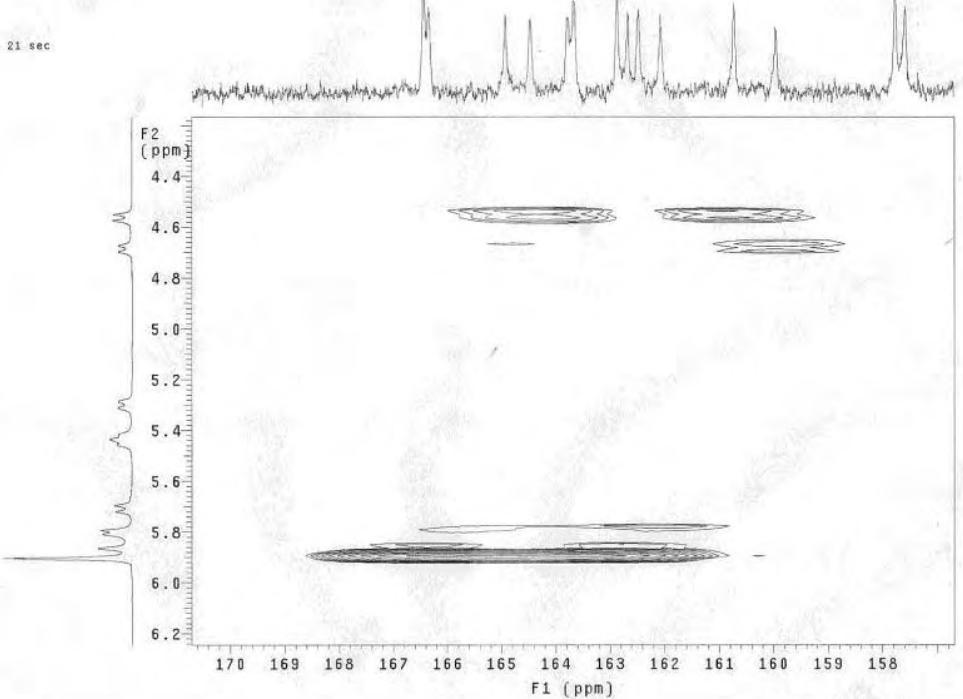

Anexo 121. Ampliação do mapa de contorno ${ }^{1} \mathrm{H}-{ }^{13} \mathrm{C} g \mathrm{HMBC}$ da substância 11.

$\left(500 \mathrm{MHz}-\mathrm{DMSO}-d_{6}\right)$

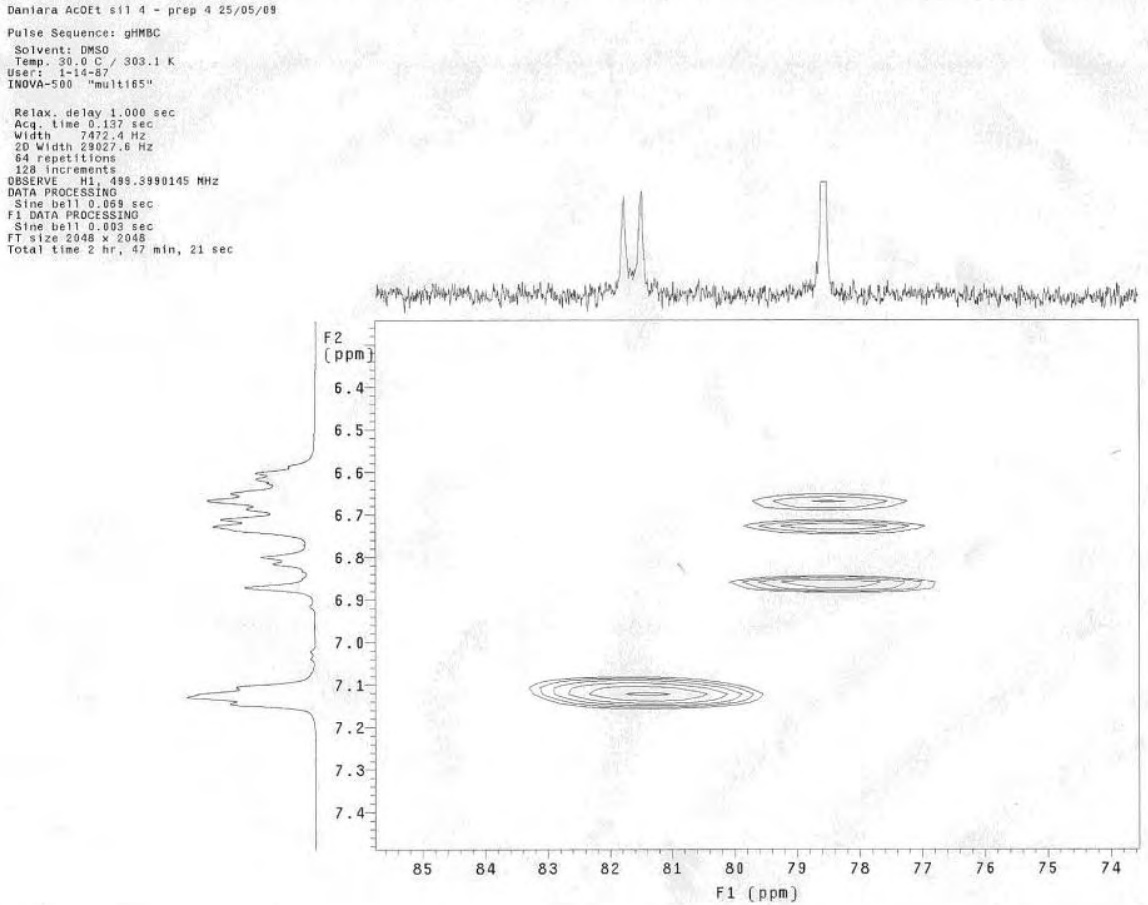

Anexo 122. Ampliação do mapa de contorno ${ }^{1} \mathrm{H}_{-}{ }^{13} \mathrm{C} g \mathrm{HMBC}$ da substância 11. $\left(500 \mathrm{MHz}-\mathrm{DMSO}-d_{6}\right)$ 


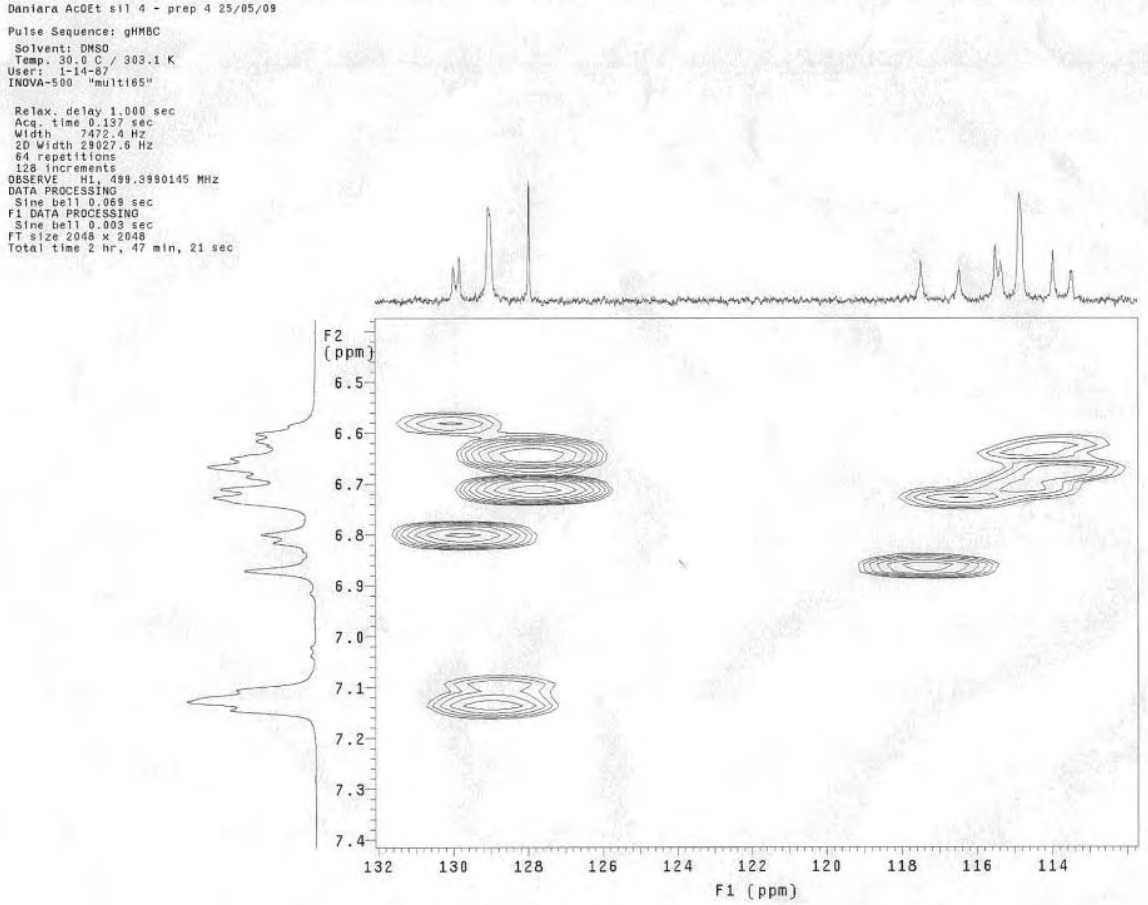

Anexo 123. Ampliação do mapa de contorno ${ }^{1} \mathrm{H}_{-}{ }^{13} \mathrm{C} g \mathrm{HMBC}$ da substância 11.

$\left(500 \mathrm{MHz}-\mathrm{DMSO}-d_{6}\right)$

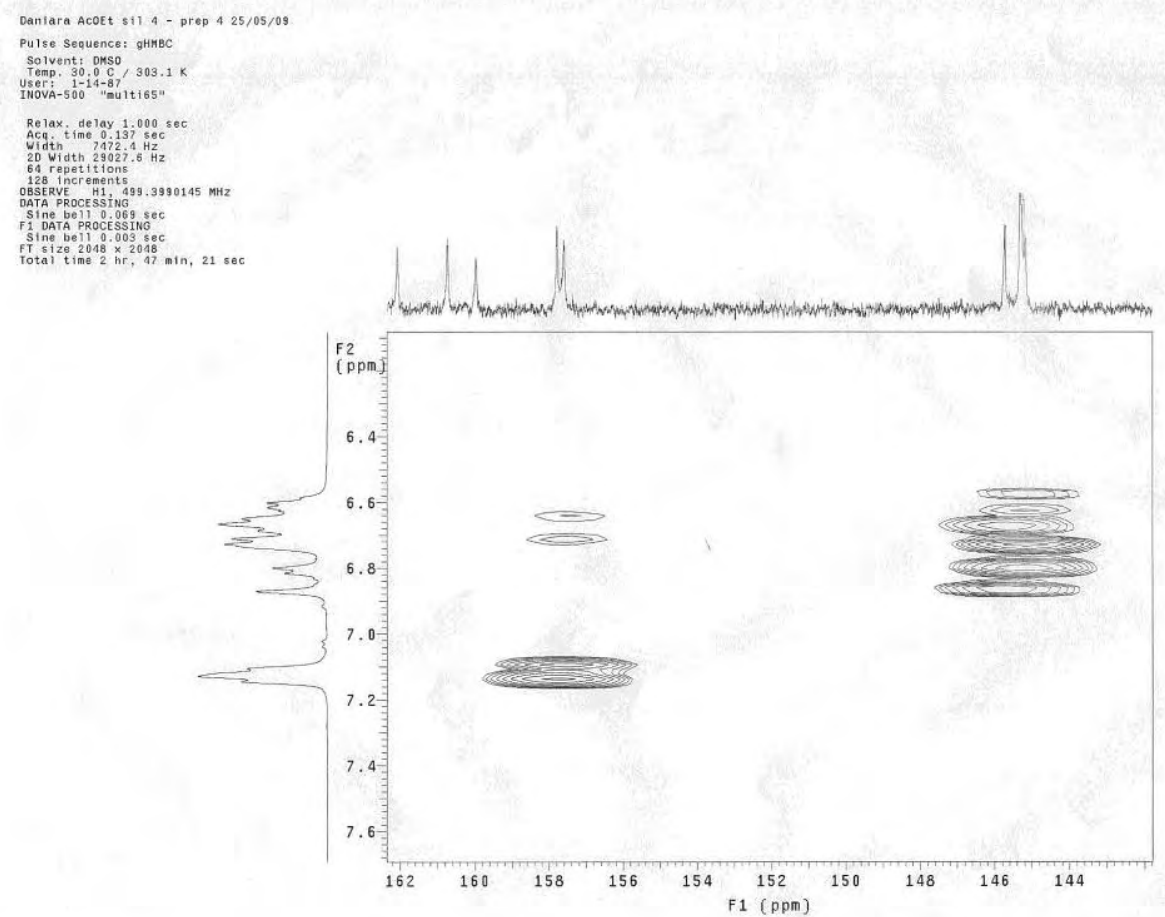

Anexo 124. Ampliação do mapa de contorno ${ }^{1} \mathrm{H}-{ }^{13} \mathrm{C} g \mathrm{HMBC}$ da substância 11.

$$
\left(500 \mathrm{MHz}-\mathrm{DMSO}-d_{6}\right)
$$


Gantara Acoet st1 4 - prep 4 25/05/09

Pulse Sequence: grimBC

Temp. $30.0 \mathrm{C} / 303.1 \mathrm{~K}$

Vun-500 "muititis5"

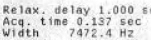

Width $7972,4 \mathrm{~Hz}$
20 Width $29027.6 \mathrm{H}$
64 repetitions

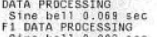

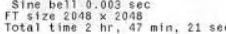

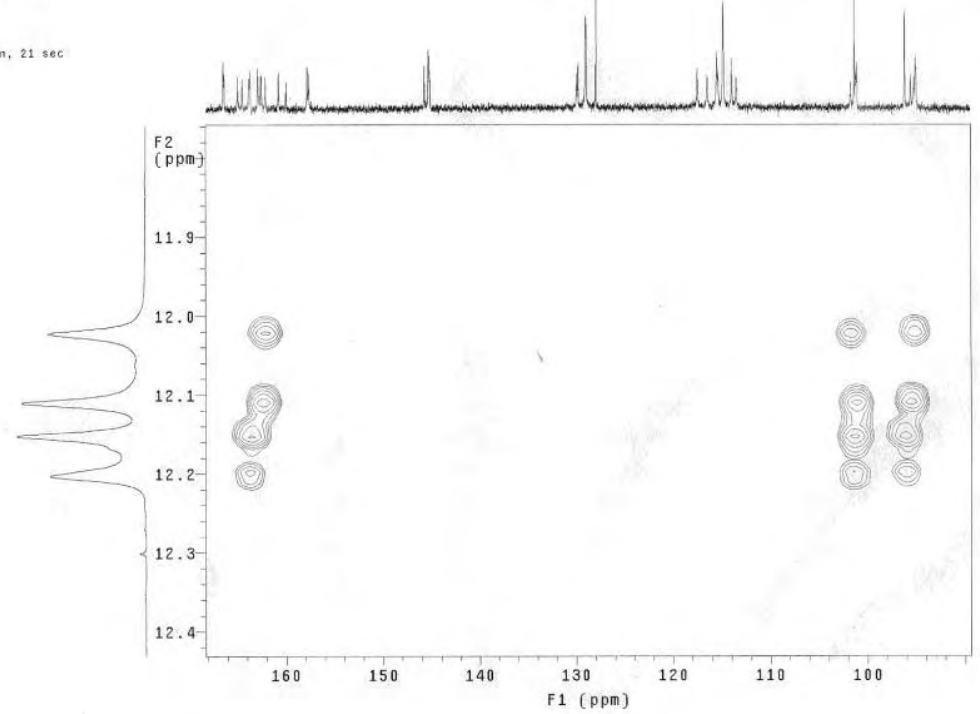

Anexo 125. Ampliação do mapa de contorno ${ }^{1} \mathrm{H}-{ }^{13} \mathrm{C} g \mathrm{HMBC}$ da substância 11.

$\left(500 \mathrm{MHz}-\mathrm{DMSO}-d_{6}\right)$

Daniara Acoet sil 4 - prep 9 08/07/0

Pulse Sequence: $82 \mathrm{put}$

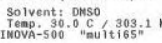

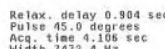

16 repetitions
OSSERV

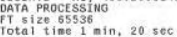

rotal time $1 \mathrm{~min}, 20 \mathrm{sec}$

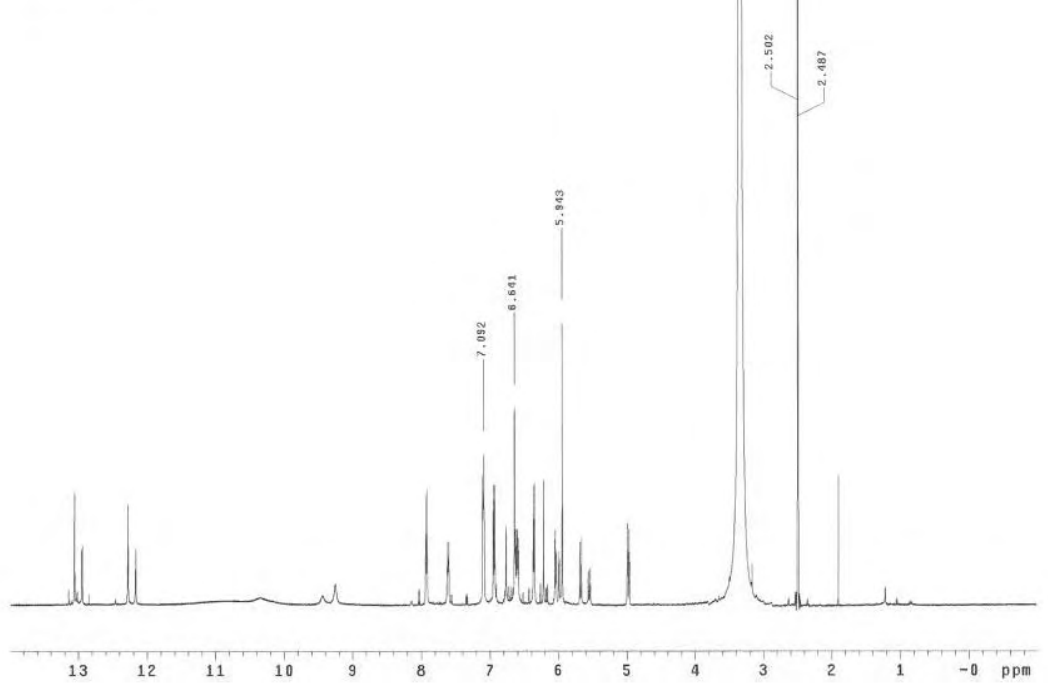

Anexo 126. Espectro de RMN de ${ }^{1} \mathrm{H}$ da substância 12

$\left(500 \mathrm{MHz}-\mathrm{DMSO}-d_{6}\right)$ 
Deniara AcoEt s11 4 - prep $908 / 07 / 09$

Pulso Sequencet sepur

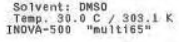

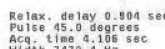

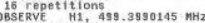

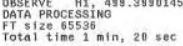

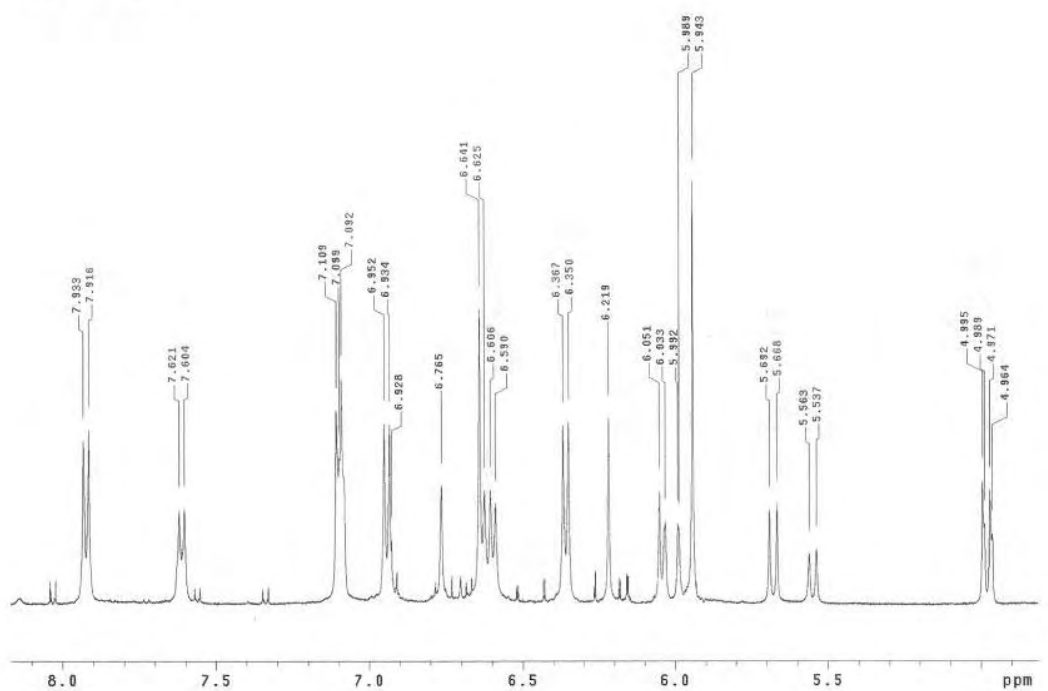

Anexo 127. Ampliação do espectro de RMN de ${ }^{1} \mathrm{H}$ da substância 12. $\left(500 \mathrm{MHz}-\mathrm{DMSO}-d_{6}\right)$

Daniara Acoet sil A - prep 9 o8/07/08

Pulse Sequence: s2put
Solvent: Dkso

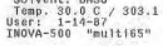

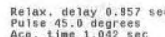

Acig ${ }^{2}$ time 1.0425

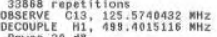

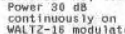

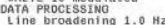

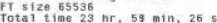
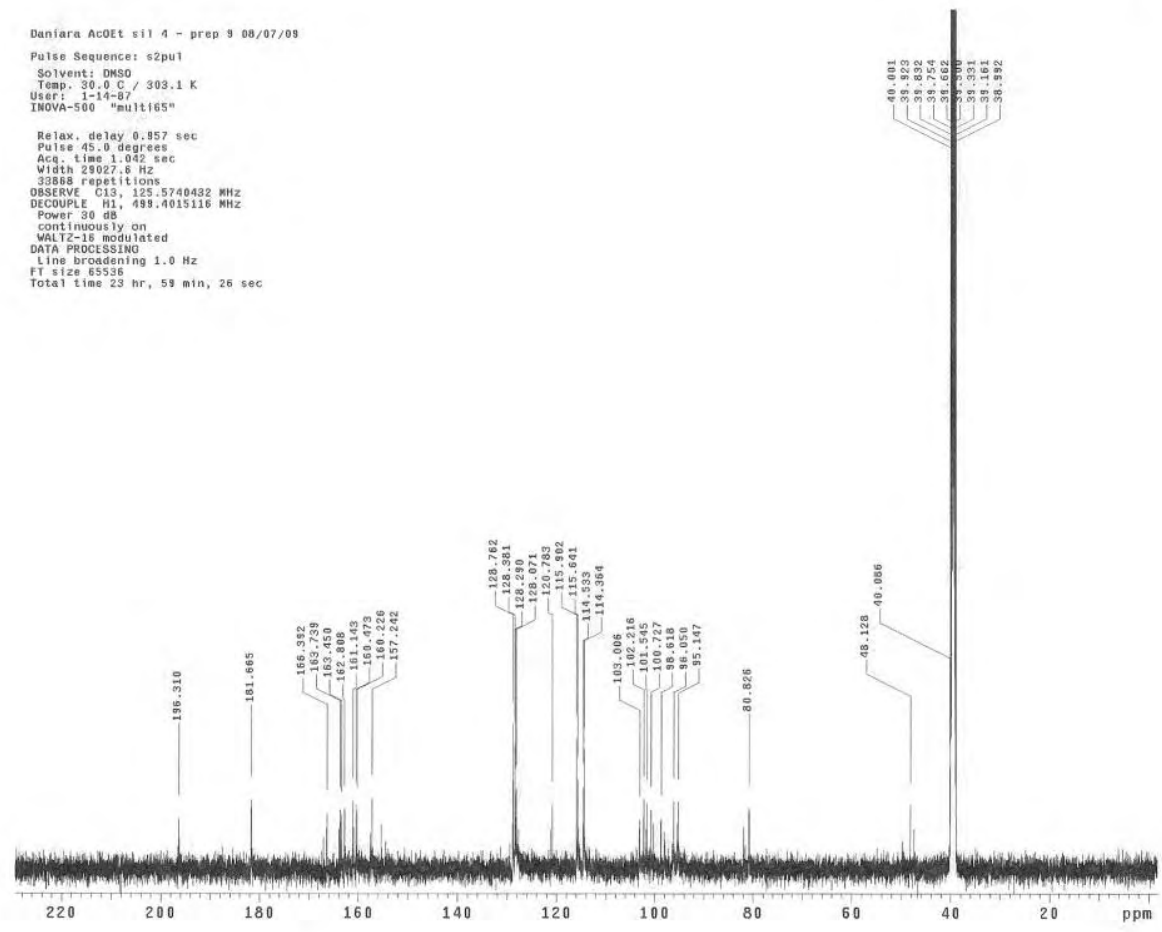

Anexo 128. Espectro de RMN de ${ }^{13} \mathrm{C}$ da substância 12.

$\left(125 \mathrm{MHz}-\mathrm{DMSO}-d_{6}\right)$ 
Pulse Sequence: 52 pur

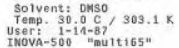

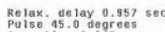

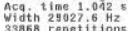

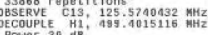

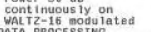

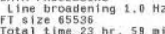

$26 \mathrm{sec}$

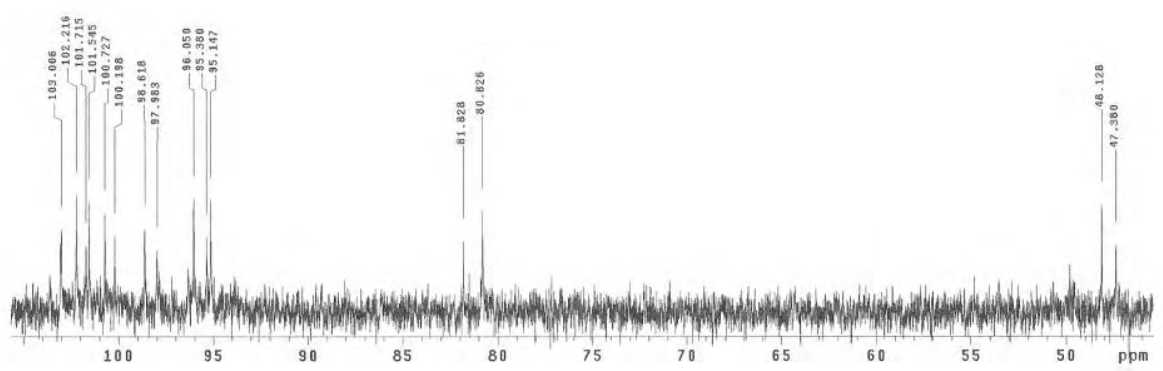

Anexo 129. Ampliação do espectro de $\mathrm{RMN}$ de ${ }^{13} \mathrm{C}$ da substância 12 $\left(125 \mathrm{MHz}-\mathrm{DMSO}-d_{6}\right)$

Danlara Acoet sil 4 - prep 9 08/07/0

Pulse Sequence: s2pul

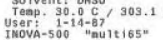

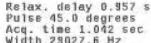

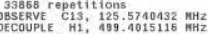

Pover 30 dB
continuous Iy on
WALI Tz-16 modulated

ting troudening $1.0 \mathrm{~Hz}$

Tr 5 ize 65536
rotal time

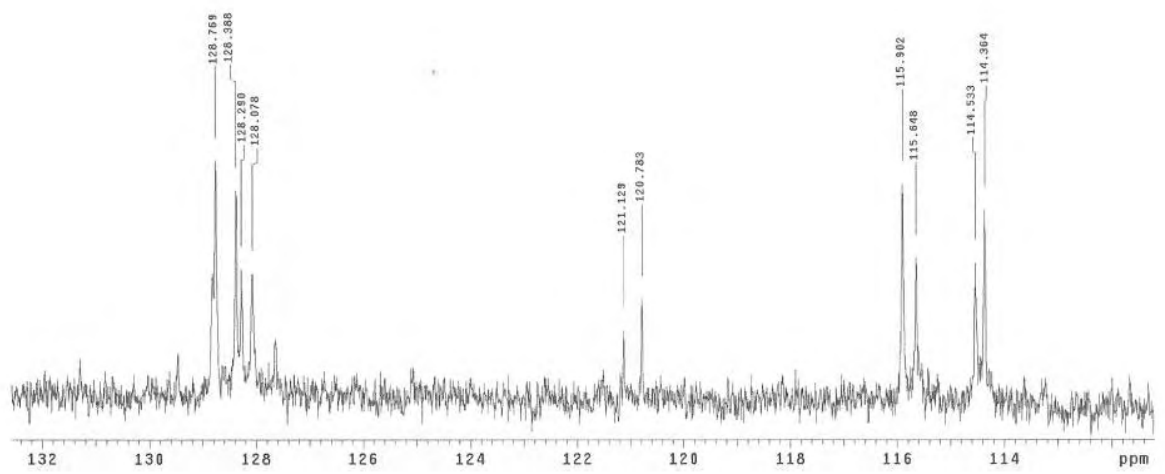

Anexo 130. Ampliação do espectro de RMN de ${ }^{13} \mathrm{C}$ da substância 12. $\left(125 \mathrm{MHz}-\mathrm{DMSO}-d_{6}\right)$ 
Daniara Acoet s11 4 - prep $908 / 07 / 09$

Pulse Sequence: s2pur
solvent: Dyso

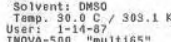

Relax. gelay $0.957 \mathrm{sec}$
Pulse

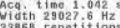

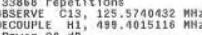

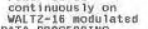

Line broadening 1.0

$\min , 26 \mathrm{sec}$

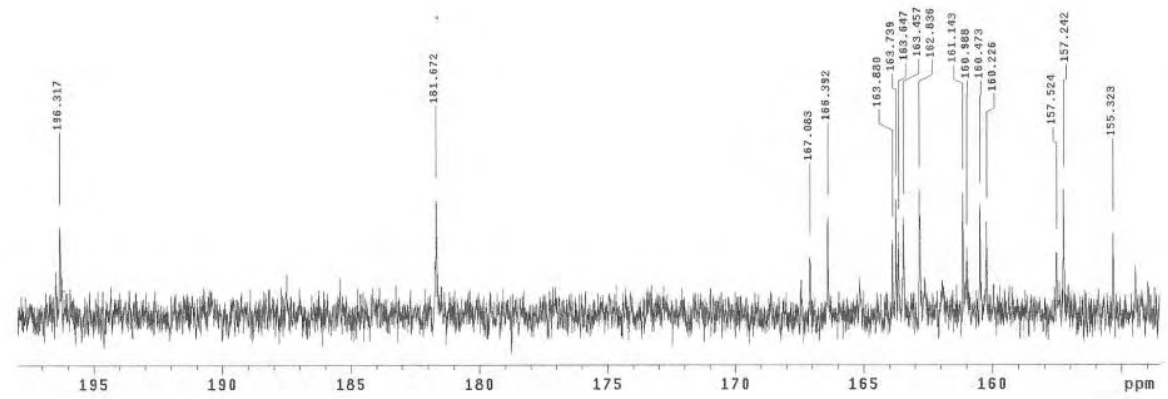

Anexo 131. Ampliação do espectro de RMN de ${ }^{13} \mathrm{C}$ da substância 12. $\left(125 \mathrm{MHz}-\mathrm{DMSO}-d_{6}\right)$

Dantara ACOEt si1 4 - prep $908 / 07 / 0$ s Pulse Sequence: gcosy

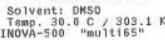

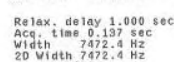

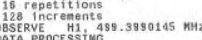

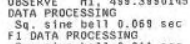

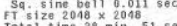

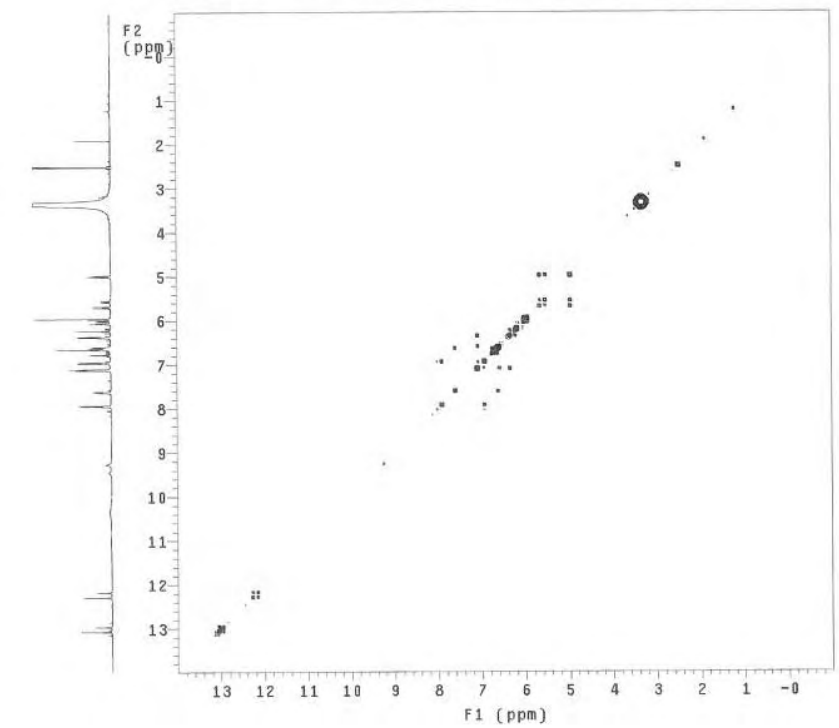

Anexo 132. Mapa de contorno ${ }^{1} \mathrm{H}-{ }^{1} \mathrm{H} g \operatorname{COSY}$ da substância 12.

$\left(500 \mathrm{MHz}-\mathrm{DMSO}-d_{6}\right)$ 
Dantara Acott st1 4- prep $808 / 07 / 09$

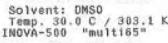

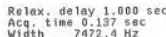

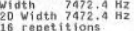

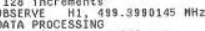

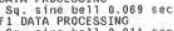

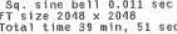

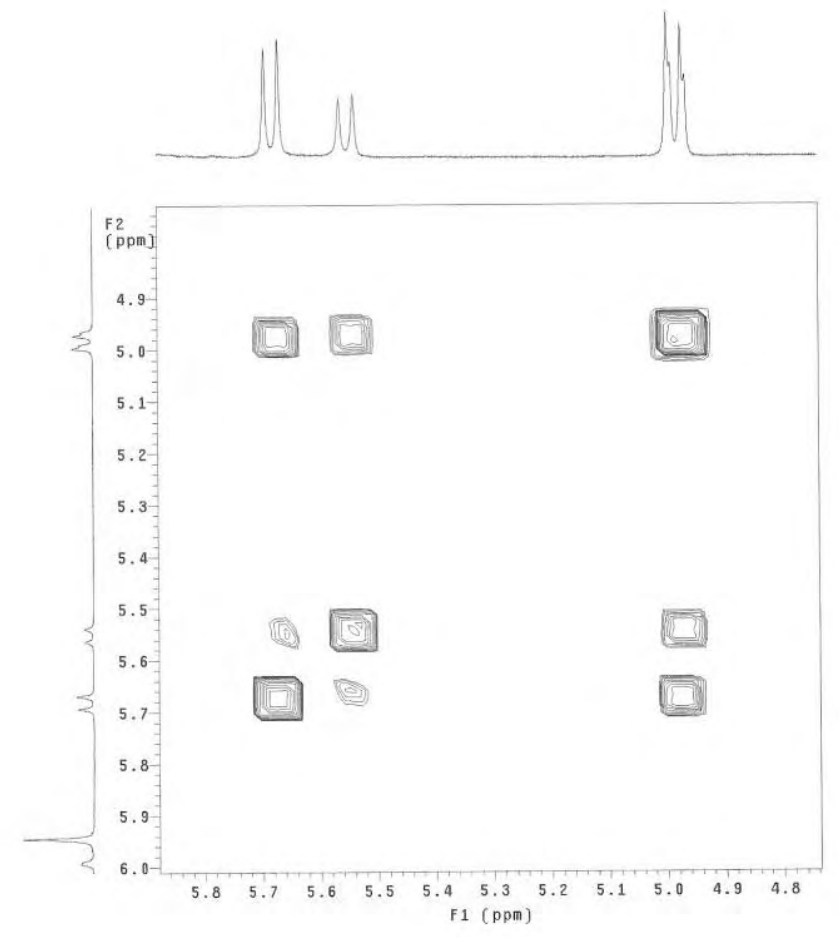

Anexo 133. Ampliação do mapa de contorno ${ }^{1} \mathrm{H}-{ }^{1} \mathrm{H} g \mathrm{COSY}$ da substância 12.

$\left(500 \mathrm{MHz}-\mathrm{DMSO}-d_{6}\right)$

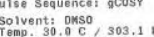

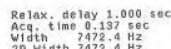

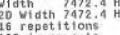

OBSERVE H1 499.3990145 HHZ

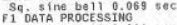

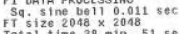

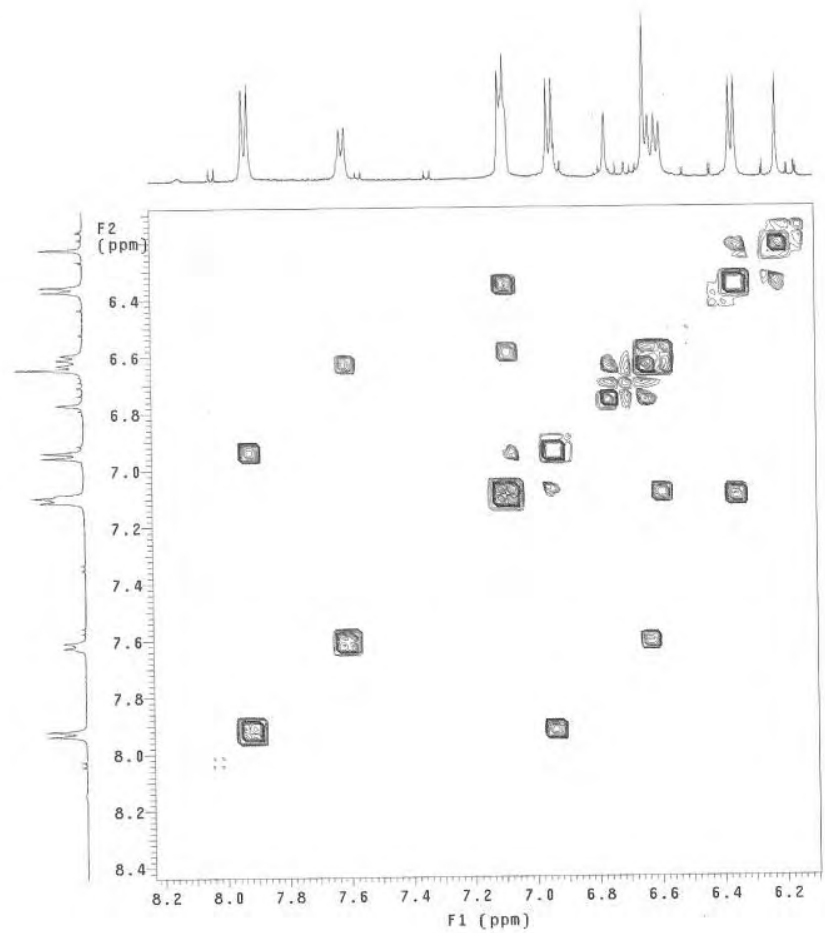

Anexo 134. Ampliação do mapa de contorno ${ }^{1} \mathrm{H}-{ }^{1} \mathrm{H} g \mathrm{COSY}$ da substância 12.

$\left(500 \mathrm{MHz}-\mathrm{DMSO}-d_{6}\right)$ 


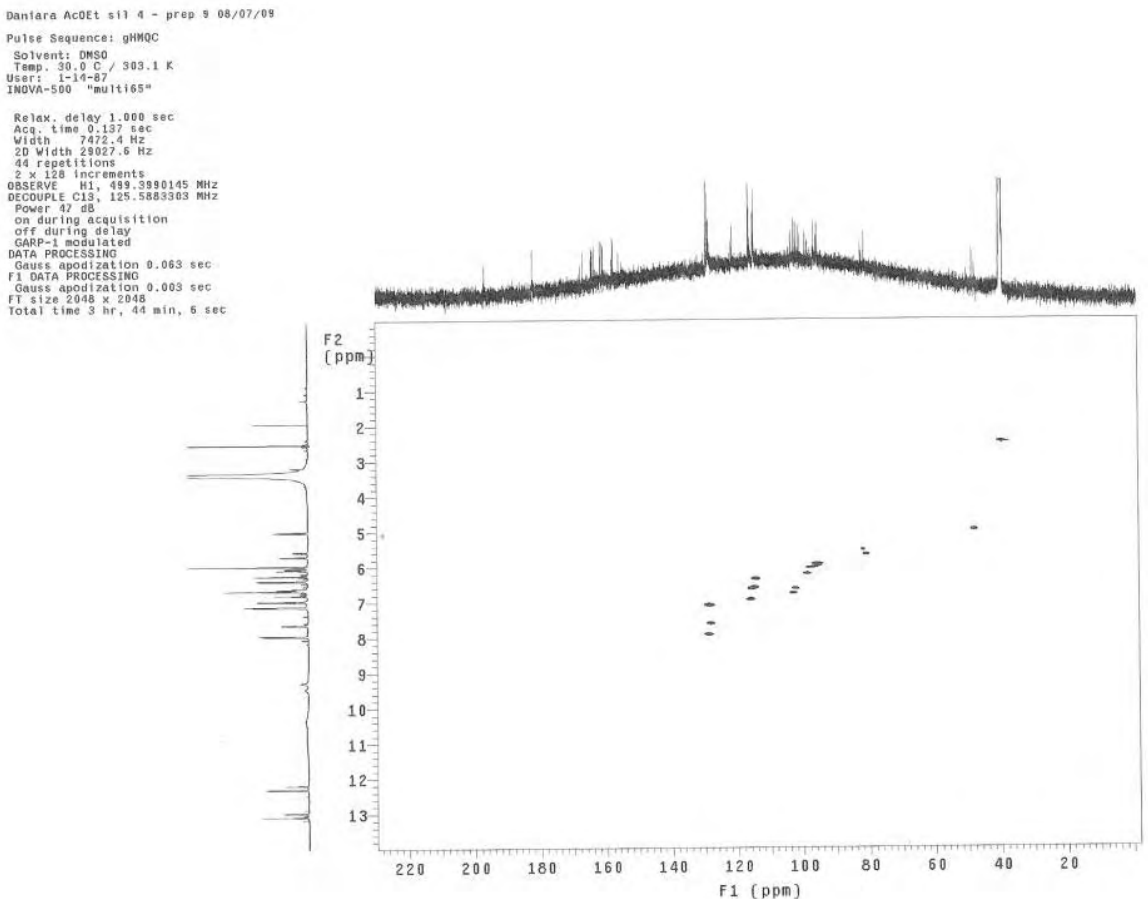

Anexo 135. Mapa de contorno ${ }^{1} \mathrm{H}^{-13} \mathrm{C} g \mathrm{HMQC}$ da substância 12.

$$
\left(500 \mathrm{MHz}-\mathrm{DMSO}-d_{6}\right)
$$

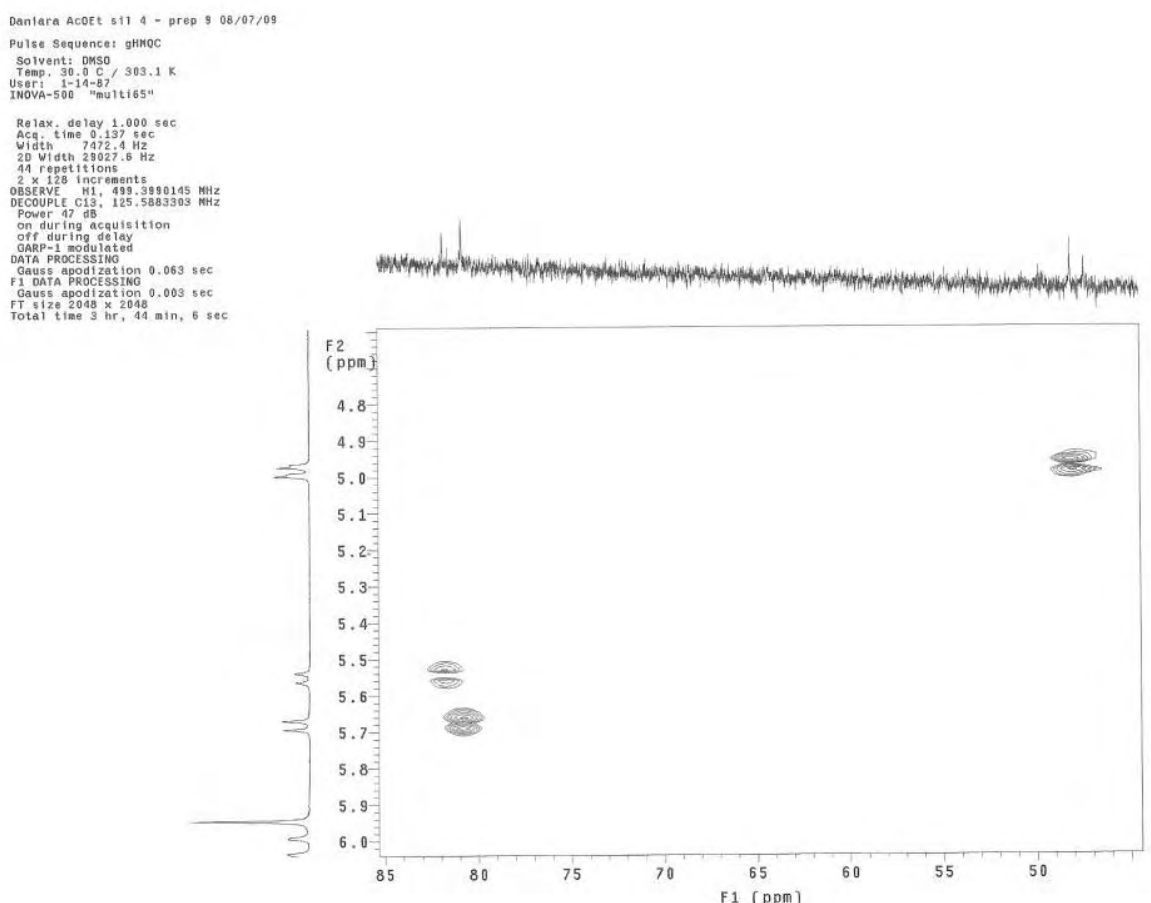

Anexo 136. Ampliação do mapa de contorno ${ }^{1} \mathrm{H}^{-13} \mathrm{C} g \mathrm{HMQC}$ da substância 12.

$$
\left(500 \mathrm{MHz}-\mathrm{DMSO}-d_{6}\right)
$$


Daniara Acoet s11 A - prep $308 / 07 / 09$

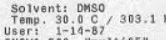

Relax, delay 1,000 sec

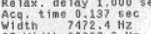

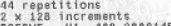

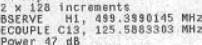

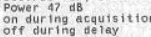

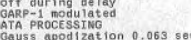

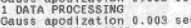

Total time 3 hr. $44 \mathrm{~min}, 6 \mathrm{sec}$
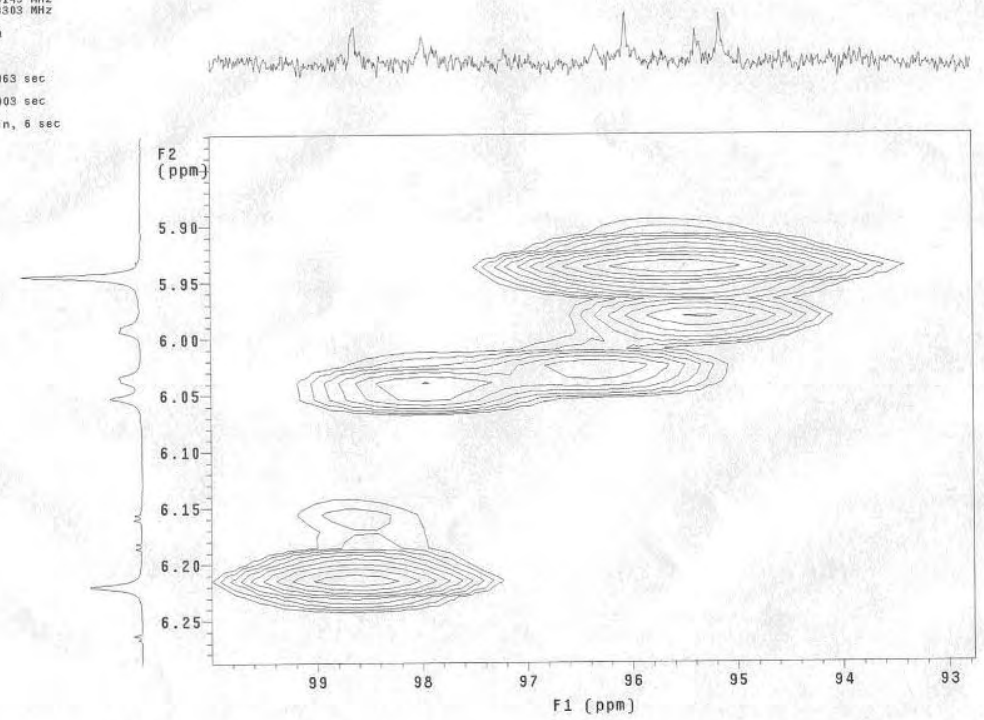

Anexo 137. Ampliação do mapa de contorno ${ }^{1} \mathrm{H}^{-13} \mathrm{C} g \mathrm{HMQC}$ da substância 12.

$$
\left(500 \mathrm{MHz}-\mathrm{DMSO}-d_{6}\right)
$$

Daniara ACOEt s11 4 - prep 9 08/07/09

Pulse Sequence: GHHoc
Solvent: Douso

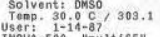

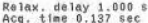

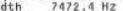

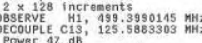

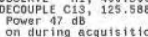
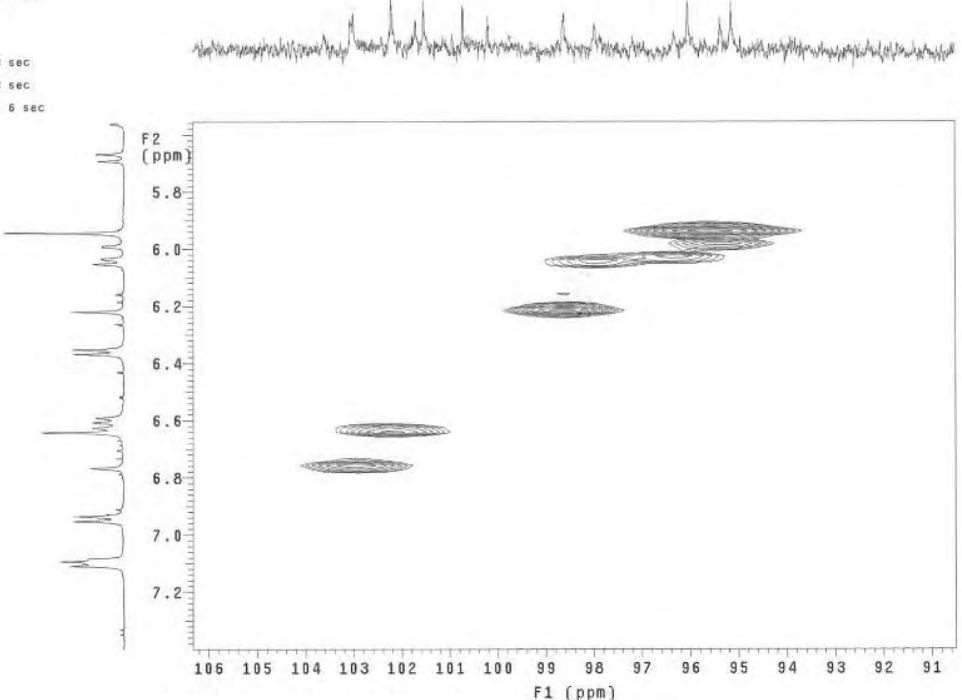

Anexo 138. Ampliação do mapa de contorno ${ }^{1} \mathrm{H}-{ }^{13} \mathrm{C} g \mathrm{HMQC}$ da substância 12.

$$
\left(500 \mathrm{MHz}-\mathrm{DMSO}-d_{6}\right)
$$


Dantara Acott s11 4 - prep 9 08/07/09

Pulse Sequence: gknoc
Solvent: DHSO

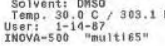

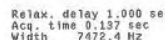

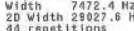

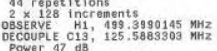

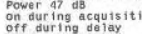

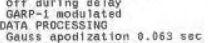

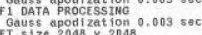

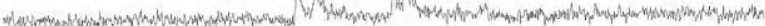

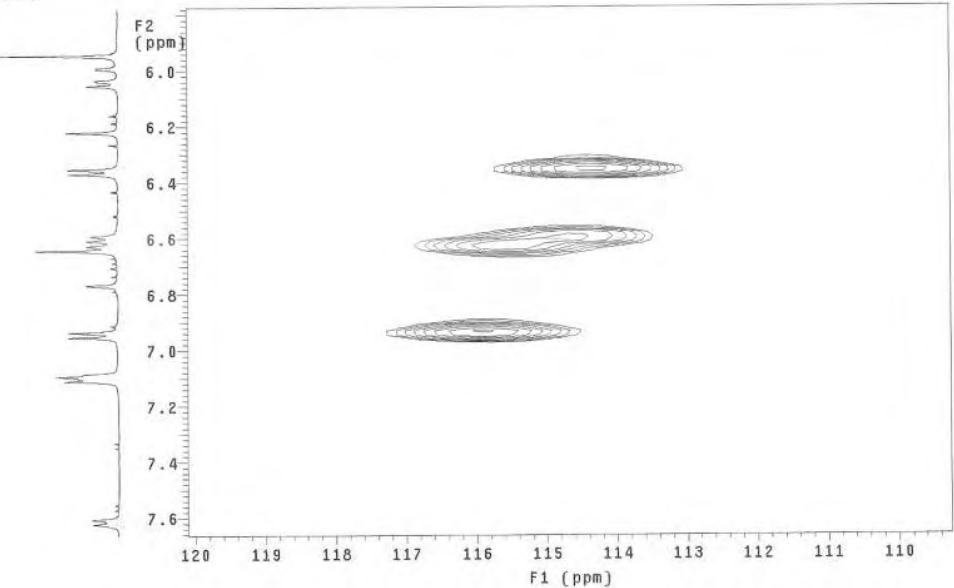

Anexo 139. Ampliação do mapa de contorno ${ }^{1} \mathrm{H}^{13}{ }^{13} \mathrm{C} g \mathrm{HMQC}$ da substância 12. $\left(500 \mathrm{MHz}-\mathrm{DMSO}-d_{6}\right)$

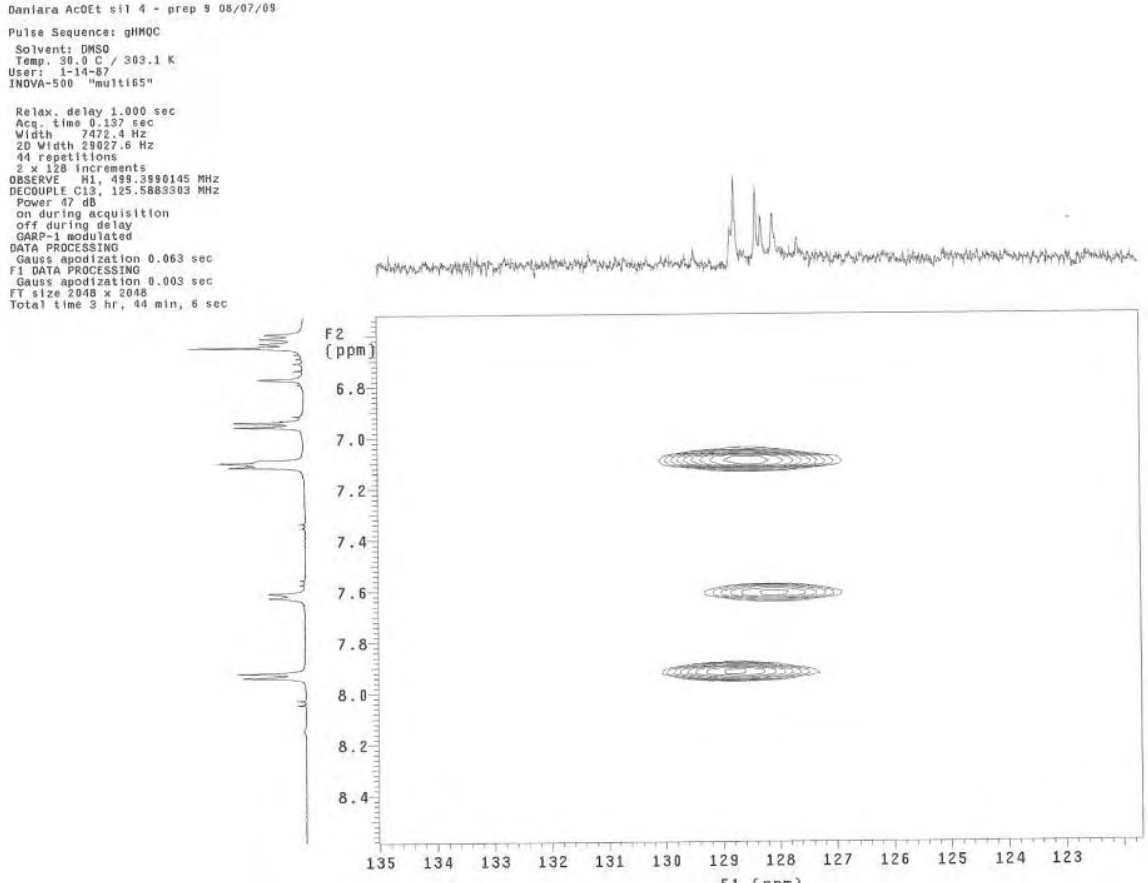

Anexo 140. Ampliação do mapa de contorno ${ }^{1} \mathrm{H}^{-13} \mathrm{C} g \mathrm{HMQC}$ da substância 12.

$$
\left(500 \mathrm{MHz}-\mathrm{DMSO}-d_{6}\right)
$$


Daniara Ac0et sil 4 - prep $908 / 07 / 09$

Pulse Sequence: githBc

Solvent: DHs

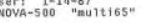

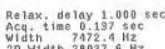

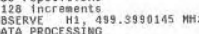

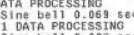

0
1

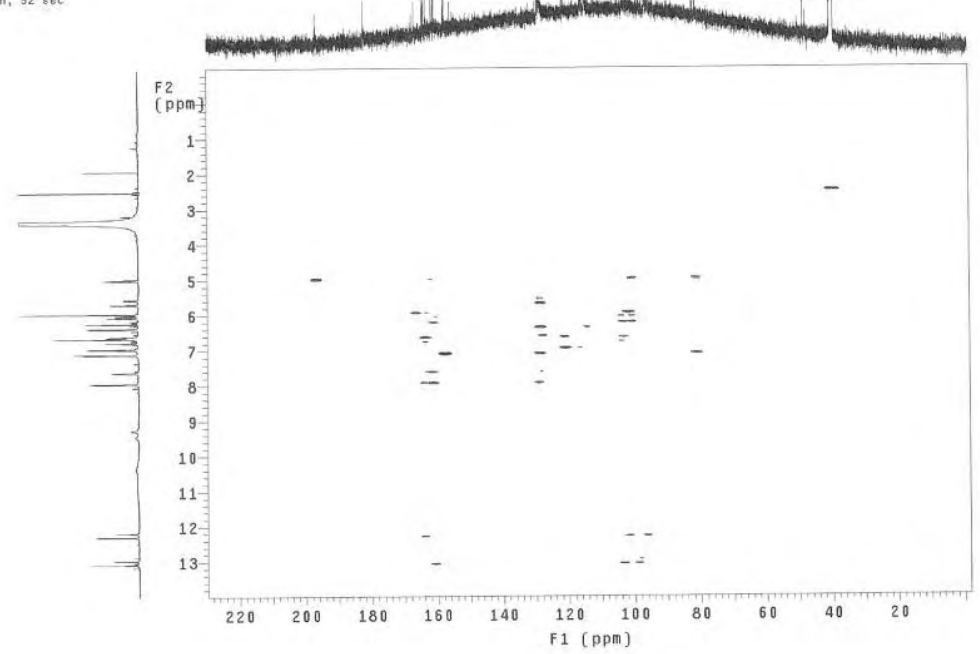

Anexo 141. Mapa de contorno ${ }^{1} \mathrm{H}_{-}{ }^{13} \mathrm{C} g \mathrm{HMBC}$ da substância 12. $\left(500 \mathrm{MHz}-\mathrm{DMSO}-d_{6}\right)$

Dantara ACOEt st1 4 - prep $908 / 07 / 0$

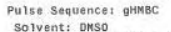

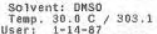

A. 500 "sulti

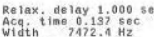

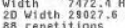

OSERVE H1, A99. 3930145

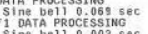

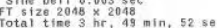

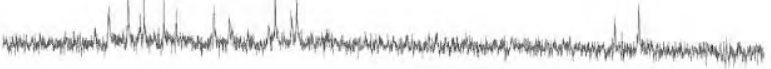

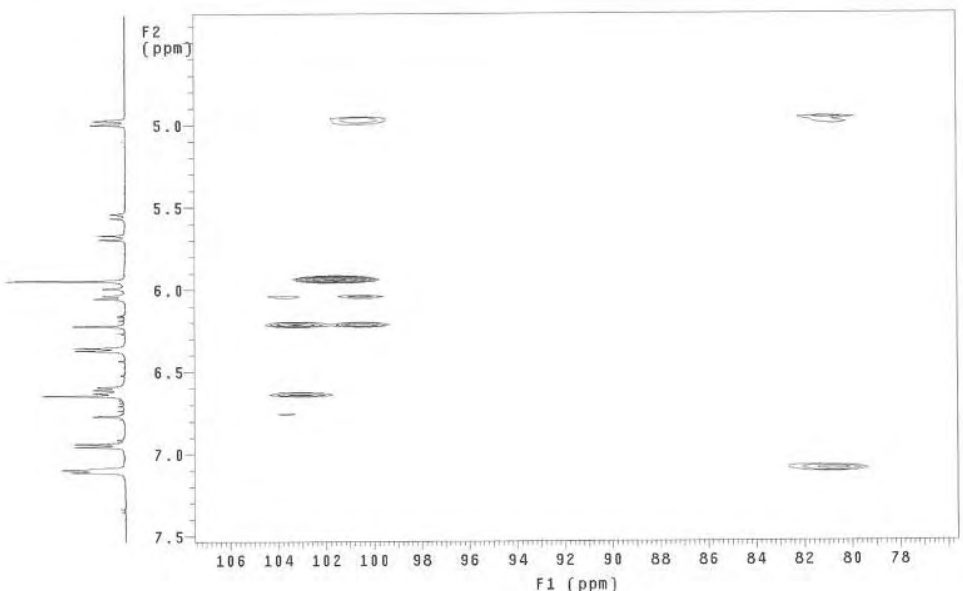

Anexo 142. Ampliação do mapa de contorno ${ }^{1} \mathrm{H}-{ }^{13} \mathrm{C} g \mathrm{HMBC}$ da substância 12.

$\left(500 \mathrm{MHz}-\mathrm{DMSO}-d_{6}\right)$ 
Daniara AcoEt s11 4 - prep $908 / 07 / 05$

F11 ename:

Pulse Sequence: ghrme

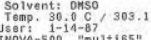

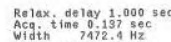

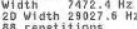

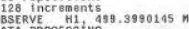

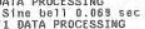

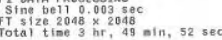

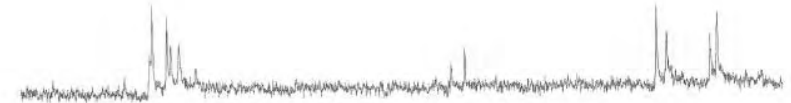

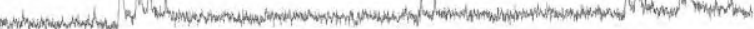

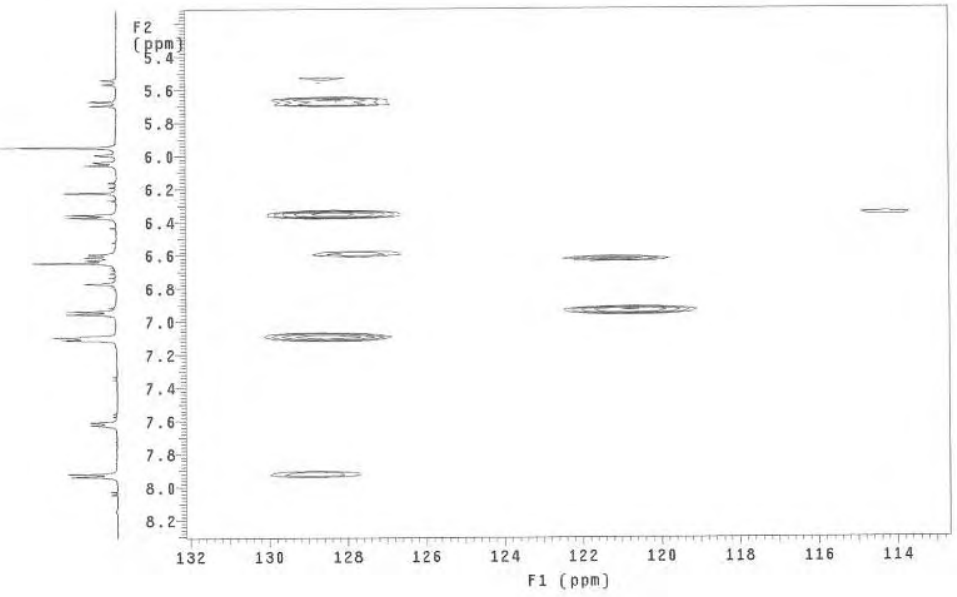

Anexo 143. Ampliação do mapa de contorno ${ }^{1} \mathrm{H}-{ }^{13} \mathrm{C} g \mathrm{HMBC}$ da substância 12.

$\left(500 \mathrm{MHz}-\mathrm{DMSO}-d_{6}\right)$

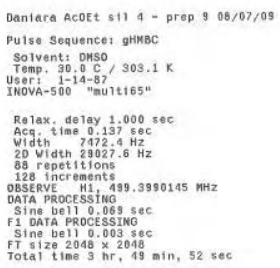

H1ename:

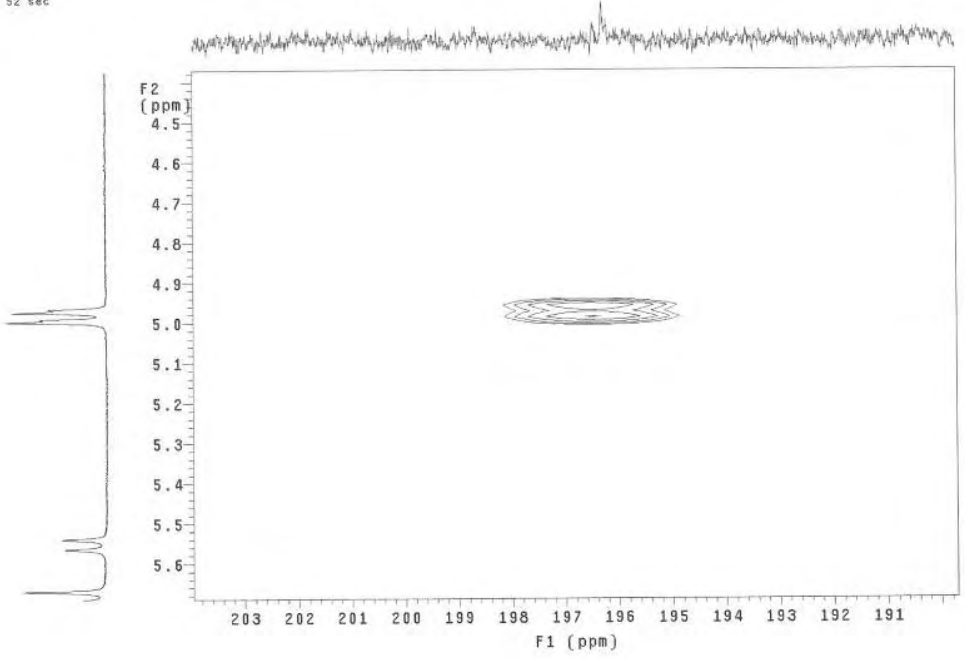

Anexo 144. Ampliação do mapa de contorno ${ }^{1} \mathrm{H}^{-13} \mathrm{C} g \mathrm{HMBC}$ da substância 12.

$$
\left(500 \mathrm{MHz}-\text { DMSO- } d_{6}\right)
$$


Danlara Acott sil 4 - prep $908 / 07 / 09$

Filename: -

Pulse Sequence: gHHBC
Solvent: DSSO

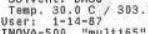

Relax de 1 lay $1,000 \mathrm{sec}$

Acg time $0.13758 \mathrm{gcc}$
Width $742.4 \mathrm{~Hz}$
20 vidth $29027.6 \mathrm{~Hz}$

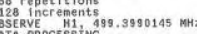

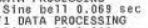

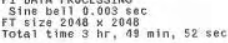

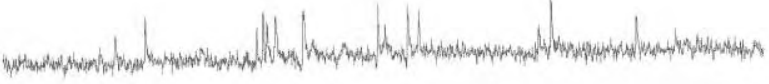

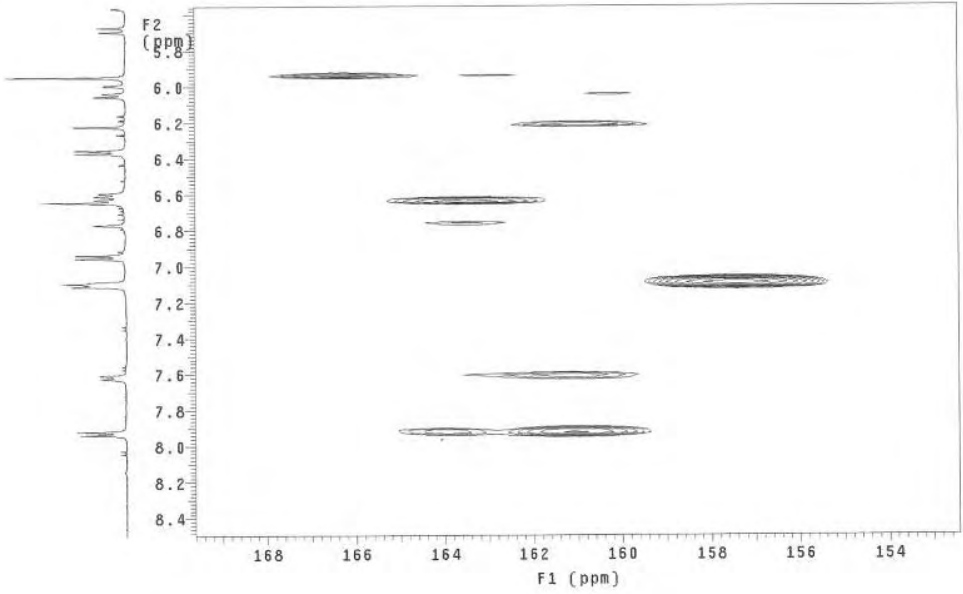

Anexo 145. Ampliação do mapa de contorno ${ }^{1} \mathrm{H}^{13} \mathrm{C} g \mathrm{HMBC}$ da substância 12. $\left(500 \mathrm{MHz}-\mathrm{DMSO}-d_{6}\right)$
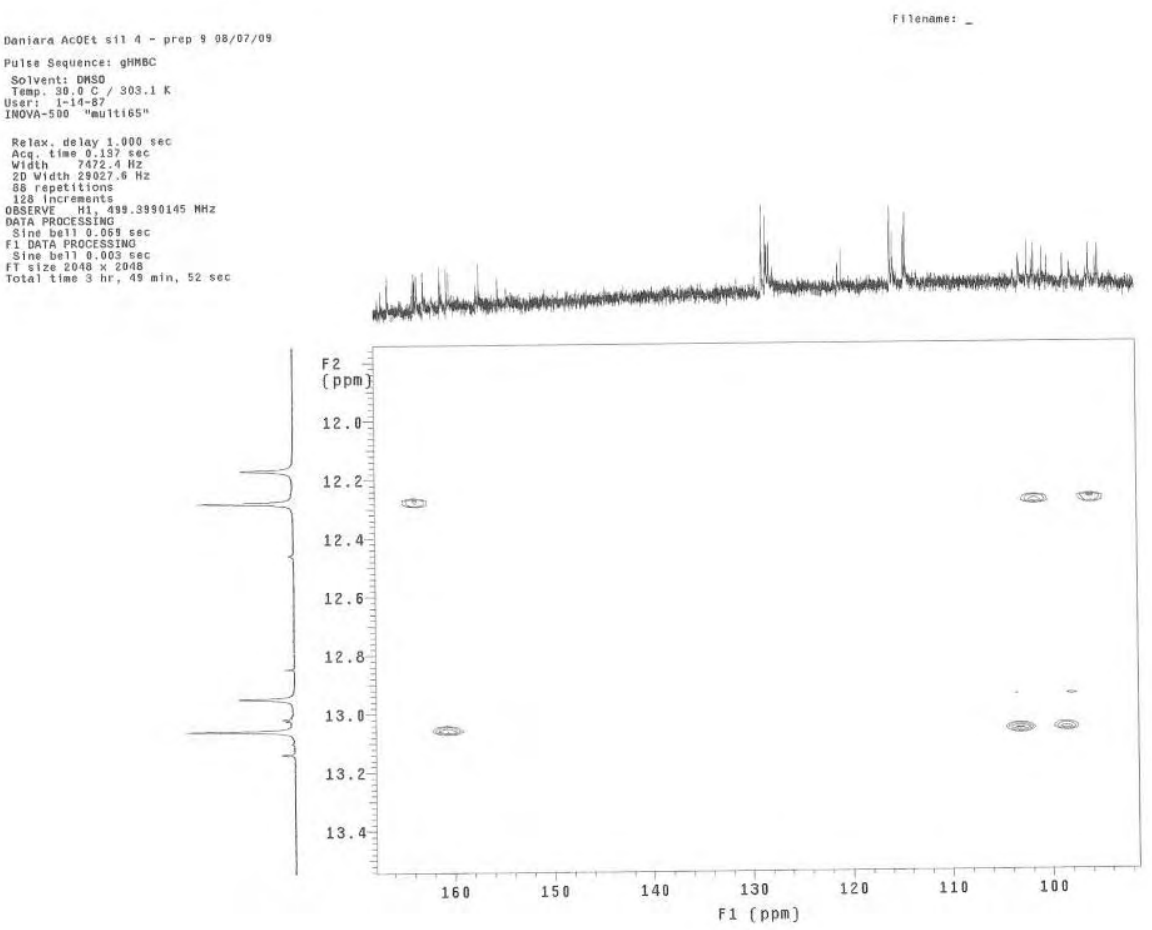

Anexo 146. Ampliação do mapa de contorno ${ }^{1} \mathrm{H}^{-13} \mathrm{C} g \mathrm{HMBC}$ da substância 12. $\left(500 \mathrm{MHz}-\mathrm{DMSO}-d_{6}\right)$ 


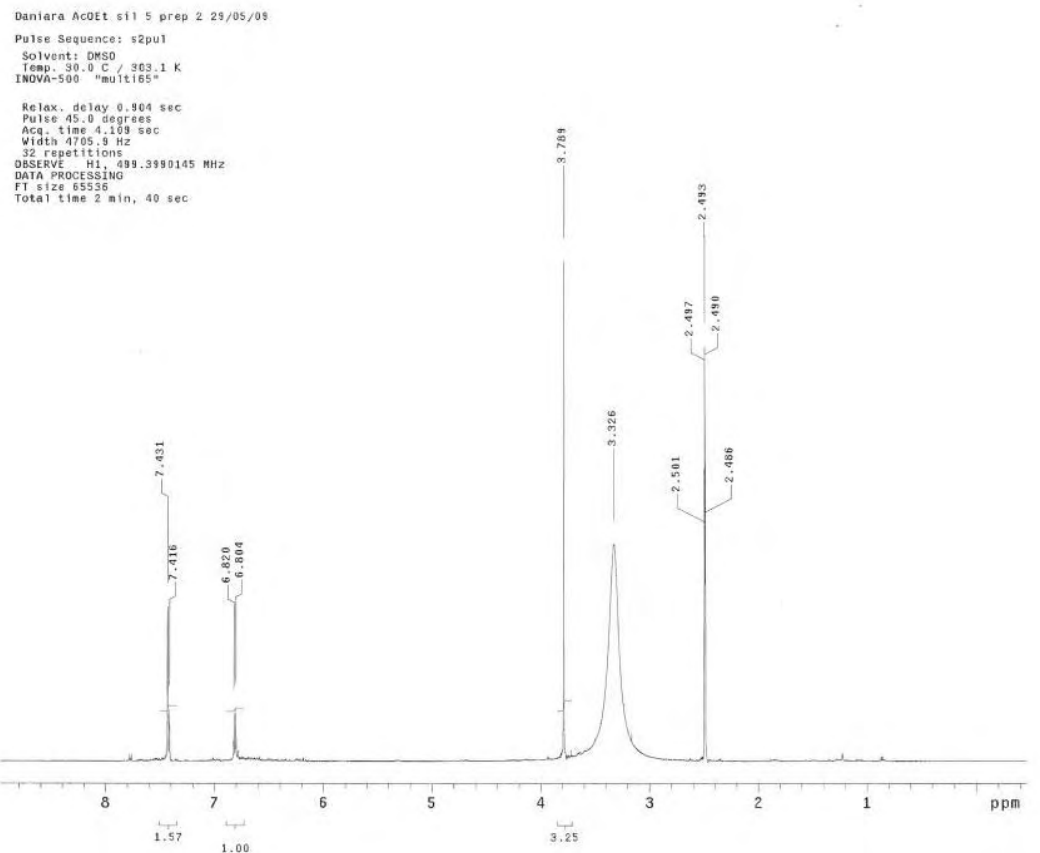

Anexo 147. Espectro de RMN de ${ }^{1} \mathrm{H}$ da substância 13. $\left(500 \mathrm{MHz}-\mathrm{DMSO}-d_{6}\right)$

vaniara Acoet s11 5 - prep 2 06/07/09

Putse Sequence: 52 pur
Solvent: Doso

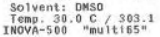

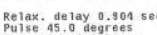

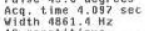

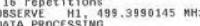

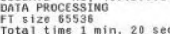

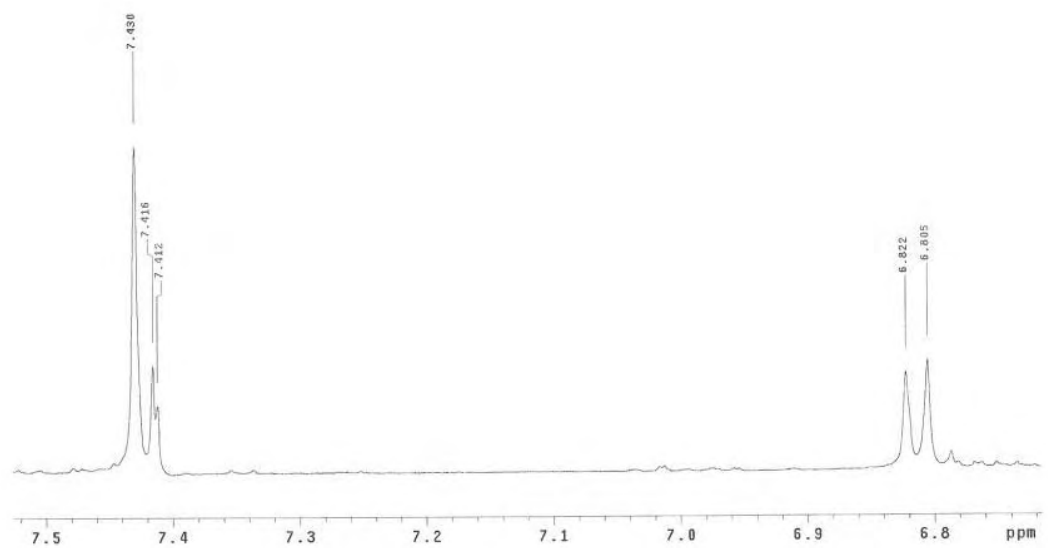

Anexo 148. Ampliação do espectro de RMN de ${ }^{1} \mathrm{H}$ da substância 13.

$\left(500 \mathrm{MHz}-\mathrm{DMSO}-d_{6}\right)$ 
Daniara Acoet sil 5 prep $229 / 05 / 09$ Pulse Sequance: gCosY
Solvent: OPso

INOVA 500 "nuUtitis:

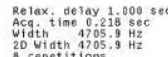

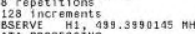

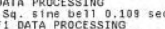

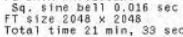

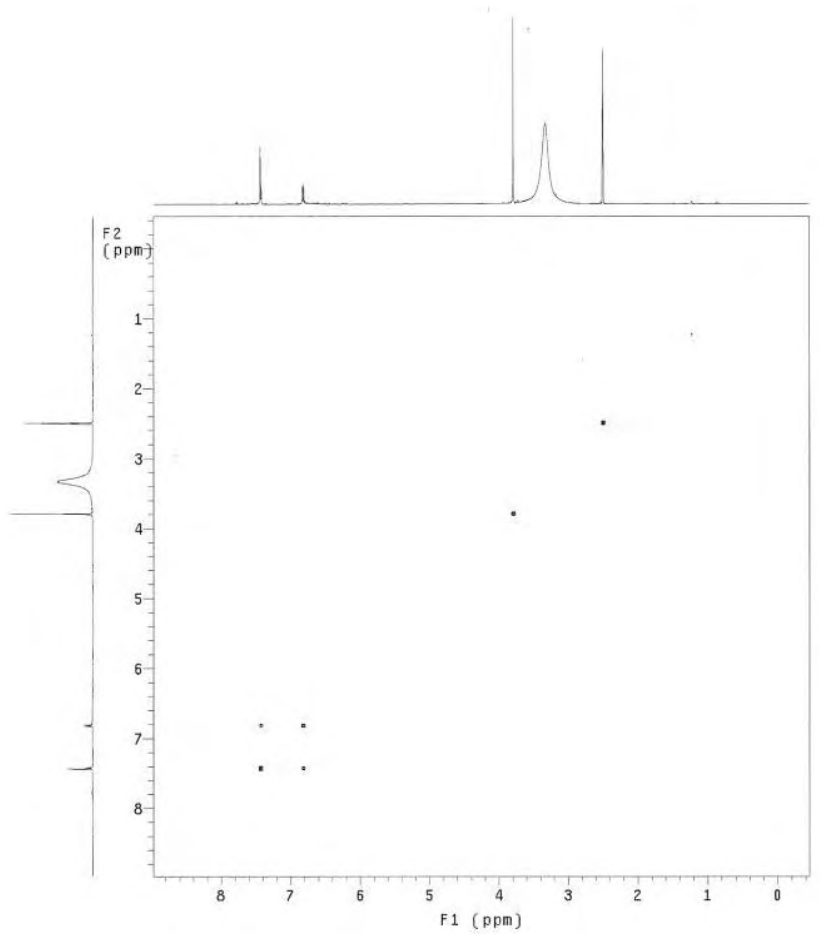

Anexo 149. Mapa de contorno ${ }^{1} \mathrm{H}-{ }^{1} \mathrm{H} g \mathrm{COSY}$ da substância 13.

$\left(500 \mathrm{MHz}-\mathrm{DMSO}-d_{6}\right)$

Dantiara ACOEt s11 5 prep 2 29/05/00

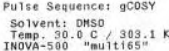

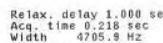

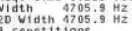

BSERVE H1, 499.3990145 MHI

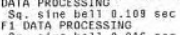

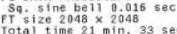

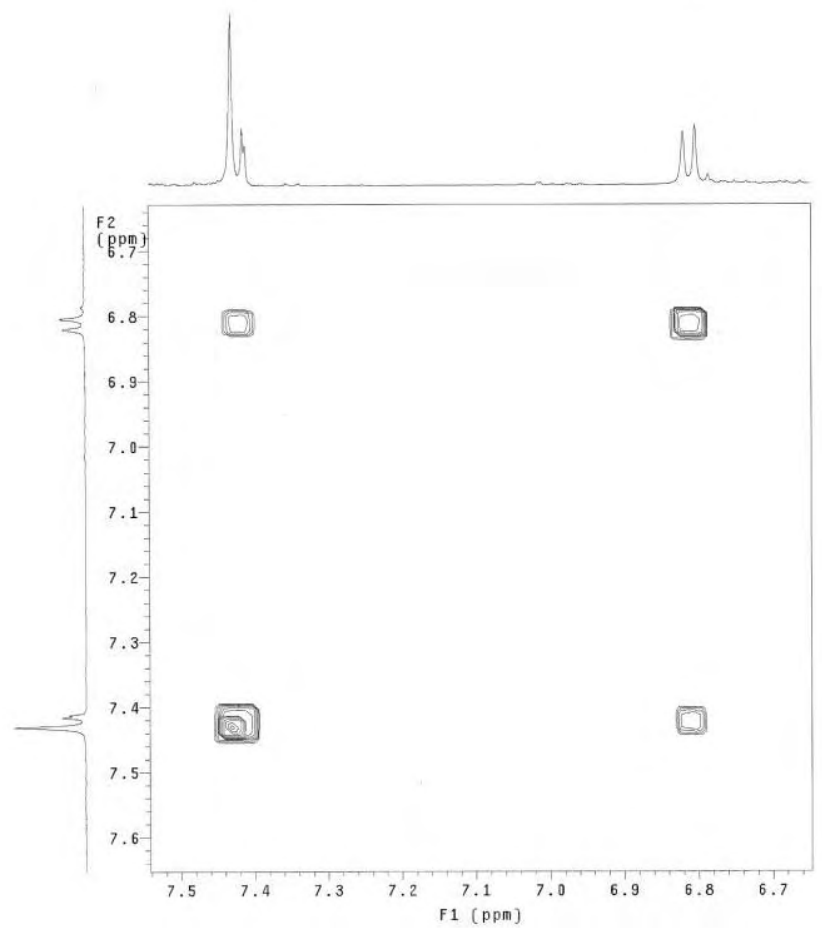

Anexo 150. Ampliação do mapa de contorno ${ }^{1} \mathrm{H}^{-1} \mathrm{H} g \mathrm{COSY}$ da substância 13.

$\left(500 \mathrm{MHz}-\mathrm{DMSO}-d_{6}\right)$ 


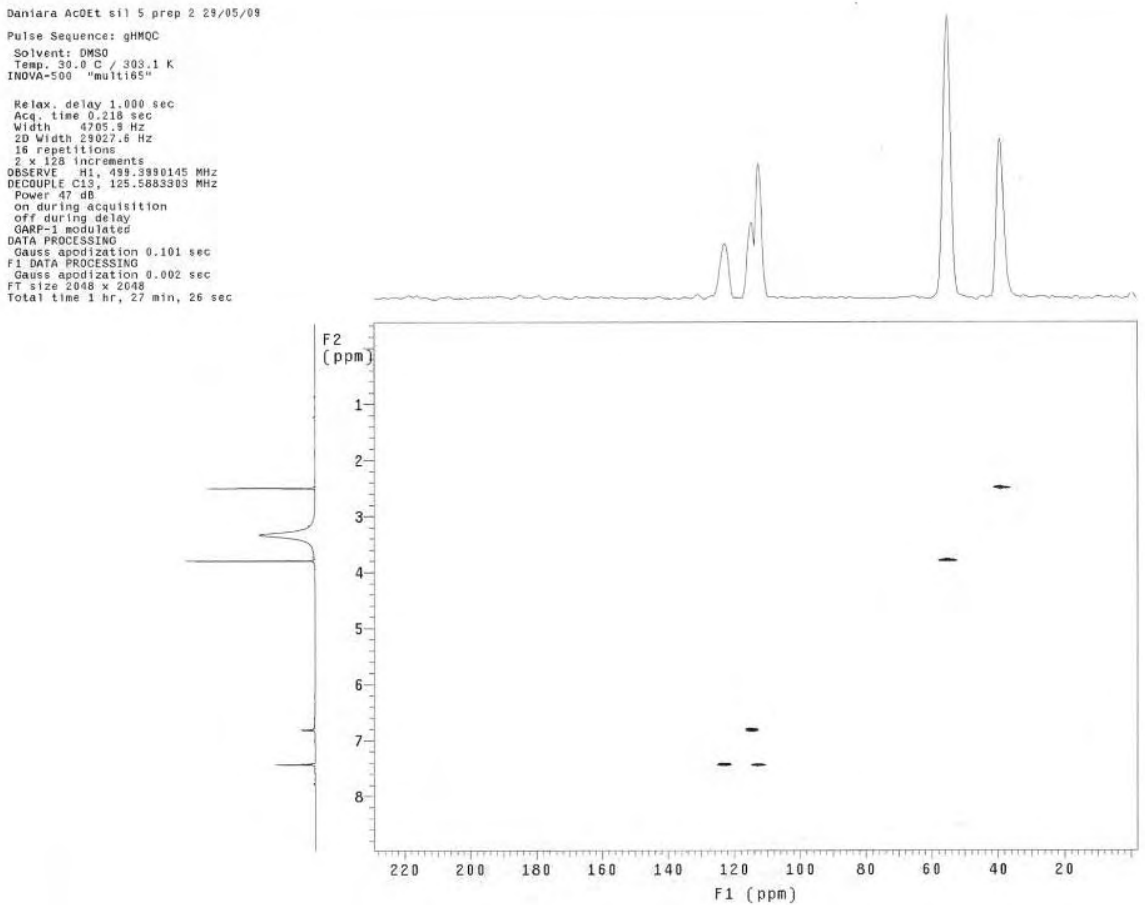

Anexo 151. Mapa de contorno ${ }^{1} \mathrm{H}^{13} \mathrm{C} g \mathrm{HMQC}$ da substância 13.

$\left(500 \mathrm{MHz}-\mathrm{DMSO}-d_{6}\right)$

Daniara Acoet sil 5 prep 2 28/05/09

Pulse Sequence: ghMoC
Solvent

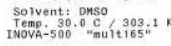

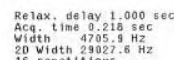

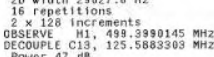

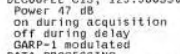

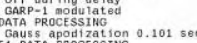

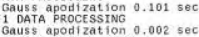

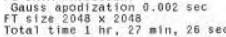

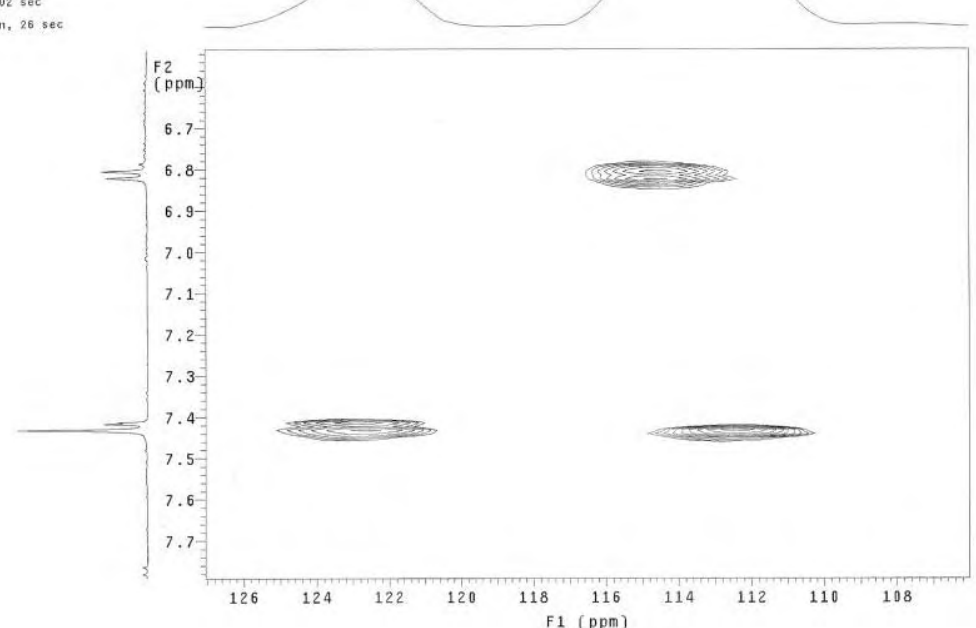

Anexo 152. Ampliação do mapa de contorno ${ }^{1} \mathrm{H}^{-13} \mathrm{C} g \mathrm{HMQC}$ da substância 13.

$\left(500 \mathrm{MHz}-\mathrm{DMSO}-d_{6}\right)$ 
Daniara ACOEt sil 5 prep 2 29/05/09

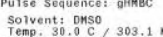

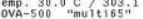

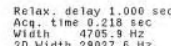

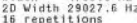

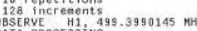

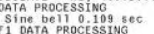

0
1

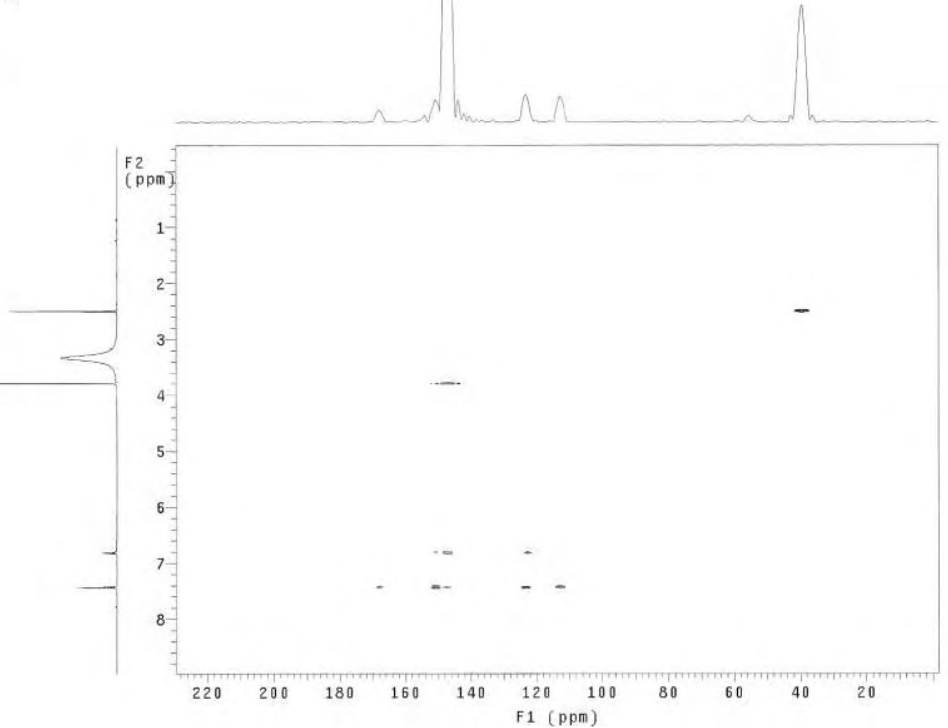

Anexo 153. Mapa de contorno ${ }^{1} \mathrm{H}^{13} \mathrm{C} g \mathrm{HMBC}$ da substância 13. $\left(500 \mathrm{MHz}-\mathrm{DMSO}-d_{6}\right)$

Daniara ACOEt si1 5 prep 2 29/05/09

Puise Sequence: gHrBC

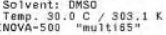

Relax, delay $1.000 \mathrm{sec}$

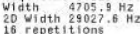

OBSERVE

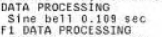

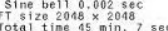
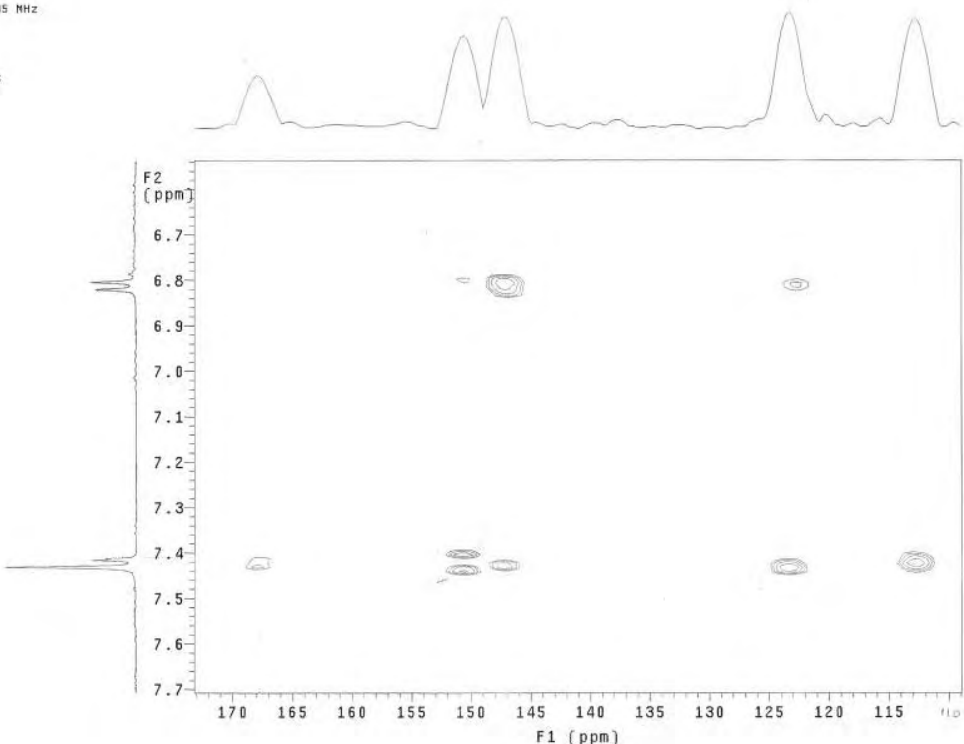

Anexo 154. Ampliação do mapa de contorno ${ }^{1} \mathrm{H}-{ }^{13} \mathrm{C} g \mathrm{HMBC}$ da substância 13.

$$
\left(500 \mathrm{MHz}-\mathrm{DMSO}-d_{6}\right)
$$


Daniara sil 5 prep 4 20/05/0 Pulse Sequence: s2put

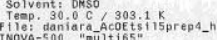

Re lax. de lay 0.904 se
Pulse 45.0 degrees

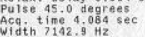

16 repetitions
BSERVE

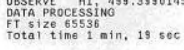

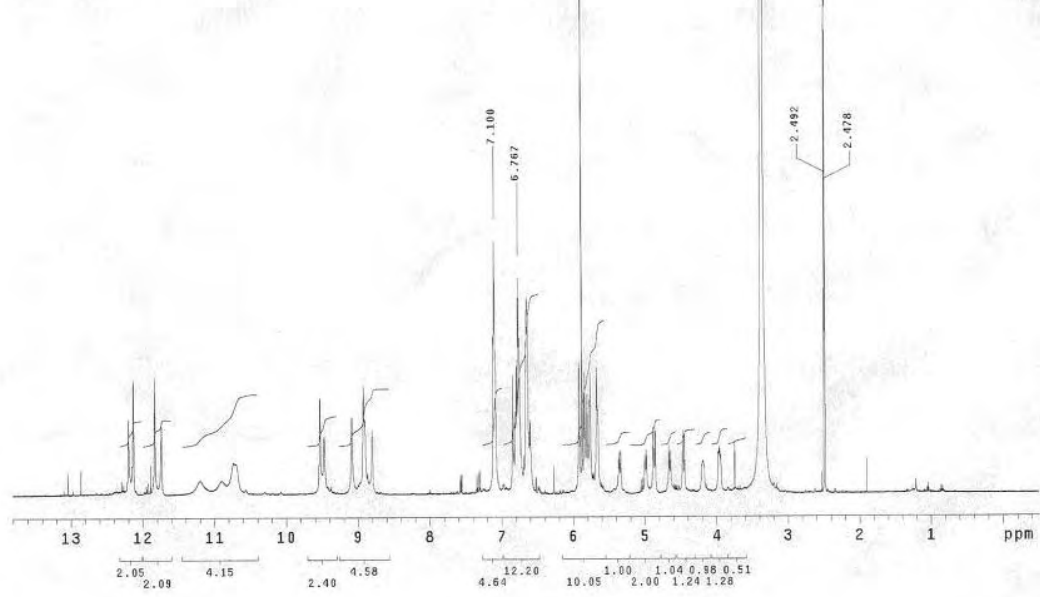

Anexo 155. Espectro de RMN de ${ }^{1} \mathrm{H}$ da substância 14.

$\left(500 \mathrm{MHz}-\mathrm{DMSO}-d_{6}\right)$

Dantara 5115 prep 4 20/05/09

Solvente nuso: s2pur

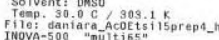

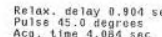

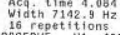

DSERVE

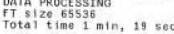

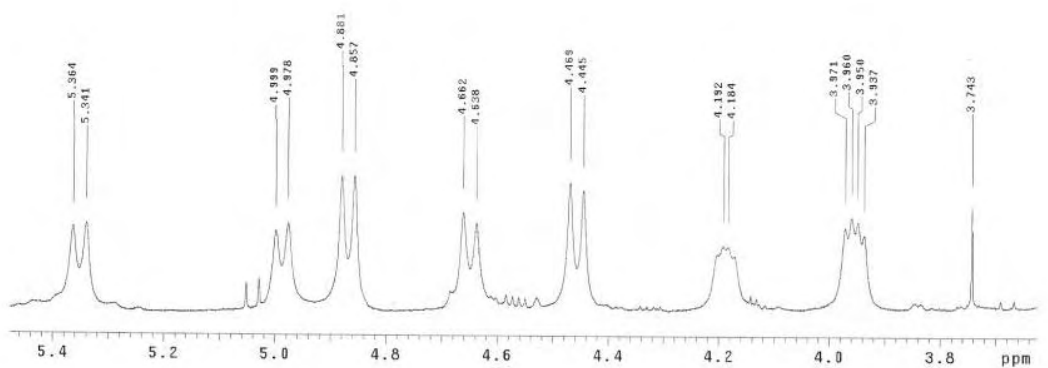

Anexo 156. Ampliação do espectro de RMN de ${ }^{1} \mathrm{H}$ da substância 14.

$\left(500 \mathrm{MHz}-\mathrm{DMSO}-d_{6}\right)$ 
Dantiara sil 5 prep 4 20/05/

Pulse sequences s2pul

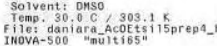

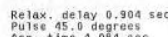

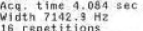

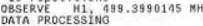

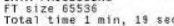

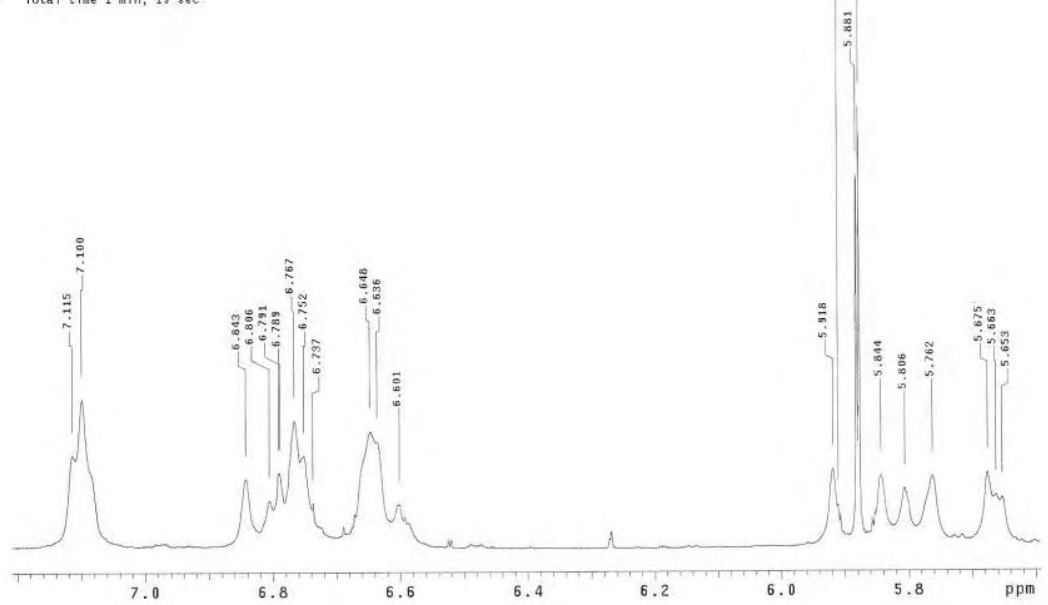

Anexo 157. Ampliação do espectro de RMN de ${ }^{1} \mathrm{H}$ da substância 14. $\left(500 \mathrm{MHz}-\mathrm{DMSO}-d_{6}\right)$

Daniara sil 5 prep 4 20/05/00

Pulse Sequence: s2put
solvents 0 Hso

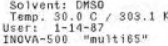

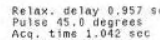

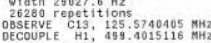

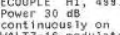

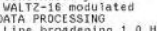

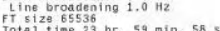

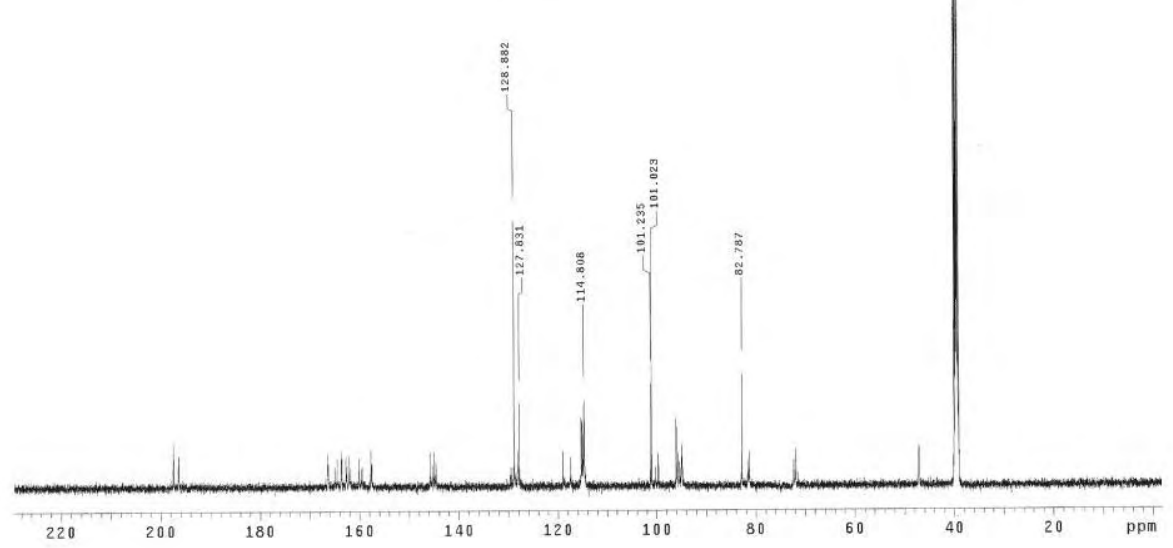

Anexo 158. Espectro de RMN de ${ }^{13} \mathrm{C}$ da substância 14.

$\left(125 \mathrm{MHz}-\mathrm{DMSO}-d_{6}\right)$ 
Daniara 5115 prep $420 / 05 / 09$

Pulse Sequence: s2pu1

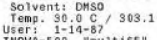

Relax. de lay 0.957 s.

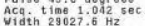

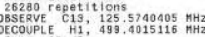

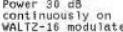

DAP PROCESTIN

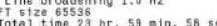

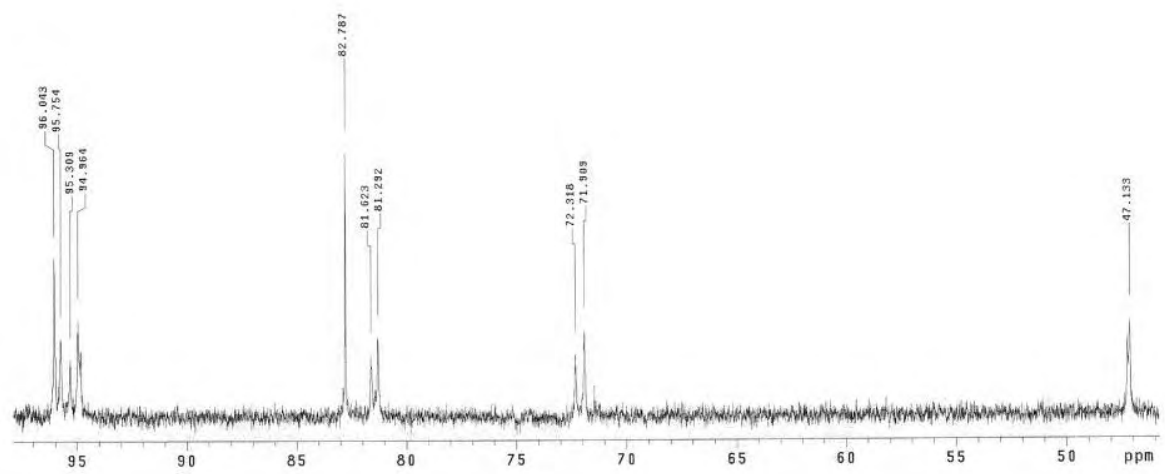

Anexo 159. Ampliação do espectro de RMN de ${ }^{13} \mathrm{C}$ da substância 14. $\left(125 \mathrm{MHz}-\mathrm{DMSO}-d_{6}\right)$

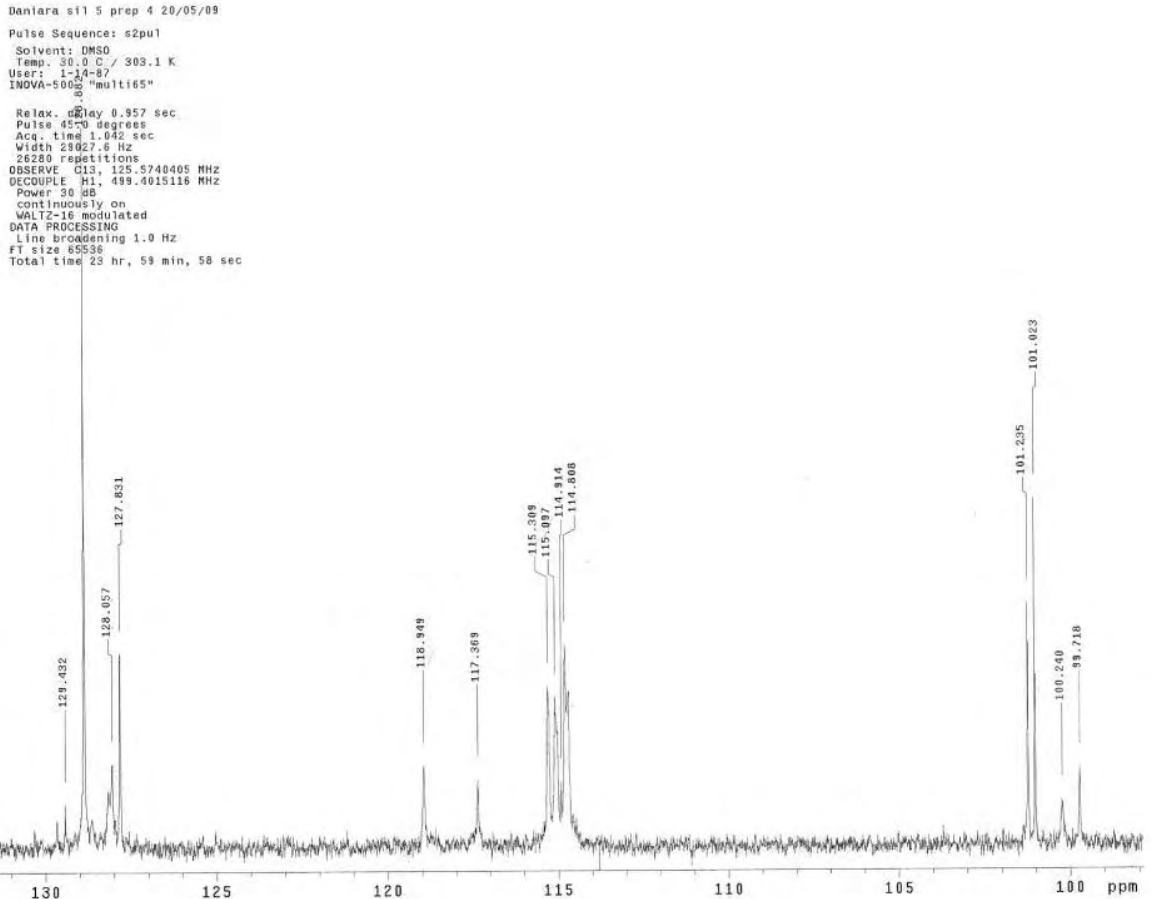

Anexo 160. Ampliação do espectro de RMN de ${ }^{13} \mathrm{C}$ da substância 14.

$$
\left(125 \mathrm{MHz}-\mathrm{DMSO}-d_{6}\right)
$$


Daniara si1 5 prep 4 20/05/09

Pulse Sequence: s2pul

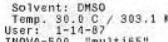

Relax. delay 0.957 see
Pulse

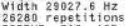

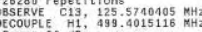

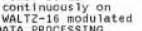

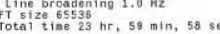

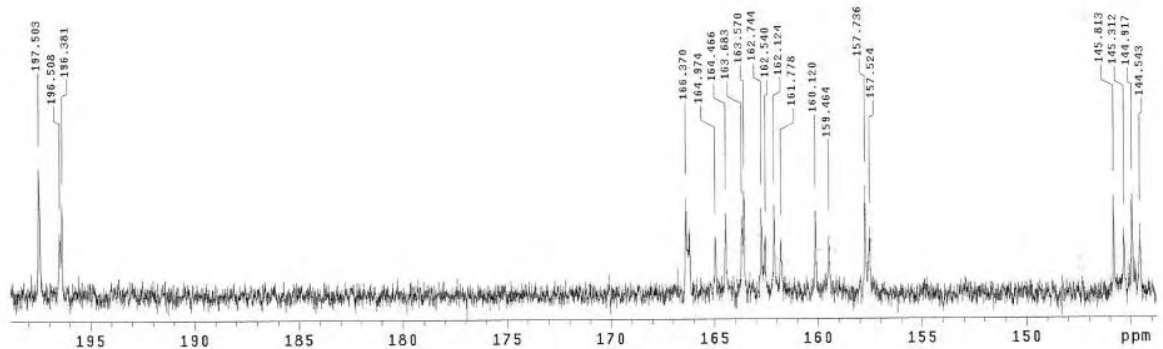

Anexo 161. Ampliação do espectro de RMN de ${ }^{13} \mathrm{C}$ da substância 14. $\left(125 \mathrm{MHz}-\mathrm{DMSO}-d_{6}\right)$
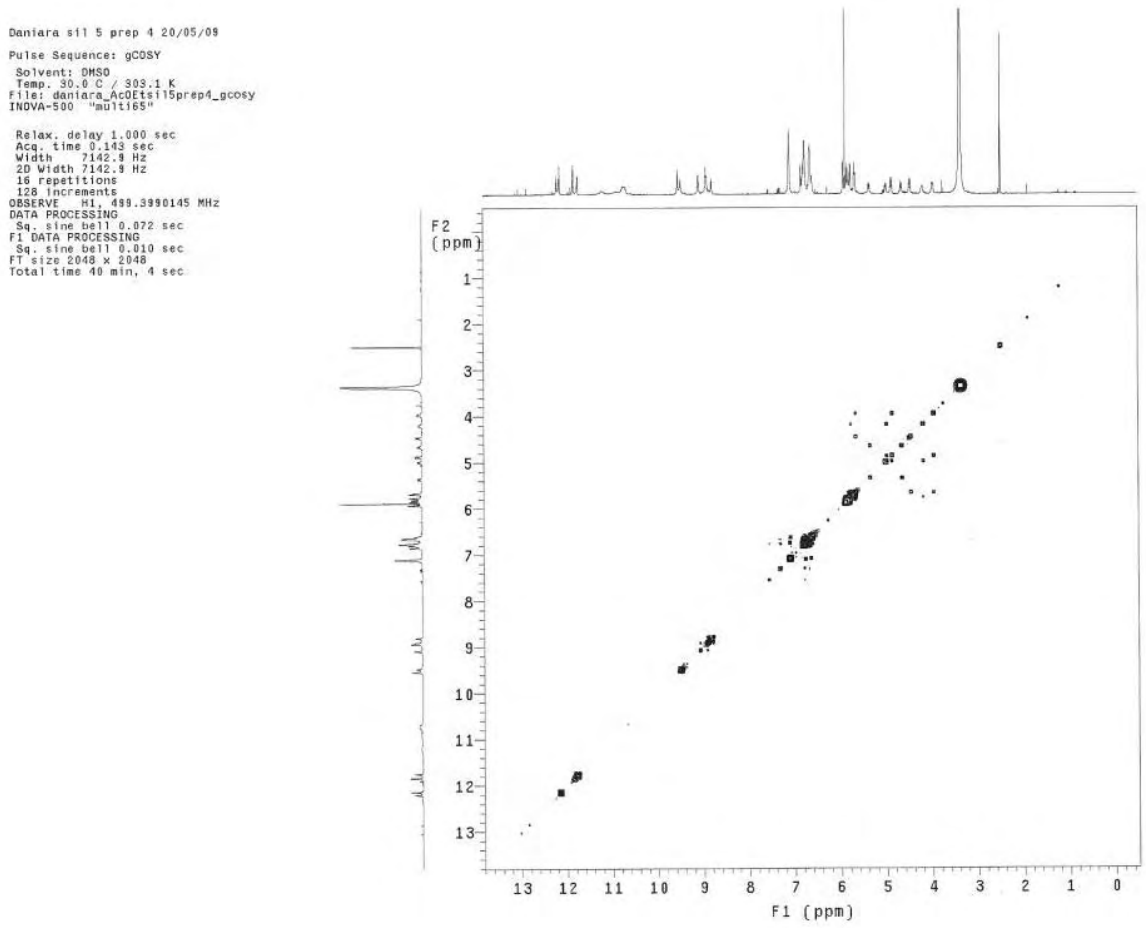

Anexo 162. Mapa de contorno ${ }^{1} \mathrm{H}-{ }^{1} \mathrm{H} g \mathrm{COSY}$ da substância 14 $\left(500 \mathrm{MHz}-\mathrm{DMSO}-d_{6}\right)$ 
Dantara 5115 prep 4 20/05/

Pulse Sequence: gcosy

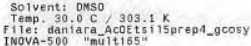

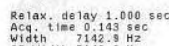

Width 712.9
20 thdth $7142.9 \mathrm{~Hz}$
16 repetstions

OESERVECrants 99.3990145 MHZ

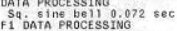

FT

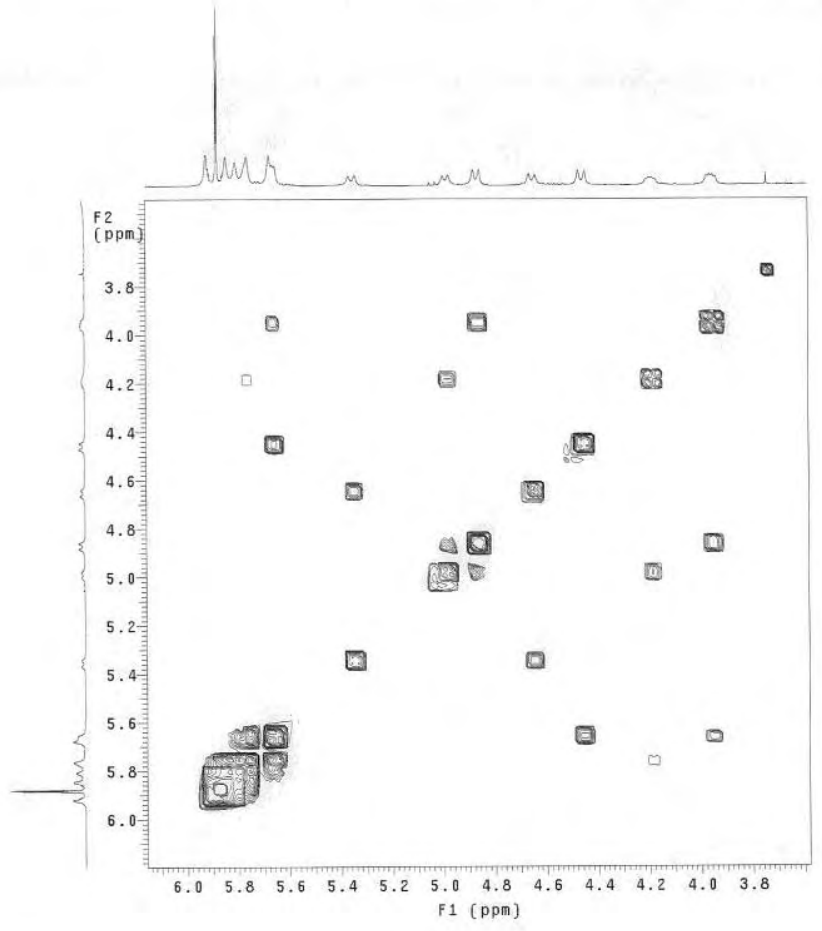

Anexo 163. Ampliação do mapa de contorno ${ }^{1} \mathrm{H}^{1}{ }^{1} \mathrm{H} g \mathrm{COSY}$ da substância 14. $\left(500 \mathrm{MHz}-\mathrm{DMSO}-d_{6}\right)$

Dantara st1 5 prep 4 20/05/00 Pulse Sequence: gcosy

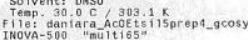

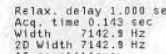

20 width $7142.8 \mathrm{~Hz}$
16 repetitions
128
in increments

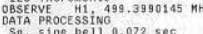

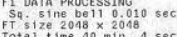

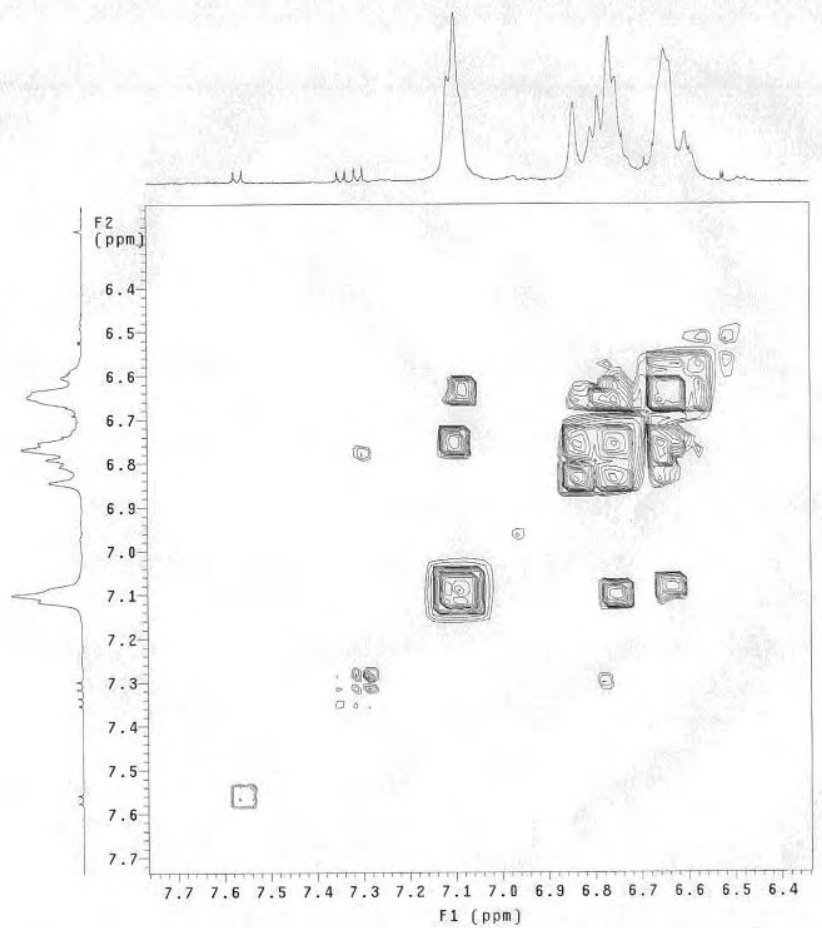

Anexo 164. Ampliação do mapa de contorno ${ }^{1} \mathrm{H}-{ }^{1} \mathrm{H} g \mathrm{COSY}$ da substância 14.

$$
\left(500 \mathrm{MHz}-\mathrm{DMSO}-d_{6}\right)
$$


Daniara s11 S prep 4 20/05/00

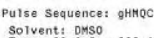

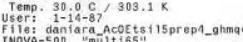

Relax. delay $1.000 \mathrm{sec}$
Acg time o $14.0 \mathrm{sec}$

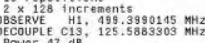

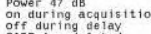

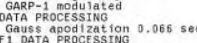

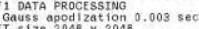

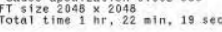

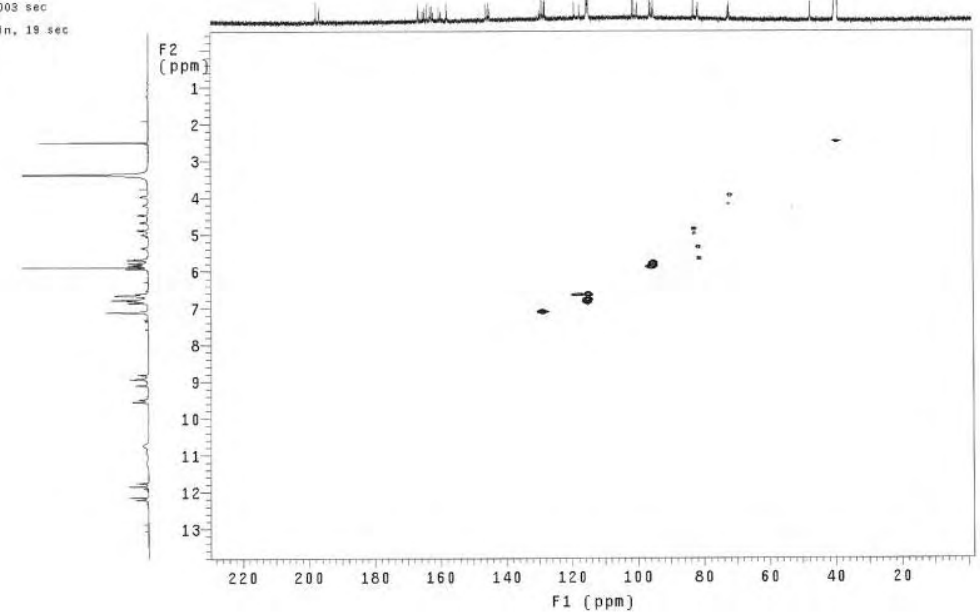

Anexo 165. Mapa de contorno ${ }^{1} \mathrm{H}_{-}{ }^{13} \mathrm{C} g \mathrm{HMQC}$ da substância 14.

$$
\left(500 \mathrm{MHz}-\mathrm{DMSO}-d_{6}\right)
$$

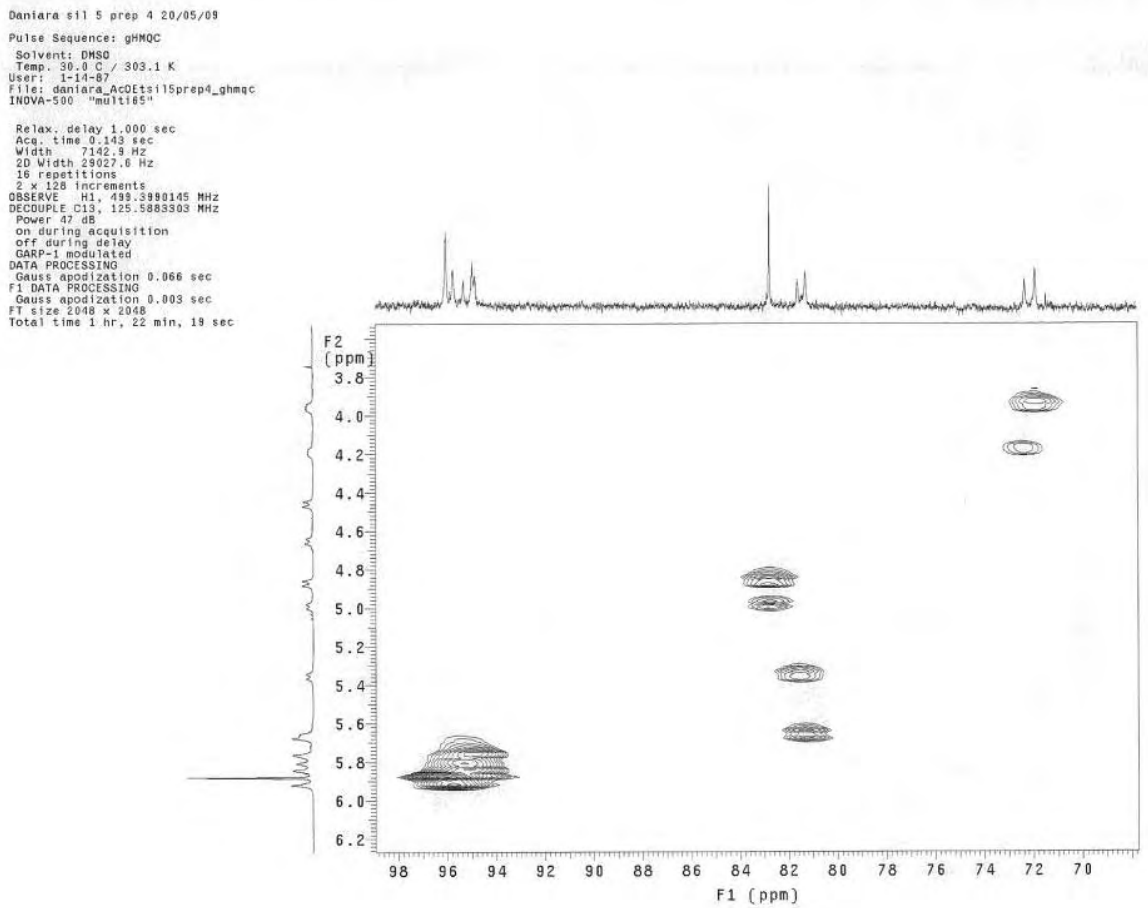

Anexo 166. Ampliação do mapa de contorno ${ }^{1} \mathrm{H}-{ }^{13} \mathrm{C} g \mathrm{HMQC}$ da substância 14.

$$
\left(500 \mathrm{MHz}-\mathrm{DMSO}-d_{6}\right)
$$


Dantara s+11 5 prep 4 20/05/0

Pulse Sequence: gHroc

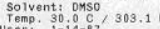

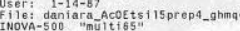

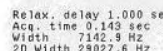

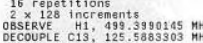

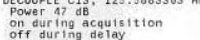

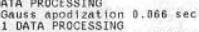

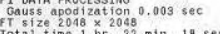

n, $19 \mathrm{sec}$

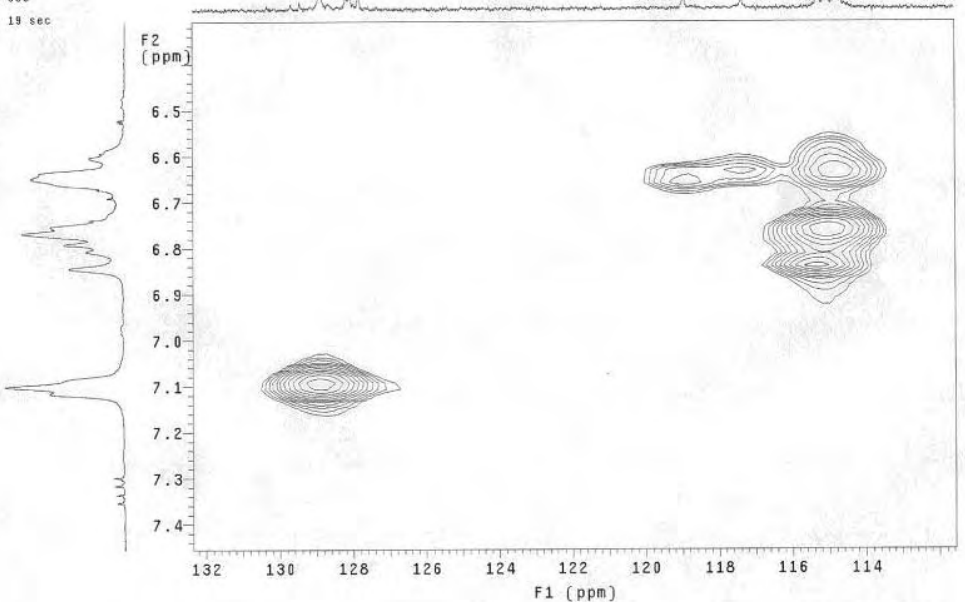

Anexo 167. Ampliação do mapa de contorno ${ }^{1} \mathrm{H}-{ }^{13} \mathrm{C} g \mathrm{HMQC}$ da substância 14. $\left(500 \mathrm{MHz}-\mathrm{DMSO}-d_{6}\right)$

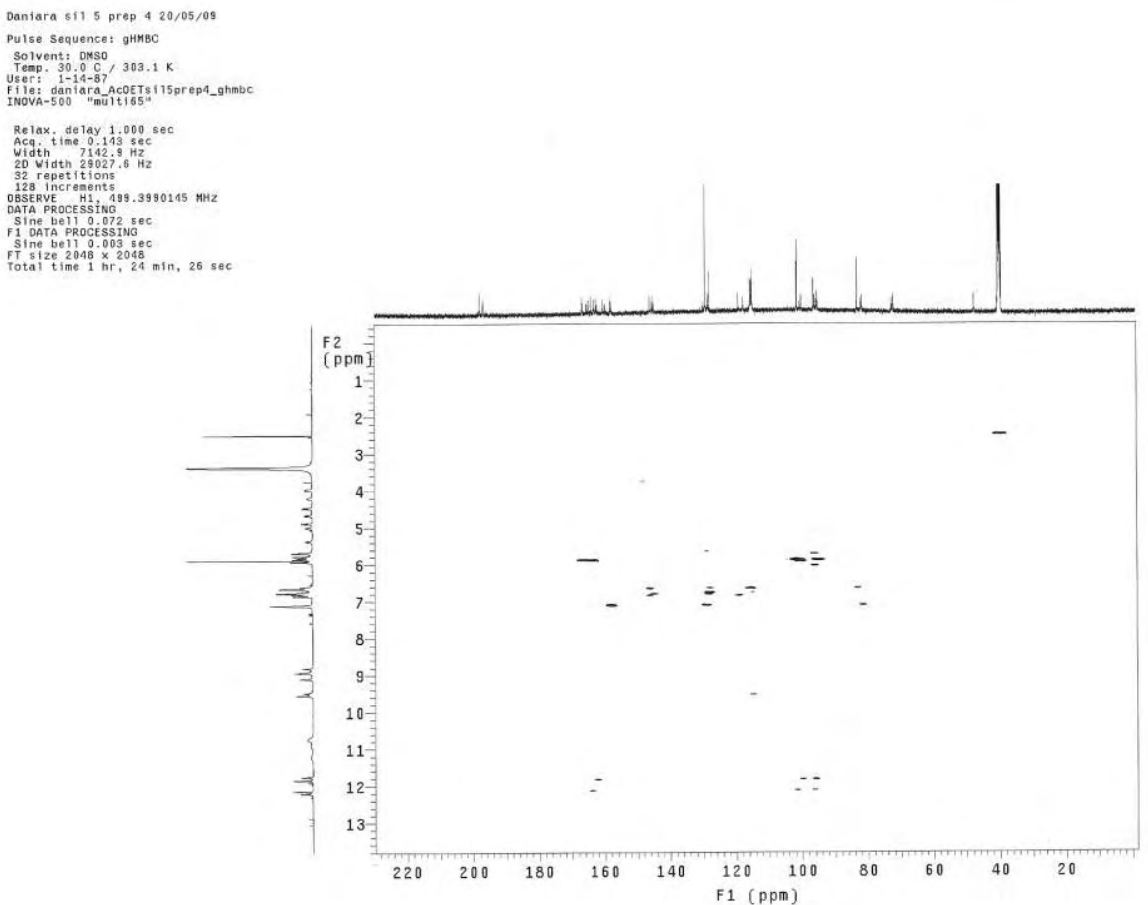

Anexo 168. Mapa de contorno ${ }^{1} \mathrm{H}-{ }^{13} \mathrm{C} g \mathrm{HMBC}$ da substância 14.

$$
\left(500 \mathrm{MHz}-\mathrm{DMSO}-d_{6}\right)
$$


Daniara sil 5 prep 4 20/05/09

Pulse Sequence: ghMBC

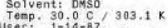

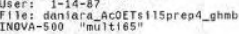

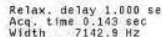

20
20
32 repet
reptitions

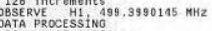

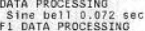

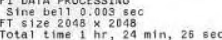

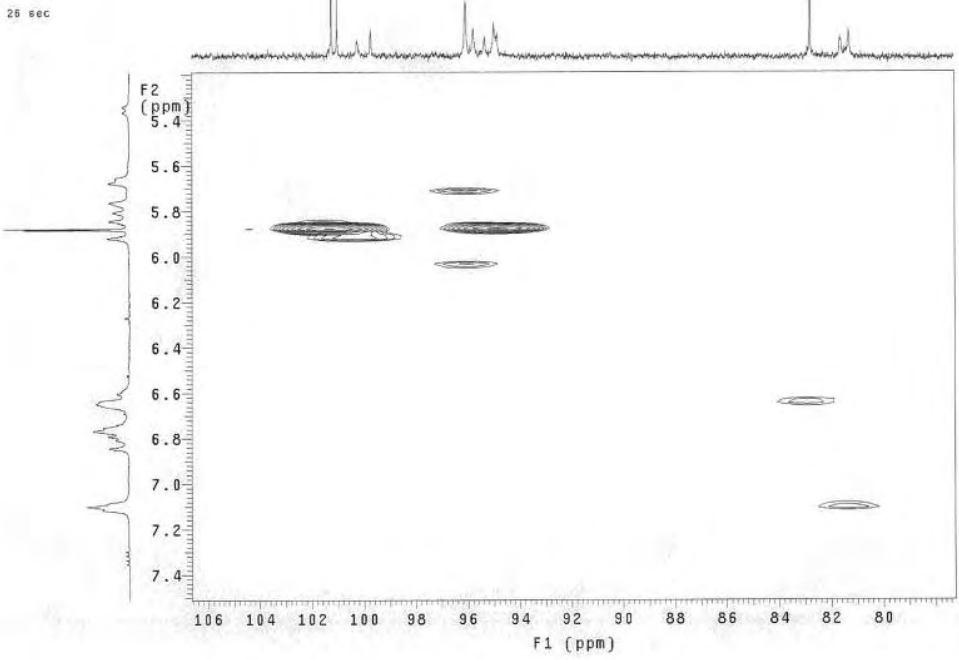

Anexo 169. Ampliação do mapa de contorno ${ }^{1} \mathrm{H}-{ }^{13} \mathrm{C} g \mathrm{HMBC}$ da substância 14. $\left(500 \mathrm{MHz}-\mathrm{DMSO}-d_{6}\right)$

Daniara sit 5. prep 4 20/05/0

Pulse Sequence: oHABC
solvent: Duso

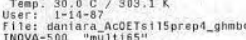

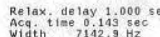

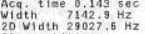

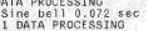

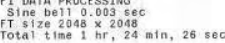

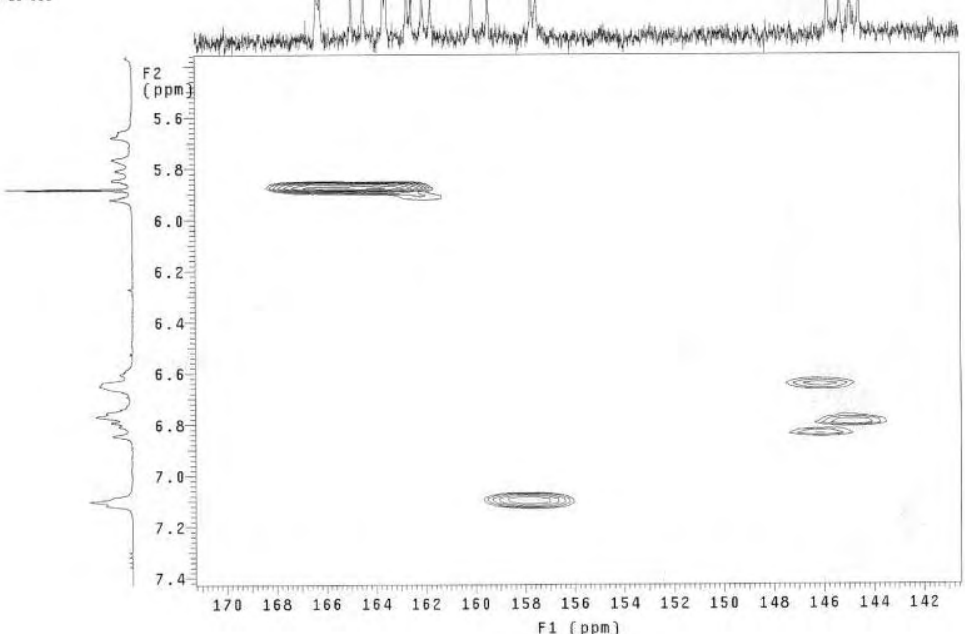

Anexo 170. Ampliação do mapa de contorno ${ }^{1} \mathrm{H}-{ }^{13} \mathrm{C} g \mathrm{HMBC}$ da substância 14.

$$
\left(500 \mathrm{MHz}-\mathrm{DMSO}-d_{6}\right)
$$


Daniara sil 5 prep 4 20/05/09

Pulse Sequence: ghrBC
Solvent: orso

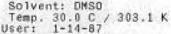

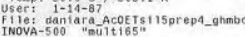

Relax detay 1.000 sec

128 increments

DAFA PROCESSIMG

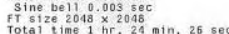

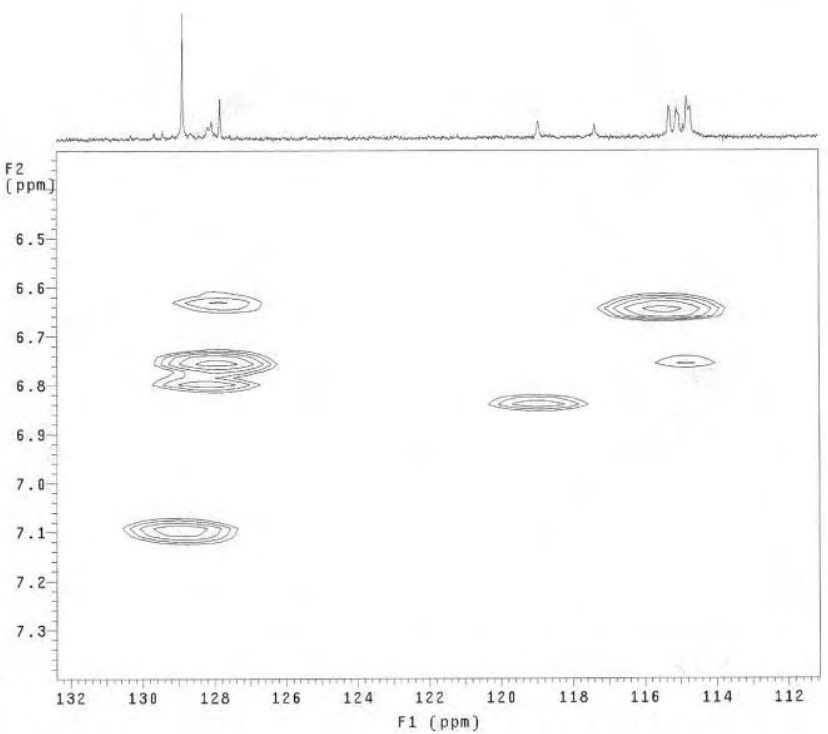

Anexo 171. Ampliação do mapa de contorno ${ }^{1} \mathrm{H}-{ }^{13} \mathrm{C} g \mathrm{HMBC}$ da substância 14 $\left(500 \mathrm{MHz}-\mathrm{DMSO}-d_{6}\right)$

Dantara sil 5 prep 4 20/05/0

Pulse Sequence: grinBC

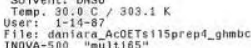

Relax, de lay $1.000 \mathrm{sec}$

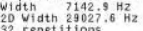

GBSERE H H.

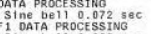

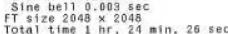

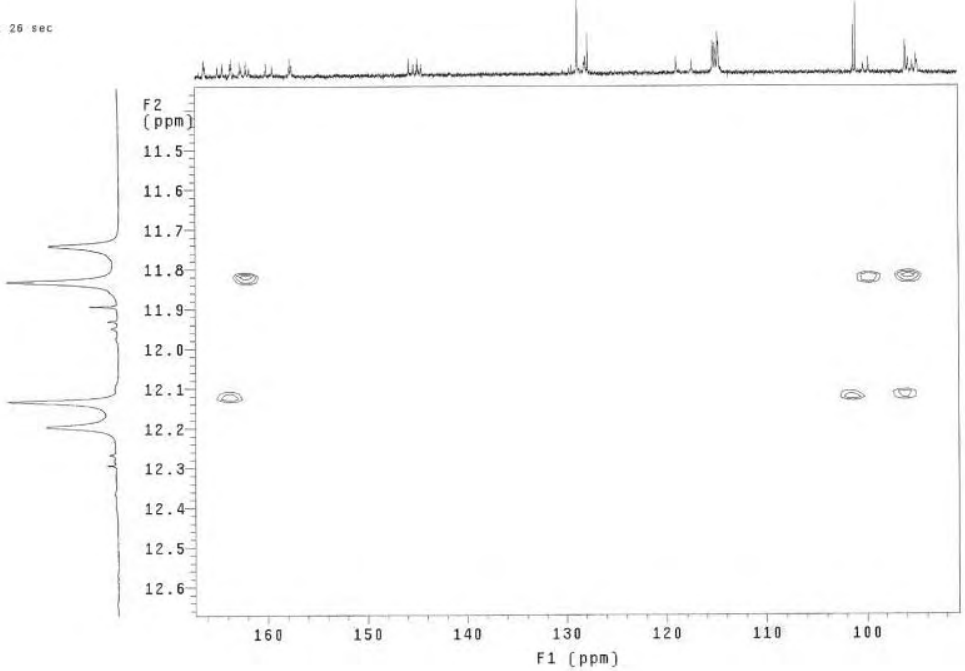

Anexo 172. Ampliação do mapa de contorno ${ }^{1} \mathrm{H}-{ }^{13} \mathrm{C} g \mathrm{HMBC}$ da substância 14 $\left(500 \mathrm{MHz}-\mathrm{DMSO}-d_{6}\right)$ 
Daniara suoH 11 Prep 2 09/06/09

H15e Sequence: s2pur

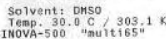

Relax. delay 0.904 sec
Pulse 45.0 degees

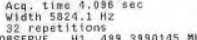

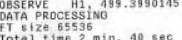

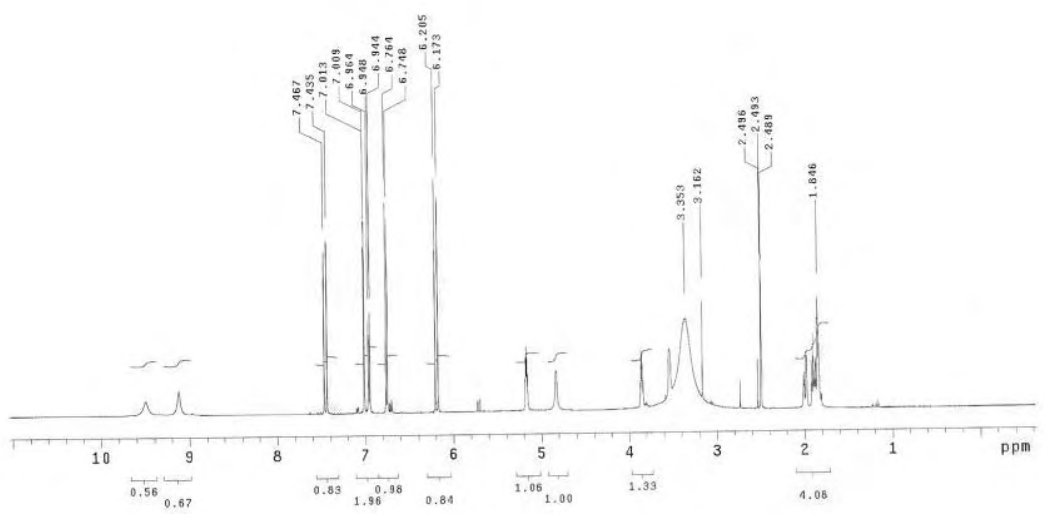

Anexo 173. Espectro de RMN de ${ }^{1} \mathrm{H}$ da substância 17. $\left(500 \mathrm{MHz}-\mathrm{DMSO}-d_{6}\right)$

Daniara BuOH 11 Prep 2 09/06/05

Pulse Sequence: s2pul

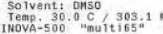

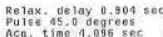

S2 repetitions

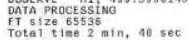

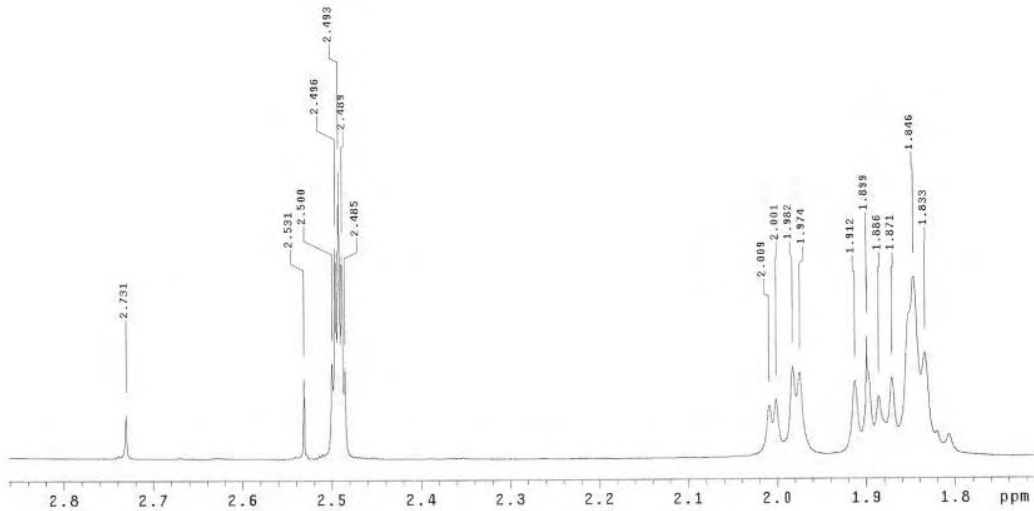

Anexo 174. Ampliação do espectro de RMN de ${ }^{1} \mathrm{H}$ da substância 17.

$\left(500 \mathrm{MHz}-\mathrm{DMSO}-d_{6}\right)$ 
Daniara Buor 11 Prep 2 99/06/09

Thise Sequence: s2pur

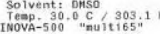

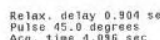

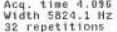

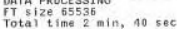

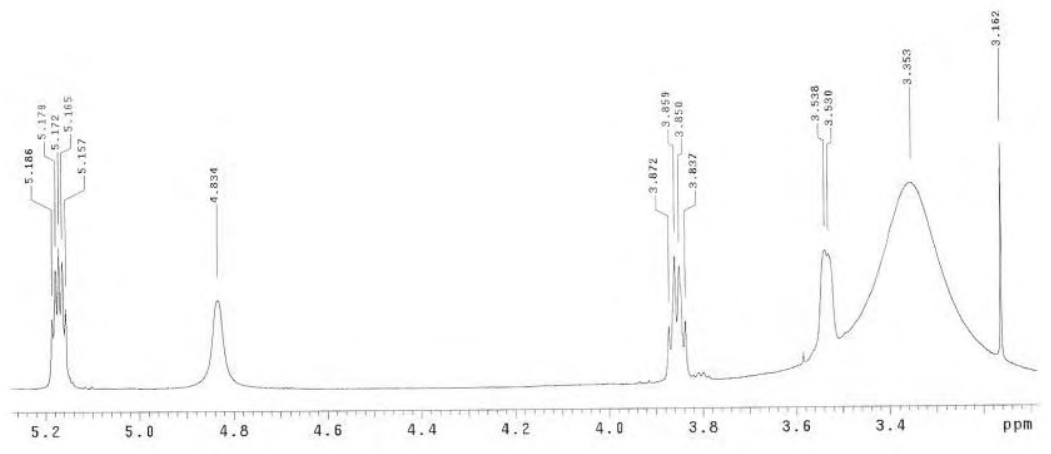

Anexo 175. Ampliação do espectro de RMN de ${ }^{1} \mathrm{H}$ da substância 17. $\left(500 \mathrm{MHz}-\mathrm{DMSO}-d_{6}\right)$

Dantara Buor 11 Prep 2 09/06/09

Pulse Sequence: s2pul

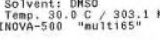

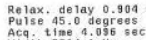

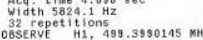

DATA PRoCESSING
FT Eize 65536
Total time $2 \mathrm{~min}, 40 \mathrm{sec}$

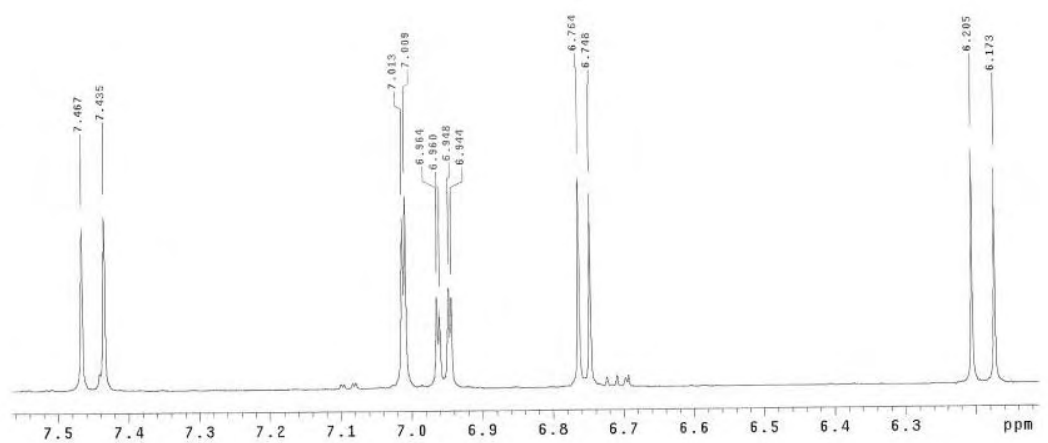

Anexo 176. Ampliação do espectro de RMN de ${ }^{1} \mathrm{H}$ da substância 17.

$$
\left(500 \mathrm{MHz}-\mathrm{DMSO}-d_{6}\right)
$$


Daniara BuoH 11 Prep $209 / 06 / 09$

Pulse Sequence: s2puT

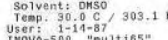

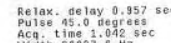

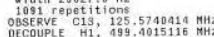

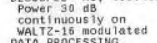

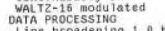

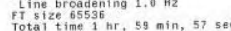

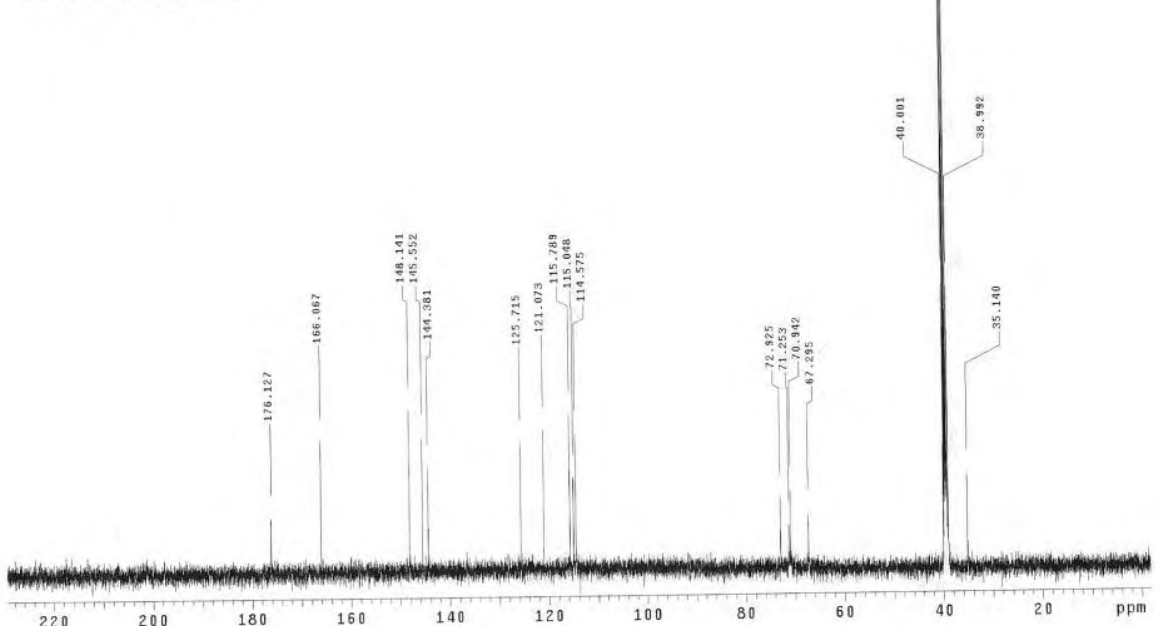

Anexo 177. Espectro de RMN de ${ }^{13} \mathrm{C}$ da substância 17. $\left(125 \mathrm{MHz}-\mathrm{DMSO}-d_{6}\right)$

Dantara BuoH 11 Prep 2 09/06/09

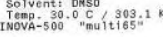

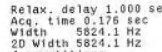

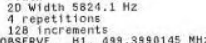

Sa. S sine bet1 $0.088 \mathrm{sec}$

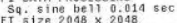

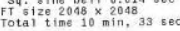

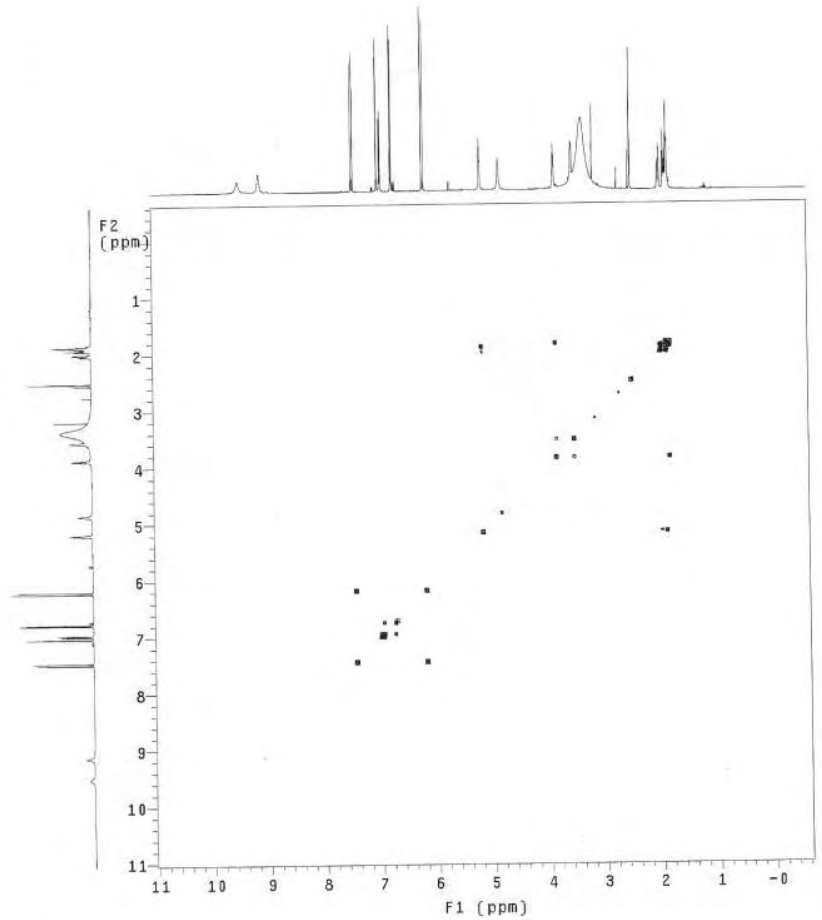

Anexo 178. Mapa de contorno ${ }^{1} \mathrm{H}-{ }^{1} \mathrm{H} g \mathrm{COSY}$ da substância 17.

$\left(500 \mathrm{MHz}-\mathrm{DMSO}-d_{6}\right)$ 
Dantara BuOH 11 Prep 2 09/06/09 Pulse Sequence: $g \cos Y$

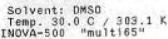

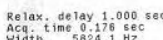
Vidath $5824.1 \mathrm{~Hz}$
20 Width $5824: 1 \mathrm{~Hz}$
4 Wepetititions

128
125
nncrements

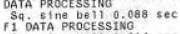

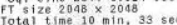

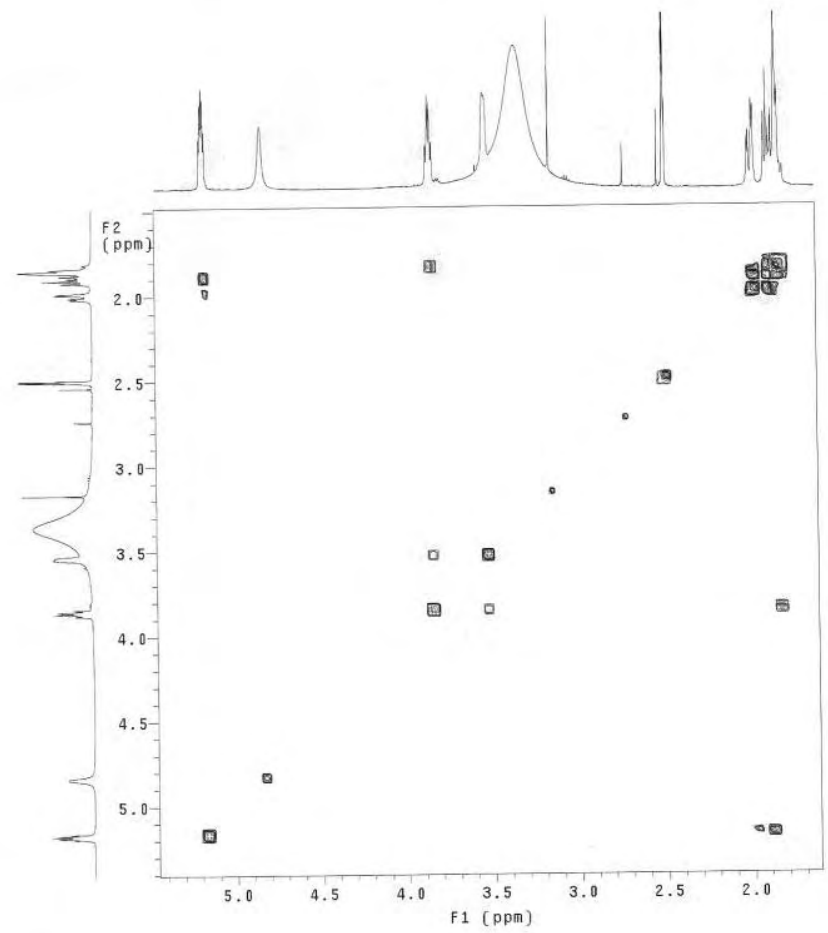

Anexo 179. Ampliação do mapa de contorno ${ }^{1} \mathrm{H}-{ }^{1} \mathrm{H} g \mathrm{COSY}$ da substância 17. $\left(500 \mathrm{MHz}-\mathrm{DMSO}-d_{6}\right)$

Jantara вuон 11 Prep 2 09/06/09

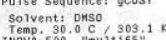

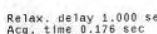

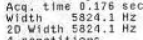

128 increments
BSSRYE

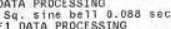

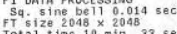

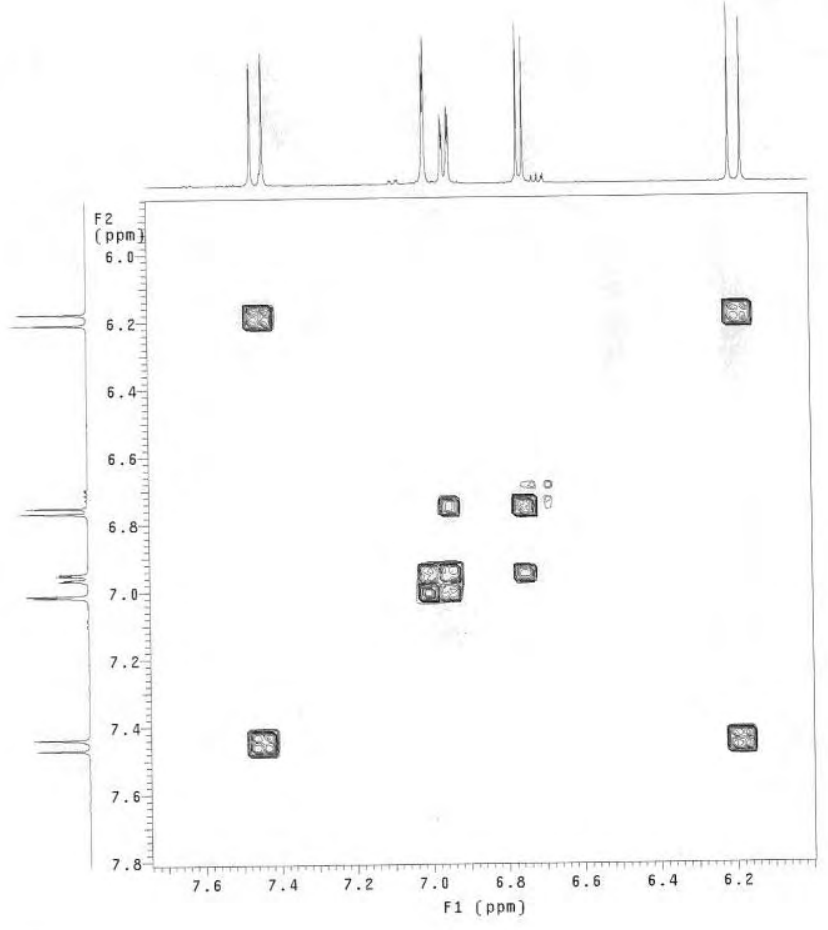

Anexo 180. Ampliação do mapa de contorno ${ }^{1} \mathrm{H}^{-1} \mathrm{H} g \mathrm{COSY}$ da substância 17. $\left(500 \mathrm{MHz}-\mathrm{DMSO}-d_{6}\right)$ 
Daniara Buot 11 Prep $200 / 06 / 09$

Puise Sequence: ghroc

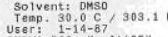

Re lax. de lay 1.000 sec

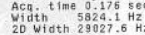

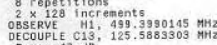

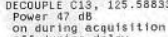

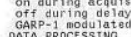

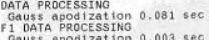

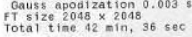

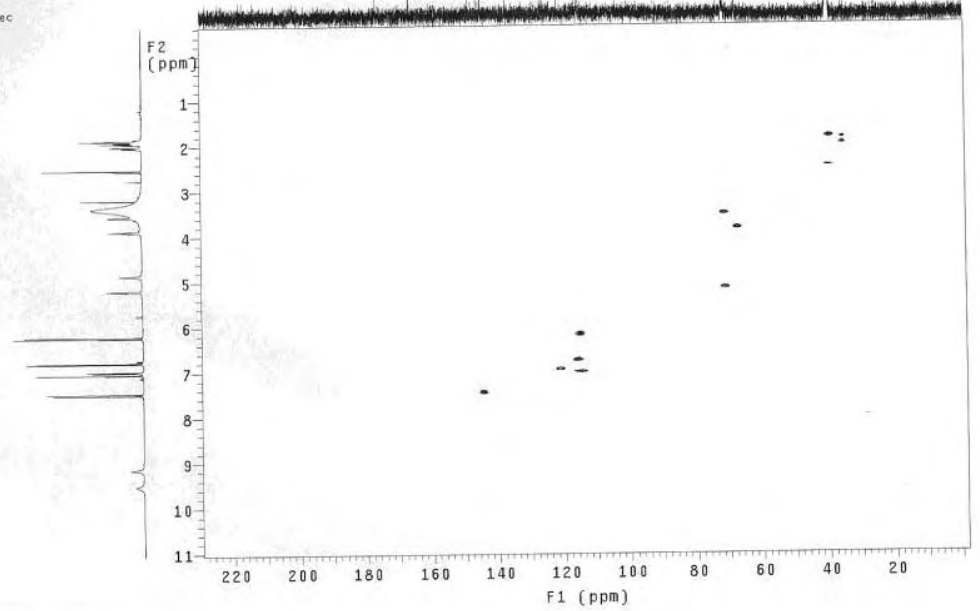

Anexo 181. Mapa de contorno ${ }^{1} \mathrm{H}^{-13} \mathrm{C} g \mathrm{HMQC}$ da substância 17.

$\left(500 \mathrm{MHz}-\mathrm{DMSO}-d_{6}\right)$

Dantara Buoh 11 Prep 2 09/06/09

ulse Sequence: grimoc

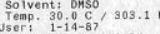

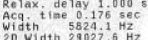

$2 \times 126$ increments

ECOUPLE C13, ${ }^{2} 25.5883903$ KHH

on during acquisitio

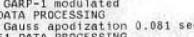

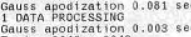

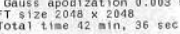

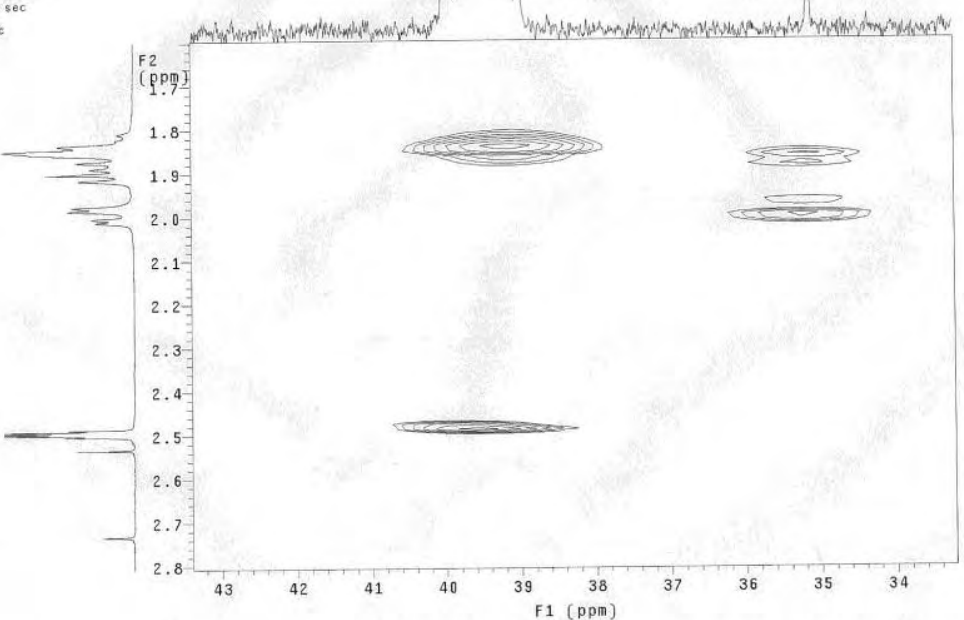

Anexo 182. Ampliação do mapa de contorno ${ }^{1} \mathrm{H}-{ }^{13} \mathrm{C} g \mathrm{HMQC}$ da substância 17 $\left(500 \mathrm{MHz}-\mathrm{DMSO}-d_{6}\right)$ 


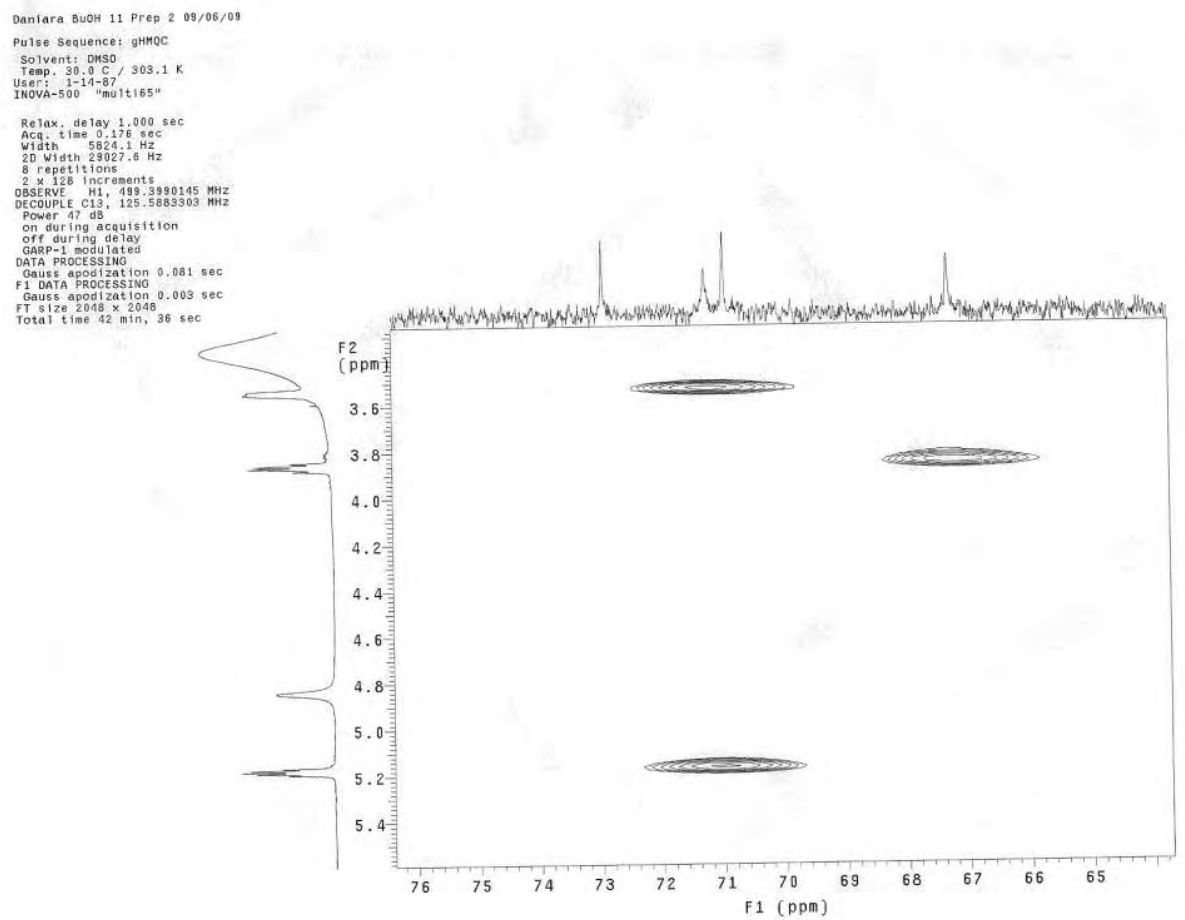

Anexo 183. Ampliação do mapa de contorno ${ }^{1} \mathrm{H}-{ }^{13} \mathrm{C} g \mathrm{HMQC}$ da substância 17. $\left(500 \mathrm{MHz}-\mathrm{DMSO}-d_{6}\right)$

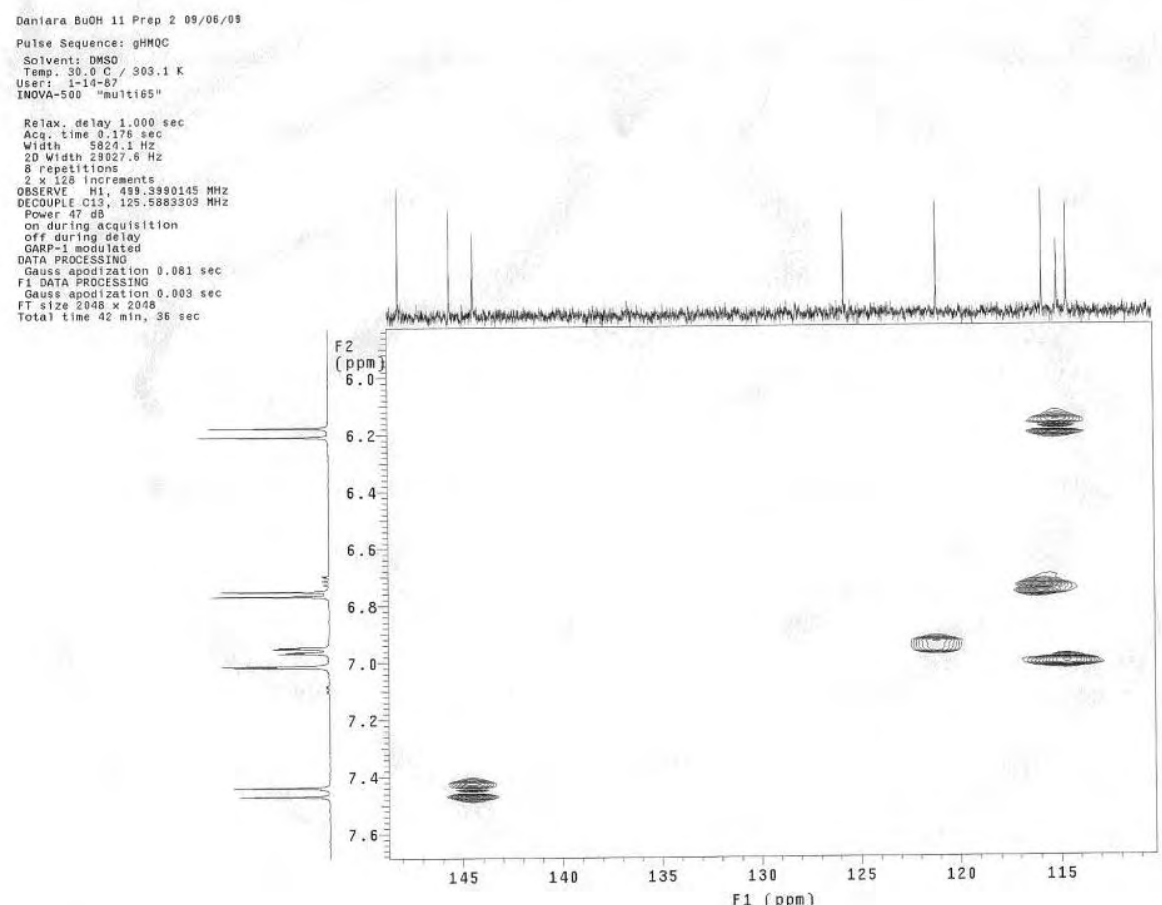

Anexo 184. Ampliação do mapa de contorno ${ }^{1} \mathrm{H}-{ }^{13} \mathrm{C} g \mathrm{HMQC}$ da substância 17.

$$
\left(500 \mathrm{MHz}-\mathrm{DMSO}-d_{6}\right)
$$


Dantara BuOH 11 Prep 2 09/06/09

Pulse Sequence: ghthBC

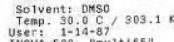

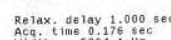

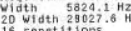

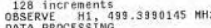

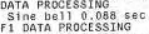

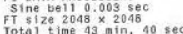

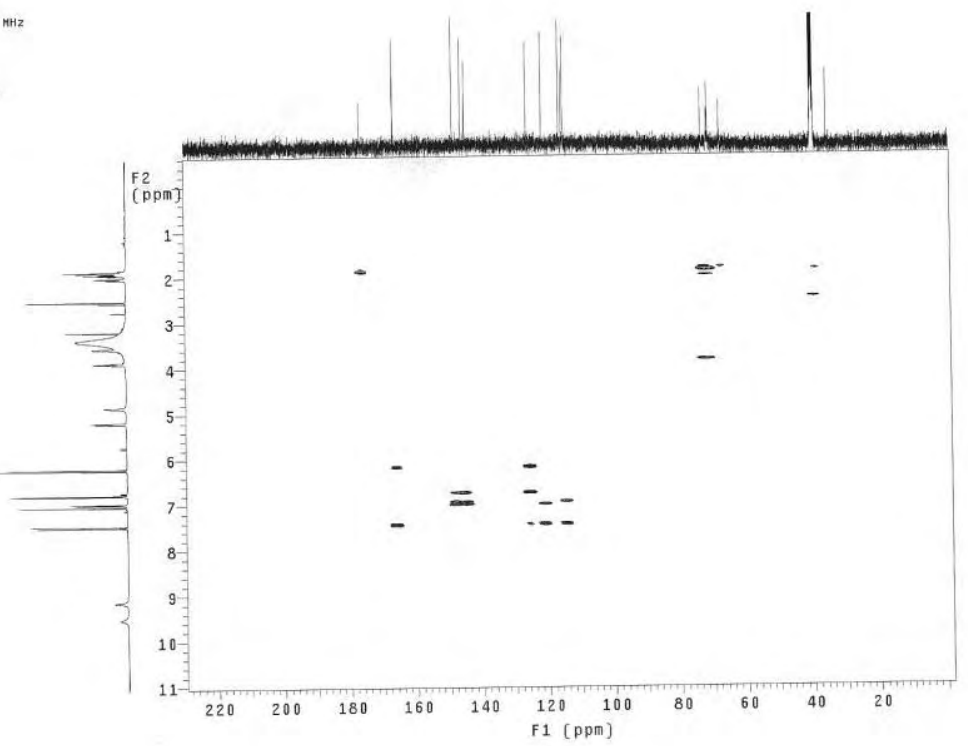

Anexo 185. Mapa de contorno ${ }^{1} \mathrm{H}^{-13} \mathrm{C} g \mathrm{HMBC}$ da substância 17.

$\left(500 \mathrm{MHz}-\mathrm{DMSO}-d_{6}\right)$

Daniara BuoH 11 Prep 2 09/06/09

Pulse Sequence: oHrBC

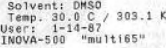

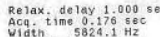

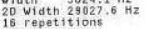

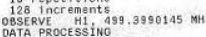

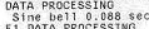

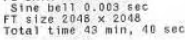

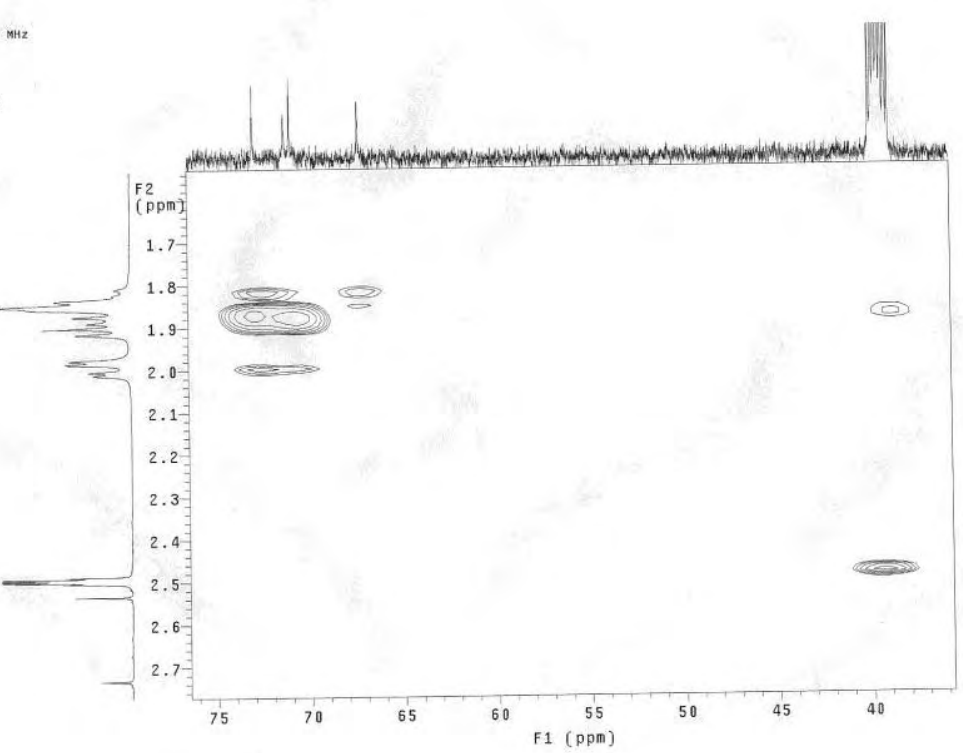

Anexo 186. Ampliação do mapa de contorno ${ }^{1} \mathrm{H}-{ }^{13} \mathrm{C} g \mathrm{HMBC}$ da substância 17. $\left(500 \mathrm{MHz}-\mathrm{DMSO}-d_{6}\right)$ 


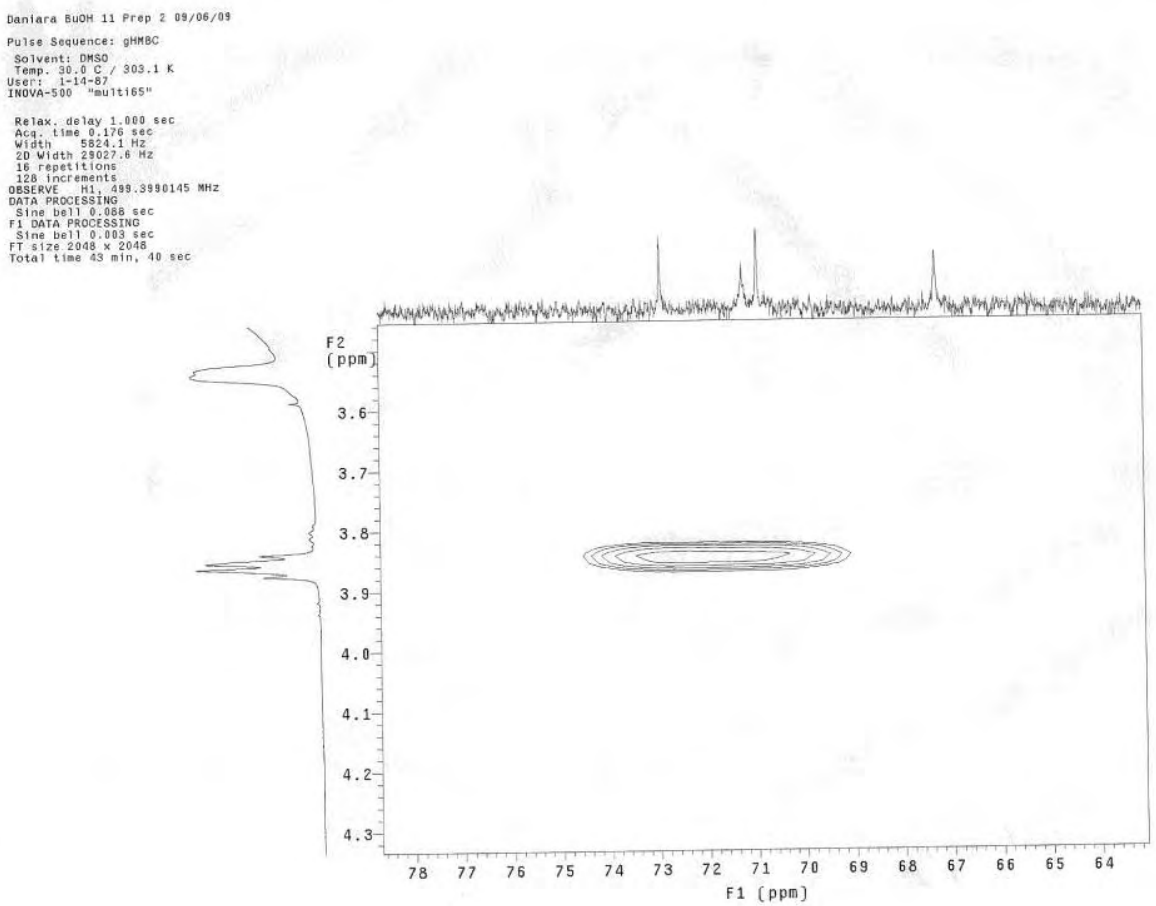

Anexo 187. Ampliação do mapa de contorno ${ }^{1} \mathrm{H}^{13}{ }^{13} \mathrm{C} g \mathrm{HMBC}$ da substância 17. $\left(500 \mathrm{MHz}-\mathrm{DMSO}-d_{6}\right)$

Daniara Buol 11 Prep 2 09/06/09

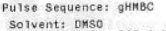

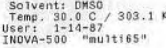

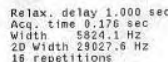

128 Rncrements
BSSEVE

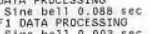

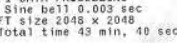

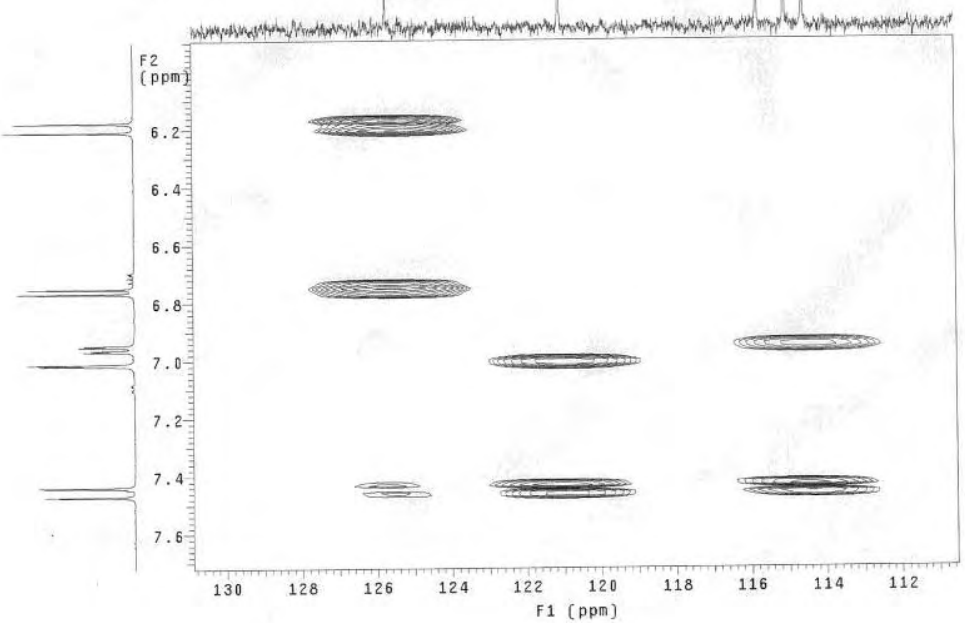

Anexo 188. Ampliação do mapa de contorno ${ }^{1} \mathrm{H}-{ }^{13} \mathrm{C} g \mathrm{HMBC}$ da substância 17. $\left(500 \mathrm{MHz}-\mathrm{DMSO}-d_{6}\right)$ 


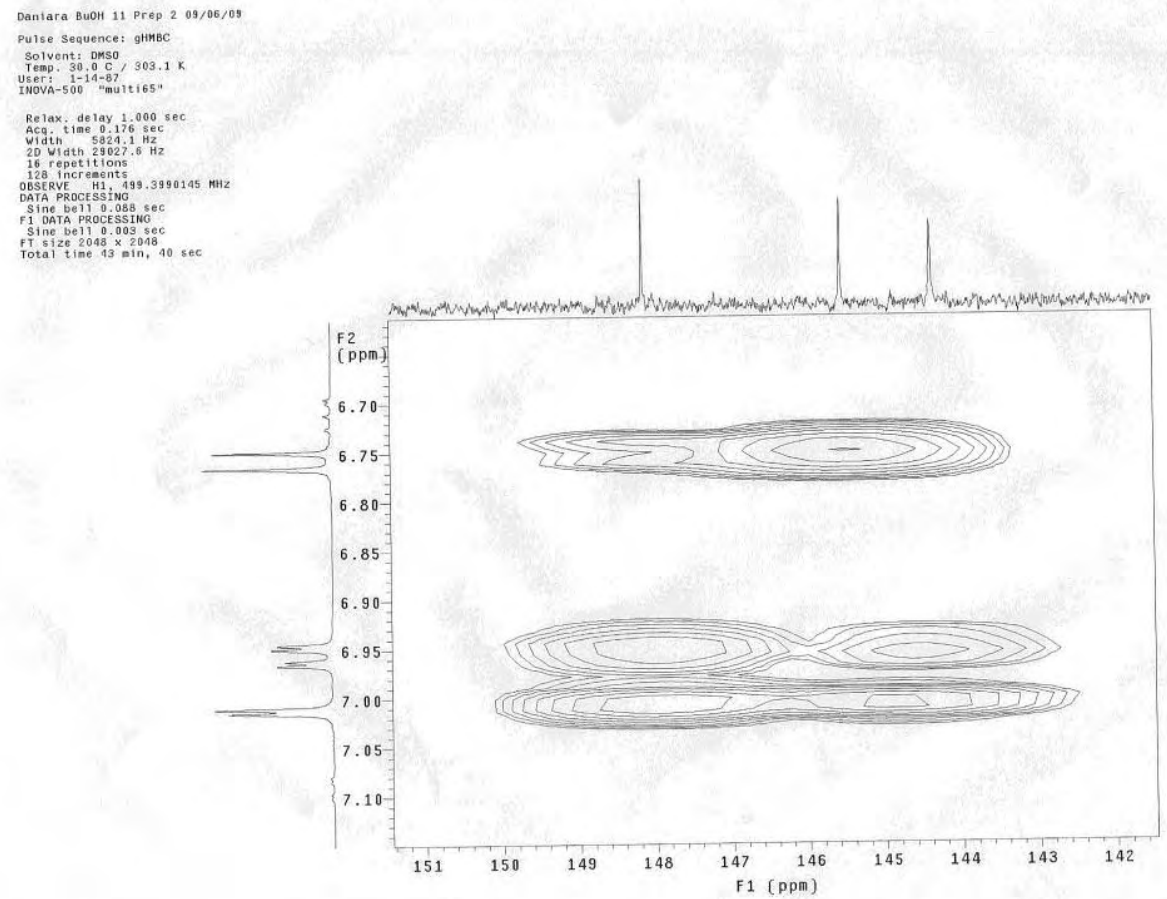

Anexo 189. Ampliação do mapa de contorno ${ }^{1} \mathrm{H}_{-}{ }^{13} \mathrm{C} g \mathrm{HMBC}$ da substância 17. $\left(500 \mathrm{MHz}-\mathrm{DMSO}-d_{6}\right)$

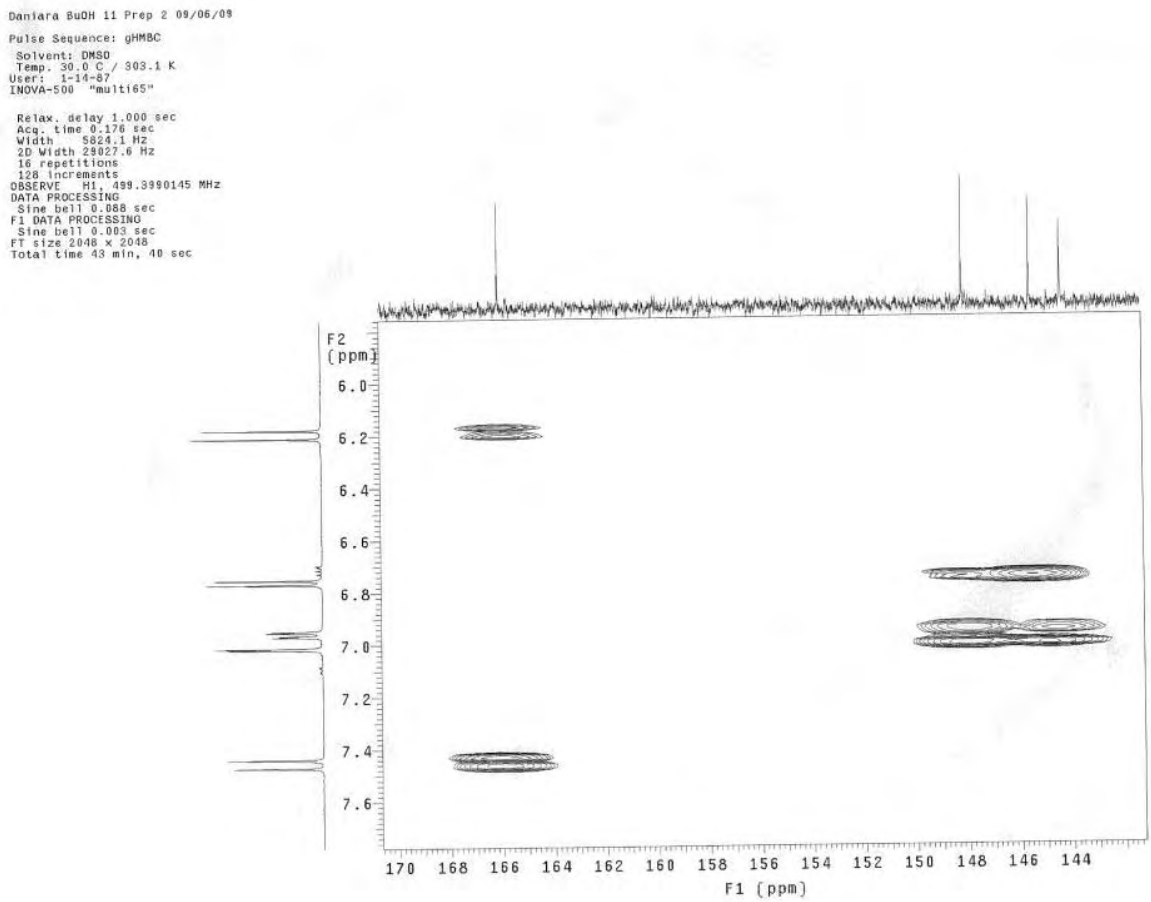

Anexo 190. Ampliação do mapa de contorno ${ }^{1} \mathrm{H}-{ }^{13} \mathrm{C} g \mathrm{HMBC}$ da substância 17. $\left(500 \mathrm{MHz}-\mathrm{DMSO}-d_{6}\right)$ 
Dantiara Buor 11 prep 5 09/06/09

Solvent: Drso 12 pir

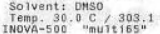

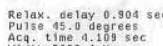

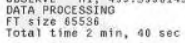

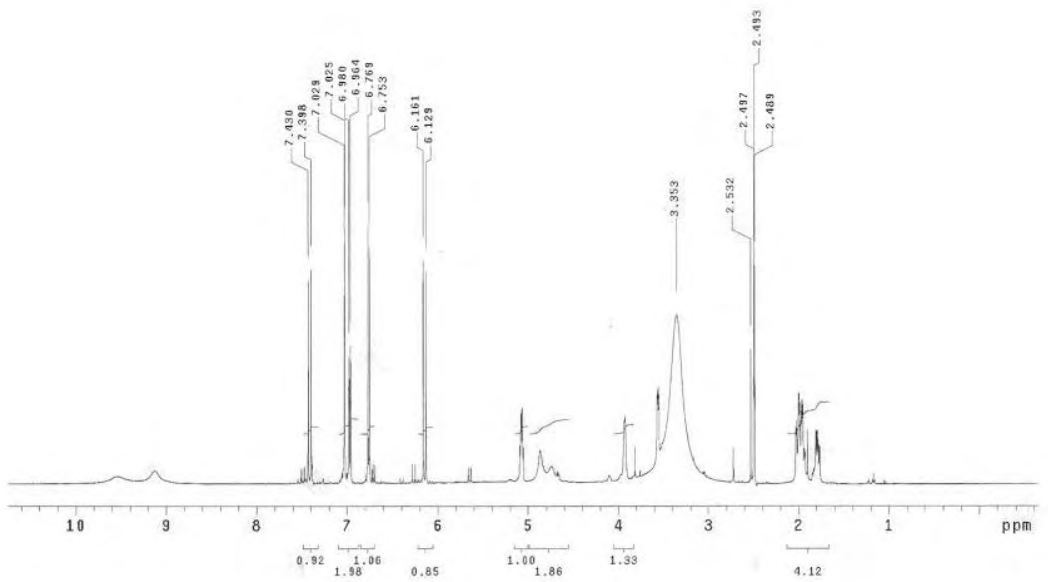

Anexo 191. Espectro de RMN de ${ }^{1} \mathrm{H}$ da substância 18.

$\left(500 \mathrm{MHz}-\mathrm{DMSO}-d_{6}\right)$

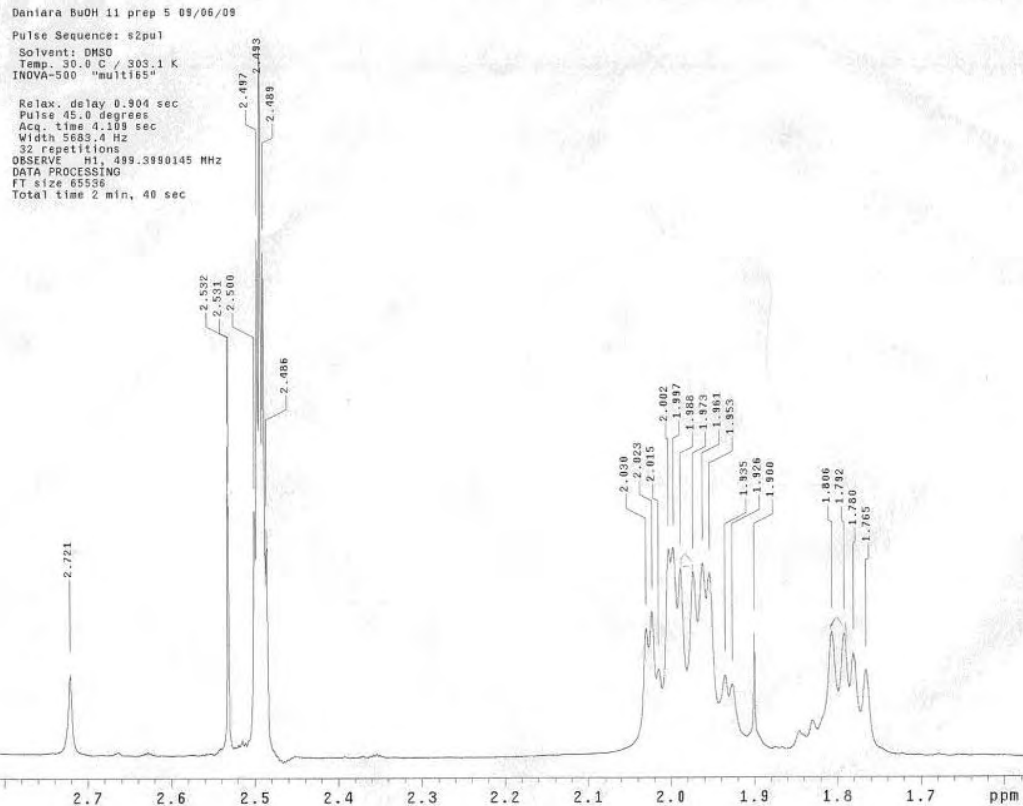

Anexo 192. Ampliação do espectro de RMN de ${ }^{1} \mathrm{H}$ da substância 18.

$\left(500 \mathrm{MHz}-\mathrm{DMSO}-d_{6}\right)$ 


\section{।}

Dantara Buot 11 prep 5 09/06/0

Pulse Sequence: s2pul

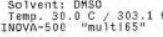

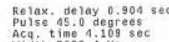

32 repet titons
Bes

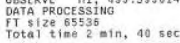

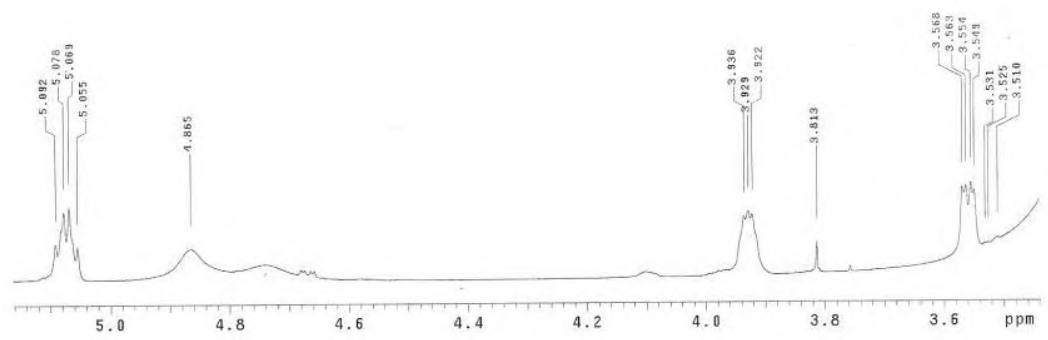

Anexo 193. Ampliação do espectro de RMN de ${ }^{1} \mathrm{H}$ da substância 18. $\left(500 \mathrm{MHz}-\mathrm{DMSO}-d_{6}\right)$

Daniara Buoll 11 prep 5 09/06/08

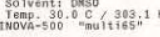

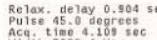

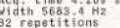

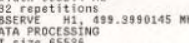

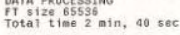

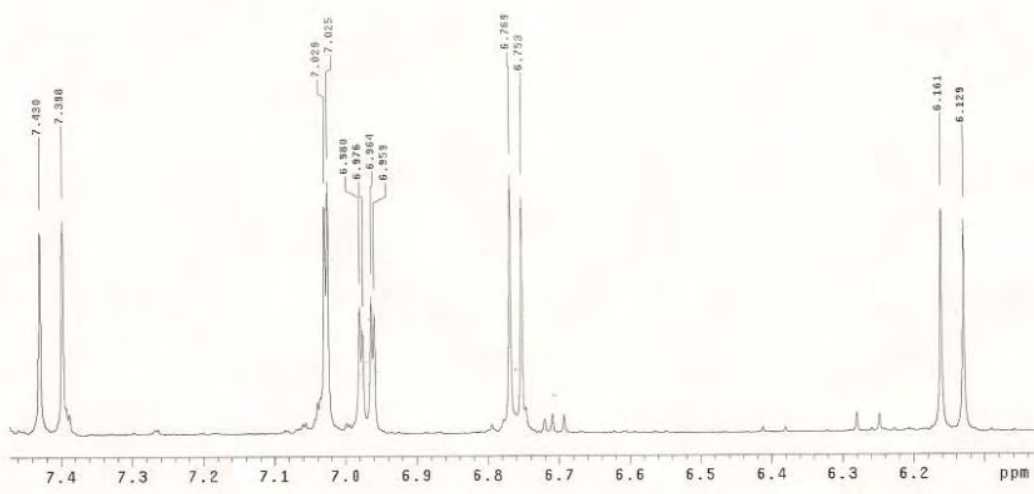

Anexo 194. Ampliação do espectro de RMN de ${ }^{1} \mathrm{H}$ da substância 18.

$\left(500 \mathrm{MHz}-\mathrm{DMSO}-d_{6}\right)$ 
Daniara BuoH 11 prep 5 09/06/0

Pulse Sequence: $52 \mathrm{puT}$
Solvent: 0yso

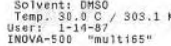

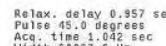

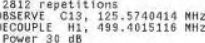

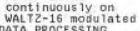

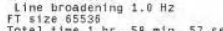

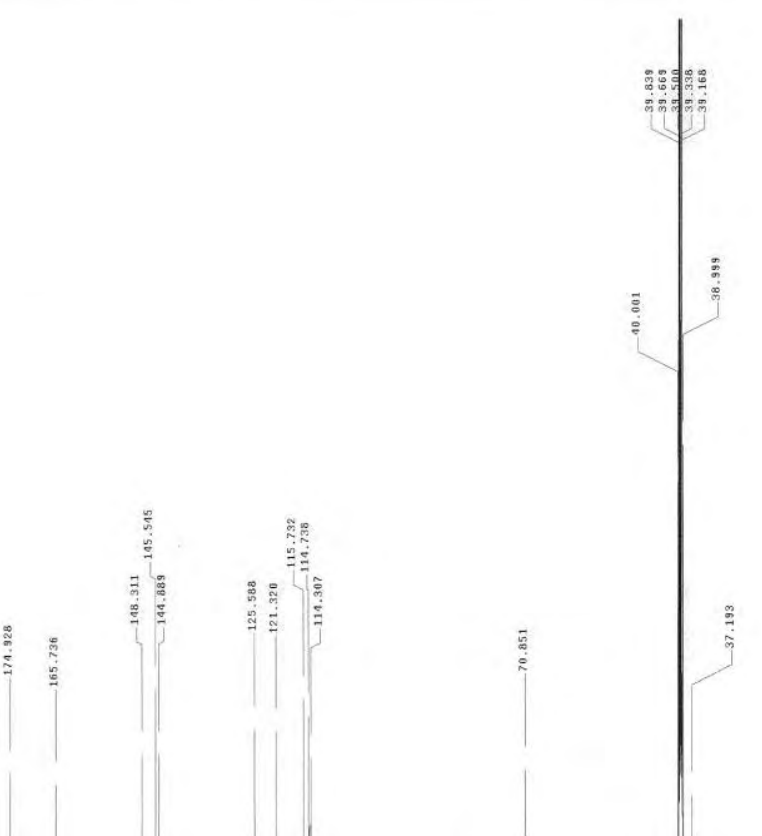

$\quad 80$

Anexo 195. Espectro de RMN de ${ }^{13} \mathrm{C}$ da substância 18

$\left(125 \mathrm{MHz}-\mathrm{DMSO}-d_{6}\right)$

Dantara BuoH 11 prep $509 / 06 / 00$

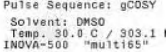

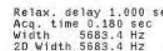

20 Uidth 5683.4 Hz

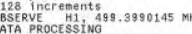

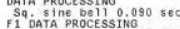

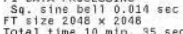

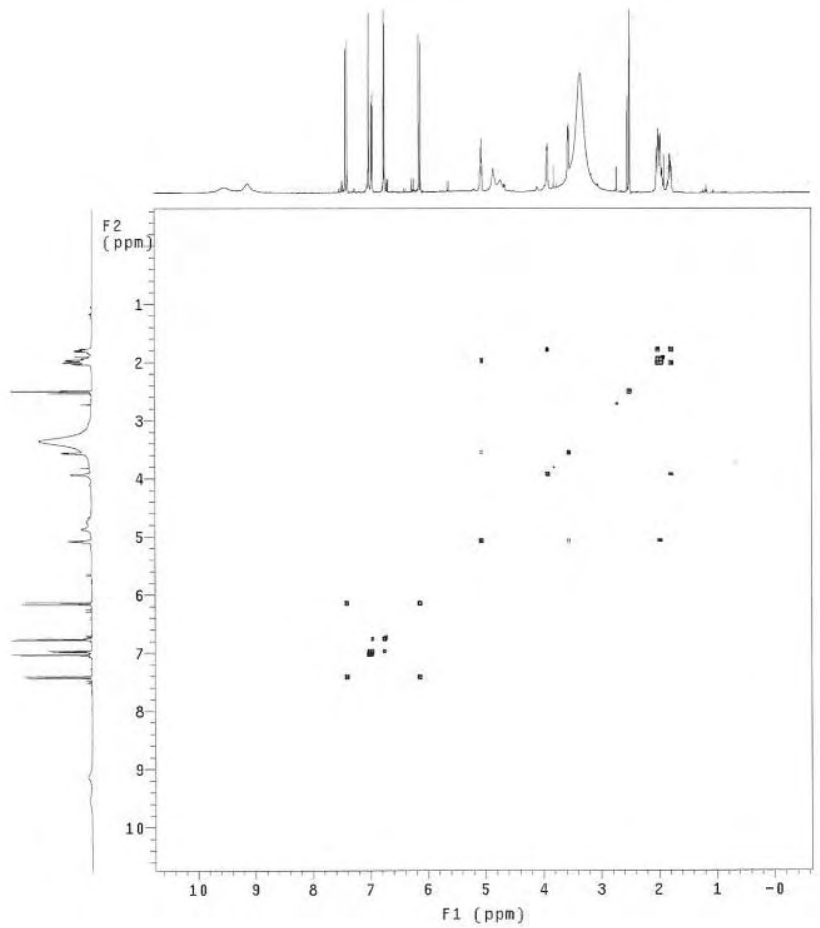

Anexo 196. Mapa de contorno ${ }^{1} \mathrm{H}-{ }^{1} \mathrm{H} g \mathrm{COSY}$ da substância 18.

$\left(500 \mathrm{MHz}-\mathrm{DMSO}-d_{6}\right)$ 
Dantara BuoH 11 prep 5 09/06/0,

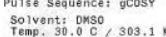

Re Tax, delay 1.000 sec

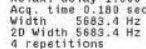

128 increments
BSERVE
BSt

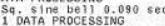

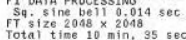

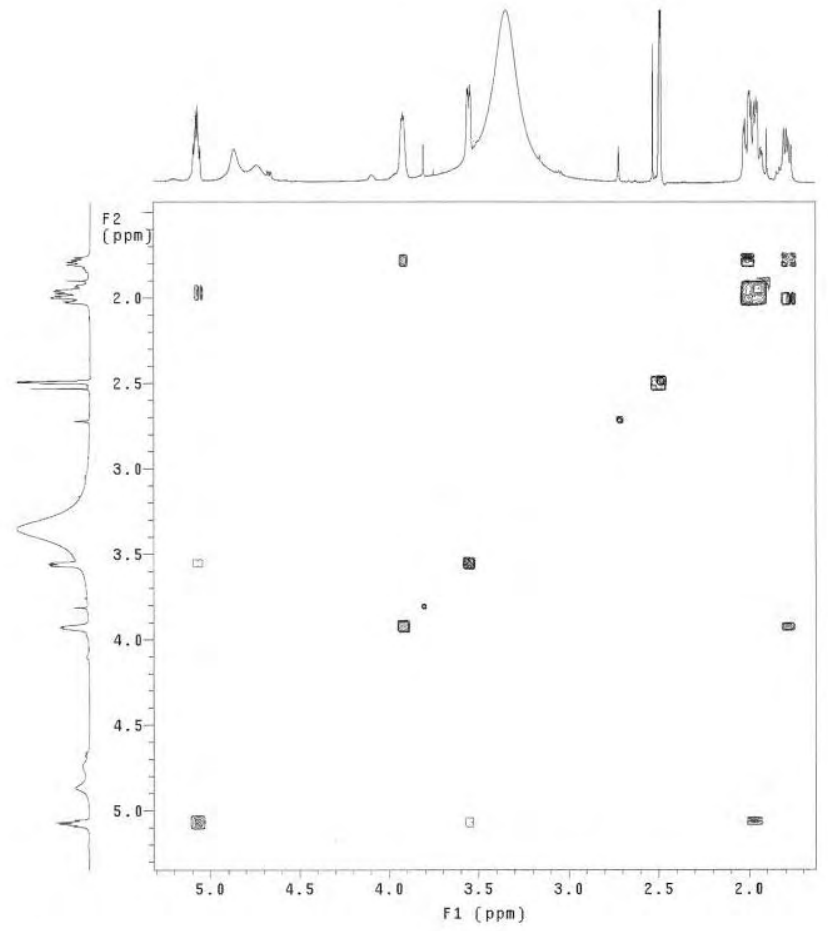

Anexo 197. Ampliação do mapa de contorno ${ }^{1} \mathrm{H}^{1}{ }^{1} \mathrm{H} g \mathrm{COSY}$ da substância 18. $\left(500 \mathrm{MHz}-\mathrm{DMSO}-d_{6}\right)$

Daniara BuoH 11 prep 5 09/06/09

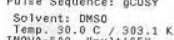

Relax , de tay 1.000 sec

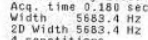

128 nCrements
OBSERVE
OBST

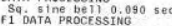

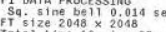

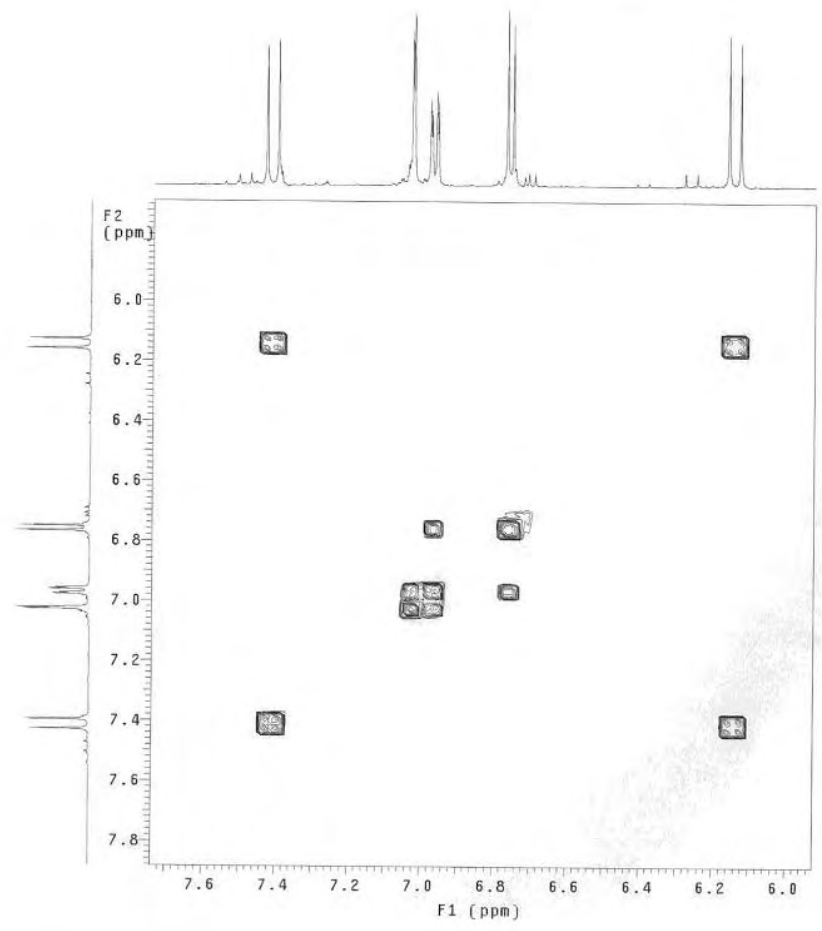

Anexo 198. Ampliação do mapa de contorno ${ }^{1} \mathrm{H}^{-1} \mathrm{H} g \mathrm{COSY}$ da substância 18.

$$
\left(500 \mathrm{MHz}-\mathrm{DMSO}-d_{6}\right)
$$


Dantara Buol 21 prep 5 09/06/0

Pulse Sequence: ghmoc

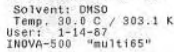
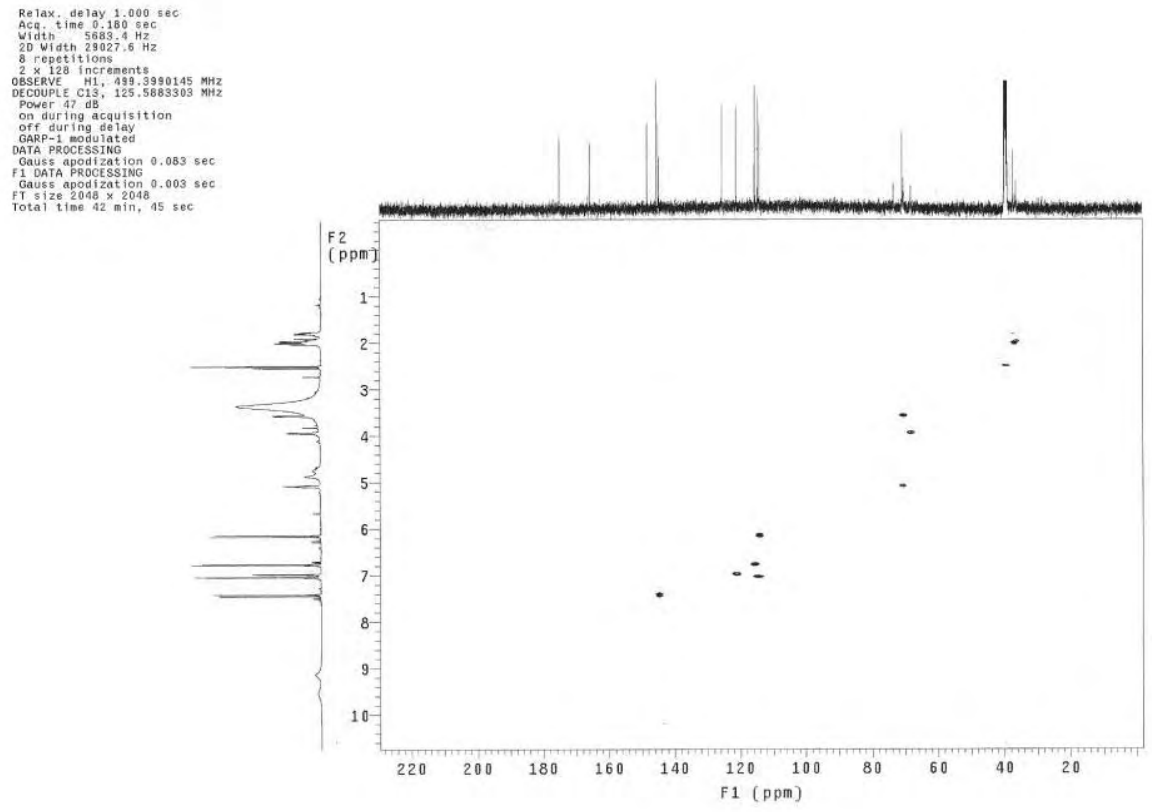

Anexo 199. Mapa de contorno ${ }^{1} \mathrm{H}_{-}{ }^{13} \mathrm{C} g \mathrm{HMQC}$ da substância 18. $\left(500 \mathrm{MHz}-\mathrm{DMSO}-d_{6}\right)$

Daniara BuoH 11 prep 5 09/06/0

Pulse sequence: gHhoc
Solvent: puss

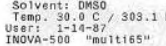

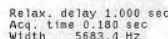

8 repetitions

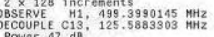

Power 47 dB
on durng acquisition
off during de lay

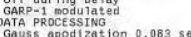

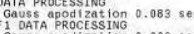

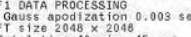
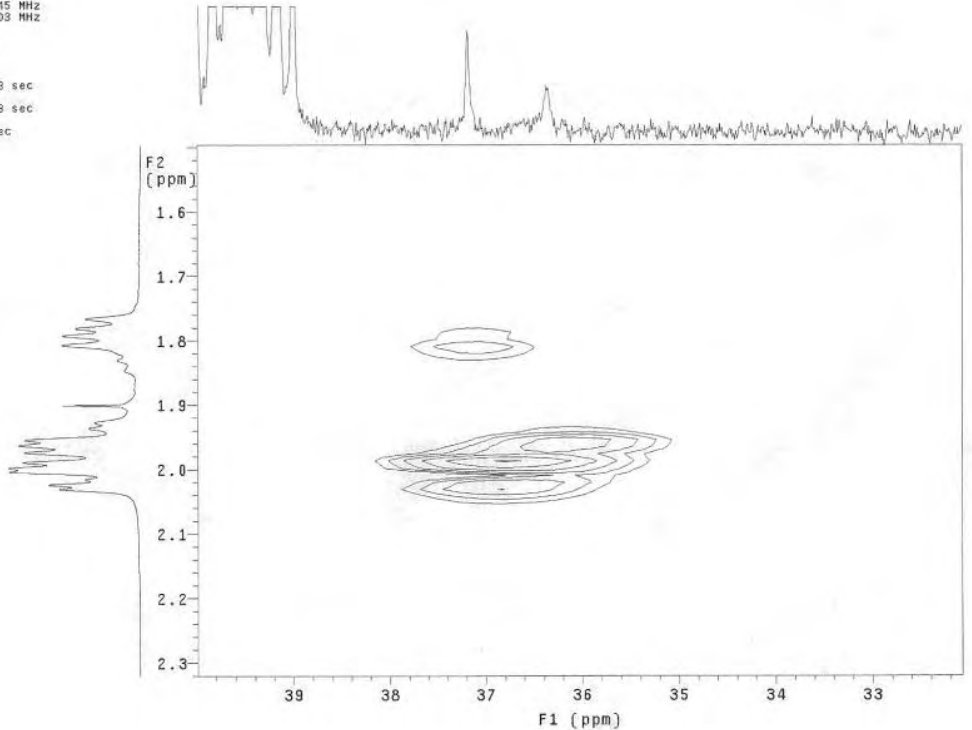

Anexo 200. Ampliação do mapa de contorno ${ }^{1} \mathrm{H}_{-}{ }^{13} \mathrm{C} g \mathrm{HMQC}$ da substância 18.

$$
\left(500 \mathrm{MHz}-\mathrm{DMSO}-d_{6}\right)
$$


Dantara Buor 11 prep 5 09/06/09

Pulse Sequence: gHroc

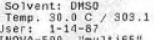

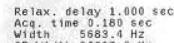

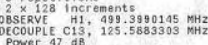

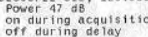

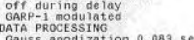

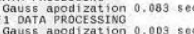

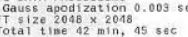

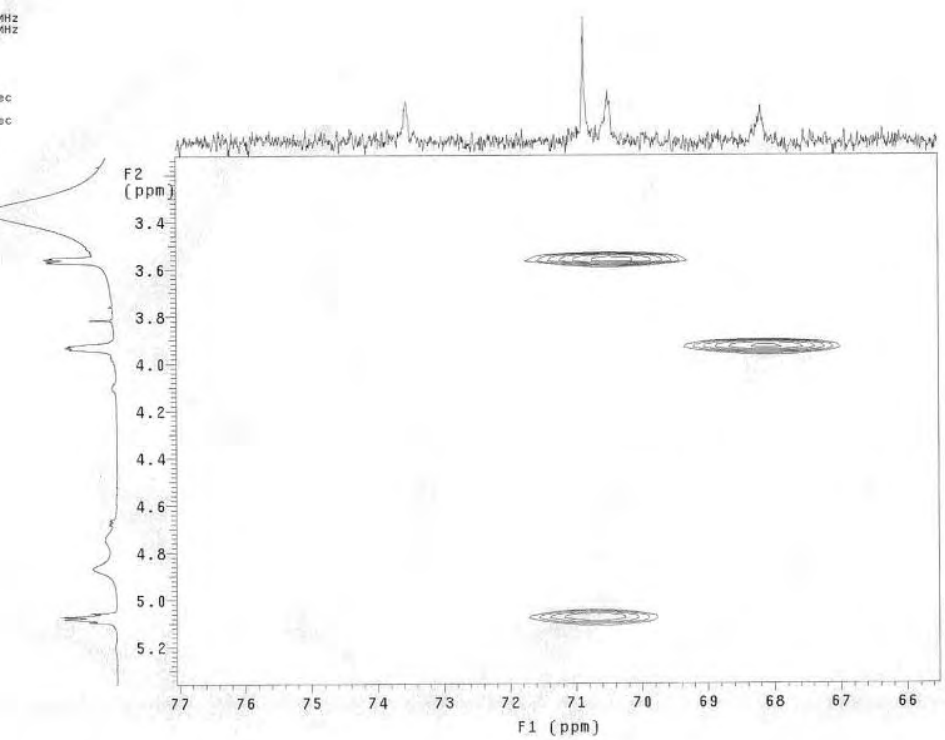

Anexo 201. Ampliação do mapa de contorno ${ }^{1} \mathrm{H}-{ }^{13} \mathrm{C} g \mathrm{HMQC}$ da substância 18.

$\left(500 \mathrm{MHz}-\mathrm{DMSO}-d_{6}\right)$

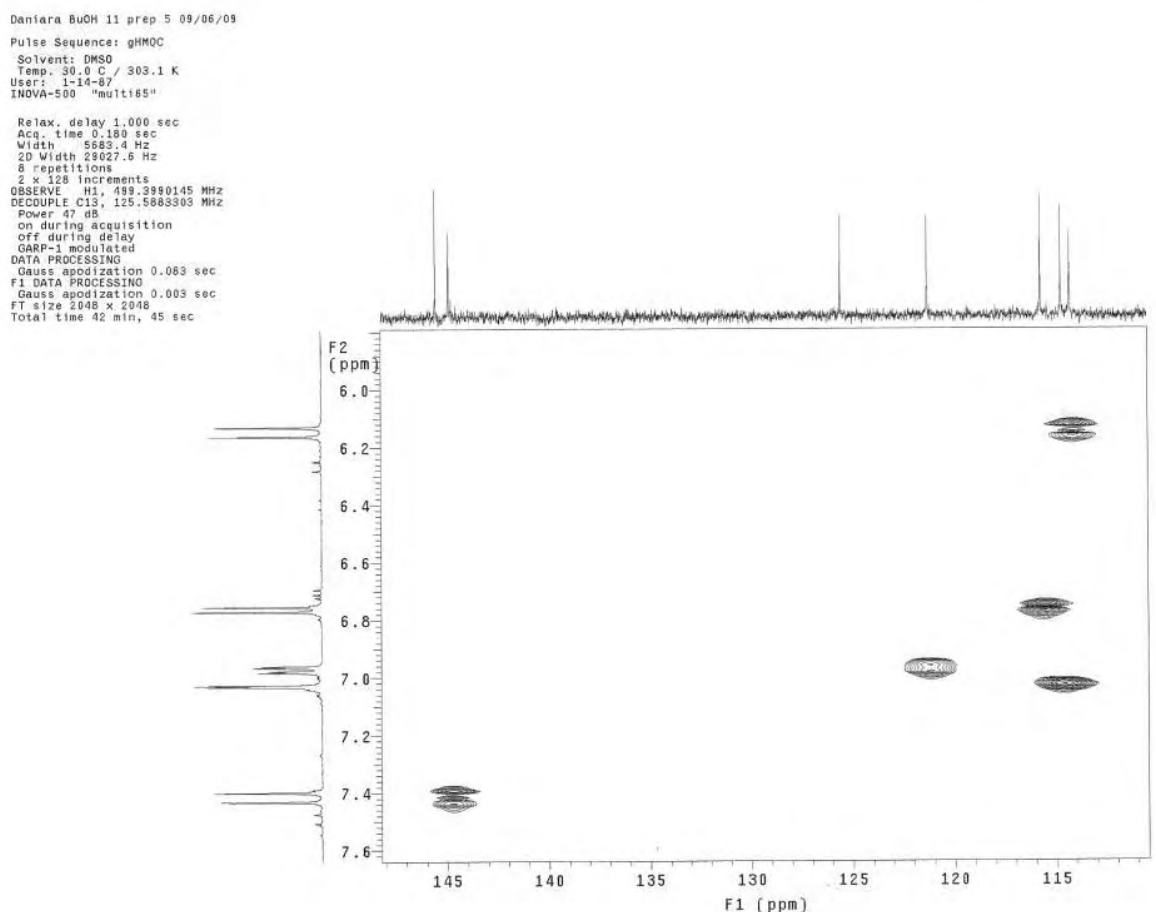

Anexo 202. Ampliação do mapa de contorno ${ }^{1} \mathrm{H}-{ }^{13} \mathrm{C} g \mathrm{HMQC}$ da substância 18.

$\left(500 \mathrm{MHz}-\mathrm{DMSO}-d_{6}\right)$ 
Dantara BuoH 11 prep 5 09/06/09

Puise Sequence: grhBC
solvent: OHSO

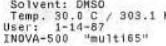
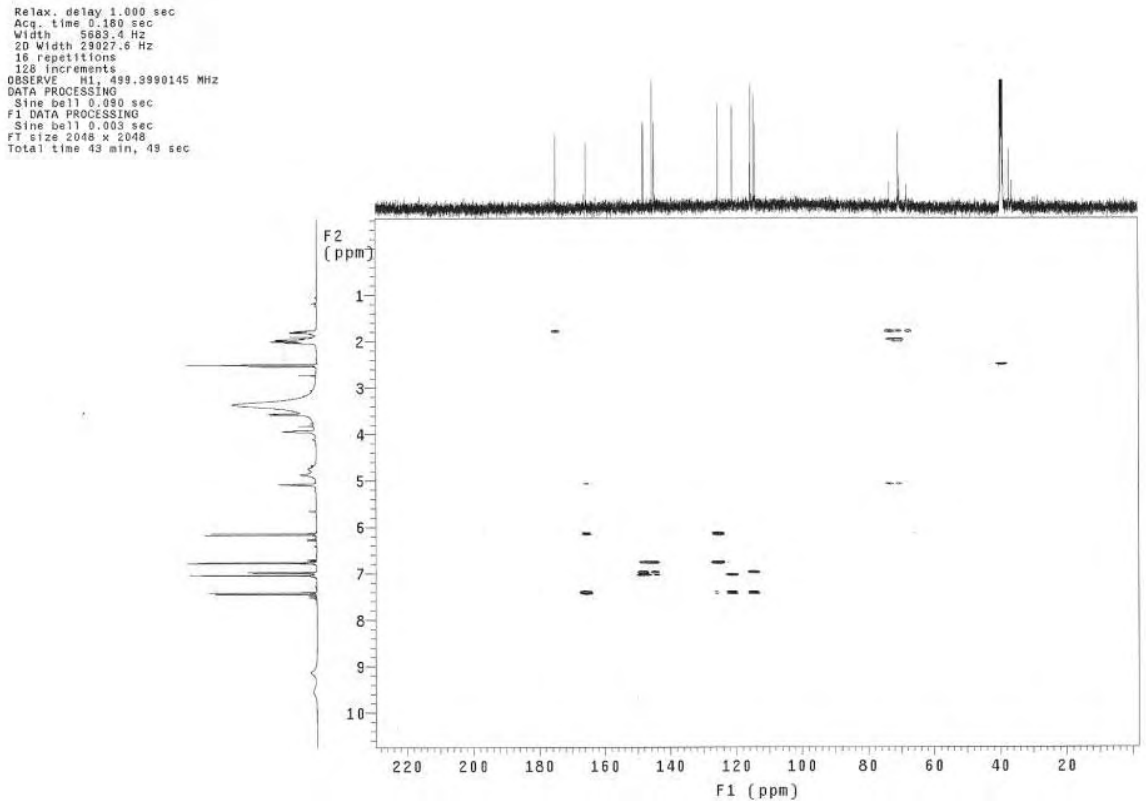

Anexo 203. Mapa de contorno ${ }^{1} \mathrm{H}-{ }^{13} \mathrm{C} g \mathrm{HMBC}$ da substância 18 $\left(500 \mathrm{MHz}-\mathrm{DMSO}-d_{6}\right)$

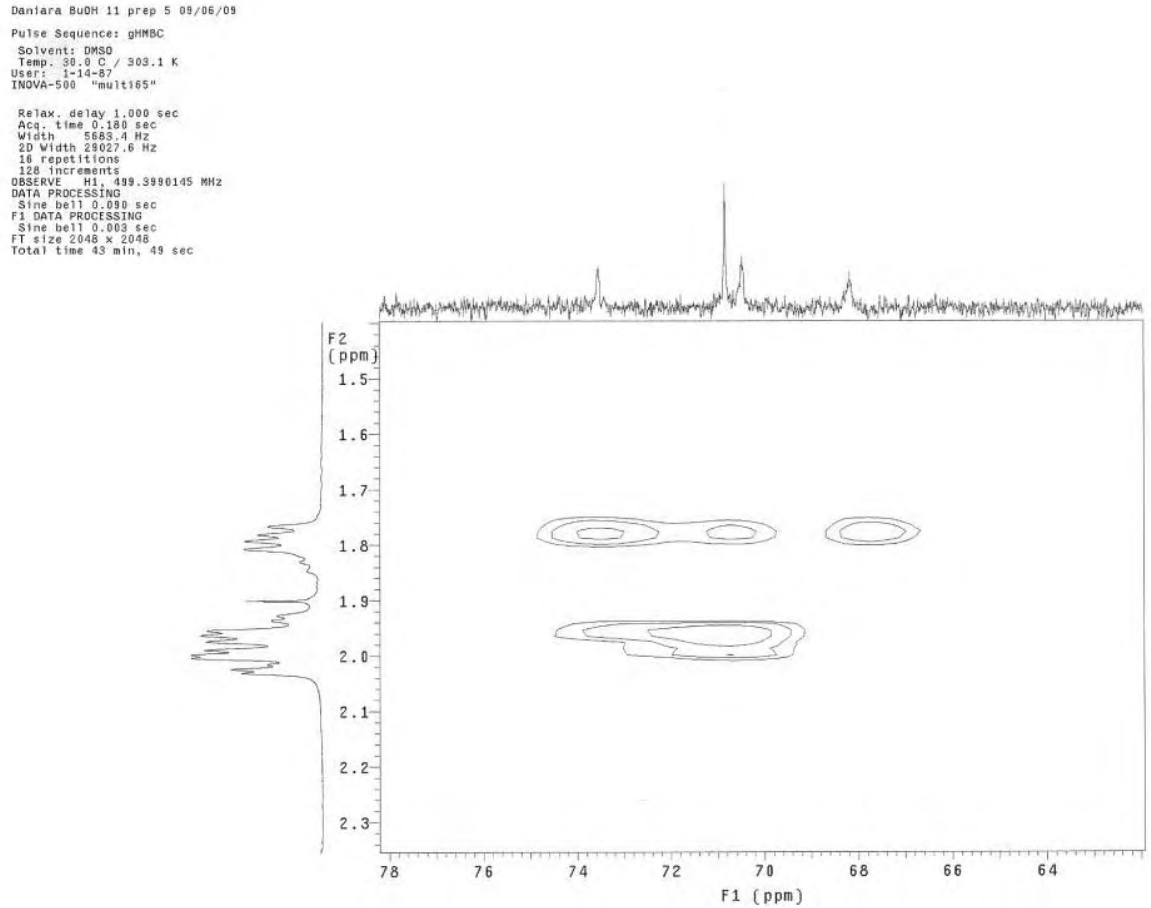

Anexo 204. Ampliação do mapa de contorno ${ }^{1} \mathrm{H}^{13}{ }^{13} \mathrm{C} g \mathrm{HMBC}$ da substância 18.

$$
\left(500 \mathrm{MHz}-\mathrm{DMSO}-d_{6}\right)
$$


Daniara Buor 11 prep 5 09/06/09

Pulse sequence: OHHBC
Solvent: Drso

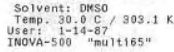

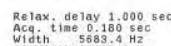

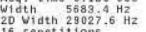

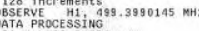

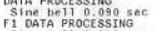

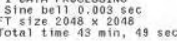

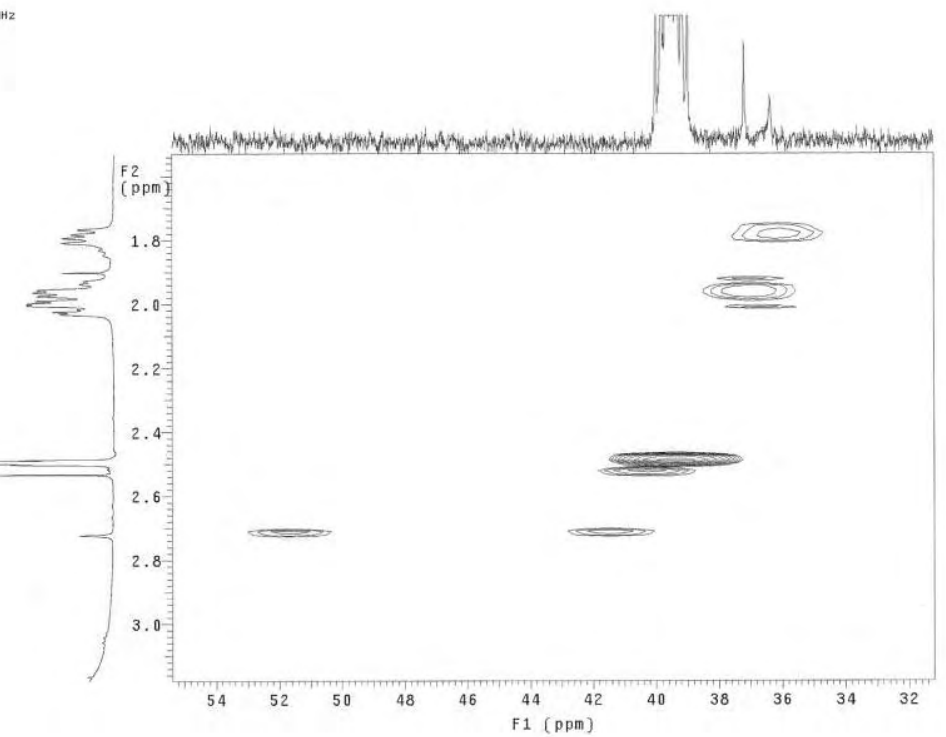

Anexo 205. Ampliação do mapa de contorno ${ }^{1} \mathrm{H}-{ }^{13} \mathrm{C} g \mathrm{HMBC}$ da substância 18.

$$
\left(500 \mathrm{MHz}-\mathrm{DMSO}-d_{6}\right)
$$

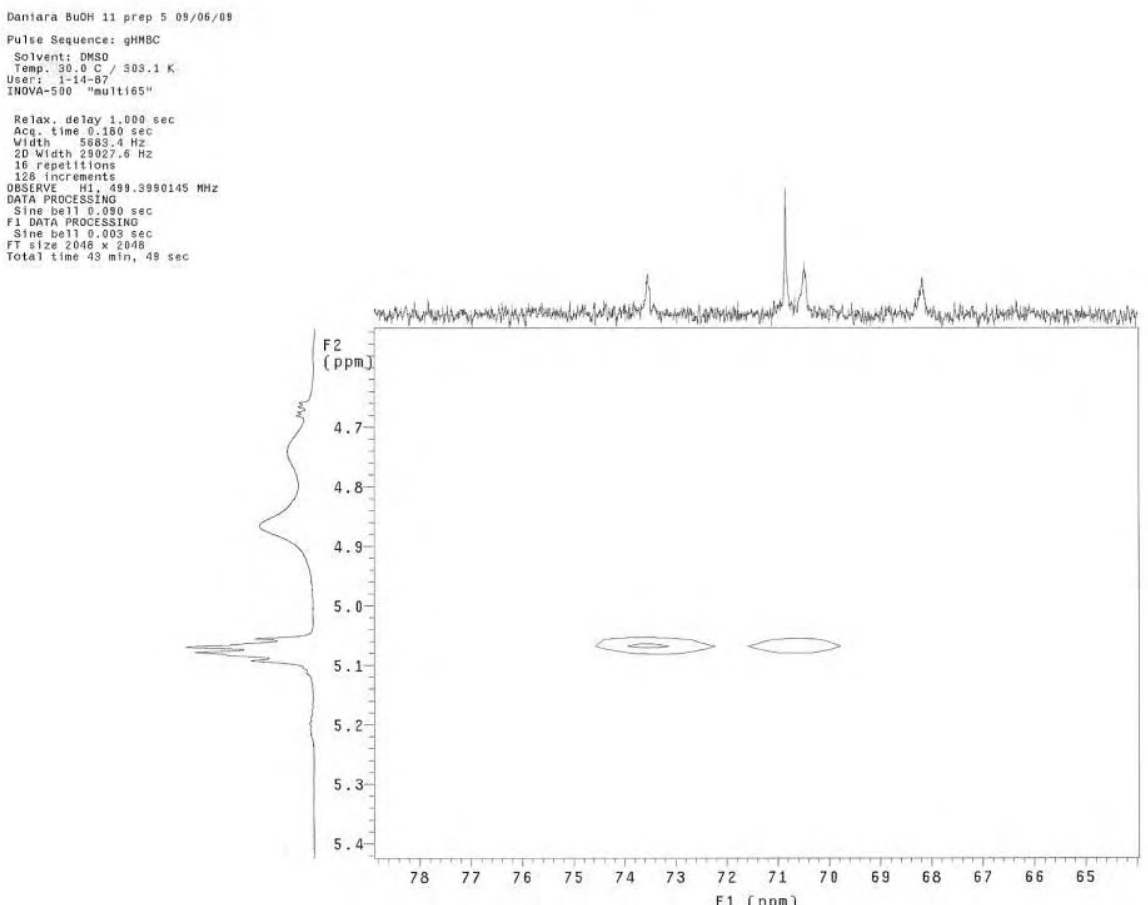

Anexo 206. Ampliação do mapa de contorno ${ }^{1} \mathrm{H}_{-}{ }^{13} \mathrm{C} g \mathrm{HMBC}$ da substância 18.

$$
\left(500 \mathrm{MHz}-\mathrm{DMSO}-d_{6}\right)
$$


Dantara BuoH 11 prep 5 09/06/09

Polvent: Duso : gHrBC

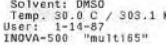
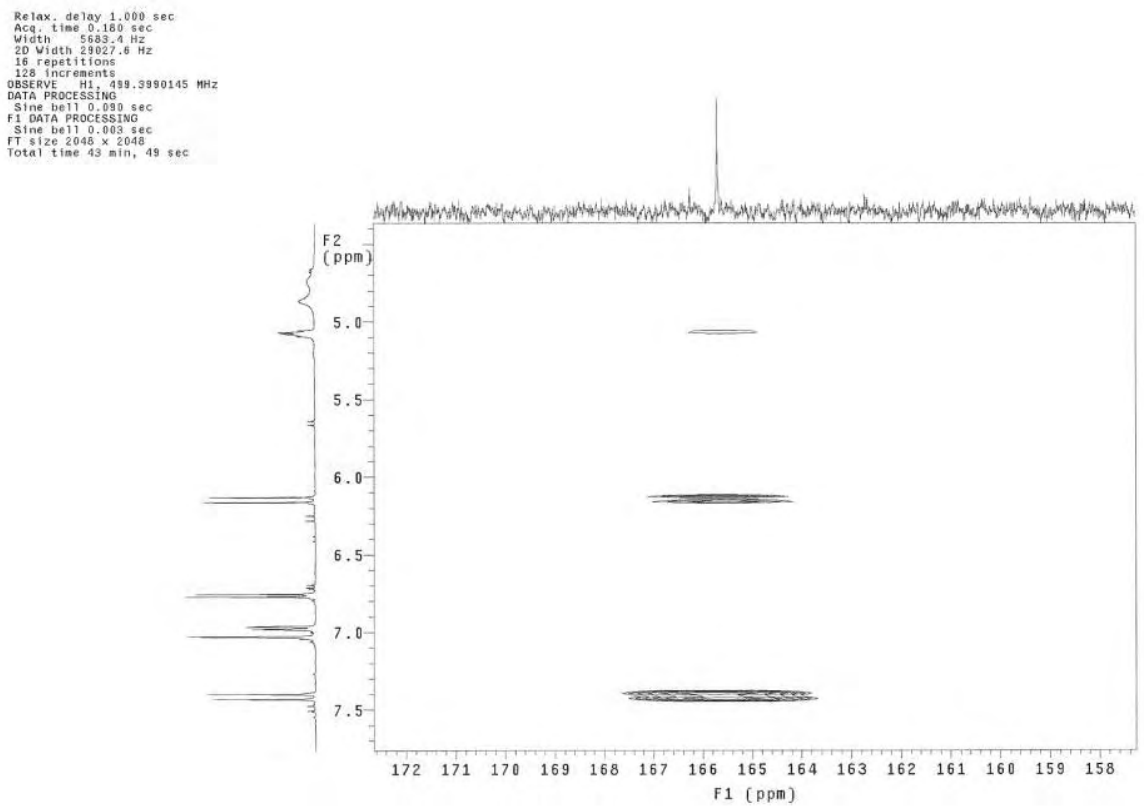

Anexo 207. Ampliação do mapa de contorno ${ }^{1} \mathrm{H}-{ }^{13} \mathrm{C} g \mathrm{HMBC}$ da substância 18.

$$
\left(500 \mathrm{MHz}-\mathrm{DMSO}-d_{6}\right)
$$

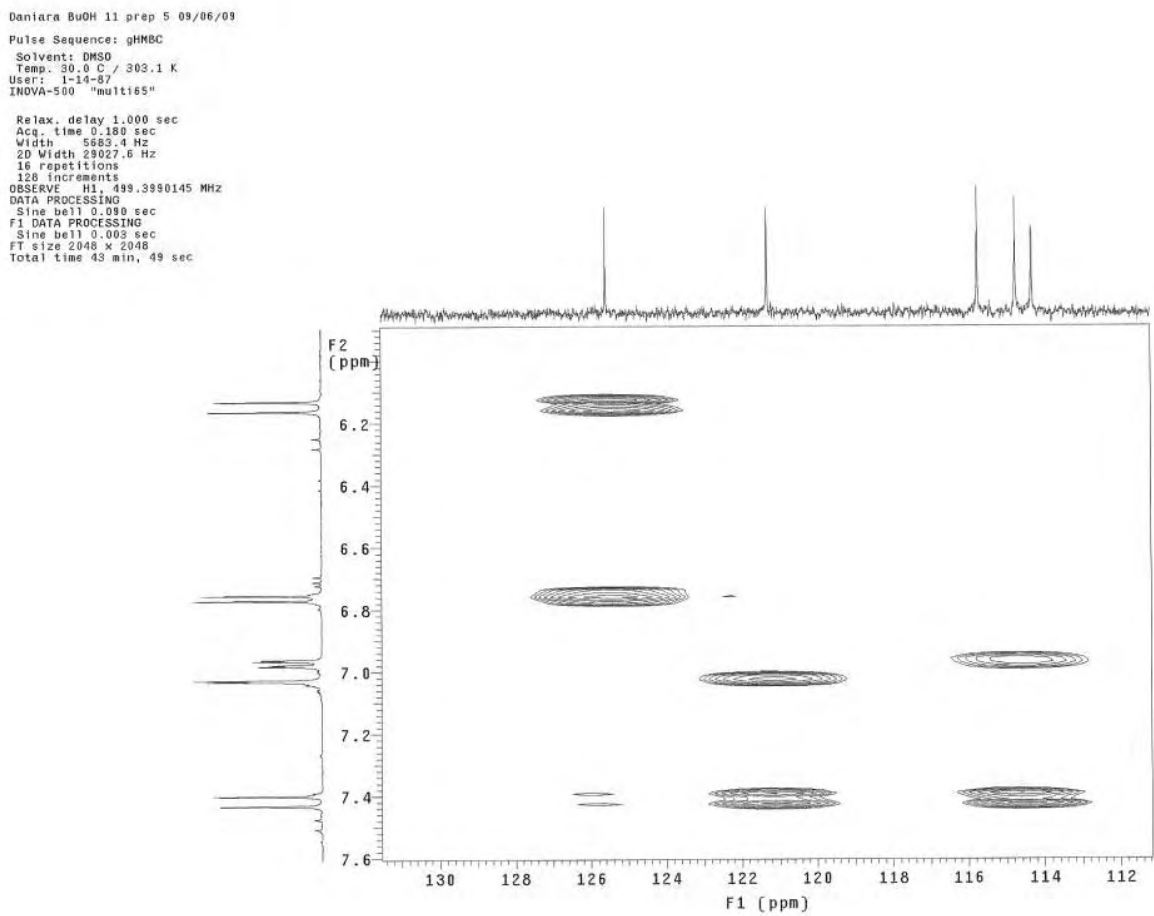

Anexo 208. Ampliação do mapa de contorno ${ }^{1} \mathrm{H}-{ }^{13} \mathrm{C} g \mathrm{HMBC}$ da substância 18.

$$
\left(500 \mathrm{MHz}-\mathrm{DMSO}-d_{6}\right)
$$


Daniara BuoH 11 prep 5 09/06/0s

solvent: onso

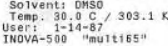

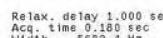

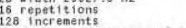

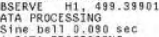

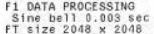

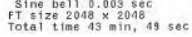

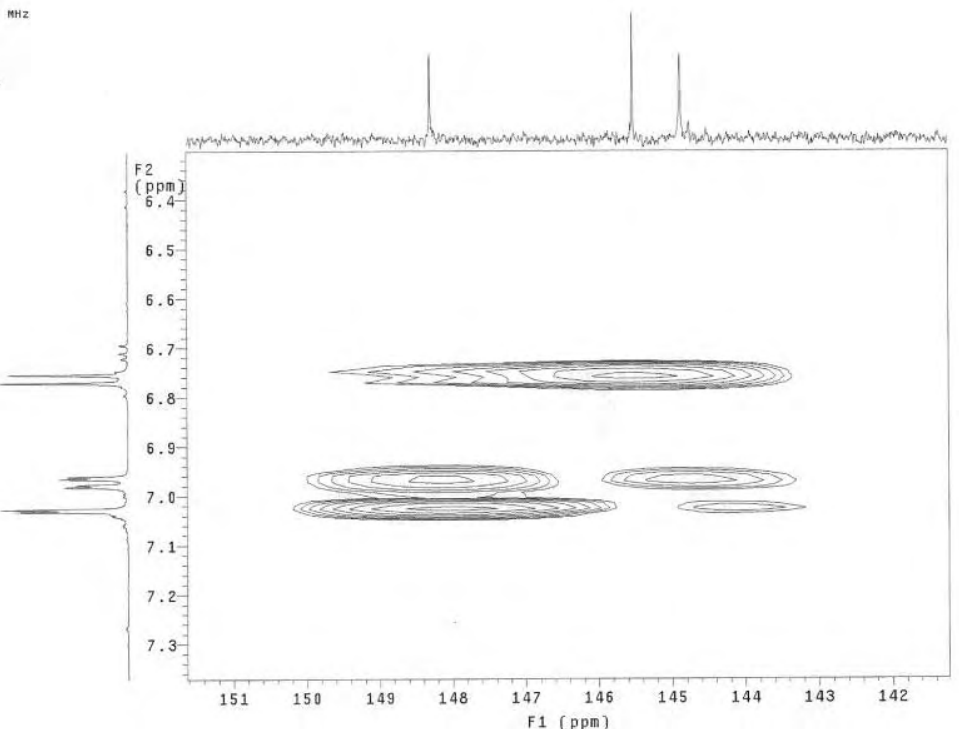

Anexo 209. Ampliação do mapa de contorno ${ }^{1} \mathrm{H}^{13}{ }^{13} \mathrm{C} g \mathrm{HMBC}$ da substância 18.

$\left(500 \mathrm{MHz}-\mathrm{DMSO}-d_{6}\right)$ 